VALORACIÓN Y GESTIÓN DEL PAISAJE SEGÚN EL CONVENIO EUROPEO DEL PAISAJE YEL

REGLAMENTO DEL PAISAJE DE LA COMUNIDAD VALENCIANA: APLICACIÓN MEDIANTE UN ESTUDIO

DE PAISAJE A UNESPACIO ABIERTO ENLA COMUNIDAD VALENCIANA

DOCTORANDO: JUAN JOSÉ GALÁN VIVAS (Universidad Politécnica de Valencia, enero 2011)

\title{
1. OBJETIVOS
}


VALORACIÓN Y GESTIÓN DEL PAISAJE SEGÚN EL CONVENIO EUROPEO DEL PAISAJE YEL

REGLAMENTO DEL PAISAJE DE LA COMUNIDAD VALENCIANA: APLICACIÓN MEDIANTE UN ESTUDIO

DE PAISAJE A UNESPACIO ABIERTO ENLA COMUNIDAD VALENCIANA

DOCTORANDO: JUAN JOSÉ GALÁN VIVAS (Universidad Politécnica de Valencia, enero 2011) 


\section{OBJETIVOS.}

\subsection{Antecedentes y Objeto de la Tesis:}

El nuevo marco derivado de la ratificación por España del Convenio Europeo del Paisaje y de la puesta en marcha de una política de paisaje en la Comunidad Valenciana, requirió en ésta última de la creación de los estudios de Paisaje, como herramientas específicas para la planificación del paisaje y para su integración en el planeamiento y ordenación territorial.

Tomando como punto de partida la estructura y contenidos de los estudios de paisaje tal y como son definidos por el Reglamento de Paisaje de la Comunidad Valenciana, la presente tesis pretende, tras una revisión de distintos procedimientos y metodologías existentes para la planificación del paisaje, detectar los aspectos en los que dichos estudios son efectivos o insuficientes para la consecución de sus fines y proponer una metodología a testar posteriormente mediante su aplicación en un ámbito concreto.

Se parte en consecuencia de la hipótesis de que los estudios de paisaje presentan aspectos pendientes de ajuste o desarrollo, que en concreto afectarían al análisis y descripción del paisaje, a los contenidos propositivos de los estudios, a los procedimientos previstos para la participación pública y a su efectiva inserción en la planificación territorial y urbanística. Dichos ajustes y desarrollos pormenorizados quedan recogidos en la propuesta metodológica que se propone en la presente tesis, y que es testada en un ámbito específico (entorno del Parque Natural de las Lagunas de La Mata y Torrevieja), seleccionado por la confluencia de valores ambientales, culturales y paisajísticos, por la coexistencia de competencias de distintas administraciones locales y regionales, así como por la compleja compatibilización de los citados recursos con fuertes presiones para la transformación del paisaje, derivadas principalmente de la urbanización y construcción de infraestructuras. Dicha situación, considerada característica de muchos de los paisajes sometidos a dinámicas de cambio más intensas, pretende aportar a la tesis y a sus conclusiones una aplicabilidad e interés en una amplia diversidad de contextos.

A partir de la aplicación práctica anteriormente mencionada se obtienen unas conclusiones genéricas y metodológicas que pretenden apoyar el desarrollo de estudios de paisaje como herramientas efectivas de planificación paisajística y de apoyo a la ordenación territorial.

Los trabajos realizados se complementan a su vez con una investigación paralela referida a aspectos económicos asociados a la gestión y valoración del paisaje.

\subsection{Objetivos específicos:}

Considerando el estado actual de las cuestiones tratadas en la presente tesis (ver capítulo 2) y partiendo de los aspectos pendientes de concreción o susceptibles de ajuste y mejora en la metodología propuesta por el Reglamento de Paisaje de la Comunidad Valenciana para la redacción de estudios de paisaje, se establecen como objetivos específicos de la tesis los siguientes:

1. Generar una metodología que sistematice y simplifique, sin perjuicio para la calidad de los resultados, la redacción de documentos para la planificación del paisaje (estudios de paisaje en el caso concreto de la Comunidad Valenciana).

2. Definir una metodología flexible y aplicable a distintos ámbitos y escalas del territorio.

3. Incorporar de forma efectiva la planificación del paisaje definida en escalas superiores y apoyar adecuadamente la posible planificación o definición de acciones en escalas inferiores (permeabilidad entre escalas)

4. Garantizar la incorporación del conjunto de factores físicos, sociales, culturales, visuales y económicos que configuran el paisaje y prever o utilizar de forma proactiva sus posibles cambios en el tiempo.

5. Establecer un criterio para definir los ámbitos en los que desarrollar los estudios de paisaje.

6. Determinar un mecanismo para contextualizar un estudio de paisaje en un ámbito superior si se carece de información paisajística sobre este último.

7. Reforzar la utilidad de la caracterización del paisaje en la definición posterior de objetivos de calidad paisajística y de acciones de paisaje. Considerar en este punto la función de la unidad de paisaje.

8. Sistematizar la metodología para la caracterización del paisaje de forma que integre tanto criterios técnicos como las percepciones de la población y que considere la evolución del paisaje como consecuencia tanto de las dinámicas naturales, sociales y económicas como del planeamiento y aplicación de las políticas sectoriales vigentes. 
9. Analizar la utilidad del análisis visual en la planificación del paisaje y definir un procedimiento técnico basado en las herramientas SIG (Sistemas de Información Geográfica) para la determinación de la visibilidad del paisaje según las premisas marcadas por el Reglamento de Paisaje de la Comunidad Valenciana.

10. Reforzar, si procede, la utilidad de la valoración del paisaje en la definición posterior de objetivos de calidad paisajística y de acciones de paisaje.

11. Desarrollar una metodología para la valoración visual- cultural del paisaje incorporando la opinión de la población, los juicios técnicos de expertos y el grado de visibilidad del paisaje.

12. Sistematizar los apartados propositivos de los estudios de paisaje, con especial atención a los siguientes aspectos:

a. Objetivos de calidad paisajística: Establecer un procedimiento que integre la participación pública y que relacione los objetivos de calidad paisajística con el valor paisajístico.

b. Sistema de espacios abiertos: Desarrollar criterios para la definición del Sistema y para diagnosticar su viabilidad como red territorial interconectada y como soporte de la diversidad y calidad paisajística (ambiental, cultural y visual).

c. Programas de Paisaje: Definir las distintas tipologías de programas, vinculándolos tanto a actuaciones constructivas como de carácter administrativo-social y establecer una estructura y contenidos para las fichas explicativas de los programas. Se valorará en este punto la posibilidad de establecer la figura del Plan de Ordenación Paisajística como apartado de los estudios de paisaje que agrupe y muestre de forma sintética y unificada las acciones propuestas en los programas.

d. Normativa de paisaje: Se considerará las implicaciones paisajísticas que a menudo tienen otras normativas urbanísticas de aplicación así como la definición de normas de integración paisajística y posibles recomendaciones específicas que complementen las normas estándar (de aplicación directa y de integración paisajística) previstas por el Reglamento de Paisaje de la Comunidad Valenciana.

13. Definición de un procedimiento para la participación pública en la planificación del paisaje, con especial atención a:

a. Realización de consultas que permitan conocer tanto las opiniones de expertos como las de grupos de interés, y muy especialmente, la de muestras representativas de la población.

b. Integración efectiva y ágil de las conclusiones del proceso de participación pública en la caracterización, valoración y definición de acciones sobre el paisaje.

c. Optimización de recursos y de tiempos en los procesos de participación pública.

14. Integrar las variables económicas en la definición de propuestas dirigidas a la protección, ordenación y gestión del paisaje, considerando para ello aspectos vinculados al valor económico del paisaje, a la exploración de vías para financiar la custodia y gestión del paisaje y las implicaciones que sobre la actividad económica tiene la decisión de integrar un determinado espacio en el sistema de espacios abiertos.

15. Reforzar los mecanismos de incorporación del paisaje a las herramientas de planeamiento territorial y urbanístico (directrices/normas/recomendaciones o determinación de espacios físicos con un tratamiento urbanístico específico). 


\section{MARCOS DE REFERENCIA Y ESTADO ACTUAL}


VALORACIÓN Y GESTIÓN DEL PAISAJE SEGÚN EL CONVENIO EUROPEO DEL PAISAJE YEL

REGLAMENTO DEL PAISAJE DE LA COMUNIDAD VALENCIANA: APLICACIÓN MEDIANTE UN ESTUDIO

DE PAISAJE A UNESPACIO ABIERTO ENLA COMUNIDAD VALENCIANA

DOCTORANDO: JUAN JOSÉ GALÁN VIVAS (Universidad Politécnica de Valencia, enero 2011) 


\section{MARCOS DE REFERENCIA Y ESTADO ACTUAL:}

El estudio de los marcos ofrecidos en el ámbito europeo por el Convenio Europeo del Paisaje y a nivel autonómico por la Ley de Ordenación del Territorio y Protección del Paisaje y el Reglamento de Paisaje de la Comunidad Valenciana tiene una doble finalidad: Por un lado, integrar los objetivos de la tesis en los vigentes en materia de paisaje dentro de la Comunidad Valenciana. Por otro lado, analizar y considerar las metodologías propuestas por dichos marcos para la consecución de sus objetivos, proporcionando claves para el desarrollo de la presente tesis.

\subsection{Marcos de referencia}

\section{1.a Convenio Europeo del Paisaje}

El Convenio Europeo del Paisaje establece una serie de definiciones y principios que permitan contribuir desde la perspectiva del paisaje a la consecución de un desarrollo sostenible basado en una relación equilibrada y armoniosa entre las necesidades sociales, la economía y el medio ambiente. El Convenio así definido constituye un marco desde el que desarrollar, a nivel nacional, regional o local, políticas de paisaje basadas en la percepción del paisaje como cualidad de todo territorio, independientemente de su carácter o valor estético y en el desarrollo de las medidas generales y específicas recogidas respectivamente en sus artículos 5 y 6 .

\section{1.b. Reglamento de Paisaje de la Comunidad Valenciana:}

De acuerdo a los principios del Convenio Europeo del Paisaje (firmado por la Comunidad Valenciana en el año 2004), la Política de Paisaje de la Comunidad Valenciana asume una visión integral del territorio, considerando todos sus ámbitos y escalas, y un acercamiento participativo, por el que la evolución del paisaje debe ser fruto del consenso de todos los agentes sociales y económicos, públicos y privados.

La Ley de Ordenación del Territorio y del Paisaje de la Comunidad Valenciana (LOTPP, 2004) asume como propios los objetivos del Convenio Europeo del Paisaje, definiendo los instrumentos y planes de acción territorial (PAT) que permitan su articulación e implementación efectiva. Dicha Ley detalla a su vez los organismos que deberán definir y coordinar la política de paisaje en dicha comunidad y establece los estudios de paisaje como herramienta que, incorporando procesos de participación pública, permita integrar el paisaje en el planeamiento regional y municipal. Igualmente la LOTPP introduce el concepto de Integración paisajística, detallando una serie de normas generales y de normas específicas para los ámbitos rural y urbano.

El Reglamento de Paisaje de la Comunidad Valenciana desarrolla entre otros aspectos, la estructura, contenidos, tramitación y relación con otras herramientas de planeamiento, de los estudios de paisaje y los estudios de integración paisajísticas, instrumentos clave para la aplicación de la política valenciana de paisaje. A su vez, el Reglamento define los catálogos de paisaje como las herramientas que permitan la identificación y reconocimiento jurídico de los espacios o recursos paisajísticos de mayor valor o importancia y los programas de paisaje como los instrumentos que permitan proponer las actuaciones dirigidas a preservar, mejorar y poner en valor los paisajes que por su valor natural, visual o cultural, requieren intervenciones específicas e integradas. Adicionalmente, el Reglamento de Paisaje detalla los contenidos de los planes de participación pública que deberán acompañar, entre otros, a los estudios de paisaje y estudios de integración paisajística.

\section{1.c. Otros marcos de interés:}

La firma en el año 2000 por el gobierno de Cataluña del Convenio Europeo del Paisaje, abrió un proceso para la integración del paisaje en el planeamiento territorial y en las políticas sectoriales de dicha comunidad, proceso que culminó en el año 2005, con la aprobación de la Ley 8/2005 de protección, gestión y ordenación del paisaje y que supuso a su vez la creación en el año 2004 del Observatorio de Paisaje, como institución responsable de apoyar técnica y divulgativamente al gobierno y sociedad catalana en la aplicación de los principios del Convenio y de las determinaciones de la Ley.

En dicho contexto, se establecieron los catálogos de paisaje como los documentos de carácter técnico que debían establecer las condiciones y objetivos para la ordenación y gestión del paisaje desde la perspectiva del planeamiento territorial y cuyos ámbitos de aplicación corresponden a las 7 regiones objeto de planificación mediante los Planes Territoriales Parciales de Cataluña (PTP), en los que, la incorporación de la variable paisajística es especialmente importante por el hecho de situarse, jerárquicamente, por encima del planeamiento urbanístico y por centrarse en tres sistemas básicos de la estructura y funcionalidad del territorio: 
- $\quad$ "El sistema de espacios abiertos, que comprende todo el suelo clasificado como no urbanizable para el planeamiento urbanístico.

- El sistema de asentamientos urbanos, que corresponde a los asentamientos existentes (ciudades, pueblos, urbanizaciones, equipamientos, suelo industrial,...) y la propuesta de estrategias de extensión, reforma o consolidación de los mismos.

- El sistema de infraestructuras de movilidad, que corresponde a la red viaria, la ferroviaria, el sistema aeroportuario, el sistema portuario, así como el sistema logístico y los intercambiadores nodales asociados".

Adicionalmente, el planeamiento territorial catalán incluye las figuras del Plan Director Territorial (PDT) como avance de los Planes Territoriales Parciales (PTP) en parte de sus ámbitos, y de los Planes Territoriales Sectoriales, "que abarcan toda Cataluña, pero se ocupan de un único aspecto...", estos tipos de planes no son objeto directo de los catálogos de paisaje, "aunque la Ley de paisaje establece que los planes territoriales parciales pueden determinar cuándo y cómo las directrices paisajísticas se convierten en recomendaciones para los planes sectoriales y, por lo tanto, cuándo los planes y programas aprobados posteriormente deberán ser congruentes con estas recomendaciones de paisaje".

En el ámbito del planeamiento urbanístico, los planes directores urbanísticos (PDU), que comprenden ámbitos supramunicipales (sobre todo sistemas urbanos y metropolitanos o comarcas) y los planes de ordenación urbanística municipal (POUM), como instrumento de ordenación a escala local, deberían asumir las directrices, normas y recomendaciones paisajísticas propuestas en los catálogos y recogidas en el planeamiento territorial.

Con el objeto de establecer la metodología, funciones y contenidos de los Catálogos, el Observatorio del Paisaje, redactó en el año 2006 el correspondiente prototipo, asumiendo a su vez la redacción de dichos documentos y colaborando o desarrollando íntegramente la preparación de manuales, guías, materiales formativos y actividades divulgativas necesarias para la aplicación de la política de paisaje catalana en distintos sectores y ámbitos físicos.

A nivel internacional, existen precedentes de elevado interés en la identificación, caracterización y evaluación del paisaje, disponiéndose a su vez, de una importante base de conocimiento al respecto. Como ejemplos de países o regiones con trabajos desarrollados en dichas materias cabe citar los Países Bajos, Bélgica, Eslovenia, Francia y España, con sus correspondientes atlas paisajísticos, o el Reino Unido, en el que la metodología propuesta para la evaluación del paisaje (Landscape Character Assessment) por la Countryside Agency (año 2002), ha influido notablemente en las metodologías desarrolladas en el resto de países del ámbito europeo. Debe destacarse que, sin embargo, muchos de estos referentes no han profundizado en la integración del paisaje en las herramientas o cauces del planeamiento territorial o urbanístico, aspecto, este último, esencial para dotar al paisaje de un papel proactivo y que da especial valor a nivel internacional, a las iniciativas y herramientas desarrolladas al efecto en la Comunidad Valenciana y Cataluña.

\subsection{Estado actual de la cuestión}

\section{2.a Convenio Europeo del Paisaje}

La redacción en el año 2000 del Convenio Europeo del Paisaje, auspiciado por el Consejo de Europa, fue seguida de una progresiva firma y ratificación por la mayor parte de los países miembros del citado Consejo, hasta alcanzarse la situación siguiente (consultar http://www.coe.int/t/dg4/cultureheritage/heritage/landscape)

- Países miembros del Consejo de Europa (47)

- Países que han firmado y ratificado en Convenio Europeo del Paisaje (32): Armenia, Bélgica, Bulgaria, Croacia, Chipre, República Checa, Dinamaca, Finlandia, Francia, Georgia, Grecia, Hungría, Irlanda, Italia, Lituania, Luxemburgo, Moldavia, Montenegro, Holanda, Noruega, Polonia, Portugal, Rumania, San Marino, Eslovaquia, Eslovenia, España, Macedonia, Turquía, Ucrania, Gran Bretaña

- Países que han firmado pero no ratificado el Convenio Europeo del Paisaje (6): Azerbaiyán, Bosnia- Herzegovina, Malta, Serbia, Suecia, Suiza.

- Países que no lo han firmado (9): Albania, Andorra, Austria, Estonia, Alemania, Islandia, Liechtenstein, Mónaco, Rusia. 
El Convenio Europeo del Paisaje, "como instrumento jurídico, proporciona un marco cuyo alcance normativo debe ser establecido por los estados firmantes" (ZOIDO, Florencio, 2005), e incorpora explícitamente la posibilidad de ser asumido por regiones o municipios, aspecto éste, que resulta especialmente conveniente en la mayor parte de países miembros del Consejo de Europa dado el relevante papel que las administraciones regionales y locales juegan en el planeamiento territorial y urbanístico así como la necesidad de abordar la ordenación y gestión del paisaje en todas las escalas del territorio.

Con el objeto de promover los principios del Convenio y de facilitar el intercambio de conocimientos y experiencias, han surgido, al amparo del Consejo de Europa, las siguientes redes, agrupadas a su vez en la red Eurolandscape:

- ENELC / RECEP: Organización abierta a las autoridades representantes de las regiones y municipios firmantes del Convenio Europeo del Paisaje. A fecha de redacción de la presente tesis, incluía 35 miembros, mayormente localizados en el ámbito mediterráneo (21 en Italia y 5 en España)

- UNISCAPE: Organización surgida con el objeto de apoyar y reforzar la cooperación interdisciplinar entre las universidades europeas con líneas formativas y de investigación en el campo de la planificación del paisaje. A fecha de redacción de la presente tesis, incluía 50 universidades pertenecientes a 8 países europeos (24 en Italia y 9 en España).

- CIVILSCAPE: Organización integrada por asociaciones, organizaciones no gubernamentales y agrupaciones civiles con el fin de facilitar la colaboración e intercambio de conocimientos y experiencias en materia de paisaje, tanto entre sus miembros, como entre éstos y las autoridades públicas o los principales agentes en la gestión del territorio y del paisaje. A fecha de redacción de la presente tesis, incluía 27 organizaciones pertenecientes a 12 países europeos.

Transcurridos 10 años de la redacción del Convenio Europeo del Paisaje, cabe la posibilidad de considerar los logros conseguidos en dicho periodo. Según expone el profesor Florencio Zoido, dicho balance puede realizarse considerando tres aspectos principales:

1) Reconocimiento jurídico-institucional del paisaje

2) Identificación y cualificación de los paisajes propios.

3) Aplicaciones reales del Convenio.

En el primero de los casos, cabe reseñar que el paisaje, incluido con antelación en las constituciones de algunos países como Alemania, Italia, Suiza o Portugal, ha pasado a figurar, a partir de la creación del Convenio, en un número creciente de normas, leyes estatales y leyes regionales, entre las que se incluyen leyes específicas o fuertemente vinculadas al paisaje en las comunidades autónomas de Valencia, Cataluña, Galicia, etc. o en algunos länders alemanes y regiones italianas. De igual modo, a fecha 2006 estaban en redacción leyes específicas sobre paisaje en Chipre, Croacia, Valonia (Bélgica), así como inserciones y ampliaciones en instrumentos legales más amplios (Holanda, Irlanda, Italia, Valonia). Tal y como expone el profesor Florencio Zoido, "en conjunto este aspecto progresa en algunos países contratantes (con ratificación) al ritmo propio del tiempo legislativo. Al mismo nivel puede considerarse el reforzamiento institucional del paisaje; algunas iniciativas merecen ser mencionadas: la constitución del Consejo Nacional del Paisaje en Francia, o la figura del Consejero Nacional del Paisaje en Holanda, de carácter moral -equivalente al Defensor del Pueblo-, pero con influencia real".

En lo referente a la identificación y cualificación de los paisajes propios, completamente necesarios para sustentar políticas de paisaje consistentes, se han producido significativos aunque desiguales avances en los distintos estados y regiones firmantes del Convenio. Entre los trabajos realizados destacan los atlas de paisajes producidos o en redacción a nivel estatal (Croacia, Eslovenia, España, Francia, Holanda, Noruega, Portugal...) o a nivel regional (Cataluña, Andalucía, Comunidad Valenciana, etc). A nivel metodológico cabe reseñar los procedimientos puestos en práctica para la redacción de Catálogos de Paisaje en Cataluña (NOGUE y SALA, 2006), el Reglamento de Paisaje de la Comunidad Valenciana, el Plan Visual de Paisaje de la Comunidad Valenciana (STEINITZ y MUÑOZ, 2008) o los estudios sobre tipos de paisaje (WASCHER, 2005), procesos o rasgos dominantes en el paisaje (CLARK, DARLINGTON y FAIRCLOUGH, 2004) o desarrollo de políticas paisajísticas (JANCIC, 2005).

Finalmente, las aplicaciones del Convenio, son a fecha de hoy su aspecto menos desarrollado. Dicha situación obedece, por un lado, a constituir el paso posterior al reconocimiento jurídico y a la realización de trabajos de 
identificación y diagnóstico del paisaje, y en segundo y principal lugar, a la necesidad de pasar de la esfera legal y teórica al plano real y aplicado.

Se hace en este punto preciso definir, articular y coordinar las herramientas de planificación del paisaje con las de planeamiento territorial y urbanístico, establecer los procedimientos o criterios por los que el paisaje puede ser tenido en cuenta en el desarrollo de actuaciones con incidencia sobre el territorio, y muy especialmente, generar una cultura del paisaje a nivel de la población, de las administraciones públicas, de los planificadores y de los técnicos o agentes vinculados a la gestión u ordenación del territorio y del paisaje.

Una revisión de las iniciativas desarrolladas hasta la fecha, pone de manifiesto que, en gran medida, las aplicaciones del Convenio se han desarrollado o se han asimilado a menudo a proyectos, planes o actuaciones aisladas, quedando recogidas en libros de buenas prácticas, en publicaciones sobre proyectos de paisaje o en concursos de carácter nacional o internacional. Los ejemplos de aplicaciones del Convenio planificadas y estructuradas, tanto a nivel formativo, divulgativo, de participación pública, planificador como proyectual, han sido sin embargo hasta la fecha escasas, y únicamente han sido posibles cuando han venido apoyadas, de forma consistente y continua desde las más altas instituciones de los gobiernos nacionales o regionales y cuando han sido compartidas por los distintos departamentos o sectores con competencias o influencia sobre el territorio y el paisaje. En este punto, España, a través de las políticas de paisaje puestas en marcha en Cataluña, Comunidad Valenciana y de las políticas territoriales sensibles al paisaje, desarrolladas en Andalucía, ofrece algunos de los ejemplos más destacados en la aplicación del Convenio.

Tal y como se expone en el punto 4 del informe sobre el Convenio Europeo del Paisaje, redactado en el año 2006 por el profesor Florencio Zoido, a dicha fecha, el Consejo de Europa consideraba que se había llegado a la fase de aplicación territorializada en dos países (Dinamarca y Holanda). Paralelamente, el Consejo Nórdico en su conjunto (Dinamarca, Finlandia, Islandia, Noruega y Suecia) lo había adoptado en el marco de cooperación común; la Oficina Federal suiza o la Countryside Agency británica lo habían incluido en sus planteamientos de planificación y gestión, mientras que Irlanda, Holanda, Cataluña y la Comunidad Valenciana estaban desarrollando ambiciosas políticas de paisaje basadas en los criterios marcados por el Convenio.

Los seminarios organizados con ocasión del decimo aniversario del Convenio Europeo de Paisaje por la Fundación Europea para la arquitectura del paisaje (Bruselas, noviembre 2010) o por el programa LE-NOTRE, bajo el título, "Landscape Planning and the European Landscape Convention", han permitido constatar los aspectos antes indicados así como la necesidad de concretar las aplicaciones del Convenio.

\section{2.b. Comunidad Valenciana:}

La valoración de nivel de desarrollo de la política de paisaje de la Comunidad Valenciana se realiza seguidamente atendiendo al índice expuesto anteriormente:

1) Reconocimiento jurídico-institucional del paisaje: La Ley $4 / 2004$ de Ordenación del Territorio y del Paisaje de la Comunidad Valenciana (LOTPP, 2004) otorga entidad legal al paisaje y define los procedimientos y herramientas (Estudios de Paisaje) para su integración en la planificación territorial (Planes de acción territorial (PAT)) y en el planeamiento urbanístico (Planes Generales de Ordenación Urbana (PGOU)). De igual manera, el paisaje se integra mediante los Estudios de Integración Paisajística en la valoración de proyectos de alta incidencia territorial (infraestructuras de transporte o crecimientos urbanos) o que afecten a ámbitos especialmente sensibles (suelo no urbanizable).

Por otro lado, la creación de una Dirección General de Paisaje, adscrita a la Consejería de Medio Ambiente, Agua, Urbanismo y Vivienda, posteriormente ampliada a Dirección General de Territorio y Paisaje, generó una estructura administrativa específica, dedicada a poner en marcha y supervisar la aplicación de la política de paisaje de la Comunidad Valenciana. Entre sus funciones se incluyó:

- La elaboración y desarrollo del Plan de Acción Territorial del Paisaje de la Comunidad Valenciana.

- La difusión y sensibilización en materia de paisaje.

- La supervisión y tramitación de los instrumentos previstos en la legislación de paisaje.

- El fomento de la participación pública y la coordinación con otras administraciones públicas.

- La cooperación con los ayuntamientos en la elaboración, tramitación y aplicación de los instrumentos de paisaje.

- La planificación del paisaje y el impulso de actuaciones singulares de protección, ordenación y gestión de paisajes. 
- El desarrollo y ejecución de propuestas concretas con carácter ejemplar.

- La promoción de la colaboración científica y académica en materia de paisaje y la redacción de guías metodológicas para la participación pública y la redacción de estudios de paisaje / estudios de integración paisajística.

2) Identificación y cualificación de los paisajes propios: Al vincularse a la redacción de estudios de paisaje, y estar éstos a su vez asociados a la revisión de Planes General de Ordenación Urbana o a la redacción de Planes de Acción Territorial, la identificación del paisaje ha quedado supeditada al desarrollo de otras herramientas.

La actual redacción del Plan de Acción Territorial de Paisaje de la Comunidad Valenciana, que de acuerdo a la LOTPP y al Reglamento de Paisaje de la Comunidad Valenciana, debe consistir en un estudio de paisaje de escala y grado de detalle autonómico, en el que, se precisen a su vez ámbitos supramunicipales para el desarrollo de estudios de paisaje regionales, proporcionará, una vez se concluya, un necesario marco de referencia para los estudios de paisaje locales que se redacten a partir de su aprobación.

A fecha 30 de noviembre de 2010, transcurridos 6 años desde la aprobación de la Ley de Ordenación del Territorio y Protección del Paisaje de la Comunidad Valenciana y 4 años desde la aprobación del Reglamento de Paisaje, y considerando que la Comunidad Valenciana consta de 542 municipios, se han tramitado o están en tramitación los estudios de paisaje siguientes:

- Estudio suprarregional (PAT de paisaje de la Comunidad Valenciana): 1

- Estudios de paisaje regionales: 2

- Plan de Acción Territorial para la protección de la Huerta de Valencia

- Plan de Paisaje del valle de Guadalest (Alicante)

- Estudios de Paisaje municipales: 160 (sobre un total de 542 municipios)

Considerando que la calidad y utilidad real de dichos estudios de paisaje se valora en el punto siguiente, se indica seguidamente el porcentaje de territorio de la Comunidad Valenciana que ha sido objeto de caracterización del paisaje a distintas escalas o grados de detalle:

- Escala autonómica o suprarregional (PAT de paisaje de la Comunidad Valenciana): $100 \%$

- Escala regional (en Estudios de Paisaje asociados a Planes de Acción Territorial o similares): 1,5\%

- Plan de Acción Territorial para la protección de la Huerta de Valencia

- Plan de Paisaje del valle de Guadalest (Alicante)

- Escala local (en Estudios de Paisaje asociados a Planes Generales de Ordenación Urbana): 25 \%

Según fuentes consultadas de la Dirección General de Territorio y Paisaje, la próxima publicación del Atlas de los Paisajes de la Comunidad Valenciana complementará la definición de unidades de paisaje regionales recogida en el borrador del PAT de Paisaje de dicha comunidad y permitirá identificar aquellos paisajes significativos que recogen la diversidad del territorio valenciano y que deben ser objeto de una especial atención.

Las mismas fuentes, estiman que, la renovación progresiva de los Planes Generales de Ordenación Urbana, que necesariamente deben ir desde el año 2004 acompañados de un Estudio de Paisaje, supondrá que en el año 2020, la práctica totalidad de la Comunidad Valenciana, dispondrá de estudios de paisaje de carácter local.

3) Aplicaciones reales del Convenio: Análisis y Valoración de la situación actual

a. Planificación del paisaje: tal y como se mostraba en el punto anterior, la obligatoria inclusión de los estudios de paisaje en los instrumentos de planificación (PAT y PGOU), ha permitido la introducción de la variable "paisaje" tanto en el planeamiento territorial como urbanístico. Sin embargo, se constata que muchos de los estudios elaborados hasta la fecha, presentan deficiencias derivadas principalmente de:

- Falta de marcos paisajísticos regionales de referencia (que previsiblemente se solucionará cuando se concluya el PAT de paisaje de la Comunidad Valenciana y se generen estudios de paisaje de carácter regional) 
- Escaso desarrollo y operatividad de las partes propositivas requeridas por el Reglamento de Paisaje para los Estudios de Paisaje: objetivos de calidad paisajística, sistema de espacios abiertos, programas de paisaje y normativa de paisaje.

- Frecuente falta de formación específica en planificación de paisaje de los equipos redactores de estudios de paisaje.

- Ausencia de ejemplos de referencia o guías metodológicas.

- Escasez de recursos económicos y humanos destinados a la redacción de los estudios de paisaje y al desarrollo de los planes de participación pública reglamentariamente asociados.

- Falta de cartografía en formato abierto (shp, dwg, dxf, dgn)

b. Proyectos de paisaje: Los principales proyectos de paisaje a desarrollar en la Comunidad Valenciana deberían ser aquellos que se concluyan de los estudios de paisaje asociados al Plan de Acción Territorial de Paisaje de dicha comunidad o a Planes de Acción Territorial regionales, por ejemplo, al de Protección de la Huerta de Valencia. Dado que ambos documentos están en fase de revisión y aprobación, desde la Dirección General de Territorio y Paisaje, se promueven actualmente proyectos en áreas cuya importancia se conoce a pesar de no haber quedado determinada en estudios específicos. Entre dichas áreas destacan los corredores fluviales y los entornos de cascos urbanos históricos. Paralelamente, el Plan Visual de la Comunidad Valenciana (STEINITZ; MUÑOZ, 2008) permitió detectar algunos de los principales conflictos paisajísticos, facilitando criterios objetivos para seleccionar áreas objeto de proyectos prioritarios (carreteras, accesos urbanos, etc).

c. Divulgación y sensibilización: La divulgación y sensibilización son la base para disponer del apoyo social e institucional necesario para aplicar las políticas de paisaje. En este punto, los planes de participación pública y la web de la Dirección General de Territorio y Paisaje, son las principales vías de difusión utilizadas. Dichas vías no son sin embargo conocidas o utilizadas por la población, observándose la necesidad de que el paisaje sea incorporado en el discurso y estrategias de otros sectores de la administración pública.

d. Formación: No se ha observado una incorporación de contenidos sobre territorio y paisaje en los distintos niveles de enseñanza. Igualmente, la transversalidad de los aspectos tratados en la planificación del paisaje, requeriría de titulados universitarios específicos en la materia, no habiéndose dado hasta la fecha avances significativos en este campo dentro de las universidades valencianas. Quedaría a su vez por desarrollar guías metodológicas para la redacción de estudios de paisaje, estudios de integración paisajística o planes de participación pública, si bien, dichos contenidos, podrían ser adecuadamente impartidos en las necesarias e inexistentes titulaciones universitarias regladas dedicadas a la planificación y proyectación del paisaje.

e. Participación: La participación pública es obligatoriamente requerida en la redacción de todo estudio de paisaje o estudio de integración paisajística. Dicha participación se debe desarrollar en paralelo a la redacción del Estudio y es específicamente solicitada en la valoración del paisaje y en la formulación de objetivos de calidad paisajística. Un estudio de las participaciones públicas realizadas hasta la fecha pone de manifiesto lo siguiente:

- Los procesos de participación son atendidos por grupos o personas con vinculaciones o directas con los espacios o recursos incluidos en el ámbito del estudio pero no por amplios segmentos de la población residente o visitante, que a pesar de no tener una vinculación directa con los mismos, pueden verse beneficiados o perjudicados por su correcta o deficiente ordenación o gestión.

- Las partes propositivas de los estudios (generalmente poco desarrolladas y elaboradas) no suelen recoger las opiniones de la población.

- Los procedimientos de participación pública se desarrollan, bien con plazos y recursos muy escasos, no alimentando adecuadamente el estudio al que se vinculan, o bien absorbiendo gran parte de los recursos destinados a éste, sacrificando en ese caso la calidad de los contenidos del estudio. Ante esta situación cabe plantearse la necesidad de explorar metodologías más efectivas para los procesos de participación. 


\section{2.c. Otros ámbitos:}

\section{2.c.1 Cataluña:}

La valoración de nivel de desarrollo de la política de paisaje en Cataluña se realiza seguidamente atendiendo a los epígrafes propuestos por el profesor Florencio Zoido:

1) Reconocimiento jurídico-institucional del paisaje: La Ley 8/2005 de Protección, Gestión y Ordenación del Paisaje otorga entidad legal al paisaje y define los procedimientos y herramientas (Catálogos y Directrices de Paisaje) para su integración en la planificación territorial (Planes Territoriales Parciales (PTP) y Planes Directores Territoriales (PDT)). En lo referente al planeamiento urbanístico, articulado en Cataluña en las figuras del Plan Director Urbanístico (PDU), que comprende ámbitos supramunicipales, y al Plan de Ordenación Urbanística Municipal (POUM), de carácter municipal; la legislación catalana prevé que asuman las directrices o recomendaciones previstas por los catálogos de paisaje para el planeamiento territorial. Adicionalmente, el marco legal paisajístico define las Cartas de Paisaje como instrumentos de concertación social entre los agentes públicos y privados para desarrollar las acciones de protección, gestión y ordenación del paisaje. Finalmente, el decreto 343/2006, por el que se desarrolla la Ley 8/2005, establece los Estudios de Impacto e Integración Paisajística como documento técnico que permita determinar las consecuencias que una determinada actuación tiene sobre el paisaje y su entorno, así como exponer los criterios que deben adoptarse para su integración paisajística.

Con el fin de articular la aplicación de la política catalana de paisaje se creó la Dirección General de Arquitectura y Paisaje y el Observatorio del Paisaje, entidad está última, de carácter consorcial, adscrita al Departamento de Política Territorial y Obras Públicas e integrada por instituciones y organismos públicos y privados. Entre las funciones del observatorio se incluyó el diagnóstico, desarrollo de trabajos técnicos y la sensibilización social en materia de paisaje

2) Identificación y cualificación de los paisajes propios: La identificación y cualificación del paisaje queda supeditada en el caso de Cataluña a la redacción por el Observatorio de Paisaje de los Catálogos de Paisaje.

De los 7 catálogos previstos (asociados a los 7 ámbitos en los que se estructura territorialmente Cataluña), a fecha de redacción de la presente tesis, están ya concluidos y aprobados los correspondientes a las Tierras de Lleida, al Campo de Tarragona y a las Tierras del Ebro. El catálogo de las Comarcas de Girona está sometido actualmente a información pública, y el resto de catálogos (Región Metropolitana de Barcelona, Alto Pirineo y Arán, Comarcas Centrales) podrían recibir la primera aprobación en los próximos meses. Se concluye de lo expuesto, que los trabajos técnicos para caracterizar y evaluar el paisaje en la totalidad de Cataluña están prácticamente concluidos.

Debe reseñarse en este punto, que, a diferencia de la Comunidad Valenciana, en la que los Estudios de Paisaje (figura prácticamente análoga al catálogo de paisaje), se desarrollan a tres niveles: autonómico, regional y municipal, la caracterización del paisaje en Cataluña se ha previsto únicamente a nivel regional. Dicha caracterización se ha realizado en 5 años y de forma sincronizada, de forma que generase a la mayor brevedad un marco paisajístico para el planeamiento urbanístico.

\section{3) Aplicaciones reales del Convenio: Análisis y Valoración de la situación actual}

a. Planificación del paisaje: Tal y como se indicaba anteriormente, la realización de los Catálogos de Paisaje desde el Observatorio de Paisaje de Cataluña y la adscripción de éstos a un nivel regional, ha permitido concluir los trabajos de caracterización y evaluación del paisaje. Dichos catálogos anticipan a su vez las correspondientes Directrices de Paisaje a definir por la Secretaría para la Planificación Territorial de la Generalitat de Cataluña con el apoyo del Observatorio del Paisaje para los mismos ámbitos que los catálogos. En particular, el contenido de las directrices queda en gran medida definido en los apartados siguientes de los catálogos:

- Objetivos de calidad paisajística (para el ámbito territorial de cada catálogo y, con carácter más específico, para las distintas unidades de paisaje incluidas dicho ámbito)

- Criterios y Acciones genéricas para la consecución de los objetivos de calidad paisajística formulados para el conjunto del ámbito y determinación de áreas especialmente susceptibles de protección, gestión y ordenación para cada unidad de paisaje. 
A fecha de redacción de la presente tesis, se han aprobado las directrices de paisaje de 3 de las 7 demarcaciones territoriales catalanas. En concreto, las correspondientes a Tierras del Ebro, Región Metropolitana de Barcelona y Comarcas de Girona, previéndose que las directrices correspondientes a las 4 demarcaciones restantes se aprueben en los próximos meses.

Dichas directrices, detallan e incorporan normativamente las propuestas de objetivos de calidad paisajística en los planes territoriales parciales y planes directores territoriales, que deberán ser su vez considerados en la planificación urbanística (Planes Directores Urbanísticos y Planes de Ordenación Urbanística Municipal). En lo relativo a directrices se distingue entre:

- Directrices generales: aplicables a los distintos paisajes de Cataluña

- Directrices específicas: definidas especialmente el ámbito territorial de cada Catálogo de Paisaje.

Dada la secuencial aplicación de las herramientas de planificación previstas en Cataluña, la efectividad de las directrices debería ser valorada una vez se apliquen y se incorporen al planeamiento urbanístico.

En lo referente a las Cartas de Paisaje, a fecha 2010, se habían redactado o estaban en elaboración un total de 6 cartas (Alto Penedés, Bergueda, valle de Camprodón, Anto Ampurdán, valle de Tenes y Priorato). Dichas cartas parten de una caracterización y determinación de objetivos de calidad paisajística a un grado de detalle mayor del proporcionado por los catálogos de paisaje. A partir de dicho punto, las cartas definen acciones de paisaje consensuadas por los distintos actores concernidos, así como un programa de gestión.

Como posibles aspectos a evaluar en la planificación del paisaje realizada hasta la fecha se citarían los siguientes:

- Ordenación paisajística detallada: la escala de trabajo de los catálogos de paisaje puede ser insuficiente para la ordenación paisajística a escala local. Esta circunstancia ya es señalada en las directrices de paisaje pero no se dispone de una herramienta específica y de obligado desarrollo, para caracterizar, evaluar y fijar objetivos de calidad paisajística o acciones de paisaje a nivel municipal. Como alternativa, cabe la redacción de Cartas de Paisaje, de desarrollo voluntario, o la redacción de planes especiales o planes directores. Esta posible insuficiencia no se daría con la metodología de la Comunidad Valenciana, al requerirse estudios de paisaje a escala autonómica, regional y local.

- Valoración paisajística: En los catálogos de paisaje se renuncia expresamente a asignar un valor paisajístico a los elementos del paisaje, lo que impide que las administraciones afectadas dispongan de elementos claros de juicio para priorizar las acciones o propuestas de paisaje. Esta circunstancia es señalada en las directrices de paisaje, donde se señalan los factores que deberían ser tenidos en cuenta para realizar dicha valoración.

- Acciones concretas sobre el paisaje: Las acciones previstas en los ámbitos tratados en cada Catálogo de Paisaje y en sus correspondientes unidades de paisaje, son de tipo genérico y no concretan estimaciones del coste de su implementación u observaciones sobre su urgencia o necesidad. Las cartas de paisaje concretarían las acciones a un nivel mayor de detalle pero su voluntaria redacción hace que, a fecha de hoy, esto se haya dado en sólo 6 áreas geográficas.

b. Proyectos de paisaje: Con el objeto de promover la cooperación del Departamento de Política Territorial y Obras Públicas con las administraciones locales, de marcar estrategias de intervención y de generar modelos de referencia ejemplarizante se han realizado actuaciones piloto en 4 ámbitos paisajísticos estratégicos:

a. Accesos a los núcleos urbanos

b. Espacios litorales

c. Carreteras

d. Espacios fluviales 
c. Divulgación y sensibilización: La intensa labor divulgativa y la diversidad de grupos sociales con los que ha trabajado el Observatorio del Paisaje han contribuido a generar una creciente cultura del paisaje en Cataluña. En este punto, los planes de participación pública y la web del Observatorio han sido fundamentales.

d. Formación: A pesar de la larga trayectoria de las universidades catalanas con respecto al resto de España en la docencia de la arquitectura del paisaje y de la creación de másteres no oficiales sobre planificación del paisaje, no se dispone en la actualidad de titulaciones del tipo grado o másteres oficiales que impartan la diversidad de materias vinculadas a la planificación y proyectación del paisaje. Desde el Departamento de Política Territorial y Obras Públicas se ha apoyado las iniciativas planteadas para la ampliación de los estudios universitarios en dicha materia, siendo previsible que se concreten en un breve plazo de tiempo. Por otro lado, desde el citado Departamento y desde el Observatorio del paisaje se han elaborado distintas guías y publicaciones, dirigidas, tanto a técnicos, como a estudiantes de secundaria o a público general. Entre éstas cabe destacar las siguientes:

- Prototipo de Catálogo de paisaje.

- Guía de Estudios de Impacto e Integración Paisajística

- Guía de integración paisajística de polígonos industriales

- Guía de integración paisajística de huertos urbanos y periurbanos

- Guía de integración paisajística de construcciones agrarias

- Ciudad, territorio y paisaje (materiales para la educación secundaria obligatoria)

- Ordenación y gestión del paisaje en Europa

- Indicadores del paisaje: retos y perspectivas

- Paisaje y salud

- Paisaje y participación ciudadana

e. Participación: La consulta pública es contemplada en el proceso de redacción de los Catálogos de Paisaje y de las Cartas de Paisaje. En el caso de los catálogos, los procesos de consulta se integran en todas las fases de su redacción (caracterización del paisaje, evaluación paisajística, definición de objetivos de calidad paisajística y propuesta de medidas y acciones), incluyendo entrevistas a agentes del paisaje, talleres abiertos o cerrados, encuestas telefónicas, consultas en la web del observatorio mediante encuestas dirigidas al conjunto de la sociedad. Del estudio del capítulo 1 del Catálogo de las Tierras de Lérida se deduce que las consultas de tipo presencial y directo se aplican especialmente en las fases de caracterización y evaluación, y que el sector más participativo para las encuestas abiertas a la población (disponibles en la web del Observatorio) fue el segmento de población con edades comprendidas entre 21 y 45 años (81\% de las 537 participaciones válidas). A modo de síntesis, podría concluirse que en los procesos de participación realizados hasta la fecha:

- Los procesos de participación son atendidos por grupos o personas con vinculaciones o lazos directos con los espacios o recursos incluidos en el ámbito del estudio pero no por amplios segmentos de la población residente o visitante, que a pesar de no tener una vinculación directa con los mismos, pueden verse beneficiados o perjudicados por su ordenación o gestión. Esto queda constatado en el no y perfil de visitantes de las encuestas disponibles en las webs empleadas.

- Las consultas se concentran en las fases de caracterización y evaluación del paisaje, quedando más limitadas en las partes propositivas de los catálogos.

- Cabe plantearse la necesidad de explorar metodologías más efectivas para los procesos de participación y reforzar su papel en la definición de objetivos de calidad paisajística y de acciones de paisaje.

\section{2.c.2 Otros ámbitos:}

A pesar de la ratificación por el estado español del Convenio Europeo del Paisaje en el año 2007, la transferencia a las comunidades autónomas de las competencias urbanísticas otorga una capacidad de maniobra limitada al gobierno central en la ordenación, gestión y protección del paisaje. Las iniciativas desarrolladas hasta la fecha por el Ministerio de Medio Ambiente y Medio Rural y Marino, ofrecen sin embargo ejemplos de referencia como la publicación del Atlas de los Paisajes de España (MATA OLMO, R y SANZ HERRAIZ, C. 2004) o las intervenciones en el dominio público hidráulico realizadas por algunas Confederaciones Hidrográficas, en las que se coordinan los objetivos marcados por la Directiva Europea Marco delAgua con los del Convenio Europeo del Paisaje. Las competencias del gobierno central en ordenación territorial, en el desarrollo de proyectos de carácter estatal o su capacidad para coordinar las acciones entre distintas 
comunidades autónomas, sugieren sin embargo que su papel puede ser relevante, especialmente en lo que se refiere a promover políticas de paisaje en las comunidades autónomas que carecen de éstas.

Analizados ya los casos de la Comunidad Valenciana y Cataluña, se resume a continuación la situación en el resto de Comunidades Autónomas, en las que, tal y como indican Valerià Paül y Arnau Queralt en su capítulo "Las políticas y los instrumentos de protección, gestión y ordenación del paisaje en España", incluido en la publicación "Ordenación y Gestión del Paisaje en Europa" (Observatorio del Paisaje de Cataluña, 2009), se distinguirían cuatro situaciones diferentes:

- Comunidades con leyes especificas de paisaje y con políticas o herramientas de paisaje en marcha: Comunidad Valenciana (2004) y Cataluña (2005).

- Comunidades con leyes especificas de paisaje pero sin políticas o herramientas de paisaje en marcha: Galicia (2008)

- Comunidades, que careciendo de leyes específicas de paisaje, han desarrollado estrategias y documentos generales de ordenación territorial en los que se incorpora la variable paisajística sin concretarse en muchos casos cómo se trasladará dicha variable a la planificación territorial detallada o al planeamiento urbanístico: caso de Navarra (2004), Andalucía (2006), Castilla-León (2008) y Canarias. A este grupo es previsible que se sumen en breve el Pais Vasco, La Rioja, Aragón y Castilla La Mancha.

- Comunidades en las que únicamente se incorporan consideraciones puntuales de tipo paisajístico en documentos urbanísticos o de planificación territorial: caso de Extremadura y Madrid.

A nivel europeo, se constata una situación muy desigual, sobresaliendo por el grado de integración del paisaje en la ordenación territorial los casos de Holanda, Dinamarca, Reino Unido y Suiza.

HOLANDA: En el caso de Holanda se partía de una situación previa especialmente favorable que ha sido sin embargo potenciada y reforzada por medio del Convenio Europeo del Paisaje. Tal y como indican Dirk M. Wascher y Rob Schröder en la publicación "Ordenación y Gestión del Paisaje en Europa" (Observatorio del Paisaje de Cataluña, 2009), el Memorandum del paisaje (Nota Landschap) del año 1992 planteaba como objetivos principales "el fomento de la conservación, la recuperación y el desarrollo de un paisaje de calidad, es decir, de un paisaje que tenga como rasgos distintivos la identidad y la sostenibilidad. De esta manera, la calidad del paisaje, entendida en términos estéticos, ecológicos y económicos, queda definida como el aspecto más relevante de la política del paisaje". El Memorandum del paisaje asumía los principios holandeses de segregación funcional, por los que se realiza una separación entre las funciones más estáticas del territorio (por ejemplo la silvicultura, la protección de la naturaleza o la retención de aguas), y las funciones más dinámicas, expuestas a las tendencias del mercado y los avances tecnológicos.

Tal y como exponen Wascher y Schröder, "con la aplicación del Memorandum del paisaje, la definición y la delimitación de las tipologías paisajísticas y las evaluaciones del paisaje pasaron a ser instrumentos decisivos, si bien en los Países Bajos la evaluación del paisaje ya formaba parte del planeamiento territorial y regional desde tiempo atrás" Posteriormente al Memorandum de Paisaje, el Memorandum Belvedere (1999), creado a iniciativa de cuatro ministerios, sentó las bases para salvaguardar y desarrollar la identidad histórica y cultural como un factor determinante en la ordenación territorial, adquiriendo en este punto una importancia esencial el concepto de paisaje cultural. De igual modo, el Manifiesto del Paisaje (2005), "se enmarca en el actual contexto de desregulación y descentralización administrativa de los Países Bajos" y tiene entre sus objetivos la creación de una fundación de carácter mixto publico y privado, destinada a continuar recuperando y desarrollando el paisaje.

La política de paisaje holandesa se complementa a su vez con políticas sectoriales y, en especial, con la planificación territorial, quedando estructurada en los siguientes tres ámbitos de acción política, coordinados por sus respectivos ministerios:

- La planificación territorial: incluye la planificación del conjunto del territorio y la arquitectura del paisaje

- Las políticas ambientales, vinculadas a la conservación de paisajes naturales y a la creación de nuevos espacios verdes o naturales.

- Las políticas culturales, sobre todo la conservación de monumentos históricos y panorámicas de interés cotidiano y de especial interés.

REINO UNIDO: A partir de los conceptos "Tipo de Paisaje" (landscape type) y "Área de Carácter paisajístico" (landscape carácter area), asimilable en gran medida al concepto de unidad de paisaje, las organizaciones Countryside Agency, English Nature , con la colaboración de English Heritage y del Departamento de Medio Ambiente, Transporte y Regiones, realizaron en los años 90 una caracterización del paisaje de Inglaterra en la 
que se tuvo en cuenta los factores que determinaban el carácter y las dinámicas que podían llevar a su transformación. El mapa de caracteres desarrollado constituye un marco de referencia susceptible de ser desarrollado a más detalle, contemplándose distintos niveles de precisión para los "tipos" y "áreas de carácter" paisajístico. En opinión de la profesora Caryn Swanwick, "ya es visible el uso de la evaluación del carácter del paisaje en una gran variedad de aplicaciones en el Reino Unido y es muy posible que en el futuro su presencia este aun más extendida".

Las iniciativas en materia de pasaje podrán a su vez integrarse en una intensa y articulada línea de acciones dirigidas por la Oficina del Primer Ministro que quedan recogidas en una serie de Principios de Planeamiento (Planning Policy Statements) en los que se plantean las bases para lograr un desarrollo y uso sostenible del territorio así como la creación de comunidades cohesionadas y entornos de calidad.

FRANCIA: En el caso de Francia, a raíz de la aprobación de la ley de paisaje en el año 1993, se iniciaron los trabajos de redacción de un atlas de paisajes para los 100 departamentos en los que se organiza administrativamente dicho país. El atlas, se realizaría a una escala 1:25.000 y se basaba en una metodología que, partiendo de la identificación de las estructuras paisajísticas y de la percepción social de éstas, permitía en una segunda fase definir las correspondientes unidades de paisaje. Dichas unidades eran analizadas seguidamente en lo referente a las dimensiones de su percepción social (paisajes reconocidos., paisajes representados, paisajes destacados y paisajes percibidos), así como en sus dinámicas internas. Según explica el profesor Jean-François Seguín en el capítulo "Identificación y cualificación de los paisajes: la experiencia Francesca de los atlas de paisaje" incluido en la publicación Ordenación y Gestión del Paisaje en Europa (Observatorio del Paisaje de Cataluña, 2009), a fecha 2009 estaban publicados 69 de los 100 atlas y 16 estaban en proceso de elaboración, si bien, los primeros atlas producidos habían demostrado una utilidad limitada y cabría plantearse, a partir de la experiencia propia y la de otros países, revisar las metodologías aplicadas en su preparación.

SUIZA: Tal y como expone Matthias Stremlow, en el capítulo "Paisaje y desarrollo sostenible: proyecciones de futuro. Resultados del proyecto suizo Paysage 2020" de la publicación citada anteriormente, Suiza, ofrece un interesante ejemplo de modelización de un escenario ideal de la naturaleza y del paisaje en el país alpino para el año 2020. La caracterización previa del paisaje y la modelización de su evolución se basó en 9 criterios y 37 indicadores, que permitieron seguidamente definir 32 objetivos de calidad paisajística y un paquete de medidas agrupadas en 8 campos de acción: paisaje y usos del suelo; paisaje y política territorial; paisaje e hidrología; especies y medio natural; ser humano y paisaje (percepción y experiencias); participación; instrumentos económicos y uso de los recursos, e investigación y posibilidades de futuro.

\section{2.d. Conclusiones:}

Transcurridos 10 años de la redacción del Convenio Europeo del Paisaje, 6 años de la aprobación de la ley Valenciana de paisaje y 5 de la ley catalana, el estudio de la situación actual en Europa y España en lo referente a la planificación de paisaje, ha permitido determinar los siguientes aspectos susceptibles de estudio y consideración en la presente tesis. Dichos aspectos se sintetizan a su vez en la figura 2.1. (Conclusiones y cuadro comparativo de herramientas de planificación del paisaje y de su integración en el planeamiento territorial urbanístico entre las comunidades autónomas de Valencia y Cataluña):

1. Necesidad de establecer una estructura legal, administrativa y las conexiones interdepartamentales que permitan sustentar, dirigir e incorporar la transversalidad del paisaje.

2. El estudio y planificación del paisaje está directamente vinculado a las distintas escalas del territorio (macro-regional, regional o local), siendo necesario considerar detenidamente en cual o cuales de ellas se quiere que se utilicen las herramientas de paisaje.

3. En caso de abordarse la caracterización, evaluación, determinación de objetivos de calidad y establecimiento de directrices, normativas o acciones de paisaje a distintas escalas, se recomendaría trabajar coordinada y secuencialmente los trabajos en dichas distintas escalas.

4. La valoración del paisaje y de sus elementos definitorios supone un reto técnico y metodológico pero permite sustentar la posterior toma de decisiones o la priorización de acciones.

5. Los objetivos de calidad paisaíistica pueden y deben ser definidos para las distintas escalas del territorio.

6. Las acciones (programas, proyectos, etc) que se sugieran como conclusión de los trabajos de planificación del paisaje, deberían estar acompañadas de información referente a su importancia, urgencia y coste estimativo. 
7. La participación pública debe ser regulada de forma que alimente adecuadamente las distintas fases de la planificación del paisaje y que recoja las sensibilidades y opiniones tanto de muestras representativas de la población residente y visitante, como de grupos o particulares con vinculaciones más directas al territorio objeto de estudio.

8. La incorporación del paisaje al planeamiento territorial y urbanístico se puede dar, tanto a nivel de directrices/normas/recomendaciones, como por la determinación de espacios físicos con un tratamiento urbanístico específico justificado por sus valores paisajísticos.

9. La unidad de paisaje constituye un módulo adecuado para la caracterización del paisaje pero puede resultar limitante en la definición de objetivos de calidad paisajística, criterios de intervención o acciones de paisaje, especialmente en lo que se refiere a sistemas o redes compartidas por distintas unidades.

10. La aplicación de las herramientas previstas en la planificación del paisaje requiere disponer de técnicos con una formación específica en la materia. Dicha formación debería, en base a los casos estudiados, tener un carácter altamente transversal, multi-escalar y tratar aspectos analíticos y propositivos. Adicionalmente, la existencia de guías metodológicas para la redacción de los documentos asociados a las citadas herramientas y de ejemplos de referencia, facilitaría sustancialmente su desarrollo y uso.

11. La formación en los distintos niveles de la enseñanza, la participación pública y la divulgación, son las bases para crear una cultura del territorio y del paisaje que sustente la efectiva aplicación de políticas en dichos campos.

12. La realización y difusión de proyectos piloto que concreten las políticas de paisaje, son de gran importancia para que el conjunto de la sociedad pueda constatar los beneficios de apoyar dichas políticas y contar con referentes ejemplarizantes. 


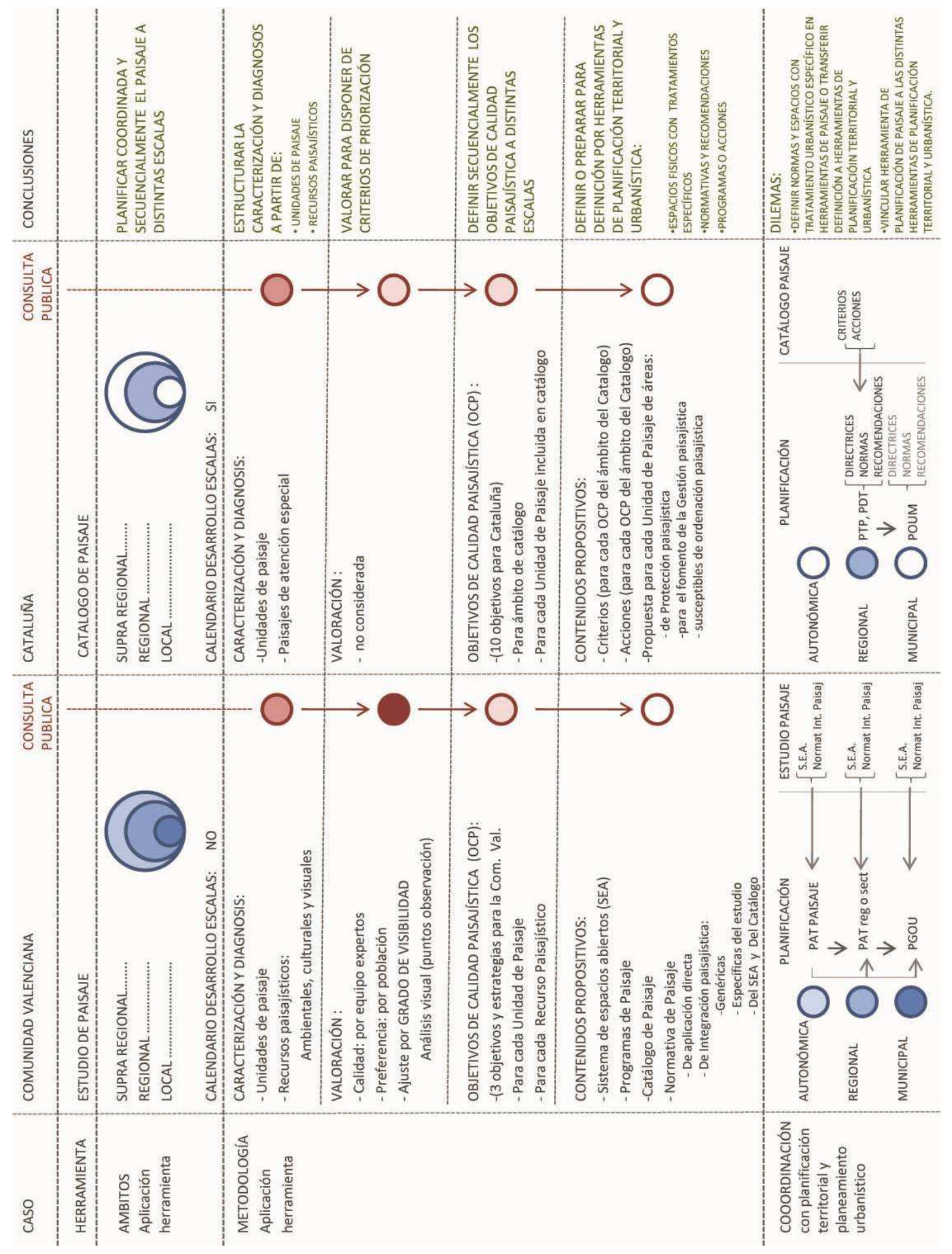

Tabla 2.1. Conclusiones y cuadro comparativo de herramientas de planificación del paisaje y de su integración en el planeamiento territorial urbanístico entre las comunidades autónomas de Valencia y Cataluña. 
VALORACIÓN Y GESTIÓN DEL PAISAJE SEGÚN EL CONVENIO EUROPEO DEL PAISAJE YEL

REGLAMENTO DEL PAISAJE DE LA COMUNIDAD VALENCIANA: APLICACIÓN MEDIANTE UN ESTUDIO

DE PAISAJE A UNESPACIO ABIERTO EN LA COMUNIDAD VALENCIANA

DOCTORANDO: JUAN JOSÉ GALÁN VIVAS (Universidad Politécnica de Valencia, enero 2011) 
VALORACIÓNY GESTIÓN DEL PAISAJE SEGÚN EL CONVENIO EUROPEO DEL PAISAJE YEL

REGLAMENTO DEL PAISAJE DE LA COMUNIDAD VALENCIANA: APLICACIÓN MEDIANTE UN ESTUDIO

DE PAISAJE A UNESPACIO ABIERTO EN LA COMUNIDAD VALENCIANA

DOCTORANDO: JUAN JOSÉ GALÁN VIVAS (Universidad Politécnica de Valencia, enero 2011)

\section{REVISIÓN BIBLIOGRÁFICA}


VALORACIÓN Y GESTIÓN DEL PAISAJE SEGÚN EL CONVENIO EUROPEO DEL PAISAJE YEL

REGLAMENTO DEL PAISAJE DE LA COMUNIDAD VALENCIANA: APLICACIÓN MEDIANTE UN ESTUDIO

DE PAISAJE A UNESPACIO ABIERTO EN LA COMUNIDAD VALENCIANA

DOCTORANDO: JUAN JOSÉ GALÁN VIVAS (Universidad Politécnica de Valencia, enero 2011) 


\section{REVISIÓN BIBLIOGRÁFICA}

\subsection{Conceptos}

A grandes rasgos, las fuentes bibliográficas estudiadas y la definición de términos, recogida en el apartado 3.2 del presente capítulo (estudio terminológico y metodológico), tienen por objeto evaluar el estado actual de las siguientes cuestiones vinculadas a la presente tesis:

1) ¿Qué se entiende por paisaje?.

2) ¿Cómo se puede caracterizar y valorar el paisaje?

3) ¿Es adecuado y conveniente que el paisaje se incorpore en la planificación territorial y urbanística? Y en caso afirmativo, ¿Cómo se puede hacer esto de una forma efectiva?.

El carácter transversal del paisaje, y en particular, su vinculación en la presente tesis a la ordenación del territorio y a la planificación urbanística, exige la consulta de fuentes bibliográficas relacionadas con materias diversas, agrupables de acuerdo a la siguiente temática:

- Concepto de paisaje.

- Descripción y valoración estética del paisaje.

- Análisis visual del paisaje.

- Valoración económica del paisaje.

- Gestión, protección y ordenación del paisaje.

- Paisaje y ordenación territorial.

- Paisaje y planificación urbanística.

- Herramientas para la planificación del paisaje.

Tal y como se resume a continuación, las fuentes bibliográficas y autores consultados en la presente tesis han permitido determinar una serie de aspectos de especial relevancia en cada uno de los temas arriba listados:

\section{1.a. Paisaje}

La ampliación de concepto d,e paisaje hacia el de cualidad territorial, su desvinculación de espacios de especial valor o de carácter natural, y muy especialmente, su percepción como variable útil y necesaria para una adecuada ordenación territorial y para la creación de comunidades identificadas con su territorio, han generado una revisión intensa del concepto de paisaje que, tal y como se expone en el apartado 2 del presente capítulo (Estudio terminológico y metodológico), ha culminado en la redacción del Convenio Europeo del Paisaje y en la definición de paisaje contenida en éste.

\section{1.b. Caracterización y valoración física del paisaje}

La descripción física del paisaje como suma o combinación de elementos y variables centró históricamente los primeros pasos del estudio del paisaje e, inevitablemente, fue acompañada del estudio de los procesos perceptivos y cognitivos por los que el sujeto capta y valora el paisaje, entendiendo a su vez que dicho sujeto es a la vez individuo y parte de una determinada sociedad y cultura. De igual modo, la caracterización del paisaje asume que su configuración en un determinado momento es fruto de una serie de procesos de índole natural y antrópica que lo modelan y que de igual modo llevarán a su transformación posterior.

El conjunto de fuentes consultadas y las conclusiones obtenidas aparecen detalladas en el apartado 2 (Estudio terminológico y metodológico) del presente capítulo, en el que, paralelamente a la caracterización del paisaje y sus principales metodologías, se analizan conceptos altamente vinculados como el de unidad de paisaje o el de recurso paisajístico.

Igualmente, han resultado especialmente útiles al objeto del desarrollo de la presente tesis, las investigaciones realizadas por el profesor Carl Steinitz, cuyos trabajos y materiales docentes, escritos o agrupados durante su periodo como profesor de Arquitectura y Planificación del Paisaje en la Universidad de Harvard, permiten seguir la evolución en las técnicas y metodologías de caracterización y valoración visual del paisaje, diferenciando entre modelos de caracterización y valoración visual del paisaje desde puntos, líneas o áreas extensas y estableciendo a su vez vínculos con otros investigadores como Kevin Lynch, Stephen Kaplan, Donald Appleyard, K, Craik, Richard Forman o J. Appleton. 
Dentro del ámbito nacional, los trabajos desarrollados por A. Ramos, R. Mata, R. Escribano, Mํ P. Aramburu o F. Galiana han permitido avanzar en la definición de metodologías dirigidas a describir y predecir el valor o preferencia del Paisaje.

Del conjunto de fuentes consultadas se concluye que, desde hace más de 100 años, viene desarrollándose una intensa investigación sobre el proceso de percepción del paisaje y sobre los criterios o factores que determinan su mayor o menor calidad para un individuo o sociedad. Fruto de dichas investigaciones, se puede afirmar que existen aspectos, tanto de tipo cultural como de tipo natural, que explican el valor de un paisaje y se han desarrollado metodologías que permiten realizar una valoración tanto técnica como participativa de éste. En este segundo caso, la calidad del paisaje puede pasar a ser entendida como "preferencia", asumiéndose, que ésta, es fundamentalmente el resultado de un proceso empírico, y que al igual que gran parte de nuestros códigos sociales, obedece a un consenso y a un hecho cultural. Entre las metodologías consultadas para valorar estéticamente el paisaje destaca la propuesta por el Reglamento de Paisaje de la Comunidad Valenciana que aúna ambos criterios, el de calidad paisajística y el de preferencia paisajística, asociando el primero a la opinión de expertos y el segundo al de la población.

\section{1.c. Visibilidad del paisaje:}

El estudio de la visibilidad del paisaje se ha centrado tradicionalmente en los siguientes cuatro aspectos:
Proceso físico, cognitivo y memorístico vinculado a la visualización Determinación del espacio físico visible (desde un punto, línea o área) Influencia de la frecuencia de observadores y de la intensidad de los estímulos en el grado de visibilidad Integración del grado de visibilidad de un elemento o espacio en los procesos de proyectación o planificación del paisaje

Tal y como se expone más extensamente en el apartado 3.2 (Estudio terminológico y metodológico) del presente capítulo, los estudios realizados sobre este tema se encuentran estrechamente vinculados a los de percepción y memorización del paisaje, destacando los trabajos realizados en esta campo por Kevin Lynch en sus publicaciones "The Image of the City" o "City Sense and Design" o por Donald Appleyard, Kevin Lynch y John R. Myer en su "The View from the Road".

En lo referente a análisis visual del territorio resultan de especial interés a efectos del desarrollo de la presente tesis el estudio de modelos puntuales, lineales o extensos, realizado por Carl Steinitz así como sus trabajos "Towards a Sustainable Landscape with High Visual Preference and High Ecological Integrity: the Loop Road in Acadia National Park, U.S.A.”, "Alternative Futures for Changing Landscapes: The Upper San Pedro River Basin in Arizona and Sonora", "The Visual Landscape of the Veneto: Past, Present and Future", o muy especialmente el "Plan Visual de la Comunidad Valenciana", realizado en el año 2008. En el ámbito nacional, destacan las bases teóricas y metodologías desarrolladas por los profesores Ángel Ramos, Rafael Escribano, Francisco Galiana, Miguel Aguilo y Paz Aramburu en sus estudios sobre la visualización y caracterización del paisaje.

Igualmente, sobresalen por su carácter aplicado y funcionamiento a distintas escalas, los trabajos de la profesora Rosa Barba, en los que la visibilidad adquiere un papel principal como herramienta de planeamiento ( $P G O U$ de Sant Feliu de Guixols, de Soller, de Torroella de Montgri y de Alcañiz), de ordenación territorial (Plan Insular de Gran Canaria), de integración visual de infraestructuras (Estudio de los entornos de la autopista A-7) y de configuración interna de proyectos de espacios abiertos.

En lo referente a la valoración de la incidencia paisajística y visual resulta de espacial relevancia la guía elaborada en el año 2002 por el Instituto Británico de Paisajismo "Guidelines for Landscape and Visual Impact Assessment".

Finalmente, la aplicación en la Comunidad Valenciana y Cataluña de políticas de paisaje que apoyen la planificación territorial, ha requerido una revisión del papel de la visibilidad en el estudio del paisaje, constituyendo las metodologías propuestas por el Prototipo de Catálogos de Paisaje de Cataluña (Observatorio del Paisaje de Cataluña, 2007) y por el Reglamento de Paisaje de la Comunidad Valenciana (2006) dos ejemplos especialmente ilustrativos. En el primero de los casos, la visibilidad se considera un factor de especial importancia para la "definición de las unidades de paisaje, ya que la observación y comprensión del paisaje está fuertemente condicionada por la existencia de unos ciertos puntos de observación y de recorridos visuales (hitos 
topográficos, núcleos urbanos, vías de comunicación,...), que son los que en mayor medida contribuyen a la percepción del paisaje". En el caso del Reglamento de Paisaje de la Comunidad Valenciana, se parte de las mismas consideraciones pero se procede además a integrar la visibilidad de forma específica y detallada en la metodología para la redacción de estudios de paisaje y estudios de integración paisajística.

A partir de la revisión bibliográfica realizada se puede concluir que el análisis visual del paisaje se corresponde al de la estructura visual del territorio y al de la percepción de éste por posibles observadores. Frente a los análisis que determinan la visibilidad de un punto del territorio desde el resto de puntos, cabe incorporar la idea de que no existe paisaje sin observador, y otorgar una mayor visibilidad, no solo a los puntos físicamente más visibles, sino a aquellos percibidos por un oㅡ mayor de observadores. El conjunto de técnicas para determinar la "visibilidad estructural", entendida esta como la dada por su estructura fisiográfica del territorio y la de los elementos sobre él dispuesto, y para determinar la "visibilidad adquirida" del territorio, entendida ésta como la ajustada en función del número y grado de atención de los observadores, se ha visto mejorada sustancialmente en las últimas décadas como consecuencia del desarrollo de las herramientas SIG. Existe sin embargo, especialmente en lo referente a la "visibilidad adquirida", un importante trabajo preparatorio al análisis visual del paisaje por el que debe definirse el grado de frecuentación del territorio, con especial atención tanto a las áreas habitadas como a las infraestructuras de transporte.

Asumiendo lo anteriormente expuesto, y con la consideración adicional de la especial importancia del sentido de la vista en la percepción del paisaje, las herramientas de paisaje de la Comunidad Valenciana consideran que los espacios más vistos deben tener mayor "importancia paisajística" y deben, consecuentemente, ser objeto de actuaciones preferentes dirigidas a su protección, gestión u ordenación. A su vez, con el objeto de evitar la posible desatención de espacios poco visibles de alto valor paisajístico, la metodología prevista por el reglamento de paisaje de la Comunidad Valenciana prevé la ubicación en éstos de "puntos de observación principales" que aumenten su "importancia visual" y prioricen, o al menos no desincentiven, la aplicación en ellos de acciones de protección, gestión u ordenación.

\section{1.d. Valoración económica del paisaje:}

Los aspectos económicos vinculados al desarrollo de la presente tesis son podrían ser tratados de acuerdo a un triple objetivo:

1) Valoración económica del paisaje como procedimiento para determinar el valor económico directo e indirecto de un determinado espacio o elemento como consecuencia de sus características paisajísticas. Valoración de aspectos económicos asociados al paisaje como indicadores indirectos del nivel de preferencia o disconformidad de la población con un determinado paisaje y como exploración de vías de financiación de programas de protección, gestión u ordenación del paisaje.

3) Consideración de variables económicas en la determinación de la estabilidad de territorios productivos y en la predicción u orientación de su evolución futura.

En lo referente al primero de los objetivos, la valoración económica del paisaje exige asignar un valor económico a un activo que participa de las siguientes características (CABALLER, 2005): (1) Se trata de bienes de uso público, de tal manera que el uso por determinados agentes económicos, no es exclusivo ni impide el uso por otros grupos sociales, (2) son bienes que no generan flujos de caja apropiables, (3) debido a las dos características anteriores, son bienes que no son susceptibles de sufrir transacciones y por lo tanto no están sujetos al mercado, al ser éste inexistente.

Como consecuencia de esta última característica no es posible utilizar la estimación de su valor monetario por comparación con otros bienes que hayan sido expuestos a una transacción económica, lo que obliga a desechar toda la metodología clásica del campo de la tasación.

Los estudios sobre la valoración económica del paisaje se relacionan de este modo con los estudios de otros activos como el medio ambiente y el patrimonio arquitectónico, requiriendo la determinación de métodos de valoración indirectos entre los que se incluyen fundamentalmente: el "travel cost" o coste del viaje, el valor contingente y el valor hedónico. En todos ellos se pretende deducir la parte de valor económico objetivo y medible que corresponde a la variable paisaje. En particular el coste de viaje se define como el gasto realizado por un determinado individuo para disfrutar de un determinado bien, tangible o intangible. Se infiere que a mayor coste de viaje, mayor satisfacción obtiene el individuo. Ejemplos clásicos de este coste serían los gastos por visitas a lugares de alto atractivo turístico o enclaves naturales de alta singularidad, de los que quedaría por 
determinar la parte del gasto debida a la intención de disfrutar de un determinado paisaje, segregando para ello las partes correspondientes a otras variables (prestigio, salud, cultura, etc).

El valor contingente se define como la predisposición de un sujeto a asumir un gasto con el objeto de mantener un determinado lugar o escenario ante la posibilidad de que en dicho territorio se desarrollen cambios. Un posible ejemplo sería la realización de una recolecta para salvar un paisaje ante el riesgo de su desaparición. Finalmente, el valor hedónico es el efecto positivo o negativo que tiene un determinado paisaje sobre los activos inmobiliarios que lo rodean.

A efectos del desarrollo de la presente tesis resultan de especial interés los trabajos realizados por Vicente Caballer sobre valoración de activos inmateriales o los artículos "Public Welfare and the Economics of Landscape Aesthetics" o "The Price of Aesthetic Externalities" (Bourassa et al; 2006), que proporcionan una sólida introducción a los problemas a los que se enfrenta la valoración económica del paisaje.

Los procedimientos y metodologías existentes en este campo son a su vez desarrollados y explicados en las publicaciones de D. W. Pearce "Cost-Benefit Analysis", de Charles Cooper "Economic Evaluation and the Environment" y Guy Garrod y Kenneth G. Willis, en cuyo libro "Economic Valuation of the Environment' se incluye un capítulo especifico dedicado al paisaje.

Finalmente, el trabajo de suficiencia investigadora elaborado como paso previo a la redacción de la presente tesis (GALÁN VIVAS, JJ. Ver anexo I)) incluye a su vez ejemplos de valoración económica del paisaje según las distintas metodologías existentes.

A partir del estudio de la bibliografía consultada, se concluye que las metodologías existentes en la valoración económica del paisaje están progresando y que pueden constituir en un futuro una herramienta fundamental en la justificación y aplicación de medidas para la protección, gestión o mejora del paisaje, cuya mejora de calidad genera unas externalidades positivas difíciles de cuantificar, y aun más difíciles de separar de las correspondientes a otras variables altamente asociadas como son el medio ambiente, el patrimonio arquitectónico y cultural, etc.

En lo referente al segundo objetivo de la valoración económica del paisaje en la presente tesis, correspondiente al uso de aspectos económicos como indicadores indirectos del nivel de preferencia o disconformidad de la población con un determinado paisaje, se aprecia que los métodos de valoración contingente, al preguntar al encuestado o participante cuanto estaría dispuesto a pagar para disfrutar de un paisaje, o inversamente, en cuanto debería ser indemnizado para dejar de hacerlo, establecen un indicador indirecto de preferencia paisajística. Dicho indicador, al asociarse a una cantidad económica concreta, adquiere un carácter cuantitativo y proporciona un elemento de comprobación de grados de preferencia manifestados por la población por otras vías.

Adicionalmente, la presentación de cuestiones destinadas a conocer la disposición de la población a contribuir monetaria o físicamente en los trabajos de gestión, protección u ordenación del paisaje, permiten explorar vías de financiación o de asignación de recursos.

El conjunto de aspectos tratados en este segundo objetivo se incorporan a la metodología propuesta en el capítulo 4 de la presente tesis, presentándose los resultados de su aplicación práctica en el capítulo 5, y más detalladamente, en el anexo I "Valoración económica del paisaje".

Finalmente, el tercer objetivo, correspondiente a la determinación de aspectos económicos para el análisis, diagnóstico y desarrollo de propuestas sobre el paisaje, se constata que, a pesar de que los territorios (y paisajes) productivos ocupan la mayor parte de la superficie de los países desarrollados, y que por lo tanto, su permanencia o cambio obedece en gran medida a motivos económicos, las variables económicas no suelen considerase suficientemente en la planificación del paisaje.

\section{1.e. Planificación del paisaje}

La planificación del Paisaje nos sitúa en un área, que por su escala, herramientas de trabajo y documentación generada, presenta una mayor vinculación con la ordenación territorial y planificación urbanística que con los ámbitos propios del proyecto de paisaje. Así, esta planificación, excede ampliamente los trabajos de integración paisajística y busca contribuir a un mejor ordenamiento y planificación territorial, al bienestar individual y colectivo, 
y al desarrollo sostenible, incomorando adicionalmente aspectos asociados a la calidad visual y de uso del territorio.

El paisaje así entendido se convierte en un agente activo, y no en el resultado de la modificación del territorio de acuerdo a criterios sectoriales, aportando a su vez una visión transversal que necesariamente debe estar apoyada en un conocimiento de los procesos naturales y humanos existentes o futuros.

Así pues, y tal como expone Joan Ganyet en la introducción de la publicación "Ordenación y Gestión del Paisaje en Europa" (Observatorio del Paisaje de Cataluña, 2009), serían objetivos de la legislación, en este caso catalana, de paisaje, y por ende de la planificación del paisaje, "la protección, la gestión y la ordenación de todos los paisajes, lo que representa un gran reto". Con dicho fin y asumiendo los límites de lo posible, la legislación y planificación del paisaje, "no pretende regular todos y cada uno de los elementos que influyen en la producción y la transformación del paisaje, sino que se inscribe en un modelo mucho mas general que incluye la ordenación del territorio y el planeamiento de las actividades sectoriales".

La planificación del paisaje así entendida, se concretaría en documentos (planes estratégicos de paisaje, catálogos de paisaje, estudios de paisaje, etc) que describirían los criterios o las acciones a desarrollar para dirigir su evolución, y que, necesariamente, partiendo de trabajos previos de análisis y diagnóstico, deberían seguidamente establecer unos objetivos paisajísticos y los mecanismos para conseguirlos.

En el ámbito europeo, y probablemente a nivel mundial, la redacción del Convenio Europeo del Paisaje ha establecido un antes y un después en este campo, reforzando la participación pública y estableciendo tres grandes aproximaciones al paisaje: protección, gestión y ordenación.

Dicho convenio culmina un proceso de décadas y supone en la actualidad una referencia obligada en la elaboración de políticas y planes de paisaje de carácter internacional, nacional, regional o local en la mayor parte de Europa.

La revisión bibliográfica en este campo requiere el estudio de las metodologías y ejemplos desarrollados en Gran Bretaña, donde la guía de la Countryside Agency para la Evaluación del Paisaje (Landscape Character Assessment), del año 2002, incluye indicaciones para la redacción de planes, o donde el gobierno británico a través de su "Planning Policy Statement $n^{\circ}$ 11", dedicado a las Estrategias de Ordenación Regional, expone aspectos de alto interés para la planificación y monitorización del paisaje.

Como resultado de la aplicación de las citadas guías se han producido a su vez planes estratégicos, entre los que destaca "A Landscape Strategy for Lancashire" (Diciembre, 2000), un interesante trabajo en el que, tras una caracterización del paisaje, en la que se definen tipos y unidades de paisaje, se pasa a exponer los principales factores de transformación, las estrategias a aplicar en cada unidad y los indicadores que permitan monitorizar la evolución del paisaje. Vinculados a este documento, se desarrollaron a su vez estudios sectoriales como el dedicado a la implantación de campos de aerogeneradores en el citado condado de Lancashire.

Ejemplos igualmente interesantes a nivel regional son el "Landscape Character Supplementary Planning Document", redactado el año 2006 para la mancomunidad de High Peak, limítrofe con el Parque Natural de "Peak District", en el que, para cada unidad de paisaje, se marcan criterios generales que orienten el desarrollo urbanístico, detallándo a su vez criterios concretos para pequeñas y grandes construcciones. Dentro del ámbito estrictamente rural resulta igualmente relevante el trabajo desarrollado por Baker Associates Planning Consultants en su "Integrated Approach to Sustainable Rural Planning in East Northamptonshire", (octubre 2005) en el que se desarrollan, con una fuerte influencia del paisaje, directrices de desarrollo rural en una zona con un marcado y valioso carácter agrícola. Finalmente, atendiendo principalmente al objetivo de crear comunidades sostenibles, la guía "Planning for Sustainable Settlements in the High Weald AONB" proporciona interesantes criterios a los planificadores a la hora de definir políticas, herramientas e indicadores de seguimiento en los aspectos siguientes:

- $\quad$ Sostenibilidad ambiental: (1) Paisaje, (2) Biodiversidad, (3) Patrimonio Cultural, (4) Tranquilidad, (5) Gestión del medio rural, (6) Patrones en asentamientos humanos, (7) Diseño y materiales, (8) Uso de los recursos: energía y transporte, (9) Productos locales y (10): Residuos

- $\quad$ Sostenibilidad social: (1): equilibrio demográfico, (2) Equilibrio social, (3) Acceso a la vivienda, (4) Servicios, (5) Empleo, (6) Ocio, (7) Gobernanza, (8): Integración social, (9) Modos de vida sostenibles, (10) calidad de vida 
- $\quad$ Sostenibilidad económica: (1) Economía local, (2) Recursos locales y (3) Ocio y Turismo.

A escala regional resulta igualmente valioso el informe "From Special Landsacape Areas to Landscape Character" elaborado en febrero del año 2006 por Countryscape, en el que se exponen para el condado de Derbyshire, los procedimientos que deberían permitir vincular el estudio de paisaje del condado con el nuevo planeamiento de desarrollo urbano.

La consulta de los trabajos realizados en planificación del paisaje en el ámbito de los Estados Unidos proporciona a su vez interesantes referentes, entre los que se incluyen los ya comentados de Carl Steinitz "Towards a Sustainable Landscape with High Visual Preference and High Ecological Integrity: the Loop Road in Acadia National Park, U.S.A." y "Alternative Futures for Changing Landscapes: The Upper San Pedro River Basin in Arizona and Sonora", en los que, tras tratar aspectos de carácter regional, se pasa a continuación a desarrollar aspectos de detalle, tales como la intervención en el entorno de infraestructuras o la definición de criterios para la ubicación de nuevos edificios.

Finalmente, y ya dentro del ámbito español, son de referencia obligada las metodologías propuestas para los Catálogos de Paisaje en Cataluña y para los Estudios de Paisaje en la Comunidad Valenciana, expuestas respectivamente en el "Prototipo de Catálogo de Paisaje" (Observatorio del Paisaje, 2006) y en el "Reglamento del Paisaje de la Comunidad Valenciana" (2006). Dichas metodologías, resumidas en el capítulo 2 de la presente tesis y en el apartado 3.7 del presente capítulo, han sido ya aplicadas, contándose con ejemplos de referencia en los Catálogos de Paisaje de las siete regiones administrativas en las que ha quedado estructurada territorialmente Cataluña o en algunos de los Estudios de Paisaje redactados hasta la fecha en la Comunidad Valenciana.

Adicionalmente, y también dentro del ámbito nacional, cabe diferenciar los ejemplos de planes territoriales apoyados en el paisaje y los estudios vinculados a la gestión del paisaje.

En el primero de los grupos se incluirían ejemplos como el "Plan Territorial Insular de Menorca", redactado por Rafael Mata Olmo en el año 2003, que tuvo por objeto establecer el marco de planeamiento para la Ordenación Sostenible del territorio de Menorca, determinando para ello: (1) Las dimensiones físicas de los asentamientos, (2) la distribución espacial de las instalaciones productivas propias de los asentamiento primarios y secundarios, (3) Los núcleos de población que deban facilitar el desarrollo socioeconómico de la isla, (4) las áreas territoriales objeto de especial protección por motivos productivos, paisajísticos y ecológicos, (5) las principales infraestructuras, instalaciones equipamientos y servicios y (6) el marco de referencia para las políticas sectoriales. El Plan incluyó a su vez un Plan de Ordenación de la Oferta turística (POOT) así como la definición de una red interconectada de espacios abiertos, proponiendo en casos puntuales la desclasificación de zonas urbanizables. El paisaje se integra a todos los niveles en la redacción del Plan, si bien, dada su redacción previa a la difusión del Convenio Europeo del Paisaje, incluye un acercamiento fundamentalmente proteccionista, sin referencias explicitas a la gestión y ordenación. Las unidades de paisaje definidas en el Plan no incluyen normativas o directrices pero guían la redacción del mismo y apoyan propuestas concretas referentes a problemas tales como la ubicación de aerogeneradores o antenas de telefonía. De gran interés resultan igualmente las "Directrices de Ordenación del Paisaje de la Comarca Noroeste de la Región de Murcia", redactadas por Santiago Fernández Muñoz, Luis Galiana Martín y Rafael Mata Olmo en el año 2006.

Por su metodología y vinculación con el ámbito en el que se desarrollan los trabajos de la presente tesis, debe de destacarse el "Plan de Acción Territorial (PAT) para la Protección de la Huerta de Valencia" (2008), dirigido por Arancha Muñoz Criado. Dicho documento constituye el documento marco para la ordenación sostenible del área metropolitana de Valencia, una de las zonas más dinámicas del Mediterráneo occidental, y persigue compatibilizar la preservación de sus valores agrícolas, paisajísticos, culturales y patrimoniales con el crecimiento urbano y con la implantación de nuevas infraestructuras, confiriendo a la Huerta el papel de matriz territorial capaz de articular los grandes elementos de paisaje del área metropolitana de Valencia, de facilitar el adecuado desarrollo de los procesos naturales en la plana litoral del mismo nombre y de proporcionar espacios aptos para el uso recreativo y social. De acuerdo a los principios expuestos en el Convenio Europeo del Paisaje y en la legislación valenciana, el PAT de Protección de la Huerta incorpora igualmente la participación pública como elemento indispensable en la valoración del paisaje y en el establecimiento de objetivos de calidad y de grados de protección, asumiendo el carácter dinámico del paisaje y la necesidad de desarrollar propuestas económica y socialmente viables en las que se conjuguen los distintos usos posibles del territorio. 
En un segundo grupo de referencias estudiadas a nivel nacional, se incluirían las que aluden a la gestión del paisaje, aspecto este que está cobrando cada vez más importancia al ser una pieza clave en la aplicación de las políticas de paisaje en grandes sectores del territorio. Las recopilaciones y publicaciones coordinadas en este campo por Rafael Mata y Alex Tarroja en la publicación "El Paisaje y la gestión del Territorio" y por Jaume Busquets y Albert Cortina en la publicación "Gestión del Paisaje: Manual de protección, gestión y ordenación del paisaje", proporcionan valiosos ejemplos.

Tal y como se expuso anteriormente, la efectiva planificación del paisaje requiere en cualquier caso de su vinculación a la planificación territorial y urbanística, siendo este tema el objeto de estudio en el siguiente punto.

\section{1.f. Paisaje, planificación territorial y planeamiento urbanístico.}

El estudio de distintos modelos de integración de la variable "paisaje" en la ordenación territorial y en la planificación urbanística pone en evidencia la importancia que, independientemente de las especificidades propias de cada contexto geográfico, cultural, social, de propiedad de la tierra, etc, tiene la articulación del paisaje con otros instrumentos de planeamiento territorial y urbanístico. Dicha articulación puede darse por medio de la inclusión del paisaje en los instrumentos clásicos de planeamiento o mediante la creación de instrumentos específicos que apoyen u orienten la creación o actualización de los primeros (caso por ejemplo de los Estudios de Paisaje en la Comunidad Valenciana o de los Catálogos de Paisaje en Cataluña).

Adicionalmente, el paisaje debe de ser considerado en las distintas escalas de la ordenación del territorio y la planificación urbanística, resultando esencial una complementariedad y coordinación entre los objetivos en cada una de ellas, corriéndose en caso contrario el riesgo de no conseguir una concreción perceptible a nivel de observador (caso de considerarse únicamente las grandes escalas) o de generar actuaciones o propuestas que atienden a problemas puntuales pero que no articulen o conecten los paisajes protegidos, gestionados 0 transformados dentro de la escala regional (caso de considerar únicamente las escalas locales o puntuales). De igual modo, el estudio de los referentes existentes, pone de manifiesto la importancia de disponer de una estrategia temporal que permita que las escalas menores de planificación del paisaje se apoyen en estudios o planes paisajísticos de rango superior, lo que implica una progresiva y jerárquica aplicación de las políticas de paisaje así como una efectiva transmisión de la información desde las administraciones centrales o autonómicas a las municipales.

Finalmente, la revisión bibliográfica subraya la necesidad de aproximarse al paisaje desde una perspectiva multidisciplinar y transversal que permita entender las distintas demandas e intereses que confluyen en el territorio, y muy especialmente, prever su futura evolución.

El estudio de los procedimientos previstos en las dos Comunidades Autónomas españolas con políticas de paisaje en marcha, muestra como en Cataluña (ver Ley de Protección, Gestión y Ordenación del paisaje de Cataluña y web del Observatorio del paisaje de Cataluña (http://www.catpaisatge.net/cat/observatori)), los Catálogos de Paisaje constituyen documentos de carácter supramunicipal que deberán apoyar en un futuro los Planes Territoriales Parciales, los Planes Directores Territoriales, la actualización de los Planes de Ordenación Urbana Municipal así como las políticas sectoriales. En el caso de la Comunidad Valenciana (ver Ley de Ordenación del Territorio y Protección del Paisaje y Reglamento de Paisaje de la Comunidad Valenciana), a pesar de estar en redacción un Plan de Acción Territorial de Paisaje para el conjunto de la comunidad autónoma, consistente en un estudio de paisaje de carácter suprarregional y la definición en éste, de los ámbitos para la elaboración de estudios de paisaje supramunicipales (vinculados a su vez a Planes de Acción Territorial), la aplicación real de la política de paisaje se ha centrado en la escala municipal por medio de la redacción de estudios de paisaje asociados a los Planes Generales de Ordenación Urbana.

\section{1.g. Herramientas para la planificación del paisaje}

Dentro de dichas herramientas se agrupan a efectos de la presente tesis aquellos documentos que analizan y realizan propuestas dirigidas a la protección, gestión u ordenación del Paisaje. La utilidad de dichos documentos radica, no solo en su carácter descriptivo, sino en su función como elementos de diagnóstico y como bases para orientar la ordenación del territorio, el planeamiento o la valoración de actuaciones susceptibles de afectar de forma sensible el paisaje. Para la consecución de este segundo tipo de fines las herramientas deben de leer el paisaje como una variable dinámica, entendiendo los procesos, naturales o antrópicos, que lo transforman así como incorporar una parte propositiva que generalmente adopta la forma de objetivos de calidad, estrategias, 
recomendaciones, normativas, la propuesta de programas o actuaciones concretas, y, eventualmente. La delimitación y regulación de espacios por motivos paisajísticos.

Dependiendo del ámbito objeto de estudio, se alcanzan distintos grados de resolución, si bien la mayor parte de trabajos consultados, entre los que destacan especialmente los desarrollados en el Reino Unido, se observa una estructuración en los siguientes apartados:

- Descripción del contexto histórico, natural, socio-cultural y de planeamiento

- Caracterización del Paisaje: generalmente distinguiendo Tipos de Paisaje y Unidades de Paisaje (en el Reino Unido se distingue entre Landscape Character Types, y asociados a éstos, Landscape Character Areas). Para cada Unidad de Paisaje se suele presentar de forma sistemática:

- Principales elementos característicos

- Fuerzas de cambio e implicaciones en el paisaje.

- Estrategias de Paisaje (u objetivos de calidad)

- Recomendaciones, guías y/o Programas para el desarrollo de las estrategias

- Indicadores para la monitorización de la evolución del paisaje

En los casos particulares de Cataluña y la Comunidad Valenciana, la estructura propuesta para las herramientas de planificación del paisaje es la siguiente:

\section{- Cataluña (Catálogo de Paisaje):}

- Identificación y Caracterización del paisaje: Se sistematiza en Unidades de Paisaje definidas de acuerdo a criterios o elementos ambientales, culturales, visuales, perceptivos y simbólicos. En las Unidades así determinadas se definen y cartografían los aspectos siguientes:

- Elementos definitorios del carácter de la unidad y valor paisajístico (tomando en consideración la opinión de la población).

- Fuerzas o factores modeladores del Paisaje.

- Dinámicas de cambio (naturales, socioeconómicas o las derivadas de la legislación vigente o de la implementación de políticas territoriales, urbanísticas o sectoriales).

- Evaluación del Paisaje: amenazas y oportunidades para proteger, gestionar u ordenar el paisaje.

- Definición de los objetivos de calidad paisajística.

- Establecimiento de medidas y propuestas de actuación (directrices de paisaje para los Planes Territoriales Parciales o criterios y acciones específicas para las administraciones afectadas).

- Definición de indicadores de seguimiento.

- Comunidad Valenciana (Estudios de Paisaje):

- Contexto Territorial: Incluye :

- Síntesis de los planes o normas de carácter territorial, urbanístico, medioambiental, paisajístico o cualquier otra de carácter sectorial que le sean de aplicación.

- Análisis de las actividades y procesos con incidencia en el paisaje. Características, dinámicas y presiones que los modifican.

- Definición justificada del ámbito del estudio.

- Caracterización del paisaje

- Caracterización de unidades del paisaje: para cada unidad se detallarán:

- Elementos existentes que definen la singularidad de la unidad.

- Recursos paisajísticos existentes dentro de cada unidad.

- Tendencias y procesos de cambio presentes y futuros

- Efectos sobre el paisaje de planes y proyectos que afecten al área de estudio.

- Principales conflictos existentes y previsibles.

- Caracterización de los recursos paisajísticos (ambientales, culturales y visuales).

- Análisis visual del paisaje: definición de grados de visibilidad del territorio a partir de puntos de observación elegidos en función del nivel de frecuentación y de la singularidad/representatividad del paisaje visible.

- Valoración del Paisaje: mediante un proceso que integra calidad (definida por expertos), preferencia (definida por la población) y visibilidad del paisaje.

- Determinación de objetivos de calidad paisajística para las unidades de paisaje y recursos paisajísticos. 
- Definición de un sistema de espacios abiertos (como zona de Ordenación Urbanística con normas de integración paisajística específicas).

- Definición de programas de paisaje: incluirán las actuaciones y proyectos de paisaje que permitan cumplir los objetivos de calidad paisajística.

- Catálogo de paisaje: incluye las unidades y recursos paisajísticos de valor alto o muy alto e incluye Normas de Integración Paisajística específicas.

- Normativa paisajística: Incluye las normas de integración paisajística, diferenciando dentro de éstas las aplicables al sistema de espacios abiertos y a los espacios y elementos incluidos en el catálogo de paisaje.

Tal y como se expone en el apartado 2.2.d y en la figura 2.1. de la presente tesis, del análisis comparado de la estructura y aplicación práctica de los catálogos de paisaje (Cataluña) y de los estudios de paisaje (Comunidad Valenciana), se extraen conclusiones de gran importancia para el desarrollo de la metodología a proponer en el capítulo 4 de la presente tesis. En particular dichas conclusiones afectan a los aspectos siguientes de las herramientas de planificación del paisaje:

1. Escala de los ámbitos y secuenciación: La planificación del paisaje requiere ser realizada en las distintas escalas de la planificación territorial-urbanística y atender a un cronograma secuencial.

2. Caracterización del paisaje: La caracterización debe considerar los aspectos tangibles e intangibles del paisaje así como su carácter dinámico. La unidad del paisaje constituye la base para los trabajos de caracterización, pudiendo ser complementada con figuras que hagan referencia a elementos puntuales, lineales o extensos (recursos paisajísticos) y cabiendo adaptar su grado de detalle a la escala sobre la que se define la unidad.

3. Valoración del paisaje: A pesar de las dificultades técnicas para su realización, la valoración del paisaje proporciona criterios necesarios para la priorización de acciones de protección, gestión u ordenación del paisaje.

4. Objetivos de Calidad Paisajística: La secuenciación de los objetivos de calidad paisajística para las distintas escalas del territorio, incrementa la coherencia de éstos. Se observa a su vez que la adscripción estricta de objetivos de calidad paisajística a unidades de paisaje resulta a menudo poco efectiva.

5. Vías para concretar la planificación del paisaje: se constata la existencia de los siguientes tipos de vías: (1): Directrices, normativas y recomendaciones, (2) Delimitación de espacios con tratamiento urbanístico diferenciado por motivos de paisaje, (3) Definición de programas o acciones. Cada una de estas vías, puede adquirir distinta importancia según la escala de trabajo y pueden quedar definidas directamente en las herramientas de planificación del paisaje 0 , indirectamente, en las herramientas de planificación territorialurbanística.

6. Vinculación a herramientas de planificación territorial y planeamiento urbanístico: A partir de lo expuesto anteriormente, se recomienda que las herramientas de planificación del paisaje se vinculen a las herramientas de planificación territorial y urbanística en las distintas escalas de estas últimas (autonómica, regional o municipal) y que detallen en el mayor grado posible las vías de concreción de la planificación del paisaje, con el fin de garantizar su adecuada interpretación e integración en las herramientas de planificación territorial y urbanística.

7. Participación pública: Se constata la importancia de desarrollar metodologías que incorporen la participación pública en todas las fases de la planificación del paisaje y que recojan la opinión y sensibilidades del conjunto de la población.

8. Indicadores: Se constata la importancia de establecer indicadores que permitan determinar la efectividad de la aplicación de la planificación del paisaje. 


\subsection{Estudio terminológico y metodológico.}

Frente a la definición a menudo abstracta y adjetivada del paisaje y frente a la aceptación de su carácter subjetivo y difícilmente valorable, el nuevo escenario que se prevé, requiere del establecimiento de definiciones precisas y de metodologías sistemáticas y reproducibles que permitan introducir el paisaje en las políticas sociales, económicas y de ordenación del territorio con criterios lo más objetivos posibles.

Con dicho objeto, se ha procedido a realizar un estudio y selección de los términos que a continuación se exponen. Dada la diversidad de temas a tratar, se propone un avance progresivo desde lo general a lo particular y desde lo conceptual a lo concreto y aplicado.

Para cada uno de los términos se han estudiado las definiciones de mayor uso o mayor aceptación y se ha procedido a realizar una selección o definición terminológica que será de aplicación en la presente tesis.

Los términos estudiados han sido los siguientes:

a. Paisaje

b. Caracterización del paisaje

c. Valor, calidad y preferencia del paisaje

d. Visibilidad del paisaje

e. Capacidad, fragilidad y fragilidad adquirida del paisaje

f. Objetivos de calidad paisajística

g. Protección del paisaje

h. Gestión del paisaje

i. Ordenación del paisaje

j. Política de paisaje

k. Ordenación del territorio

I. Planificación urbanística / urbanismo / plan urbanístico

m. Planificación del paisaje

n. Participación pública

o. Valoración económica del paisaje

p. Acciones de paisaje: estrategias del paisaje / directrices de paisaje/ programas de paisaje / normativa de paisaje / sistema de espacios abiertos / plan de acción territorial de paisaje de la comunidad valenciana / catálogos de paisaje

q. Estudios de paisaje / planes de paisaje

r. Custodia del territorio y del paisaje

\section{2.a. Paisaje}

\section{2.a.1. Definiciones y consideraciones preliminares}

La complejidad del concepto es directa consecuencia de la confusa delimitación epistemológica de las disciplinas que lo abordan (SUÁREZ VIVERO, 1989 en: ESPAÑOL ECHÁNIZ, 1998). Así, se constata una división entre definiciones que asocian el término paisaje al espacio percibido desde un determinado lugar y aquellas que lo asocian a una cualidad del territorio. Entre las primeras, vinculadas a las definiciones lingüísticas del término, cabe destacar las siguientes:

- Paisaje: 1. m. Extensión de terreno que se ve desde un sitio. 2. m. Extensión de terreno considerada en su aspecto artístico. 3. m. Pintura o dibujo que representa cierta extensión de terreno (Real Academia de la Lengua Española)

- Paisaje: $n 1$ an extensive area of land regarded as being visually distinct, 2. a painting, drawing, or photograph depicting natural scenery. (Diccionario Collins)

- Paisaje: an expanse of scenery that can be seen in a single view. An area of countryside or land of a particular type, used especially when talking about its appearance (Diccionario Farlex)

- Paisaje: all the visible features of an area of land, often considered in terms of their aesthetic appeal (Diccionario Oxford)

- Paisaje: 1. Étendue d'un territoire que l'œil peut embrasser. Étendue de terrain dont l'aspect est propre à un lieu, à une région, qui présente des caractères particuliers.. 2. CEuvre graphique ou picturale prenant pour sujet la représentation, la description de sites naturels. (Diccionario de la Academia Francesa) 
Tal y como se percibe, en las lenguas romances ha quedado conservada la visión del paisaje en lo campestre, la vida y el cultivo en el campo, con la palabra que nace en las lenguas romances como les ocurre a paysage (francés), paisaje, paisatge (valenciano) y paessagio (italiano). Su origen está en el latín pagensis, campestre, el que vive en el campo, que se mantiene a través de la raíz pays del francés, inicialmente territorio rural o campo. Las lenguas germánicas toman sin embargo la raíz tierra (Land para Landscape -inglés- o Länder en alemán, que toma la denominación landschaf) haciéndose también valedor de esta acepción (GALIANA, 2004)

Las definiciones que asocian paisaje a una cualidad territorial han sido elaboradas principalmente por las distintas disciplinas que analizan el paisaje. Se destacan a continuación aquellas vinculadas a los métodos de la valoración ambiental y la gestión del territorio:

- Paisaje: Naturaleza, territorio, área geográfica, medio ambiente, sistema de sistemas, recurso natural, hábitat, escenario, ambiente cotidiano, entorno de un punto, pero ante todo y en todos los casos el paisaje es manifestación externa, imagen, indicador o clave de los procesos que tienen lugar en el territorio, ya correspondan al ámbito natural o al humano (MOPT, 1992).

- Paisaje: Complejo de interacciones derivadas de la interacción de rocas, agua, plantas y animales (Dunn, 1974)

- Paisaje: Superficie de terreno heterogénea compuesta por un conjunto de ecosistemas en interacción que se repite de forma similar en ella (Forman \& Gordon, 1986).

- Paisaje: Muchas cosas están comprendidas en nuestra concepción de la palabra paisaje: la estructura geológica de la tierra, sus suelos, animales y su vegetación; el modelo de la distribución de la actividad humana - campos, bosques, asentamientos e industrial locales- tanto en el pasado como en el presente. No es solo una cuestión de belleza, de apreciación estética de la naturaleza y de la arquitectura, sino de toda la ecología de un área y la historia de su ocupación y uso por la gente (Poore \& Poore, 1987)

- Paisaje: Cualquier parte del territorio tal como la percibe la población, cuyo carácter sea el resultado de la acción y la interacción de factores naturales y/o humanos (Convenio Europeo del Paisaje, Florencia, 2000).

Estas últimas definiciones muestran como, la escuela anglosajona de planificadores del territorio (y del paisaje), que tuvo su origen en la planificación física, ha ido elaborando el concepto de paisaje poniendo especial énfasis en su cualidad territorial. Igualmente adquieren gran relevancia en el desarrollo epistemológico del concepto las visiones dadas por la ecología del paisaje y que incide en los procesos que determinan las interrelaciones señaladas por DUNN (1974), y en la que se manifiesta el paisaje, sistémico, asociado a una realidad geográfica heterogénea. (GALIANA, 2004)

En el desarrollo del concepto, por tanto, ha permanecido un sustrato común, referido al espacio o al territorio, y de una forma u de otra, queda siempre implícita una determinada percepción de ese lugar o territorio. Hay que añadir a la acepción el aspecto que se refiere a que es el hombre como sujeto de la percepción, quien interpreta la realidad objetiva del paisaje (territorial o geográfico) convirtiéndola en un sentimiento personal dependiente de la apreciación que realiza.

La última acepción del término paisaje es la que se refiere a su dimensión cultural, siendo el paisaje "el escenario de la actividad humana" (LAURIE, 1970, ESCRIBANO et Al., 1991). El hombre ha sido la causa de grandes modificaciones en la naturaleza, y esta acepción le sitúa como el agente modelador del entorno que lo rodea.

\section{2.a.2. Conclusiones}

Considerando los objetivos de la presente tesis, en la que se pretende definir y testar un procedimiento para la valoración y análisis del paisaje así como la integración de este último en la ordenación y gestión territorial, se asumen como especialmente útiles las definiciones de paisaje que asocian dicho concepto al territorio, y dentro de éstas, se considerará a todos los efectos la definición dada por el Convenio Europeo del Paisaje:

- Paisaje: Cualquier parte del territorio tal como la percibe la población, cuyo carácter sea el resultado de la acción y la interacción de factores naturales y/o humanos.

Dicha elección se justifica por los siguientes motivos:

- Carácter integral: Considera que hay "paisaje" en cualquier territorio, desde el momento que es percibido por la población 
- Carácter desadjetivado: no asocia paisaje a territorios o espacios con valores específicos, facilitando de este modo la integración del paisaje a la ordenación y planificación de todo el territorio

- Carácter cultural: establece una relación directa entre el medio físico y el ser humano, facilitando de este modo una vinculación del concepto de paisaje a espacios con distinto grado de antropización.

- Carácter dinámico: Asume el paisaje como resultado de la interacción de factores naturales y humanos, facilitando una visión sistémica y ecológica del mismo.

\section{2.b. Caracterización del paisaje}

\section{2.b.1. Definiciones y consideraciones preliminares}

A efectos de la presente tesis se han considerado inicialmente en las siguientes definiciones de caracterización del Paisaje:

- Caracterización del Paisaje (Countryside Agency): Proceso de identificación de áreas con similar carácter paisajístico para su clasificación, delimitación y descripción de las características y procesos que le otorgan su carácter,

- Caracterización del Paisaje (según el Reglamento de Paisaje de la Comunidad Valenciana): Se entiende por caracterización del paisaje, la descripción, clasificación y delimitación cartográfica de las Unidades de Paisaje de un territorio determinado y de los Recursos Paisajisticos que las singularizan. Se entiende por Unidad de Paisaje el área geográfica con una configuración estructural, funcional o perceptivamente diferenciada, única y singular, que ha ido adquiriendo los caracteres que la definen tras un largo período de tiempo. Se identifica por su coherencia interna y sus diferencias con respecto a las unidades contiguas. Se entiende por Recursos Paisajísticos los elementos lineales o puntuales singulares de un paisaje o grupo de éstos que definen su individualidad y que tienen un valor visual, ecológico, cultural y/o histórico.

- Caracterización del Paisaje (Convenio Europeo del Paisaje) La identificación y calificación del paisaje se desarrollaría con la participación activa de las partes interesadas e incluiría la: (1) Identificación de los paisajes en todo su territorio; (2) el análisis de sus características y de las fuerzas y presiones que los transforman; (3) las transformaciones en curso.

Tal y como recogen las tres definiciones anteriores, la caracterización del paisaje tiene por objeto identificar los distintos tipos de paisajes presentes en un determinado territorio haciendo para ello una descripción precisa de sus elementos constitutivos y características específicas o genéricas. Dichos paisajes constituyen la dimensión percibida del territorio y surgen como resultado de la interacción de un medio físico determinado, de una serie de acciones humanas pasadas y de una serie de procesos, tanto naturales como de origen antrópico, con capacidad para modificar el paisaje en el futuro.

Los paisajes así definidos presentan una serie de características generales, de atributos y de recursos que los particularizan y los distinguen de otros paisajes. La caracterización del paisaje supone por lo tanto un análisis que implica a menudo la definición por comparación y que lleva asociada una escala de trabajo en la que los factores que permiten la caracterización cobran sentido o se dan a un determinado grado de detalle. De igual modo, la escala del análisis permite, hacer imperceptibles o relevantes ciertos matices, los tipos de paisajes que podemos definir a una escala 1:200.000 son distintos de los que apreciamos si ese mismo lugar se estudia a una escala 1:20.000. Se hace necesario en este punto definir escalas operativas de trabajo, que son aquellas que, de acuerdo a lo expuesto previamente, faciliten la introducción del paisaje en la ordenación y planificación del territorio a nivel regional o local.

Los métodos actuales de caracterización del paisaje presentan una visión integral y holística que agrupa una serie de componentes y que considera sus relaciones y sus características visuales básicas. Así, ESCRIBANO et Al en 1991 o la "Guía para la Elaboración de Estudios del Medio Físico" (MOPT, 1992), diferencian en el paisaje los componentes físicos, bióticos y humanos, y ESPAÑOL ECHANIZ,1999 o el MOPT (1992) establecen la definición de dichos componentes como punto de partida para la diferenciación física de sus propiedades visuales, entendidas estas como el "conjunto de rasgos que caracterizan visualmente un paisaje o sus componentes y que puede ser utilizadas para su análisis o diferenciación". Dichas características se asimilan al "color, forma línea, textura, escala o dimensiones y al carácter espacial".

El objetivo fundamental de la caracterización del paisaje no es sin embargo la pura descripción de éste, sino, y de acuerdo a los objetivos de la presente tesis, la introducción del paisaje como elemento activo y operativo en la ordenación y planificación territorial, siendo en este punto necesario que dicha caracterización sea capaz de 
apoyar la valoración del mismo así como la definición de acciones o espacios operativos para la gestión conjunta de paisaje y territorio. Este aspecto queda claramente expuesto por R. A. Preece en su libro "Designs on the Landscape", cuando establece la definición de áreas visuales y la determinación de su carácter como pasos previos al establecimiento de políticas y acciones concretas.

Como conclusión de lo expuesto se deduce que a efectos de caracterización se pueden establecer dos objetivos:

1) Definir los espacios y elementos a caracterizar

2) Definir los parámetros o sistemas que permitan desarrollar dicha caracterización.

Dentro de las metodologías existentes de caracterización del paisaje se resumen seguidamente dos de las más elaboradas:

1. Metodología de la Countryside Agency (Landscape Character Assessment: A Guide for England and Scotland): La caracterización incluiría dos pasos: la clasificación y la descripción del paisaje. La primera de ellas se ocupa de la división del paisaje en áreas con un carácter distinto y reconocible. Para ello se distingue entre clasificaciones nacionales o regionales, en las que se puede partir de una aproximación de "arriba a abajo" (top-down), basada en la identificación de grandes patrones de carácter paisajístico (geología, litología, topografía, patrones urbanísticos o de uso del suelo, etc), o de una aproximación de "abajo a arriba" (bottom up), en la que se fusionan zonas con caracteres paisajísticos similares que hayan sido identificadas a escalas de trabajo menores. Se trata en ambos casos de escalas de trabajo en las que los sistemas SIG, apoyados por trabajo de campo, resultan especialmente útiles. En escalas municipales o locales, es conveniente encajar la clasificación en divisiones de paisaje realizadas a escala regional, que, en un acercamiento "top-down" se subdividirían a escalas menores al percibirse en éstas patrones de mayor detalle.

A efectos de clasificación, el sistema británico distingue entre:

Tipos de Paisaje (Landscape Character Areas): Corresponde a tipos de paisaje relativamente homogéneos en su carácter. Son genéricos por naturaleza (pueden darse en distintas zonas) y admiten variaciones internas en la medida que compartan combinaciones similares de geología, topografía, hidrología, vegetación y patrones históricos de influencia humana (usos del suelo, asentamientos, etc).

Vinculado a este concepto se encuentra el de "Carácter del Paisaje", definido por la Countryside Agency como el Patrón reconocible de elementos definitorios del paisaje que se da en un determinado tipo de paisaje y que es percibido como tal por la población.

Áreas de Paisaje (Landscape Character Areas): Se trata de espacios físicos únicos y son la concreción de los tipos de paisaje en un área determinada, motivo por el que, a diferencia de los segundos, que presentan nombres genéricos, tales como "valle fluvial", se nombran con términos que hacen referencia a la toponimia concreta del lugar afectado, por ejemplo "valle del río Palancia".

Tal y como se aprecia en las figuras siguientes, esta división entre tipos y áreas de paisaje, se puede dar en las distintas escalas de trabajo (regional / local / puntual). 


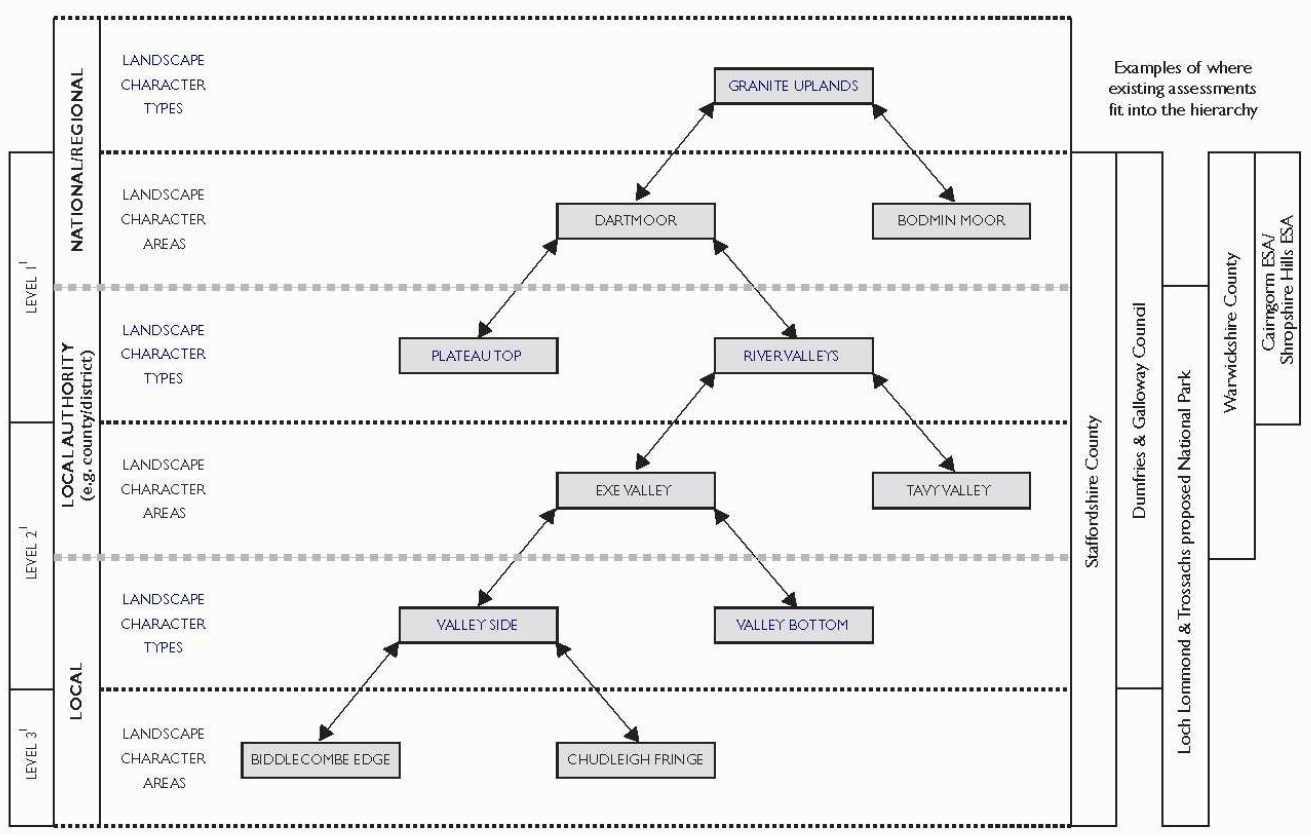

Fig. 3.1: Escalas y niveles en la definición de Tipos y Unidades de Paisaje (Landscape Character Assessment: Guidance for England and Scotland; Countryside Agency, 2002)

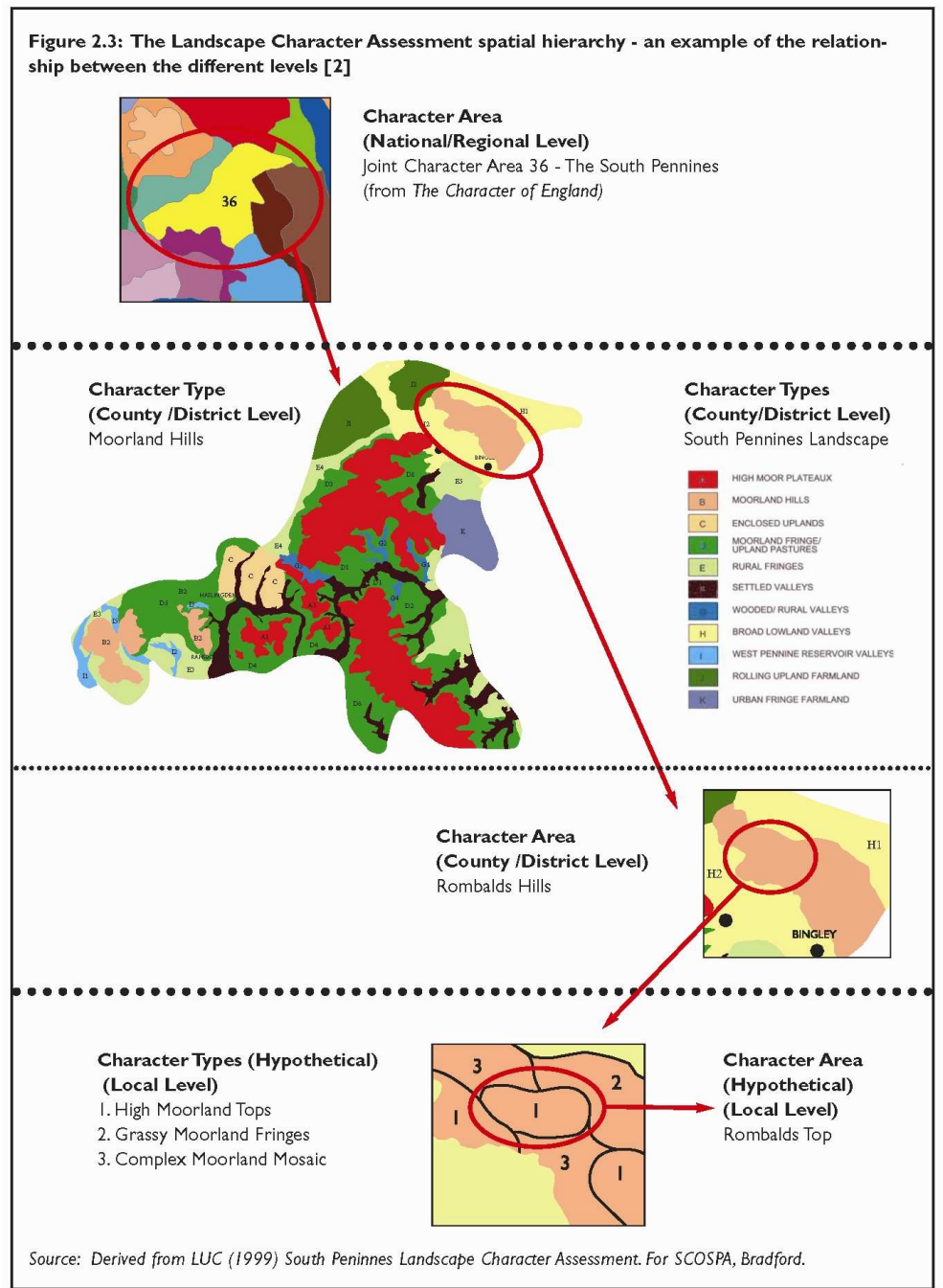

Fig. 3.2: Ámbitos y niveles en la definición de Tipos y Unidades de Paisaje (Landscape Character Assessment: Guidance for England and Scotland; Countryside Agency, 2002) 
En lo referente a la descripción del paisaje en los Tipos y Áreas de Paisaje, la guía metodológica de la Countryside Agency, lista una serie de factores de carácter físico a considerar. Dichos factores, listados a continuación, presentan a su vez distintos tipos y pueden generar una descripción de carácter factual (objetivo), personal (subjetiva) o mixta.

- Factores naturales:

- Geología

- Relieve

- Suelos (litología)

- Vegetación

- Factores culturales:

- Usos del suelo

- Parcelario y cierres

- Asentamientos humanos y construcciones.

A su vez la metodología descriptiva propuesta por la Countryside Agency propone la incorporación de descriptores genéricos que expliquen aspectos estéticos o perceptivos del paisaje. Entre los primeros se incluyen variables como la escala, cierre, diversidad, equilibrio, unidad, etc. Entre los segundos, aspectos vinculados a la vivencia subjetiva del espacio (tranquilidad, seguridad, etc).

El conjunto de factores listados debe de quedar recogido en una ficha descriptiva en la que debe de incorporarse el factor tiempo, tanto en su dimensión pasada o histórica como en la futura, asimilando esta última, a los procesos y tendencias de cambio.

2. Metodología Propuesta por el Reglamento de Paisaje de la Comunidad Valenciana: El desarrollo de la legislación valenciana en materia de paisaje aporta en los artículos 32, 34 y 35 del Reglamento de Paisaje (2006) una valiosa metodología para la definición de los ámbitos o elementos objeto de análisis paisajístico (unidades de paisaje y recursos paisajísticos respectivamente), así como para su descripción con fines proactivos.

\section{Artículo 32. Caracterización del paisaje}

1. El análisis y el tratamiento del paisaje exigirá, a efectos instrumentales, la delimitación de las Unidades de Paisaje y de los Recursos Paisajísticos, en los términos definidos en el presente artículo y en los siguientes. Se entiende por caracterización del paisaje, la descripción, clasificación y delimitación cartográfica de las Unidades de Paisaje de un territorio determinado y de los Recursos Paisajísticos que las singularizan.

2. Se entiende por Unidad de Paisaje el área geográfica con una configuración estructural, funcional o perceptivamente diferenciada, única y singular, que ha ido adquiriendo los caracteres que la definen tras un largo período de tiempo. Se identifica por su coherencia interna y sus diferencias con respecto a las unidades contiguas.

3. Se entiende por Recursos Paisajísticos los elementos lineales o puntuales singulares de un paisaje o grupo de éstos que definen su individualidad y que tienen un valor visual, ecológico, cultural y/o histórico.

\section{Artículo 34. Caracterización de las Unidades de Paisaje}

1. La caracterización de las Unidades de Paisaje tiene por objeto:

a) La definición, descripción y delimitación de las características paisajísticas en el ámbito de estudio.

b) El análisis de sus características y de las dinámicas y presiones que las modifican.

c) Identificar los recursos paisajísticos que singularizan positivamente su valor y los conflictos paisajísticos que las degradan negativamente.

d) Posibilitar la definición de los Objetivos de Calidad Paisajística.

2. Las Unidades de Paisaje se delimitarán conforme a los siguientes criterios:

a) Las Unidades de Paisaje se definirán a partir de la consideración de los elementos y factores naturales y/o humanos, que le proporcionan una imagen particular y lo hacen identificable o único. Se considerarán, al menos, los siguientes:

- Naturales: relieve, aspectos geológicos e hidrológicos, suelo, clima, especies de fauna y flora silvestres.

- Humanos: población, asentamiento, intervención humana, patrón y usos del suelo tales como agricultura, trashumancia, silvicultura, actividades rurales, hidráulica, minería, industria, transporte, turismo, servicios, infraestructuras y usos recreativos entre otros.

b) Las Unidades de Paisaje serán coherentes con las Unidades Ambientales para incorporar la información física, biológica, cultural y social en un planteamiento interdisciplinario que mejor integre el patrón ecológico y sus relaciones de forma que la gestión del paisaje promueva los principios de sostenibilidad.

c) Las Unidades de Paisaje se delimitarán independientemente de límites administrativos y como tal se enmarcarán en su contexto regional e integrarán con aquellas que ya se han llevado a cabo en las zonas limítrofes, y hayan sido objeto de aprobación por la administración competente. 
3. El análisis de las características de las Unidades de Paisaje definidas y delimitadas reflejará para cada Unidad, al menos, los siguientes aspectos:

a) Elementos existentes que definen la singularidad de la unidad, incluyendo aquellos que afectan a otra experiencia sensorial además de la vista.

b) Recursos paisajísticos existentes dentro de cada Unidad conforme a lo dispuesto en el artículo siguiente.

c) Tendencias y procesos de cambios presentes y futuros y como éstas pueden afectar a las características de la unidad de paisaje. En particular se analizarán las procedentes de planes y proyectos que afecten al área de estudio.

d) Principales conflictos existentes y previsibles.

\section{Artículo 35. Caracterización de los Recursos Paisajísticos}

1. Se realizará una caracterización de los Recursos Paisajísticos con las áreas o elementos del territorio de relevancia e interés ambiental, cultural y visual que incluirán:

a) Por su interés ambiental, las áreas o elementos que gocen de algún grado de protección, declarado o en tramitación, de carácter local, regional, nacional o supranacional; el dominio público marítimo y fluvial; así como aquellos espacios que cuenten con valores acreditados por la Declaración de Impacto Ambiental. Las áreas o elementos del paisaje altamente valoradas por la población por su interés natural.

b) Por su interés cultural y patrimonial las áreas o los elementos con algún grado de protección, declarado o en tramitación, de carácter local, regional, nacional o supranacional y los elementos o espacios apreciados por la sociedad local como hitos en la evolución histórica y cuya alteración, ocultación o modificación sustancial de las condiciones de percepción fuera valorada como una pérdida de los rasgos locales de identidad o patrimoniales.

c) Por su interés visual las áreas y elementos visualmente sensibles cuya alteración o modificación puede hacer variar negativamente la calidad de la percepción visual del paisaje. Se definirá a partir del Análisis Visual definido en el artículo siguiente y contendrá, al menos, los siguientes elementos:

- Los elementos topográficos y formales que definen la estructura espacial que hace singular un lugar, tales como hitos topográficos, laderas, crestas de las montañas, línea de horizonte, ríos y similares.

- Los elementos y áreas significativas o características no estructurantes que conforman un paisaje tanto derivadas de su configuración natural como por la acción del hombre-perfiles de asentamientos históricos, hitos urbanos, culturales, religiosos o agrícolas, siluetas y fachadas urbanas, y otros similares.

- Las principales vistas y perspectivas hacia los elementos identificados en los apartados anteriores y de los inventariados por causas medioambientales o culturales.

- Los puntos de observación y los recorridos paisajísticos de especial relevancia por su alta frecuencia de observación, o la calidad de sus vistas.

- Las cuencas visuales que permitan observar la imagen exterior de los núcleos urbanos a los que se haya reconocido un extraordinario valor y su inserción en el territorio, su escena urbana interior y las vistas desde ellos del entorno que los circunda.

- $\quad$ Las áreas de afección visual desde las carreteras

Tal y como se deduce de la lectura de los párrafos previos, la legislación valenciana otorga a la percepción visual del paisaje una especial relevancia, que se extiende a su valoración y a la definición de acciones para su protección, gestión y ordenación

\section{2.b.2. Conclusiones}

Considerada su inspiración en el Convenio Europeo del Paisaje y su explicito carácter proactivo y orientación a la planificación territorial, se asume a efectos de desarrollo de la presente tesis la definición de caracterización del paisaje contenida en el Reglamento de Paisaje de la Comunidad Valenciana:

- Caracterización del Paisaje: Descripción, clasificación y delimitación cartográfica de las unidades de paisaje de un territorio determinado y de los recursos paisajísticos que las singularizan.

Se considerarán a su vez en adelante las definiciones correspondientes a los términos siguientes:

- Tipo de paisaje: Clase genérica de paisaje atribuible a espacios que presenten configuraciones parecidas de elementos primarios definitorios del paisaje (geología, topografía, hidrología, vegetación y patrones históricos de influencia humana (usos del suelo, asentamientos, etc)).

- Carácter del paisaje: Patrón reconocible de elementos definitorios del paisaje que se da en un determinado Tipo de paisaje y que es percibido como tal por la población.

- Unidad de paisaje: Área geográfica con una configuración estructural, funcional o perceptivamente diferenciada, única y singular, que ha ido adquiriendo los caracteres que la definen tras un largo período de tiempo. Se identifica por su coherencia interna y sus diferencias con respecto a las unidades contiguas. (asimilable a Landscape Character Areas).

- Recurso paisajístico: Elemento lineal o puntual o extenso singular de un paisaje o grupo de éstos que definen su individualidad y que tienen un valor visual, ecológico, cultural y/o histórico. 


\section{2.c. Valor, calidad y preferencia del paisaje}

3.2.c.1. Definiciones y consideraciones preliminares

A efectos de la presente tesis se han considerado inicialmente las siguientes definiciones de "valor paisajístico":

- Valor Paisajístico (Countryside Agency): Valor relativo que se asocia a un determinado paisaje, que expresa un consenso regional o local y que está relacionado a su calidad, y cualidades específicas

- Valor paisajístico (Reglamento de Paisaje de la Comunidad Valenciana): Valor relativo que se asigna a cada Unidad de paisaje y a cada Recurso Paisajístico por razones ambientales, sociales, culturales o visuales y que se establece en función de su calidad paisajística, las preferencias de la población y su visibilidad.

- Valor paisajístico (Convenio Europeo del Paisaje): Atributo propio de un paisaje obtenido a partir de los valores particulares que les atribuyen las Partes y la población interesadas.

Tal y como recogen las tres definiciones anteriores, la valoración del paisaje tiene por fin asignar un valor a un determinado paisaje (y recurso paisajístico, en el caso del Reglamento de la Comunidad Valenciana). Para la asignación de dicho valor se han desarrollado históricamente distintas metodologías que han intentado asociar dicho valor a factores objetivos, cuantificables, y preferentemente, cartografiables.

De igual modo y a efectos de la presente tesis se han considerado inicialmente las siguientes definiciones de "calidad paisajística":

- Calidad Paisajística (Countryside Agency): Valoración del estado físico del grado de alteración de alteración de un paisaje en función de criterios visuales, funcionales y ecológicos.

- Calidad Paisajística (Reglamento de Paisaje de la Comunidad Valenciana): La calidad paisajística será propuesta de forma justificada por un equipo pluridisciplinar de expertos en paisaje, a partir de la calidad de la escena, la singularidad o rareza, la representatividad, el interés de su consenvación y su función como parte de un paisaje integral. La calidad se manifestará como muy baja, baja, media, alta o muy alta. La administración competente para la aprobación del correspondiente instrumento de paisaje podrá fijar una calidad distinta a la propuesta de forma justificada.

Finalmente, se expone igualmente la definición considerada de "preferencia paisajística":

- Preferencia Paisajística (Reglamento de Paisaje de la Comunidad Valenciana): La preferencia paisajística se definirá a partir de los valores atribuidos al paisaje por los agentes sociales y las poblaciones concernidas y se definirá a partir de la consulta pública establecida por el Plan de Participación Pública conforme a lo determinado por el artículo 17.2 del Reglamento de Paisaje de la Comunidad Valenciana.

En su conjunto, el establecimiento de factores universales explicativos del valor paisajístico no ha resultado satisfactorio dada la dificultad en valorar la dimensión cultural, social e individual del paisaje. Sin embargo, como fruto de los estudios realizados sobre este tema, se han obtenido importantes conclusiones asociadas a la percepción y se han desarrollado procedimientos de valoración del paisaje basados en la apreciación particular, que en un determinado momento y lugar, tiene la sociedad de un determinado paisaje.

\section{2.c.1.a. Sobre la valoración del paisaje y la subjetividad}

La valoración visual del paisaje (o de su calidad visual) ha generado dos escuelas con aproximaciones y resultados complementarios (GALIANA, 2003). La primera de ellas basa sus métodos en el análisis y sistematización de los factores o variables que explicarían el valor de un paisaje. Son los llamados métodos de valoración de la calidad visual (DUNN, 1974, RAMOS, 1979; ESCRIBANO ET AL., 1991).

La segunda de las escuelas establece el valor de la calidad paisajística a partir de las preferencias visuales de la población y ha tenido en los estudios de preferencias paisajísticas para la obtención de escalas de su técnica más representativa. Actualmente la valoración del paisaje mediante este tipo de métodos es ampliamente utilizada en números países y con distintos fines, siendo a su vez un procedimiento que hace uso de las potentes herramientas estadísticas disponibles y que resulta plenamente coherente con los requerimientos legales de dar participación a la población en los procesos de ordenación y planificación del territorio y del paisaje. 
En cualquiera de las dos escuelas antes citadas existe una firme intención de reducir la presunta subjetividad en la valoración del paisaje, a menudo empleada como argumento para aceptar la modificación sustancial de este último ante la ausencia de criterios sólidos en contra.

Los debates en la subjetividad de la valoración del paisaje han sido y son todavía amplios. Frente al sujeto como individuo y frente a la afirmación de que el ser humano es capaz de apreciar positivamente cualquier tipo de paisaje si el hábito o la educación le llevan a ello, se plantean la existencia del sujeto como grupo social, sobrepasándose de este modo la componente puramente individual, y de factores objetivos que justifiquen la mayor o menor valoración del paisaje y que tengan relación con aspectos consustanciales o instintivos al ser humano.

Así, la propia fisiología del ser humano como animal, puede explicar la preferencia por espacios desde los que se dispone de vistas amplias y desde los que se disfruta de una posición segura (APPLETON, J, 1975) o el hecho de que el color verde genere de forma instintiva una sensación de relax por asociación con espacios en los que sea más fácil la supervivencia o por el hecho de que sea el color que requiere un menor esfuerzo para su captación por el ojo humano.

R. A. Preece plantea como alternativas a la subjetividad, entendida ésta como producto de la mente, gustos y prejuicios individuales, las alternativas de la objetividad y del empirismo. En el caso de la objetividad, los juicios sobre el valor del paisaje deberían derivar estrictamente del propio paisaje. En el caso del empirismo, Preece propone dos vías, una primera o general por la que se llega al conocimiento, en este caso del valor del paisaje, a través de un mayor conocimiento de los distintos paisajes existentes y otra restringida en la que se mide la preferencia de la población en lo referente a los paisajes y se concluyen una serie de reglas (método científicoempírico) u otra de enfoque intelectual por la que el valor del paisaje es determinado por una serie de expertos en base a una serie de factores técnicos o económicos.

Tal y como se ha anticipado previamente en el presente trabajo, las bases teóricas de la planificación del paisaje deben de responder a una serie de preguntas fundamentales tales como: ¿Qué es paisaje?, ¿Cómo debería ser descrito el paisaje?, ¿Qué entendemos por paisaje visual?, ¿Cómo podemos representar y transmitir el paisaje? o preguntas asociadas con los denominados "modelos de procesamiento", por los que se determina cómo percibimos el paisaje y se estudia el papel activo o pasivo del observador.

Las bases teóricas de la planificación del paisaje analizan a su vez mediante los "modelos de evaluación" el modo por el que se valora el paisaje y la posible existencia de factores que expliquen las preferencias de los individuos o de la población. Las conclusiones en este punto presentan una gran trascendencia en la medida que pueden justificar la existencia de reglas y políticas universales en materia de calidad visual del paisaje, o por el contrario, pueden llevar a la necesidad de ajustar la valoración del paisaje según ámbitos culturales o grupos de población. De igual manera el papel de los expertos en la valoración del paisaje queda sujeto primeramente a que el valor del paisaje venga dado por las preferencias de ciertos grupos sociales 0 , por el contrario, del conjunto de la población; y en segundo lugar, a la capacidad de dichos expertos para interpretar en cualquiera de los dos casos dichas preferencias.

Las investigaciones desarrolladas durante los años 1980's en la preferencia visual, mostraron diferencias significativas entre hombres y mujeres en la valoración del paisaje, especialmente en países con conductas muy distintas según el sexo. De igual forma se han detectado diferencias según edades, especialmente en el segmento de la población joven, según la procedencia geográfica o cultural, o entre la población rural y urbana, siendo esta última más proclive a idealizar la vida y el paisaje agrícola. A título de ejemplo de las diferencias expuestas cabe citar un experimento realizado en un hospital norteamericano en el que se observó una recuperación más rápida de los pacientes alojados en habitaciones con vistas a un bosque, excepto en el caso de la población joven que prefería el disponer de vistas a una zona con alta actividad como un centro comercial, o la experiencia de distintas zonas residenciales de California en las que los tonos pastel preferidos por la población anglosajona para pintar sus fachadas, contrastaba con los tonos más vivos preferidos por la población de origen latino.

La existencia de criterios genéricos que expliquen la preferencia visual de las poblaciones, sirvió a su vez a Lorris para realizar un interesante trabajo en el que, tomando como punto de partida la tradicional vinculación entre paisaje y pintura, realizó unos cuadros en los que condensaba todos los elementos preferidos por la población. La experiencia, realizada en un total de doce países, mostró importantes analogías entre las distintas poblaciones, así como significativas diferencias en aspectos concretos. Por lo general, la presencia del agua, de 
montañas en la distancia, de algún edificio antiguo y de un paisaje rural en el que se combinaban espacios agrícolas y forestales, fueron elementos compartidos independientemente de la nacionalidad.
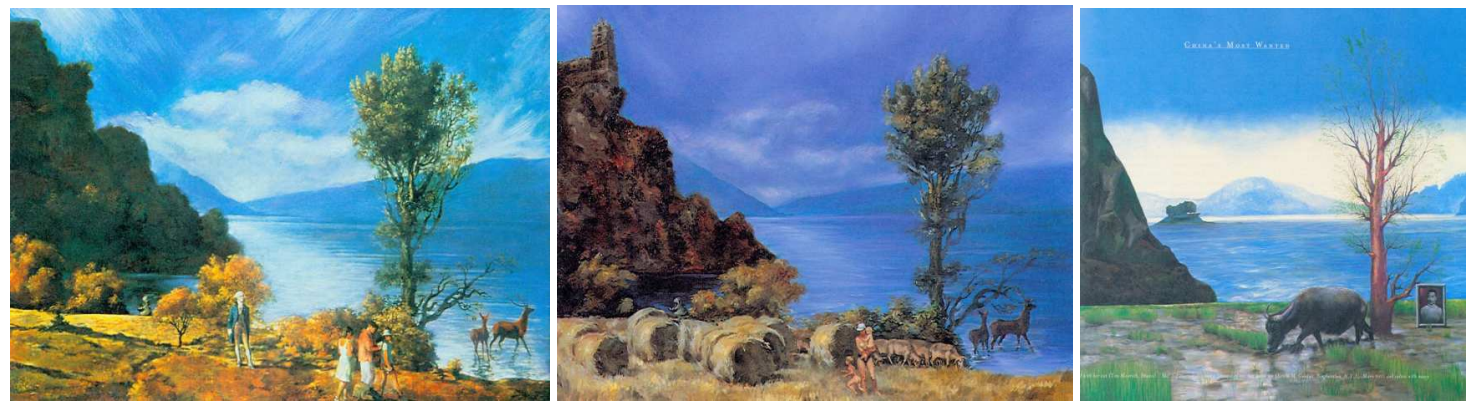

Fig. 3.3 Composición pictórica con elementos de paisaje preferidos por la población de EEUU, Francia y China (Fuente CARL STEINITZ, 2008)

Se debe considerar igualmente situaciones particulares que concurren en el paisaje visual y que modifican su percepción. Nadie hablaría de un paisaje bonito en Chernobil dadas sus connotaciones con la catástrofe nuclear o en un río del que sabemos de antemano que está contaminado. La psicología y las cargas subjetivas condicionan la percepción y la preferencia visual. De acuerdo con esta premisa, Fair hizo un interesante estudio en el que probó que la presencia de animales mejoraba la preferencia visual en un $20 \%$ o $30 \%$ respecto al mismo paisaje sin animales. De igual modo, el río Ganges, sagrado para los hindús, es a su paso por Benarés prácticamente una cloaca que sin embargo la gente encuentra hermosa. Análogamente, los católicos valoran más la catedral de San Pedro de lo que lo haría una persona que profesase otra religión.

Conforme a los estudios del profesor Carl Steinitz, en la valoración del paisaje se constata su vez una preferencia general por los lugares reconocibles y asociados a modos de vida deseados 0 a elementos de prestigio. Tal es el caso de espacios vinculados a lugares idílicos de vacaciones, de lugares diseñados por proyectistas de renombre o la preferencia por los edificios originales frente a replicas exactamente idénticas. En estos casos, las asociaciones subjetivas y que no devienen del objeto o paisaje observado se hacen evidentes, aunque no por ello dejan de ser explicables o generalizables. La cuestión que surge en este punto es la procedencia de dichos clichés. Las evidencias indican que estas ideas se adquieren durante la infancia, concretamente con edades de menos de 12 años. Estas imágenes construyen un repertorio visual al que acudimos en busca de referentes y que, sólo, mediante una actitud abierta y receptiva, potenciable por nuestro modo de vida y por los medios de comunicación, puede ser expandida. La diferencia entre un experto y un no experto es por lo tanto el número de categorías o registros que maneja.

\section{2.c.1.b. Valoración visual del paisaje como preferencia visual: antecedentes internacionales}

Los principales referentes internacionales en la definición de la calidad visual del paisaje a partir de las preferencias visuales de la población nos remiten a los Estados Unidos de América, donde, en la década de los 60 fue aprobada la NEPA (National Environmental Policy Act). Dicha ley fue la primera a nivel internacional en considerar el posible impacto medioambiental de un proyecto y en dar participación a los ciudadanos, a los municipios, a los condados y a los estados en una toma de decisiones, que por principio debía de fluir desde las bases de la sociedad a los más altos estamentos políticos. Igualmente, la ley NEPA definió como atribuciones del gobierno central el velar por la salud, seguridad, bienestar y calidad estética del país, exigiendo a todas las agencias federales que valorasen las implicaciones estéticas de sus proyectos o planes.

Esta nueva situación legal supuso que en el periodo comprendido entre 1968 y 1975 los principales departamentos y agencias americanas desarrollasen una intensa labor investigadora en el campo de la estética y el medio ambiente, y que, frente a las políticas de paisaje previas, basadas en las opiniones de expertos, se contemplase la necesidad de contar con las preferencias de la población.

Los trabajos teóricos desarrollados por distintos investigadores como Appleton, Cuplin, Steinitz, o distintos servicios como el Forestry Service, buscaron explicar la calidad visual del paisaje a partir de una serie de parámetros que podían ser cuantificados por expertos. Así, el Forestry Service, a partir de los trabajos desarrollados previamente por Sylvia Crowe y Angus Hill en el Reino Unido, estableció que la calidad del paisaje forestal estaba vinculada a 7 factores valorables por expertos: relieve, vegetación (diversidad), agua, color (variedad e intensidad), distancia y variación de vistas, singularidad o rareza y ausencia de intervenciones humanas. Las distintas combinaciones posibles de dichos factores fueron plasmadas en una serie de fotografías 
con distintos grado de calidad visual, que sirvieron a su vez (dada la ausencia en esa época de Sistemas de Información Geográfica o de imágenes satélite) para realizar un intenso trabajo de campo en el que se determinaba la calidad del paisaje visto desde las carreteras por comparación con lo mostrado en las distintas fotografías de referencia, construyéndose de este modo unos mapas con isolíneas de preferencia visual.

Dichos métodos fueron sin embargo incapaces de explicar con una fiabilidad estadística aceptable las preferencias visuales de la población ante lo cual se planteó la necesidad de redefinir los posibles factores o parámetros explicativos de la misma. En un interesante experimento, el profesor Carl Steinitz generó para el Acadia Nacional Park (Estados Unidos), un modelo hibrido en el que se incluían los factores o parámetros que habían resultado más explicativos de la preferencia visual en los modelos previos. El resultado fue prometedor y supuso la puesta a punto de una metodología de trabajo en la que la definición de los parámetros explicativos de la preferencia visual, formaba parte del propio proceso de trabajo y de consulta.

La valoración por preferencias visuales así definida es básicamente un proceso experimental. Se debe preguntar sobre preferencias sin tener estándares o factores explicativos prefijados y determinar a continuación si la gente coincide en sus gustos. Si es así, será posible definir una política de paisaje para ese lugar y esa población. Si la discrepancia es absoluta esa definición será imposible. Si estamos en un punto intermedio o en un punto en el que se aprecie la existencia de distintos gustos según segmentos de población, será difícil pero posible.

\section{2.c.1.c. Valoración visual del paisaje como preferencia Visual: antecedentes nacionales}

Las metodologías empleadas hasta la fecha en España presentan analogías y diferencias con las utilizadas en Estados Unidos y el Reino Unido.

Tal y como se expuso anteriormente, muchas de las metodologías disponibles para la determinación de la calidad visual parten de la premisa que existe un consenso general sobre la apreciación del paisaje y tratan de evaluar mediante la calidad paisajística cómo se interpreta este consenso según los distintos paisajes.

En el contexto de España es de referencia obligada la "Guía para la elaboración de estudios del medio físico" (MMARM, 2006) que agrupa los principales metodologías en tres grandes bloques: métodos directos de valoración de la calidad visual del paisaje (que valoran el paisaje en su conjunto), métodos indirectos de valoración de la calidad visual del paisaje (que valoraran el paisaje desagregándolo en los factores determinantes por la calidad visual de sus componentes o por las denominadas categorías estéticas) y los métodos mixtos de valoración de la calidad visual, combinando los procedimientos anteriores de modo complementario.

\section{a) Métodos directos de valoración de la calidad visual del paisaje:}

Se caracterizan por valorar la calidad del paisaje en su totalidad o en su conjunto, tal cual es visto desde un punto de observación o mediante una muestra o sustituto del paisaje (imagen), sin desagregarlo por factores o elementos.

El proceso de la evaluación se realiza por medio de la contemplación del paisaje o de las imágenes sustitutivas de éste por un grupo de evaluadores más o menos amplio, con la utilización de un sistema de valoración que permita establecer escalas de rango o de orden de preferencia.

Con el objeto de disminuir la subjetividad se han desarrollado métodos que abarcan desde la consulta a pocos expertos capacitados para obviar sus percepciones subjetivas, a la consulta a una muestra numerosa no cualificada pero representativa de las sensibilidades generales de la sociedad.

Dentro de este grupo se distingue a su vez entre los métodos de (1) subjetividad aceptada, en los que se acepta como punto de partida que la apreciación estética del paisaje es algo subjetivo y que la valoración también es subjetiva, (2) los métodos de subjetividad controlada, en los que la subjetividad se controla mediante la utilización de una escala universal de valores del paisaje, de modo que los resultados se expresan en una escala absoluta comparable entre distintas zonas, (3) los métodos de subjetividad compartida, que son similares a los de subjetividad controlada, pero así como en aquellos (en caso de trabajar en equipo) las valoraciones personales son tratadas individualmente, calculando la media de cada valoración, aquí en caso de haber discordancias entre las valoraciones, éstas se someten a discusión, por medio de dinámica de grupo en un proceso iterativo, hasta que se alcanza un consenso final y finalmente (4), los métodos de subjetividad representativa, en los que los evaluadores no son expertos sino un grupo de personas cuya opinión global sea representativa de los intereses 
sociales respecto a la conservación del paisaje. La principal dificultad de este último tipo de métodos parte del propio proceso de valoración, conseguir precisamente que la muestra de evaluadores sea representativa de las preferencias del público.

Dentro de este tipo de métodos, se han empleado diferentes tipos de técnicas para recoger las opiniones de los evaluadores:

- Técnica de las diferencias semánticas: se emplean escalas de adjetivos opuestos y los evaluadores deben ir señalando uno de los dos adjetivos ante las imágenes expuestas.

- Listas de adjetivos: se emplean listas de adjetivos, de las que los evaluadores tienen que seleccionar aquellos que describen mejor los paisajes mostrados en una serie de fotografías.

- Asignación directa de valor: los evaluadores deben asignar un valor numérico a cada fotografía (por ejemplo del 1 al 5$)$.

- Ordenación por pares: se presentan las imágenes por todas las combinaciones de pares y en cada caso los evaluadores deben señalar cuál de ellas prefieren, mostrando todos los posibles pares.

El resultado final consiste en una ordenación de todas las fotografías que representan paisajes o aspectos de los paisajes que están siendo valorados.

b) Métodos indirectos de valoración de la calidad visual del paisaje:

Se trata de métodos en los que la valoración del paisaje para una unidad de inventario o de referencia paisajística se efectúa por medio de la combinación de los valores parciales de las variables que tengan significado paisajístico en el modelo territorial de planificación física deseado (RAMOS, 1979; ESCRIBANO et Al., 1991; MOPT, 1992).

Estos métodos se caracterizan por valorar la calidad visual del paisaje desagregándolo en la calidad de sus componentes o bien por categorías estéticas, partiendo en cualquier caso de las tres presuposiciones siguientes (ARTHUR et Al., 1977):

- El valor de la calidad del paisaje puede explicarse como la combinación de los valores de calidad de sus componentes de forma aislada.

- La belleza o calidad visual del paisaje radica en sus componentes.

- La evaluación es realizada por expertos cuyos criterios de calidad son extensibles a toda la sociedad.

La evaluación se realiza a través de modelos basados en las calidades visuales de los componentes (vegetación, formas del terreno, presencia de agua, etcétera) o de las categorías estéticas del paisaje (atributos calificadores de la calidad del paisaje como: unidad de paisaje, variedad del paisaje, contraste de los elementos, ritmo de la distribución espacial, etcétera) o en una mezcla de ambas, y suelen llevarse a cabo siguiendo las siguientes fases:

1. Identificación o selección de las variables (componentes o categorías estéticas) a considerar. No existe un listado predeterminado de variables a incluir en la valoración de la calidad del paisaje debiendo realizar la selección en función de la escala, las características del territorio y los objetivos del estudio. Pero sí que hay que decir que el listado de las variables seleccionadas deberá ser exhaustivo y por otra parte se deberá tratar de evitar la redundancia de cualquier factor considerado.

2. Medición de la calidad de los componentes en cada unidad de paisaje de referencia (en el mismo terreno o sobre cartografía temática preparada al efecto).

3. Establecimiento de importancia relativa de cada componente mediante pesos o coeficientes de ponderación con la que cada elemento contribuye a la calidad.

4. Combinación de los valores precedentes en cada unidad para obtener un valor de la calidad visual de cada unidad de paisaje en cuestión.

Las principales críticas a este tipo de métodos son (DUNN, 1974):

- Su debilidad está en el hecho de considerar el paisaje como una serie de elementos aislados, ignorando el efecto de composición del paisaje. Existen infinidad de evidencias, proporcionadas por la psicología de la percepción, de que los componentes no explican adecuadamente el conjunto que forman, ya que el todo es algo más que la suma de las partes, pudiendo ser las relaciones entre los componentes más importantes que los propios componentes. 
- Detrás de la aparente objetividad de estos métodos, existe la subjetividad del experto a la hora de seleccionar las variables del modelo, así como a la hora de valorar sus diferentes tipos y ponderaciones.

Dentro del grupo de este grupo de métodos indirectos de valoración de la calidad visual del paisaje, se distinguen:

b.1) Métodos indirectos de valoración de la calidad visual del paisaje a través de los componentes:

Son también conocidos como modelos ecológicos o ambientales de planificación de la calidad visual del paisaje, y en esencia, valoran la calidad visual de un paisaje desagregándola en la valoración de la calidad visual de sus componentes. Las diferencias entre los diferentes métodos radican en:

- Selección de los componentes

- Forma de valorar cada componente

- Forma de combinar las variables.

Por su amplia aplicación cabe destacar el modelo general de valoración de la calidad visual del paisaje para la Planificación Física desarrollado por Escribano y colaboradores (1987; 1991; MOPT, 1992), quienes establecen un modelo de valoración indirecta por componentes del medio físico aplicado en sus estudios territoriales, por lo general de escala media.

Según el modelo, en la determinación de la calidad visual, se debe integrar en un primer paso las características visuales intrínsecas de la unidad valorada, en lo que se denomina CALIDAD VISUAL INTRÍNSECA del territorio; después, en segundo lugar, integrar la calidad del paisaje exterior, obtenida según la influencia del paisaje del entorno inmediato (las vistas directas inmediatas) que se denomina CALIDAD VISUAL DEL ENTORNO INMEDIATO y , en tercer lugar, la contribución que se puede observar cuando como telón de fondo figura un elemento de valor estético reconocido, y que contribuye a aumentar la calidad de la unidad según lo que se ha denominado tradicionalmente como CALIDAD VISUAL DEL FONDO ESCÉNICO.

Estos métodos son sencillos de aplicar pues se trabaja con variables tangibles y fácilmente definibles pero se les critica que no pueden explicar de una forma completa la calidad del paisaje al no considerar las interacciones entre los diferentes elementos.

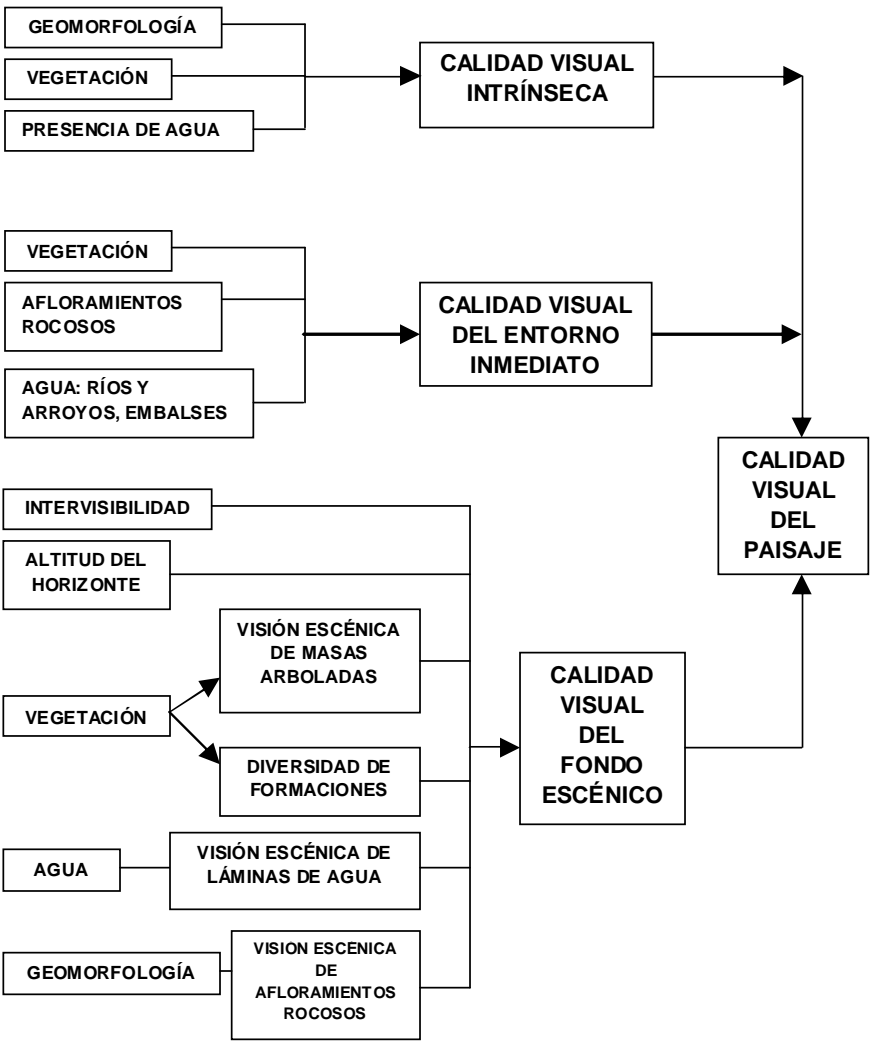

Fig. 3.4: Modelo general para la evaluación de la calidad visual del paisaje presentado por R. Escribano y colaboradores (1987; 1991; MOPT, 1992). 


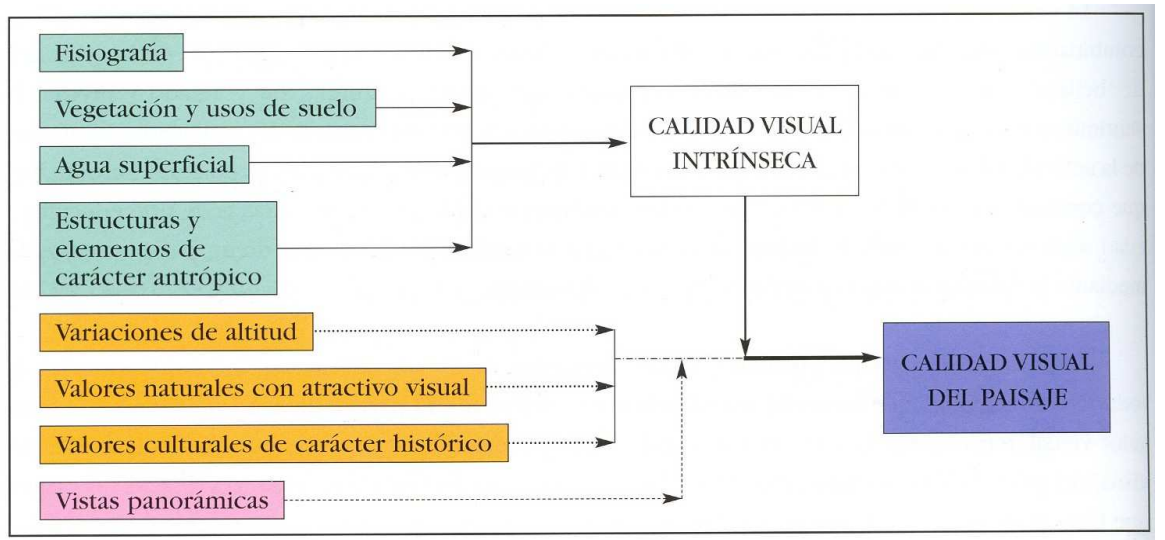

Fig. 3.5: Modelo para la valoración de la calidad visual del paisaje de la Comunidad de Madrid (Aramburu et Al., 2003).

b.2) Métodos indirectos de valoración de la calidad visual mediante las Categorías Estéticas:

Son también llamados métodos formalistas, porque valoran la calidad del paisaje según la desagregación del paisaje en categorías estéticas, atributos de calificación de la belleza de los componentes del paisaje o del paisaje. Burtton Litton (1972), uno de los pioneros en este tipo de métodos, valoró la calidad de una forma cualitativa, empleando una serie de factores de reconocimiento del paisaje y unos criterios estéticos.

Tabla 3.1 Factores aplicados por Litton para la valoración de la calidad visual del paisaje (MOPT, 1992)

\begin{tabular}{|l|l|l|}
\hline $\begin{array}{l}\text { FACTORES DE RECONOCIMIENTO } \\
\text { PRIMARIOS }\end{array}$ & $\begin{array}{l}\text { FACTORES DE RECONOCIMIENTO } \\
\text { SECUNDARIOS }\end{array}$ & CATEGORIAS ESTÉTICAS \\
\hline $\begin{array}{l}\text { Formas del terreno (refiriéndose a a } \\
\text { elementos convexos como sierras o lomas) }\end{array}$ & $\begin{array}{l}\text { Posición del observador (inferior, } \\
\text { normal y superior) }\end{array} \quad \begin{array}{l}\text { Unidad } \\
\text { Intensidad } \\
\text { Espacios (referidos a elementos } \\
\text { cóncavos como valles o depresiones) } \\
\text { Variabilidad en el tiempo (referida a } \\
\text { las posibilidades de luz y color y a las } \\
\text { medio y fondo). } \\
\text { influencias efímeras del clima). }\end{array}$ & $\begin{array}{l}\text { Secuencia (orden y ritmo). } \\
\text { Variedad }\end{array}$ \\
\hline
\end{tabular}

Este tipo de métodos incorpora propiedades estéticas del paisaje en la valoración de la calidad pero se le critica el hecho de estar trabajando con términos difícilmente definibles y por tanto cuantificables. Por otra parte, no está claro el que la aportación a la belleza de definida por las categorías estéticas sea una función lineal de su magnitud.

c) Métodos mixtos de valoración de la calidad visual del paisaje:

La tendencia actual es la combinación de ambos procedimientos, de modo que se utilicen ventajas de los métodos directos e indirectos. Los objetivos son:

1. Recabar información y reducir la subjetividad a la hora de identificar las variables del modelo y los estereotipos de paisajes

2. Conocer la aportación de cada variable a la calidad total del paisaje de modo que se puedan definir ponderaciones adecuadas a las exigencias locales y ambientales en general, y medir su valor utilizando métodos estadísticos que relacionen las preferencias paisajísticas con los componentes y características visuales del paisaje.

Un ejemplo reciente de este tipo de métodos es el aplicado en la valoración de los paisajes agrícolas de una zona rural de Andalucía (ARRIAZA et Al., 2004). El estudio comenzó dividiendo el territorio en unidades homogéneas; 160 fotos representaron los principales usos del suelo de cada unidad, que se sometieron posteriormente a valoración de los paneles de expertos (cada panel de expertos valoró 16 fotos). Los resultados de la valoración se utilizaron para conocer, a través de una regresión lineal, la contribución de cada componente del paisaje a la percepción de la calidad visual. 


\section{d) Valoración visual del paisaje por Preferencia Visual}

Frente a los modelos empleados hasta el último cuarto del siglo XX, basados en la determinación de la calidad del paisaje a partir de la consulta de expertos, los métodos actualmente más empleados asocian calidad visual del paisaje a las preferencias visuales de la población. Dicho planteamiento resulta por otro lado plenamente coherente con las indicaciones recogidas en el artículo 6 del Convenio Europeo del Paisaje, por las que se debe hacer partícipe a la población de la valoración del paisaje y de la definición de las políticas que guíen su posterior evolución.

El método de trabajo puesto a punto por el profesor Carl Steinitz y aplicado en lugares tan diversos como La Paz (Baja California, México), Venecia (Italia) o la Comunidad Valenciana (España) supone que la población, a partir de la visualización y valoración de imágenes representativas de los paisajes de una determinada zona, proporciona las claves para determinar los factores explicativos de la preferencia visual en dicha zona, partiendo para ello de un amplio listado en cuya redacción puede haber participado previamente parte de la población.

Dichos modelos hacen uso de las potentes herramientas informáticas disponibles para el tratamiento estadístico de datos y de los Sistemas de Información Geográfico, que una vez determinados los factores explicativos de la preferencia visual, permiten generar cartografías específicas para cada uno de ellos y combinarlas de acuerdo a su importancia relativa, recogida en el modelo derivado del estudio estadístico.

El plano final así obtenido expone la preferencia visual de todo el territorio analizado sin necesidad de desplazarse a éste y su fiabilidad está fundamentalmente asociada a tres factores. El primero de ellos es la adecuada selección de los posibles factores explicativos de la preferencia visual de la población, el segundo es la precisión, grado de actualización y disponibilidad de capas cartográficas que reflejen las variables antes mencionadas. El tercero y último sería el adecuado desarrollo del proceso de consulta pública, tanto en lo referente a la representatividad de la muestra de población seleccionada, como en la realización de encuestas y posterior procesado y creación de modelos estadísticos a partir de los datos obtenidos.

El esquema siguiente sintetiza los posibles pasos a seguir en la aplicación de dicho método:

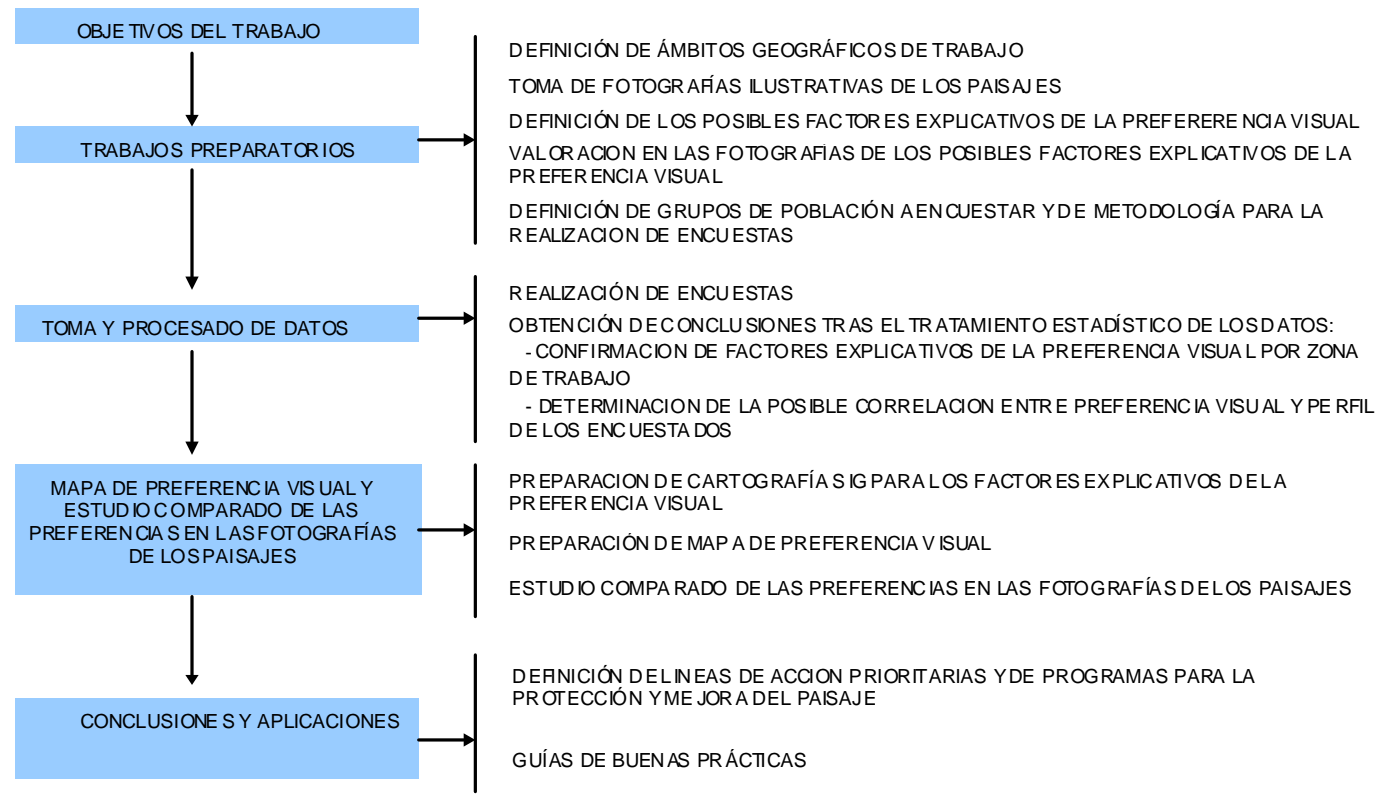

Fig. 3.6. Metodología para la determinación de la preferencia visual (2008, STEINITZ, MUÑOZ, GALÁN, 2008)

e) Valoración visual del paisaje en el Reglamento de Paisaje de la Comunidad Valenciana

La Valoración del paisaje en el Reglamento de Paisaje de la Comunidad Valenciana (2006) considera conjuntamente la opinión de expertos, quienes haciendo uso de alguna de las metodologías existentes, emiten juicios de "calidad paisajística" sobre las unidades de paisaje y sobre los recursos paisajísticos", y la opinión de la población, quien, transmite a su vez mediante procesos de consulta pública sus "preferencias paisajísticas".

El valor paisajístico obtenido como media de las preferencias y calidades paisajísticas de las distintas unidades de paisaje y recursos paisajísticos es a su vez ajustado en función de sus respectivas visibilidades. 
Se transcriben a continuación los artículos del Reglamento de Paisaje de la Comunidad Valenciana en los que se detalla el proceso para la determinación del valor paisajístico (ver los aspectos relativos a la "Visibilidad del paisaje" en el correspondiente apartado del presente estudio terminológico):

\section{Artículo 37. Valor Paisajístico}

1. El valor paisajístico es el valor relativo que se asigna a cada Unidad de paisaje y a cada Recurso Paisajístico por razones ambientales, sociales, culturales o visuales. Para cada una de las Unidades de Paisaje y Recursos Paisajísticos, se establecerá un valor en función de su calidad paisajística, las preferencias de la población y su visibilidad.

2. La calidad paisajística será propuesta de forma justificada por un equipo pluridisciplinar de expertos en paisaje, a partir de la calidad de la escena, la singularidad o rareza, la representatividad, el interés de su conservación y su función como parte de un paisaje integral.

3. La calidad se manifestará como muy baja, baja, media, alta o muy alta. La administración competente para la aprobación del correspondiente instrumento de paisaje podrá fijar una calidad distinta a la propuesta de forma justificada.

4. La preferencia de la población incorporará los valores atribuidos al paisaje por los agentes sociales y las poblaciones concernidas y se definirá a partir de la consulta pública establecida por el Plan de Participación Pública conforme a lo determinado por el artículo 17.2 de este Reglamento.

5. La visibilidad se determinará desde las principales carreteras y puntos de observación a partir del Análisis Visual desarrollado en el artículo 36.

6. El valor de cada Unidad de Paisaje y de cada Recurso Paisajístico, será el resultado de la media de las puntuaciones resultantes de la calidad otorgada técnicamente y de las preferencias del público, ponderada por el grado de su visibilidad desde los principales puntos de observación. El resultado del valor paisajístico se manifestará como muy bajo, bajo, medio, alto o muy alto.

7. En cualquier caso deberá atribuirse el máximo valor a los paisajes que ya están reconocidos por una figura de la legislación en materia de protección de espacios naturales y patrimonio cultural.

8. La Conselleria competente en ordenación del territorio y protección del paisaje elaborará y publicará guías metodológicas para la valoración de paisajes que actualizará periódicamente incorporando la experiencia adquirida y el intercambio de información internacional conforme a los mecanismos de implementación del artículo 8 del Convenio Europeo del Paisaje. Hasta tanto no se disponga de ellas podrán utilizarse tanto métodos cualitativos como cuantitativos de valoración siempre que se expresen los indicadores o parámetros utilizados y se empleen normas o metodologías técnicas de general aceptación, tales como el Método de Valoración de la Preferencia Visual u otros similares. En este caso se detallarán las metodologías y procesos de cálculo utilizados en la valoración que siempre deberán referirse a muestreos de carácter representativo de la población concernida.

\section{2.c.2. Conclusiones}

Considerando los objetivos de la presente tesis se asumen las definiciones dadas por el Reglamento de Paisaje de la Comunidad Valenciana para los términos vinculados al paisaje por considerarse que incorporan los conceptos incluidos en el resto de definiciones estudiadas, detallándolas en mayor grado y estructurando dentro del proceso de valoración una combinación de procesos de consulta a expertos (determinación de la calidad paisajística) y de consulta a la población (determinación de la preferencia paisajística)

- Valor paisajístico: Valor relativo que se asigna a cada unidad de paisaje y a cada recurso paisajístico por razones ambientales, sociales, culturales o visuales y que se establece en función de su calidad paisajística, las preferencias de la población y su visibilidad.

- Valor paisajístico preliminar: Valor relativo que se asigna a cada unidad de paisaje y a cada recurso paisajístico por razones ambientales, sociales, culturales o visuales y que se establece en función de su calidad paisajística y de las preferencias de la población (no se incluye el ajuste debido a la visibilidad).

- Calidad paisajística: La calidad paisajística será propuesta de forma justificada por un equipo pluridisciplinar de expertos en paisaje, a partir de la calidad de la escena, la singularidad o rareza, la representatividad, el interés de su conservación y su función como parte de un paisaje integral. La calidad se manifestará como muy baja, baja, media, alta o muy alta. La administración competente para la aprobación del correspondiente instrumento de paisaje podrá fijar una calidad distinta a la propuesta de forma justificada.

- Preferencia paisajística: La preferencia paisajística se definirá a partir de los valores atribuidos al paisaje por los agentes sociales y las poblaciones concernidas y se definirá a partir de la consulta pública establecida por el Plan de Participación Pública conforme a lo determinado por el artículo 17.2 del Reglamento de Paisaje de la Comunidad Valenciana 


\section{2.d. Visibilidad del paisaje}

\section{2.d.1. Definiciones y consideraciones preliminares}

El objetivo del análisis visual es la determinación de los aspectos de visibilidad del territorio. Vinculado al concepto de visibilidad del paisaje surgen conceptos como el de "cuenca visual" o "punto de observación" que se estudian a continuación:

- Visibilidad del paisaje: La visibilidad del paisaje detemina la importancia relativa de lo que se ve y se percibe y es función de la combinación de distintos factores como son los puntos de observación, la distancia, la duración de la vista, y el número de observadores potenciales (Reglamento de paisaje de la Comunidad Valenciana)

- Cuenca Visual: La cuenca visual de un punto se define como la zona que es visible desde ese punto (AGUILÓ, 1981; MOPT, 1992). Por extensión se puede ampliar el concepto a un conjunto de puntos próximos o que constituyan una unidad u objeto (un embalse, un tramo de carretera, etcétera), y considerarla como la porción de territorio vista desde ellos o, lo que es lo mismo, desde donde pueden ser vistos (GALIANA; 2003)

- Puntos de Observación: Lugares del territorio desde donde se percibe principalmente el paisaje. (Reglamento de paisaje de la Comunidad Valenciana)

La valoración del paisaje en el Reglamento de Paisaje de la Comunidad Valenciana (2006) otorga una gran importancia a la percepción visual y a la cantidad de observadores potenciales. Por este motivo, una vez caracterizado el paisaje y determinadas las unidades de paisaje y recursos paisajísticos, el reglamento requiere la preparación de un análisis visual del territorio en el que se determinen una serie de puntos altamente frecuentados, ubicados preferentemente en infraestructuras de transporte y accesos urbanos. Ante el riesgo de realizar una valoración del paisaje que no considere paisajes de gran valor escasamente visitados, el reglamento solicita explícitamente que se incluyan entre los puntos de observación miradores desde los que se puedan apreciar paisajes representativos o singulares.

El plano final que recoge la calidad visual es denominado "plano de valor paisajístico". Dicho plano se define primeramente a partir de las preferencias expresadas por la población y por un grupo de expertos. En una segunda fase, el plano de preferencias es ajustado en función del plano de visibilidad obtenido en el análisis visual. Finalmente, se incorporan con valor paisajístico muy alto todas aquellas zonas o elementos con algún tipo de protección medioambiental o cultural.

Se transcriben a continuación el artículo del Reglamento de Paisaje de la Comunidad Valenciana en los que se detalla el proceso para la determinación del valor paisajístico:

\section{Artículo 36. Visibilidad del paisaje. Análisis visual}

1. La visibilidad del paisaje determina la importancia relativa de lo que se ve y se percibe y es función de la combinación de distintos factores como son los puntos de observación, la distancia, la duración de la vista, y el número de observadores potenciales.

2. El análisis visual determina la visibilidad del paisaje y tiene por objeto:

- Identificar las principales vistas hacia el paisaje y las zonas de afección visual hacia los Recursos Paisajísticos.

- Asignar el valor visual de los Recursos Paisajísticos Visuales en función de su visibilidad.

- Identificar los recorridos escénicos

- Identificar y valorar posibles impactos visuales de una actuación sobre el paisaje.

3. Los recorridos escénicos son aquellas vías de comunicación, caminos tradicionales, senderos o similares, o segmentos de ellas que tienen un valor paisajístico excepcional por atravesar y/o tener vistas sobre paisajes de valor natural, histórico y/o visual.

4. Los Puntos de Observación son los lugares del territorio desde donde se percibe principalmente el paisaje. Se seleccionarán los puntos de vista y secuencias visuales de mayor afluencia pública que incluirán entre otros los siguientes:

a) Principales vías de comunicación, considerándolas como punto de observación dinámico que definen secuencias de vistas.

b) Núcleos de población.

c) Áreas recreativas, turísticas y de afluencia masiva principales.

d) Puntos de observación representativos por mostrar la singularidad del paisaje.

5. Para cada punto de observación el análisis visual:

a) Delimitará la cuenca visual o territorio que puede ser observado desde el mismo, marcando las distancias corta (hasta $300 \mathrm{~m}$ ), media (300 hasta $1.500 \mathrm{~m}$ ) y larga (más de $1.500 \mathrm{~m}$ ) desde el punto de observación. Estas distancias pueden ser modificadas de forma justificada en función del entorno.

b) Identificará los recursos visuales o las áreas y elementos que definen visualmente la singularidad de un paisaje.

c) Determinará el número de observadores potenciales del paisaje objeto de estudio, diferenciando la proporción de los mismos en relación con las siguientes categorías: residentes, turistas y en itinerario, y la duración estimada de la observación 
6. Los Puntos de Observación se clasificarán como principales y secundarios, en función del número de observadores potenciales, la distancia y la duración de la visión.

7. En función del grado de importancia se obtendrán las zonas de máxima visibilidad, las de visibilidad media, las de visibilidad baja y las no visibles o zonas de sombra. Son zonas de máxima visibilidad las perceptibles desde algún punto de observación principal. Son zonas de visibilidad media, las perceptibles desde más de la mitad de los puntos de observación secundarios, y baja desde menos de la mitad de éstos.

En lo referente a la determinación del plano de visibilidad se observa que la elección de puntos de observación condiciona completamente el resultado obtenido, siendo en este punto necesario:

1. Establecer unos criterios objetivos que justifiquen la elección de puntos de observación (por ejemplo: niveles de afluencia o de paso, existencia de mirador en ruta de alto interés recreativo o medioambiental, etc)

2. Justificar la clasificación de los puntos de observación como principales o secundarios. En este punto es esencial considerar si la asignación de un nivel principal o secundario, obedece a consideraciones territoriales absolutas o relativas, es decir, si se considera principal un punto que se considera especialmente importante dentro del ámbito de estudio, o si, por el contrario, se atiende a consideraciones absolutas, por ejemplo, baremos de frecuentación o intensidad de uso a nivel regional, nacional, etc. A este respecto es pertinente destacar que, dado que el valor paisajístico a calcular con la visibilidad, se define como valor "relativo", puede entenderse que dicho calculo de visibilidad también lo sea.

\section{2.d.2. Conclusiones}

Considerando los objetivos de la presente tesis se asumen las definiciones dadas por el Reglamento de Paisaje de la Comunidad Valenciana para los términos vinculados a la visibilidad del paisaje por considerarse que apoyan una metodología que consigue dos fines especialmente importantes:

1. Vincular la visibilidad del territorio no con las zonas más "visibles" sino con las zonas más "vistas".

2. Generar un elemento que permita gestionar el paisaje y sus recursos, no solo en función de su calidad o preferencia pública, sino en función de la frecuencia con que son vistos.

Las definiciones asumidas a efectos del desarrollo de la tesis serían las siguientes:

- Visibilidad del Paisaje: La visibilidad del paisaje determina la importancia relativa de lo que se ve y se percibe y es función de la combinación de distintos factores como son los puntos de observación, la distancia, la duración de la vista, y el número de observadores potenciales

- Cuenca Visual: Zona que es visible desde un punto o conjunto de puntos (línea, superficie)

- Puntos de Observación: Lugares del territorio desde donde se percibe principalmente el paisaje.

\section{2.e. Capacidad, fragilidad y fragilidad adquirida del paisaje}

3.2.e.1. Definiciones y consideraciones preliminares

Al realizar la caracterización de un paisaje y con el objeto de poder valorar su sensibilidad a los cambios se hace necesario introducir los siguientes conceptos:

- Capacidad del paisaje (Countryside Agency): Grado hasta el que un determinado Tipo o Unidad de Paisaje es capaz de asimilar cambios sin sufrir efectos adversos inaceptables en su carácter.

- Fragilidad visual del paisaje: Susceptibilidad de un paisaje al cambio cuando se desarrolla una actividad sobre él. Dicha variable expresa el grado de deterioro que el paisaje experimentaría ante la incidencia de determinadas actuaciones (AGUILÓ, 1981; MOPT, 1992).

- Fragilidad visual adquirida del paisaje: Fragilidad Visual del paisaje debida a la presencia potencial de observadores (definido este atributo normalmente por la accesibilidad) (AGUILÓ, 1981; MOPT, 1992; DÍAZ Y GALIANA, 1996).

En el caso del Reglamento de Paisaje de la Comunidad Valenciana debe de reseñarse que no se emplea ninguno de los tres conceptos arriba listados. En el caso de la "Capacidad del paisaje" esto es debido a que el propio grado de transformación admisible en una unidad o recurso paisajístico se define de algún modo al establecer los objetivos de calidad paisajísticos, si bien no se realiza un diagnóstico específico sobre esta variable. En el caso de la fragilidad visual del paisaje, se observa que ciertos espacios de alta fragilidad (por 
ejemplo laderas) son por normativa objeto de protección. Finalmente la importancia de la frecuentación y accesibilidad visual del paisaje contemplada en la fragilidad visual adquirida del mismo, se incorpora en el caso del citado Reglamento del Paisaje al ajustar el valor paisajístico en función de la visibilidad.

\section{2.e.2. Conclusiones}

Se asumen en consecuencia a efectos del desarrollo de la presente tesis las siguientes definiciones:

- Capacidad del Paisaje: Grado admisible de transformación de un determinado paisaje sin que éste sufra efectos adversos inaceptables en su carácter.

- Fragilidad Visual del Paisaje: Susceptibilidad de un paisaje al cambio cuando se desarrolla una actividad sobre él..

- Fragilidad Visual Adquirida del paisaje: Fragilidad Visual del paisaje ajustada en función de la presencia potencial de observadores

\section{2.f. Objetivos de calidad paisajística}

\section{2.f.1. Definiciones $y$ consideraciones preliminares}

Una vez conocido (caracterizado) el paisaje, tanto en su configuración como en los procesos que lo sustentan o lo modifican, y considerando el importante papel que el paisaje desempeña en las dimensiones cultural, ecológica, medioambiental, económica y social del territorio, se hace necesario establecer unos objetivos que orienten su evolución.

Dichos objetivos, denominados en adelante "Objetivos de Calidad Paisajística" pueden centrarse estrictamente en aspectos vinculados al carácter del paisaje o pueden definirse para contribuir a estrategias territoriales transversales en las que el paisaje es uno de los temas a tratar (Countryside Agency).

En el estudio de la finalidad de dichos objetivos se han preseleccionado las siguientes definiciones:

- Objetivo de Calidad Paisajística (Según Convenio Europeo del Paisaje): Formulación, por parte de las autoridades públicas competentes, de las aspiraciones de las poblaciones en lo que concieme a las características paisajísticas de su entorno (Convenio Europeo del Paisaje).

- Objetivo de Calidad Paisajística (según Countryside Agency): Finalidad de las acciones aplicadas al paisaje y que podrán adscribirse dentro de las siguientes categorías:

- Conservación y Mantenimiento del carácter existente

- Mejora del carácter del paisaje existente mediante la introducción de nuevos elementos y recursos o nuevas formas de gestión de los existentes.

- Restauración del carácter, siempre que éste sea acorde con el desarrollo de actividades existentes y con las opiniones de los agentes sociales afectados o interesados

- Creación de un nuevo carácter

- Una combinación de los anteriores.

- Objetivo de Calidad Paisajística (según Reglamento de Paisaje de la Comunidad Valenciana): Formulación, por parte de las autoridades públicas competentes, de las aspiraciones de las poblaciones en lo que concierne a las características paisajísticas de su entorno. Se definirán para cada Unidad de Paisaje o Recurso Paisajístico en función de su valor paisajístico y se ajustarán a una de las siguientes opciones:

- Conservación y mantenimiento del carácter existente.

- Restauración del carácter

- Mejora del carácter existente a partir de la introducción de nuevos elementos o la gestión de los existentes.

- Creación de un nuevo paisaje.

- Una combinación de los anteriores.

Como se puede apreciar, existe una alta convergencia entre las definiciones expuestas, debida en gran medida al marco común establecido por el Convenio Europeo del Paisaje. Se observa sin embargo que los objetivos de calidad paisajísticos expuestos son de carácter muy genérico y pueden exigir en la práctica la definición de objetivos más específicos adaptados a las particularidades del área o recurso paisajístico objeto de planificación.

Por otro lado, los objetivos de "Conservación y Mantenimiento" recogidos en las definiciones valenciana y británica, tienen una finalidad esencialmente, protectora, los de "Creación y Restauración" una voluntad 
reordenadora o transformadora y los de "Mejora" una aceptación parcial de las condiciones existentes, pudiendo ser asimilados a una finalidad gestora.

\section{2.f.2. Conclusiones}

Se asumen como definiciones a efectos del desarrollo de la presente tesis las siguientes:

- Objetivo Genérico de Calidad Paisajística: Formulación, por parte de las autoridades públicas competentes, de las aspiraciones de las poblaciones en lo que concierne a las características paisajísticas de su entorno. Se definirán para cada Unidad de Paisaje o Recurso Paisajístico en función de su valor paisajístico y se ajustarán a una de las siguientes opciones:

- Protección del Paisaje (ver definición en apartado específico)

- Re-ordenación del Paisaje (ver definición en apartado específico)

- Gestión del Paisaje (ver definición en apartado específico)

- Objetivo Específico de Calidad Paisajística: Concreción a nivel de Unidad de Paisaje o de Recursos Paisajístico de los objetivos de Protección, reordenación o gestión del paisaje hasta un punto que facilite la definición de programas de Paisaje.

3.2.g. Protección del paisaje

3.2.g.1. Definiciones y consideraciones preliminares

- Protección del Paisaje (Convenio Europeo del Paisaje): "Acciones encaminadas a consenvar y mantener los aspectos significativos o característicos de un paisaje, justificados por su valor patrimonial derivado de su configuración natural y/o la acción del hombre". Esta definición es a su vez coincidente con la expuesta en el Reglamento de Paisaje de la Comunidad Valenciana, al inspirarse el segundo en el citado Convenio.

- Protección del Paisaje (Countryside Agency): Estrategia global dirigida a presenvar y mantener el carácter existente del paisaje.

\section{2.g.2. Conclusiones}

De acuerdo con la definición de Objetivo Genérico de Calidad Paisajística asumida para el desarrollo de la presente tesis, se considerará en adelante la siguiente definición:

Protección del Paisaje: Objetivo Genérico de Calidad Paisajística, materializable mediante el conjunto de acciones que permitan conservar y mantener el carácter general de un paisaje o los aspectos significativos o característicos naturales y antrópicos que lo constituyen.

\section{2.h. Gestión del paisaje}

\section{2.h.1. Definiciones y consideraciones preliminares}

- Gestión del Paisaje (Convenio Europeo del Paisaje): "Acciones encaminadas, desde una perspectiva de desarrollo sostenible, a garantizar el mantenimiento regular de un paisaje, con el fin de guiar y armonizar las transformaciones inducidas por los procesos sociales, económicos y medioambientales". Esta definición es a su vez coincidente con la expuesta en el Reglamento de Paisaje de la Comunidad Valenciana, al inspirarse el segundo en el citado Convenio.

- Gestión del Paisaje (Jaime Busquets y Albert Cortina): Acciones encaminadas, desde una perspectiva de desarrollo sostenible, a garantizar el mantenimiento regular de un paisaje, con el fin de guiar y amonizar las transformaciones inducidas por los procesos sociales, económicos y medioambientales. Dichas acciones se orientan a su vez a la consecución de los siguientes objetivos:

- Contribuir al mantenimiento armónico de los paisajes y a la creación de nuevos paisajes de calidad.

- Promover el desarrollo local a partir de los valores y las oportunidades que ofrecen los paisajes

- Mejorar la calidad de vida

- Mejorar la organización espacial de las actividades en el territorio

- Contribuir mediante directrices paisajísticas a la ordenación territorial, planificación urbanística, políticas sectoriales e intervenciones concretas sobre el territorio.

- Incrementar el capital paisajístico de un determinado territorio, entendiendo el paisaje como un recurso económico y patrimonial de primer orden. 
- Potenciar la participación ciudadana y la implicación de los agentes sociales e institucionales en la definición e implementación de los planes, programas o proyectos dirigidos a la consecución de los objetivos de calidad paisajística.

\section{2.h.2. Conclusiones}

De acuerdo con la definición de Objetivo Genérico de Calidad Paisajística asumida para el desarrollo de la presente tesis, se considerará en adelante la siguiente definición:

Gestión del Paisaje: Objetivo Genérico de Calidad Paisajística, materializable mediante el conjunto de acciones encaminadas, desde una perspectiva de desarrollo sostenible, a garantizar el mantenimiento regular de un paisaje, con el fin de guiar y armonizar las transformaciones inducidas por los procesos sociales, económicos y medioambientales.

\section{2.i. Ordenación del paisaje}

\section{2.i.1. Definiciones y consideraciones preliminares}

- Ordenación del Paisaje (Convenio Europeo del Paisaje): "Acciones que presenten un carácter prospectivo particularmente acentuado con vistas a mejorar, restaurar o crear paisajes". Esta definición es a su vez coincidente con la expuesta en el Reglamento de Paisaje de la Comunidad Valenciana, al inspirarse el segundo en el citado Convenio.

\section{2.i.2. Conclusiones}

$\mathrm{Si}$, conforme a la definición de la Real Academia de la Lengua, se entiende el término "ordenación" como la "colocación de las cosas en el lugar que les corresponde" se puede concluir que la ordenación del paisaje incluiría fundamentalmente las acciones dirigidas a conseguir una estructuración óptima del paisaje y de sus recursos paisajísticos. Dicha ordenación tendría, a diferencia de la gestión o de la protección, una actitud fundamentalmente transformadora y proactiva, idea que se intenta reforzar en la definición asumida en la presente tesis:

- Ordenación del Paisaje: Objetivo Genérico de Calidad Paisajística, materializable mediante el conjunto de acciones orientadas a generar un nuevo paisaje acorde con las aspiraciones de la población y a criterios de desarrollo sostenible.

\section{2.j. Política de paisaje}

\section{2.j.1. Definiciones y consideraciones preliminares}

- Política de Paisaje (Convenio Europeo del Paisaje): Formulación, por parte de las autoridades públicas competentes, de los principios generales, estrategias y directrices que permitan la adopción de medidas específicas con vistas a la protección, gestión y ordenación del paisaje.

La aplicación de las medidas específicas dirigidas a la protección, gestión y ordenación del paisaje requiere su inserción dentro de una marco legal, normativo y operativo que les de justificación y cobertura. Tal y como se expone seguidamente, de acuerdo al Convenio Europeo del paisaje, dicho marco debe ser específico del paisaje en los estados o regiones firmantes y debería ser coordinado con cualquier otra política que pueda tener efectos sensibles sobre el paisaje:

"Cada Parte se compromete a: a) reconocer jurídicamente los paisajes como elemento fundamental del entorno humano, expresión de la diversidad de su patrimonio común cultural y natural y como fundamento de su identidad; b) definir y aplicar en materia de paisajes políticas destinadas a la protección, gestión y ordenación del paisaje mediante la adopción de las medidas específicas contempladas en el artículo 6; c) establecer procedimientos para la participación del público, las autoridades locales y regionales y otras partes interesadas en la formulación y aplicación de las políticas en materia de paisaje mencionadas en la anterior letra b); d) integrar el paisaje en las políticas de ordenación territorial y urbanística y en sus políticas en materia cultural, medioambiental, agrícola, social y económica, así como en cualesquiera otras políticas que puedan tener un impacto directo o indirecto sobre el paisaje" (artículo 5 del Convenio Europeo del Paisaje)

\section{2.j.2 Conclusiones}

Tomando como base la definición propuesta por el Convenio Europeo del Paisaje y con el objeto de reforzar los aspectos jurídicos, participativos e intersectoriales propuestos por el citado Convenio, se asume como definición de política de paisaje la siguiente: 
- Política de Paisaje: Formulación, por parte de las autoridades públicas competentes, del marco jurídico-legal, principios generales, estrategias, directrices y mecanismos de participación pública y de coordinación intersectorial que permitan la adopción de medidas específicas con vistas a la protección, gestión y ordenación del paisaje.

\section{2.k. Ordenación del territorio}

\section{2.k.1. Definiciones y consideraciones preliminares}

El carácter transversal del paisaje y su vinculación a la ordenación del territorio sugiere la necesidad de considerar el significado preciso de este segundo término, para lo que se han consultado las siguientes definiciones

- Ordenación del Territorio: "La Ordenación del Territorio tiene por objeto (...) la delimitación de los diversos usos a que puede destinarse el suelo o espacio físico territorial" (Sentencia 77/84 del Tribunal Constitucional).

- Ordenación del Territorio: "Conjunto de criterios, normas y planes que regulan las actividades y asentamientos sobre el territorio con el fin de conseguir una adecuada relación entre territorio, población, actividades, senicios e infraestructuras" (Ley Cántabra Ordenación del Territorio).

- Ordenación del territorio: "Expresión espacial de la política económica, social, cultural y ecológica de toda la sociedad, cuyos objetivos fundamentales son el desarrollo socioeconómico y equilibrado de las regiones, la mejora de la calidad de vida, la gestión responsable de los recursos naturales, la protección del medio ambiente y, por último, la utilización racional del territorio". (Carta Europea de Ordenación del Territorio, 1983)

- Ordenación del Territorio: "Proyección espacial de las políticas social, cultural, ambiental y económica de una sociedad". (Domingo Gómez Orea)

- Ordenación del Territorio: "Ordenar un territorio significa identificar, distribuir, organizar y regular las actividades humanas en ese territorio de acuerdo a ciertos criterios y prioridades; cabría hablar, por tanto, de ordenación de las actividades humanas en un territorio organizado para acogerlas" (Domingo Gómez Orea, 2002).

- Ordenación del Territorio "Proceso a través del cual se analizan los factores físico-naturales y socio-económicos de un área geográfica, se determinan las formas de uso que se consideran idóneas para cada parte de la misma, se define la amplitud y localización y se establecen las normas que han de regular el uso del territorio y los recursos de dicha área" (Cendrero, 1982)

La consideración de la ordenación del territorio, como "adecuada relación entre territorio, población, actividades, servicios e infraestructuras" o como "expresión espacial de la política económica, social, cultural y ecológica de toda la sociedad" plantean la necesidad de definir lo que se considera "adecuado" o lo que se entiende por "expresión espacial" y permiten establecer un puente directo con el concepto de paisaje, en la medida que éste posibilita la "adecuada" ordenación del territorio desde su dimensión percibida, que a menudo no es sino la manifestación de su coherencia interna funcional. Paralelamente, la planificación del paisaje, encuentra respectivamente en el ámbito del espacio urbano, el medio rural y el espacio forestal aspectos de coincidencia con el urbanismo, la agronomía o las disciplinas forestales, a las que desde el paisaje se puede incorporar la visión transversal, integral e interconectada del territorio así como aspectos de tipo perceptual, escénico o de identidad y carácter que orienten su ordenación, gestión o protección.

Esta apuesta por el paisaje como elemento transversal y como herramienta para un acercamiento proactivo e integral al territorio han constituido de hecho una práctica habitual en distintas regiones del contexto europeo, contribuyendo a un uso inteligente y eficiente del territorio, aumentando su capacidad de acogida para todos los usos del suelo exigibles en una sociedad desarrollada, planteando acercamientos que superan los límites administrativos o sectoriales y facilitando la preservación de los recursos medioambientales y culturales así como su disfrute efectivo por la población.

Estos objetivos coinciden a su vez con los marcados por la Estrategia Territorial Europea, cuyo fin último es lograr el desarrollo equilibrado y sostenible del espacio europeo, estableciendo para ello tres grandes objetivos genéricos (FARINÓS, 2006): la cohesión económica y social (principio de equilibrio), el desarrollo sostenible (principio de protección) y la competitividad a escala global (principio de desarrollo). 


\section{2.k.2. Conclusiones}

Dado el carácter global de la definición propuesta en la Carta Europea de Ordenación del Territorio, en la que implícitamente, al hablar de "expresión espacial de políticas", se alude a definición de usos, normas y ámbitos geográficos, así como a la convergencia de objetivos con el Convenio Europeo del Paisaje, se selecciona dicha definición a efectos del desarrollo de la presente tesis:

- Ordenación del Territorio: Expresión espacial de la política económica, social, cultural y ecológica de toda la sociedad, cuyos objetivos fundamentales son el desarrollo socioeconómico y equilibrado de las regiones, la mejora de la calidad de vida, la gestión responsable de los recursos naturales, la protección del medio ambiente y, por último, la utilización racional del territorio. (Carta Europea de Ordenación del Territorio, 1983).

\subsection{Planificación urbanística / urbanismo / plan urbanístico}

\subsection{I.1. Definiciones y consideraciones preliminares}

La especial y tradicional importancia de los espacios urbanos en la ordenación territorial sugiere la conveniencia de estudiar los términos que afectan a su planificación y desarrollo. En un primera prospección se seleccionan las siguientes definiciones:

- Planeamiento Urbanístico: El planeamiento urbanístico o planificación urbana es el conjunto de instrumentos técnicos y normativos que se redactan para ordenar el uso del suelo y regular las condiciones para su transformación o, en su caso, conservación. Comprende un conjunto de prácticas de carácter esencialmente proyectivo con las que se establece un modelo de ordenación para un ámbito espacial, que generalmente se refiere a un municipio, a un área urbana o a una zona de escala de barrio.

- Planificación urbana: Planeamiento de una futura comunidad o guía para la expansión de una comunidad actual, de una manera organizada, teniendo en cuenta una serie de condiciones medioambientales para sus ciudadanos, así como necesidades sociales y facilidades recreacionales; tal planeamiento incluye generalmente propuestas para la ejecución de un plan determinado. También llamada planeamiento urbano, ordenación urbana. (Diccionario de Arquitectura y Construcción).

- Urbanismo: Conjunto de conocimientos relativos a la planificación, desarrollo, reforma y ampliación de los edificios y espacios de las ciudades (Real Academia de la Lengua).

- Urbanismo: El urbanismo es la disciplina que tiene como objetivo de estudio a las ciudades, desde una perspectiva holística enfrenta la responsabilidad de estudiar y ordenar los sistemas urbanos. También es la forma en que los edificios y otras estructuras de las poblaciones se organizan o la agregación y forma de estar distribuidas las poblaciones en núcleos mayores como ciudades.

- Plan Urbanístico: El que se refiere a la ordenación del espacio urbano comprendiendo la previsión de desarrollo y asignando los diferentes usos del suelo. (Real Academia de la Lengua).

La vinculación del paisaje a la ordenación y planificación territorial recomienda a su vez considerar el estudio del concepto de territorio, que entendido de acuerdo a la definición de la Real Academia de la Lengua, como "porción de la superficie terrestre perteneciente a una nación, región, provincia, etc", abarca los ámbitos propios de estudio o trabajo de distintas disciplinas tales como el urbanismo, la agronomía, la ingeniería civil o la ingeniería forestal. En este punto cabe destacar la convergencia parcial de los términos planificación territorial (asimilable a la ordenación territorial) y planificación urbanística, entre los que existe sin embargo diferencias significativas de matiz referentes a las escalas de trabajo (de mayor grado de detalle en el caso del planeamiento urbanístico) y al nivel de concreción física y normativa, mayor en el planeamiento urbanístico, al que se vinculan a su vez muchos de los instrumentos clásicos de planificación (Planes Generales, Planes Especiales, etc).

\subsubsection{Conclusiones}

Se listan a continuación las definiciones asumidas al efecto del desarrollo de la presente tesis. En el caso de instrumentos de planeamiento urbanístico, y dado que el ámbito de aplicación de la metodología propuesta en la tesis se ubica en la Comunidad Valenciana, se asumen las definiciones vigentes en ésta:

- Planeamiento Urbanístico (o Planificación Urbanística): Conjunto de instrumentos técnicos y normativos que se redactan para ordenar el uso del suelo y regular las condiciones para su transformación o, en su caso, conservación. 
- Planeamiento Territorial (o Planificación Territorial): Ver Planeamiento Urbanístico y Ordenación Territorial.

- Urbanismo: Conjunto de conocimientos relativos a la planificación, desarrollo, reforma y ampliación de los edificios y espacios de las ciudades (Real Academia de la Lengua)

- Plan Urbanístico: El que se refiere a la ordenación del espacio urbano comprendiendo la previsión de desarrollo y asignando los diferentes usos del suelo. (Real Academia de la Lengua)

- Plan de Acción Territorial: Instrumentos de ordenación territorial que desarrollan, en ámbitos territoriales concretos o en el marco de sectores específicos, los objetivos y criterios de la Ley de Ordenación del Territorio y de Protección del Paisaje así como la Estrategia Territorial de la Comunidad Valenciana. El ámbito de los planes de acción territorial puede comprender, en todo o en parte, varios términos municipales. Los planes de acción territorial serán de carácter sectorial o integrado, según sus objetivos y estrategias estén vinculados a uno o a varios sectores de la acción pública. (Ley de Ordenación y Protección del Paisaje de la Comunidad Valenciana, 2004

- Plan General: Plan que define el modelo de evolución urbana y su ordenación urbanística estructural, para términos municipales completos y los desarrollan pormenorizadamente en todo o parte del suelo urbano. (Ver definición de Ordenación estructural) (Ley Urbanística Valenciana, 2005)

- Plan Parcial: Plan que, siguiendo las directrices del Plan General, ordena pormenorizadamente sectores concretos de suelo urbanizable. (Ley Urbanística Valenciana, 2005)

- Plan de Reforma Interior: Plan que, en suelo urbano, establece o completa la ordenación pormenorizada en operaciones de renovación urbana a fin de moderar densidades, reequipar barrios enteros, modernizar su destino urbanístico o preservar el patrimonio arquitectónico de interés. (Ley Urbanística Valenciana, 2005)

- Plan Especial: Plan que, en desarrollo, complemento o incluso modificación del planeamiento general y parcial, cumplen cualquiera de los siguientes cometidos: crear o ampliar reservas de suelo dotacional; definir y proteger las infraestructuras o vías de comunicación, el paisaje y el medio rural; adoptar medidas para la mejor conservación de inmuebles de interés cultural o arquitectónico; definir las condiciones de urbanización y edificación de ámbitos concretos sujetos a actuaciones urbanísticas singulares; concretar el funcionamiento de las redes de infraestructuras; y vincular áreas o parcelas, urbanas o urbanizables, a la construcción o rehabilitación de viviendas sujetas a algún régimen de protección pública. (Ley Urbanística Valenciana, 2005)

- Ordenación estructural: Determinaciones (establecidas mediante el Plan General para todo el Territorio Municipal) que sirven para dar coherencia a la ordenación urbanística del territorio en su conjunto, y, en particular, las siguientes (Ley Urbanística Valenciana, 2005):

a) Directrices definitorias de la estrategia de evolución urbana y ocupación del territorio.

b) Clasificación del suelo.

c) División del territorio en zonas de ordenación urbanística, determinando para cada una de ellas sus usos globales y tipos básicos de edificación.

d) Ordenación del Suelo No Urbanizable.

e) Red Primaria de reservas de suelo dotacional público y equipamientos de titularidad privada cuya función o relevancia contribuyan a la articulación de la ciudad.

f) Tratamiento de los bienes de dominio público no municipal.

g) Ordenación de los centros cívicos y de las actividades susceptibles de generar tránsito intenso.

h) Expresión de los objetivos, directrices y criterios de redacción de los instrumentos de desarrollo del Plan General, delimitando los sectores definitorios de ámbitos mínimos de planeamiento parcial o de reforma interior, los usos o intensidades de cada sector, así como su aprovechamiento tipo.

i) Para sectores de suelo urbanizable de uso residencial, y, en su caso, urbanos: fijación del porcentaje mínimo de edificación con destino a vivienda de protección pública.

\section{2.m. Planificación del paisaje.}

3.2.m.1. Definiciones y consideraciones preliminares

Se listan a continuación una selección de definiciones para el término en estudio:

- Planificación del paisaje: Estudio científico de los paisajes con el fin de evaluar sus capacidades pasadas, presentes y futuras para acoger diferentes usos del suelo tomando para ello en consideración criterios medioambientales y ecológicos. (O'ROURKE, MARK, American Association of Landscape Architects ASLA). 
- Planificación del paisaje: Área de conocimiento que se ocupa de la planificación regional y que se centra en los paisajes y el diseño urbano en las grandes y medianas escalas (Programa Grado en Planificación del Paisaje de la Universidad de Kingston, Londres).

Frente a la definición a menudo abstracta y adjetivada del paisaje y frente a la aceptación de su carácter subjetivo y difícilmente valorable, el nuevo escenario que se plantea en un futuro, requiere del establecimiento de definiciones precisas y de metodologías sistemáticas y reproducibles que permitan introducir el paisaje en las políticas sociales, económicas y de ordenación del territorio con criterios lo más objetivos posibles y con una vocación proactiva.

Dicha necesidad no debería ser percibida como fruto de una situación coyuntural y local, sino como respuesta a una tendencia de carácter global, por la que los condicionantes previos de ocupación del territorio, capaces de generar paisajes específicos para cada tiempo y lugar, han sido sustituidos por un nuevo sistema de reglas en el que, tecnología y globalización, se han probado capaces de generar paisajes a menudo "deslocalizados" en los que la proximidad de recursos materiales y energéticos o la identidad cultural han dejado de ser elementos modeladores del paisaje.

El cuestionamiento desde las más altas instituciones europeas de este nuevo contexto de territorios y paisajes exigentes en energía y materiales, pensados para el corto plazo y determinados por criterios sectoriales o estrictamente económicos, unido a la creciente toma de conciencia del concepto de "límite" y de "perdida irreversible" de recursos medioambientales, culturales y paisajísticos, son algunos de los factores, que condujeron a la creación del Convenio Europeo del Paisaje del Consejo de Europa, en el que el paisaje se constituye en un factor fundamental en la planificación y ordenación territorial, así como en objeto de participación pública y de identidad cultural.

El paso de la percepción del paisaje como "resultado" o "consecuencia" de la interacción del ser humano con el medio a elemento "configurador" u "ordenador" del territorio, constituye por lo tanto una de las principales aportaciones del Convenio, poniendo a su vez sobre la mesa el reto de avanzar en el desarrollo de métodos que haciendo uso del creciente conocimiento sobre los procesos y agentes que intervienen en el territorio, facilite su adecuada planificación.

La planificación del paisaje debe por lo tanto aplicarse al conocimiento del territorio y del paisaje integrando para ello a nivel académico y profesional las distintas disciplinas afectadas.

\section{2.m.2. Conclusiones}

Considerado el marco del Convenio Europeo del Paisaje y la Planificación del Paisaje como disciplina específica vinculada a la consecución de sus fines, se asume la siguiente definición a efectos del desarrollo de la presente tesis:

- Planificación del Paisaje: Conjunto de conocimientos e instrumentos técnicos y normativos de carácter territorial que permiten conocer y orientar la evolución (protección, gestión u ordenación) del paisaje a partir de criterios perceptivos, medioambientales, ecológicos, culturales, urbanísticos, económicos y sociales.

\section{2.n. Participación pública}

\section{2.n.1. Definiciones y consideraciones preliminares}

Los procesos de participación pública surgen con el objeto de facilitar la implicación directa de la población en la toma de decisiones en el ámbito de lo público y en su aplicación posterior. Dichos procesos persiguen profundizar en los principios democráticos y requieren para su correcto desarrollo de: (1) una adecuada información/formación de la población participante, (2) el establecimiento de los cauces adecuados para que dicha participación sea fácil y abierta y (3) una implicación de los participantes en la definición, ajuste y aplicación de aquellos temas a los que han sido invitados a participar.

Partiendo de una política lanzada desde Naciones Unidas y concretada en el Convenio de la Comisión Económica para Europa (Comisión Ambiental) sobre el acceso a información, participación pública en la toma de decisiones y el acceso a la justicia en materia de medio ambiente (Convenio de Aarhus, 1998), han sido aprobadas distintas directivas europeas (Directiva 2003/4/CE del Parlamento Europeo y del Consejo, de 28 de enero de 2003, relativa al acceso del público a la información medioambiental y Directiva 2003/35/CE del 
Parlamento Europeo y del Consejo, de 26 de mayo de 2003, para la participación del público en la elaboración de determinados planes y programas relativos al medio ambiente) cuya transposición a los ámbitos nacionales y regionales están permitiendo una progresiva introducción de los procesos de participación pública. En particular, en lo referente al paisaje, el Convenio Europeo del Paisaje requiere de las partes firmantes el establecimiento de procedimientos para la participación del público en la formulación y aplicación de las políticas en materia de paisaje (artículo 5), apoyando dichos procedimientos con políticas de formación y sensibilización (artículo 6).

A título de ejemplo, en España, en aquellos campos en los que el gobierno central tiene competencias (por ejemplo gestión de las cuencas por medio de las Confederaciones Hidrológráficas) o en la definición y aplicación de políticas de paisaje en aquellas comunidades autónomas que las han puesto en marcha (Cataluña y Comunidad Valenciana), se observa una progresiva y regulada incorporación de procesos de participación pública.

A nivel de ordenación del territorio y de planificación urbanística y del paisaje, los retos que se están encontrando son múltiples y diversos, siendo los principales escollos, la complejidad de los temas que deben ser valorados por la población y la dificultad en implicar a grandes sectores de la población que no perciben una vinculación directa con los temas tratados.

Con el objeto de resolver estas dificultades y de regular los procesos de participación pública se definieron en el ámbito de la Comunidad Valenciana (Ley de Ordenación del Territorio y Protección del Paisaje (año 2004) y Reglamento de Paisaje (año 2006)) los procedimientos de participación pública, cuyo desarrollo se detalla en los artículos siguientes del citado reglamento:

\section{Artículo 10. Participación pública en las políticas en materia de paisaje}

1. La política territorial de la Generalitat dirigida a la mejora de la calidad de vida de los ciudadanos y el desarrollo sostenible se basa, entre otros criterios, en la participación activa de éstos en los procesos de planificación paisajística.

2. La utilización de procesos de participación pública tiene por objeto:

a) Aumentar la transparencia de las actuaciones de la administración en materia de paisaje y lograr una mayor viabilidad del proyecto, implicando desde el origen de la gestión del espacio, a los interesados.

b) Obtener información valiosa sobre el paisaje aportada por los ciudadanos que de otra forma podría no tenerse en cuenta.

c) Hacer partícipes a los ciudadanos en la toma de decisiones que afecten a los paisajes que les conciernen

3. El Consell fomentará la utilización de los cauces de participación existentes y creará aquellos otros que sean necesarios para facilitar, fomentar y garantizar la participación institucional y de los ciudadanos en la toma de decisiones en los procesos de protección, gestión y ordenación de los paisajes. Corresponde al Consell fomentar mecanismos de participación de los ciudadanos que contribuyan a la formación de las políticas y estrategias de paisaje y en particular:

a) Definir los procedimientos para la difusión, acceso y puesta a disposición del público de la información sobre el paisaje.

b) Organizar y actualizar la información de paisaje relevante que obre en su poder o en el de otras entidades con vistas a su difusión al público de forma activa y sistemática.

c) Controlar la efectiva participación del público en la elaboración de los Instrumentos de protección, gestión y ordenación del paisaje previstos en este Reglamento por medio de sus Planes de Participación Pública, conforme a lo determinado en la Sección Primera del presente capítulo.

d) Impulsar la constitución de las Juntas de Participación de Territorio y Paisaje.

\section{Artículo 11. Acceso Público a la información}

1. Todas las Administraciones Públicas y los órganos de la administración de la Comunidad Autónoma garantizarán en las materias relacionadas con el paisaje el pleno cumplimiento de lo dispuesto en los artículos 34, 37, 38, 84, 86 y concordantes de la Ley 30/1992, de 26 de noviembre, de Régimen Jurídico de las Administraciones Públicas y del Procedimiento Administrativo Común, y, en particular, en la Ley 27/2006, de 18 de julio, por la que se regulan los derechos de acceso a la información, de participación pública y de acceso a la justicia en materia de medio ambiente.

2. La Conselleria competente en ordenación del territorio y paisaje facilitará mediante una página web, cuanta información pueda ser de interés al ciudadano para el ejercicio de su derecho a la información en materia de paisaje tal como textos de carácter normativo de ámbito regional, nacional o europeo; instrumentos de protección, gestión u ordenación del paisaje de ámbito supramunicipal; guías metodológicas para la elaboración de los instrumentos previstos en este Reglamento o algunos de sus documentos; cartografía básica; etc. La información será accesible y estará relacionada con otras fuentes de información, conforme a lo determinado por el artículo 8 del Convenio Europeo del Paisaje.

3. La Conselleria competente en materia de territorio y paisaje centralizará los archivos de documentos relativos a los procedimientos de participación pública y establecerá los mecanismos adecuados para su acceso.

4. La Conselleria competente en materia de ordenación del territorio y paisaje publicará manuales y guías que faciliten la adecuada aplicación de las determinaciones de este Reglamento o de cualquier otra cuestión relacionada con las políticas de paisaje. Se habilita al conseller competente en esta materia para establecer mediante orden las que deban ser de obligada observancia. 


\section{Artículo 12. Juntas de Participación de Territorio y Paisaje}

1. De conformidad con el artículo 100 de la Ley 4/2004, de 30 de junio, de la Generalitat, de Ordenación del Territorio y Protección del Paisaje, las Juntas de Participación de Territorio y Paisaje constituyen el cauce directo de intervención ciudadana en la política territorial y del paisaje, debiendo dar cabida tanto a las instituciones públicas como a las asociaciones cuyos fines tengan vinculación directa con el territorio o el paisaje.

2. El Consell aprobará mediante Decreto la composición y funciones de las Juntas de Participación de Territorio y Paisaje.

\section{Artículo 13. Derechos de los ciudadanos en relación con la participación pública en los instrumentos de paisaje}

Con independencia de la plena aplicación en las políticas de paisaje de cuantos derechos se consagren en los artículos 34 y siguientes y 84 y siguientes de la Ley 30/1992, de 26 de noviembre, de Régimen Jurídico de las Administraciones Públicas y del Procedimiento Administrativo Común, y, en particular, en la Ley por la que se regulan los Derechos de Acceso a la Información, de Participación Pública y de Acceso a la Justicia en Materia de Medio Ambiente, los ciudadanos y público interesado podrán ejercer los siguientes derechos en relación con la participación pública en los instrumentos de paisaje:

1. A participar de manera efectiva y real en la valoración de los paisajes identificados en los instrumentos del paisaje a través de las metodologías específicas reguladas al respecto en el título III de este Reglamento.

2. A acceder con antelación suficiente a la información relevante relativa a los referidos Instrumentos de paisaje y a recibir información actualizada, veraz y comprensible incluso para un público no especializado.

3. A formular alegaciones y observaciones cuando estén aún abiertas todas las opciones y antes de que se adopte la decisión sobre los mencionados instrumentos de paisaje y a que aquéllas sean tenidas debidamente en cuenta por la administración Pública correspondiente.

4. A que se haga público el resultado definitivo del procedimiento en el que ha participado y se informe de los motivos y consideraciones en los que se basa la decisión adoptada; Así como a recibir una respuesta, escrita y motivada, sobre las alegaciones, sugerencias o recomendaciones que hubieran formulado, debiendo notificarse de conformidad con lo establecido en la Ley 30/1992, de 26 de noviembre, de Régimen Jurídico de las Administraciones Públicas y del Procedimiento Administrativo Común.

\section{Artículo 14. Definiciones}

1. El Plan de Participación Pública es el documento que define la estrategia de participación pública que debe acompañar todo Instrumento de paisaje y la desarrolla detalladamente para cada una de las fases del proceso de elaboración.

2. El Público Interesado es el público afectado o que puede verse afectado por procedimientos de toma de decisiones de las políticas en materia de paisaje o que tenga un interés en el lugar. En relación al paisaje se establecen dos grandes grupos:

a) Grupos de interés: organismos y agencias públicas, autoridades locales, asociaciones no gubernamentales, grupos académicos y científicos. Tienen interés tanto local como regional y pueden contribuir en todas las escalas tanto a escala regional como un proyecto local.

b) Grupos del lugar: residentes locales, visitantes, grupos locales. Son individuos que viven y trabajan en un área en particular o la visitan y tiene un interés particular en esa zona.

3. Actividades de Participación son los métodos y mecanismos que se definen en el Plan de Participación Pública y que permiten ejercer los derechos de los ciudadanos en materia de participación definidos en el presente Capítulo.

\section{Artículo 15. Plan de Participación Pública de los instrumentos para la protección, gestión y ordenación del paisaje}

1. Los instrumentos para la protección, gestión y ordenación del paisaje, regulados en el título III del presente reglamento, deben contar con un Plan de Participación Pública que formará parte de éstos y garantizará eficazmente, en especial, la participación ciudadana en la valoración de las unidades de paisaje y de los recursos paisajísticos para la definición de los objetivos de calidad paisajística.

2. El Plan de Participación Pública se definirá al inicio del proceso contemplando tanto las fases de consultas previas como en las de desarrollo del instrumento, así como previsión de las de su revisión.

3. El Plan de Participación Pública tiene por objeto:

a) Hacer accesible la información relevante sobre el instrumento de paisaje a que se refiera el Plan de Participación.

b) Informar del derecho a participar y de la forma en que se puede ejercer este derecho.

c) Reconocer el derecho a formular observaciones y comentarios en aquellas fases iniciales del procedimiento en que estén abiertas todas las opciones.

d) Obtener información útil del público interesado.

e) Identificar los valores atribuidos al paisaje por los agentes sociales y las poblaciones mediante las metodologías reguladas en el Título III.

f) Justificar la opción adoptada y la forma en que se ha desarrollado el trámite de participación.

\section{Artículo 16. Contenido del Plan de Participación Pública}

Contenido del Plan de Participación Pública El Plan de Participación Pública contendrá, como mínimo, una memoria que de forma clara y esquemática defina:

1. Fases de elaboración y aplicación del instrumento a que se refiere el Plan.

2. Objetivos del proceso de participación y programación de actividades y trabajos.

3. Público interesado y afectado para cada uno de ellos y del papel que desempeñan en el proceso de planificación.

4. Metodología y actividades a realizar así como de los programas de trabajo para asegurar el intercambio de información y la consulta conforme al artículo siguiente.

5. Evaluación periódica del proceso de participación.

6. Resumen, actualizado periódicamente, de los resultados del Plan de Participación Pública que deberá ser comunicado al público a través de la página web y que contenga como mínimo: 
a) Información pública y consultas formuladas, sus resultados, las decisiones adoptadas para la definición de los objetivos de calidad y consideración de los resultados de la participación en la toma de éstas.

b) Autoridades locales designadas como interlocutores así como representantes de las partes interesadas.

c) Puntos de contacto y procedimientos para obtener la documentación de base y la información requerida por las consultas públicas.

\section{Artículo 17. Actividades y métodos del Plan de Participación Pública}

Las actividades y métodos a que hace referencia el apartado 4 del artículo anterior serán como mínimo los siguientes:

1. En relación con el suministro e intercambio de información.

a) La administración competente asegurará que el suministro e intercambio de información se lleve a cabo desde el inicio y a lo largo de todo el proceso de redacción de los instrumentos para la protección, ordenación y gestión del paisaje dy para ello utilizará diferentes métodos: página web, notas de prensa, publicaciones etc. A tal fin podrá celebrar consultas, encuestas y reuniones, formales e informales, tanto con los grupos de interés como con los grupos del lugar, en su condición de interesados, con la finalidad de articular mecanismos efectivos de participación ciudadana en la elaboración de los instrumentos de paisaje y de facilitar intercambios reales de información y de opinión, antes de llegar a la fase de toma de decisiones por los órganos competentes.

b) Al inicio del proceso se definirá y pondrá a disposición del público interesado el Plan de Participación Pública definido en el artículo anterior y se irán incorporando el resto de contenidos conforme se desarrolle.

c) Cuando sea posible se resaltarán y divulgarán las consecuencias visuales, medioambientales, sociales y económicas de los objetivos de calidad paisajística definidos.

2. En relación con la consulta pública.

a) La consulta pública es una parte esencial de los instrumentos de paisaje regulados en el título III, tanto en la recopilación de información del lugar como en la valoración de la Unidades de Paisaje y de los Recursos Paisajísticos. b) La consulta pública se llevará a cabo con el público interesado seleccionando los métodos más adecuados .tales como grupos de consulta, encuestas, sesiones públicas con o sin tercero mediador u otros de naturaleza similar. sin que en ningún caso sea suficiente la mera fase de información pública regulada en el artículo 86 de la Ley 30/1992, de 26 de noviembre, de Régimen Jurídico de las Administraciones Públicas y del Procedimiento Administrativo Común.

c) El Consell elaborará Guías de Participación Pública en Paisaje en donde se definan las actividades y métodos de consulta que mejor transmitan la importancia que los paisajes tienen para el público interesado a partir de los valores, deseos y preferencias que les son atribuidos. Estas guías se actualizarán cada tres años incorporando los resultados y experiencias obtenidos.

\section{2.n.2. Conclusiones}

Considerando que el procedimiento previsto por el Reglamento de Paisaje de la Comunidad Valenciana responde a los objetivos generales previstos para los procesos de Participación Pública y que establece una metodología clara, sencilla y con un margen de adaptación suficiente a las condiciones particulares de cada trabajo, se asumen las indicaciones dadas en los planes de participación pública (artículos 15, 16 y 17 del citado reglamento). Igualmente se estima que la obligatoriedad de acompañar de un plan de participación pública todo estudio de paisaje o todo estudio de integración paisajística, constituye un valioso modo de recoger las sensibilidades e inquietudes de la población y de implicarlos en gestión del territorio y del paisaje.

A partir de estas consideraciones se asumen a efectos del desarrollo de la presente tesis las siguientes definiciones:

- Participación pública: Procesos previsto para facilitar la implicación directa de la población en la toma de decisiones en el ámbito de lo público y en su aplicación posterior. Dichos procesos persiguen profundizar en los principios democráticos y requieren para su correcto desarrollo de: (1) una adecuada información/formación de la población participante, (2) el establecimiento de los cauces adecuados para que dicha participación sea fácil y abierta y (3) una implicación de los participantes en la definición, ajuste y aplicación de aquellos temas a los que han sido invitados a participar.

- Plan de Participación Pública: Documento que define la estrategia de participación pública y la desarrolla detalladamente para cada una de las fases del proceso de elaboración.

- Público Interesado: sector de la población que puede verse afectado por procedimientos de toma de decisiones de las políticas territoriales o que tenga un interés en el lugar. En relación al paisaje se establecen dos grandes grupos:

- Grupos de interés: organismos y agencias públicas, autoridades locales, asociaciones no gubernamentales, grupos académicos y científicos. Tienen interés tanto local como regional y pueden contribuir en todas las escalas tanto a escala regional como un proyecto local.

- Grupos del lugar: residentes locales, visitantes, grupos locales. Son individuos que viven y trabajan en un área en particular o la visitan y tiene un interés particular en esa zona.

- Actividades de Participación: Métodos y mecanismos que se definen en el Plan de Participación Pública y que permiten ejercer los derechos de los ciudadanos en materia de participación pública. 
- Carta de Paisaje: Instrumento de concertación de estrategias entre los agentes públicos y privados, aplicables a escala local, supramunicipal o comarcal, con el fin de llevar a cabo actuaciones de protección, gestión y ordenación del paisaje, que tengan por objetivo mantener sus valores. (Ley de Ordenación, Gestión y Protección del Paisaje de Cataluña).

\section{2.o. Valoración económica del paisaje}

\subsubsection{Definiciones y consideraciones preliminares}

El conjunto de definiciones consideradas y las consideraciones relativas a la valoración económica del paisaje se recogen en el ANEXO I de la presente tesis.

A partir del estudio de las distintas metodologías existentes se concluye que la valoración económica del paisaje está en una fase de desarrolló incipiente y que los paisajes de alta calidad (tanto a escala territorial como a nivel de ámbitos reducidos), generan externalidades positivas que repercuten en un aumento del atractivo turístico y recreativo, del precio de la propiedad o vivienda, o incluso en una disposición de los usuarios a pagar por mantener ese entorno o disfrutar de él. El razonamiento inverso podría hacerse para paisajes o entornos perceptivos de baja calidad o preferencia. Sin embargo este tipo de estudios no tienen una aplicación tan clara en entornos con calidad o preferencia paisajística media, a la que de hecho se adscriben gran parte de nuestros territorios y en los que más que una valoración económica del paisaje existente, tendría sentido su mejora en aras a un aumento del potencial económico del territorio.

Adicionalmente, como principal dificultad para la realización de valoraciones económicas del paisaje, se detecta que el propio concepto de paisaje, incorpora, entre otras, dimensiones perceptivas, patrimoniales, culturales y medioambientales, lo que hace especialmente difícil determinar un valor económico del paisaje específico e independiente de dichas dimensiones.

\section{2.o.2. Conclusiones}

Se asume a efectos de desarrollo de la presente tesis la definición siguiente:

- Valor económico del Paisaje: Valor económico de un lugar atribuible exclusivamente a la calidad de su paisaje o entorno perceptivo.

- Valoración económica del Paisaje: Conjunto de técnicas, conocimientos y procedimientos que permiten determinar el valor económico del paisaje.

3.2.p. Acciones de paisaje: estrategias del paisaje directrices de paisaje/ programas de paisaje / normativa de paisaje / sistema de espacios abiertos / Plan de Acción Territorial de paisaje de la Comunidad Valenciana / catálogos de paisaje

\section{2.p.1. Definiciones y consideraciones preliminares}

Asumidos los objetivos recogidos en el Convenio Europeo del Paisaje referentes a la necesidad de responder a la aspiración general de la población de disfrutar de paisajes de gran calidad y de participar activamente en el desarrollo de éstos y a la voluntad de hacer del paisaje un elemento clave del bienestar individual y social, se hace necesario definir los mecanismos que permitan conseguir dichos objetivos.

Esta intención, es de hecho, la que otorga al paisaje un papel proactivo en la ordenación, gestión y protección del territorio y que, a efectos de la presente tesis, se articularía entorno a los objetivos de calidad paisajística y de los mecanismos previstos para su consecución, que en el caso de la Comunidad Valenciana y de Cataluña serían los siguientes:

- Directrices de paisaje (Ley de Protección, Gestión y Ordenación del Paisaje de Cataluña, 2005): "Determinaciones que, basándose en los Catálogos de Paisaje, precisen e incomoren normativamente las propuestas de objetivos de calidad paisajística en los Planes Territoriales Parciales o en los Planes Directores Territoriales".

- Programas de Paisaje (Reglamento de Paisaje de la Comunidad Valenciana): "Documentos que concretan las actuaciones dirigidas a proteger, mejorar y poner en valor los paisajes que por su valor 
natural, visual, cultural o urbano requieren intervenciones específicas e integradas. En el caso de Estudios de Paisaje los Programas de Paisaje concretarán las medidas, actuaciones y proyectos de paisaje necesarios para cumplir los Objetivos de Calidad Paisajística definidas para el ámbito del Estudio. Los contenidos de los Programas de Paisaje se ajustarán a los de los Programas para la Sostenibilidad y para la Calidad de Vida y contendrán los siguientes documentos:

a) Memoria descriptiva que proponga el ámbito de la actuación, identifique los problemas detectados y establezca los objetivos que se plantean.

b) Memoria justificativa de su adecuación a los fines establecidos para esta clase de actuaciones, a los criterios establecidos por esta Ley y a las determinaciones de los planes de acción territorial vigentes en su ámbito. Justificación de los beneficios que se esperan obtener en relación con los problemas detectados.

c) Relación de proyectos que desarrollarán el programa. Cronograma global de las actuaciones y coste de las mismas relacionado con la obtención de las fuentes de financiación.

d) Estudio económico-financiero que concrete los medios que se comprometerán para la ejecución del programa".

- Normativa de Paisaje: Se expone a continuación lo indicado respecto a los dos tipos de normas (de Aplicación Directa y de Integración Paisajística), en los artículos 18, 19, 20, 21 y 22 del Reglamento de Paisaje de la Comunidad Valenciana:

\section{Artículo 18. Normas de aplicación directa:}

1. Las construcciones habrán de adaptarse al ambiente en que se sitúen. No se admitirán actuaciones individuales que distorsionen el cromatismo, la textura y las soluciones constructivas de los edificios o del conjunto en el cual se ubiquen.

2. No se permitirá que la situación o dimensiones de los edificios, los muros, los cierres, las instalaciones, el depósito permanente de elementos y materiales o las plantaciones vegetales rompan la armonía del paisaje rural o urbano tradicionales, o desfiguren su visión.

3. En el suelo no urbanizable, sin perjuicio de la aplicación de las normas anteriores, serán, además, normas de aplicación directa para las construcciones y edificaciones las siguientes:

a) Las edificaciones en suelo no urbanizable deberán ser acordes con su carácter aislado, armonizando con el ambiente rural y su entorno natural, conforme a las reglas que el planeamiento aplicable determine para integrar las nuevas construcciones en las tipologías tradicionales de la zona o más adecuadas a su carácter.

b) No podrán levantarse construcciones en lugares próximos a carreteras, vías pecuarias u otros bienes de dominio público, sino de acuerdo con lo que establezca la legislación específicamente aplicable.

4. En el medio rural, además de la aplicación de las normas del apartado anterior serán normas de aplicación directa las siguientes:

a) No podrán realizarse construcciones que presenten características tipológicas o soluciones estéticas propias de las zonas urbanas, salvo en los asentamientos rurales que admitan dicha tipología.

b) Se prohíbe la colocación y mantenimiento de anuncios, carteles y vallas publicitarias, excepto los que tengan carácter institucional o fin indicativo o informativo, con las características que fije, en su caso, la administración competente o, tratándose de dominio público, cuente con expresa autorización demanial y no represente un impacto paisajístico.

c) Las nuevas edificaciones deberán armonizar con las construcciones tradicionales y con los edificios de valor etnográfico o arquitectónico que existieran en su entorno inmediato. Además, deberán tener todos sus paramentos exteriores y cubiertas terminadas, empleando formas, materiales y colores que favorezcan una mejor integración paisajística, sin que ello suponga la renuncia a lenguaje arquitectónico alguno.

Artículo 19. Alcance de las Normas de Integración Paisajística: Se concretarán para cada unidad de paisaje a través de los instrumentos de paisaje, constituyendo los criterios a los que los planes y proyectos deberán ajustarse salvo que existan motivos de interés público generales o derivados de la estructura del paisaje en dicha unidad que justifiquen su excepción, lo que deberá motivarse expresamente en el planeamiento o acto de ejecución que las excepciones.

El Reglamento de Paisaje establece en sus artículos 20, 21 y 22, normas de integración paisajística genéricas dedicadas respectivamente a: Integración en la topografía y vegetación; Visualización y acceso al paisaje, y finalmente al Paisaje Urbano. Cada Estudio de Paisaje Cada Estudio de Paisaje concretará, desarrollando y definiendo con detalle, las normas de integración paisajísticas previstas en dichos artículos 20, 21 y 22. Igualmente podrán incorporarse Normas de Integración Paisajística adicionales, teniendo en cuenta que la finalidad de dichas Normas de Integración paisajística es definir los criterios de localización en el territorio y de diseño de nuevos usos y actividades sobre el paisaje para conseguir la integración paisajística en relación con: 
a. La regulación de los usos del suelo, las densidades, alturas y volúmenes, el uso de tipologías arquitectónicas y morfologías urbanas, así como el empleo de materiales, texturas y colores adecuados para la formación del entorno visual.

b. La corrección de conflictos paisajísticos existentes para la mejora de los ámbitos degradados, especialmente los existentes en las periferias de los núcleos y en las conurbaciones propias de las grandes aglomeraciones urbanas

c. La restauración o rehabilitación de los ámbitos deteriorados como consecuencia, entre otras, de su fragmentación por la proliferación de infraestructuras lineales terrestres, su contaminación visual por tendidos aéreos y vallas publicitarias, su degradación en los bordes de las ciudades y de las aglomeraciones urbanas, su transformación por procesos urbanísticos o por la introducción de técnicas, métodos o instalaciones para la explotación agrícola, ganadera y silvícola inadecuadas a su entorno.

d. $\quad$ El Régimen Jurídico de los elementos catalogados (Catálogo de Paisaje).

e. El régimen de usos y ordenación en el Sistema de Espacios Abiertos"

- Sistema de Espacios Abiertos: Se expone a continuación lo indicado respecto a los Sistemas de Espacios Abiertos en el artículo 41 del Reglamento de Paisaje de la Comunidad Valenciana:

Artículo 41. Sistema de Espacios Abiertos: Conjunto integrado y continúo de espacios en general libres de edificación, de interés medioambiental, cultural, visual, recreativo y las conexiones ecológicas y funcionales que los relacionan entre sí. En su definición y uso se considerarán lo siguiente:

- El Sistema de Espacios Abiertos constituirá una zona de Ordenación Urbanística a los efectos de los artículos 36.1.c) y 45.1.e) de la Ley 16/2005, de 30 de diciembre, de la Generalitat, Urbanística Valenciana.

- $\quad$ El Sistema de Espacios Abiertos tiene por objeto proveer de áreas recreativas al aire libre, proteger áreas y hábitats naturales así como el patrón ecológico del lugar y los valores culturales y paisajísticos, mejorar el paisaje visual y preservar zonas de transición físicas y visuales entre distintos usos y actividades.

- Incluirán los siguientes paisajes, salvo excepcionalidad que deberá ser objeto de motivación expresa:

- Los elementos incluidos en el Catalogo de Paisaje.

- Las conexiones ecológicas y funcionales o franjas de terreno que conectan los espacios del apartado anterior y que aún no teniendo elementos de singularidad manifiesta paisajística o incluso se encuentren degradados, se consideran necesarios como áreas de conexión entre los espacios de interés para lograr una continuidad física, ecológica y funcional. En cualquier caso incluirá la red hídrica, senderos históricos, vías pecuarias, infraestructuras y similares y los corredores verdes a los que se refiere la Ley de Ordenación del Territorio y Protección del Paisaje, que desempeñan funciones de conexión biológica y territorial, todo ello de conformidad con lo establecido en el artículo 20.7 de la Ley de Ordenación del Territorio y Protección del Paisaje.

- $\quad$ Aunque la inclusión de un terreno en el Sistema de Espacios Abiertos es independiente de su clasificación o calificación urbanística, la ordenación que se establezca deberá garantizar el carácter de espacio abierto. Las Normas de Integración establecerán las condiciones de uso de tales suelos"

- Plan de Acción Territorial de Paisaje: Se expone a continuación lo indicado respecto a dicho plan en el Reglamento de Paisaje de la Comunidad Valenciana:

"Plan de Acción Territorial que tendrá por objeto identificar y proteger los paisajes de interés regional y, en su caso, de relevancia local, en el territorio valenciano, se delimitarán los ámbitos territoriales que deban ser objeto de planificación y actuación a escala supramunicipal en materia de paisaje y, en particular, los recorridos escénicos y las zonas de afección visual desde las vías de comunicación. Su contenido y determinaciones se ajustarán a lo previsto para los Estudios de Paisaje en el Reglamento de Paisaje de la Comunidad Valenciana, estableciendo establecerá directrices y criterios para la elaboración de los Estudios y demás instrumentos desarrollados en el citado Reglamento, la valoración de los paisajes y la consecuente adopción de medidas de protección o, en su caso, de ordenación o gestión".

- Catálogo de Paisaje (Cataluña): Se cita a continuación la definición recogida en la legislación catalana de paisaje:

"Documentos de carácter descriptivo y prospectivo, aplicables a los ámbitos territoriales, que determinen la topología de los paisajes de Cataluña, identifiquen sus valores y estados de conservación y propongan los objetivos de calidad que han de cumplir (Ley de Ordenación, Gestión y Protección del Paisaje de Cataluña). Los Catálogos de Paisaje así definidos se conciben normativamente como unas herramientas útiles para la ordenación y la gestión del paisaje desde la perspectiva del planeamiento territorial. Es por este motivo que su alcance territorial se corresponde con el de cada uno de los ámbitos de aplicación de los Planes Territoriales Parciales, que coincide con las siete regiones en que se organizará en un futuro la estructura política administrativa de Cataluña."

- Catálogo de Paisaje: Se cita a continuación los contenidos de los catálogos de paisaje tal y como son definidos en el artículo 59 del Reglamento de Paisaje de la Comunidad Valenciana: 
"Los Catálogos de Paisaje incluirán los siguientes elementos...:

- Las Unidades de Paisaje o Recursos Paisajísticos objeto de protección especial conforme a la legislación de protección de Espacios Naturales y los entornos de los bienes y conjuntos incluidos en el perímetro de su declaración como bien de interés cultural conforme a la legislación de patrimonio cultural.

- Las Unidades de Paisaje y los Recursos Paisajísticos a los que se haya reconocido un valor alto o muy alto. Los Catálogos de Paisaje son instrumentos de gran trascendencia puesto que identifican y establecen el régimen jurídico necesario para la preservación y recuperación de los paisajes de mayor valor. Forman parte de los Estudios de Paisaje o tramitarse de forma independiente. Deberán incluir Normas de Integración específicas."

\section{2.p.2. Conclusiones}

A partir de las definiciones y consideraciones expuestas y considerando en particular que los trabajos a desarrollar en la presente tesis tendrán como ámbito la Comunidad valenciana, se asumen o proponen las siguientes definiciones:

- Programas de Paisaje: Documentos que concretan las actuaciones para garantizar la preservación, mejora y puesta en valor de los paisajes que por su valor natural, visual, cultural o urbano requieren intervenciones específicas e integradas. Dichos Programas concretarán las medidas, actuaciones y proyectos de paisaje necesarios para cumplir los Objetivos de Calidad Paisajística definidos con participación pública para el ámbito considerado.

- Normativa de Paisaje (Normas de Integración paisajística): Criterios de carácter paisajístico a los que los planes y proyectos deberán ajustarse salvo que existan motivos de interés público generales o derivados de la estructura del paisaje en dicha unidad que justifiquen su excepción. A efectos de su redacción en la Comunidad valenciana se distinguirá entre:

- Normas de aplicación directa

- Normas de Integración Paisajística (genéricas o específicas)

- Sistema de Espacios Abierto: Conjunto integrado y continúo de espacios en general libres de edificación, de interés medioambiental, cultural, visual, recreativo y las conexiones ecológicas y funcionales que los relacionan entre sí. La adscripción de una determinada zona al sistema de espacios abiertos implicará la aplicación de normativas de paisaje específicas así como la regulación específica de usos del suelo. El sistema de espacios abiertos podrá incluir suelos no urbanizables, urbanizables y urbanos, facilitando de este modo la efectiva conexión y acceso al paisaje así como la adecuada planificación pormenorizada del suelo urbanizable.

- Catálogo de Paisaje: instrumentos previstos en la legislación paisajística valenciana que identifican y establecen el régimen jurídico necesario para la preservación y recuperación de los paisajes de mayor valor. Los Catálogos de Paisaje incluirán:

- Las Unidades de Paisaje o Recursos Paisajísticos objeto de protección especial conforme a la legislación de protección de Espacios Naturales y los entornos de los bienes y conjuntos incluidos en el perímetro de su declaración como bien de interés cultural conforme a la legislación de patrimonio cultural.

- Las Unidades de Paisaje y los Recursos Paisajísticos a los que se haya reconocido un valor alto o muy alto.

- Plan de Acción Territorial de Paisaje de la Comunidad Valenciana: Plan de Acción Territorial que tendrá por objeto identificar y proteger los paisajes de interés regional y, en su caso, de relevancia local, en el territorio valenciano, se delimitarán los ámbitos territoriales que deban ser objeto de planificación y actuación a escala supramunicipal en materia de paisaje y, en particular, los recorridos escénicos y las zonas de afección visual desde las vías de comunicación. Su contenido y determinaciones se ajustarán a lo previsto para los Estudios de Paisaje en el Reglamento de Paisaje de la Comunidad Valenciana.

\section{2.q. Estudios de paisaje / planes de paisaje \\ 3.2.q.1. Definiciones y consideraciones preliminares}

Se puede definir los planes o estudios de paisaje como aquellos documentos que tienen por objeto establecer los objetivos y mecanismos para conseguir una adecuada ordenación, protección y gestión del paisaje. Por su carácter amplio tienen una aplicación territorial y pueden establecer criterios para la ordenación territorial, normativas de paisaje así como marcos de referencia para la definición de acciones, programas o proyectos concretos. Para una adecuada consecución de dichos objetivos, los planes o estudios de paisaje deberán desarrollar un análisis y diagnóstico del paisaje y aplicar dicha información para establecer una serie de propuestas espaciales, normativas y programáticas. 
La búsqueda de definiciones genéricas de términos asimilables al concepto de Plan de Paisaje, Plan Estratégico de Paisaje, Plan de Ordenación Paisajística o Estudio de Paisaje no ha resultado fructífera, encontrándose por el contrario multitud de ejemplos que desarrollan de forma particular este tipo de documentos. Como excepciones cabe destacar las indicaciones dadas al respecto por el Convenio Europeo del Paisaje, en el que se vincula a la planificación del paisaje su identificación y calificación; la definición de objetivos de calidad paisajística y la aplicación de medidas conducentes a la consecución de estos últimos. De igual modo la Countryside Agency en su guía para la "Evaluación del Paisaje" lista y considera los siguientes posibles contenidos de la parte proactiva de un Plan de Paisaje:

\section{Estrategias de Paisaje \\ Definición de potencial de desarrollo urbano \\ Propuestas de de evolución del paisaje \\ Inputs a la Evaluación de Impacto Ambiental}

En esta misma guía se expone como el trabajo de David Tyldesley Associates (1999) en su "The Use of Landscape Character Assessments in Development Plans" permitió constatar la necesidad de desarrollar determinaciones que permitan dar respuesta a temas concretos o de mayor detalle, observándose que, en las áreas con estudios de paisaje realizados, a pesar de que el planeamiento hacía alusión a éstos, pocas veces se pasaba de la pura mención teórica.

Precisamente con el objeto de salvar este vacío y de acuerdo con las indicaciones del Convenio Europeo del Paisaje por las que las partes firmantes "se comprometen a establecer instrumentos de intervención destinados a la protección, gestión y/u ordenación del paisaje”, se definen en el Reglamento de Paisaje de la Comunidad Valenciana los estudios de paisaje como documentos que "establecen los principios, estrategias y directrices, que permitan adoptar medidas específicas destinadas a la catalogación, valoración y protección del paisaje en sus respectivos ámbitos de aplicación y que...: (a) Establecen los objetivos de calidad paisajística del ámbito de estudio; (b) Analizan las actividades y procesos que inciden en el paisaje; (c) Indican las medidas y acciones necesarias para cumplir los objetivos de calidad paisajística".

\subsubsection{Conclusiones}

A partir de las definiciones y consideraciones expuestas y considerando en particular que los trabajos a desarrollar en la presente tesis tendrán como ámbito la Comunidad Valenciana, se asumen o proponen las siguientes definiciones:

- Estudio de Paisaje: Documentos que establece los principios, estrategias y directrices, que permitan adoptar medidas específicas destinadas a la catalogación, valoración y protección del paisaje en sus respectivos ámbitos de aplicación. Los estudios de paisaje: (a) Establecen los objetivos de calidad paisajística del ámbito de estudio; (b) Analizan las actividades y procesos que inciden en el paisaje; (c) Indican las medidas y acciones necesarias para cumplir los objetivos de calidad paisajística.

\section{2.r. Custodia del territorio y del paisaje}

3.2. r.1. Definiciones y consideraciones preliminares

Con el objeto de integrar la iniciativa y acción pública y privada con los intereses generales en materia de Territorio y Paisaje surgió la figura de la Custodia, para la que se han encontrado las siguientes definiciones:

- Custodia del Territorio: Filosofía que busca facilitar las iniciativas voluntarias de conservación de la naturaleza, el paisaje y el patrimonio cultural en propiedades públicas y privadas, y en las que los principales protagonistas serán, por un lado, un propietario $y$, por otro, una entidad de custodia que le asesora para llevar a cabo una gestión de su finca orientada a la conservación de sus valores y recursos (definición basada en los contenidos de la página web de la Xarxa de Custodia del Territorio)

- Custodia del Territorio: Conjunto de estrategias e instrumentos para la consenación de la natura y el paisaje que promueve la participación del propietario de los terrenos, la sociedad civil organizada, la ciudadanía e incluso las empresas privadas:

- Tiene un carácter complementario y no sustitutivo de otras iniciativas y políticas públicas que busquen preservar la biodiversidad y el paisaje. 
- Pretende implicar a los propietarios y usuarios del territorio en la conservación y el buen uso de los valores y los usos naturales, culturales y paisajístico) (Agenda XXI del Municipio de Cocentaina).

La custodia surge por lo tanto como herramienta para poder gestionar el territorio y el paisaje en espacios de propiedad privada o pública en las que se pretende que su evolución sea acorde a criterios de carácter general.

Dado el alto porcentaje de suelo privado existente en España y la Comunidad Valenciana, o los conflictos que pueden darse entre distintas administraciones públicas, la figura de la custodia del territorio y paisaje se hace esencial para una implementación efectiva de las políticas de paisaje.

\section{2. r.2. Conclusiones}

A efectos del desarrollo de la presente tesis se asume la siguiente definición:

- Custodia del territorio: Conjunto de estrategias e instrumentos para la conservación de la natura y el paisaje que promueve la participación del propietario de los terrenos, la sociedad civil organizada, la ciudadanía e incluso las empresas privadas. 
VALORACIÓN Y GESTIÓN DEL PAISAJE SEGÚN EL CONVENIO EUROPEO DEL PAISAJE YEL

REGLAMENTO DEL PAISAJE DE LA COMUNIDAD VALENCIANA: APLICACIÓN MEDIANTE UN ESTUDIO

DE PAISAJE A UNESPACIO ABIERTO EN LA COMUNIDAD VALENCIANA

DOCTORANDO: JUAN JOSÉ GALÁN VIVAS (Universidad Politécnica de Valencia, enero 2011) 
VALORACIÓN Y GESTIÓN DEL PAISAJE SEGÚN EL CONVENIO EUROPEO DEL PAISAJE YEL

REGLAMENTO DEL PAISAJE DE LA COMUNIDAD VALENCIANA: APLICACIÓN MEDIANTE UN ESTUDIO

DE PAISAJE A UNESPACIO ABIERTO ENLA COMUNIDAD VALENCIANA

DOCTORANDO: JUAN JOSÉ GALÁN VIVAS (Universidad Politécnica de Valencia, enero 2011)

\section{MÉTODOS}


VALORACIÓN Y GESTIÓN DEL PAISAJE SEGÚN EL CONVENIO EUROPEO DEL PAISAJE YEL

REGLAMENTO DEL PAISAJE DE LA COMUNIDAD VALENCIANA: APLICACIÓN MEDIANTE UN ESTUDIO

DE PAISAJE A UNESPACIO ABIERTO EN LA COMUNIDAD VALENCIANA

DOCTORANDO: JUAN JOSÉ GALÁN VIVAS (Universidad Politécnica de Valencia, enero 2011) 


\section{MÉTODOS:}

La metodología a proponer tiene como objetivo global establecer un procedimiento para el análisis, valoración y desarrollo de propuestas de ordenación, gestión o protección del paisaje que facilite a su vez la integración de este último en la ordenación y gestión territorial, en la planificación urbanística y en la definición de actuaciones o programas concretos. De acuerdo a los objetivos propuestos en el apartado de Objetivos de la presente tesis se prevé que dicha metodología se estructure en las siguientes fases:

1. Definición de ámbitos de trabajo

2. Caracterización del Paisaje

3. Visibilidad del Paisaje

4. Valoración del Paisaje

5. Determinación de Objetivos (de Calidad Paisajística)

6. Protección, Gestión y Ordenación del Paisaje

7. Participación Pública

8. Integración de aspectos económicos a la valoración, protección, gestión y ordenación del paisaje

Para cada una de estas fases se expondrán las convergencias y divergencias respecto al modelo metodológico de referencia marcado por el Reglamento de Paisaje de la Comunidad Valenciana (ver síntesis de comparación en tabla 4.2) y se considerarán las conclusiones del estudio terminológico y de la revisión bibliográfica incluidas en la presente tesis:

\subsection{Definición de ámbitos y escalas de trabajo}

4.1.a. Consideraciones preliminares:

Por motivos administrativos, los ámbitos de trabajo de los documentos vinculados a la planificación del paisaje se ajustan a menudo a límites no coincidentes con aquellos que serían más operativos para abordar aspectos paisajísticos o medioambientales.

Esta situación es agravada por la frecuente ausencia de un planeamiento paisajístico de referencia que descendiendo progresivamente en el espacio y en el tiempo hacia ámbitos y escalas de detalle, permita contextualizar adecuadamente los trabajos que deben desarrollarse en un momento y lugar determinado.

Asumido que los límites de trabajo en planificación del paisaje vienen a menudo predefinidos por criterios administrativos (términos municipales, comarcas, etc), se plantea la necesidad de reconsiderar dichos límites y de estudiar el modo por el que se pueden incorporar aspectos o elementos con continuidad fuera de éstos. Dichos aspectos o elementos pueden ser de carácter natural, por ejemplo elementos fisiográficos de escala regional (sierras o sistemas montañosos, valles, cauces, costas, etc), de carácter antrópico (infraestructuras de transporte, usos del suelo, patrones culturales de intervención en el territorio, conurbaciones, etc) o de carácter mixto (por ejemplo: unidades de paisaje).

Con el objeto de evitar estas dificultades, las políticas más consistentes y estructuradas de paisaje proponen la creación de marcos de referencia de escala regional en la planificación del paisaje, tal es el caso de Cataluña, donde los catálogos de paisaje se circunscriben a las 7 grandes unidades administrativas en las que se dividirá el territorio catalán, proporcionando de este modo un valioso apoyo para la inclusión del determinaciones de paisaje en los planes territoriales y planes generales; igualmente, es el caso de gran parte de Gran Bretaña, donde se asume que los aspectos definitorios de los tipos y unidades de paisaje (Landscape Character Types y Landscape Character Areas) se deben ajustar al descender hacia escalas de mayor detalle, o el de la Comunidad Valenciana, donde la ley prevé el desarrollo de un Plan de Acción Territorial de Paisaje consistente en un estudio de paisaje del conjunto de la comunidad, que, idóneamente, debería ser complementado a un mayor grado de detalle con estudios de paisaje de carácter regional o municipal.

Sin embargo, la frecuente ausencia de estos marcos de referencia en planeamiento de paisaje hace preciso plantear métodos de trabajo que suplan esta carencia. Dada esta situación, la propuesta para la definición de ámbitos de planificación de trabajo se concentra, por lo tanto, en los siguientes dos aspectos:

1) Definición de ámbitos estrictos en los que se desarrolle el plan o estudio de paisaje completo.

2) Incorporación de aspectos paisajísticos externos al ámbito anteriormente citado que lo sustenten y lo inscriban adecuadamente en el territorio. 


\section{1.b. Metodología propuesta de definición de ámbitos}

Se considera que para cualquier trabajo de planificación del paisaje cabe considerar dos ámbitos de trabajo:

1) Ámbito Estricto (o Ámbito de Ordenación): Correspondería a aquel en el que se desarrollan completamente los contenidos previstos en el plan o estudio de paisaje (caracterización, valoración del paisaje y desarrollo de propuestas dirigidas a su ordenación, gestión y protección del paisaje). Dicho ámbito debería incluir el propio de la administración solicitante del citado estudio, incorporando a su vez las zonas externas necesarias para que dichas propuestas sean operativas y ejecutables.

2) Ámbito ampliado (o Ámbito de Influencia): Correspondería a aquel que permite contextualizar y conectar adecuadamente el ámbito estricto, al que contendría y al que adicionaría los espacios siguientes:

a. Elementos fisiográficos relevantes en el ámbito estricto: cauces, formaciones del relieve, costas...

b. Elementos antrópicos relevantes en el ámbito estricto: infraestructuras, patrones de usos del suelo, conurbaciones, etc.

c. Unidades de paisaje que continúan fuera de los límites del ámbito estricto.

Los límites del ámbito estricto deberían estar preferentemente definidos por elementos de relevancia territorial y alta permanencia (por ejemplo formaciones del relieve).

Dentro del ámbito ampliado se propone la caracterización del paisaje, definiendo las unidades de paisaje y recursos paisajísticos (con unos contenidos y grado de detalle acordes a la escala regional), así como la delimitación de los espacios de conexión territorial con el ámbito estricto, aspecto éste último que se vincularía a la definición de un sistema de espacios abiertos en el ámbito ampliado (ver Figura 4.1: Escalas para la definición de unidades de paisaje y selección de recursos paisajísticos).

\section{ÁMBITO AMPLIADO}
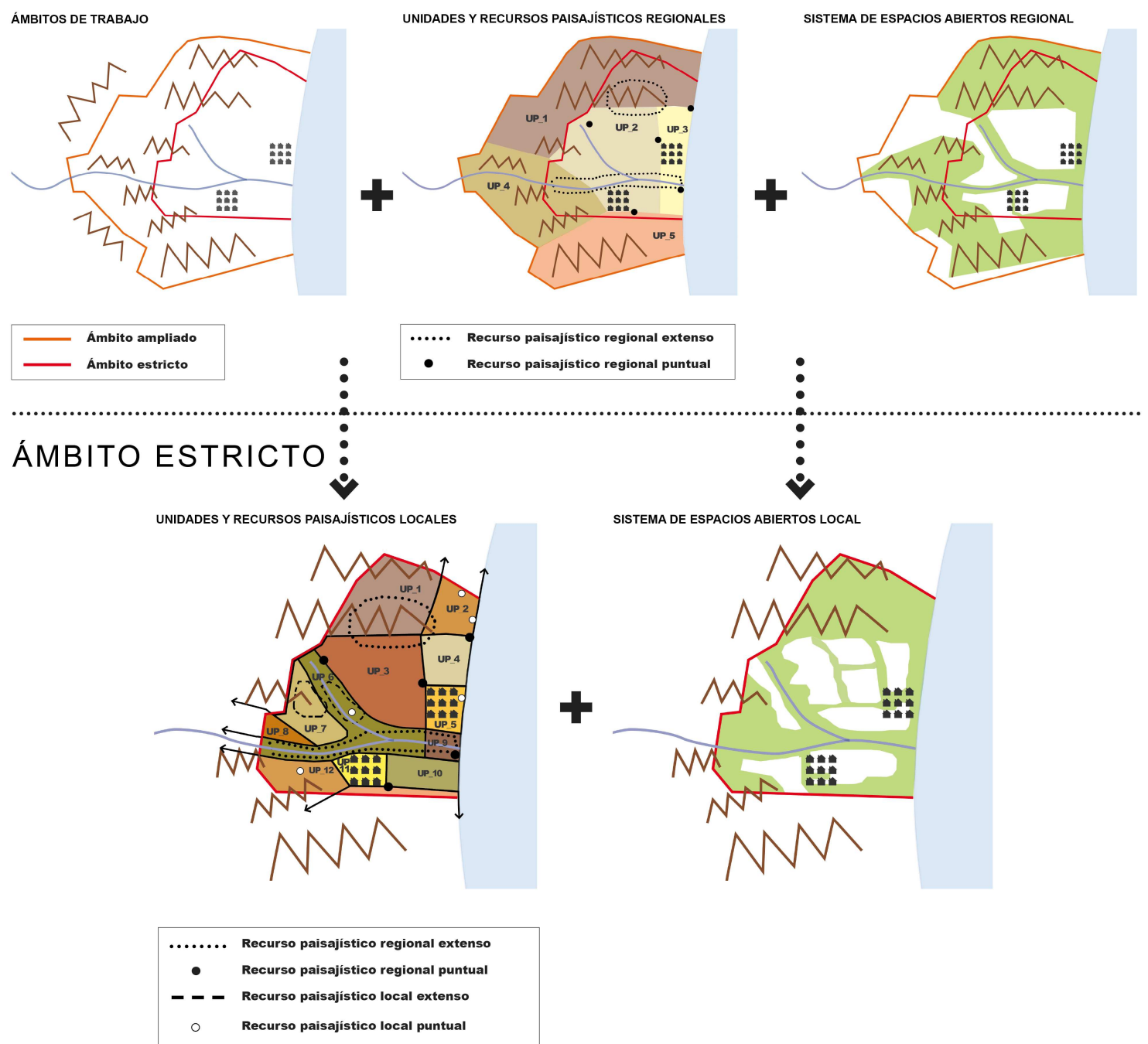

SISTEMA DE ESPACIOS ABIERTOS LOCAL

Fig. 4.1: Escalas para la definición de unidades de paisaje y selección de recursos paisajísticos 
Tal y como se recoge en la figura 3.2 del capítulo 3, dicha propuesta de diferenciación entre unidades de paisaje (character areas) a escala regional, municipal y local coincide con el modelo británico de caracterización del paisaje, que se apoya a su vez en una definición previa de tipos de paisaje (character types) a distintas escalas.

4.1.c. Comparación con la metodología prevista en el Reglamento de Paisaje de la Comunidad Valenciana El Reglamento de Paisaje de la Comunidad Valenciana expone la necesidad de independizar los ámbitos de un estudio de paisaje de los límites estrictamente administrativos. En este punto, y tal y como se recoge en su artículo 33, considera que las unidades de paisaje deben establecer los límites reales del estudio, asumiendo las determinaciones de otros estudios de paisaje de rango igual o superior (Plan de Acción Territorial del Paisaje de la Comunidad Valenciana o estudio de paisaje vinculado a otro plan de acción territorial o a un ámbito supramunicipal definido por el anterior).

La propuesta metodológica recogida en la presente tesis pretende suplir mediante la definición de un "ámbito ampliado" la ausencia de un marco paisajístico de referencia, que en el caso de la Comunidad Valenciana, debía ser proporcionado por el Plan de Acción Territorial de Paisaje de la Comunidad Valenciana (actualmente en fase de borrador) o de estudios de paisaje en Planes de Acción Territorial en ámbitos supramunicipales, de los que, a fecha de hoy, se dispone únicamente del correspondiente al del área metropolitana de Valencia (Plan de Acción Territorial para la Protección de la Huerta).

Se propone en consecuencia, dada la posible ausencia de un estudio de paisaje de rango superior al que se esté redactando, la definición de un ámbito ampliado en el que se desarrollen los principales aspectos vinculados a la caracterización del paisaje y a la conectividad territorial, siendo éstos, respectivamente, los siguientes:

- Unidades de paisaje y recursos paisajísticos en el ámbito ampliado

- Sistema de espacios abiertos en el ámbito ampliado

Dentro del ámbito estricto se desarrollarían los contenidos completos de un estudio de paisaje. Lógicamente, las unidades de paisaje y el sistema de espacios abiertos del ámbito estricto estarían condicionadas por lo definido para estos dos mismos conceptos en el ámbito ampliado, aumentando sin embargo el grado de detalle en el ámbito estricto (ver figura 4.1).

\subsection{Caracterización del Paisaje}

1. 4.2.a Consideraciones preliminares:

La caracterización del paisaje en la metodología propuesta, parte de un análisis territorial en el que se consideran los aspectos físicos y humanos que configuran e inciden en el paisaje. Con dicho fin se tendrán en cuenta los factores y condicionantes dados por el planeamiento existente así como por el medio cultural, medioambiental, agrario, social, turístico y económico.

Una vez recopilada y cartografiada la información territorial, se procede a realizar un análisis paisajístico del ámbito del estudio, definiendo como resultado las unidades de paisaje y recursos paisajísticos. Tal y como se expondrá seguidamente, dichas unidades y recursos deberán ser descritos atendiendo a una sistemática clara y justificada, e incluir la información necesaria (dinámicas, conflictos, potencialidades, etc.) para formular posteriormente los objetivos de calidad paisajística así como las acciones de protección, gestión u ordenación del paisaje que permitan la consecución de dichos objetivos.

Dados los distintos grados de detalle a alcanzar en los ámbitos ampliado y estricto, se proponen a continuación metodologías diferenciadas para cada uno de ellos.

\section{2.b Metodología propuesta:}

\section{2.b.1.: Ámbito ampliado:}

El análisis territorial del ámbito ampliado debería tratar, y cartografiar si procede, los aspectos siguientes:

- Geomorfología: considerando las principales formaciones del relieve: sierras y cadenas montañosas, llanuras, valles, etc. 
- Hidrología superficial: considerando las cuencas drenantes, los cursos de agua permanentes o temporales, las laminas naturales de aguas así como la hidrología artificial: embalses, balsas, canales y acequias de riego, azarbes, etc.

- Cubierta Vegetal: considerando los distintos tipos de cobertura vegetal forestal y agrícola.

- Infraestructuras: considerando las infraestructuras energéticas, incluyendo y diferenciando según su jerarquía e intensidad de uso las infraestructuras de transporte y teniendo en cuenta cualquier otro tipo de infraestructura con incidencia en el paisaje.

- Usos del suelo y planeamiento: detallando los usos del suelo, la clasificación y calificación urbanística así como las determinaciones de los planes vigentes (Planes de acción territorial, Planes Generales, PORN y PRUG de parques naturales, etc.)

- Espacios edificados: considerando la evolución, tipología y densidad edificatoria de los distintos espacios edificados.

- Áreas protegidas, afecciones y bolsas de suelo público: considerando los distintos tipos de áreas con protección medioambiental, cultural o paisajística, las afecciones propias de cauces, costas, infraestructuras y las bolsas de suelo público o de utilidad pública.

Una vez recopilada y estudiada la cartografía temática anteriormente expuesta se procedería a analizar paisajísticamente (y en consecuencia, ecológica, cultural y visualmente) el ámbito ampliado con los siguientes objetivos:

1. Definir las unidades de paisaje a escala regional: éstas serán entendidas como "áreas continuas con una configuración estructural, funcional o perceptivamente diferenciada, única y singular, que ha ido adquiriendo los caracteres que la definen tras un largo período de tiempo... se identifican por su coherencia interna y sus diferencias con respecto a las unidades contiguas" (Reglamento de Paisaje de la Comunidad Valenciana, 2006). Tal y como se aprecia en trabajos de referencia como el Atlas de los Paisajes de España (MATA OLMO, R y SANZ HERRAIZ, C. 2004), en los Catálogos de Paisaje de Cataluña, o en el borrador del Plan de Acción Territorial de Paisaje de la Comunidad Valenciana, en la escala regional es habitual que una misma unidad pueda incluir un mosaico de suelos urbanizados, agrícolas o forestales que conformen un espacio conjunto con un patrón perceptivamente diferenciable. De acuerdo a esto, y con el objeto de evitar la excesiva sectorización paisajística del territorio y de facilitar la aplicación de estrategias y acciones comunes, se procurará disminuir el número de unidades de paisaje en la medida que no se minusvalore su diversidad paisajística. Adicionalmente, y con el objeto de dotar a las unidades de paisaje de una mayor utilidad en la ordenación y gestión territorial, al establecer sus límites se podrá considerar las vinculaciones con otras unidades territoriales de carácter medioambiental o urbanístico (por ejemplo unidades ambientales), así como la posible aplicación en la unidad de paisaje de estrategias o acciones paisajísticas comunes.

2. Definir los Recursos Paisajísticos: éstos incluirán los elementos lineales, puntuales o extensos singulares de un paisaje o grupo de éstos que definen su individualidad y que tienen un valor visual, ecológico, cultural ó histórico. De acuerdo al Reglamento de Paisaje de la Comunidad Valenciana, se diferenciará entre recursos paisajísticos medioambientales, culturales y visuales, pudiendo un mismo recurso quedar incluido en más de una categoría.

El trabajo de campo se considera esencial para la correcta definición de unidades de paisaje y recursos paisajísticos. Por dicho motivo se recomienda realizar visitas dirigidas a:

1) Entender globalmente el territorio, sus redes de transporte que y los puntos desde los que se puede tener una visión global del mismo o de sus posibles unidades

2) Establecer los factores de caracterización que permitan diferenciar las unidades de paisaje y proceder a su delimitación.

3) Identificar los recursos paisajísticos medioambientales, culturales y visuales de relevancia regional.

Para la realización de los trabajos de campo se deberá disponer de una cartografía que permita transferir las observaciones realizadas in situ y producir un material gráfico (fotografías y opcionalmente videos o esquemas y bocetos) que ilustre las características generales o particulares de las unidades de paisaje y recursos paisajísticos. 
El trabajo de campo deberá a su vez identificar las dinámicas, conflictos y potencialidades del paisaje, siendo útil en este punto, el contactar con particulares, expertos o grupos vinculados a las actividades o intereses que confluyan en el territorio en estudio. Dado que el ámbito ampliado no corresponde al propio del estudio no se contempla la necesidad de desarrollar un proceso de participación pública.

\section{A partir de toda la información recogida se procederá a elaborar en gabinete la siguiente documentación:}

A) Documento de síntesis del análisis territorial:

Incluirá la cartografía temática vinculada a los aspectos citados anteriormente así como las explicativas de los planeamientos de aplicación. Dado el carácter regional del estudio, se proponen como escalas orientativas de trabajo las situadas entre $1: 50.000$ y $1: 200.000$

B) Fichas de unidades de paisaje: Las metodologías propuestas para describir las unidades de paisaje en los catálogos de paisaje de Cataluña, en el reglamento de paisaje de la Comunidad Valenciana o en Gran Bretaña presentan una alta convergencia en los aspectos descriptivos, explicativos y de diagnóstico a incluir (Ver apartado 3.2.b. del presente capítulo). Con el objeto de sistematizar dichas fichas, se propone su estructuración en los siguientes apartados:

1. Descripción sintética de la unidad. Se recomienda en este punto incidir en aspectos que la diferencien de las otras unidades

2. Factores de caracterización: Dichos factores serán detallados para todas las unidades paisajísticas, facilitando de este modo la detección de los aspectos diferenciales. Los factores deberán ser propuestos de forma particularizada para cada Estudio de Paisaje, proponiéndose a priori el siguiente listado orientativo:
a. Topografía
b. Hidrología
c. Cubierta el suelo
d. Estructura Visual
e. Usos del Suelo
f. Construcciones Edificación en:
i. Núcleos urbanos
ii. Urbanizaciones
iii. Edificación dispersa
iv. Construcciones y estructuras rurales

g. Infraestructuras:
i. De transporte
ii. Hidráulicas
iii. Energéticas y otras (por ejemplo forestales)

h. Propiedad del suelo y parcelario

3. Diagnóstico del Paisaje. Se recomienda en este punto incidir en aquellos aspectos que permiten conocer le estabilidad del paisaje, las dinámicas que lo pueden modificar así como los conflictos o potencialidades del mismo. A título orientativo se deberán tratar para cada unidad los aspectos siguientes:

a. Procesos Naturales.

b. Procesos Antrópicos

c. Principales Conflictos.

d. Principales Recursos y Potencialidades.

i. Recursos Paisajísticos ambientales.

ii. Recursos paisajísticos culturales.

iii. Recursos paisajísticos visuales.

iv. Potencialidades.

e. Acciones de Paisaje.

4. Información gráfica: Incluirá:

a. Plano de unidades de paisaje (se recomienda una escala de 1:50.000 - 1:150.000).

b. Plano de delimitación de la unidad de paisaje en cuestión (sobre fotografía aérea o plano topográfico).

c. Fotografías ilustrativas del carácter de la unidad y de los recursos paisajísticos más relevantes.

d. Fotografías de conflictos existentes.

e. Opcionalmente, bocetos esquemáticos o secciones explicativas del paisaje de la unidad.

C) Ficha de recursos paisajísticos ambientales. Deberá incluir:

1. Listado de los Recursos Paisajísticos Ambientales de relevancia regional. Dicho listado deberá incluir a priori:

a. Las áreas o elementos que gocen de algún grado de protección ambiental, declarado o en tramitación y aquellas áreas de valor ecológico potencialmente protegibles.

b. El dominio público marítimo y fluvial.

c. Espacios que cuenten con valores acreditados por la Declaración de Impacto Ambiental.

d. Los montes de utilidad pública.

e. Las vías pecuarias.

f. Las zonas de recarga de acuíferos.

g. Los suelos de alto valor agrológico. 
h. Los elementos o espacios naturales de alta singularidad no adscritos en alguna de las categorías anteriores.

2. Información gráfica. Incluirá:

a. Plano de localización de los recursos paisajísticos ambientales.

b. Fotografías ilustrativas de los principales recursos paisajísticos ambientales.

D) Ficha de recursos paisajísticos culturales. Deberá incluir:

1. Listado de los Recursos Paisajísticos Culturales de relevancia regional. Dicho listado deberá incluir a priori:

a. Áreas o los elementos con algún grado de protección cultural, declarado o en tramitación. (por ejemplo Bienes de Interés Cultural, elementos incluido s en Catálogos, etc.)

b. Elementos o espacios apreciados por la sociedad local como hitos en la evolución histórica y cuya alteración, ocultación o modificación sustancial de las condiciones de percepción fuera valorada como una pérdida de los rasgos locales de identidad o patrimoniales.

2. Información gráfica. Incluirá:

a. Plano de localización de los recursos paisajísticos culturales.

b. Fotografías ilustrativas de los principales recursos paisajísticos culturales.

E) Ficha de recursos paisajísticos visuales: Deberá incluir:

1. Listado de los Recursos Paisajísticos Visuales de relevancia regional. Atendiendo al Reglamento de Paisaje de la Comunidad valenciana (2006), dicho listado deberá incluir a priori:

- Elementos topográficos que definen la estructura espacial que hace singular un lugar, tales como hitos topográficos, laderas, crestas de las montañas, línea de horizonte, ríos y similares.

- Elementos y áreas construidas de alta visibilidad territorial y que singularizan positivamente un lugar: perfiles de asentamientos históricos, hitos urbanos, culturales, religiosos o agrícolas, siluetas y fachadas urbanas, y otros similares.

- Vistas y perspectivas hacia los elementos identificados en los apartados anteriores y de los inventariados por causas medioambientales o culturales.

- Puntos de observación y los recorridos paisajísticos de especial relevancia por su alta frecuencia de observación, o la calidad de sus vistas.

- Cuencas visuales hacia los núcleos urbanos a los que se haya reconocido un alto valor y las vistas desde ellos del entorno que los circunda.

- Las áreas de afección visual desde las carreteras: En este punto y como parte de los procedimientos propuestos en la presente tesis, se propone que las distancias máximas a considerar en la determinación de las zona de afección visual estén en función de la topografía y del nivel de urbanización en el entorno de la carretera. En entornos de alto valor paisajístico y escasa urbanización podrán extenderse hasta los elementos de relieve que enmarquen la cuenca visual. En espacios de menor valor paisajístico o con presencia frecuente de edificación se podrá reducir dicha distancia a 300 metros a ambos márgenes de carreteras principales (distancia marcada para vistas cortas en la metodología de análisis visual propuesta en el Reglamento de Paisaje de la Comunidad Valenciana) o a 150 metros en carreteras secundarias.

2. Información gráfica. Incluirá:

a. Plano de localización de los recursos paisajísticos visuales.

b. Fotografías ilustrativas de los principales recursos paisajísticos visuales.

\section{2.b.2.: Ámbito estricto:}

Los aspectos listados en el análisis territorial del ámbito ampliado, deberían ser a su vez considerados con mayor grado de detalle en el ámbito estricto. Con el objeto de facilitar el establecimiento de objetivos de calidad paisajística y la definición de acciones de ordenación, gestión y protección del paisaje se recomienda a su vez realizar estudios específicos relativos a:

- Calidad de las vistas desde las infraestructuras de transporte y puntos más frecuentados.

- Circulaciones rodadas, peatonales y ciclistas y detección de posibles conflictos entre ellas.

- Conflictos paisajísticos: distinguiendo entre extensos, lineales y puntuales.

A partir de las unidades de paisaje definidas a nivel regional (ámbito ampliado) se deberán definir las unidades de paisaje (o subunidades) a nivel del ámbito estricto. Idealmente, estas unidades de paisaje de rango menor deberán darse dentro de los límites de las unidades de paisaje de rango superior (ver Figura 4.1: Escalas para la definición de unidades de paisaje y selección de recursos paisajisticos) y presentarán por lo general una mayor, aunque no necesaria, vinculación a los usos del suelo (residencial, industrial, frutales de secano, etc.). Así, podrán darse dentro de un uso de suelo determinado distintas unidades de paisaje, por ejemplo "frutales de secano en llanura" o "frutales de secano en relieve colinado", o inversamente, usos del suelo distintos, tales como residencial disperso y agrícola de secano pueden configurar una unidad de paisaje del tipo "mixto residencial disperso-agrícola de secano". Al igual que en el ámbito regional, y con el objeto de dotar a las unidades de paisaje de una mayor utilidad en la ordenación y gestión territorial, se podrá considerar al establecer 
sus límites, las vinculaciones con otras unidades territoriales de carácter medioambiental o urbanístico (por ejemplo Unidades Ambientales) así como la posible aplicación en la unidad de estrategias paisajísticas comunes. Como criterio general, y con el objeto de evitar la excesiva sectorización paisajística del territorio, se procurará disminuir el número de unidades de paisaje hasta una cantidad que no ignore o minusvalore la posible diversidad paisajística de éste.

Los recursos paisajísticos se definirán y agruparán de acuerdo a los mismos criterios expuestos en el ámbito ampliado.

En lo referente a la realización de trabajos de campo se seguirán igualmente las indicaciones marcadas para el ámbito ampliado con la importante adición en el ámbito estricto de una fase del proceso de participación pública que permita conocer los principales paisajes y recursos paisajísticos, tangibles e intangibles, que la población y expertos ajenos al estudio encuentran en el ámbito estricto. Dicha fase y Plan son explicados en el apartado correspondiente de este capítulo de métodos.

A partir de toda la información recogida se procederá a elaborar en gabinete la siguiente documentación:

A) Documento de síntesis del análisis territorial:

Incluirá la cartografía temática vinculada a los aspectos citados anteriormente así como las explicativas de los planeamientos de aplicación. Dado el mayor grado de detalle necesario en el ámbito estricto se proponen como escalas orientativas de trabajo las situadas entre 1:20.000 y 1:50.000.

B) Fichas de unidades de paisaje: Las metodologías propuestas para describir las unidades de paisaje en los catálogos de paisaje de Cataluña, en el reglamento de paisaje de la Comunidad Valenciana o en Gran Bretaña presentan una alta convergencia en los aspectos descriptivos, explicativos y de diagnóstico a incluir (Ver apartado 3.2.b. del presente capítulo). Con el objeto de sistematizar dichas fichas, se propone su estructuración en los siguientes apartados. Deberá incluir:

1. Descripción sintética de la unidad. Se recomienda en este punto incidir en aspectos que la diferencien de las otras unidades, siendo útil en este punto seguir el listado de factores de caracterización marcado para las fichas de Unidades de Paisaje en el ámbito ampliado.

2. Diagnóstico del Paisaje. Se recomienda en este punto incidir en aquellos aspectos que permiten conocer la estabilidad del paisaje, las dinámicas que lo pueden modificar así como los conflictos o potencialidades del mismo. A título orientativo se deberán tratar para cada unidad los aspectos siguientes:

a. Procesos Naturales.

b. Procesos Antrópicos.

c. Principales Conflictos.

d. Principales Recursos Paisajísticos:

i. Recursos Paisajísticos ambientales.

ii. Recursos paisajísticos culturales.

iii. Recursos paisajísticos visuales.

3. Información gráfica: Incluirá:

a. Plano de Unidades Paisajísticas (se recomienda una escala de 1:20.000, coincidente con la propuesta en el Reglamento de Paisaje) o menor si el ámbito territorial es reducido.

b. Plano de delimitación de la Unidad Paisajística en cuestión (sobre fotografía aérea o plano topográfico).

c. Fotografías ilustrativas del carácter de la Unidad y de los Recursos Paisajísticos más relevantes.

d. Fotografías de conflictos existentes.

e. Opcionalmente, bocetos esquemáticos o secciones explicativas del paisaje de la Unidad.

C) Fichas de recursos paisajísticos ambientales, culturales y visuales. Se seguirán las indicaciones marcadas para los recursos paisajísticos en el ámbito ampliado, si bien en este caso, los planos que recojan los recursos deberían prepararse a una escala de 1:20.000 - 1:50.000. Por razones operativas se recomienda, dentro de cada tipo de recurso (medioambiental, cultural o visual) agruparlos según la unidad paisajística en la que se localizan dado que esto facilitará la posterior definición de objetivos de calidad o programas de paisaje.

4.2.c. Comparación con la metodología prevista en el Reglamento de Paisaje de la Comunidad Valenciana La metodología propuesta para la caracterización del paisaje coincide mayormente en el ámbito estricto y ampliado con la propuesta en el reglamento valenciano del paisaje, diferenciándose en el caso del ámbito estricto por la incorporación expresa de una fase del plan de participación pública conducente a conocer los paisajes y recursos paisajísticos que población, expertos externos y grupos estiman presentes en dicho ámbito. Dicha incorporación temprana de la consulta pública, permite a su vez obtener información útil para la determinación de las unidades de paisaje y de las variables territoriales a analizar. 
Adicionalmente, en el caso del ámbito ampliado se recomiendan escalas cartográficas de menor detalle que las previstas en el ámbito detallado para la presentación de conclusiones.

Por último, la presente propuesta metodológica concreta respecto al Reglamento de Paisaje de la Comunidad Valenciana (2006) los contenidos y estructura de la documentación (fichas) a elaborar sobre unidades de paisaje y recursos paisajísticos.

\subsection{Análisis Visual: Visibilidad del Paisaje}

4.3.a. Consideraciones preliminares:

Considerados los precedentes estudiados en el apartado 3.1. y 3.2.d. del capítulo 3 (revisión bibliográfica), entre los que se incluyen los trabajos de Kevin Lynch, Carl Steinitz, Donald Appleyard, John R. Myer, y Rosa Barba, sobre visibilidad del paisaje y su aplicación a la planificación territorial, integración de infraestructuras y redacción de proyectos, se propone a efectos de desarrollo de la presente tesis que el análisis visual del paisaje se aplique únicamente en el ámbito estricto del estudio y que, coincidiendo con lo previsto por el Reglamento de Paisaje de la Comunidad Valenciana, tenga por objeto determinar la visibilidad del territorio, vinculando a su vez de forma directa el grado de visibilidad al número de observadores.

Dada esta última premisa y considerando que la visibilidad es una cualidad inherente al territorio, sería en consecuencia más adecuado hablar de "visibilidad adquirida", asimilando parcialmente dicho concepto a la "fragilidad visual adquirida" (Ramos, 1978 y Aguilo, 1980). La introducción del concepto de "visibilidad adquirida" (en adelante visibilidad), pretende evitar expresamente los análisis visuales clásicos, en los que el grado de visibilidad estaba en función de la superficie desde la que era visto un determinado punto, independientemente de que en esa superficie hubiese más o menos observadores.

Con el objeto de que este análisis visual, que pretende establecer un factor de corrección que priorice las acciones en aquellas zonas visualmente más frecuentadas, no desproteja zonas poco visitadas pero con un alto valor paisajístico, se deberán prever los mecanismos que mantengan en estas últimas un nivel de visibilidad suficientemente alto.

La realización del análisis visual así definido requiere:

1. Determinar dónde y cuándo se encuentran los posibles observadores del paisaje.

2. Elaborar una cartografía de visibilidad que parta de los elementos que delimitan la profundidad de las vistas desde un determinado punto:

a. Topografía

b. Vegetación de porte arbustivo o arbóreo

c. Edificación y construcciones.

Con el objeto de dar respuesta a estos requerimientos se deberá:

1. Disponer de datos sobre la intensidad de uso de las infraestructuras de transporte y sobre la posible concentración regular o esporádica de observadores en determinados puntos.

2. Determinar los espacios visibles desde las líneas o puntos anteriores, realizando para ello observaciones directas en campo o generando modelos digitales que permitan predecir adecuadamente las cuencas visuales. Esta segunda opción resulta lógicamente más adecuada pero exige el disponer de una completa y actualizada información SIG del territorio así como la realización de ajustes que permitan:

a. Dar altura a los elementos susceptibles de actuar como barreras visuales (topografía, arbustos, arbolado y construcciones)

b. Garantizar que las líneas y puntos de observación (a menudo ubicados sobre topografías modificadas) tengan las cotas correctas.

\section{3.b. Metodología propuesta para el Análisis Visual}

Se distinguen tres tipos de trabajos vinculados respectivamente a:

1. Selección de los puntos y líneas de observación

2. Determinación de las cuencas visuales

3. Calculo de los grados de visibilidad 


\section{Selección de Puntos y líneas de observación:}

Asumiendo las indicaciones de artículo 36 del Reglamento de Paisaje de la Comunidad Valenciana, como "Puntos de Observación" se incluyen entre otros los siguientes elementos:
a. Principales vías de comunicación, considerándolas como punto de observación dinámico que definen secuencias de vistas.
b. Núcleos de población.
c. Áreas recreativas, turísticas y de afluencia masiva principales.
d. Puntos de observación representativos por mostrar la singularidad del paisaje.

Los puntos de observación se clasificarán en principales o secundarios atendiendo al número de observadores potenciales, la distancia y la duración de la visión. Al valorar el ํㅜ de observadores se atenderá a valores relativos del área del estudio. Se asume de esta forma que, en un estudio de paisaje de carácter regional, el carácter principal o secundario se establecería de acuerdo a un baremo diferente del empleado en un estudio de paisaje local.

La selección de vías de comunicación y su clasificación como líneas de observación principales o secundarias se realizará atendiendo a la intensidad de tráfico medio que soporten, utilizando para ello indicadores estándar como el IMD.

En los núcleos de población se identificarán los accesos urbanos, diferenciando los principales como aquellos de uso más intensivo dentro del ámbito del estudio. Igualmente se considerarán espacios internos urbanos de uso intensivo, si bien en éstos, la edificación configurará en muchos casos cuencas visuales reducidas. Estas mismas consideraciones serán tomadas en cuenta en áreas turísticas de tipo urbano.

En áreas recreativas, turísticas de tipo no urbano y zonas de afluencia esporádica masiva (por ejemplo zonas en las que se realicen regularmente eventos), se localizarán puntos de observación de rango generalmente secundario, o principal en caso de niveles de afluencia muy alta.

Por último, dentro de la categoría de "puntos de observación representativos por mostrar la singularidad del paisaje" se incluirán aquellos desde los que se puedan tener una lectura global del territorio (por ejemplo elevaciones topográficas) o de elementos de alto valor o singularidad, por ejemplo, miradores a recursos paisajísticos de alto valor.

\section{Determinación de las cuencas visuales}

Para el cálculo de las cuencas visuales se sugiere la realización de un trabajo preliminar con cartografía SIG y una posterior comprobación y ajuste in situ.

A nivel de trabajo con las herramientas SIG se propone seguir la metodología siguiente:

- En el caso de infraestructuras de transporte u otras "líneas de observación" se dispondrán puntos de observación con una equidistancia acorde a la escala de trabajo y a la longitud de la línea en estudio.

- Para cada uno de los puntos se deberá determinar las zonas visibles y no visibles haciendo para ello uso de la cartografía SIG disponible y siguiendo las siguientes premisas o condiciones de cálculo:

- Considerar un modelo de relieve que incorpore la topografía, la vegetación arbórea existente (asignar una altura media para las masas arbóreas forestales y para los frutales, especialmente perennes), así como la edificación existente a la que por motivos de simplificación de los trabajos se asignará una altura media, por ejemplo de 10 metros. En el caso de la presencia consistente de cerramientos o vallas visualmente impermeables se les dará a su vez una altura que permita que actúen como barreras en el cálculo de cuencas visuales.

- Considerar una altura del observador diferente para peatones (1,6 metros), viajeros en coche ( 1,2 metros) y viajeros en tren (2,5 metros).

- Establecer una distancia máxima para el cálculo de la cuenca visual desde cada punto. Se propone como criterio general una distancia máxima de 5 a 10 kilómetros.

- Trabajar los cálculos con una malla de celdas de 10 × 10 metros.

- Confirmar que las cotas del terreno en los puntos de observación situados sobre infraestructuras de transporte fueron ajustadas de acuerdo a la presencia de posibles 
plataformas o desmontes. En caso contrario proceder a ajustar la cota de los puntos de observación.

Una vez calculadas las cuencas visuales desde cada punto o línea de observación se recomienda comprobar in situ su exactitud, realizando, si procede, los ajustes oportunos y reajustando las cuencas en la capa SIG correspondiente.

En caso de estudios de paisaje en superficies no muy extensas o con pocos puntos de observación se recomendaría reconsiderar el uso de las herramientas SIG y proceder, por el contrario, a la delimitación de las cuencas visuales in situ. Esta recomendación obedece a los intensos trabajos de ajuste en la cartografía SIG y a la fiabilidad media de los resultados obtenidos por esta vía.

\section{Calculo de los rangos de visibilidad}

Para la determinación de los grados de visibilidad se atenderá a las indicaciones dadas al respecto en el artículo 36 del Reglamento de Paisaje de la Comunidad Valenciana, según el cual "En función del grado de importancia se obtendrán las zonas de máxima visibilidad, las de visibilidad media, las de visibilidad baja y las no visibles o zonas de sombra. Son zonas de máxima visibilidad las perceptibles desde algún punto de obsenvación principal. Son zonas de visibilidad media las perceptibles desde más de la mitad de los puntos de observación secundarios, y baja desde menos de la mitad de éstos".

La determinación de las zonas visibles desde los puntos de observación podrá realizarse mediante programas SIG en los que se considerará que, dados $\mathrm{N}$ puntos y líneas de observación secundaria, a cada celda de territorio visible desde un punto o línea secundaria se le asignará un valor X. Se procederá a continuación a sumar todas las capas de visibilidad desde puntos o líneas de observación secundarios. Las celdas con valores superiores a $\left(\mathrm{N}^{*} \mathrm{X}\right) / 2$ tendrán una visibilidad media (y podrán ser coloreadas en un color $\mathrm{B}$ ), las celdas con valores inferiores $a\left(N^{*} X\right) / 2$ tendrán una visibilidad baja (y podrán ser coloreadas en un color $\mathrm{C}$ ).

Por otro lado se asignará un valor superior a $\mathrm{N}^{*} \mathrm{X}$ a cada celda visible desde un punto o línea de observación principal. Esta operación se repetirá para cada punto o línea de observación principal, procediéndose a continuación a superponer todas las capas de visibilidad y sumar los valores correspondientes.

El plano de visibilidad se presentará a una escala de 1:20.000 y se realizará sumando el plano de visibilidad desde puntos o líneas de observación secundarios, y el de puntos o líneas de observación principales. Una vez sumados, se identificará el grado de visibilidad del siguiente modo:

- VISIBILIDAD MAXIMA (color A): Celdas con valores superiores a $\mathrm{N}^{*} \mathrm{X}$

- VISIBILIDAD MEDIA (color B): Celdas con valores comprendidos entre $\mathrm{N}^{*} \mathrm{X}$ y $\left(\mathrm{N}^{*} \mathrm{X}\right) / 2$

- VISIBILIDAD BAJA (color $\mathrm{C}$ ): Celdas con valores inferiores a $\left(\mathrm{N}^{*} \mathrm{X}\right) / 2$ 


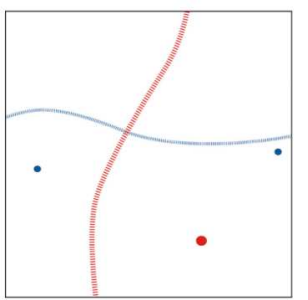

PASO1: Definición de puntos y líneas de observación principales (en rojo) y secundarios (en azul)

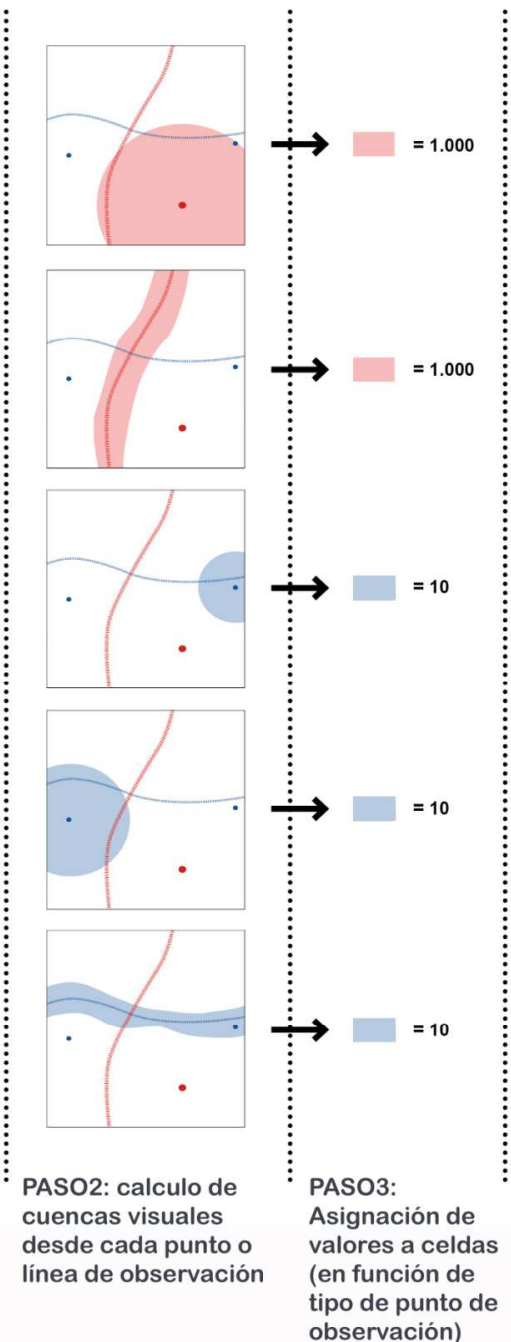

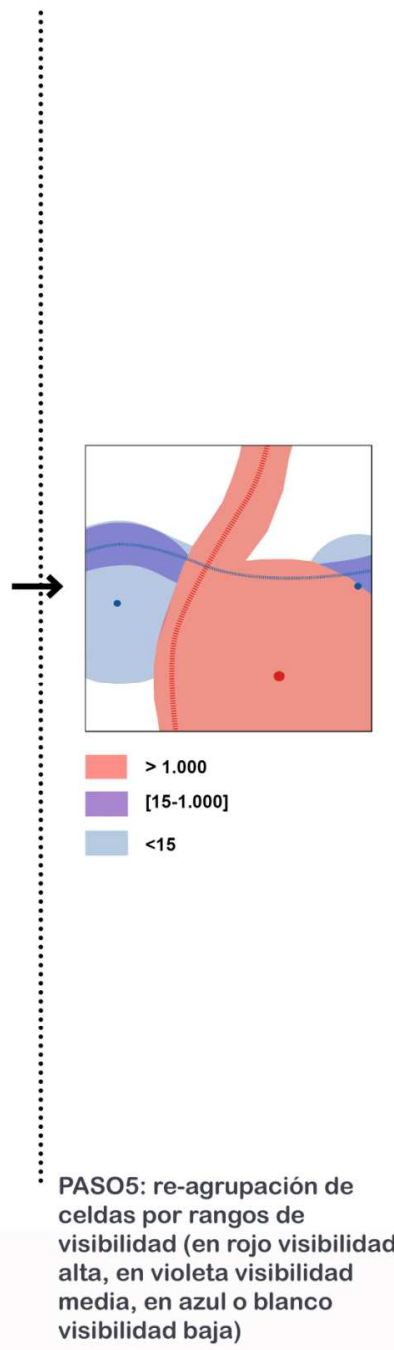

Fig. 4.2: Proceso de definición de los rangos de visibilidad (adquirida) del territorio.

4.3.c. Comparación con la metodología prevista en el Reglamento de Paisaje de la Comunidad Valenciana La metodología propuesta para la realización del análisis visual coincide mayormente con la prevista en el Reglamento de Paisaje de la Comunidad Valenciana, incorporando aspectos referentes a los criterios para asignar a un punto de observación la categoría de "principal" o "secundario" y un método para el cálculo de cuencas visuales y para la determinación del grado de visibilidad mediante herramientas SIG.

\subsection{Valoración del Paisaje}

\section{4.a. Consideraciones preliminares}

Dados los dos ámbitos de trabajo propuestos, la valoración del paisaje se realizará únicamente en el "ámbito estricto", entendiendo que éste es el ámbito propio del estudio completo y que será en éste en el que la valoración del paisaje deberá de sustentar la definición de objetivos de calidad paisajística y de acciones de protección, gestión u ordenación del paisaje.

De acuerdo a los principios establecidos por el Convenio Europeo del Paisaje, a la aplicación concreta de la Directiva 2003/4/CE del Parlamento Europeo y del Consejo, de 28 de enero de 2003, relativa al acceso del público a la información medioambiental, y a la Directiva 2003/35/CE del Parlamento Europeo y del Consejo, de 26 de mayo de 2003 y en cumplimiento de los establecido por el Reglamento de Paisaje de la Comunidad Valenciana, se asume que la asignación de valores al paisaje, en cualquiera de las formas en que este haya sido caracterizado, debe de realizarse con la participación activa de la población. Dichos valores podrán ser a su vez coordinados con aquellos dados por expertos que podrán emitir sus juicios de valor a partir de procedimientos justificados. Los valores asignados por la población corresponderán a valores de "preferencia", mientras que los valores asignados por los expertos corresponderán a valores de "calidad". 
Por otro lado, la inclusión por el Reglamento de Paisaje de la Comunidad Valenciana del grado de visibilidad del paisaje como corrector del valor paisajístico se considera una aportación especialmente útil en la medida que justifica la priorización de acciones de ordenación, gestión o mejora del paisaje hacia zonas altamente frecuentadas, en las que (ver Plan Visual de la Comunidad Valenciana, STEINITZ \& MUÑOZ, 2008), a menudo, se localizan paisajes de valor bajo o muy bajo. Dicha aportación requiere sin embargo diferenciar entre "valor paisajístico preliminar" y "valor paisajístico final" (o adquirido), entendido este último como el ajustado en función de la visibilidad (adquirida), así como establecer el procedimiento para que el ajuste se realice sin decrecer el valor paisajístico de las áreas o recursos con valor paisajístico alto o muy alto, independientemente de su nivel de frecuentación o visibilidad "adquirida".

Se concluye que, asumida que la valoración del paisaje debe de partir de la opinión de la población y expertos y que puede ser ajustada en función del nivel de visibilidad, los principales aspectos a resolver metodológicamente serían los siguientes:

1) Procedimiento de valoración del Paisaje por la población

2) Procedimiento de valoración del paisaje por expertos

3) Integración de los valores otorgados por población y por los expertos

4) Ajuste del valor paisajístico en función el grado de visibilidad.

\section{4.b. Metodología propuesta para la valoración del Paisaje}

De acuerdo a la metodología propuesta por el Reglamento de Paisaje de la Comunidad Valenciana y asumida a efectos del desarrollo de la presente tesis que la caracterización del paisaje tiene por objeto determinar y describir las unidades de paisaje y los recursos paisajísticos (medioambientales, culturales y visuales), la valoración del paisaje deberá realizarse en consecuencia sobre dichas unidades y recursos, siendo necesario generar una documentación que permita la emisión de juicios por la población y expertos.

\section{4.b.1. Procedimiento de valoración del paisaje por la población}

Siguiendo los procedimientos desarrollados por las escuelas americanas de planificación del paisaje, ajustados y perfeccionados a su vez por el profesor Carl Steinitz para el Plan Visual de la Comunidad Valenciana (2008), se propone la valoración por la población de las unidades de paisaje y recursos paisajísticos mediante fotografías ilustrativas de los mismos que deberán ser calificadas por la población con un valor mínimo de 1 para las unidades o recursos de valor muy bajo, de 2 para los de valor bajo, de 3 para los de valor medio, de 4 para los de valor alto y de 5 para los de valor muy alto.

El procedimiento para la realización de las consultas a la población aparece detallado en el apartado correspondiente a "Participación Pública" del presente capítulo de métodos, y permite determinar niveles de "preferencia paisajística" comprendidos entre 1 (mínimo) y 5 (máximo) para las distintas unidades y recursos paisajísticos.

Los niveles de preferencia se calcularán como media de los distintos valores expresados por una muestra representativa de la población, deduciéndose la composición de dicha muestra a partir de datos estadísticos sobre la población residente y visitante (turistas o personas que por motivos de trabajo permanezcan o se desplacen por la zona), así como sobre el género, edad y actividad personal (empleado (y en ese caso en qué sector), estudiante, jubilado, desempleado, ama de casa, etc.). A partir de dichos datos estadísticos, se definirá para el ámbito del estudio una muestra tipo de 100 personas en la que se detallará el porcentaje de cada perfil que deberá ser consultado. El tamaño final de la muestra a consultar estará en función del grado de precisión deseado.

Ante la duda sobre si los valores deben de basarse en una escala absoluta (por ejemplo de tipo universal) o relativa (en la que se asigna un 5 a los recursos o unidades paisajísticas de mayor valor en el ámbito específico del estudio), se recomienda seguir un criterio relativo, entendiéndose que será en los estudios de paisaje de rango mayor (por ejemplo regionales, nacionales, etc.) en los que las unidades o recursos paisajísticos de la zona del estudio en curso habrán sido valorados en un contexto más amplio. Se asume en este punto la posible divergencia entre valores paisajísticos de, por ejemplo, un mismo recurso, en función de que se valore a nivel local, regional o nacional, entendiéndose que los estudios de paisaje a nivel local, regional o nacional tienen precisamente la función de proteger, ordenar y gestionar lo mejor, lo peor y lo anodino dentro de sus respectivos ámbitos. 


\section{4.b.2. Procedimiento de valoración del paisaje por expertos}

Para la consulta a expertos se propone la selección de un cuadro de personas con formación y dedicación profesional relacionada con la planificación territorial o paisajística y a la ordenación territorial. Dichos expertos deberán estar preferentemente vinculados a la administración pública, universidades, gabinetes profesionales o agrupaciones relacionadas con la gestión y custodia del paisaje y del territorio, siendo capaces de emitir juicios de calidad sobre las unidades de paisaje y los recursos paisajísticos.

La composición del cuadro deberá de recoger de forma equilibrada las distintas sensibilidades y acercamientos al paisaje.

Los expertos deberán valorar a partir de la documentación que se les facilite y de sus conocimientos o investigaciones propias, las unidades y recursos paisajísticos, asignándoles valores de "calidad paisajística" comprendidos entre 1 (valor mínimo) y 5 (valor máximo).

Ante la duda de si los valores deben de basarse en una escala absoluta (por ejemplo de tipo universal) o relativa (en la que se asigna un 5 a los recursos o unidades paisajísticas de mayor valor en el ámbito del Estudio), se considerará lo indicado anteriormente para el procedimiento de valoración del paisaje por la población.

De acuerdo al Reglamento de Paisaje de la Comunidad valenciana (2006), los niveles de calidad "serán propuestos de forma justificada por el equipo pluridisciplinar de expertos antes citado, a partir de la calidad de la escena, la singularidad o rareza, la representatividad, el interés de su consenvación y su función como parte de un paisaje integral'.

\section{4.b.3. Integración de los valores otorgados por población y por los expertos}

Obtenidos los valores de preferencia y de calidad paisajística para cada unidad de paisaje y recurso paisajístico, se procederá a calcular el "Valor Paisajístico Preliminar" como media aritmética de ambos valores.

Se trata este de un punto controvertido en el que cabría considerar si el peso de las opiniones dadas por la población o los expertos debe ser similar o diferente. Tras valorar las distintas ventajas y desventajas se opta por la primera opción al ser coherente tanto con la transferencia a la población de la capacidad para tomar decisiones a nivel territorial como con la necesidad de incorporar criterios basados en un estudio y conocimiento sistemático del paisaje y del territorio.

\section{4.b.4 Ajuste del valor paisajístico preliminar en función del grado de visibilidad.}

Ante la cuestión de cómo debe de actuar el grado de visibilidad en el ajuste del valor paisajístico preliminar, cabe considerar el objetivo de la inclusión de la variable "visibilidad" en la determinación del valor paisajístico.

Dicho objetivo es conseguir que aquellas unidades de paisaje o recursos más visibles adquieran, a igualdad de valor paisajístico preliminar, un mayor o menor valor paisajístico respecto a otros menos visibles, justificando de este modo la acción prioritaria de acciones de protección, gestión u ordenación sobre los primeros.

Por dicho motivo y partiendo de la escala de valor paisajístico preliminar antes indicada (1: muy bajo; 2: bajo; 3 : medio; 4: alto y 5 :muy alto) se considera que los valores 1 y 5 , al indicar espacios 0 elementos altamente negativos o positivos no deben ver respectivamente aumentado o disminuido su valor paisajístico en función de su visibilidad. Por el contrario, los espacios o elementos con un valor paisajístico preliminar bajo o alto, deberían ver disminuido o aumentado su valor en caso de ser muy visibles (nivel de visibilidad alta) al ser su impacto negativo o positivo especialmente evidente y poder obtenerse beneficios inmediatos de su mejora o protección. Finalmente, en el caso de unidades o recursos paisajísticos con valores paisajísticos preliminares medios, no se procederá a su ajuste en función del grado de visibilidad al no haber justificación razonada para su alza o baja. El procedimiento propuesto evita expresamente disminuir el valor paisajístico de las unidades o recursos con valores altos aunque sean poco visibles y viceversa, evita aumentar el valor paisajístico de unidades o recursos con valores paisajísticos bajos por el hecho de ser poco visibles.

4.4.c. Comparación con la metodología prevista en el Reglamento de Paisaje de la Comunidad Valenciana La metodología propuesta para la valoración del paisaje coincide mayormente con la indicada en el Reglamento de Paisaje de la Comunidad Valenciana, incorporando aspectos referentes a los métodos de consulta a la población y expertos, a la integración de los valores emitidos respectivamente por éstos, y al ajuste del valor paisajístico en función del grado de visibilidad, introduciendo a su vez el concepto de valor paisajístico preliminar. 


\subsection{Objetivos de Calidad Paisajística}

4.5.a. Consideraciones preliminares

Dados los dos ámbitos de trabajo propuestos, la definición de objetivos de calidad paisajística se realizará únicamente en el "ámbito estricto", entendiendo que éste es el ámbito propio del estudio completo y que será en éste en el que los objetivos deberán sustentar la definición de acciones de protección, gestión u ordenación del paisaje.

Asumidos los objetivos de calidad paisajística como la "formulación por parte de las autoridades públicas competentes, de las aspiraciones de las poblaciones en lo que concieme a las características paisajísticas de su entomo" (Convenio Europeo del Paisaje, 2000) y Reglamento del paisaje de la Comunidad Valenciana (2006), así como la indicación expresa del Reglamento de Paisaje de la Comunidad Valenciana de que los objetivos de calidad paisajística deben ser marcados para cada unidad de paisaje o recursos paisajístico, se hace necesario destacar dos aspectos fundamentales:

1. Los objetivos de calidad paisajística deben ser definidos en la Comunidad Valenciana a partir de un proceso que incluya la participación pública y que los detalle para cada unidad de paisaje y recurso paisajístico.

2. Las "aspiraciones" de la población se pueden formular de forma general o específica. En el primero de los casos se entiende que se la población podrá manifestar cuatro tipos de juicios sobre la Unidad de Paisaje o Recursos Paisajístico: (1) debe ser sustancialmente mejorado, (2) su estado actual es correcto pero caben ajustes, (3) tiene un gran valor y debe de ser preservado tal y como está y (4) una combinación de los anteriores. Estas 4 situaciones coinciden de hecho con los tipos de acciones sobre el paisaje previstos por el Convenio Europeo del Paisaje y el Reglamento de Paisaje de la Comunidad Valenciana: (1) Ordenación, (2) Gestión, (3) Protección, o (4) una combinación de las tres anteriores. En lo referente a los objetivos de calidad paisajísticos de tipo específico manifestados por la población se ha observado que se trata a menudo de sugerencias de tipo puntual que deben ser sistematizadas, abstraídas o agrupadas.

\section{5.b. Metodología propuesta para la definición de Objetivos de Calidad Paisajística}

Atendiendo a las consideraciones previas se incluirá en el Plan de Participación Pública (ver apartado específico en el presente capítulo de Métodos) una fase en la que se consulte a la población de forma sencilla sobre cómo cree que debe de evolucionar una unidad de paisaje o recurso paisajístico determinado, requiriendo por un lado una respuesta genérica y por otro la sugerencia de acciones u objetivos más concretos. Esta fase del Plan de Participación Pública proporcionará por lo tanto información referente a los objetivos de calidad paisajística y a las acciones de protección, gestión y ordenación que deben de permitir lograr dichos objetivos y que se tratarán en el apartado siguiente del presente capítulo.

Este mismo tipo de consulta se realizará al cuadro de expertos que participó en la valoración del paisaje y a partir de la información recogida de ambas fuentes (población y expertos), de los valores paisajísticos obtenidos en la fase previa del estudio de paisaje y de las consideraciones propias, se definirán para cada unidad de paisaje y recurso paisajístico los siguientes objetivos:

- Objetivos genéricos de Calidad Paisajística. Podrán ser los siguientes:

- Ordenación: sugiere la transformación paisajística sustancial de la unidad o recurso y se aplicará preferentemente a unidades recursos con valor paisajístico bajo o muy bajo.

- Gestión: sugiere la transformación moderada o mantenimiento de la unidad o recurso y se aplicará preferentemente a unidades recursos con valor paisajístico medio o alto.

- Protección: sugiere la preservación de la unidad o recurso en sus condiciones actuales y se aplicará preferentemente a unidades recursos con valor paisajístico muy alto, en los que cabrá sin embargo acciones de mejora o puesta en valor.

- Una combinación de los objetivos anteriores: será el caso más frecuente en muchas unidades dado que dentro de éstas se apreciaran aspectos o elementos a reordenar, gestionar o proteger.

- Objetivo Específico de Calidad Paisajística. concretarán a nivel de unidad de paisaje o de recurso paisajístico los objetivos genéricos de calidad paisajística hasta un punto que facilite la definición de programas de paisaje. Se deberá expresamente evitar aludir en las unidades a acciones precisas sobre elementos o aspectos concretos. 
4.5.c. Comparación con la metodología prevista en el Reglamento de Paisaje de la Comunidad Valenciana La metodología propuesta para la definición de objetivos de calidad paisajística coincide mayormente con la indicada en el Reglamento de Paisaje de la Comunidad Valenciana, incorporando aspectos referentes a los métodos de consulta a la población y expertos, diferenciando entre objetivos genéricos y específicos, y sugiriendo el establecimiento de una relación directa entre objetivos genéricos de calidad paisajística y los tipos de acciones aplicables según el Convenio Europeo del Paisaje (protección, gestión y ordenación).

\subsection{Protección, Gestión y Ordenación del Paisaje}

4.6.a. Consideraciones preliminares:

Una vez establecidos los objetivos de calidad paisajística para las unidades y recursos paisajísticos, deberá definirse los mecanismos que permitan su consecución.

\section{Dichos mecanismos podrían concretarse en:}

1. Delimitación de espacios estratégicos para la mejora y preservación de la calidad paisajística, medioambiental, cultural y visual. Dichos espacios, para su efectiva regulación, deberían ser incorporados al planeamiento como zonas de ordenación urbanística diferenciada.

2. Definición de elementos y espacios de especial protección de acuerdo a criterios paisajísticos, medioambientales, culturales y visuales, y para los que se preverá un tratamiento jurídico y normativo diferenciado.

3. Normativas que permitan definir criterios para la integración en el paisaje de nuevos usos y actividades. Dichas normativas deberán quedar integradas en el planeamiento de aplicación (planes generales, parciales, etc.) y deberían ser especialmente vinculantes en los espacios protegidos o de interés paisajístico estratégico (ver los dos puntos anteriores).

4. Programas: que identifiquen y describan las acciones de protección, gestión u ordenación del paisaje.

A partir de estos 4 tipos de modos de regulación y conforme a lo estipulado por el Reglamento del Paisaje de la Comunidad Valenciana, se asumen las siguientes vías para la protección, gestión y ordenación del paisaje:

1. Sistema de espacios abiertos: tiene por fin regular los usos y evolución de espacios de interés estratégico paisajístico, medioambiental, cultural, recreativo y visual. Se concibe como una red continua de espacios, básicamente exentos de edificación que relaciona e integra suelos urbanos, urbanizables y no urbanizables y que facilita el acceso físico y visual de la población al paisaje. En su definición podrán incluirse espacios cuyo interés radique tanto en su importancia ambiental, cultural o visual, como únicamente en su función conectora entre espacios de mayor valor, siendo necesario en dicho caso considerar una anchura suficiente para su correcto funcionamiento como área o corredor ecológico y paisajístico. Con el objetivo de regular adecuadamente la evolución del sistema de espacios abiertos, éste deberá ser asumido como una zona de ordenación urbanística en el planeamiento y deberá de tener asociadas unas normas que regulen los usos, actividades y elementos que puedan darse sobre él.

2. Catálogo de Paisaje: Deberá permitir un tratamiento jurídico y normativo específico de los espacios o recursos paisajísticos de mayor valor, facilitando de este modo su correcta protección y evolución.

3. Normativa Paisajística: La normativa paisajística deberá establecer criterios para la integración en el paisaje de nuevos usos y actividades. Dichas normativas deberán quedar integradas en el planeamiento de aplicación (planes generales, parciales, etc.) y deberían ser específicas para los espacios o elementos protegidos (incluidos en el Catálogo de Paisaje) y para el Sistema de Espacios Abiertos.

4. Programas de Paisaje: Concretarían las actuaciones necesarias para cumplir los objetivos de calidad paisajística, tanto los genéricos como los específicos. Dichos programas podrán vincularse opcionalmente a las unidades de paisaje y deberán ser debidamente justificados y valorados con el fin de permitir a las administraciones o particulares afectados conocer su urgencia, importancia e implicaciones de su realización. En lo referente a la justificación de los programas, debe indicarse que el Convenio Europeo del Paisaje y el Reglamento de Paisaje de la Comunidad Valenciana requieren una participación de la población en la determinación de objetivos de calidad paisajística 
pero, sin embargo, la metodología propuesta en la presente tesis, considera que la población puede sugerir en este mismo proceso de consulta, programas o intervenciones concretas.

Por otro lado, se deberá evitar la asociación directa de un determinado programa a un proyecto concreto, al ser el primero un marco genérico en el pueden tener cabida distintos proyectos o acciones de tipo social, constructivo, divulgativo ,etc... Por dicho motivo se procurará definir programas de carácter amplio que no tendrían que estar necesariamente vinculados a unidades de paisaje o recursos paisajísticos concretos.

\section{6.b. Metodología propuesta para la Protección, Gestión y Ordenación del Paisaje:}

De los 4 tipos de mecanismos previstos para la protección, gestión y ordenación del paisaje (Sistema de Espacios Abiertos, Catálogo, Normativa y Programas de Paisaje), en el ámbito ampliado únicamente se determinará el Sistema de Espacios Abiertos, dado que la función principal de los trabajos en dicho ámbito es precisamente establecer los elementos de conexión y el contexto paisajístico en el que se inserta el ámbito estricto. El primero de los objetivos se lograría definiendo en el ámbito ampliado un Sistema de Espacios Abiertos de carácter regional, y el segundo, tal y como se explicó anteriormente, realizando una caracterización del paisaje (unidades y recursos paisajísticos).

Tomando en consideración lo indicado por el Reglamento de Paisaje de la Comunidad Valenciana y los objetivos específicos de la presente tesis, se expone seguidamente la metodología propuesta para definir los Sistemas de Espacios Abiertos, Catálogos de Paisaje, Normativa de Paisaje y Programas de Paisaje:

\section{6.b.1. Sistema de Espacios Abiertos (SEA)}

\section{6.b.1.1. En el ámbito ampliado}

Tendrá por objeto establecer las principales conexiones paisajísticas y ecológicas con el ámbito estricto, se elaborará con un grado de precisión correspondiente a una escala comprendida entre 1:50.000 y 1:200.000 y deberá garantizar:

- La preservación de la diversidad de paisajes existentes en el ámbito ampliado.

- La inclusión, conexión y adecuado acceso o protección a los recursos paisajísticos medioambientales, culturales y visuales en el ámbito ampliado.

Con el objeto de valorar las implicaciones territoriales del sistema de espacios abiertos, que deberá ser desarrollado a mayor grado de detalle (1:10.000 - 1:20.000) en el ámbito estricto y en los estudios de paisaje de rango municipal afectados, se diagnosticará para dicho sistema sus implicaciones sobre:

- La diversidad de paisajes, valorándose positivamente la inclusión de espacios representativos de las distintas unidades de paisaje existentes en el territorio.

- Los recursos paisajísticos medioambientales, culturales y visuales, valorándose positivamente la inclusión o facilitación del acceso a los mismos.

- El desarrollo urbanístico previsto, valorándose positivamente la creación de sistemas interconectados de espacios abiertos, verdes o duros, en suelo urbano, la identificación de áreas estratégicas para futuros espacios libres en suelo urbanizable y la inclusión de los suelos de mayor valor medioambiental, cultural y visual en suelo no urbanizable.

- La actividad económica, para lo que se deberá conocer la productividad económica del suelo incluido en el sistema de espacios abiertos. Dichas condiciones económicas permitirán estimar la estabilidad de los paisajes productivos incluidos en dicho sistema y valorar las implicaciones y viabilidad económica de las acciones de protección, gestión y ordenación que puedan proponerse.

- La conectividad y movilidad territorial, valorándose positivamente la creación de conectores ecológicos así como la creación de entornos paisajísticamente positivos entorno a los distintos sistemas de comunicación (vías peatonales, ciclistas, rodadas, etc.).

De acuerdo al Reglamento de Paisaje de la Comunidad Valenciana y a las consideraciones previas, el sistema de espacios abiertos incluirá a priori los siguientes espacios:

a) Las unidades de paisaje y recursos paisajísticos de valor alto o muy alto.

b) Las unidades de paisaje o recursos paisajísticos objeto de protección especial conforme a la legislación de protección de Espacios Naturales y los entornos de los bienes y conjuntos incluidos en el perímetro de su declaración como bien de interés cultural conforme a la legislación de patrimonio cultural. 
c) Las conexiones ecológicas y funcionales o franjas de terreno que conectan los espacios del apartado anterior y que aún no teniendo elementos de singularidad manifiesta paisajística o incluso se encuentren degradados, se consideran necesarios como áreas de conexión entre los espacios de interés para lograr una continuidad física, ecológica y funcional. En cualquier caso incluirá la red hídrica, el dominio público marítimo, senderos históricos, vías pecuarias, infraestructuras y similares y los corredores verdes a los que se refiere la Ley de Ordenación del Territorio y Protección del Paisaje, que desempeñan funciones de conexión biológica y territorial, todo ello de conformidad con lo establecido en el artículo 20.7 de dicha Ley.

d) Las zonas de afección visual de las principales infraestructuras de transporte y de los sistemas de movilidad peatonal y ciclista en espacios no urbanizados. La zona de afección visual se definirá en función de la topografía y del nivel de urbanización del entorno visual de la carretera. En entornos de alto valor paisajístico y escasa urbanización podrán extenderse hasta los elementos de relieve que enmarquen la cuenca visual. En espacios de menor valor paisajístico o con presencia frecuente de edificación se podrá reducir a una distancia mínima de 300 metros a ambas márgenes de los recorridos principales (distancia marcada para vistas cortas en la metodología de análisis visual propuesta en el Reglamento de Paisaje de la Comunidad Valenciana) o a 150 metros en recorridos secundarios.

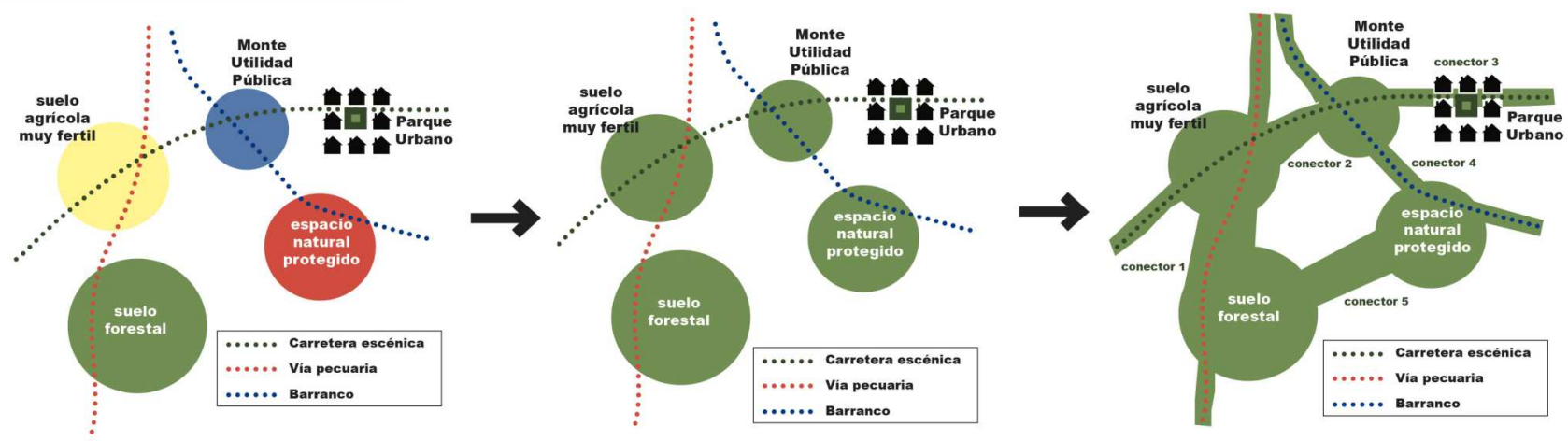

Fig. 4.3 Esquema simplificado de proceso de definición de sistema de espacios abiertos

\section{6.b.1.2. En el ámbito estricto:}

Se seguirán las mismas indicaciones dadas para el sistema de espacios abiertos del ámbito ampliado, si bien en este caso, el segundo proporcionará un sistema primario, a ajustar y definir en mayor grado de detalle (escala 1:10.000 - 1:20.000) en el ámbito estricto en base a los trabajos de caracterización y valoración del paisaje.

Adicionalmente, y para el sistema de espacios abiertos en el ámbito estricto, deberán definirse normas de integración paisajística específicas que determinen el grado de protección y régimen de usos del suelo en las distintas zonas que integren dicho sistema.

\section{6.b.2. Catálogo de Paisaje.}

Se desarrollará únicamente dentro del ámbito estricto. De acuerdo al Reglamento de Paisaje de la Comunidad Valenciana, el catálogo de paisaje incluirá:

a) Las unidades de paisaje y recursos paisajísticos de valor alto o muy alto.

b) Las unidades de paisaje o recursos paisajísticos objeto de protección especial conforme a la legislación de protección de espacios naturales y los entomos de los bienes y conjuntos incluidos en el perímetro de su declaración como bien de interés cultural conforme a la legislación de patrimonio cultural.

El catálogo deberá ir complementado a su vez con unas normas de integración paisajística específicas.

\section{6.b.3 Normativa de Paisaje:}

Se desarrollará únicamente dentro del ámbito estricto. Se considerará la doble diferenciación que realiza el Reglamento de Paisaje de la Comunidad Valenciana entre "normas de aplicación directa" y "normas de integración paisajística". 
En lo referente a las normas de aplicación directa, se listarán aquellas recogidas en el artículo 18 del Reglamento de Paisaje que tengan una relación directa con el paisaje del ámbito estricto.

En lo referente a las normas de integración paisajística, se definirán para cada unidad de paisaje o ámbito territorial concreto e incluirán aquellas normas de tipo genérico incluidas en los artículos 20, 21 y 22 del Reglamento de Paisaje de la Comunidad Valenciana que sean de aplicación, así como normas de integración específicas, a desarrollar de forma particular en cada estudio de paisaje y que tendrán por fin regular $\mathrm{n}$ los usos del suelo, actividades o elementos que se estime necesario, complementándolas si procede con recomendaciones de carácter orientativo.

Dentro de las normas de integración paisajística se señalarán o desarrollarán a su vez las que permitan regular el grado de protección y usos permitidos en las distintas zonas que integren el sistema de espacios abiertos y las que acompañen al catálogo de paisaje (ver figura 4.4):

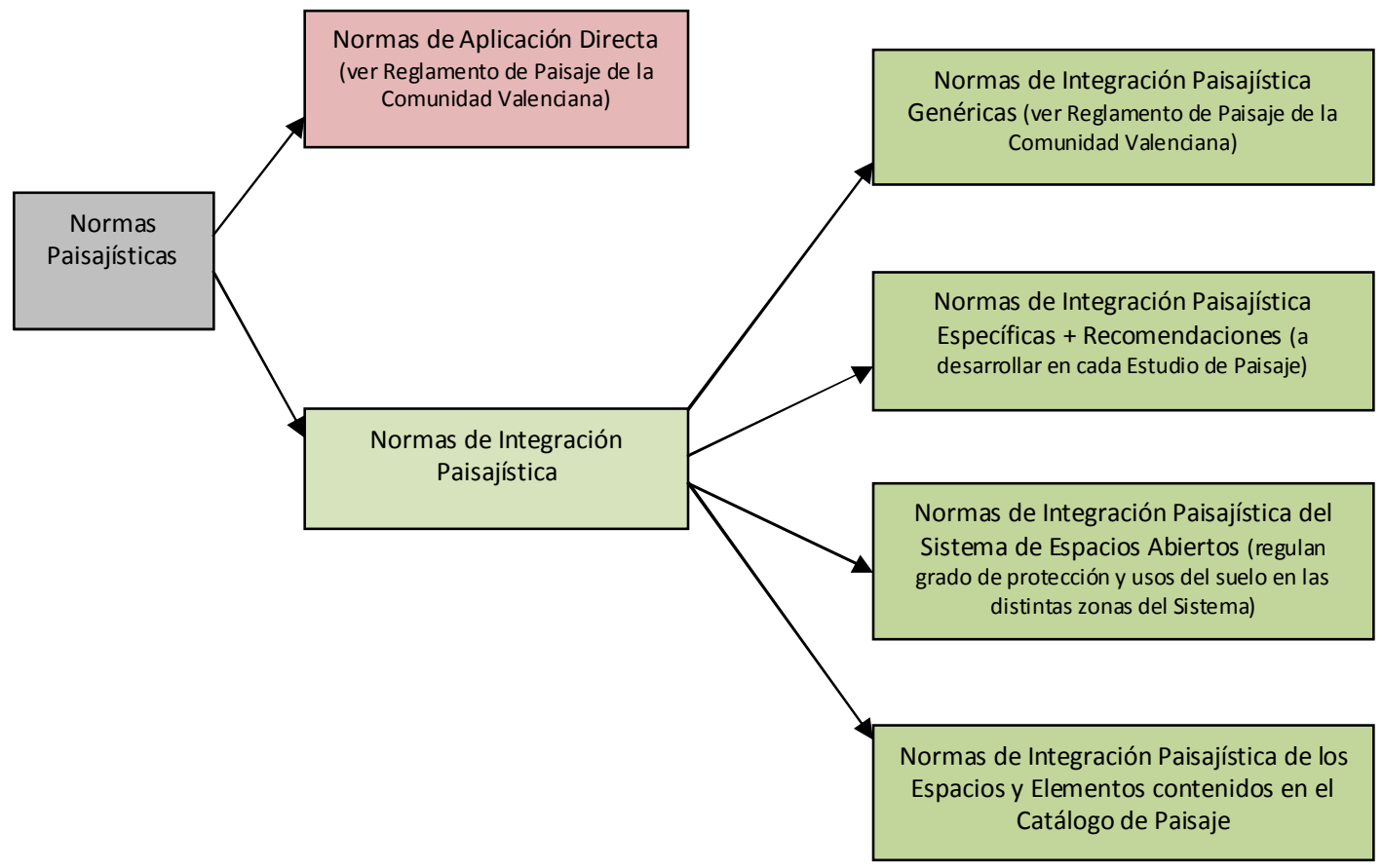

Fig. 4.4 Esquema de los tipos y aplicación de normas paisajísticas en los estudios de paisaje

\section{6.b.4 Programas de Paisaje:}

Los programas de paisaje se desarrollarán para el ámbito estricto del estudio, donde concretarán las medidas, actuaciones y proyectos de paisaje necesarios para cumplir los objetivos de calidad paisajística definidos en dicho ámbito. Los programas deben ser en consecuencia estructuras de carácter amplio a los que puedan asociarse a acciones o proyectos concretos de tipo constructivo, administrativo, social, divulgativo, etc.

A pesar de que los objetivos de calidad paisajística deben ser fijados para cada unidad o recurso paisajístico, los programas no tienen porque vincularse a dichas unidades o recursos, debiendo en ese caso sopesarse las posibles ventajas ejecutivas de hacerlo y los inconvenientes de fragmentar programas cuyo ámbito de aplicación sea compartido por distintas unidades o recursos.

Con el objeto de desarrollar programas más coherentes, se sugiere la definición previa de un Plan de Paisaje (o Plan de Ordenación Paisajística) en el que se concreten el conjunto de estrategias y acciones previstas para cumplir los objetivos de calidad paisajística y del que se desprendan los programas de paisaje, especialmente aquellos que implican una intervención física sobre el territorio.

De acuerdo al Reglamento de Paisaje de la Comunidad Valenciana y a los objetivos marcados en la presente tesis, cada programa de paisaje debería incluir las partes siguientes: 
1. Memoria descriptiva que exponga:

- Ámbito de aplicación del programa.

- Procesos, oportunidades y problemas detectados

- Objetivos de calidad paisajística considerados.

2. Memoria justificativa que exponga:

- Justificación genérica de acuerdo a los artículos 62, 65 y 66 del Reglamento de Paisaje de la Comunidad Valenciana.

- Justificación de acuerdo a planeamiento de aplicación

- Justificación según beneficios y mejoras esperadas

- Urgencia e Importancia global del programa: especificando la "Urgencia" como la necesidad de actuaciones inmediatas con el fin de lograr los objetivos del programa y la "Importancia" entendida como la trascendencia a medio y largo plazo de las actuaciones propuestas. Ambas variables se valorarán en una escala de 1 (mínima) a 5 (máxima) y pretenden facilitar a las administraciones competentes la priorización de los distintos programas y su ejecución en el tiempo.

3. Relación de proyectos que desarrollarán el programa y estimación económica de éstos. Adicionalmente podrá incluirse un estudio económico-financiero que concrete los medios que se comprometerán para la ejecución del programa.

Los programas de paisaje se presentarán en formato de Fichas normalizadas con los contenidos anteriormente expuestos.

\section{6.c. Comparación con la metodología prevista en el Reglamento de Paisaje de la Comunidad Valenciana} La metodología propuesta coincide mayormente con la prevista en el Reglamento de Paisaje de la Comunidad Valenciana con las siguientes adiciones:

- Sistema de Espacios Abiertos: Se propone su desarrollo en el ámbito estricto y en el ámbito ampliado, con el objeto de suplir, en el segundo caso, las indefiniciones o descontextualización debidas a la posible ausencia de un estudio de paisaje de rango superior. Se propone a su vez la realización de un trabajo de diagnóstico del sistema de espacios abiertos con el fin de valorar su efecto territorial, paisajístico y económico.

- Catálogos de Paisaje: no se realizan adiciones respecto a lo indicado por el Reglamento

- Normativa de Paisaje: Se proponen dos categorías de normas de integración paisajística: las genéricas (correspondientes a las listadas en el Reglamento de Paisaje) y las específicas, a desarrollar de forma particular en cada estudio de paisaje y a las que se podrán adicionar recomendaciones paisajísticas.

- Programas de Paisaje: Se propone la definición de un plan de paisaje que establezca el conjunto de estrategias y acciones que permitan cumplir los objetivos de calidad paisajística y que apoyen la posterior definición de los programas de paisaje. Respecto a estos últimos, se recomienda la definición de programas de carácter amplio que no coincidan sino que proporcionen un marco a proyectos concretos y que puedan aplicarse sobre espacios distintos de las unidades de paisaje incluidas dentro del estudio. Se propone por último una estructura de la ficha para cada programa que incluya, entre otros aspectos, una estimación de la urgencia e importancia de éste y de los proyectos asociados.

\subsection{Participación Pública}

\section{7.a Consideraciones preliminares}

La inclusión de un Plan de Participación Pública dentro de los Estudios de Paisaje queda establecida en el Reglamento de Paisaje y en la Ley de Ordenación del Territorio y Protección del Paisaje de la Comunidad Valenciana y atiende a los principios marcados por el Convenio Europeo del Paisaje, a la trasposición a la legislación española de la Directiva 2003/4/CE del Parlamento Europeo y del Consejo, de 28 de enero de 2003, relativa al acceso del público a la información medioambiental y a la Directiva 2003/35/CE del Parlamento Europeo y del Consejo, de 26 de mayo de 2003.

Dichos planes de participación pública tienen por objeto regular la implicación directa de la población en la realización de los estudios de paisaje y en la elaboración de las determinaciones en ellos contenidos.

El Reglamento de paisaje describe el procedimiento que deberá permitir los siguientes objetivos propios de una actividad de participación pública: 
1. Adecuada información/formación de la población afectada.

2. Establecimiento de los cauces adecuados para que dicha participación sea fácil y abierta.

3. Implicación de los participantes en la definición, ajuste y aplicación de aquellos temas en los que han sido invitados a participar.

\section{7.b. Metodología propuesta para el plan de participación pública}

Las determinaciones contenidas en los artículos 15, 16 y 17 del Reglamento de Paisaje de la Comunidad Valenciana se adoptarán como punto de partida para la propuesta metodológica de planes de participación pública en la presente tesis. A partir de dichas determinaciones, y con el objeto de agilizar el proceso de redacción del estudio sin perjuicio de la calidad del proceso de participación pública, se propone el desarrollo de este último de acuerdo a un cronograma del siguiente tipo:

- FASE_0: preparación de los cauces para el desarrollo del plan de participación pública. Durante esta fase se realizarían las acciones siguientes:

- Selección y contacto preliminar con los grupos de interés (durante el desarrollo del plan podrán sin embargo adicionarse nuevos grupos).

- Definición de los perfiles de los integrantes de la muestra de población a encuestar.

- Contacto con las administraciones públicas colaboradoras y elaboración de los materiales y herramientas (webs) de difusión y volcado de conclusiones parciales y finales del plan de participación pública.

- Elaboración de los materiales de la FASE1, que incluirán necesariamente la memoria explicativa del plan de participación.

- FASE_1: Caracterización del paisaje (duración estimada 3-4 semanas). Fase en la que se presenta el Plan de Participación Pública a la población y se le pregunta qué paisajes, qué recursos paisajísticos y qué cambios o conflictos paisajísticos identifican en el ámbito del estudio.

- FASE_2: Valoración del paisaje (duración estimada 3-4 semanas): Fase en la que, tomando como base las unidades de paisaje y los recursos paisajísticos identificados a partir de los trabajos propios y de la información facilitada por la población y expertos en la FASE1, se pide a ambos grupos que los valoren en una escala de 1 a 5 (muy bajo, bajo, medio, alto o muy alto).

- FASE_3: Objetivos de calidad paisajística y programas de paisaje (duración estimada 3-4 semanas): Fase en la que a partir de la cartografía en la que se recogen las unidades de paisaje, recursos paisajísticos (ambos valorados) y conflictos detectados, se pregunta a la población y expertos sobre los objetivos de calidad paisajística a aplicar en cada unidad o recurso y sobre las actuaciones que estiman que deberían desarrollarse sobre ambos o sobre el conjunto del ámbito del estudio.

Para la participación de la población se elaborará en cada fase un cuestionario de las características de los recogidos en el anexo VIII de la presente tesis, que necesariamente irá acompañado de las conclusiones de la fase previa, de forma que estas últimas proporcionen la información de apoyo para plantear nuevas cuestiones. Dichas conclusiones deberán ser redactadas en un periodo breve de tiempo ( 2 semanas) con el objeto de no romper la continuidad temporal del plan de participación.

Los cuestionarios deberán elaborarse con planos e imágenes ilustrativas y neutras de las áreas o elementos sobre los que la población deba de hacer su valoración paisajística o sus sugerencias de objetivos de calidad paisajística y programas de paisaje. En la fase1 se proporcionará una copia de la memoria del plan de participación pública así como una información genérica (con planos e imágenes) de los principales paisajes encontrados a priori dentro del ámbito del estudio.

Con el objeto de facilitar la participación pública, el tiempo de respuesta a cada cuestionario deberá ser inferior a 15-20 minutos y los conceptos sobre los que se realicen las cuestiones deberán ser presentados de forma sencilla, cabiendo en el caso de encuestas a pie de calle o actividades presenciales, un mayor margen de maniobra y explicación por personal conocedor de la materia.

\section{7.c. Comparación con la metodología prevista en el Reglamento de Paisaje de la Comunidad Valenciana} La metodología propuesta para la realización del Plan de Participación Pública se ajusta a la prevista en el Reglamento de Paisaje de la Comunidad Valenciana con las siguientes adiciones o incorporaciones: 
1. Participación pública diferenciada en las fases de Caracterización, Valoración y Establecimiento de objetivos de calidad paisajística/programas de paisaje

2. Requerimiento de la realización de encuestas a pie de calle a un grupo representativo de la población.

3. Establecimiento de un calendario secuencial que agilice el proceso de participación y evite su pérdida de continuidad.

\subsection{Aspectos económicos asociados a la valoración, protección, gestión y ordenación del paisaje} 4.8. a Consideraciones preliminares

Los aspectos económicos asociados al paisaje podrían ser agrupados en cuatro grupos principales:

1. Aspectos dirigidos a determinar el valor económico de un espacio o elementos físicos, estrictamente por sus cualidades visuales.

2. Aspectos vinculados a la disposición de los particulares a contribuir a la mejora, protección o gestión del paisaje.

3. Aspectos asociados a la productividad económica del territorio.

4. Aspectos vinculados a la obtención/generación de recursos económicos para la custodia y gestión del territorio / paisaje.

A partir de la información recogida en el capítulo 3 (revisión bibliográfica) y en los apartados 1 y 2 del anexo I de la presente tesis, se concluye lo siguiente sobre su posible utilidad en la redacción de estudios de paisaje y la forma por la que se podrían introducir en la metodología de redacción de estos últimos.

Tabla 4.1. Posible uso y forma de introducción en la metodología de redacción de estudios de paisaje de variables económicas.

Tipo de aspecto
Posible utilidad en estudios del paisaje
Propuesta de introducción en la metodología de redacción de Estudios de Paisaje
1. Aspectos dirigidos a determinar el valor económico de un espacio o elementos físico estrictamente por sus cualidades visuales.

\section{Aspectos vinculados a la} disposición de los particulares a contribuir a la mejora, protección o gestión del paisaje.

\section{Productividad económica del} territorio.

4. Aspectos vinculados a la obtención/generación de recursos económicos para la custodia y gestión del territorio / paisaje.

\section{$\longrightarrow$ Valoración económica} del paisaje.
Desestimada dada la difícil separación de valores económicos exclusivos del paisaje en los métodos de valoración contingente.

4.8.b. Metodología propuesta para la integración de aspectos económicos en la valoración, protección, gestión y ordenación del paisaje.

A partir de lo expuesto en la tabla 4.1 se proponen las siguientes vías para la introducción de aspectos económicos en la planificación del paisaje:

\section{a. En la valoración indirecta de la preferencia del paisaje:}

- Modo: Mediante la incorporación en los planes de participación pública de preguntas en las que se requiera a la población que indique su disposición a contribuir económicamente de forma personal a la mejora, protección y gestión del paisaje, y en caso afirmativo, la cantidad con la que lo haría dentro de una serie de rangos predeterminados.

- Utilidad: Considerando que la contribución económica personal es un indicador del interés real de una persona por proteger /gestionar aquello que más valora o por mejorar aquello que más le perturba, se espera disponer de un validador de los niveles de preferencia paisajísticos obtenidos por estricta preferencia visual. 
b. En la determinación de la estabilidad funcional de un territorio (y de sus paisajes asociados):

- Modo: Mediante el estudio de las productividades del suelo. El estudio se aplicaría dentro del diagnóstico del sistema de espacios abiertos o, adicionalmente, en la caracterización de unidades de paisaje en las que se detecte una posible e intensa transformación del paisaje como consecuencia de la pérdida de rentabilidad de las actividades económicas que en él se desarrollen o de la introducción de nuevas actividades o usos del suelo.

- Utilidad: Determinar la estabilidad del paisaje, prever su posible transformación y definir, en consecuencia, medidas de ordenación, gestión u ordenación coherentes con el contexto económico.

\section{c. En la determinación y valoración de vías adicionales de financiación para las acciones de} paisaje:

- Modo: Mediante la inclusión en el plan de participación pública de cuestiones que permitan explorar y cuantificar posibles vías para apoyar la gestión del territorio y paisaje (disposición a pagar por utilizar espacios naturales, posible apoyo a productos agrícolas locales, etc)

- Utilidad: Definir justificadamente posibles vías adicionales de financiación para las acciones de protección, gestión y ordenación del paisaje. Dichas vías se considerarían en cualquier caso complementarias a las asignables desde instituciones públicas, fundaciones, etc.

4.8.c. Comparación con la metodología prevista en el Reglamento de Paisaje de la Comunidad Valenciana La metodología propuesta introduce aspectos económicos en la redacción de estudios de paisaje con un triple objetivo:

1. Corroborar los niveles de preferencia paisajística mediante un indicador indirecto (en este caso económico)

2. Determinar la estabilidad del paisaje en territorios contablemente productivos o con potencialidad de serlo.

3. Explora vías suplementarias de financiación de las acciones de paisaje.

La metodología actualmente vigente en la Comunidad Valenciana podría considerar indirectamente el segundo de los objetivos en la redacción de programas de paisaje o en los trabajos de caracterización, valorando el interés de utilizar variables como la productividad o precio del suelo, y proponiendo, si procede, su incorporación sistemática en distintos apartados de los estudios de paisaje.

En el caso de los otros dos objetivos, su introducción metodológica se hace con carácter novedoso y exploratorio, previéndose valorar su utilidad real tras la aplicación de la metodología propuesta en un ámbito concreto (ver capítulo 5).

Adicionalmente, se utilizarán los perfiles socio-demográficos de los encuestados para determinar posibles divergencias significativas en la preferencia paisajística y en la disposición a contribuir económicamente a la protección, gestión y ordenación del paisaje en función del género, nivel formativo y nivel de renta. Aspecto, este último de gran relevancia para determinar la universalidad de aplicación de las políticas de paisaje (ver Plan Visual de la Comunidad Valenciana, STEINITZ, MUÑOZ, 2008). 


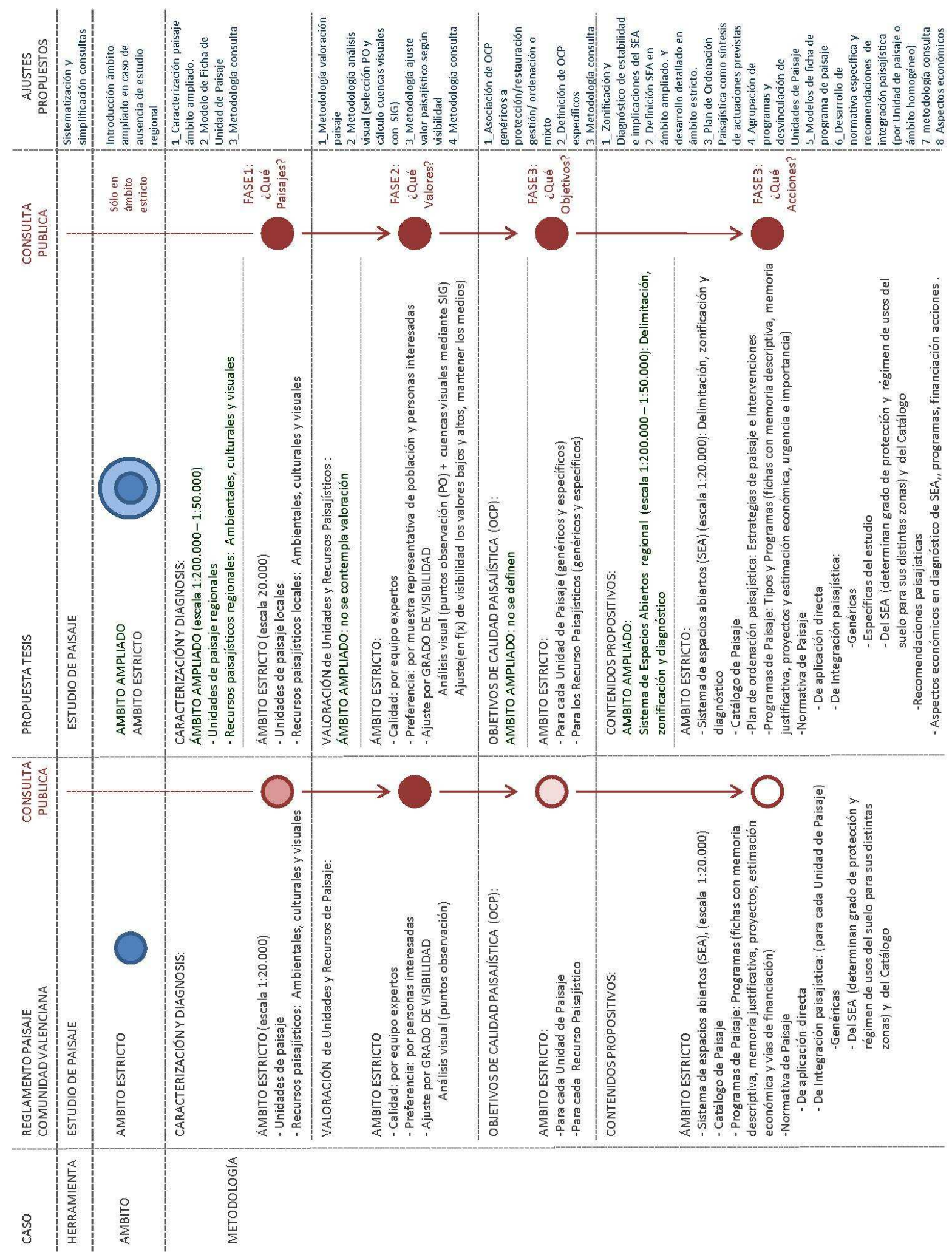

Tabla 4.2. Comparación de las metodologías para la redacción de estudios de paisaje según el Reglamento de Paisaje de la Comunidad Valenciana y según la presente tesis (en la última columna se incluyen los principales ajustes y sugerencias). 

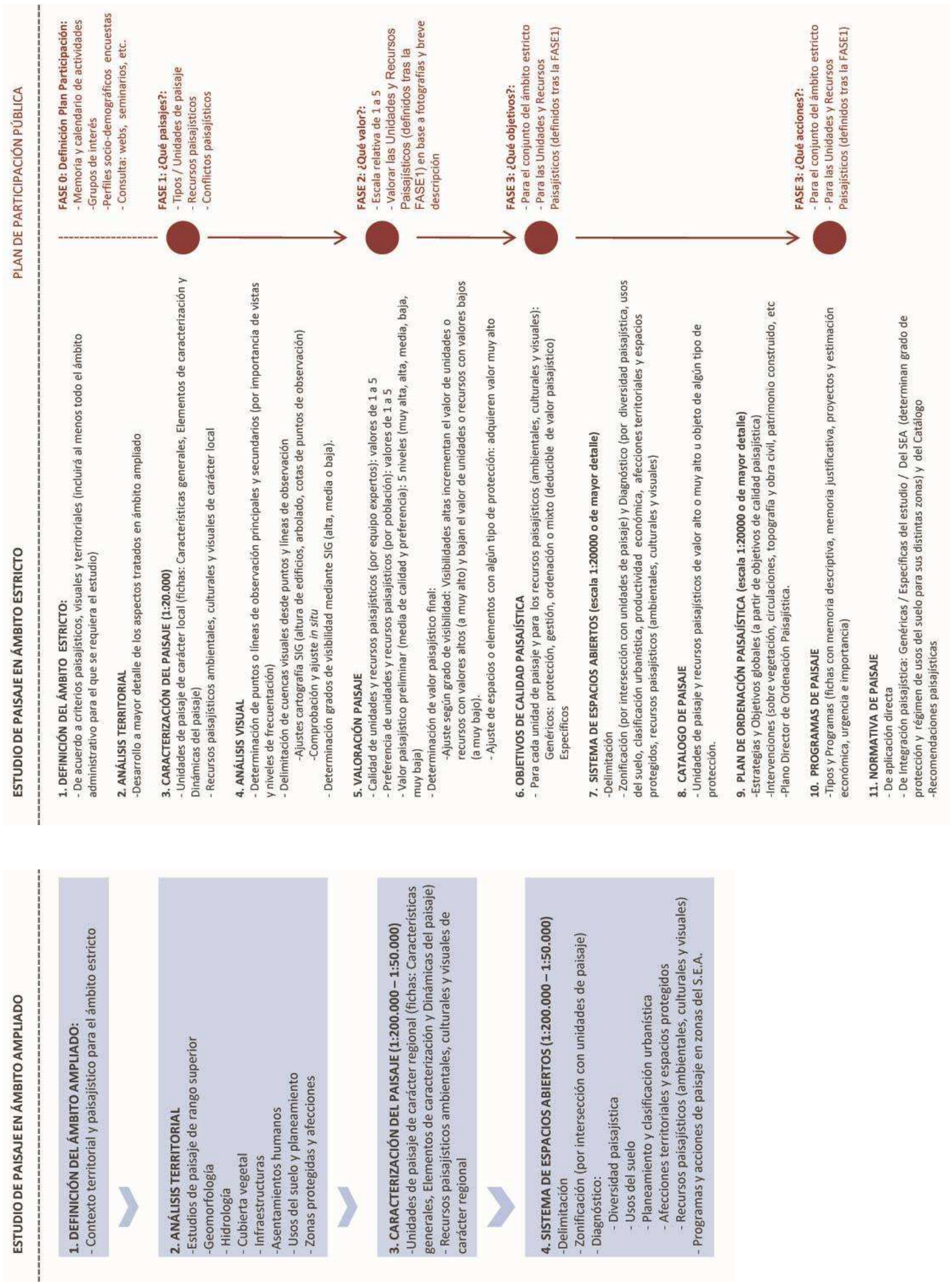

Tabla 4.3. Esquema de procedimiento propuesto para la redacción de un estudio de paisaje 


\section{APLICACIÓN DE LA METODOLOGÍA A UN ESPACIO ABIERTO DE LA COMUNIDAD VALENCIANA}


VALORACIÓN Y GESTIÓN DEL PAISAJE SEGÚN EL CONVENIO EUROPEO DEL PAISAJE YEL

REGLAMENTO DEL PAISAJE DE LA COMUNIDAD VALENCIANA: APLICACIÓN MEDIANTE UN ESTUDIO

DE PAISAJE A UNESPACIO ABIERTO EN LA COMUNIDAD VALENCIANA

DOCTORANDO: JUAN JOSÉ GALÁN VIVAS (Universidad Politécnica de Valencia, enero 2011) 


\section{APLICACIÓN DE LA METODOLOGÍA A UN ESPACIO ABIERTO DE LA COMUNIDAD VALENCIANA}

5.1. Selección del ámbito de aplicación:

5.1.a. Criterios de selección:

Con el objeto de testar la metodología para la planificación del paisaje propuesta en la presente tesis, se incluye como parte de ésta el desarrollo de una aplicación práctica sobre un ámbito geográfico representativo de la Comunidad Valenciana y de la cuenca del Mediterráneo occidental. A dichos efectos se consideran factores adecuados para la selección del ámbito del estudio los siguientes:

- Definición del ámbito de acuerdo a criterios fisiográficos, paisajísticos y culturales, evitando ceñirse estrictamente a límites administrativos.

- Ámbito con una superficie asimilable a la propia de los supuestos en los que reglamentariamente deba de desarrollarse un Estudio de Paisaje en la Comunidad Valenciana: término municipal o área objeto de un plan de acción territorial.

- Existencia de un abanico amplio de usos del suelo, de tipos de paisaje y presencia de elementos de espacios protegidos (parques naturales o dominios públicos costeros o fluviales), así como de una amplia variedad de recursos medioambientales, culturales y visuales.

- Necesidad de coordinar distintos tipos de planeamiento (municipales, rectores de espacios protegidos, etc.) y existencia de espacios de dimensión regional que precisen de estrategias de intervención supramunicipales (espacios fluviales, costeros o protegidos).

- Existencia de presiones y dinámicas para la modificación intensa del paisaje, entre ellas:

- Procesos de Urbanización

- Construcción de Infraestructuras

- Abandono de la actividad agrícola.

\section{1.b. Ámbito seleccionado:}

Tras estudiar la demanda de estudios de paisaje en distintos ámbitos de la Comunidad Valenciana se selecciona el correspondiente al Parque Natural de las Lagunas de la Mata y Torrevieja y su entorno, desde cuya dirección se había manifestado un interés expreso en contar con el citado documento a fin de poder disponer de criterios paisajísticos a aplicar en el parque y en zonas colindantes. Dicho interés fue a su vez recogido por la Dirección General de Territorio y Paisaje de la Comunidad Valenciana, desde donde se encargó en la persona del presente doctorando la redacción del citado estudio.

Tras estudiar las particularidades del ámbito, se estima idóneo para el desarrollo del trabajo por los siguientes motivos:

1. El Parque Natural es una unidad territorial definida por criterios fisiográficos y medioambientales que, considerado el plan de ordenación de los recursos naturales que lo protege, afecta a un total de 5 municipios (Torrevieja, Guardamar del Segura, Rojales, San Miguel de Salinas y Los Montesinos), brindando, en consecuencia, una oportunidad para desarrollar un estudio de paisaje supramunicipal que apoye el planeamiento regional y local.

2. A falta de determinar exactamente el ámbito estricto del estudio de paisaje, la superficie comprendida dentro de los límites del Parque (37 kilómetros cuadrados), sumada a la de su zona de amortiguación de impactos, tal y como se define en el Plan de Ordenación de los Recursos Naturales del Sistema de Zonas Húmedas del Sur de Alicante, proporciona un área de dimensiones propias de términos municipales amplios o de planes de acción territorial reducidos.

3. Coexistencia en el ámbito del estudio de una amplia diversidad de:

3.1. Usos del Suelo: industrial salinero, agrícola de regadío (hortícolas y cítricos), agrícola de secano (viñedos), residencial de media densidad, residencial no programado, recreativo extensivo, infraestructuras de transporte, dominios hidráulicos, etc.

3.2. Tipos de Paisaje.

3.3. Espacios protegidos por su interés medioambiental, entre los que destaca el propio Parque Natural

3.4. Recursos paisajísticos medioambientales, culturales y visuales, con una significada presencia de muestras del patrimonio arquitectónico e hidráulico del sur de Alicante y con una alta visibilidad de los recursos como consecuencia del carácter plano de la topografía y de la presencia de importantes núcleos de población e infraestructuras.

4. Necesidad de coordinar planeamientos de tipo regional (Plan Rector de Usos y Gestión y Plan de Ordenación de los Recursos Naturales del Parque) con Planes Generales de Ordenación Urbanística de los 
términos afectados, muchos de ellos pendientes de revisión y por lo tanto susceptibles de incorporar las sugerencias del estudio de paisaje a redactar.

5. Existencia de fuertes presiones transformadoras y serias amenazas sobre el paisaje y entorno visual del Parque Natural. Estas circunstancias se consideran características de muchos espacios costeros mediterráneos y por lo tanto darían al estudio de paisaje un interés y aplicabilidad general. En concreto se constata en un primer análisis la presencia de:

- Fuertes procesos de urbanización con patrones de escasa calidad, alto impacto paisajístico y escasa sostenibilidad.

- Imagen precaria de los bordes y accesos urbanos.

- Construcción de infraestructuras con alta incidencia paisajística y funcional sobre el Parque.

- Deterioro de los Recursos paisajísticos en el entorno del Parque

- Problemas de conectividad territorial del Parque y de acceso al mismo por parte de la población.

- Ausencia de criterios supramunicipales de ordenación y planeamiento, proporcionando el Parque una oportunidad única para remediar esta carencia.

El conjunto de motivos expuestos permite concluir que el área correspondiente al entorno del Parque Natural de las Lagunas de La Mata y Torrevieja resulta idónea para testar la metodología propuesta dada su alta representatividad y la confluencia en dicha área de algunos de los problemas y oportunidades más característicos de la ordenación territorial y planificación del paisaje actual.

Por el contrario, son hándicaps a salvar los siguientes:

- Inexistencia de un estudio de paisaje de rango superior al propuesto, lo que, conforme a lo expuesto en la metodología de la presente tesis, exigiría definir un ámbito ampliado que proporcione información básica sobre el contexto paisajístico y sobre sus conexiones territoriales.

- El estudio de paisaje a realizar no se encontraría vinculado a ninguno de las herramientas de planificación previstas al efecto por la legislación valenciana (planes de acción territorial y planes generales de ordenación urbana), motivo por el que su función sería de apoyo a la gestión del parque, dentro de los límites del mismo y en su zona de amortiguación, donde deberá ser compatible y acorde respectivamente con el Plan Rector de Usos y Gestión (PRUG) y con el Plan de Ordenación de los Recursos Naturales (PORN). Paralelamente, el documento podrá orientar los estudios de paisaje que en su día se elaboren en las revisiones de los Planes Generales de los términos municipales afectados, y permitirá por otro lado a la dirección del parque, disponer de un documento que sustente, de acuerdo a criterios de paisaje, los posibles informes que se le solicite respecto a actuaciones que puedan afectar al parque.

Una vez definido el área en a que se testará la metodología propuesta en la presente tesis, se procede a aplicarla de acuerdo al procedimiento expuesto en el capítulo 4.

\subsection{Introducción:}

5.2.a. Objetivo y estructura del Estudio de Paisaje:

El presente estudio tiene por objeto testar la metodología de planificación del paisaje propuesta en el capítulo 4 de esta tesis.

El ámbito del estudio es el Parque Natural de las lagunas de La Mata y Torrevieja y su entorno, para el que el se deberá establecer acciones que faciliten la ordenación, gestión y protección del paisaje, asumiendo que éste, como cualidad percibida del territorio, está indisolublemente vinculado a la ordenación, gestión y transformaciones que puedan darse en dicho territorio. En concreto el estudio deberá potenciar los recursos paisajísticos, tanto de tipo ambiental, como cultural y visual, proponer medidas correctoras o de integración paisajística de las dinámicas o elementos inadecuados para la calidad visual y ecológica del parque y, finalmente, establecer estrategias y programas que resuelvan el encuentro de éste con las zonas agrícolas, infraestructuras y zonas urbanizadas que lo circundan.

Como primera parte del estudio y con el objeto de establecer las conexiones necesarias con otros espacios de valor del sur de la provincia de Alicante y de poder desarrollar adecuadamente las propuestas de relación del parque con su entorno inmediato, se ha definido un ámbito ampliado para el que se desarrollarán los aspectos siguientes: 
- Definición del Ámbito Ampliado

- Análisis Territorial:

- Caracterización del paisaje: Incluirá la definición de unidades de paisaje y recursos paisajísticos medioambientales, culturales y visuales de escala regional.

- Definición de un sistema de espacios abiertos de carácter regional.

Una vez determinados los aspectos anteriormente listados, se procederá a desarrollar el estudio de paisaje del ámbito estricto apoyado en un Plan de Participación Pública. Los aspectos a tratar en el Estudio de Paisaje del ámbito estricto serán los siguientes:

- Definición del ámbito estricto

- Análisis Territorial

- Definición del Plan de <participación Pública

- Caracterización del Paisaje (apoyado en la FASE1 del Plan de Participación Pública)

- Análisis Visual: Visibilidad del Paisaje

- Valoración del Paisaje (apoyado en la FASE 2 del Plan de Participación Pública)

- Definición de Objetivos de Calidad paisajística (apoyado en la FASE3 del Plan de Participación Pública)

- Definición de Sistema de Espacios Abiertos

- Definición de Catálogo del Paisaje

- Definición de un Plan de Ordenación Paisajística

- Definición de Programas de Paisaje (apoyado en la FASE3 del Plan de Participación Pública)

- Definición de Normativa de Paisaje.

5.3. Estudio de Paisaje en el ámbito ampliado:

\section{3.a. Definición del ámbito ampliado}

El ámbito ampliado del estudio de paisaje del Parque Natural de la Mata Torrevieja se define atendiendo principalmente a la estructura fisiográfica territorial e incluye el tramo inferior del valle del Segura, la cuenca endorreica de las lagunas de la Mata y Torrevieja así como las sierras y humedales que delimitan el valle y cuencas anteriormente citados.

El ámbito así definido queda delimitado en su cara oeste por las Sierras de Orihuela y Callosa de Segura, en su cara norte por los parques naturales del Fondo y Salinas de Santa Pola, al este por el Mar Mediterráneo y al sur por el parque Natural de la Dehesa de Campoamor - Sierra de Escalona y por las elevaciones que rodean el Embalse de la Pedrera.

Dicho ámbito incluye la totalidad o parte de los Términos Municipales siguientes: Albatera, Algorfa, Almoradí, Benejúzar, Benijófar, Bigastro, Callosa de Segura, Catral, Cox, Crevillente, Daya vieja, Dolores, Elche, Formentera del Segura, Granja de Rocamora, Guardamar del Segura, Jacarilla, Los Montesinos, Rojales, Orihuela, Pilar de la Horadada, Rafal, Redován, San Fulgencio, San Miguel de las Salinas, Santa Pola y Torrevieja. 
VALORACIÓNY GESTIÓN DEL PAISAJE SEGÚN EL CONVENIO EUROPEO DEL PAISAJE YEL

REGLAMENTO DEL PAISAJE DE LA COMUNIDAD VALENCIANA: APLICACIÓN MEDIANTE UN ESTUDIO DE PAISAJE A UNESPACIO ABIERTO EN LA COMUNIDAD VALENCIANA

DOCTORANDO: JUAN JOSÉ GALÁN VIVAS (Universidad Politécnica de Valencia, enero 2011)

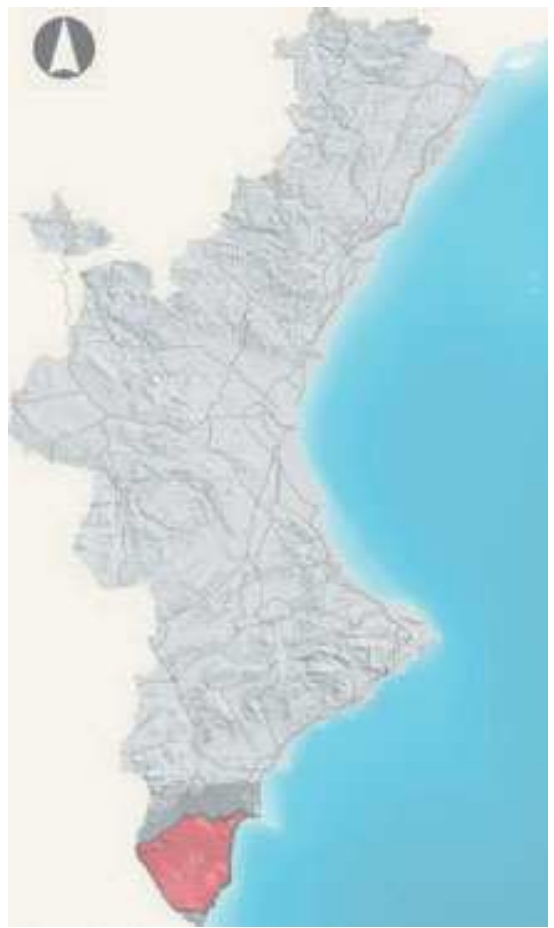

$\begin{array}{lr}\text { Población } & \mathbf{2 . 0 0 7} \\ \text { Albatera } & 11.102 \\ \text { Algorfa } & 3.645 \\ \text { Almoradi } & 17.945 \\ \text { Benejúzar } & 5.419 \\ \text { Benijófar } & 3.707 \\ \text { Bigastro } & 6.588 \\ \text { Callosa de Segura } & 17.423 \\ \text { Catral } & 8.105 \\ \text { Cox } & 6.414 \\ \text { Crevillente } & 28.172 \\ \text { Daya vieja } & 459 \\ \text { Dolores } & 6.954 \\ \text { Elche } & 222.422 \\ \text { Formentera del Segura } & 3.518 \\ \text { Granja de Rocamora } & 2.271 \\ \text { Guardamar del Segura } & 15.132 \\ \text { Jacarilla } & 1.957 \\ \text { Los Montesinos } & 4.284 \\ \text { Rojales } & 17.543 \\ \text { Orihuela } & 80.468 \\ \text { Pilar de la Horadada } & 20.338 \\ \text { Rafal } & 3.901 \\ \text { Redován } & 6.982 \\ \text { San Fulgencio } & 10.583 \\ \text { San Miguel de las Salinas } & 7.625 \\ \text { Santa Pola } & 29.221 \\ \text { Torrevieja } & 94.006\end{array}$

Fig. 5.1 Localizador y población de los términos municipales incluidos dentro del ámbito ampliado

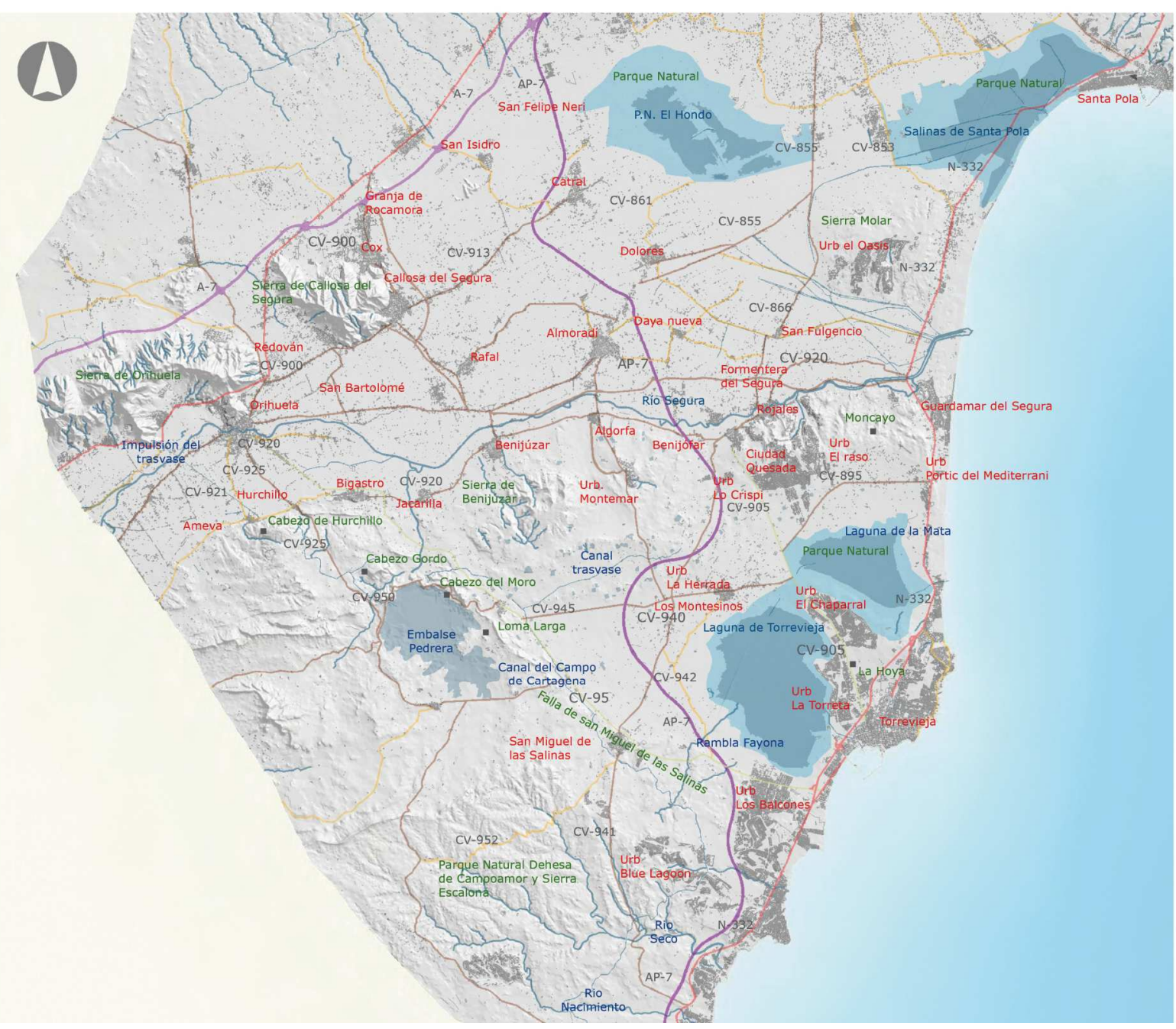

Fig. 5.2 Estructura básica territorial del ámbito ampliado (escala aproximada 1:400.000) 


\section{3.b. Análisis Territorial:}

\section{3.b.1. Geomorfología}

La fisiográfica de ámbito ampliado del estudio presenta un fuerte contraste entre las elevaciones montañosas pertenecientes al zócalo oriental bético y las extensas llanuras aluviales y lacustres asociadas al río Segura y a las lagunas del Fondo, Santa Pola y La Mata Torrevieja.

Las elevaciones fisiográficas emergen de forma abrupta de la matriz aluvial en las sierras de Orihuela y Callosa, y de forma menos remarcada, en la sierra del Molar, situada al sur de las Salina de Santa Pola, así como en la línea de falla situada entre Benejuzar y el norte de Torrevieja. En la zona sur del ámbito se localiza la falla de San Miguel de Salinas, al sur de la cual se extienden las Sierras de la Dehesa de Campoamor, con pequeños valles en dirección este-oeste y una zona elevada en la que se localiza el embalse de la Pedrera.

Concretamente, las lagunas de la Mata y Torrevieja se encuentran enmarcadas en una gran cuenca vertiente delimitada por un conjunto de formaciones montañosas que son producto del juego de las fallas del Bajo Segura al norte, y de San Miguel de las Salinas al sur.

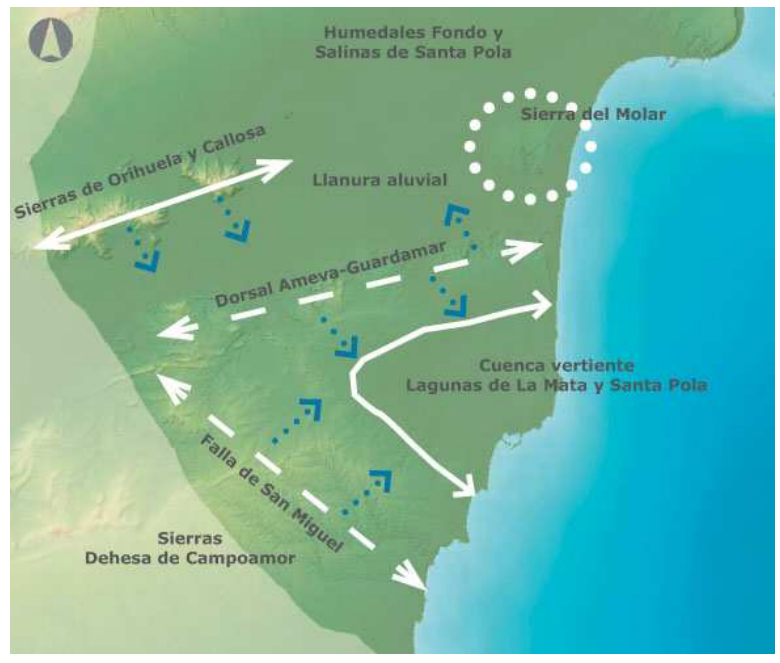

Fig. 5.3 Estructura topográfica básica del ámbito ampliado (escala aproximada $1: 600.000$ )

\section{3.b.2. Hidrología superficial}

El río Segura constituye el principal curso permanente de agua del ámbito ampliado del estudio. En su tramo final vertebra una extensa red de canales que permiten el riego de fértil llanura aluvial que se conecta a su vez con las planicies lacustres del Fondo y las Salinas de Santa Pola, en las que desemboca el río Vinalopó.

El caudal fuertemente variable del río Segura, hace que la mayor parte de las llanuras aluviales del Segura, presenten un riesgo de inundación alto o medio, fruto de lo cual, se ha realizado recientemente una adecuación de su cauce en la que se ha incluido la construcción de sendas motas en cada uno de sus márgenes y de unos recorridos que discurren por sus.

El ámbito ampliado del estudio presenta numerosas ramblas que fluyen de las sierras y elevaciones hacia el mar o hacia las llanuras aluviales y humedales. Por su relevancia cabe citar el río Nacimiento y río Seco, que fluyen desde la Dehesa de Campoamor hacia el mar o la rambla de la Fayona, que vierte formando un pequeño delta en la laguna de Torrevieja. Se observa que las ramblas han sido objeto de urbanización intensa en sus márgenes, perdiéndose con ello la oportunidad de generar conectores hacia el interior y de preservar espacios de alto valor ambiental y paisajístico.

La principales láminas de agua del ámbito ampliado del estudio se localizan en el Fondo, las Salina de Santa Pola, las lagunas de la Mata y de Torrevieja, separados por el anticlinal del Chaparral (33 m.s.n.m) y, como elemento de origen artificial, el embalse de La Pedrera, alimentado mediante impulsión desde el trasvase TajoSegura, y en el que se origina el canal del Campo de Cartagena. 
El carácter altamente intervenido de la llanura aluvial del Segura se manifiesta hidrológicamente en una extensa red de canales de distinto rango, entre los que se incluyen los elementos de conexión de los humedales del Fondo y las Salinas de santa Pola, el canal antes citado, del campo de Cartagena, y el canal que deriva las agua hacia las zonas agrícolas situadas en el entorno de Los Montesinos.

El riego, tradicionalmente realizado a manta, pero con una creciente introducción de los sistemas localizados, es administrado en su mayor parte por las comunidades de regantes de la margen derecha e izquierda del Segura, existiendo puntualmente zonas, como los campos al este de San Miguel de Salinas, en las que se riega mediante agua de pozo o proveniente de la depuradora de Torrevieja.

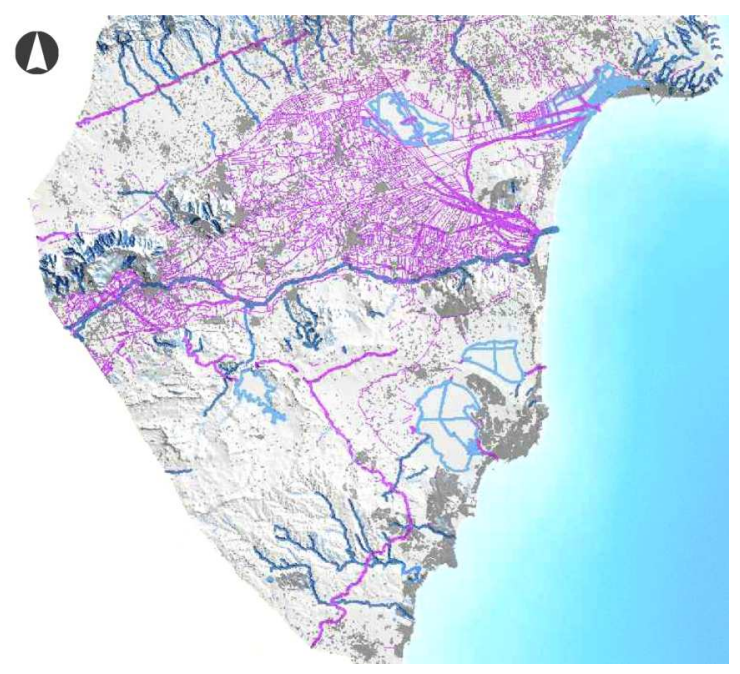

Fig. 5.4 Hidrografía básica del ámbito ampliado. En azul principales cursos naturales de agua, en violeta principales canales y azarbes (escala aproximada 1:600.000)

\section{3.b.3. Cubierta vegetal}

Las zonas elevadas y abruptas del relieve presentan mayormente una cubierta de matorral, que se acompaña de un estrato arbóreo (pinar) en la dehesa de Campoamor, al pie de las sierras de Orihuela y Callosa del Segura y en las laderas norte de algunas elevaciones de rango secundario. Por su extensión y relevancia cabe reseñar los pinares de repoblación situados en las dunas de Guardamar y en la cara norte del anticlinal del Chaparral, al sur de la Laguna de La Mata.

Por su singularidad y alto valor botánico destaca la vegetación halófila e hidrófila que se localiza en las orlas de las lagunas de La Mata, Torrevieja, el Hondo y las salinas de Santa Pola, y que se extiende, especialmente en lo referente a la vegetación palustre (puntualmente acompañada de arbolado frondoso de ribera), a lo largo de algunos canales, siendo sin embargo su presencia poco significativa en el corredor verde del propio río Segura.

La agricultura de regadío se localiza mayormente en las llanuras de la Vega Baja del Segura y del entorno de las Lagunas de la Mata y Torrevieja, observándose la presencia de frutales de secano en el entorno de San Miguel de Salinas y al sur del embalse de La Pedrera, si bien, en dichas zonas, se ha constatado una creciente implantación de frutales de regadío (cítricos) en extensas parcelas altamente tecnificadas.

Los cultivos de regadío antes citados, configuran un mosaico en el que se combinan cítricos y hortícolas / herbáceos, predominando los primeros en la zona situada entre Orihuela y Torrevieja y los segundos en la franja al sur del Parque Natural del Hondo. Entre ambas zonas se localiza una franja intermedia en el que coexisten ambos tipos de cultivos, con mayor presencia de los cítricos en el entorno de zonas urbanizadas.

Por su singularidad cabe destacar la presencia de hortícolas en los pequeños valles de la dehesa de Campoamor, configurando, junto con una envolvente de pinar, un paisaje de especial valor, así como los viñedos situados al este de la laguna de La Mata y los palmerales existentes en el entorno de el Hondo y al noreste de Orihuela.

Con carácter general, durante las últimas décadas se ha observado la creciente implantación del cítrico en las laderas de las formaciones montañosas que definen la orografía del ámbito de estudio, produciéndose una marcada modificación del relieve, y anticipando en muchos casos su posible urbanización. 


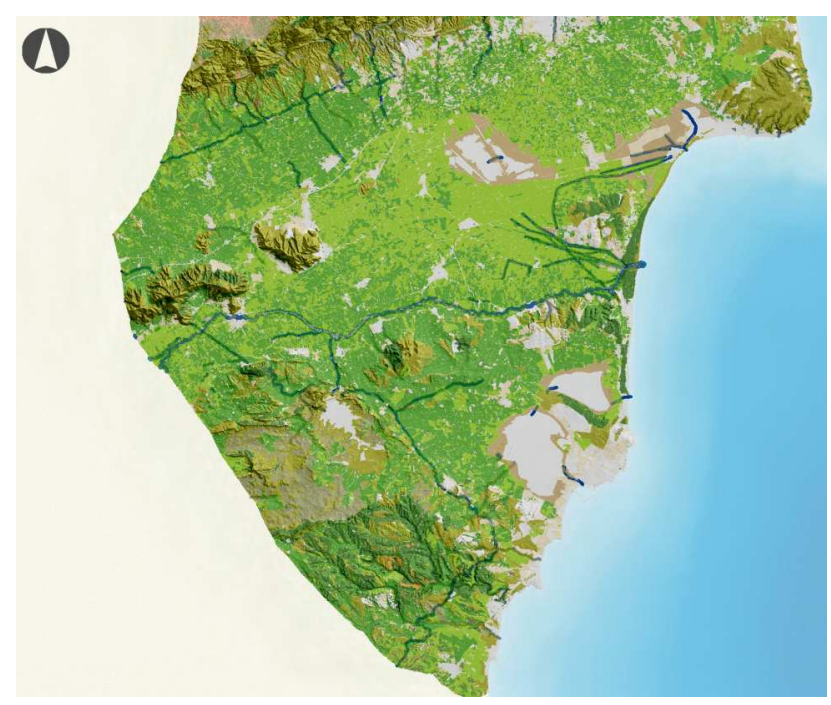

Fig. 5.5 Cubierta del suelo en el ámbito ampliado (escala aproximada 1:600.000)

\section{3.b.4. Infraestructuras de transporte}

Dos grandes ejes recorren de norte a sur la zona de estudio:

- En la zona litoral, la N-332 discurre entre las Lagunas de la Mata y Torrevieja y la costa. Atraviesa por tanto el núcleo poblacional de Torrevieja, actuando como límite a la urbanización junto al Parque Natural. Más al norte, atraviesa las dunas de Guardamar hasta su encuentro con las Salinas de Santa Pola.

- La autovía AP-7 atraviesa en diagonal y de norte a sur el ámbito ampliado dejando en su margen este el parque natural de las Lagunas de La Mata y Torrevieja y la población de los Montesinos y cruzando en su recorrido zonas dedicadas fundamentalmente al cultivo de cítricos.

- En el límite oeste discurren la N-340 y la autovía A7, conectando diversas poblaciones de gran importancia como Orihuela, Albatera y Crevillente.

En cuanto a las conexiones este-oeste cabe destacar:

- La CV-95, que discurre a los pies de las formaciones montañosas de los altos de San Miguel, conectando las poblaciones de Torrevieja, San Miguel de las Salinas, Bigastro y Orihuela.

- La CV-910, que conecta con la N-332 a la altura de Guardamar del Segura y discurre de este a oeste hasta Orihuela. Su trazado en su tramo oriental discurre paralelo al río Segura, del que se separa junto a la localidad de Rojales para pasar a discurrir entre campos de cítricos hasta su encuentro con la población de Orihuela.

Destaca a su vez la carretera CV-905, que conecta la población de Torrevieja con Benijofar, y que transita en su tramo final entre las laguna de la Mata y Torrevieja, conectando en su recorrido diferentes núcleos urbanizados que se han ido conformando en sus márgenes. Se establece de esta forma un triángulo de conexión perimetral ocupado en sus vértices por las poblaciones de Orihuela, Guardamar del Segura y el sur de Torrevieja, conformado por la autopista AP7 y las carreteras CV-905 y N332, y que engloba un gran número de núcleos poblacionales, conectados entre sí por medio de carreteras de menor orden y por caminos rurales.

El ámbito ampliado del estudio presenta a su vez una extensa red de caminos y carreteras secundarias de alto valor escénico que discurren por las zonas montañosas o en el entorno de el Hondo y las salinas de Santa Pola.

La calidad visual en los accesos urbanos desde las infraestructuras es por lo general muy deficiente, con una fuerte implantación de zonas industriales, urbanizaciones de distinta densidad, y "túneles edificados" entre los pueblos de la margen norte del Segura. Dicho carácter continuo de la edificación a lo largo de las infraestructuras del transporte se hace especialmente notable en la franja litoral, desde Torrevieja a Pilar de la Horadada.

La presencia de infraestructuras ferroviarias en el ámbito del estudio es casi nula a falta de la posible puesta en marcha del corredor férreo costero, recogido en el PAT del Litoral. Existe por el contrario una vía verde en las trazas del antiguo acceso a Torrevieja. Dicha vía presenta en algunos tramos una sección escasa y tiene pendiente la resolución de su continuidad al norte del río Segura. 


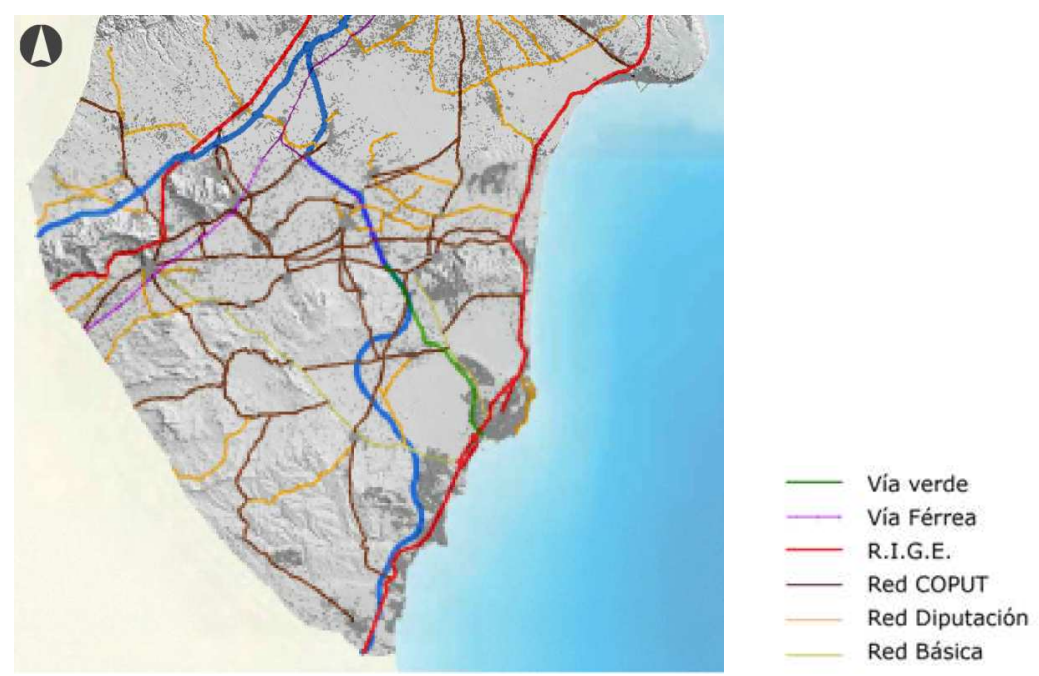

Fig. 5.6 Sistema de infraestructuras de transporte en el ámbito ampliado (escala aproximada 1:600.000)

\section{3.b.5. Asentamientos humanos}

El estudio de la ubicación de yacimientos arqueológicos y de elementos del patrimonio arquitectónico pone de manifiesto la histórica presencia de pueblos y ciudades en la zona costera y en las cotas no inundables situadas a los pies de las sierras de Callosa y de Orihuela así como en las elevaciones situadas al sur del río Segura. Dicho patrón de asentamientos adosados a las elevaciones del relieve ha cambiado sin embargo notablemente durante las últimas décadas, dando paso a un crecimiento de los núcleos urbanos situados en la llanura aluvial del río Segura y, especialmente, de los situados en el frente litoral.

Paralelamente al crecimiento de las ciudades y pueblos existentes, se ha constatado la proliferación de urbanizaciones de baja y media densidad, preferentemente en zonas de ladera, con su consiguiente incidencia en el paisaje. Dichas urbanizaciones han ido acompañadas de la construcción de una densa red de infraestructuras de transporte y, salvo escasas excepciones, han fragmentado altamente el territorio e ignorado elementos esenciales para su adecuado funcionamiento hidrológico y ecológico. Esta situación resulta especialmente crítica en el entorno del Parque Natural de las lagunas de la Mata y Torrevieja y en la sierra Molar, donde, el carácter llano de las zonas que rodean las nuevas urbanizaciones, hacen que éstas últimas tengan una fuerte intrusión visual en espacios protegidos o de gran valor.

Igualmente, se constata la proliferación de polígonos industriales y continuos edificados de baja calidad a lo largo de las carreteras que conectan los pueblos de la margen norte del Segura, generándose una percepción desproporcionada de ocupación urbana del territorio e impidiendo la percepción del paisaje agrícola que predomina en dicha zona. Dicha situación se multiplica de forma exponencial en la franja costera, en la que se ha configurado un continuo edificado de 10 kilómetros en el que se suceden zonas de uso residencial y servicios.

El ámbito ampliado del estudio presenta a su vez zonas con edificación dispersa no programada que, si bien en un pasado estuvo asociada a construcciones de carácter rural, dio paso a segundas residencias fuera de ordenación. 


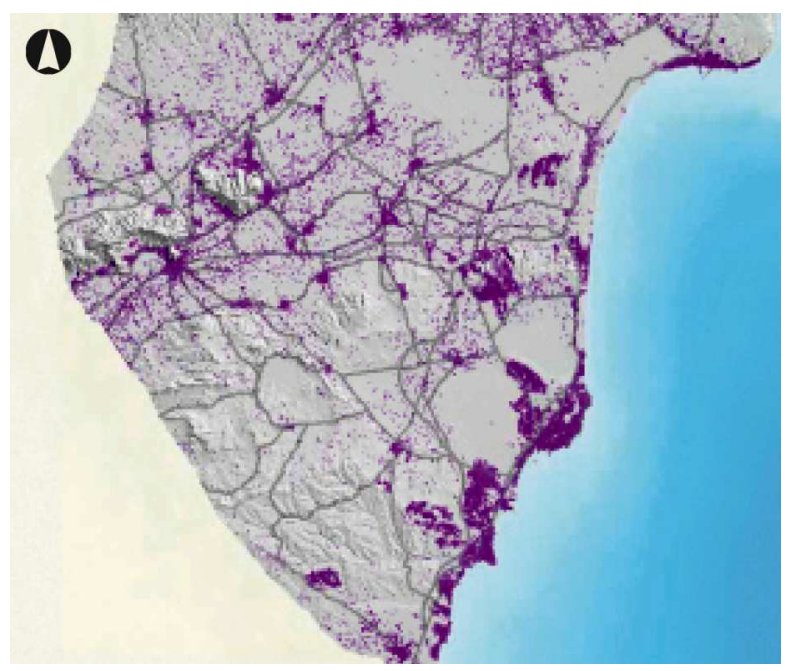

Fig. 5.7 Desarrollos urbanos en el ámbito ampliado (escala aproximada 1:600.000)

\section{3.b.6. Usos del suelo y planeamiento}

El planeamiento considerado a efectos de realización del estudio ha incluido el Plan de Ordenación de los Recursos Naturales (PORN) del Sistema de Zonas húmedas del Sur de Alicante, los Planes Rectores de Uso y Gestión de los parques naturales de las lagunas de La Mata y Torrevieja, El Hondo y las Salina de Santa Pola, el Plan de Acción Territorial del Litoral de la Comunidad Valenciana (pendiente de aprobación), así como la información referente a Planeamiento de la Comunidad Valenciana elaborada en 1998 por la Consellería de Obras Públicas, Urbanismo y Transporte. Dicha información sintetiza las clasificaciones y calificaciones del suelo en la citada comunidad y ha sido actualizada con los Planes Generales de Ordenación Urbanística (PGOU’s) de algunos de los municipios en estudio y la identificación en fotografías aéreas de las infraestructuras y urbanizaciones más recientes.

A efectos de usos del suelo se ha consultado la cartografía temática de la Generalitat valenciana y una ortofoto del año 2007.

Se observa un desigual uso del suelo según los términos municipales, con un incremento notable del suelo urbanizado en todos ellos, un incremento de las superficies dedicadas a frutales de regadío (básicamente cítricos) y un descenso de las zonas dedicadas a cultivo de secano. Las zonas forestales se extienden en zonas agrícolas de secano en abandono y pierden superficie debido a la creación de urbanizaciones y campos de golf en zonas de relieve montañoso. La superficie ocupada por infraestructuras aumenta notablemente a raíz de la construcción de la autovía AP-7, de la nueva carretera de conexión entre Cox - Callosa del Segura y Rafal y la ampliación de la carretera N-332. Con el objeto de prever la evolución futura se ha consultado a su vez el Plan de Infraestructuras Estratégicas (2004 - 2010) de la Comunidad Valenciana (PIE).

El fuerte incremento en población residente y temporal de la zona ha ido acompañada de la creación de nuevos equipamientos, dotaciones y zonas de servicios, que se concentran especialmente en Orihuela (nivel 5 en la jerarquía urbana definida en las Estrategias de Vertebración Territorial de la Comunidad Valenciana) y Torrevieja (nivel 6).

Dadas la superficies cubiertas por lagunas y humedales y las amplias zonas urbanizadas, el porcentaje de Superficie Agraria Útil (SAU) por municipio es muy baja en Torrevieja y Santa Pola $(<15 \%)$. Dicho índice adquiere un valor medio (51-75\%) en Elche, Guardamar, San Fulgencio, Rojales, San Miguel de Salinas y Orihuela y alta $(>75 \%$ ) en Los Montesinos y pueblos de la parte interior de la margen norte del Segura.

De forma general se constata una alta fragmentación del territorio como consecuencia principalmente de la construcción de nuevas urbanizaciones e infraestructuras, una fuerte presencia de usos mixtos del suelo (residencial-industrial), especialmente a lo largo de las infraestructuras de transporte así como la presencia de importantes bolsas de espacios naturales y agrícolas, susceptibles de generar los elementos primarios del sistema de espacios abiertos del sur de la provincia de Alicante. 


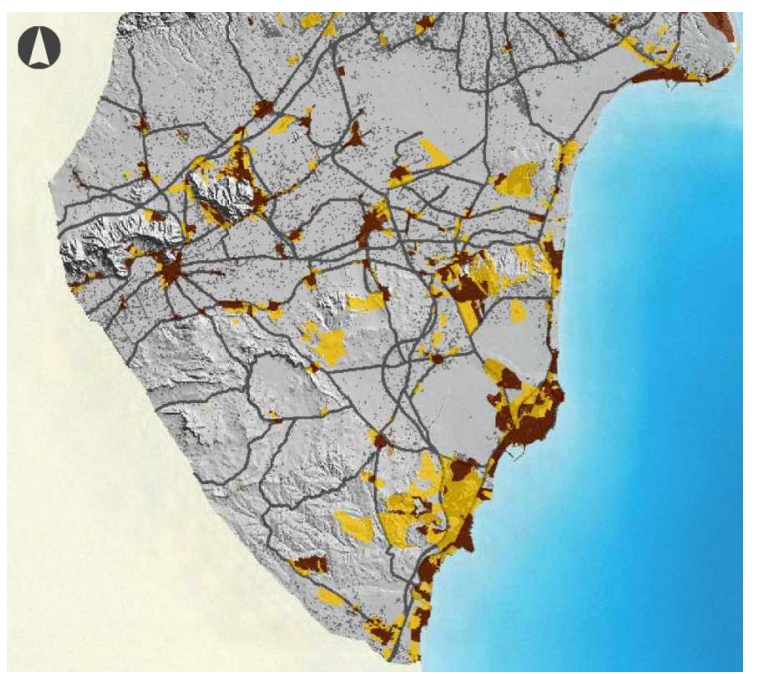

Suelo urbano

Suelo urbanizable

Fig. 5.8 Suelo urbano (en marrón), urbanizable (en beige) y no urbanizable (en gris) en el ámbito ampliado (escala aproximada 1:600.000)

\section{3.b.7. Zonas protegidas y afecciones}

El ámbito ampliado del estudio incluye el Parque Natural de La Mata y Torrevieja (3700 has), situado en un entorno sometido a un fuerte proceso urbanizador, el parque Natural del Fondo (2387 has), una extensa zona húmeda con dos láminas principales de agua en la laguna de Poniente y de Levante, y el Parque Natural de las Salina de Santa Pola (2470 has), que incluye una alta diversidad de paisajes, entre los que se incluye el propio de las dunas costeras, las zonas de producción de sal o las lagunas interiores.

A diferencia de los tres parques anteriores, situados en amplias llanuras escasamente elevadas sobre el nivel del mar, el futuro Parque Natural de la Sierra de Escalona y la Dehesa de Campoamor, se extiende sobre una superficie de 4697 hectáreas de terrenos montañosos, densamente arbolados con un valor ornitológico excepcional.

Los montes de utilidad pública situados dentro del ámbito ampliado del estudio se localizan fundamentalmente en las sierras de Orihuela, Callosa de Segura, cara norte de la sierra Molar, en el pico de Moncayo, situado al noreste de la Laguna de La Mata, el cabezo de Hurchillo y en las dunas de Guardamar. Por su carácter público, constituyen espacios estratégicos para la definición del sistema de espacios abiertos del ámbito ampliado del estudio.

En lo referente a vías pecuarias, se observa que sus trazas han servido de base para la construcción de numerosas carreteras o han quedado absorbidas dentro de áreas urbanizadas. Este es especialmente el caso de la cañada del Mar, situada a lo largo de la costa o el de muchos de los cordeles, veredas y coladas. Dado el carácter de dominio público de dichas vías, se consideran de alta importancia para definir conectores del sistema de espacios abiertos, especialmente en caso de mantenerse libres de otros usos (caso de algunas vías pecuarias situadas en la dehesa de Campoamor, sierra de Escalona o entorno al embalse de la Pedrera).

Los dominios públicos hidráulicos constituyen el cuarto elemento de apoyo del sistema de espacios abiertos. En el ámbito de trabajo presentan un elemento primario en el río Segura, así como elementos secundarios en las ramblas que fluyen desde las sierras colindantes. Dichas ramblas han sido seccionadas frecuentemente por infraestructuras de transporte y urbanizaciones, lo que limita su uso como corredores ecológicos y de acceso peatonal a las zonas naturales. En lo referente al río Segura, las recientes obras de encauzamiento han generado una nueva sección con sendos viales ciclistas y peatonales sobre las motas que lo delimitan, si bien, dicha sección, de escasa anchura y pronunciados taludes, no facilita el desarrollo de arbolado de ribera y lo desvincula visualmente de las llanuras aluviales que lo rodean. Finalmente, los canales de riego y azarbes, algunos de ellos de gran sección y dotados de viales paralelos de mantenimiento, constituyen elementos con gran potencial e interés en la definición del citado sistema de espacios abiertos.

El quinto espacio considerado corresponde al dominio público marítimo, que establece uno de los pocos elementos continuos en un entorno, el litoral, altamente fragmentado. 
Se han incluido por último una serie de recorridos de alto interés entre los que se incluye el Camino del Cid, que, en el ámbito de trabajo, conectaba Orihuela con Callosa del Segura, Cox y Elche, dos PR (pequeños recorridos), un GR (gran recorrido), una vía verde, esencial para conectar por el interior el Parque Natural de la Mata y Torrevieja con el del Fondo y la antigua Vía Augusta, mayormente cubierta ahora por carreteras y zonas urbanizadas.
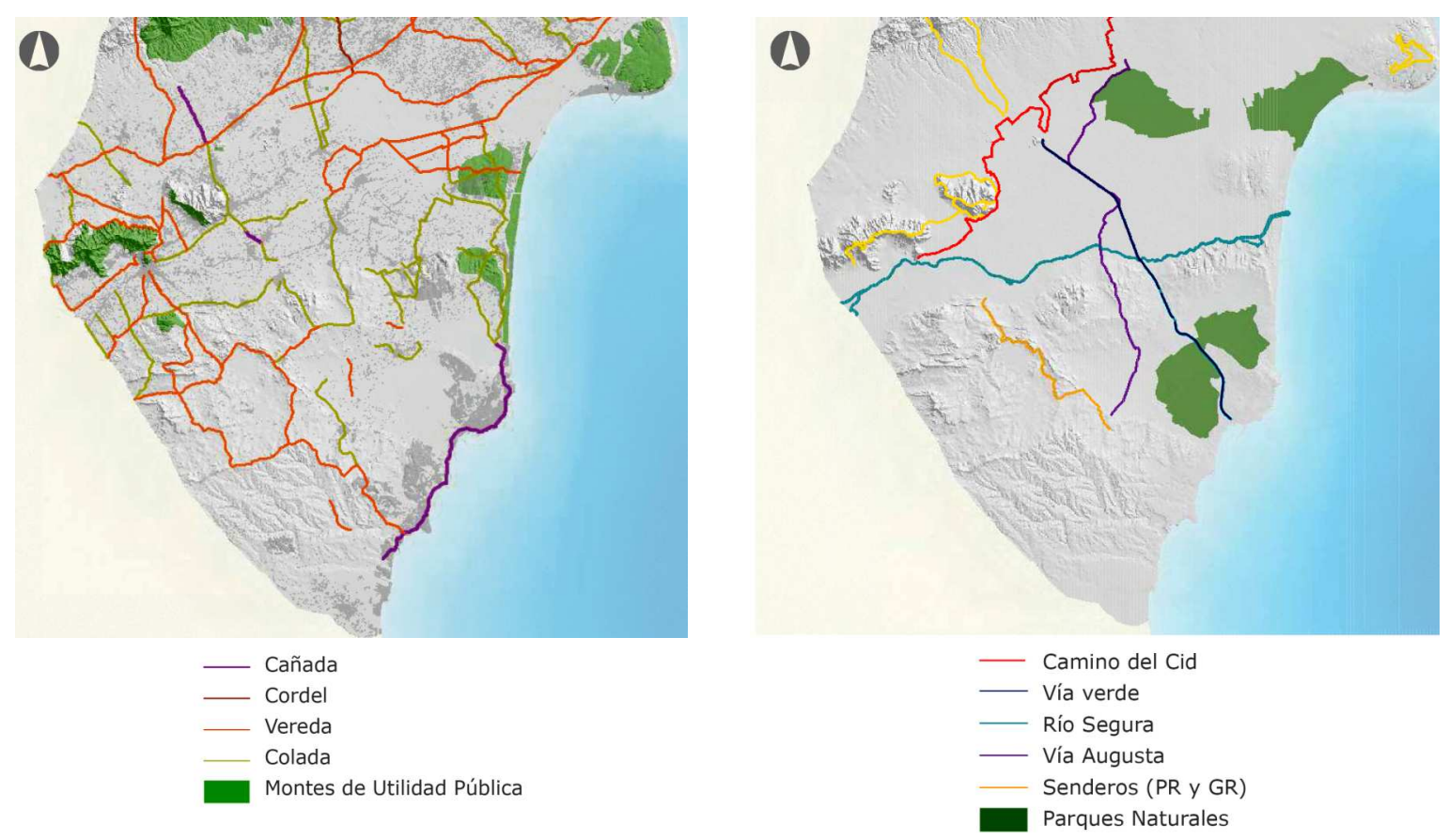

Fig. 5.9 Ámbito ampliado: Vías pecuarias y montes de utilidad pública (izquierda) y otros recorridos y parques naturales (derecha). (escala aproximada 1:600.000)

\section{3.c. Caracterización del Paisaje}

\section{3.c.1. Unidades de paisaje}

Para la determinación de las unidades de paisaje se ha atendido a los criterios expuestos en el capítulo 4 así como a aspectos vinculados a la gestión territorial. Por dicho motivo se han agrupado espacios fuertemente relacionados (sierras de Orihuela y de Callosa de Segura), se han unido elementos perceptivamente distintos pero fisiográficamente relacionados (colinas y valles de la dorsal Guardamar - Bigastro - Arneva) o se han integrado espacios que podrían precisar de programas de gestión y normativas similares (franja de cultivos hortícolas y herbáceos al sur del Fondo y las Salinas de Santa Pola).

Las unidades así definidas han sido caracterizadas de acuerdo a los criterios marcados en el capítulo de Métodos de la presente tesis exponiéndose seguidamente un listado de las mismas y un ejemplo de una de las fichas desarrolladas para cada unidad (ver la totalidad de fichas en el ANEXO III: Unidades de paisaje en el ámbito ampliado) 
VALORACIÓN Y GESTIÓN DEL PAISAJE SEGÚN EL CONVENIO EUROPEO DEL PAISAJE Y EL

REGLAMENTO DEL PAISAJE DE LA COMUNIDAD VALENCIANA: APLICACIÓN MEDIANTE UN ESTUDIO DE PAISAJE A UNESPACIO ABIERTO EN LA COMUNIDAD VALENCIANA

DOCTORANDO: JUAN JOSÉ GALÁN VIVAS (Universidad Politécnica de Valencia, enero 2011)

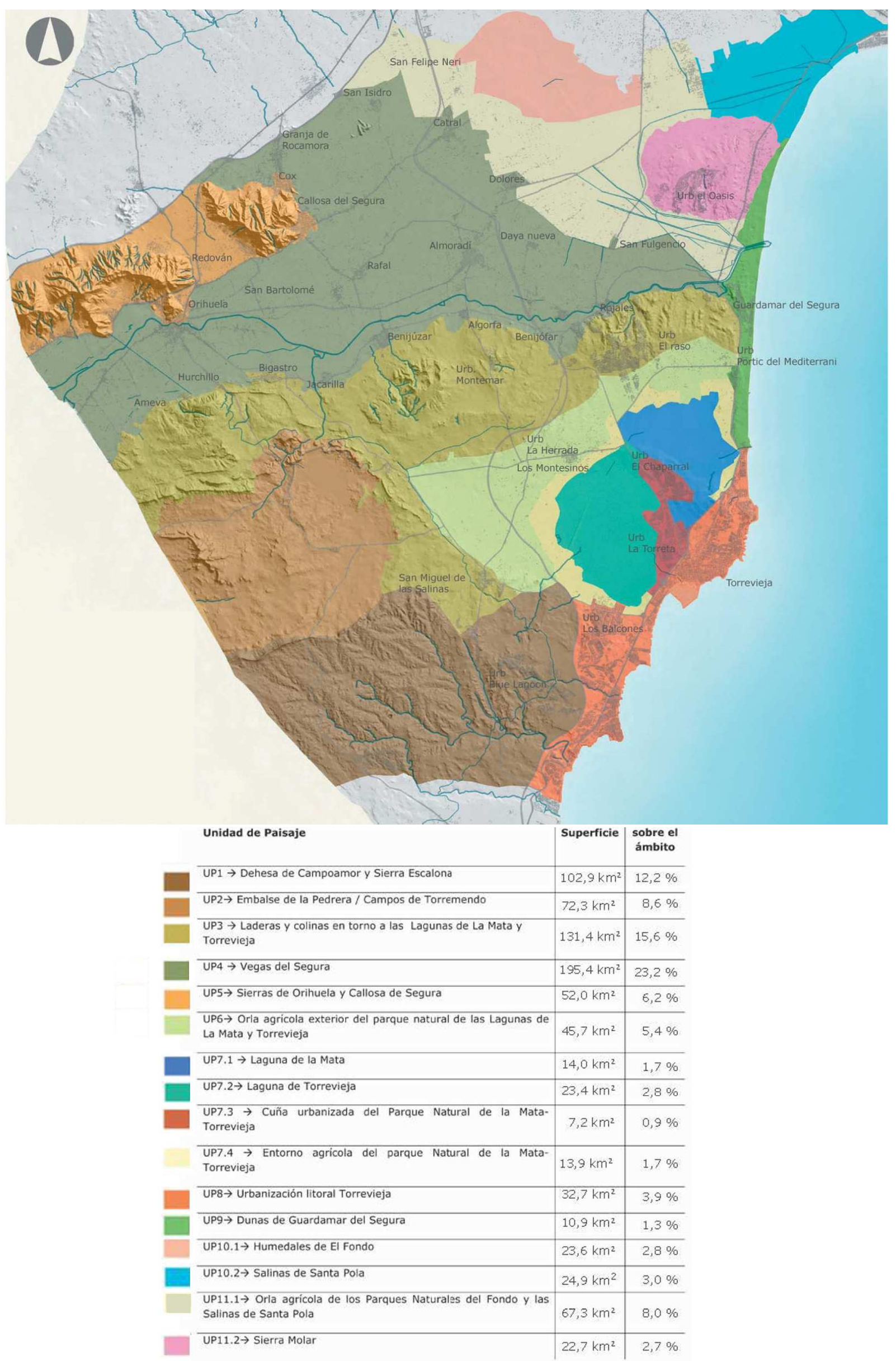

Fig. 5.10 Unidades de paisaje en el ámbito ampliado (escala aproximada 1:250.000) 


\section{UP6 ORLA AGRÍCOLA EXTERIOR DEL PARQUE NATURAL DE LAS LAGUNAS DE LA MATA Y TORREVIEJA}

1. Características Generales: Llanura agrícola situada a los pies de las elevaciones que cierran la cuenca endorreica de las Lagunas de La Mata y Torrevieja y que queda separada de éstas por una orla interior agrícola incluida en la Unidad de Paisaje $n^{\circ} 7$ y mayormente adscrita al ámbito del PORN de las Zonas Húmedas del Sur de Alicante. Históricamente poco urbanizada, presenta en la actualidad un único casco urbano, el de Los Montesinos, así como una incipiente proliferación de urbanizaciones que alcanzan unas dimensiones excesivas y que impactan severamente en el Parque Natural en la zona de Ciudad Quesada y en la urbanización del Raso

2. Elementos de caracterización:

a) Topografía: Zona llana a los pies de las elevaciones que circundan las lagunas de La Mata y Torrevieja.

b) Hidrología: Ramblas de pequeñas dimensiones y caudal que cobran más importancia en la cara norte de la laguna de La Mata. Presenta a su vez un canal de riego situado al oeste de la unidad que parte del embalse de La Pedrera y permite el riego de los campos de Los Montesinos

c) Cubierta vegetal: mosaico de cítricos y hortícolas

d) Estructura visual: Paisaje llano con vistas cercanas bloqueadas por las plantaciones de cítricos, entre las que se insertan edificaciones rurales poco perceptibles.

e) Usos del suelo: Predominancia del uso agrícola excepto en las zonas urbanizadas situadas al norte de la laguna de La Mata.

f) Construcciones y Edificación

a. Núcleos urbanos: Los Montesinos

b. Urbanizaciones: Nuevas urbanizaciones de baja y media densidad en la proximidad de la autovía AP7, y muy especialmente en la cara norte de la laguna de La Mata.

c. Edificación dispersa: Presente pero poco visible, fundamentalmente de uso agrícola.

d. Estructuras rurales construidas: poco relevantes

g) Infraestructuras

a. Transporte: vías de comunicación concentradas en el corredor Orihuela - Torrevieja, en el eje de la autovía AP7 y en el eje de la carretera CV905

b. Hidráulica: Canales y balsas de riego

c. Energía: línea eléctrica de alta y baja tensión. Propuesta de tendido de nueva línea de media tensión entre Los Montesinos y la EDAR de Torrevieja

h) Parcelario rural: Agrupación parcelaria en curso

\section{Dinámicas del paisaje:}

a. Procesos naturales: Cierre de ramblas

b. Procesos antrópicos: Urbanización

c. Principales problemas: Urbanización de alto impacto en la cara norte de la Laguna de La Mata. Abandono de la actividad agrícola en zonas susceptibles de reclasificación urbanística. Pérdida del patrimonio arquitectónico y etnográfico. Acceso paisajísticamente deficiente a Los Montesinos. Cierre urbano de Montesinos en su fachada sur. Relación funcional entre la urbanización La Herrada y el casco urbano de los Montesinos. Presencia de líneas eléctricas en zonas verdes urbanizadas.

d. Principales recursos y oportunidades

i. Recursos paisajísticos ambientales: Pinada de Lo Meseguer, orla agrícola hacia el Parque Natura, área agrícola estratégica entre el pico Moncayo y la laguna de La Mata (Campico de Guardamar)

ii. Recursos paisajísticos culturales: antiguas casas rurales (Lo Reche, La Marquesa, etc), aljibes, torre medieval

iii. Recursos paisajísticos visuales: recorridos entre aljibes y casas rurales (Ruta de la Sal y Ruta de los Aljibes).

iv. Principales potencialidades: Existencia de una red de elementos culturales en la zona. Iniciativas para la rehabilitación de antiquos edificios y su adaptación a usos terciarios. Interés social y político en establecer un marco de planeamiento adecuado.

e. Acciones: Extender la Ruta de la Sal y de los Aljibes a otros términos municipales entorno al Parque Natural. Definir una infraestructura verde que permita conexiones internas verdes, aunque sea en contexto urbano, y que preserve el entorno visual desde el Parque Natural. Resolver el cruce de la vía verde por debajo de la autovía AP7.
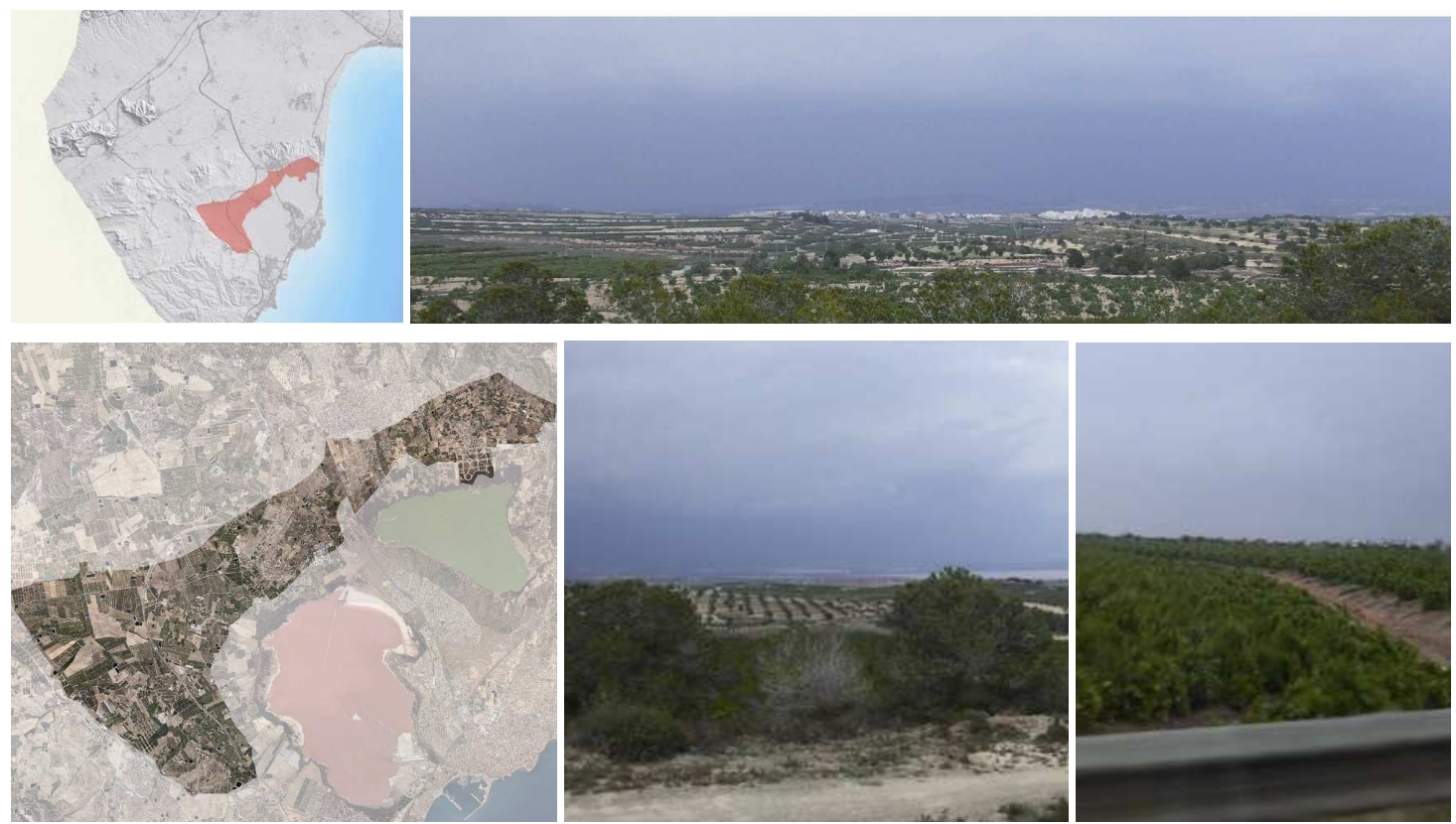

Fig. 5.11 Ficha de Unidad de paisaje en el ámbito ampliado 
Se procede a continuación a listar y localizar los recursos paisajísticos medioambientales, culturales y visuales identificados en el ámbito ampliado del estudio:

\section{3.c.2. Recursos paisajísticos medioambientales}

El sistema de espacios abiertos del Sur de Alicante debería integrar los espacios y elementos de mayor interés medioambiental. Dichos espacios y elementos deben incluir, de acuerdo al Reglamento de Paisaje de la Comunidad Valenciana, "Ias áreas o elementos que gocen de algún grado de protección, declarado o en tramitación, de carácter local, regional, nacional o supranacional; el dominio público marítimo y fluvial; así como aquellos espacios que cuenten con valores acreditados por la Declaración de Impacto Ambiental y las áreas o elementos del paisaje altamente valoradas por la población por su interés natural'

Dentro del ámbito ampliado del Estudio se han incluido:

- Todos los espacios con algún grado de Protección ambiental, que en el ámbito ampliado del presente estudio incluyen:

- Parques Naturales de la Comunidad Valenciana (se consideran los ámbitos marcados por el PORN del Sistema de Zonas Húmedas del sur de Alicante):

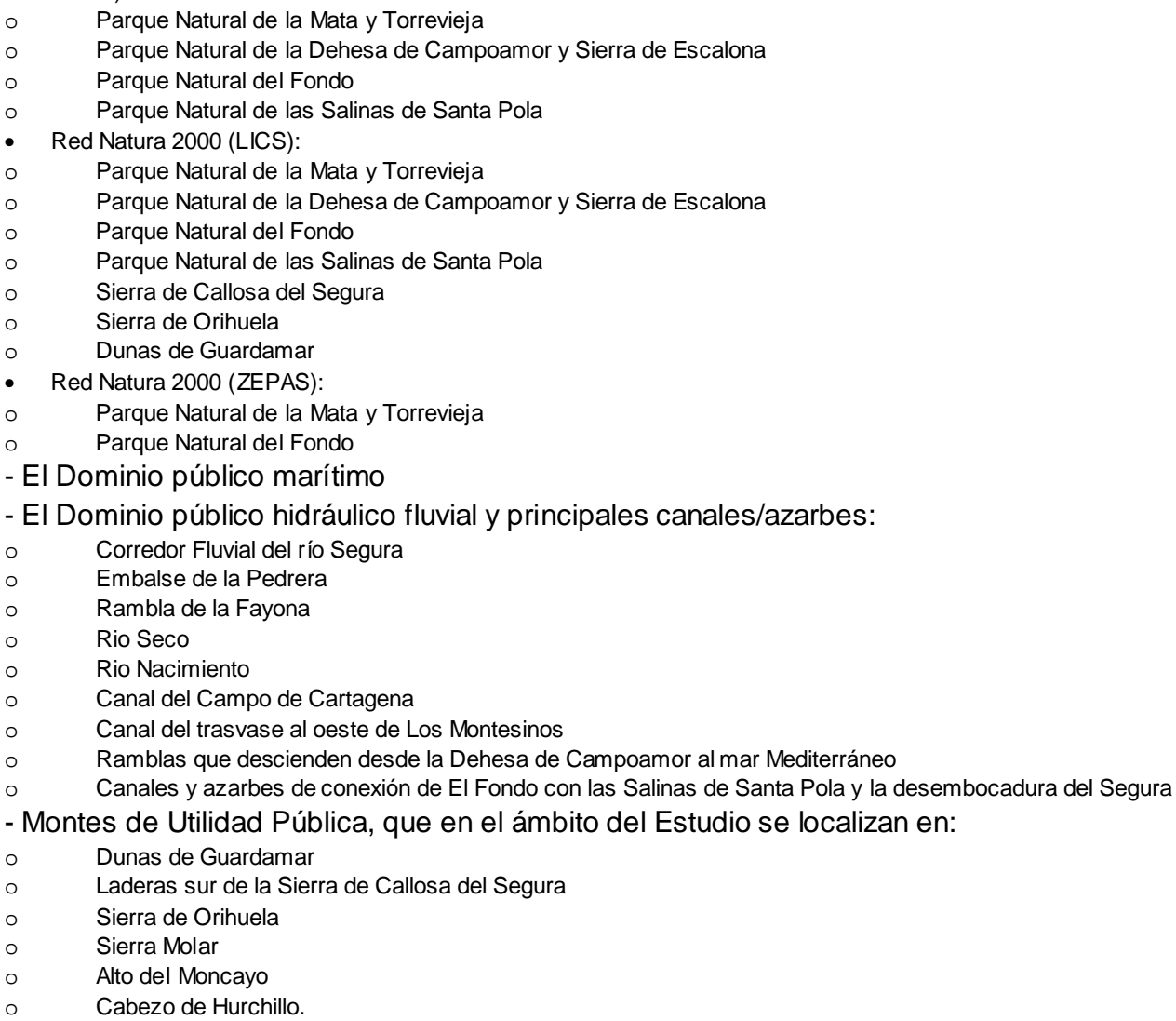

- Vías Pecuarias (cañadas, coladas, veredas y cordeles): mayormente ocupadas por carreteras o incluidas en zonas urbanizadas.

- Elementos o espacios singulares:

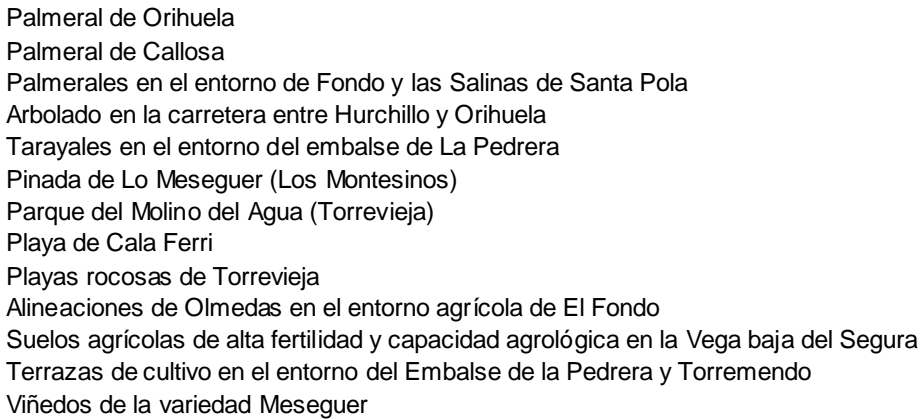




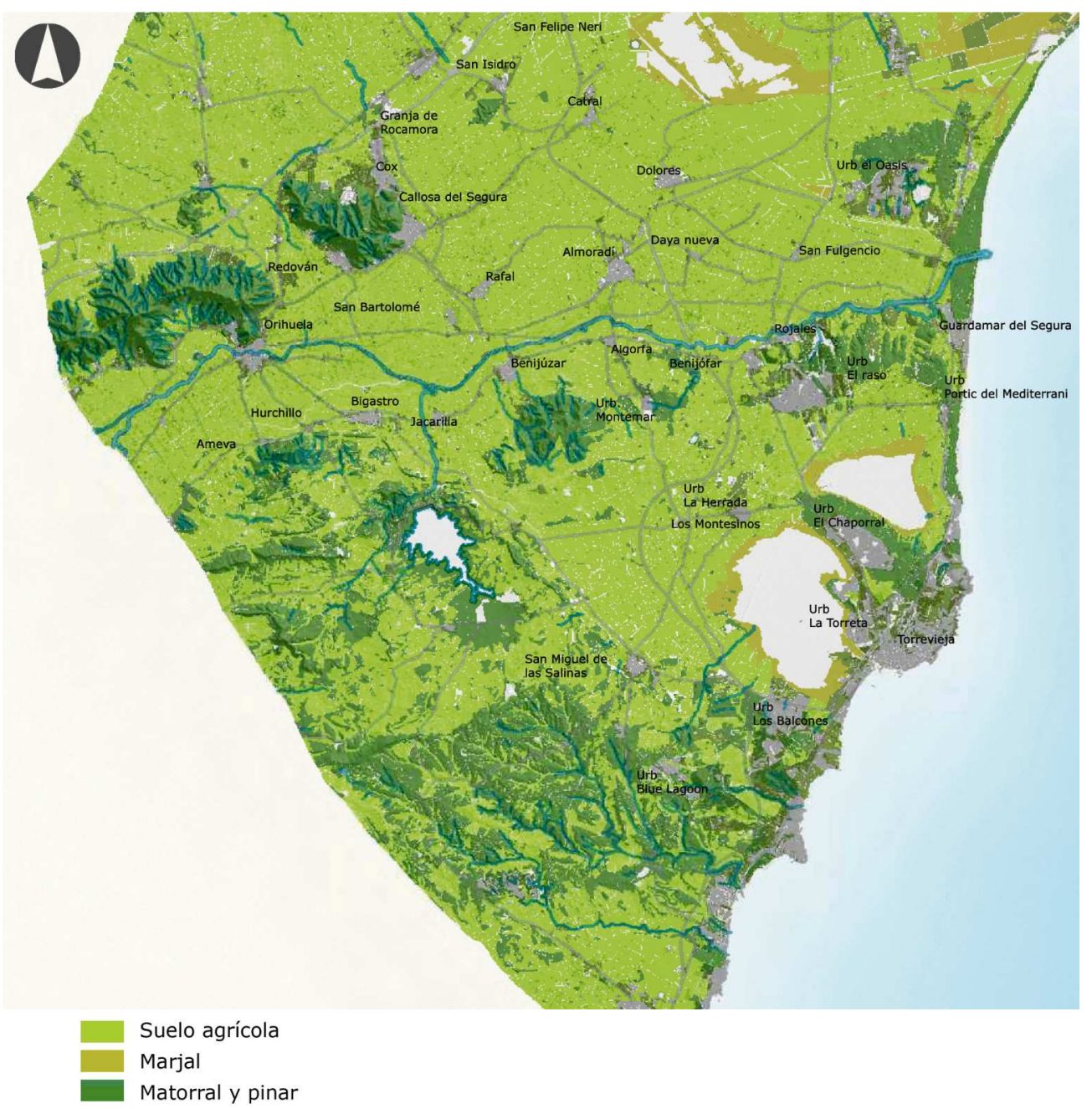

Fig. 5.12 Principales tipos de vegetación en el ámbito ampliado (escala aproximada 1:300.000)

\section{3.c.3 Recursos Paisajísticos Culturales}

El sistema de espacios abiertos del sur de Alicante debería integrar los espacios y elementos de mayor interés cultural. Dichos espacios y elementos deben incluir, de acuerdo al Reglamento de Paisaje de la Comunidad Valenciana, "las áreas o los elementos con algún grado de protección, declarado o en tramitación, de carácter local, regional, nacional o supranacional y los elementos o espacios apreciados por la sociedad local como hitos en la evolución histórica y cuya alteración, ocultación o modificación sustancial de las condiciones de percepción fuera valorada como una pérdida de los rasgos locales de identidad o patrimoniales".

Se observa una clara concentración de recursos culturales en los pies de ladera de las sierras y elevaciones que circundan la Vega Baja del Segura (sierra de Orihuela, sierra de Callosa del Segura, dorsal Guadamar del Segura- Bigastro), así como en el frente costero, y en el entorno.

Dentro del ámbito del Estudio se han identificado:

\section{Termino Municipal de Orihuela:}

- SEMINARIO DIOCESANO DE SAN MIGUEL

- PALACIO DE LA GRANJA. Conjunto histórico artístico. BIC Conjunto Histórico

- BIBLIOTECA PÚBLICA Y ARCHIVO HISTÓRICO FERNANDO DE LOACES .BIC Monumento

- CASTILLO RUINAS GLORIOSAS. BIC Monumento

- CONVENTO DE SANTO DOMINGO. BIC Monumento

- IGLESIA CATEDRAL DEL SALVADOR Y SANTA MARÍA . BIC Monumento

- IGLESIA DE LAS SANTAS JUSTA Y RUFINA . BIC Monumento

- IGLESIA PARROQUIAL DE SANTIAGO EL MAYOR . BIC Monumento

- MONASTERIO DE LA VISITACIÓN RR. SALESAS . BIC Monumento

- PALACIO DE RUBALCAVA. BIC Monumento

- PALACIO EPISCOPAL. BIC Monumento

- SANTUARIO DE NTRA. SRA. DE MONSERRATE . BIC Monumento

- TEATRO-CIRCO. BIC Monumento 
- TORRE CABO ROIG. BIC Monumento

- TRAMO DE MURALLAS. BIC Monumento

- PALMERAL DE SAN ANTÓN. BIC Sitio Histórico

- LOS SALADARES. BIC Zona Arqueológica

- CARRETERA PAVIMENTADA CON ADOQUIN ENTRE HURCHILLO Y ORIHUELA

\section{Termino Municipal de Torrevieja:}

- ACEQUION DE TORREVIEJA Y PUENTE ROMANO

- CANAL DE LA MATA

- INSTALACIONES DE LA INDUSTRIA SALINERA

- PARROQUIA DE LA INMACULADA CONCEPCIÓN.

- CONJUNTO HISTORICO MONUMENTAL "ERAS DE LA SAL" Y "EMBARCADERO" . BIC monumento

- IGLESIA DE NUESTRA SEÑORA DEL ROSARIO. BIC Monumento

- SOCIEDAD CULTURAL CASINO DE TORREVIEJA. BIC Monumento

- TORRE DEL MORO. BIC Monumento

- TORRE LA MATA. BIC Monumento

- PARQUE DEL MOLINO DE AGUA

- BALNERARIO

Termino Municipal de Guardamar del Segura:

- RÁBITA CALIFAL DE LAS DUNAS. BIC Monumento

- CASTILLO DE GUARDAMAR (Y ANTIGUA VILLA) . BIC Monumento

- MURALLA Y FORTALEZA FENICIA. BIC Monumento

- YACIMIENTO IBÉRICO CABEZO LUCERO. BIC Monumento

Termino Municipal de Rojales:

- CUEVAS DE ROJALES

- MOLINO DE AGUA

- PUENTE DE PIEDRA

- Termino Municipal de Formentera del Segura:

- NORIA Y MOLINO DE AGUA

Termino Municipal de Callosa de Segura:

- IGLESIA DE SAN MARTIN. BIC Monumento

- EMITA DE SAN ROQUE

- ERMITA DEL ROSARIO

Termino Municipal de Cox:

- CASTILLO

- IGLESIA de SAN JUAN BAUTISTA

Termino Municipal de Crevillente:

- IGLESIA DE SAN FELIPE NERI

Termino Municipal de Santa Pola:

- TORRE DE TAMARIT. BIC Monumento

Conjunto de casas rurales en el entorno del Parque natural de la Mata y Torrevieja:

- CASA DE LA CORONELA

- CASA DE LO TIMOR

- CASA DEL PURGATORIO

- CASA DE LOS RECHE

- CASA DE LA MARQUESA

- CASA DE MORALES

- CASA DE LA CISTERNA

- CASA DE LOS BLANC

- CASA DEL RELOJ

- CASA LO ROMERO

- CASA DE LA LOMA

- CASA DE LA MÁQUINA

- CASA DE FALT

- CASA DEL RASO

- CASA FORESTAL

- CASA DE SALA 


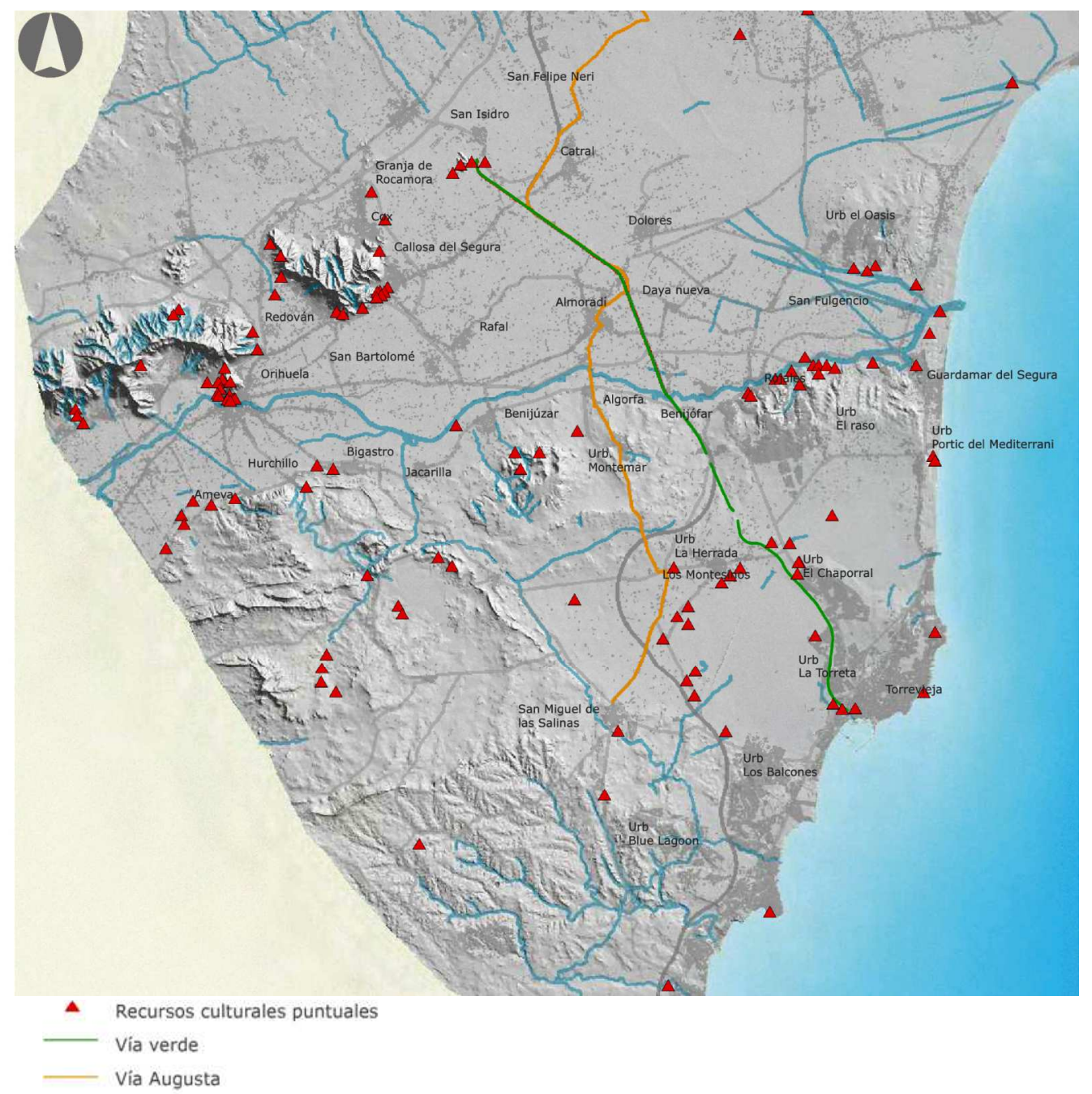

Fig. 5.13 Recursos paisajísticos culturales en el ámbito ampliado (escala aproximada 1:300.000)

\section{3.c.4 Recursos Paisajísticos Visuales}

El sistema de espacios abiertos del sur de Alicante debería integrar los espacios y elementos de mayor interés visual. Dichos espacios y elementos han incluido los contemplados en el artículo 35 del Reglamento del Paisaje de la Comunidad Valenciana, quedando configurado el listado siguiente:

1. ELEMENTOS TOPOGRÁFICOS: Laderas, picos y crestas de las sierras de Orihuela, Callosa de Segura y Molar, falla de San Miguel de Salinas, dorsal Guardamar - Arneva, sierra de los Pinos, dorsal del cabezo del Moro-Loma Larga (cierre norte del embalse de la Pedrera), rio Segura, laminas de agua (EI Hondo, salinas de Santa Pola, lagunas de la Mata y Torrevieja, embalse de La Pedrera.

2. ELEMENTOS Y ÁREAS CONSTRUIDAS: Centro Histórico y construcciones históricas en cotas altas de Orihuela, Callosa y Cox; Castillo de Guardamar; torre Tamarit, aldea de San Felipe Neri, salinas de Santa Pola y de Torrevieja, muelle de la Sal de Torrevieja, canales y azarbes del Hondo, salinas de Santa Pola y conexiones de éstas con la desembocadura del Segura.

4. PUNTOS de OBSERVACIÓN y RECORRIDOS PAISAJÍSTICOS:

- Miradores en elevaciones topográficas

- Carreteras escénicas:

- N332 a su paso por las Salinas de Santa Pola, las lagunas de La Mata y Torrevieja y la Dehesa de Campoamor

- Carreteras en el entorno del Fondo (CV9281 (acceso a San Felipe Neri desde Catral), CV 855 (acceso norte a Dolores), CV860 acceso norte a San Fulgencio).

- Carreteras en la Dehesa de Campoamor y Sierra Escalona (CV952 y CV941)

- Carretera del embalse de La Pedrera a Hurchillo y de Hurchillo a Orihuela (CV950 y CV925)

- Carretera Orihuela - Redovan - Callosa (CV900)

- Carretera San Miguel de Salinas - Bigastro (CV95)

- Recorridos escénicos:

- Vía Verde

- GR125, PRCV5, PRCV69

- Ruta del Cid

- Vía Augusta

5. VISTAS HACIA NÚCLEOS URBANOS: Vistas hacia Orihuela, Cox, Callosa del Segura y Rojales (ciudades en ladera) y San Felipe Neri.

6.- ÁREAS de AFECCIÓN VISUAL DESDE CARRETERAS: Se considera especialmente las vistas desde la nueva autovía AP-7, principal infraestructura de transporte del área de estudio. 


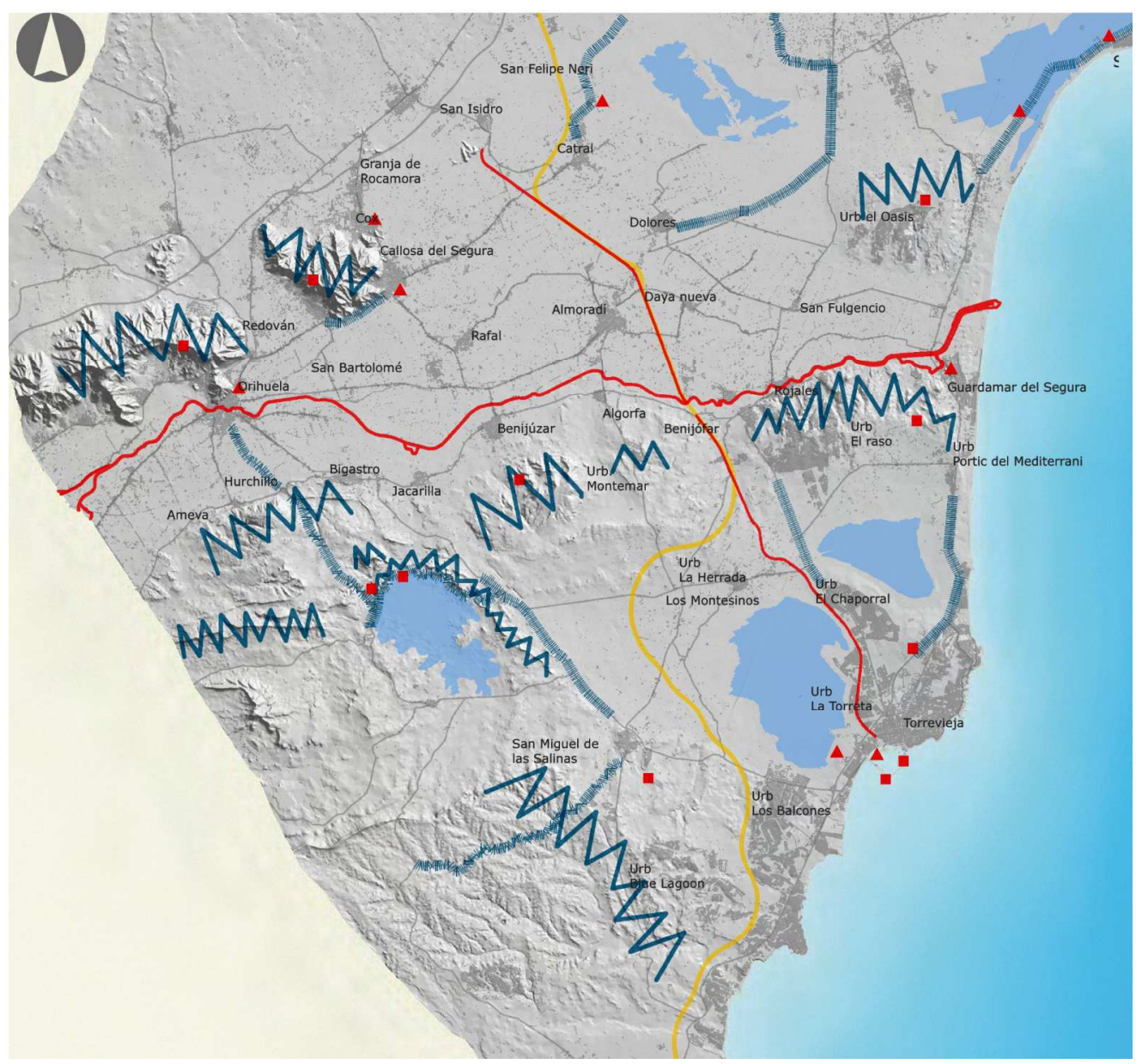

\footnotetext{
A Recursos visuales_Elementos construidos

- Miradores al Paisaje

Recorridos escénicos

Crestas

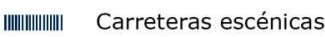

Autopista_AP7

Láminas de agua
}

Fig. 5.14 Recursos paisajísticos visuales en el ámbito ampliado (escala aproximada 1:300.000)

\section{3.d. Sistema de Espacios Abiertos.}

\section{3.d.1 Definición.}

El sistema de espacios abiertos propuesto tiene un carácter regional y ha sido definida para una escala de trabajo de 1:50.000. Constituye por lo tanto una red de carácter primario que serviría de elemento estructural para la definición de sistemas de espacios abiertos de carácter local.

- Superficie del Ámbito Ampliado del Estudio: 843,5 km2

- Superficie del sistema de espacios abiertos propuesto: $541,3 \mathrm{~km} 2(64,0 \%)$

En la definición de la Sistema de espacios abiertos se han seguido los siguientes criterios (ver códigos de ubicación de las aéreas afectadas por cada criterio en la figura 5.15.

1) Incluir todos los espacios protegidos existentes en el ámbito de actuación, entre los que se incluyen 4 parques naturales, montes de utilidad pública y espacios de la Red Natura 2000. En el caso de los parques naturales del Fondo, Salinas de Santa Pola y Lagunas de La Mata y Torrevieja se han considerado los ámbitos definidos por el PORN del Sistema de Zonas Húmedas del Sur de Alicante.

2) Incluir las vías pecuarias (cañadas, cordeles, veredas y coladas), con especial atención a aquellas cuyas trazas discurren todavía en suelos no urbanizados o no utilizados para infraestructuras de transporte (caso de algunas vías pecuarias situadas en la dehesa de Campoamor, sierra de Escalona o entorno del embalse de la Pedrera). 
3) Incluir los espacios vinculados a dominios públicos hidráulicos, que en el ámbito concreto del estudio presentan en el río Segura un elemento de primer orden y que incorpora a su vez una extensa red de ramblas e infraestructuras lineales de riego. Algunas de las ramblas presentan una gran importancia ecológica y vertebran posibles corredores de gran importancia (caso de la rambla de La Fayona), a pesar de lo cual, han sido a menudo constreñidas por urbanizaciones e infraestructuras. Finalmente, los canales de riego, algunos de ellos de gran sección y dotados de viales paralelos de mantenimiento, constituyen elementos con gran potencial e interés en la definición del citado sistema de espacios abiertos.

4) Incluir el continuo del dominio público marítimo, ampliando la anchura del sistema de espacios abiertos litoral en caso de discurrir por tramos costeros no urbanizados.

5) Definir un corredor sobre la alineación de elevaciones que definen la dorsal Guardamar - Bigastro - Arneva y que constituye un espacio clave en la delimitación visual de la cuenca visual del Segura y de la cuenca endorreica de las lagunas de la Mata y Torrevieja. Dicho corredor presenta en la actualidad numerosas urbanizaciones, a través de las que discurrirían hilos del sistema de espacios abiertos y entre las que se dispondrían franjas amplias que evitarían la formación de un continuo urbanizado y que conectarían con el corredor del río Segura al este de Rojales, entre Benijofar y Algorfa y a lo largo de las ramblas y canales que desembocan en la margen sur del Segura entre Hurchillo, Jacarilla y Benijofar. En lo referente a la cara sur de la dorsal, se establecen conexiones con la laguna de la Mata a través del Campillo de Guardamar y entre Ciudad Quesada y la futura urbanización de El Raso.

6) Incorporar las tierras altas que rodean el embalse de La Pedrera y los campos situados en el entorno de Torremendo, generando de ese modo un amplio sector conectado con la sierra de Escalona y la dehesa de Campoamor.

7) Establecer un conector de primer orden entre la sierra de Orihuela y la sierra de Callosa de Segura, facilitando la permanencia de la actividad agrícola e impidiendo el cierre de orlas urbanizadas alrededor de ambas sierras y de la llanura situada entre ellas.

8) Incomorar como espacio de gran profundidad visual la franja agrícola de hortícolas y herbáceos de secano situada al sur del Hondo y las salinas de Santa Pola así como al sur de la sierra Molar (canales y azarbes de conexión del Hondo y la desembocadura del Segura).

9) Incluir el conjunto de la sierra Molar (salvo las zonas urbanizadas) como pieza clave para la conexión de las salinas de Santa Pola y el Hondo al río Segura y a las dunas de Guardamar.

10) Insertar cuñas del sistema de espacios abiertos en la ladera sur de la Sierra de Orihuela, evitando la formación de un continuo urbano a los pies de ésta y facilitando la conexión al río Segura.

11) Definir corredores visuales de 300 metros de anchura (longitud de la visual corta de acuerdo al Reglamento de Paisaje) a cada lado de los siguientes ejes:
a) Rio Segura
b) Autovía AP-7
c) Vía Verde
d) Autopista A7 (en su lado sur)

12) Evitar el cierre completo del continuo urbanizado litoral entre el norte de Torrevieja y las zonas urbanizadas costeras de Orihuela, incluyendo cuñas del sistema de espacios abiertos transversales a la línea de mar en las zonas siguientes:
a) Campico de Guardamar- Dunas de Guardamar
b) Canal de la Mata
c) Acequión de Torrevieja
d) Conexión EDAR-Desaladora de Torrevieja con el Mar Mediterráneo
e) Ramblas que descienden desde la Dehesa de Campoamor

13) Evitar la fusión de las urbanizaciones al noreste de la Dehesa de Campoamor con la urbanización Los Balcones.

14) Establecer conectores entre las lagunas de La Mata y Torrevieja a través del canal de Las Salinas y de la elevación de la Hoya (suelo urbanizable). 
15) Desarrollar corredores verdes en los principales canales provenientes del Embalse de la Pedrera y estudiar el uso público de sus viales de servicio (Canal del campo de Cartagena y Canal al noroeste de Los Montesinos).

16) Definir corredores verdes secundarios (100 - 200 metros de anchura) a lo largo de las siguientes vías de comunicación o Infraestructuras:
a) Canal de Impulsión entre la sierra de Orihuela y el embalse de la Pedrera
b) Carretera Hurchillo - Orihuela
c) Carretera Rafal - Callosa (dispone carril bici)
d) Conexiones de la Vía Verde con el Parque natural del Hondo a través de la población de Dolores

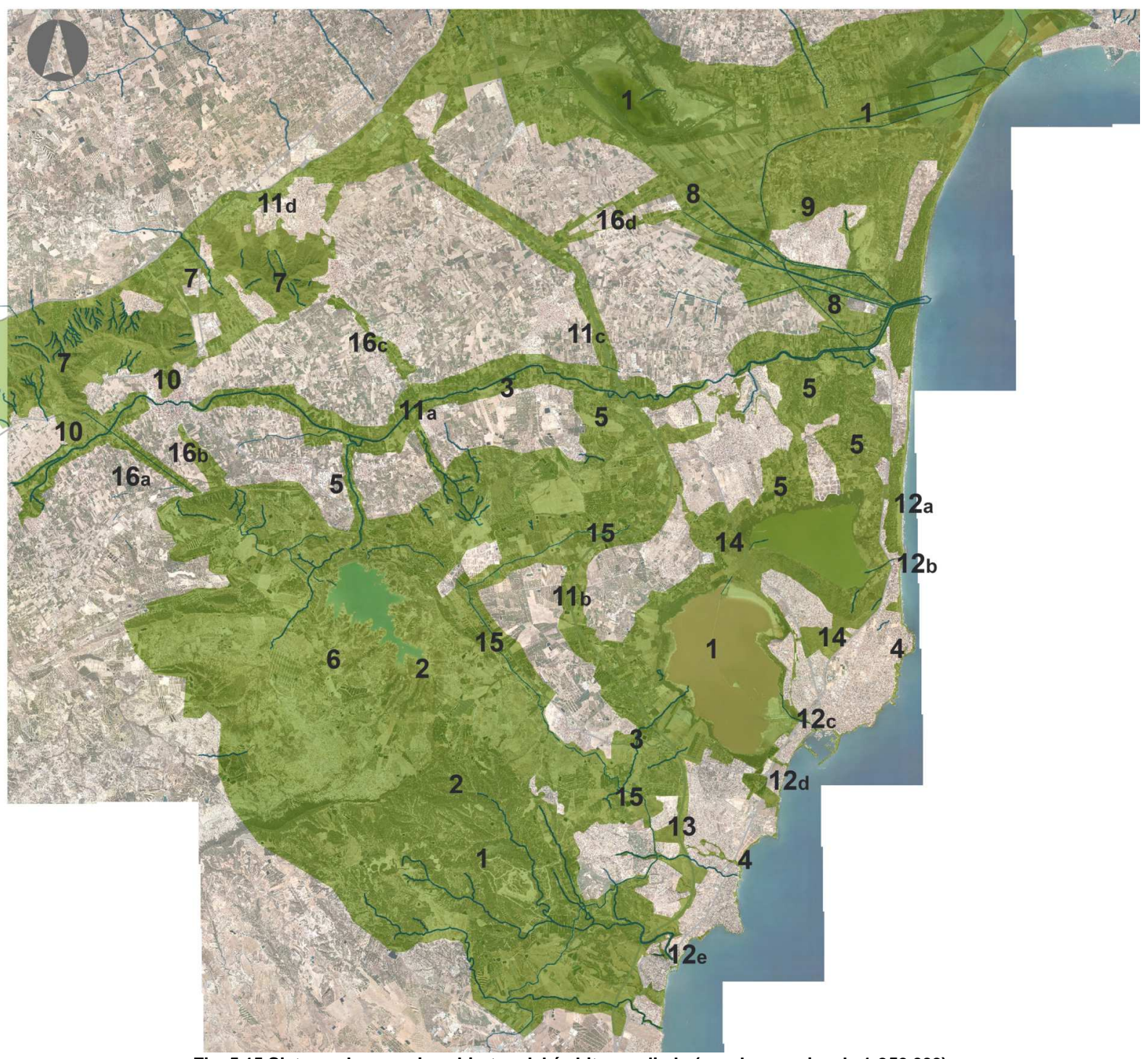

Fig. 5.15 Sistema de espacios abiertos del ámbito ampliado (escala aproximada $1: 250.000)$

El sistema de espacios abiertos así conformado presentaría una estructura con un anillo primario y tres anillos secundarios:
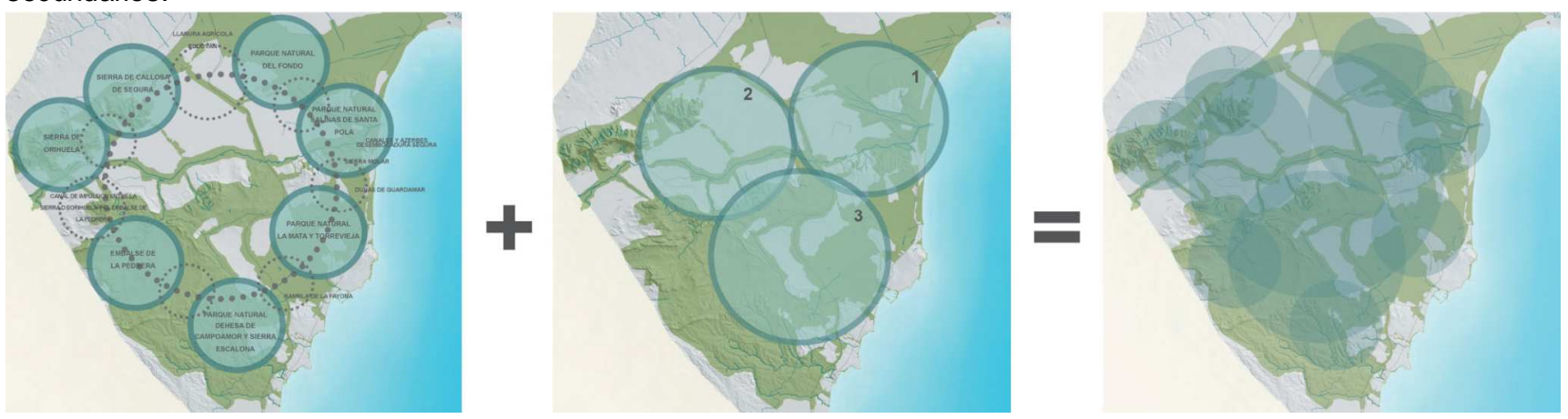

Fig. 5.16 Estructura básica del sistema de espacios abiertos del ámbito ampliado 


\section{Anillo primario (perímetro aproximado: $94 \mathrm{kms}$ ):}

- Elementos básicos:

- Parque Natural del Hondo

- Parque Natural de las salinas de Santa Pola

- Parque Natural de las lagunas de La Mata y Torrevieja

- Parque Natural de la dehesa de Campoamor y sierra Escalona

- Embalse de La Pedrera

- Sierra de Orihuela

- Sierra de Callosa de Segura

- Elementos de apoyo para el Cierre del anillo:

- Dunas de Guardamar

- Sierra Molar

- Canales y azarbes entre EI Fondo y la desembocadura del Segura

- Campico de Guardamar.

- Rambla de la Fayona

- Canal de impulsión entre la sierra de Orihuela y el embalse de la Pedrera

- Parque Natural de las salinas de Santa Pola

- Llanura Agrícola de Redovan

- Traza GR 125 y Camino del Cid

Anillos secundarios: se insertan en el previo y se apoyan en la Vía Verde y en el eje definido por el corredor del río Segura y la dorsal Guardamar Arneva.

- Anillo secundario 1 (perímetro 50 kms). Conecta los espacios siguientes:

- Parque Natural del Fondo

- Parque Natural de las Salinas de Santa Pola

- Sierra Molar

- Dunas norte de Guardamar

- Corredor del Segura - Dorsal Guardamar - Benijofar

- Vía Verde Benijofar - Dolores

- Corredor Dolores - parque Natural del Fondo

- Anillo secundario 2 (perímetro: 60 kms): Conecta los espacios siguientes:

- Parque Natural del Hondo

- Parque Natural de las salinas de Santa Pola

- Sierra Molar

- Dunas norte de Guardamar

- Corredor del Segura - Dorsal Guardamar - Benijofar

- Vía Verde Benijofar - Dolores

- Corredor Parque Natural del Hondo - Dolores

- Corredor de Segura Dorsal Benijofar - Hurchillo

- Corredor Hurchillo - Orihuela

- Sierra de Orihuela

- Llanura agrícola de Redován

- Sierra de Callosa del Segura

- Traza GR 125 y Camino del Cid

- Anillo secundario $\mathbf{3}$ (perímetro: $\mathbf{7 0}$ kms): Conecta los espacios siguientes:

- Parque Natural de las lagunas de La Mata - Torrevieja

- Rambla de la Fayona

- Parque Natural de la Dehesa de Campoamor y Sierra Escalona

- Embalse de La Pedrera

- Corredor del río Segura., Dorsal Hurchillo - Guardamar

- Campico de Guardamar. 


\section{3.d.2 Diagnóstico del sistema de espacios abiertos.}

a) Diagnóstico respecto a la diversidad de paisajes: El sistema de espacios abiertos propuesto para el sur de Alicante se extiende a lo largo de todas las unidades de paisaje definidas en el ámbito de estudio, posibilitando de este modo la apreciación y preservación de la diversidad paisajística de dicho ámbito.

Tal y como se indica en la tabla adjunta, en aquellas unidades en las que se estima necesario una mayor protección o capacidad de gestión del paisaje, la infraestructura se extiende cubriendo un mayor porcentaje parte de su territorio.

Tabla 5.1: Peso relativo de las distintas unidades de paisaje en el sistema de espacios abiertos del ámbito ampliado

\begin{tabular}{|c|c|}
\hline Unidad de Paisaje & \% en Sistema de Espacios Abiertos \\
\hline UP1_Dehesa de Campoamor y sierra Escalona & $15,3 \%$ \\
\hline UP2_Embalse de la Pedrera/ Campos de Torremendo & $12,6 \%$ \\
\hline UP4_Vegas del Segura & $10,1 \%$ \\
\hline UP5_Sieras de Orihuela y Callosa del Segura & $8,0 \%$ \\
\hline UP6_Orla agrícola exterior P.N. lagunas de La Mata y Torrevieja & $3,5 \%$ \\
\hline UP7.2_Laguna de Torrevieja & $4,3 \%$ \\
\hline UP7.3_Cuña urbanizada P.N. lagunas de La Mata y Torrevieja & $0,2 \%$ \\
\hline UP7.4_Entorno agrícola P.N. lagunas de la Mata y Torrevieja & $2,5 \%$ \\
\hline UP8_Urbanización litoral de Torrevieja & $1,1 \%$ \\
\hline UP9_Dunas de Guardamar del Segura & $1,4 \%$ \\
\hline UP_11.2_Sierra Molar & $3,1 \%$ \\
\hline
\end{tabular}

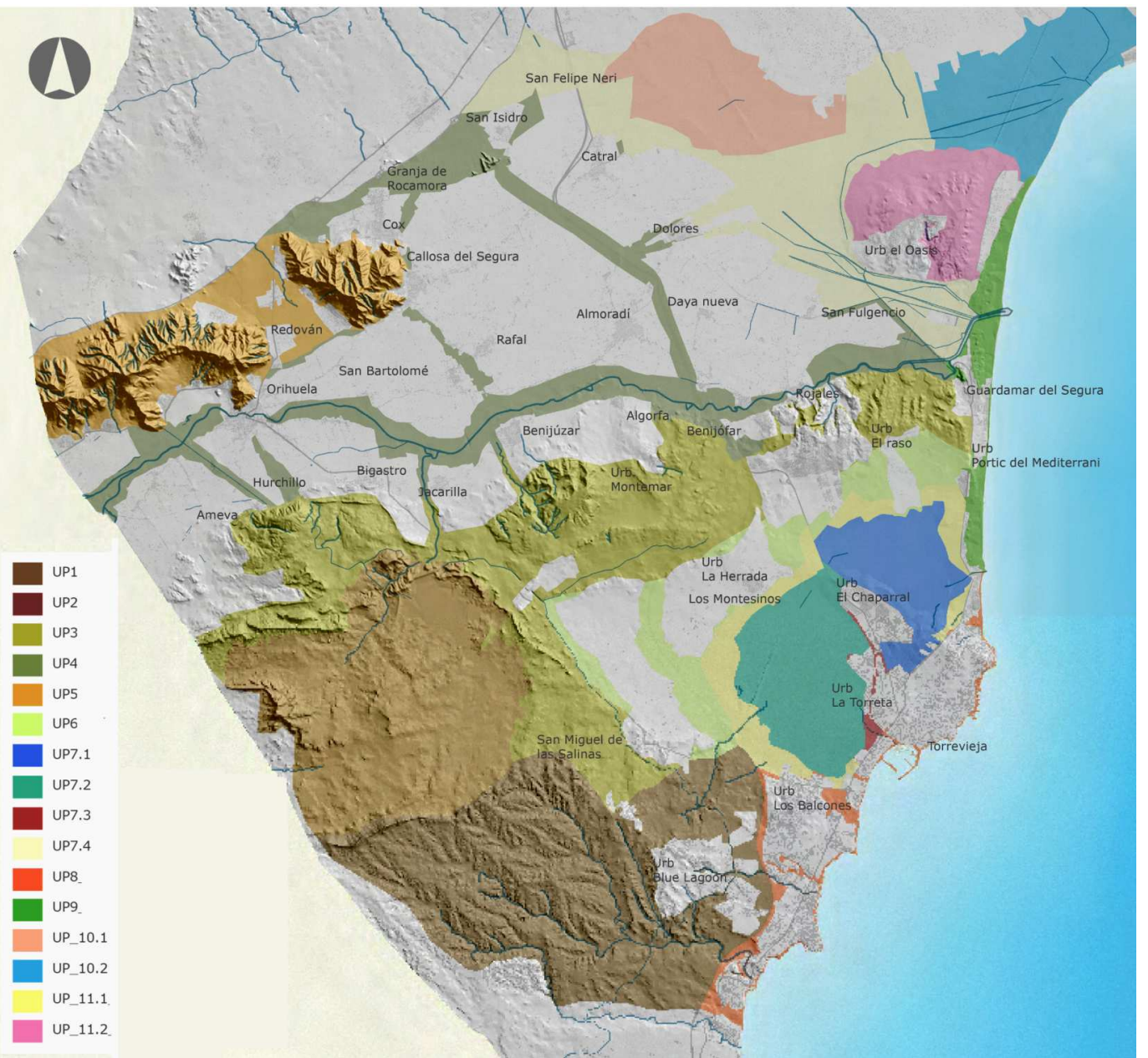

Fig. 5.17: Intersección del sistema de espacios abiertos y las unidades de paisaje del ámbito ampliado (escala aproximada 1:300.000) 
b) Diagnóstico respecto a la cubierta vegetal: El sistema de espacios abiertos propuesto incorpora espacios forestales, agrícolas y urbanizados, estableciendo conexiones entre ellos y posibilitando un más fácil acceso de la población al medio rural, una mejor integración y disfrute visual del paisaje desde las infraestructuras de transporte así como una incorporación de los sistemas naturales en las zonas urbanizadas.

En lo referente a la cubierta vegetal y tal y como se expone en la tabla siguiente, el sistema de espacios abiertos se extiende sobre una amplia diversidad de cultivos y formaciones vegetales. Los porcentajes mostrados en la tabla constituyen por otro lado una fuente de información esencial para valorar la productividad del sistema, su coste de permanencia y la viabilidad de su mantenimiento en los términos actuales.

Tabla 5.2: Peso relativo de los distintos tipos de cobertura vegetal en el ámbito ampliado y en el sistema de espacios abiertos.

\begin{tabular}{l|c|c} 
Tipo de Cubierta Vegetal & $\begin{array}{c}\% \text { sobre el Sistema de Espacios } \\
\text { Abiertos }\end{array}$ & $\begin{array}{c}\% \text { sobre el Ámbito } \\
\text { Ampliado }\end{array}$ \\
\hline Marjal-saladar & $5,8 \%$ & $3,7 \%$ \\
\hline Bosque mediterráneo & $11,7 \%$ & $7,6 \%$ \\
\hline Frutales de regadío (cítricos) & $26,5 \%$ & $17,1 \%$ \\
\hline Frutales de secano & $4,7 \%$ & $3,0 \%$ \\
\hline Herbáceos de secano & $0,3 \%$ & $0,2 \%$ \\
\hline Hortícolas y herbáceos regadío & $21,6 \%$ & $13,9 \%$ \\
\hline Viñedos & $<0,1 \%$ & $<0,1 \%$ \\
\hline Sin cultivar & $3,9 \%$ & $2,5 \%$
\end{tabular}

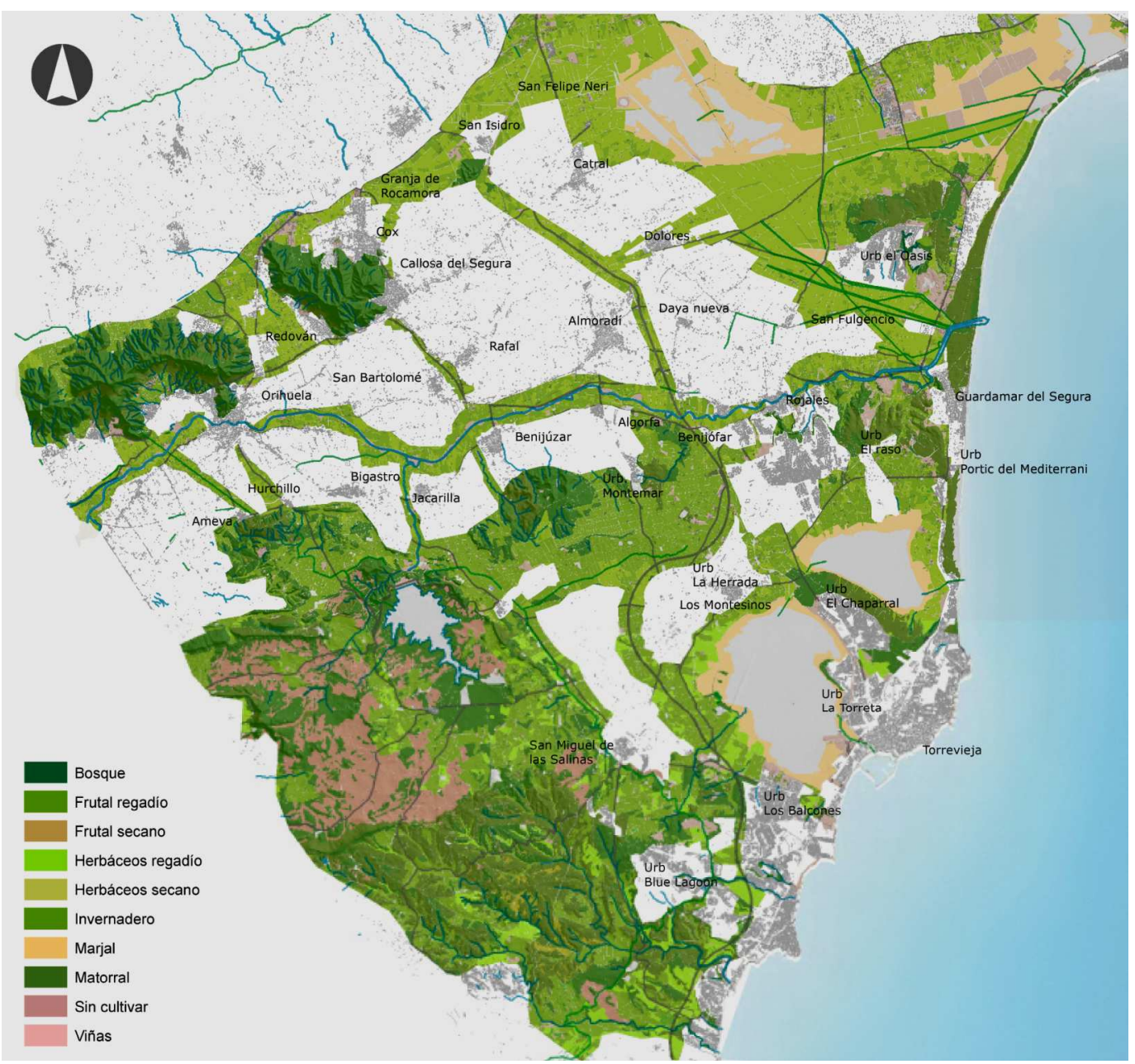

Fig. 5.18: Intersección del sistema de espacios abiertos y las coberturas vegetales del ámbito ampliado (escala aproximada 1:300.000)

c) Diagnóstico respecto a la clasificación urbanística: El sistema de espacios abiertos propuesto incorpora e interrelaciona suelos clasificados como urbanos, urbanizables y no urbanizables. En lo referente a los suelos urbanos, se incluyen zonas verdes urbanas (difícilmente apreciables a la escala de trabajo). En el caso de los espacios urbanizables, su inclusión parcial en el sistema de espacios abiertos permitiría orientar la localización de las dotaciones verdes a definir en el planeamiento pormenorizado. Por último, la mayor parte de la sistema de 
espacios abiertos se localiza sobre suelos no urbanizables agrícolas y forestales con distintos grados de protección.

La tabla siguiente muestra los porcentajes de suelo urbano, urbanizable y no urbanizable, incluidos en el sistema de espacios abiertos del sur de Alicante. Para la realización de los cálculos se ha considerado la cartografía SIG de la Consellería de Obras Públicas, Transporte y Urbanismo (año 1998), excluyéndose a partir de la información mostrada en una ortofoto del año 2007 , los suelos reclasificados a urbanizables y con urbanización ya concluida en el año 2007.

Tabla 5.3: Superficies y peso relativo de las distintas clases de suelo en el sistema de espacios abiertos.

\begin{tabular}{l|c|c} 
& $\begin{array}{c}\text { Superficie en Sistema de } \\
\text { Espacios Abiertos (km2) }\end{array}$ & $\begin{array}{c}\text { \% en Sistema de Espacios } \\
\text { Abiertos }\end{array}$ \\
\hline Suelo Urbano & $3,92 \mathrm{~km} 2$ & $0,68 \%$ \\
\hline Suelo Urbanizable & $31,05 \mathrm{~km} 2$ & $5,42 \%$ \\
\hline Suelo No Urbanizable & $537,65 \mathrm{~km} 2$ & $93,89 \%$
\end{tabular}

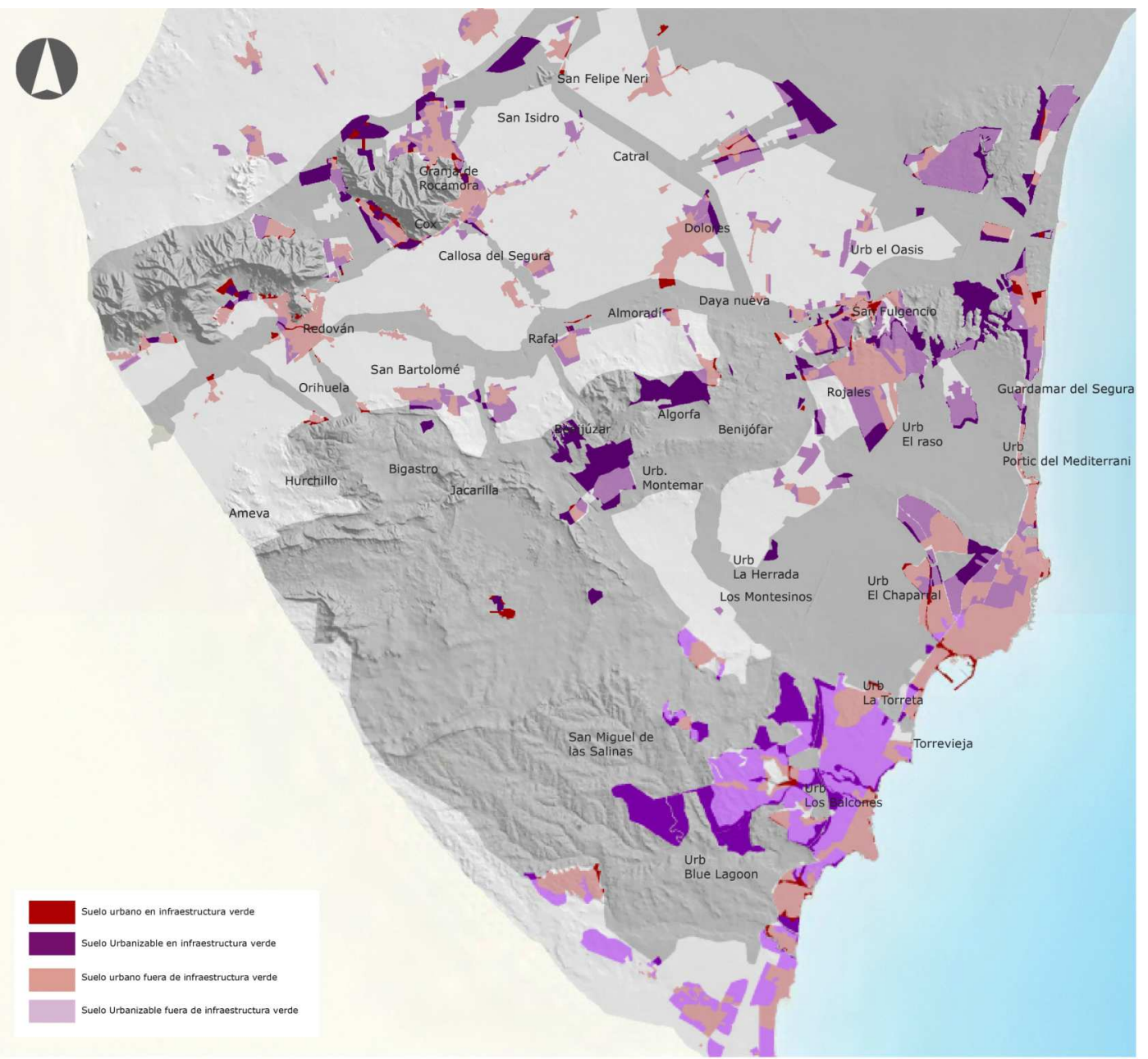

Fig. 5.19: Intersección del sistema de espacios abiertos y las distintas clases urbanísticas del suelo (escala aproximada 1:300.000)

d) Diagnóstico respecto a las afecciones territoriales y espacios protegidos: Tal y como se recoge en el plano adjunto, el sistema de espacios abiertos propuesto incorpora:

- Los espacios naturales con algún tipo de protección, ajustándose al ámbito de los PORN excepto en las zonas urbanas o urbanizables salvo que se considere oportuno replantear algunas de éstas últimas.

- La totalidad de dominios públicos (montes de utilidad pública, dominio marítimo y dominios hidráulicos asociadas a cursos naturales de agua e infraestructuras hidráulicas (grandes canales y azarbes).

- La mayor parte de las vías pecuarias, especialmente en los tramos que no han sido incluidas en espacios urbanizados o cubiertas por infraestructuras. 
- El corredor definido por el río Segura, al que se acompaña de sendas franjas laterales de afección visual de 300 metros de anchura.

- El corredor definido por la Vía Verde, al que se acompaña de sendas franjas de afección visual de 300 metros de anchura en cada orilla

- Las zonas de afección visual a lo largo de carreteras con valor escénico

- Recorridos históricos o catalogados (Camino del Cid, PR-CV5, PR-CV69 y GR-125).

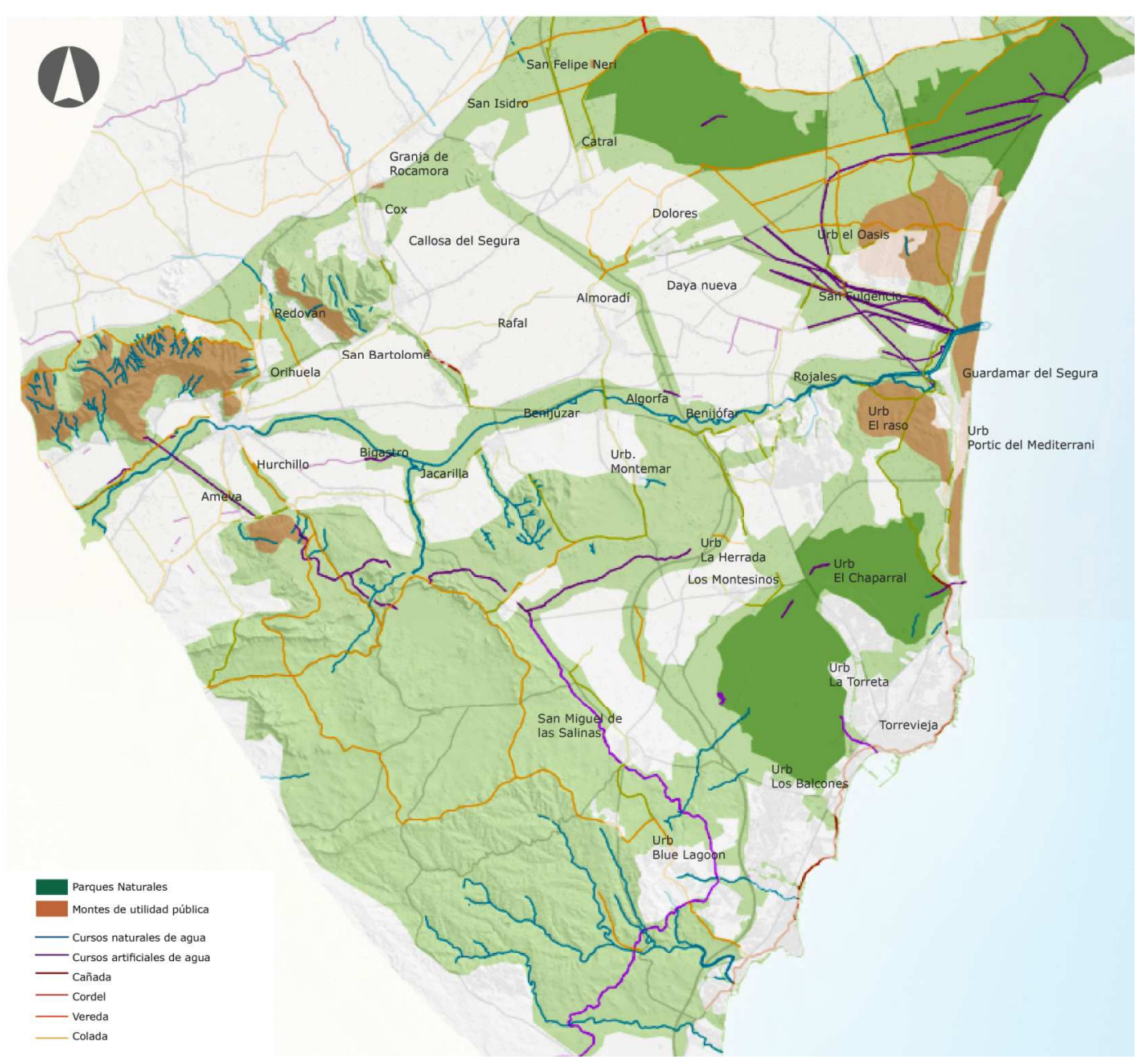

Fig. 5.20: Intersección del sistema de espacios abiertos con los espacios con protección ambiental y vías pecuarias (escala aproximada 1:300.000)

e) Diagnóstico respecto a los Recursos Paisajísticos Medioambientales: Tal y como se deduce de la comparación del plano de recursos medioambientales del ámbito del estudio (ver apartado de caracterización del paisaje) y el plano del sistema de espacios abiertos, este último ultima incorpora la práctica totalidad de recursos, con la excepción de algunos suelos de alta fertilidad, cuya protección y gestión debería ser tratada en los programas de paisaje de las unidades de paisaje correspondientes. El sistema así definido contribuiría a la continuidad ecológica de los sistemas y procesos naturales necesarios para mantener la calidad ambiental y diversidad ecológica del sur de Alicante. 


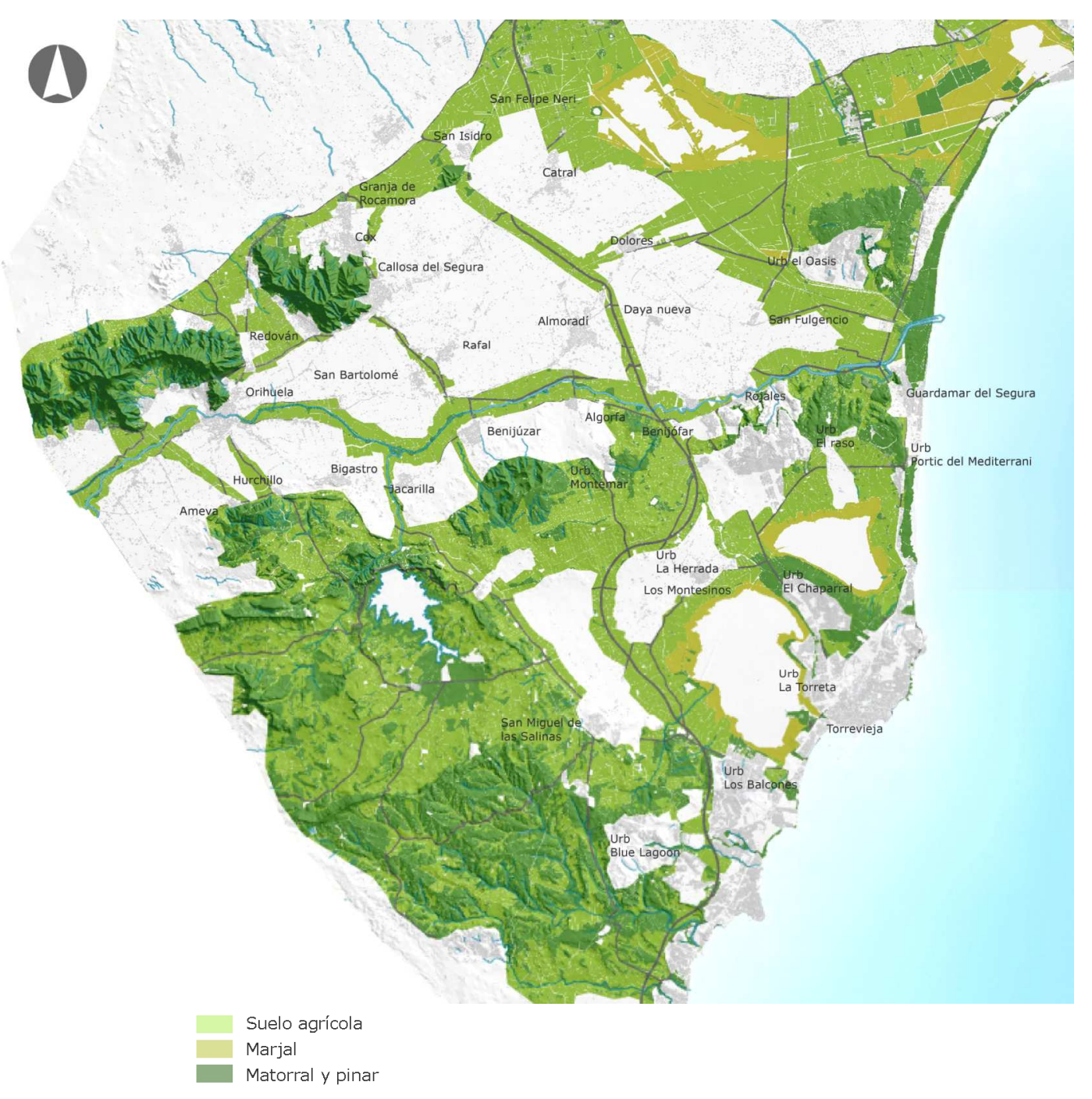

Fig. 5.21: Intersección del sistema de espacios abiertos con los principales sistemas vegetales (escala aproximada 1:300.000)

f) Diagnóstico respecto a los Recursos Paisajísticos Culturales: Tal y como se observa en el plano siguiente, el sistema de espacios abiertos del sur de Alicante incluye y facilita el acceso a la mayor parte de recursos culturales catalogados o identificados en el ámbito de estudio (ver figura 5.13).

Dichos recursos se concentran especialmente en el frente costero y en los pies de ladera de las sierras de Orihuela-Callosa de Segura y de la cara norte de la dorsal Guardamar - Bigastro - Arneva, espacios, todos ellos, que han quedado incluidos en el sistema de espacios abiertos, facilitándose de este modo la permanencia de un paisaje adecuado en su entorno.

Aparte de los recursos arqueológicos o arquitectónicos, se han considerado sistemas o elementos lineales, como redes de riego, canales, azarbes, etc., directamente vinculados al patrimonio etnográfico de la zona, y que quedan incluidos en las áreas agrícolas del sistema de espacios abiertos 


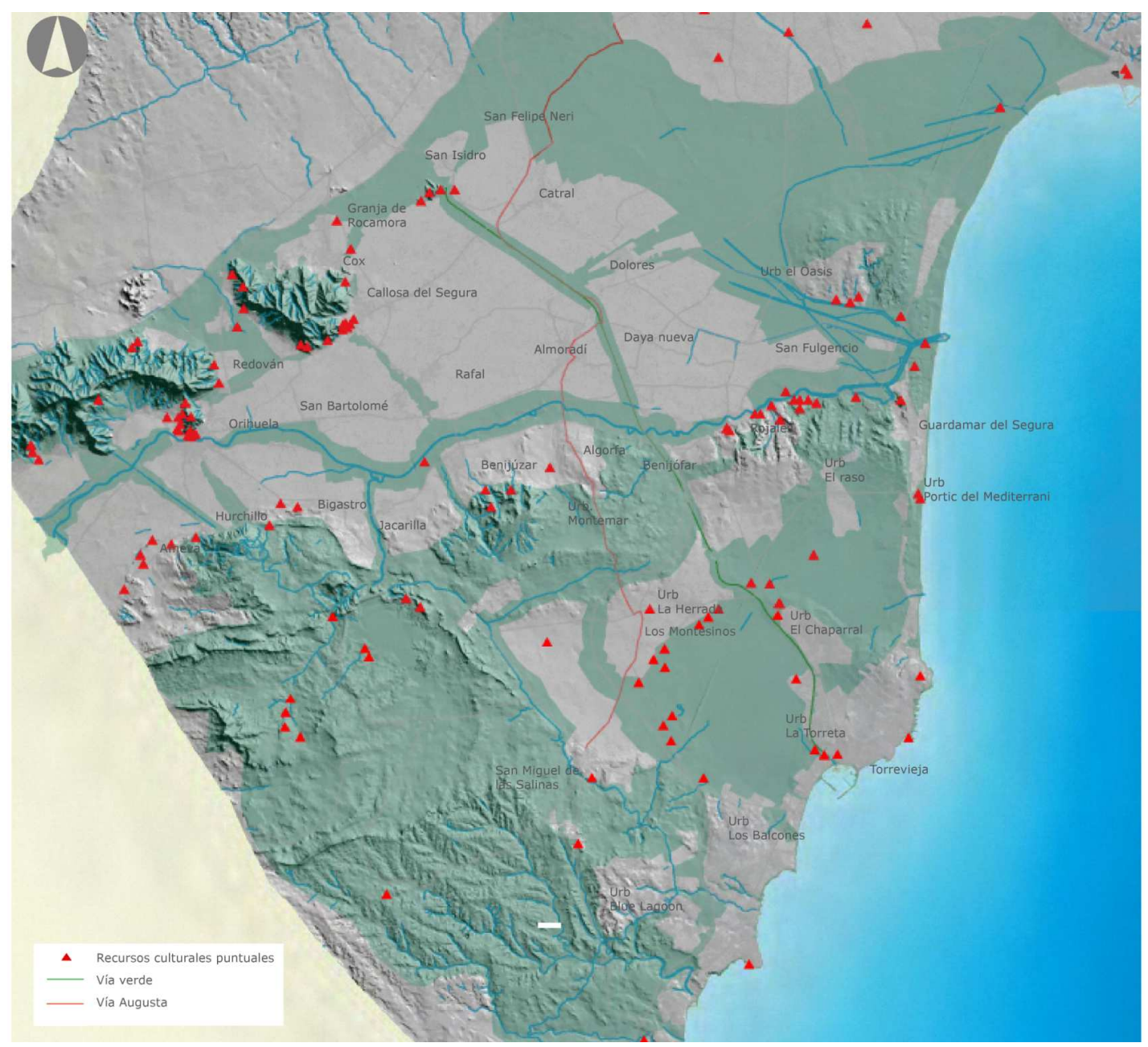

Fig. 5.22: Intersección del sistema de espacios abiertos con los recursos paisajísticos culturales del ámbito ampliado (escala aproximada 1:300.000)

g) Diagnóstico respecto a los Recursos Paisajísticos Visuales: Tal y como se deduce de la comparación del plano de recursos paisajísticos visuales en el ámbito ampliado del estudio (ver figura 5.14) y del plano siguiente, la práctica totalidad de recursos visuales quedan incluidos dentro del sistema de espacios abiertos.

Esto resulta especialmente aplicable a los recursos del tipo:

(1) Elementos topográficos y formales que definen la estructura espacial

(2) Puntos de observación y recorridos paisajísticos de especial relevancia por su alta frecuencia de observación, o la calidad de sus vistas

(3) Elementos y áreas significativas o características no estructurantes que conforman un paisaje tanto derivadas de su configuración natural como por la acción del hombre-perfiles de asentamientos históricos, hitos urbanos, culturales, religiosos o agrícolas, siluetas y fachadas urbanas, y otros similares.

El sistema de espacios abiertos preserva parcialmente las principales vistas y perspectivas hacia los elementos identificados en los puntos anteriores y hacia la imagen exterior de núcleos urbanos de excepcional valor, si bien, en algunos casos, dicha preservación resulta difícil debido a las modificaciones de usos del suelo ya en curso o a las expectativas de crecimiento urbano.

La protección de vistas en espacios altamente transitados y el mantenimiento de la estructura visual de espacios de alto valor paisajístico, ha implicado por otro lado la incorporación al sistema de espacios abiertos de importantes áreas, como los corredores visuales del río Segura, de la autovía AP-7 y otras carreteras, o de los conectores visuales entre las sierras de Callosa y Orihuela o entre el Parque Natural de las Salinas de Santa Pola y la Sierra Molar. 


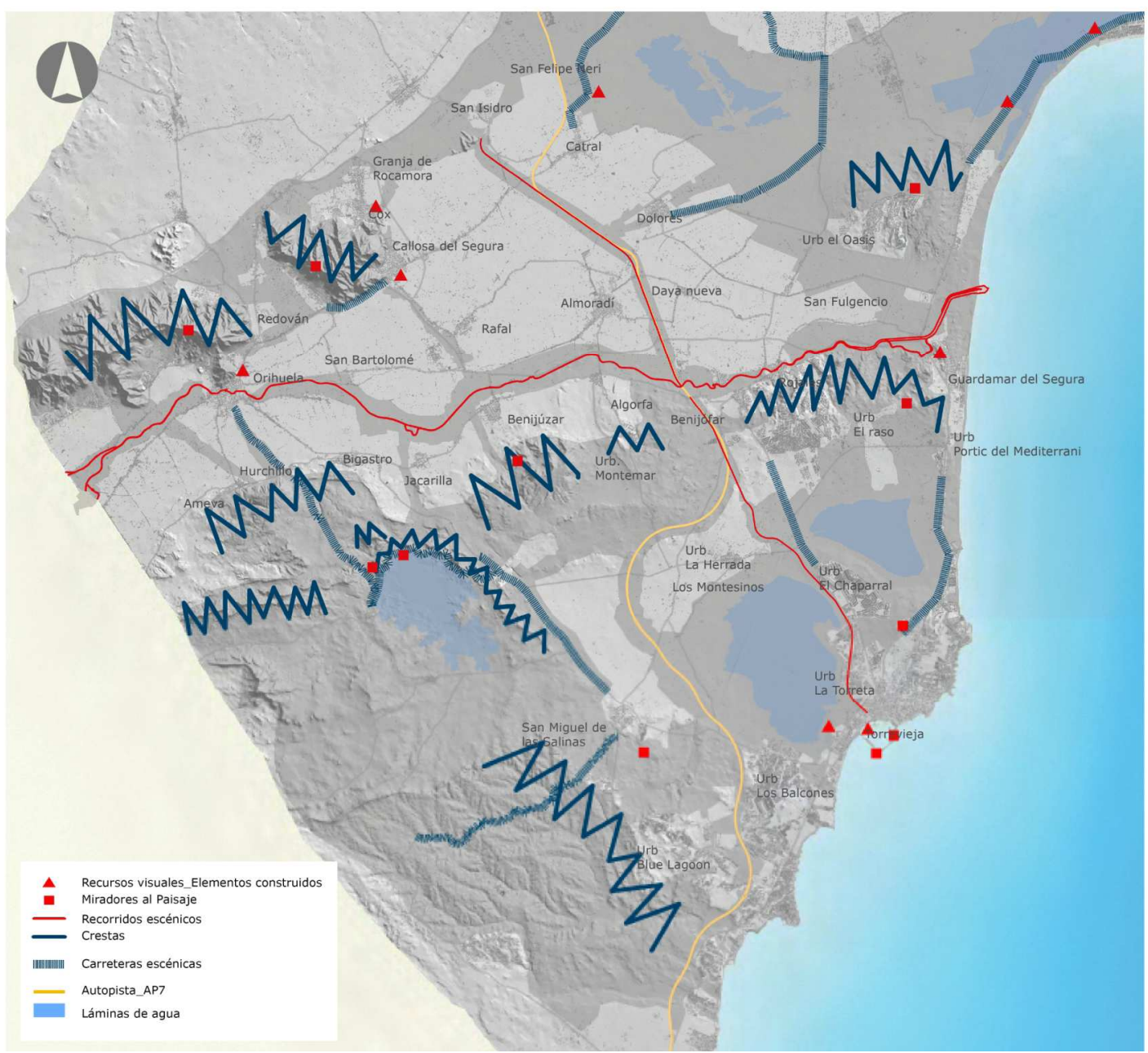

Fig. 5.23: Intersección del sistema de espacios abiertos con los recursos paisajísticos visuales del ámbito ampliado (escala aproximada $1: 300.000)$

\section{3.d.3. Zonificación y Programas de Paisaje en el Sistema de Espacios Abiertos del Sur de Alicante}

Tal y como se recoge en el presente documento, las caracterización de las unidades de paisaje definidas en el ámbito ampliado del estudio se realizó a partir de una serie de descriptores y de un listado de acciones / recomendaciones dirigidas, estas últimas, a orientar la protección, gestión o transformación del paisaje por medio de los correspondientes programas y normativas de paisaje.

La intersección de la sistema de espacios abiertos con el plano de unidades de paisaje, permite en consecuencia, una zonificación preliminar del primero, y la aplicación en cada zona de las acciones / recomendaciones propias de la unidad de paisaje atravesada o específicas del fragmento de unidad incluida en el sistema de espacios abiertos.

La tabla siguiente define a continuación una propuesta preliminar de los objetivos y programas de paisaje asociados a cada zona del sistema de espacios abiertos 
Tabla 5.4: Propuesta preliminar de programas de paisaje para las distintas zonas del sistema de espacios abiertos del ámbito ampliado.

\begin{tabular}{l|}
$\begin{array}{c}\text { Zonas del Sistema de } \\
\text { espacios abiertos } \\
\text { (por unidades de } \\
\text { paisaje) }\end{array}$ \\
\hline UP1. Dehesa de \\
Campoamor y Sierra \\
Escalona
\end{tabular}

UP2. Embalse de la Pedrera / Campos de Torremendo

1.a. Desarrollo de un corredor de carácter natural a lo largo de la rambla de la Fayona, del barranco de Garbanzuelo y de los terrenos comprendidos entre ellos.

1.b. Integración de las urbanizaciones situadas en la zona sureste y evitación de su fusión con la urbanización Los Balcones.

1.c. Reconsideración de la creación de urbanizaciones en suelos urbanizables no desarrollados.

1.d. Establecimiento de recorridos y miradores al paisaje en el ámbito del futuro Parque Natural.

1.e. Mejora de la percepción visual de la dehesa desde la AP7 y N332.

2.a. Control de la erosión mediante el desarrollo de repoblaciones y aterrazamientos.

2.b. Recomposición de la topografía modificada por la acción humana.

2.c. Integración de la edificación dispersa.

2.d. Potenciación del uso público del embalse.

2.e Implantación de vegetación en la orla del embalse.

2.e: Creación de miradores

UP3. Laderas y colinas en torno a las Lagunas de La Mata y Torrevieja 3.a. Potenciación del carácter forestal-agrícola de la dorsal Guardamar - Bigastro - Arneva, integrando la urbanización existente, evitando el desarrollo de nuevas urbanizaciones y generando corredores verdes en la parte superior de la dorsal así como entre las urbanizaciones y los pueblos situados en la margen sur del Segura.

3.b. Consolidación de la zona del alto del Moncayo como zona forestal y garantizar su continuidad hasta la desembocadura del Segura.

3.c. Creación de corredores verdes a través de Ciudad Quesada, de las urbanizaciones adosadas al Campo de Golf de Rojales y entre dichas dos urbanizaciones y Rojales.

3.d. Mantenimiento de la actividad agrícola en el corredor de la AP7 / Vía Verde.

3.e. Desarrollo de recorridos peatonales ciclistas a lo largo del Canal del Campo de Cartagena y el canal del Trasvase a Los Montesinos.

3.f: Creación de miradores en puntos altos.

\section{UP4. Vegas del} Segura

4.a. Introducción de arbolado de ribera a lo largo del corredor del Segura (puede requerir ajustes en la sección) y establecer normas para las zonas de afección visual definidas a ambos lados del río.

4.b. Potenciación del uso de Los Rojales y Orihuela como puertas de acceso al corredor del río Segura.

4.c. Extensión de la Vía Verde, resolviendo el cruce del río Segura, y su relación física, visual y acústica con la Autovía AP7.

4.d Definición de normas para las zonas de afección visual definidas a ambos lados del río.

4.e. Desarrollo en el encuentro de la Vía Verde con el corredor Verde del Segura de un núcleo principal en la red de recorridos naturales.

4.f Desarrollo de recorridos verdes entre la Vía Verde y el Hondo (a través de la población de Dolores).

4.g. Preservación de la carretera Hurchillo - Orihuela (adoquín y arbolado en los márgenes)

4.h Creación de un corredor apoyado en la tubería de impulsión del Trasvase Tajo- Segura que alimenta el embalse de la Pedrera (hacer de este elemento artificial un hito en el paisaje).

UP5. Sierras de
Orihuela y Callosa de
Segura

UP6. Orla agrícola exterior del parque natural de las Lagunas de La Mata y Torrevieja

5.a. Control

Orihuela.

5.b. Mantenimiento del carácter agrícola de la llanura entre ambas sierras.

5.c: Creación de miradores en puntos altos.

(A desarrollar en el Estudio de Paisaje del Ámbito Estricto)

6.a. Programa apara el establecimiento de corredores de carácter agrícola-forestal entre las zonas no urbanizadas de la dorsal Guardamar - Bigastro y el límite norte del Parque Natural de las lagunas de La Mata y Torrevieja. Desarrollar con carácter específico un plan de gestión agrícola para el Campico de Guardamar.

6.b. Control de la extensión de Ciudad Quesada hasta los límites del Parque Natural de las lagunas de La Mata - Torrevieja y desarrollo de acciones (plantaciones en los márgenes y viales interiores) para su integración

6.c. Establecimiento de normas para las zonas de afección visual definidas a ambos lados de la autovía AP-7.

6.d. Extensión de las Rutas de La Sal y de los Aljibes a otros términos municipales.

6.e. Puesta en valor e incorporación de usos compatibles con el Parque en el patrimonio arquitectónico rural existente.

UP7.1. Laguna de la $\quad$ (A desarrollar en el Estudio de Paisaje del Ámbito Estricto)

Mata

7.1.a. Control del desarrollo urbanístico en el alto de La Hoya (creación de mirador)

7.1.b. Creación de recorridos que permitan valorar la diversidad ecológica y paisajística del parque.

7.1.c. Establecimiento de conexiones y puntos de acceso de acuerdo a la sistema de espacios abiertos del Sur de Alicante (esencial a lo largo del Canal de La Mata, desde Ciudad Quesada y desde la rotonda de la carretera CV905 en las inmediaciones del Canal de Las Salinas). 


\section{Zonas del sistema de espacios abiertos \\ (por unidades de paisaje)}

Objetivos y programas de paisaje asociados

UP7.2.Laguna de Torrevieja

(A desarrollar en el Estudio de Paisaje del Ámbito Estricto)

7.2.a. Generación de recorridos que permitan valorar la diversidad ecológica y paisajística del parque.

7.2.b. Potenciación de la permanencia de la agricultura tradicional en el Parque.

7.2.c. Establecimiento de conexiones y puntos de acceso de acuerdo al sistema de espacios abiertos del sur de Alicante (esencial a lo largo del Acequión, desde Los Montesinos y desde la rotonda de la carretera CV905 en las inmediaciones del Canal de Las Salinas).

7.2.d. Consolidación del conector apoyado en el canal de las Salinas.

7.2.e. Potenciación de la imagen de la industria salinera y del proceso de producción de la sal.

\begin{tabular}{l|l} 
UP7.3. Cuña & (A desarrollar en el Estudio de Paisaje del Ámbito Estricto)
\end{tabular}

urbanizada del $\quad$ 7.3.a. Establecimiento de tratamientos de borde respecto al Parque Natural de las lagunas Parque Natural de la de La Mata - Torrevieja.

\begin{tabular}{l|l} 
Mata- Torrevieja & 7.3.b. Establecimiento de conexiones transversales entre las lagunas de La Mata y
\end{tabular} Torrevieja.

7.3.c. Definición de una nueva sección y carácter para la Vía Verde.

\begin{tabular}{l|l}
\hline UP7.4. Entorno & (A desarrollar en el Estudio de Paisaje del Ámbito Estricto) \\
agrícola del parque & 7.4.a. Definición de medidas y acciones de integración de la carretera N332.
\end{tabular}

\begin{tabular}{l|l} 
Natural de la Mata- & 7.4.b. Preservación de la actividad agrícola en el parque, definiendo estrategias para la
\end{tabular} Torrevieja $\quad$ producción y comercialización de los productos agrícolas, con especial atención al viñedo.

UP8. Urbanización $\quad$ (A desarrollar en el Estudio de Paisaje del Ámbito Estricto)

\begin{tabular}{l|l} 
litoral Torrevieja & 8.a. Desarrollo de un continuo accesible a lo largo de la costa, que haga uso y potencie las \\
\end{tabular} diferencias existentes (paseos marítimos urbanos, paseos marítimos blandos, dunas, zonas rocosas, etc).

8.b. Recuperación del Canal de la Mata como cauce abierto y potenciación de su uso como acceso a la Laguna de La Mata.

8.c. Potenciación del uso del Acequión de Torrevieja como acceso a la Laguna de Torrevieja.

8.d. Establecimiento de corredores verdes urbanos de conexión entre el parque natural y el litoral de Torrevieja.

8.e. Desarrollo de una dotación verde entre el mar y el área dotacional en la que se ubican el EDAR y desaladora de Torrevieja.

8.f. Contención mediante una zona verde de la posible expansión de la urbanización Los Balcones, en dirección a la Unidad Paisajística no 1.

8g. Preservación como zona verde de los espacios no urbanizados necesarios para evitar el cierre de un continuo urbanizado entre Punta Prima y el límite sur costero del ámbito de estudio.

UP9. Dunas de $\quad$ 9.a Integración y conexión del puerto de Guardamar al casco urbano.

Guardamar del $\quad 9 . b$. Conexión verde del casco urbano de Guardamar con la zona húmeda de la Segura $\quad$ desembocadura del Segura y la sierra Molar (salvar barreras generadas por la N332 y la CV91

9.c. Creación de una gran zona verde de carácter fluvial con posibles usos secundarios residenciales y terciario en la zona comprendida entre el brazo principal y secundario de la desembocadura del Segura.

9.d. Creación de una conexión peatonal- ciclista entre las dunas situadas al norte y sur de la desembocadura del Segura.

\begin{tabular}{|c|c|}
\hline $\begin{array}{l}\text { UP10.1. Humedales } \\
\text { de el Hondo }\end{array}$ & 10.1.a. Potenciación del uso científico y recreativo del Parque Natural del Hondo. \\
\hline $\begin{array}{l}\text { UP10.2. Salinas de } \\
\text { Santa Pola }\end{array}$ & $\begin{array}{l}\text { 10.2.a. Potenciación del uso científico y recreativo del Parque Natural de las salinas de } \\
\text { Santa Pola. } \\
\text { 10.2.b. Potenciación de la carretera N332 como recorrido escénico }\end{array}$ \\
\hline $\begin{array}{l}\text { UP11.1. Orla agrícola } \\
\text { de los Parques } \\
\text { Naturales del Fondo y } \\
\text { las Salinas de Santa } \\
\text { Pola }\end{array}$ & $\begin{array}{l}\text { 11.1.a Preservación del cultivo de hortícolas y herbáceos de regadío como recurso para } \\
\text { mantener la profundidad visual existente (evitar la introducción de cítricos). } \\
\text { 11.1.b. Promoción del uso público de caminos adosados a canales y azarbe e incorporación } \\
\text { de tramos de olmedas en algunas de sus márgenes. } \\
\text { 11.1.c Potenciación del uso de San Felipe Neri como zona de servicios. } \\
\text { 11.1.d. Integración y contención de posibles desarrollos industriales al norte de los núcleos } \\
\text { de Catral y Dolores. } \\
\text { 11.1.e. Integración de la urbanización pendiente de desarrollo de Plan Especial }\end{array}$ \\
\hline UP11.2 $\rightarrow$ Sierra Molar & $\begin{array}{l}\text { 11.2.a Reforestación de las laderas norte y este e integración de la edificación dispersa } \\
\text { existente. } \\
\text { 11.2.b. Integración paisajística y nuevos usos futuros para las canteras situadas en la ladera } \\
\text { sur. } \\
\text { 11.2.c: Creación de miradores hacia las Salinas de Santa Pola y Vegas del Segura. }\end{array}$ \\
\hline
\end{tabular}




\subsection{Estudio de Paisaje en el ámbito estricto:}

\section{4.a. Definición del ámbito estricto y Objetivos del estudio}

Tal y como se expuso en el apartado previo, dada la importancia del Parque Natural en el sistema de espacios abiertos del Sur de Alicante y su ubicación en suelos pertenecientes a distintos términos municipales, se ha considerado necesario incluir en el estudio un primer apartado en el que se define a título orientativo el sistema de espacios abiertos del sur de Alicante y las conexiones del parque natural con los principales espacios próximos de valor medioambiental, paisajístico y cultural.

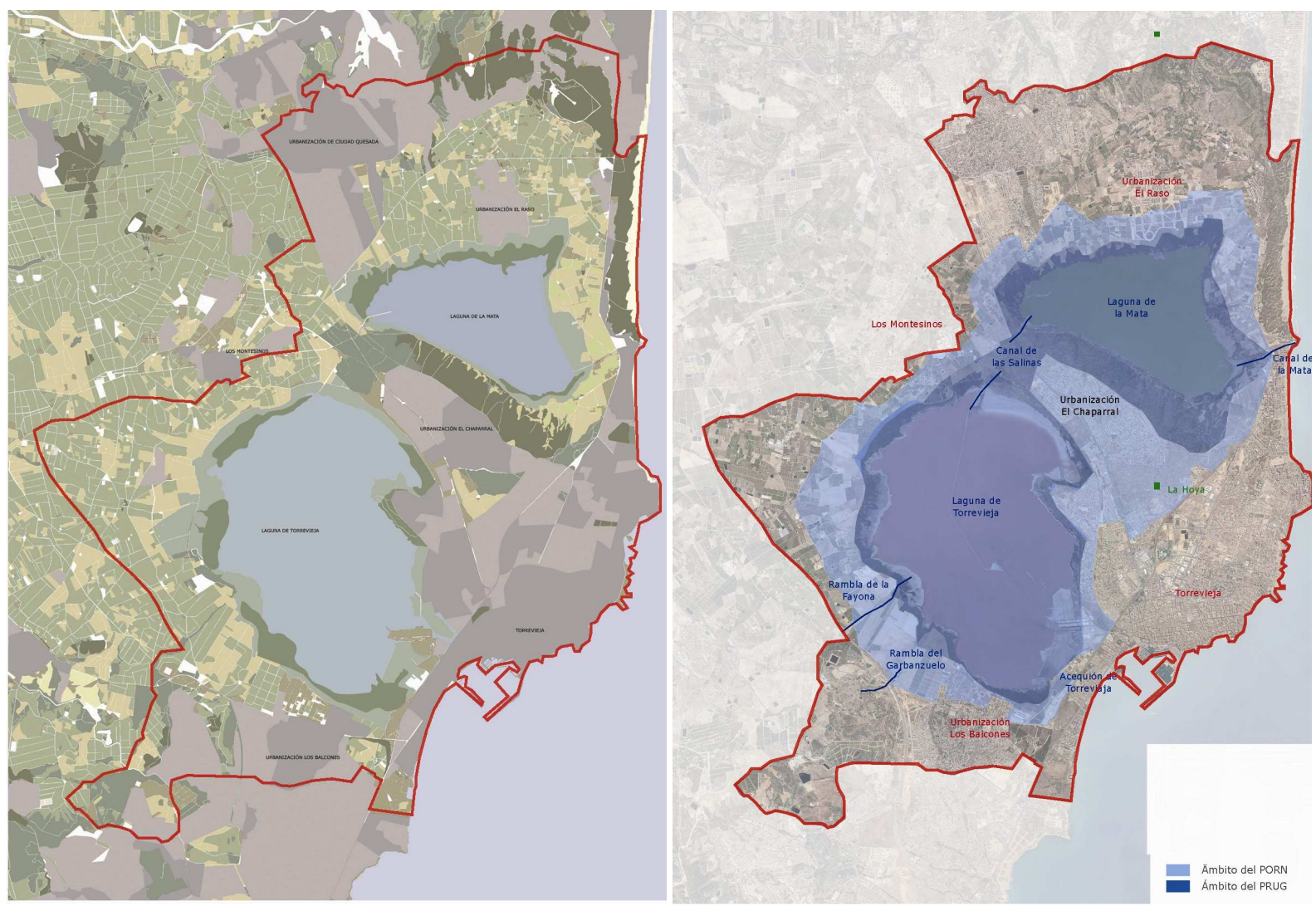

Fig. 5.24: Ámbito estricto del estudio de paisaje (línea roja) en intersección con usos del suelo (izquierda) y con las delimitaciones del Parque Natural de las lagunas de la Mata y Torrevieja y su zona de amortiguación de impactos según PORN (derecha)

En el presente apartado, se procede, en un proceso coordinado con un Plan de Participación Pública, al desarrollo de un estudio de paisaje completo dentro del denominado ámbito estricto. Dicho ámbito (10.822,4 hectáreas) incluye la totalidad del parque natural, su área de amortiguación (conforme al Plan de Ordenación de los Recursos Naturales (PORN) del sistema de zonas húmedas del sur de Alicante, los conectores ecológicos y físicos con otros espacios cercanos de interés paisajístico y medioambiental, así como áreas estratégicas para garantizar la calidad ambiental del Parque y de las vistas de éste y desde éste, con particular atención a las infraestructuras de transporte y zonas urbanizadas próximas.

Tras una caracterización y valoración del paisaje, la parte propositiva del estudio propone unos objetivos de calidad paisajísticos, un sistema de espacios abiertos asociado al Parque Natural, los programas de paisaje necesarios para la materialización de los citados objetivos y la normativa propuesta para mantener y mejorar la calidad del paisaje, especialmente en las áreas productivas (agrícolas y salineras) colindantes o incluidas dentro del Parque.

Dado el requerimiento legal de acompañar en la Comunidad Valenciana cualquier plan de acción territorial o plan general de ordenación urbana del correspondiente estudio de paisaje, se considera que el contenido del presente estudio podrá ser de utilidad para orientar el futuro planeamiento de los municipios afectados, facilitando de este modo una aproximación supramunicipal a la gestión del territorio. 


\section{4.b. Análisis Territorial}

El análisis territorial realizado en el ámbito ampliado se intensificó en el ámbito estricto. Para la realización de este análisis resultó de gran utilidad la información contenida en el Plan Rector de Usos y Gestión del Parque Natural de las lagunas de La Mata-Torrevieja y en el Plan de Ordenación de los Recursos Naturales del Sistema de Zonas Húmedas del Sur de Alicante, así como los distintos Catálogos, Planes Generales y estudios existentes en los 5 municipios afectados.

Las conclusiones de este Análisis Territorial se han incorporado en la documentación generada dentro del apartado de caracterización del Paisaje.

\section{4.c. Plan de participación pública}

5.4.c.1. Objetivos del Plan de Participación Pública:

El plan de participación pública tuvo por objeto recoger la opinión de la población visitante y residente del área sobre los aspectos siguientes:

- DETERMINACIÓN de las unidades de paisaje y recursos paisajísticos

- VALORACIÓN de las unidades de paisaje y recursos paisajísticos anteriormente determinados.

- PROPUESTA de actuaciones a desarrollar en las unidades de paisaje y recursos paisajísticos.

\section{4.c.2. Fases del Plan de Participación Pública:}

El Plan de Participación Pública se estructuró en tres fases sucesivas que proporcionaron la información básica para las fases siguientes.

- FASE1 del Plan de Participación Pública (27 de mayo al 10 de junio de 2009): En ella se presentó el Plan de Participación Pública a la población y se le preguntó qué paisajes, qué recursos paisajísticos y qué cambios o conflictos paisajísticos identificaban en el ámbito del estudio.

- FASE2 del Plan de Participación Pública (17 de junio al 6 de julio de 2009): Tomando como base las unidades de paisaje y los recursos paisajísticos identificados por la población y expertos, se pide a ambos grupos que los valoren en una escala de 1 a 5 (muy bajo, bajo, medio, alto o muy alto).

- FASE3 del Plan de Participación Pública (20 de julio al 4 de agosto de 2009): A partir de la cartografía en la que se recogían las unidades, recursos y conflictos paisajísticos detectados, se pregunta a población y expertos sobre las actuaciones que estiman que deberían desarrollarse para proteger, gestionar u ordenar el paisaje.

\section{4.c.3. Público interesado:}

El público interesado constituyen los grupos o instituciones a los se dio participación en el Plan y que se adscribieron a las siguientes dos categorías:

\section{GRUPOS DE INTERÉS:}

- Ayuntamiento de Torrevieja

- Ayuntamiento de Los Montesinos

- Ayuntamiento de Rojales

- Ayuntamiento de Guardamar del Segura

- Ayuntamiento de San Miguel de Salinas

- Dirección del Parque Natural de las Lagunas de La Mata y Torrevieja

- Personal del Parque Natural de las Lagunas de La Mat y Torrevieja

- Técnicos de la Dirección General de Territorio y Paisaje de la Comunidad Valenciana

- Universidad Miguel Hernández

- Universidad de Alicante

- Universidad Politécnica de Valencia

- Universidad de Valencia

- Asociaciones u ONG's de carácter regional, autonómico o nacional

GRUPOS DEL LUGAR:

- Visitantes del Parque

- Población y visitantes de Torrevieja

- Población y visitantes de Los Montesinos

- Población y visitantes de Rojales

- Población y visitantes de Guardamar del Segura

- Población y visitantes de San Miguel de Salinas

- Asociaciones u ONG's de carácter local 
- Comunidad de regantes de la margen derecha del Segura (Unidades de riego 71 y 52 (Unidades de Demanda Agraria de la CHS))

- Comunidad de regantes de los acuíferos del campo de Cartagena (Unidad de riego 57 (Unidades de Demanda Agraria de la CHS))

- Agricultores locales

- Propietarios de fincas agrícolas.

- Agentes urbanísticos o turísticos locales

5.4.c.4. . Suministro de Información, Consultas y Difusión del Plan de Participación Pública:

a) Suministro de Información: La información sobre el Plan de Participación Pública fue facilitada por medio de:

- Las WEB's institucionales de la Consellería de Medio Ambiente, Agua, Urbanismo y Vivienda y los 5 municipios afectados.

- Seminarios informativos programados de acuerdo al calendario siguiente: PRESENTACIÓN y FASE1:

- Torrevieja: 1 de junio de 2009 (10:00 a 13:00 horas), Auditorio del Palacio de la Música

- Los Montesinos: 1 de junio de 2009 (17:00 a 20:00 horas), Centro Cívico Municipal

- San Miguel de Salinas: 2 de junio de 2009 (10:00 a 13:00 horas), Casa de la Cultura

- Guardamar del Segura: 2 de junio de 2009 (17:00 a 20:00 horas) Casa de la Cultura

- Rojales: 3 de junio de 2009 (10:00 a 13:00 horas). Centro Social Municipal

FASE2:

- Los Montesinos: 22 de junio de 2009 (10:00 a 13:00 horas)

- Torrevieja: 22 de junio tarde de 2009 (17: a 20:00 horas) Auditorio del Palacio de la Música

- San Miguel de Salinas: 23 de junio de 2009 (10:00 a 13:00 horas), Casa de la Cultura

- Guardamar del Segura: 23 de junio de 2009 (17:00 a 20:00 horas) Casa de la Cultura

- Rojales: 24 de junio de 2009 (10:00 a 13:00 horas). Centro Social Municipal

FASE3:

- Los Montesinos: 28 de julio de 2009 (10:00 a 13:00 horas)

- Torrevieja: 28 de julio de 2009 (17: a 20:00 horas), Auditorio del Palacio de la Música

- San Miguel de Salinas: 29 de julio de 2009 (10:00 a 13:00 horas), Casa de la Cultura

- Guardamar del Segura: 29 de julio de 2009 (17:00 a 20:00 horas). Casa de la Cultura

- Rojales: 30 de julio de 2009 (10:00 a 13:00 horas). Centro Social Municipal

Como se deduce de los expuesto anteriormente, durante el Plan de Participación Publica del Estudio de Paisaje del Parque Natural de La Mata - Torrevieja se consultó en tres ocasiones a la población, haciéndose públicas las conclusiones de cada fase a la finalización de ésta y utilizando dichas conclusiones como base documental para la fase siguiente.

b) Consultas: Las consultas a la población se realizaron mediante:

- Entrevistas directas sobre una muestra representativa de la población residente y visitante.

- Entrevistas durante los seminarios informativos programados

- Cumplimentación de formularios disponibles en:

- A) Centro de Recepción de Visitantes del parque natural de La Mata-Torrevieja y puntos de información del Ayuntamiento de Torrevieja

- B) WEB de la Consellería de Medio Ambiente, Agua, Urbanismo y Vivienda: http://www.cma.gva.es

- PAISAJE > Presentación

- PAISAJE > Agenda y Noticias

- ESPACIOS PROTEGIDOS > Parques Naturales > Agenda y noticias

- ESPACIOS PROTEGIDOS > Parques Naturales $>$ Lagunas de la Mata y Torrevieja $>$ Agenda y noticias

- C) WEBs institucionales o de amplio uso de los ayuntamientos siguientes:

- Torrevieja: http://www.torrevieja.com, http://www.webtorrevieja.com

- Los Montesinos: http://www.losmontesinos.org

- Guardamar del Segura: http://www.guardamar.net

- Rojales: http://www.rojales.es

El material empleado en las encuestas a pie de calle y en los formularios disponibles en las distintas webs fue similar y consistió fundamentalmente en cuestionarios apoyados en imágenes que podían ser respondidos en 15 - 20 minutos. En el caso de la primera fase, el formulario iba precedido de una explicación del Plan de Participación, una breve introducción al Parque Natural y concluía invitando a participar en la Fase2, detallando fecha de inicio de la misma y los distintos modos de acceder a ésta.

El formulario de la fase2 (valoración del paisaje) iba precedido de los resultados de la Fase1 y concluía invitando a participar en la Fase3, detallando fecha de inicio de la misma y los distintos modos de acceder a ésta. 
Finalmente, el formulario de la fase3 (actuaciones en el paisaje) iba precedido de los resultados de la Fase 2 y concluía invitando a visitar las webs y puntos en los que se mostrará el Estudio de Paisaje del Parque Natural de La Mata - Torrevieja una vez éste quedase concluido.

En lo relativo a las encuestas a pie de calle, consideradas fundamentales para conseguir opiniones representativas del conjunto de la población residente y visitante del área de estudio, se atendió al estudio sociodemográfico realizado en su día por la Dirección General de Territorio y Paisaje para el Plan Visual de la Comunidad Valenciana (STEINITZ, MUÑOZ, GALÁN, 2008), en el que, para la zona correspondiente a las comarcas del sur de Alicante, se definía una muestra representativa de la población compuesta con los perfiles siguientes:
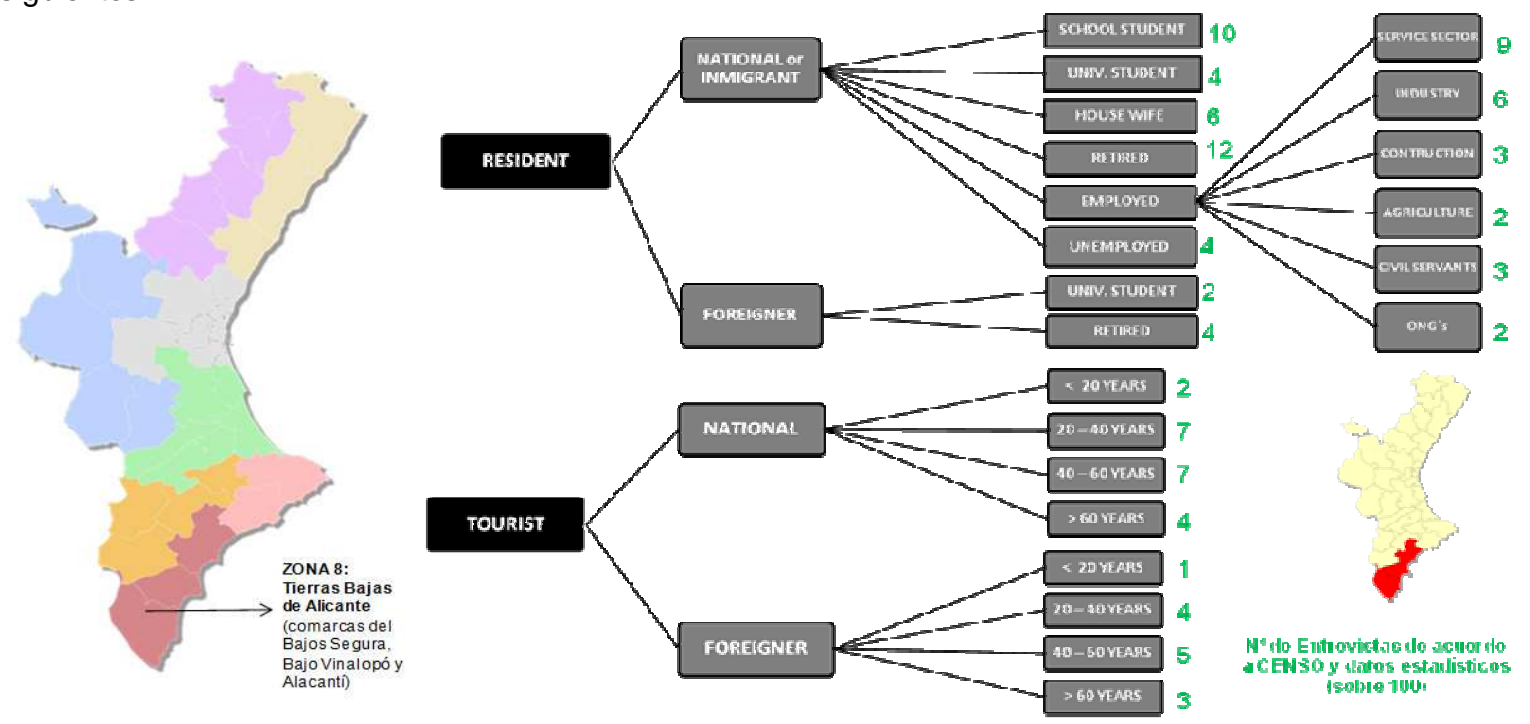

Fig. 5.25: Composición de una muestra de 100 personas, representativa de la población residente y visitantes de las comarcas del sur de Alicante (STEINITZ, MUÑOZ, GALAN, 2008)

A efectos de desarrollo del Plan de Participación, se realizaron un total de 80 a 100 encuestas en cada una de las fases, seleccionando personas acordes a las proporciones listadas en el esquema previo, que por ser propio de las Comarcas del Bajo Segura, Bajo Vinalopó y Alacantí, coincide en gran medida con el que sería característico del ámbito estricto del presente estudio de paisaje

c) Difusión: La difusión del plan de participación pública (PPP) se realizó principalmente mediante la convocatoria a los seminarios programados y mediante el envío de correos electrónicos informativos a las instituciones, asociaciones y ONG's incluidas en el listado de Grupos de Interés y Grupos del Lugar, a los que se invitó a difundir el Plan entre sus técnicos, socios o miembros. Dicha difusión incluyó las actuaciones siguientes:

- 27 de mayo de 2009: envío de documento informativo a las instituciones, organizaciones y asociaciones interesadas (para su redistribución).

- 27 de mayo de 2009: envío de invitación a participar en la fase 1 del PPP a las instituciones, organizaciones y asociaciones interesadas (para su redistribución).

- 17 de junio de 2009: envío de resultados y conclusiones de la FASE1 del PPP e invitación a participar en la FASE2 a las instituciones, organizaciones y asociaciones interesadas (para su redistribución). Inserción en las webs de los resultados de la FASE 1 y de la documentación para participar en la FASE2.

- 20 de julio de 2009: envío de resultados y conclusiones de la FASE2 del PPP e invitación a participar en la FASE3 a las instituciones, organizaciones y asociaciones interesadas (para su redistribución). Inserción en las webs de los resultados de la FASE 2 y de la documentación para participar en la FASE3.

- 10 de agosto de 2009: envío de resultados y conclusiones de la FASE3 del PPP a las instituciones, organizaciones y asociaciones interesadas (para su redistribución). Inserción en las webs de los resultados de la FASE 3.

- 15 de septiembre de 2009: envío de conclusiones finales del PPP y de enlace a sitio web desde el que visualizar el estudio de paisaje del Parque Natural de la Lagunas de La Mata y Torrevieja. Inserción en las webs municipales de las conclusiones del PPP. 
5.4.c.5. Seguimiento del Plan de Participación Publica del Estudio de Paisaje del Parque Natural de las Lagunas de La Mata y Torrevieja:

El plan de participación pública previsto en el estudio de paisaje del Parque Natural de las lagunas de La Mata y Torrevieja incluyó una serie de fechas intermedias (ver punto anterior) en las que se informó, mediante envío de correo electrónico e inserción en las respectivas webs, de los resultados de cada fase del Plan de Participación y de las conclusiones parciales y finales.

\section{4.d. Caracterización del Paisaje (apoyado en la FASE1 del Plan de Participación Pública) \\ 5.4.d.1. Introducción: \\ La caracterización de las Unidades de Paisaje en el presente tuvo por objeto: \\ - Definir y delimitar las unidades paisajísticas en el ámbito de estudio. \\ - Analizar las características de las unidades de paisaje y establecer sus dinámicas. \\ - Identificar los recursos y conflictos paisajísticos \\ - Proporcionar información relevante para la definición de los objetivos de calidad paisajística.}

Los trabajos correspondientes a la caracterización del paisaje fueron realizados en paralelo a la fase1 del plan de participación pública, en el que fueron consultados expertos y una muestra representativa de la población residente y visitante de los 5 municipios afectados.

\section{4.d.2. Resultados del Plan de Participación Pública:}

El proceso de consultas en la fase de Caracterización del Paisaje se desarrolló de acuerdo a los planteamientos y condiciones marcadas en el Plan de Participación Pública y haciendo uso del material adjuntado en el Anexo VIII: "Cuestionarios del Plan de Participación Pública", distribuido entre expertos y presentado a la población mediante encuestas a pie de calle o en las webs institucionales de apoyo.

\section{4.d.2.1. Niveles de participación:}

- Encuestas: Al tratarse de una zona con una elevada heterogeneidad de población, se estableció una muestra lo más representativa posible de la misma. Para ello se planteó que el porcentaje de entrevistados fuera entorno a un 50-60\% en Torrevieja, a un 10\% en Los Montesinos y San Miguel de Salinas y a un $15-20 \%$ en Rojales y Guardamar del Segura, así como que el $19 \%$ fuera de nacionalidad diferente a la española. Con respecto al sexo, que fuese lo más equitativo posible. Durante la fase 1 se realizaron un total de 80 encuestas.

- Consultas expertos: Entre los expertos contactados para solicitar su posible colaboración en la FASE1 del Plan de Participación Pública se incluyeron técnicos de los Ayuntamientos de Torrevieja, Guardamar del Segura, Rojales, Los Montesinos y San Miguel de Salinas, profesores de las distintas Universidades de la Comunidad Valenciana, técnicos de la Consellería de Medio Ambiente, Agua, Urbanismo y Vivienda y del Parque Natural de las lagunas de La Mata-Torrevieja, recibiéndose un total de 19 respuestas al cuestionario.

Tabla 5.5: Comparación entre los perfiles de los encuestados inicialmente previstos y finalmente encuestados en la fase1 del plan de participación pública.

\begin{tabular}{l|c|c|c}
\multicolumn{1}{c|}{ Variable encuestado } & Valores & Objetivo Encuestas & Encuestas realizadas \\
\hline \hline \multirow{3}{*}{$\begin{array}{l}\text { Lugar de realización de } \\
\text { encuestas }\end{array}$} & Torrevieja & $50-60 \%$ & $45,36 \%$ \\
\cline { 2 - 4 } & Montesinos & $10 \%$ & $11,34 \%$ \\
\cline { 2 - 4 } & Guardamar & $15-20 \%$ & $12,37 \%$ \\
\cline { 2 - 4 } $\begin{array}{l}\text { Motivo presencia en la } \\
\text { zona }\end{array}$ & Rojales & $15-20 \%$ & $10,31 \%$ \\
\cline { 2 - 4 } Nacionalidad & San Miguel de Salinas & $10 \%$ & $5,15 \%$ \\
\cline { 2 - 4 } & Residente & $66 \%$ & $22,68 \%$ \\
\cline { 2 - 4 } Edad & Expañol & $33 \%$ & $82,00 \%$ \\
\cline { 2 - 4 } & Extranjero & $81 \%$ & $18,00 \%$ \\
\hline \multirow{2}{*}{ Sexo } & $0-18$ & $19 \%$ & $8,25 \%$ \\
\cline { 2 - 4 } & $18-65$ & $13 \%$ & $83,50 \%$ \\
\cline { 2 - 4 } & $>65$ & $68 \%$ & $8,25 \%$ \\
\hline
\end{tabular}

\section{4.d.2.2. Unidades de paisaje:}

La primera de las cuestiones formulada a los entrevistados (población y expertos) fue que trataran de identificar cuáles eran los tipos y unidades de paisaje presentes en la zona del ámbito estricto del estudio. Los resultados fueron los siguientes: 
Tabla 5.6: Tipos de paisaje indicados por la población y expertos en la fase 1 del plan de participación pública.

\begin{tabular}{|c|c|}
\hline Unidades identificadas por la población & $\begin{array}{l}\text { \% de } \\
\text { elección }\end{array}$ \\
\hline Urbanizaciones & 83 \\
\hline Playa & 81 \\
\hline Monte El Chaparral & 64 \\
\hline Huertos tradicionales & 60 \\
\hline Alto de la Atalaya - Moncayo & 59 \\
\hline $\begin{array}{c}\text { Huertos de la Mata - secano (este) } \\
\text { viñedos }\end{array}$ & 48 \\
\hline Grandes explotaciones agrícolas & 38 \\
\hline Torrevieja & 37 \\
\hline $\begin{array}{c}\text { Marjales y Saladares de la laguna de } \\
\text { Torrevieja }\end{array}$ & 23 \\
\hline Marjal y Saladares de la Mata & 20 \\
\hline Puerto & 20 \\
\hline Industria salinera & 15 \\
\hline Saladar entre lagunas & 12 \\
\hline Polígonos industriales & 12 \\
\hline Playa de roca & 11 \\
\hline Cuña agrícola -Sur Torrevieja & 7 \\
\hline Monte-agrícola Falla de San Miguel & 5 \\
\hline Equipamientos Torrevieja & 1 \\
\hline Dunas de Guardamar & 1 \\
\hline Ramblas & 1 \\
\hline
\end{tabular}

\begin{tabular}{|c|c|}
\hline $\begin{array}{l}\text { Unidades identificadas por los } \\
\text { expertos }\end{array}$ & $\begin{array}{l}\text { \% de } \\
\text { elección }\end{array}$ \\
\hline $\begin{array}{l}\text { Huertos de la Mata - secano (este) } \\
\text { viñedos }\end{array}$ & 75 \\
\hline Urbanizaciones & 75 \\
\hline Huertos tradicionales & 65 \\
\hline Monte-agrícola Falla de San Miguel & 60 \\
\hline Grandes explotaciones agrícolas & 55 \\
\hline Cuña agrícola -Sur Torrevieja & 55 \\
\hline Marjal y Saladares de la Mata & 55 \\
\hline $\begin{array}{c}\text { Marjales y Saladares de la laguna de } \\
\text { Torrevieja }\end{array}$ & 55 \\
\hline Monte EL Chaparral & 50 \\
\hline Dunas de Guardamar & 50 \\
\hline Torrevieja & 40 \\
\hline Alto de la Atalaya - Moncayo & 40 \\
\hline Saladar entre lagunas & 25 \\
\hline Equipamientos Torrevieja & 15 \\
\hline Industria salinera & 15 \\
\hline Playas de arena & 15 \\
\hline Ramblas & 10 \\
\hline Playa de roca & 5 \\
\hline Puerto & 0 \\
\hline Polígonos industriales & 0 \\
\hline
\end{tabular}

Cabe señalar que la mayor parte de la población no hace referencia a unidades de paisaje compactas sino a tipos de paisaje, refiriéndose por ejemplo a urbanizaciones, cultivos, cítricos, más que a urbanizaciones o zonas de cultivo concretas.

A efectos de establecer una serie de unidades de paisaje compactas, se procedió a unificar algunas de ellas y renombrarlas, llegando a la clasificación recogida en la tabla siguiente. Entre las unidades así definidas se han incorporado espacios estratégicos para la conexión ecológica y funcional del parque (caso del Alto del Moncayo y la Atalaya, del Conector de la rambla de La Fayona o del frente litoral y casco urbano de Torrevieja), así como unidades esenciales para la gestión del entorno visual del parque (caso de la Unidad de Ciudad Quesada).

Tabla 5.7: Unidades de paisaje en el ámbito estricto.

\begin{tabular}{c|l} 
UP1 & Marjales y saladares de la laguna de la Mata \\
\hline UP2 & $\begin{array}{l}\text { Marjales, saladares e instalaciones salineras de la } \\
\text { laguna de Torrevieja }\end{array}$ \\
\hline UP3 & Viñedos y secanos de la Mata \\
\hline UP4 & $\begin{array}{l}\text { Regadíos tradicionales de las lagunas de la Mata y } \\
\text { Torrevieja }\end{array}$ \\
\hline UP5 & Regadíos extensivos de la laguna de Torrevieja \\
\hline UP6 & Altos del Moncayo y la Atalaya \\
\hline UP7 & Dunas de Guardamar \\
\hline UP8 & Alto de la Hoya y pinadas del Chaparral \\
\hline UP9 & Conector de la rambla de la Fayona \\
\hline UP10 & Urbanización El Raso \\
\hline UP11 & Urbanización Ciudad Quesada \\
\hline UP12 & $\begin{array}{l}\text { Urbanizaciones entre las lagunas de la Mata y } \\
\text { Torrevieja }\end{array}$ \\
\hline UP13 & Urbanización Los Balcones \\
\hline UP14 & $\begin{array}{l}\text { Conector sur laguna de Torrevieja - Mar } \\
\text { Mediterráneo }\end{array}$ \\
\hline UP15 & Frente litoral y casco urbano de Torrevieja
\end{tabular}

\section{4.d.2.3. Recursos paisajísticos:}

A continuación se preguntó a la población y expertos sobre los distintos tipos de recursos paisajísticos detectados en el parque y su entorno. A efectos del estudio se consideró como recursos paisajísticos los elementos puntuales, lineales o extensos singulares de un paisaje. De acuerdo a la metodología propuesta y al Reglamento de Paisaje de la Comunidad Valenciana, se distinguió entre recursos paisajísticos ambientales, culturales y visuales. 
VALORACIÓN Y GESTIÓN DEL PAISAJE SEGÚN EL CONVENIO EUROPEO DEL PAISAJE YEL

REGLAMENTO DEL PAISAJE DE LA COMUNIDAD VALENCIANA: APLICACIÓN MEDIANTE UN ESTUDIO DE PAISAJE A UNESPACIO ABIERTO EN LA COMUNIDAD VALENCIANA

DOCTORANDO: JUAN JOSÉ GALÁN VIVAS (Universidad Politécnica de Valencia, enero 2011)

\section{Recursos paisajísticos ambientales:}

Los recursos paisajísticos ambientales indicados por población y expertos fueron respectivamente:

Tabla 5.8: Recursos paisajísticos ambientales identificados por la población y expertos en la fase1 del plan de participación pública.

\begin{tabular}{c|c}
$\begin{array}{c}\text { Recursos paisajísticos ambientales } \\
\text { identificados por la población }\end{array}$ & $\begin{array}{c}\% \\
\text { Elección }\end{array}$ \\
\hline Pinares y Monte Moncayo-La Atalaya & 72 \\
\hline Saladares Torrevieja_norte & 60 \\
\hline Saladares La Mata_este & 58 \\
\hline Saladares Torrevieja_este & 58 \\
\hline Saladares La Mata_norte & 57 \\
\hline Pinada el Chaparral & 42 \\
\hline Laminas de agua & 42 \\
\hline Dunas de Guardamar & 40 \\
\hline Saladares Canal de Las Salinas & 37 \\
\hline Variedad Merseguera - viñedos & 35 \\
\hline Cubetas salinas & 23 \\
\hline Marjales La Mata_norte & 20 \\
\hline Marjales La Mata_este & 20 \\
\hline Marjales Torrevieja_este & 20 \\
\hline Marjales Torrevieja_norte & 17 \\
\hline Huertos hortícolas & 12 \\
\hline Huertos herbáceas regadío & 11 \\
\hline acequias & 11 \\
\hline Rambla La Fayona & 10 \\
\hline Costa rocosa de Torrevieja & 9 \\
\hline Litoral (playa-puerto) & 9 \\
\hline Rambla Lo Marabú & 7 \\
\hline Desembocadura barranco Fayona & 6 \\
\hline Rambla Garbanzuelo & 6 \\
\hline fauna & 5 \\
\hline Cuevas & 2 \\
\hline & 1
\end{tabular}

\begin{tabular}{c|c}
$\begin{array}{c}\text { Recursos paisajísticos ambientales } \\
\text { identificados por los expertos }\end{array}$ & $\begin{array}{c}\% \\
\text { Elección }\end{array}$ \\
\hline Pinares y Monte Moncayo-La Atalaya & 80 \\
\hline Laminas de agua & 85 \\
\hline Pinada el Chaparral & 75 \\
\hline Variedad Merseguera - viñedos & 45 \\
\hline Marjales La Mata_norte & 45 \\
\hline Marjales La Mata_este & 45 \\
\hline Marjales Torrevieja_norte & 45 \\
\hline Marjales Torrevieja_este & 45 \\
\hline Rambla La Fayona & 30 \\
\hline Rambla Lo Marabú & 30 \\
\hline Rambla Garbanzuelo & 30 \\
\hline Saladares La Mata_este & 25 \\
\hline Saladares La Mata_norte & 25 \\
\hline Dunas de Guardamar & 25 \\
\hline Huertos hortícolas & 25 \\
\hline Huertos herbáceas regadí & 25 \\
\hline Cubetas salinas & 15 \\
\hline Costa rocosa de Torrevieja & 15 \\
\hline fauna & 15 \\
\hline Saladares Torrevieja_este & 10 \\
\hline Saladares Torrevieja_norte & 10 \\
\hline acequias & 10 \\
\hline Saladares Canal de Las Salinas & 5 \\
\hline Desembocadura barranco Fayona & 5 \\
\hline Huertos de secano & 5 \\
\hline Cuevas & 5 \\
\hline Litoral (playa-puerto) & 0
\end{tabular}

Recursos paisajísticos culturales:

Los recursos paisajísticos culturales indicados por población y expertos fueron respectivamente:

Tabla 5.9: Recursos paisajísticos culturales identificados por la población y expertos en la fase1 del plan de participación pública.

\begin{tabular}{|c|c|}
\hline $\begin{array}{l}\text { Recursos paisajísticos culturales } \\
\text { identificados por la población }\end{array}$ & $\begin{array}{c}\% \\
\text { elección }\end{array}$ \\
\hline Acequión Torrevieja & 59 \\
\hline Torre del Moro & 47 \\
\hline Torre de la Mata & 30 \\
\hline Paseo marítimo de Torrevieja & 23 \\
\hline $\begin{array}{c}\text { Industria salinera y cintas } \\
\text { transportadoras }\end{array}$ & 19 \\
\hline Parque Molino del Agua & 19 \\
\hline Castillo de Guardamar & 17 \\
\hline Eras de la Sal y Embarcadero & 17 \\
\hline Iglesias y ermitas & 16 \\
\hline Aljibes de Los Montesinos & 11 \\
\hline Canal de las Salinas & 11 \\
\hline Casa de La Marquesa & 10 \\
\hline Faro de Torrevieja & 10 \\
\hline Sistema de acequias de riego & 9 \\
\hline Casas Arquitectura Tradicional & 6 \\
\hline Casa Forestal de La Mata & 5 \\
\hline Canal de La Mata & 4 \\
\hline Vía Verde & 4 \\
\hline Yacimientos & 4 \\
\hline Mezquita musulmana & 4 \\
\hline Huertos Campico de Guardamar & 2 \\
\hline Huertos de Los Montesinos & 2 \\
\hline Viñedos & 2 \\
\hline $\begin{array}{l}\text { Torres de vigilancia en el interior del } \\
\text { parque }\end{array}$ & 2 \\
\hline Balneario & 1 \\
\hline Cuevas & 1 \\
\hline Antena del Moncayo & 1 \\
\hline Tren de la sal & 1 \\
\hline Cementerio de Torrevieja y la Mata & 0 \\
\hline Centro Interpretación Industria Salinera & 0 \\
\hline
\end{tabular}

\begin{tabular}{|c|c|}
\hline $\begin{array}{l}\text { Recursos paisajísticos culturales } \\
\text { identificados por los expertos }\end{array}$ & \% elección \\
\hline Casa de La Marquesa & 50 \\
\hline Casas Arquitectura Tradicional & 50 \\
\hline Acequión de Torrevieja & 45 \\
\hline $\begin{array}{l}\text { Industria salinera y cintas } \\
\text { transportadoras }\end{array}$ & 30 \\
\hline Iglesias y ermitas & 25 \\
\hline Canal de La Mata & 20 \\
\hline Canal de las Salinas & 20 \\
\hline Sistema de acequias de riego & 20 \\
\hline Torre del Moro & 20 \\
\hline Parque Molino del Agua & 15 \\
\hline Aljibes de Los Montesinos & 15 \\
\hline Huertos de Los Montesinos & 15 \\
\hline Huertos Campico de Guardamar & 10 \\
\hline Torre de la Mata & 10 \\
\hline Yacimientos & 10 \\
\hline Balneario & 5 \\
\hline Cementerio de Torrevieja y la Mata & 5 \\
\hline $\begin{array}{c}\text { Centro Interpretación Industria } \\
\text { Salinera }\end{array}$ & 5 \\
\hline Eras de la Sal y Embarcadero & 5 \\
\hline Vía Verde & 5 \\
\hline Viñedos & 5 \\
\hline Faro de Torrevieja & 5 \\
\hline Cuevas & 5 \\
\hline Casa Forestal de La Mata & 0 \\
\hline Castillo de Guardamar & 0 \\
\hline Paseo marítimo de Torrevieja & 0 \\
\hline $\begin{array}{c}\text { Torres de vigilancia en el interior } \\
\text { del parque }\end{array}$ & 0 \\
\hline Antena del Moncayo & 0 \\
\hline Mezquita musulmana & 0 \\
\hline Tren de la sal & 0 \\
\hline
\end{tabular}


VALORACIÓNY GESTIÓN DEL PAISAJE SEGÚN EL CONVENIO EUROPEO DEL PAISAJE YEL

REGLAMENTO DEL PAISAJE DE LA COMUNIDAD VALENCIANA: APLICACIÓN MEDIANTE UN ESTUDIO DE PAISAJE A UNESPACIO ABIERTO EN LA COMUNIDAD VALENCIANA

DOCTORANDO: JUAN JOSÉ GALÁN VIVAS (Universidad Politécnica de Valencia, enero 2011)

\section{Recursos paisajísticos visuales:}

Los recursos paisajísticos visuales indicados por población y expertos fueron respectivamente:

Tabla 5.10: Recursos paisajísticos visuales identificados por la población y expertos en la fase 1 del plan de participación pública..

\begin{tabular}{|c|c|}
\hline $\begin{array}{l}\text { Recursos paisajisticos visuales } \\
\text { identificados por la población }\end{array}$ & $\begin{array}{c}\% \\
\text { elección }\end{array}$ \\
\hline Industria salinera & 64 \\
\hline Costa Torrevieja & 38 \\
\hline Depósitos de Sal & 30 \\
\hline $\begin{array}{c}\text { Cresta y laderas falla de San Miguel } \\
\text { (los Alcores) }\end{array}$ & 28 \\
\hline $\begin{array}{l}\text { Cresta y laderas entre la N332 y la } \\
\text { zona noreste de la laguna de La mata }\end{array}$ & 20 \\
\hline Vistas desde la autovia & 15 \\
\hline Laguna de La Mata & 14 \\
\hline $\begin{array}{c}\text { Vistas desde la N332 a la laguna de } \\
\text { La Mata }\end{array}$ & 14 \\
\hline $\begin{array}{c}\text { Vistas desde la N332 a la laguna de } \\
\text { Torrevieja }\end{array}$ & 14 \\
\hline Laguna de Torrevieja & 12 \\
\hline $\begin{array}{c}\text { Vistas desde la CV } 95 \text { a la Laguna de } \\
\text { La Mata }\end{array}$ & 12 \\
\hline castillo de Guardamar & 10 \\
\hline Pico y laderas Atalaya & 9 \\
\hline Pico y laderas Moncayo & 9 \\
\hline Torre del Moro & 9 \\
\hline Acequión Torrevieja & 7 \\
\hline Alto y laderas de La Hoya & 6 \\
\hline Vía Verde & 5 \\
\hline Rutas (caminos tradicionales) & 5 \\
\hline Canal de las Salinas & 4 \\
\hline Observatorios Laguna de La Mata & 4 \\
\hline Torre de la Mata & 4 \\
\hline Barranco La Fayona & 1 \\
\hline Canal de La Mata & 1 \\
\hline huertos & 1 \\
\hline Marjales y saladares & 1 \\
\hline Faro Torrevieja & 1 \\
\hline yacimientos & 1 \\
\hline Centro Visitantes la Mata & 0 \\
\hline Recorrido sur de la laguna de la Mata & 0 \\
\hline Urbanizaciones & 0 \\
\hline
\end{tabular}

\begin{tabular}{|c|c|}
\hline $\begin{array}{l}\text { Recursos paisajísticos visuales } \\
\text { identificados por los expertos }\end{array}$ & \% elección \\
\hline Alto y laderas de La Hoya & 45 \\
\hline $\begin{array}{l}\text { Cresta y laderas falla de San Miguel (los } \\
\text { Alcores) }\end{array}$ & 40 \\
\hline Depósitos de Sal & 40 \\
\hline $\begin{array}{c}\text { Cresta y laderas entre la N332 y la zona } \\
\text { noreste de la laguna de La mata }\end{array}$ & 35 \\
\hline Laguna de La Mata & 35 \\
\hline Laguna de Torrevieja & 30 \\
\hline Pico y laderas Atalaya & 30 \\
\hline Pico y laderas Moncayo & 30 \\
\hline Industria salinera & 20 \\
\hline $\begin{array}{c}\text { Vistas desde la CV } 95 \text { a la Laguna de La } \\
\text { Mata }\end{array}$ & 20 \\
\hline Vistas desde la autovia & 20 \\
\hline $\begin{array}{c}\text { Vistas desde la N332 a la laguna de La } \\
\text { Mata }\end{array}$ & 20 \\
\hline $\begin{array}{c}\text { Vistas desde la N332 a la laguna de } \\
\text { Torrevieja }\end{array}$ & 20 \\
\hline Costa Torrevieja & 15 \\
\hline Marjales y saladares & 15 \\
\hline Observatorios Laguna de La Mata & 10 \\
\hline Vía Verde & 10 \\
\hline Acequión Torrevieja & 5 \\
\hline Barranco La Fayona & 5 \\
\hline Centro Visitantes la Mata & 5 \\
\hline Recorrido sur de la laguna de la Mata & 5 \\
\hline Torre del Moro & 5 \\
\hline Rutas (caminos tradicionales) & 5 \\
\hline huertos & 5 \\
\hline Canal de La Mata & 0 \\
\hline Canal de las Salinas & 0 \\
\hline yacimientos & 0 \\
\hline Torre de la Mata & 0 \\
\hline Faro Torrevieja & 0 \\
\hline Urbanizaciones & 0 \\
\hline Castill & 0 \\
\hline
\end{tabular}

5.4.d.2.4. Procesos en el paisaje:

Durante el proceso de consulta en la FASE 1 se pidió a los participantes la identificación de los procesos o dinámicas que se dan en las unidades de paisaje y en los recursos paisajísticos. Los procesos indicados por población y expertos fueron respectivamente:

Tabla 5.11: Procesos en el paisaje identificados por la población y expertos en la fase1 del plan de participación pública..

\begin{tabular}{c|c}
$\begin{array}{c}\text { Procesos identificados por la } \\
\text { población }\end{array}$ & $\begin{array}{c}\% \\
\text { elección }\end{array}$ \\
\hline Urbanización & 84 \\
\hline $\begin{array}{c}\text { Ampliación infraestructuras } \\
\text { transporte }\end{array}$ & 58 \\
\hline Abandono hortícolas & 35 \\
\hline Abandono cítricos & 27 \\
\hline Abandono viñedos & 27 \\
\hline Ausencia zonas verdes & 27 \\
\hline $\begin{array}{c}\text { Abandono frutales secano } \\
\text { Construcción de nuevas } \\
\text { infraestructuras de transporte }\end{array}$ & 26 \\
\hline aumento turismo y presión humana & 14 \\
\hline $\begin{array}{c}\text { Uso intenso del parque } \\
\text { Dificultad de la utilización de las } \\
\text { nuevas infraestructuras }\end{array}$ & 7 \\
\hline $\begin{array}{c}\text { Introducción de servicios en el } \\
\text { entorno del parque (hostelería) }\end{array}$ & 5 \\
\hline Mejora del parque & 5 \\
\hline Aumento servicios & 5 \\
\hline Construcción de equipamientos \\
Torrevieja & 4 \\
\hline Deterioro recursos culturales & 4 \\
\hline $\begin{array}{c}\text { Construcción de nuevas } \\
\text { infraestructuras de energía }\end{array}$ & 2 \\
\hline Cultivos bajo plástico & 2 \\
\hline Reparcelación agraria & 1 \\
\hline $\begin{array}{c}\text { Ausencia servicios tratamiento } \\
\text { residuos }\end{array}$ & 1 \\
\hline Falta de mantenimiento y suciedad & 1 \\
\hline$\quad$
\end{tabular}

\begin{tabular}{|c|c|}
\hline $\begin{array}{c}\text { Procesos identificados por los } \\
\text { expertos }\end{array}$ & $\begin{array}{c}\% \\
\text { elección }\end{array}$ \\
\hline Urbanización & 75 \\
\hline Abandono cítricos & 50 \\
\hline Abandono frutales secano & 50 \\
\hline Abandono horticolas & 45 \\
\hline Abandono viñedos & 45 \\
\hline Ampliación infraestructuras transporte & 40 \\
\hline Aumento turismo y presión humana & 25 \\
\hline Reparcelación agraria & 20 \\
\hline $\begin{array}{c}\text { Construcción de nuevas infraestructuras } \\
\text { de energía }\end{array}$ & 15 \\
\hline $\begin{array}{c}\text { Construcción de nuevas infraestructuras } \\
\text { de transporte } \\
\end{array}$ & 15 \\
\hline $\begin{array}{c}\text { Dificultad de la utilización de las nuevas } \\
\text { infraestructuras }\end{array}$ & 10 \\
\hline $\begin{array}{c}\text { Construcción de equipamientos } \\
\text { Torrevieja }\end{array}$ & 10 \\
\hline deterioro recursos culturales & 10 \\
\hline Cultivos bajo plástico & 5 \\
\hline Uso intenso del parque & 5 \\
\hline Ausencia servicios tratamiento residuos & 5 \\
\hline Falta de mantenimiento y suciedad & 5 \\
\hline Mejora del parque & 5 \\
\hline $\begin{array}{c}\text { Introducción de servicios en el entorno } \\
\text { del parque (hostelería) }\end{array}$ & 0 \\
\hline Ausencia zonas verdes & 0 \\
\hline Aumento servicios & 0 \\
\hline
\end{tabular}




\section{4.d.2.5. Conflictos y Problemas en el paisaje:}

Los principales conflictos (referentes a aspectos visuales, sociales, de gestión económica del territorio, de acceso y conexión física) detectados por la población y expertos para el adecuado funcionamiento e interrelación de los espacios naturales, agrícolas, salineros y urbanos existentes en el Parque Natural y sus inmediaciones fueron los siguientes:

Tabla 5.12: Conflictos en el paisaje identificados por la población y expertos en la fase1 del plan de participación pública..

\begin{tabular}{|c|c|}
\hline $\begin{array}{c}\text { Conflictos identificados por la } \\
\text { población }\end{array}$ & $\begin{array}{c}\% \\
\text { elección }\end{array}$ \\
\hline Urbanización & 77 \\
\hline $\begin{array}{c}\text { Encuentros entre Urbanizaciones y } \\
\text { Parque Natural }\end{array}$ & 33 \\
\hline $\begin{array}{l}\text { Accesos deficientes para peatones y } \\
\text { ciclistas al Parque }\end{array}$ & 26 \\
\hline Desaparición de zonas verdes & 25 \\
\hline Abandono hortícolas & 22 \\
\hline Abandono cítricos & 19 \\
\hline Abandono frutales secano & 19 \\
\hline Abandono viñedos & 19 \\
\hline Aumento contaminación, residuos & 10 \\
\hline $\begin{array}{l}\text { Aumento de la población/presión } \\
\text { entorno }\end{array}$ & 9 \\
\hline $\begin{array}{l}\text { Falta mayor actividad y publicidad } \\
\text { en el parque }\end{array}$ & 6 \\
\hline Destrucción de marjales & 5 \\
\hline Destrucción de saladares & 5 \\
\hline Carreteras próximas al parque & 5 \\
\hline Uso del parque: paseo a caballo & 4 \\
\hline Uso del parque: paseo perros & 4 \\
\hline Uso del parque: baños en lagunas & 4 \\
\hline $\begin{array}{l}\text { Ampliación infraestructuras } \\
\text { transporte }\end{array}$ & 2 \\
\hline Cruce de AP7 & 2 \\
\hline Cruce de CV905 & 2 \\
\hline Cruce de N332 & 2 \\
\hline Deterioro casas rurales & 2 \\
\hline Deterioro de canales & 2 \\
\hline Rotondas & 2 \\
\hline $\begin{array}{c}\text { Construcción de equipamientos } \\
\text { Torrevieja }\end{array}$ & 1 \\
\hline $\begin{array}{l}\text { Introducción de servicios en el } \\
\text { entorno del parque (hostelería) }\end{array}$ & 1 \\
\hline $\begin{array}{l}\text { Márgenes de ramblas en } \\
\text { urbanizaciones }\end{array}$ & 1 \\
\hline $\begin{array}{c}\text { Vegetación exótica e invasora en } \\
\text { urbanizaciones }\end{array}$ & 1 \\
\hline $\begin{array}{c}\text { Ausencia de recogida y tratamiento } \\
\text { de residuos }\end{array}$ & 1 \\
\hline $\begin{array}{c}\text { Conexión con parque Natural Dehesa } \\
\text { de Campoamor }\end{array}$ & 0 \\
\hline $\begin{array}{l}\text { Construcción de nuevas } \\
\text { infraestructuras de transporte }\end{array}$ & 0 \\
\hline Cruces de ramblas bajo carreteras & 0 \\
\hline Cubrimiento de canales & 0 \\
\hline Cultivos bajo plástico & 0 \\
\hline Encuentro casco urbano-Torrevieja & 0 \\
\hline Introducción riego goteo & 0 \\
\hline Desaparición yacimientos & 0 \\
\hline Degradación del paisaje & 0 \\
\hline PGOU sin conexión entre municipios & 0 \\
\hline $\begin{array}{l}\text { Arquitectura alejada de la } \\
\text { tradicional }\end{array}$ & 0 \\
\hline
\end{tabular}

\begin{tabular}{|c|c|}
\hline $\begin{array}{c}\text { Conflictos identificados por los } \\
\text { expertos }\end{array}$ & $\begin{array}{c}\% \\
\text { elección }\end{array}$ \\
\hline $\begin{array}{c}\text { Encuentros entre Urbanizaciones y } \\
\text { Parque Natural }\end{array}$ & 45 \\
\hline Urbanización & 45 \\
\hline Abandono viñedos & 20 \\
\hline $\begin{array}{l}\text { Ausencia de recogida y tratamiento de } \\
\text { residuos }\end{array}$ & 20 \\
\hline $\begin{array}{l}\text { Accesos deficientes para peatones y } \\
\text { ciclistas al Parque }\end{array}$ & 15 \\
\hline $\begin{array}{l}\text { Falta mayor actividad y publicidad en el } \\
\text { parque }\end{array}$ & 15 \\
\hline Abandono cítricos & 10 \\
\hline Abandono frutales secano & 10 \\
\hline Abandono hortícolas & 10 \\
\hline $\begin{array}{c}\text { Vegetación exótica e invasora en } \\
\text { urbanizaciones }\end{array}$ & 10 \\
\hline Aumento contaminación, residuos & 10 \\
\hline PGOU sin conexión entre municipios & 10 \\
\hline arquitectura alejada de la tradicional & 10 \\
\hline $\begin{array}{l}\text { Construcción de equipamientos } \\
\text { Torrevieja }\end{array}$ & 5 \\
\hline $\begin{array}{l}\text { Construcción de nuevas infraestructuras } \\
\text { de transporte }\end{array}$ & 5 \\
\hline Cultivos bajo plástico & 5 \\
\hline Destrucción de marjales & 5 \\
\hline Destrucción de saladares & 5 \\
\hline Encuentro casco urbano-Torrevieja & 5 \\
\hline Rotondas & 5 \\
\hline Desaparición yacimientos & 5 \\
\hline Degradación del paisaje & 5 \\
\hline Desaparición de zonas verdes & 5 \\
\hline Ampliación infraestructuras transporte & 0 \\
\hline Conexión con frente litoral & 0 \\
\hline Cruce de AP7 & 0 \\
\hline Cruce de CV905 & 0 \\
\hline Cruce de N332 & 0 \\
\hline Cruces de ramblas bajo carreteras & 0 \\
\hline Cubrimiento de canales & 0 \\
\hline Deterioro casas rurales & 0 \\
\hline Deterioro de canales & 0 \\
\hline $\begin{array}{c}\text { Introducción de servicios en el entorno } \\
\text { del parque (hostelería) }\end{array}$ & 0 \\
\hline Introducción riego goteo & 0 \\
\hline Márgenes de ramblas en urbanizaciones & 0 \\
\hline Uso del parque: paseo a caballo & 0 \\
\hline Uso del parque: paseo perros & 0 \\
\hline Uso del parque: baños en lagunas & 0 \\
\hline Carreteras próximas al parque & 0 \\
\hline $\begin{array}{c}\text { Aumento de la población/presión } \\
\text { entorno }\end{array}$ & 0 \\
\hline
\end{tabular}




\section{4.d.3. Unidades de paisaje:}

La definición de las unidades de paisaje dentro del ámbito estricto se realizó a partir de los trabajos de análisis territorial y paisajístico previos y de las sugerencias de la población y expertos (FASE1 del plan de participación pública). Las Unidades de Paisaje así definidas y caracterizadas fueron las siguientes:

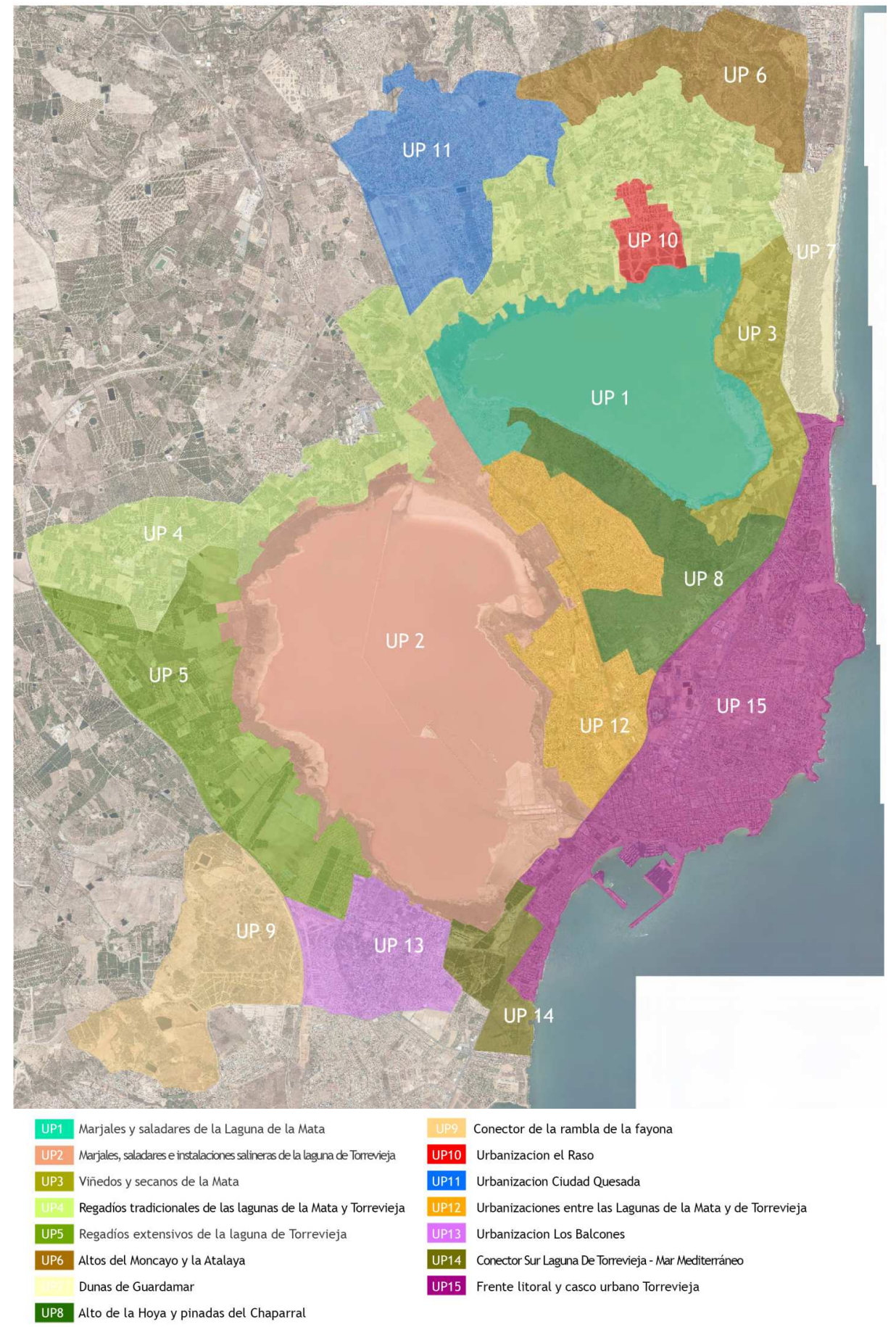

Fig. 5.26: Unidades de paisaje en el ámbito estricto del estudio (escala aproximada 1:100.000).

El conjunto de fichas elaboradas para las distintas unidades de paisaje del ámbito estricto del estudio quedan recogidas en el ANEXO IV de la presente tesis, mostrándose a continuación, a título de ejemplo, la ficha correspondiente a la Unidad de Paisaje n¹: "Marjales y Saladares de la Laguna de La Mata". 


\section{UP1: MARJALES Y SALADARES DE LA LAGUNA DE LA MATA}

1. Características Generales: Unidad definida por la laguna de la Mata y las orlas de saladar y marjal que la circundan. Zona de gran valor ambiental y ecológico con escasa presencia de elementos construidos.

\section{Elementos de caracterización:}

a) Topografía: área llana que incluye la laguna de la Mata y su entorno. Presenta una ligera elevación en la zona de saladares que la conecta al suroeste con la Unidad de la Laguna de Torrevieja

b) Hidrología: Dominada por la laguna de La Mata. Incluye la desembocadura de pequeñas ramblas que fluyen desde las elevaciones situadas al norte (Rambla de Lo Marabú) y desde el anticlinal del Chaparral. La laguna se encuentra conectada al mar Mediterráneo a través del Canal de La Mata y a la laguna de Torrevieja por medio del Canal de las Salinas.

c) Cubierta vegetal: Saladar y marjal

d) Estructura visual: Cuenca visual amplia sobre la laguna de la Mata y las zonas de saladar. Vistas bloqueadas por la vegetación en las zonas de marjal.

e) Usos del suelo: Espacio natural protegido

f) Construcciones y Edificación
a. Núcleos urbanos: ausentes
b. Urbanizaciones: ausentes
c. Edificación dispersa: Escasa (Casa de La Maquina)
d. Estructuras rurales construidas: restos de muros de mampostería en antiguos campos abandonados.

g) Infraestructuras
a. Transporte: Recorridos internos del parque, tramo de la carretera CV905.
b. Hidráulica: inicio del Canal de La Mata (conexión con el mar Mediterráneo) y del canal de Las Salinas (conexión con la laguna de Torrevieja)
c. Energía: ausentes

h) Parcelario rural: Prácticamente ausente

\section{Dinámicas del Paisaje:}

a) Procesos naturales: Recolonización de antiguas parcelas agrícolas por vegetación de saladar y marjal. Introducción de especies exóticas desde las urbanizaciones próximas.

b) Procesos antrópicos: Uso creciente recreativo de la margen sur de la laguna y desincentivación por los gestores del parque natural del uso de la margen oeste y norte.

c) Principales problemas: Usos recreativos inadecuados (suelta de perros). Ausencia de recorrido perimetral de la laguna o de recorridos que no impliquen ir y volver por el mismo camino. Conexión con la Unidad Paisajística 2 (Laguna de Torrevieja) impedida por el intenso tráfico en la carretera CV-905. Proximidad de las Urbanizaciones del Raso y de Ciudad Quesada. Isletas artificiales en la laguna. Intrusión visual de las urbanizaciones de Ciudad Quesada y El Raso. Intrusión visual del casco urbano de Torrevieja. Introducción de especies exóticas desde las urbanizaciones próximas.

d) Principales Recursos Paisajísticos:

- Recursos paisajísticos ambientales: Laguna de la Mata, marjales (con carrizales de Phragmitea), saladares (clase Arthrocnemetea) y grupos de Limonietalia (Limonio-Lygeetum) y Sarcornietum y algunas comunidades de juncos. Microreservas (futura creación de una $3^{\underline{a}}$ microreserva en la zona sureste de la laguna (orquídeas y narcisos)). En cuanto a la fauna destacan las zonas de nidificación del aguilucho cenizo al oeste y al norte de la Laguna de la Mata.

- Recursos paisajísticos culturales: Canal de la Mata, Canal de las Salinas, Casa de La Máquina, restos antigua fábrica de salazones (origen romano), Casa de la Loma.

- Recursos paisajísticos visuales: Laguna de la Mata, Marjales y saladares. Casa de La Maquina, Casa de la Loma, Casa de Sala, observatorios de aves, recorrido margen sur de la laguna, Vistas sobre la lámina de agua de la laguna, vistas a lo largo del canal de la Mata, vistas amplias sobre el saladar desde la carretera CV905, CV895 y N332.
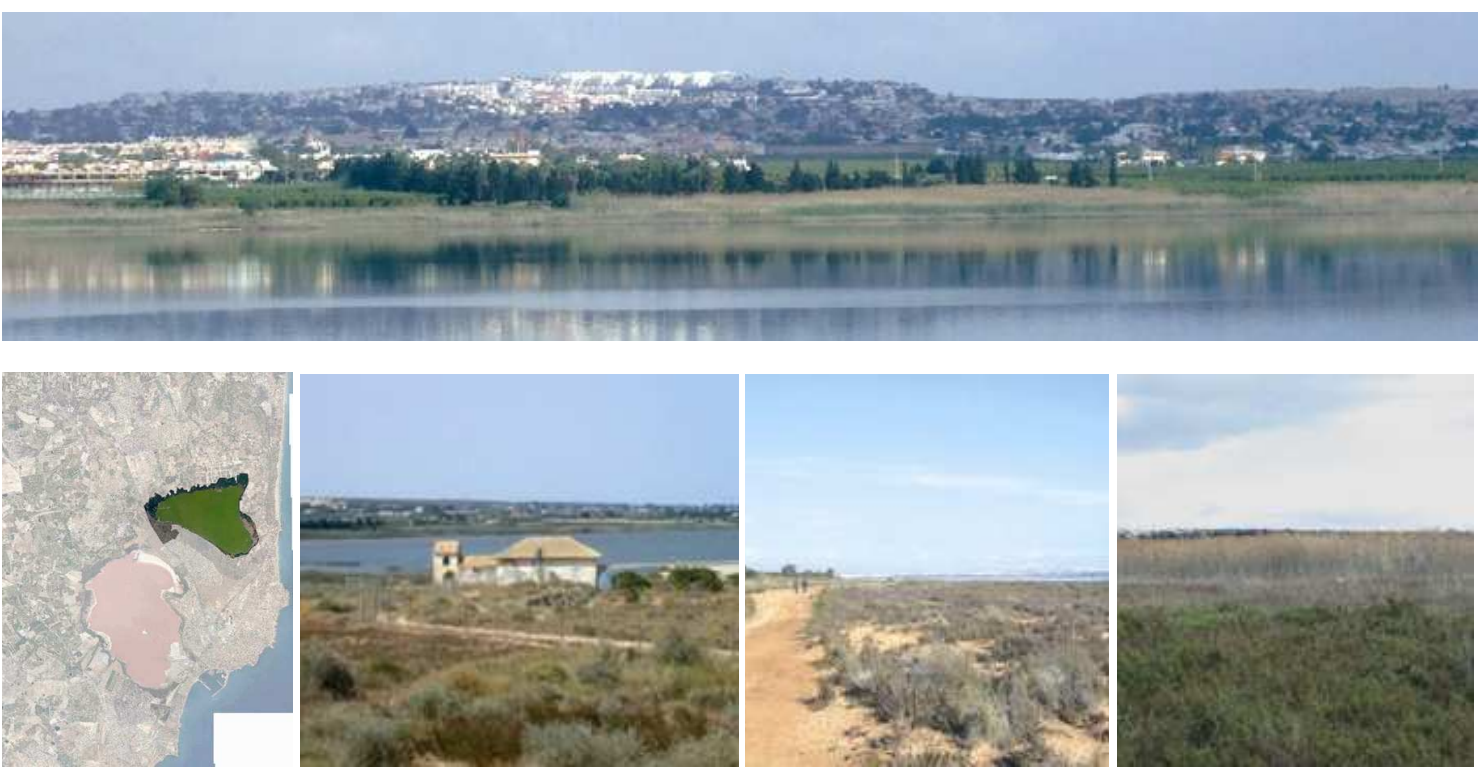

Fig. 5.27: Ficha de unidad de paisaje en el ámbito estricto del estudio. 


\section{4.d.4. Recursos paisajísticos:}

La definición de los recursos paisajísticos (ambientales, culturales y visuales) se ha realizado a partir del análisis territorial y del paisaje así como de las sugerencias de la población y expertos (FASE1 del plan de participación pública).

Los Recursos Paisajísticos medioambientales, culturales y visuales así definidos se muestran a continuación ordenados por las unidades en las que se ubican, y localizados en tres planos. A objeto de identificación cada recurso paisajístico ambiental se ha nombrado con el prefijo RPA_no, cada recurso paisajístico cultural con el prefijo RPC_no y cada recurso paisajístico visual con el prefijo RPV_no‥

\section{a) Recursos paisajísticos ambientales:}

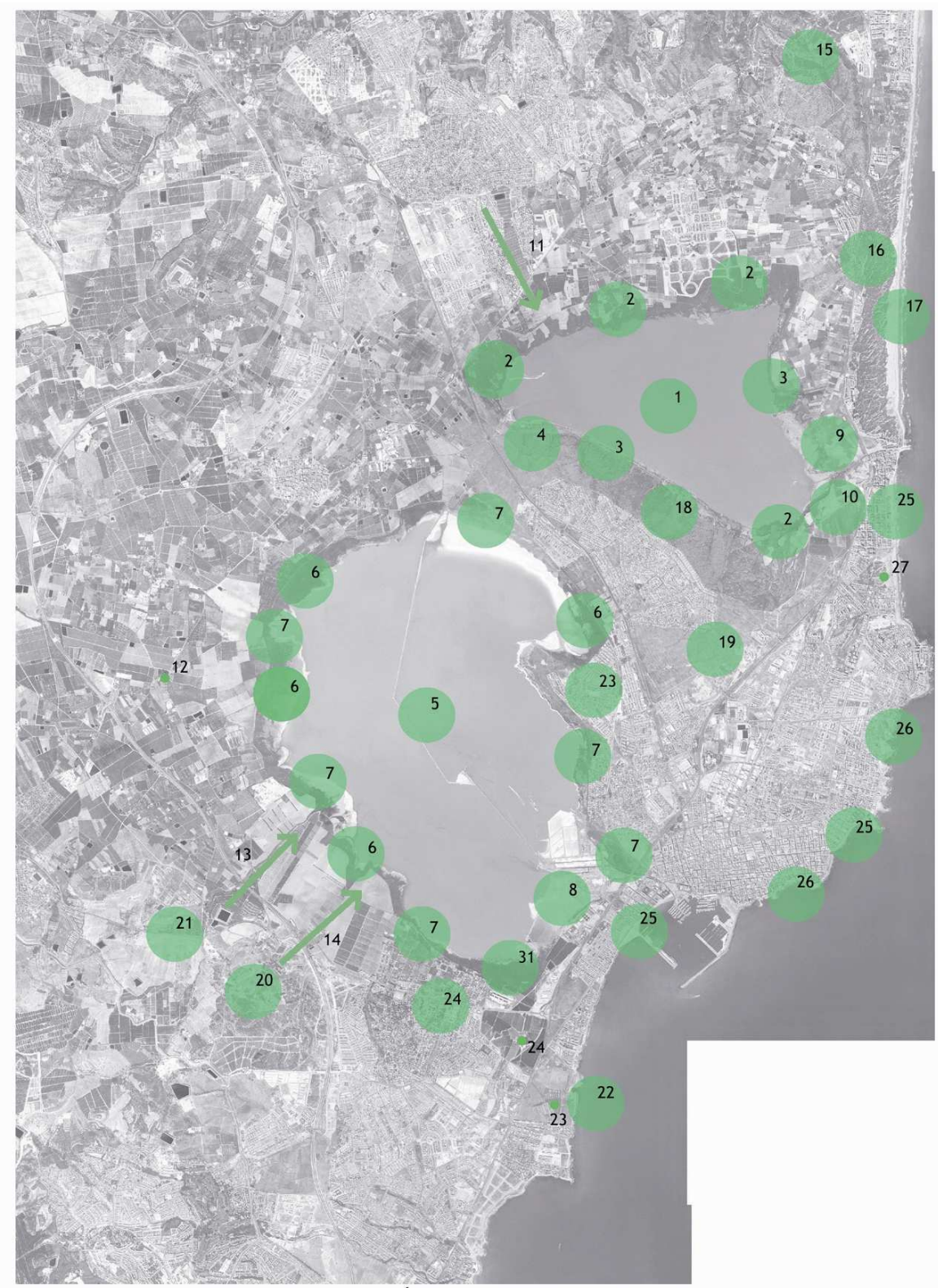

Fig. 5.28: Plano localizador de los recursos paisajísticos ambientales en el ámbito estricto (escala aproximada 1:100.000) 
VALORACIÓNY GESTIÓN DEL PAISAJE SEGÚN EL CONVENIO EUROPEO DEL PAISAJE YEL

REGLAMENTO DEL PAISAJE DE LA COMUNIDAD VALENCIANA: APLICACIÓN MEDIANTE UN ESTUDIO

DE PAISAJE A UNESPACIO ABIERTO EN LA COMUNIDAD VALENCIANA

DOCTORANDO: JUAN JOSÉ GALÁN VIVAS (Universidad Politécnica de Valencia, enero 2011)

\section{UP1: MARJALES Y SALADARES DE LA LAGUNA DE LA MATA}

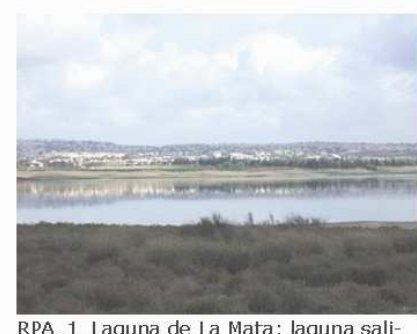

RPA_1_Laguna de La Mata: laguna na de 850 hectáreas de superficie

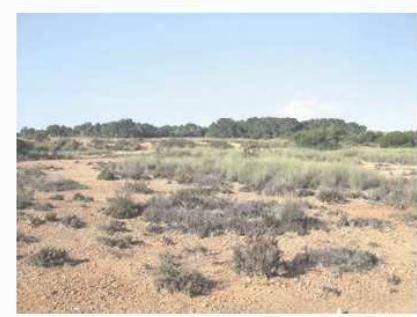

RPA_4_Microreserva de zona con orquideas y narcisos

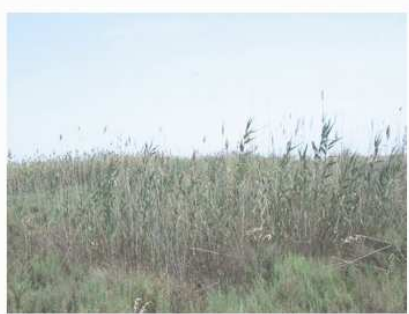

RPA_2_Marjales de la Laguna de La Mata: Carrizales y juncales localizados en las zonas norte, oeste y sureste de la laguna

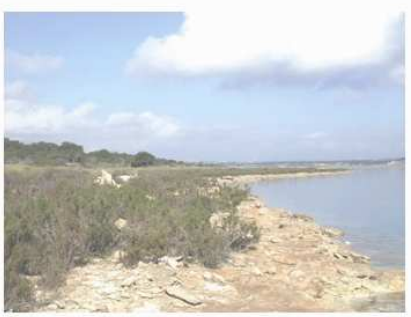

RPA_3_Saladares y zonas con Limoniums de la Laguna de La Mata: Formaciones arbustivas de especies altamente resistentes a la salinidad y a las fluctuaciones de los niveles de agua.

UP2: MARJALES, SALADARES E INSTALACIONES SALINERAS DE LA LAGUNA DE TORREVIEJA

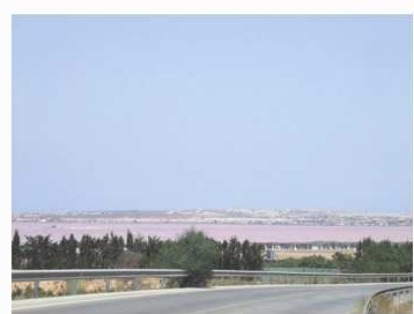

RPA_5_Laguna de Torrevieja: laguna altamente salina de 1450 hectáreas de superficie. Asociada al uso salinero y con un color rosa consecuencia de las comunidades de bacterias que lo habitan.

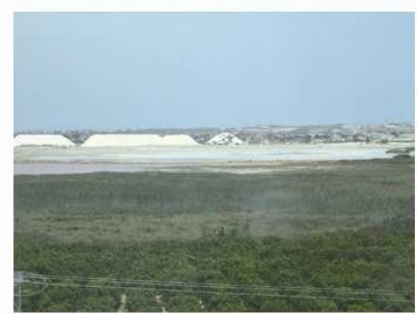

RPA_8_Cubetas de concentración de sal: Zona de nidificación de la gaviota de Andouain

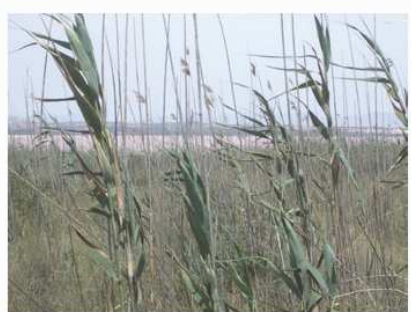

RPA_6_Marjales de la Laguna de Torrevieja: Carrizales y tramos localizados en distintos tramos del perímetro de la laguna

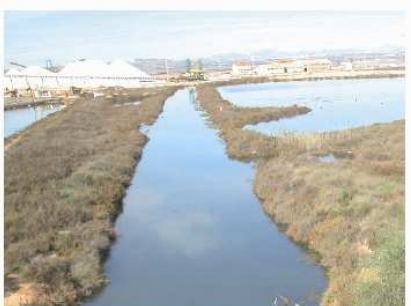

RPA_7_Saladares de la Laguna y Acequión de Torrevieja: Formac quion de Torrevieja: Formaciones arbusa la salinidad y a las fluctuaciones de los niveles de agua

\section{UP3: VIÑEDOS Y SECANOS DE LA MATA}

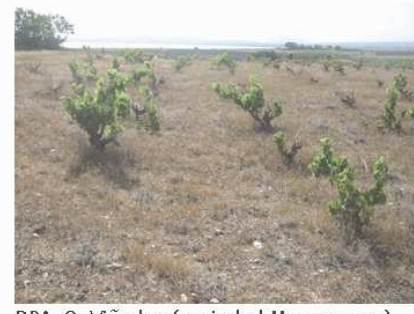

RPA_9_Viñedos (variedad Merseguera)

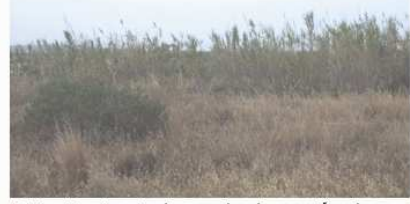

RPA_10_Carrizales en la depresión de El Hondo 

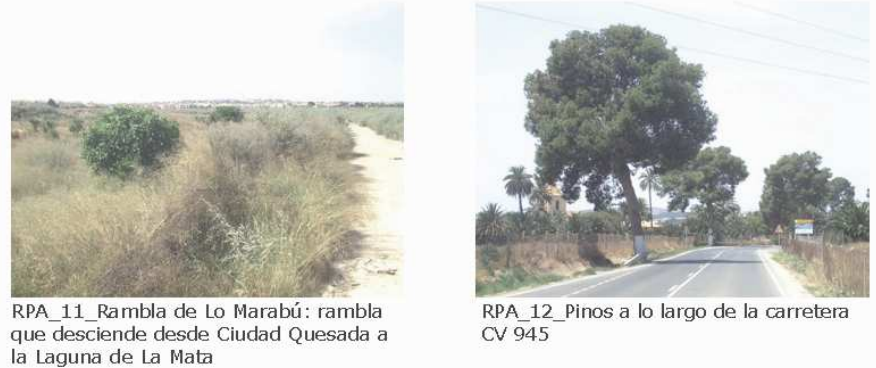

UP5: REGADÍOS EXTENSIVOS de la LAGUNA de TORREVIEJA

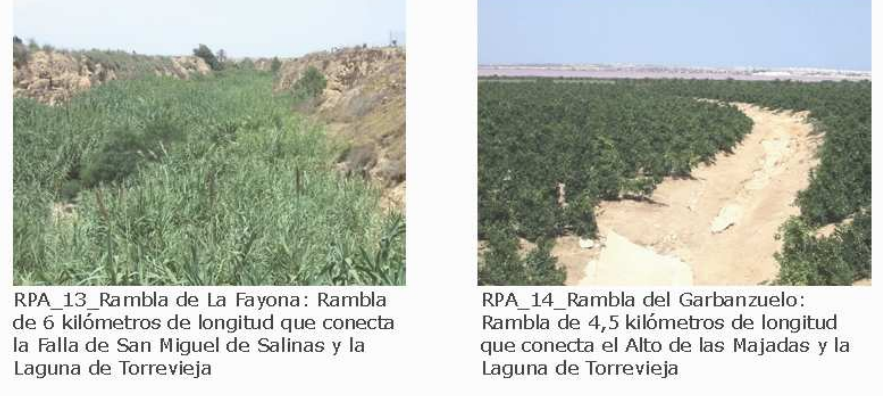

UP6: ALTOS DEL MONCAYO Y LA ATALAYA

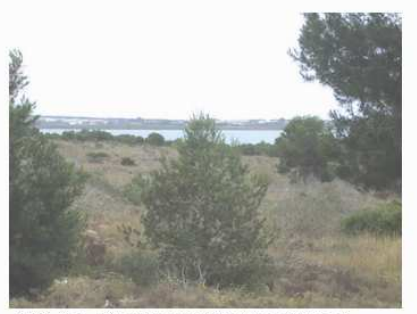

RPA_15_Pinares y matorral entre el

Moncayo y La Atalaya

UP7: DUNAS de GUARDAMAR
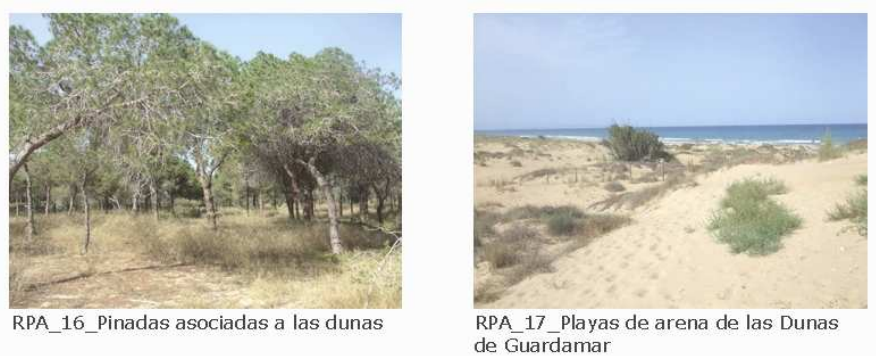

UP8: ALTO de LA HOYA y PINADAS del CHAPARRAL
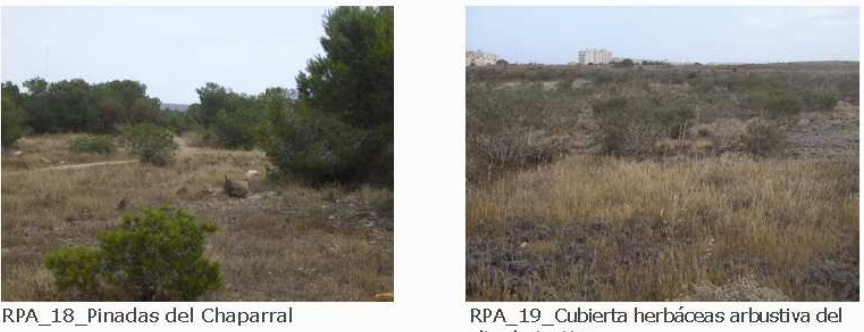

RPA_19_Cubier
alto de la Hoya 


\section{UP9: CONECTOR DE LA RAMBLA DE LA FAYONA}

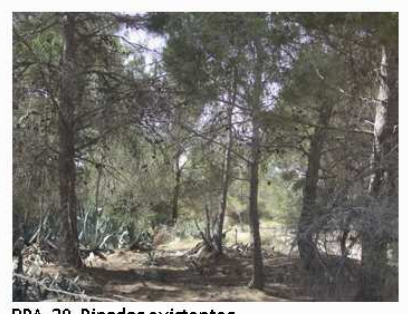

RPA_20_Pinadas existentes

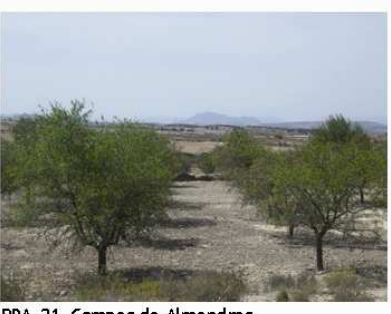

RPA_21_Campos de Almendros

UP10: URBANIZACION EL RASO

No observados

UP11: URBANIZACION CIUDAD QUESADA

No observados

UP12: URBANIZACIONES ENTRE LAS LAGUNAS DE LA MATA Y DE TORREVIEJA

No observados

\section{UP13: URBANIZACION LOS BALCONES}

No observados

\section{UP14: CONECTOR SUR LAGUNA DE TORREVIEJA - MAR MEDITERRÁNEO}

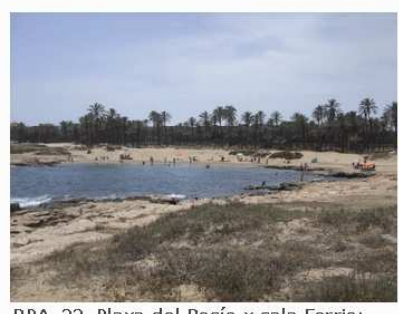

RPA_22_Playa del Rocío y cala Ferris: Playa de arena en la que se incluye la cala Ferris, característica por su

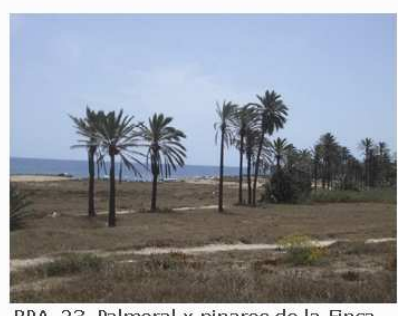

RPA_23_Palmeral y pinares de la Finca Lo Ferris

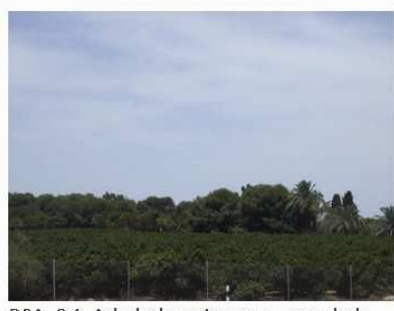
RPA_24_Arbolado entorno a casa de la
Ceñuela

UP15: FRENTE LITORAL Y CASCO URBANO TORREVIEJA

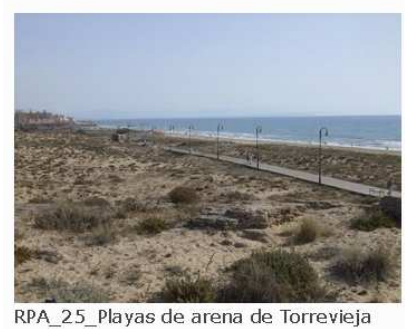

RPA_25_Playas de arena de Torrevieja

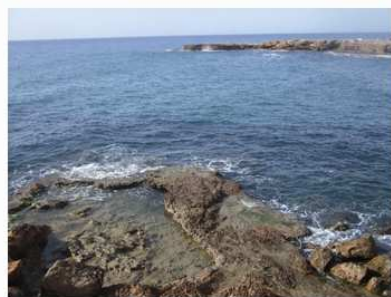

RPA_26_Playas de roca, acantilados y vegetación asociada

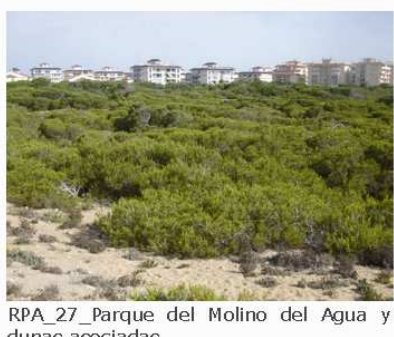
dunas asociadas 


\section{b) Recursos paisajísticos culturales}

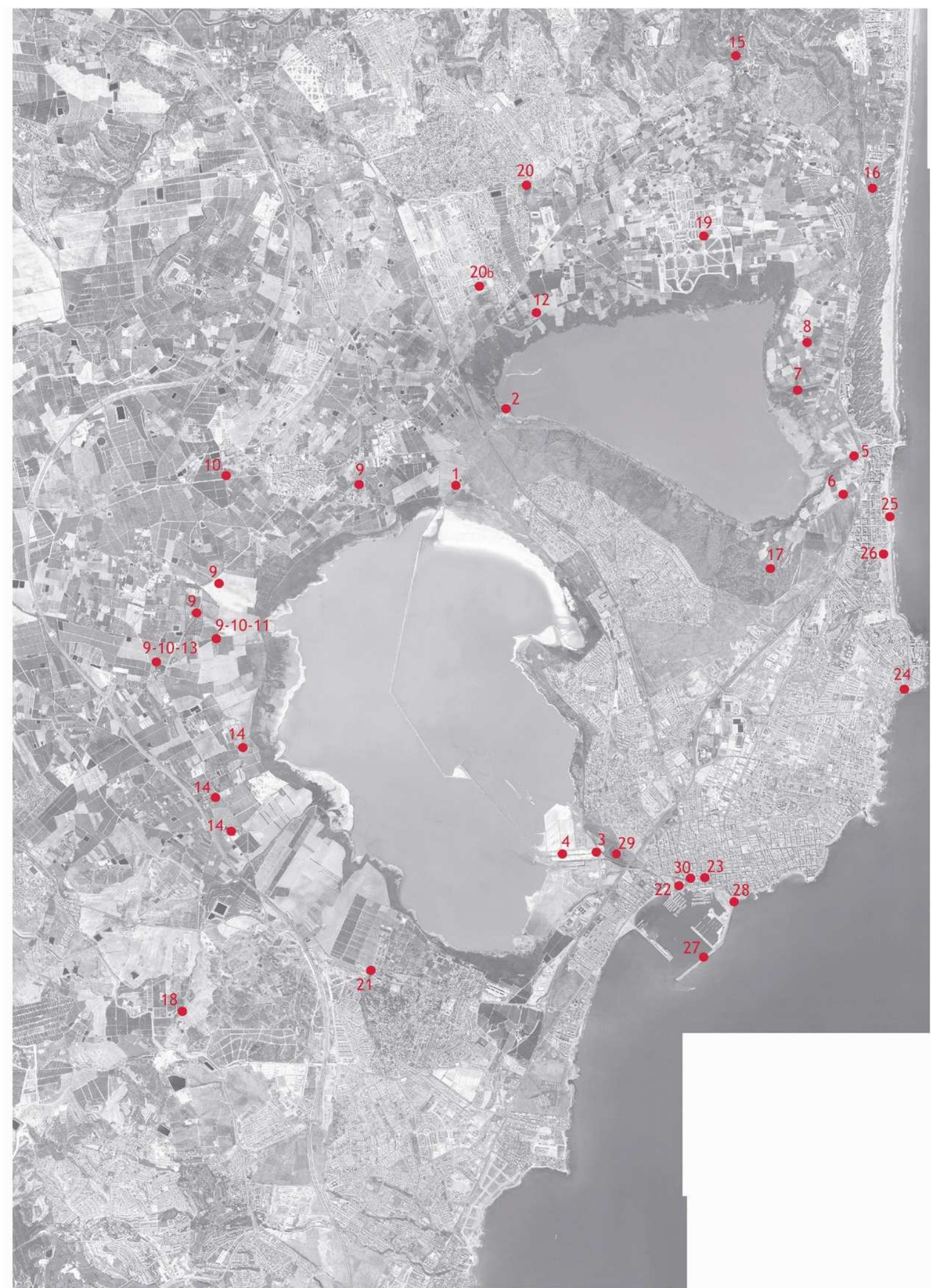

Fig. 5.29: Plano localizador de los recursos paisajísticos culturales en el ámbito estricto (escala aproximada 1:75.000) 
UP1: MARJALES Y SALADARES DE LA LAGUNA DE LA MATA

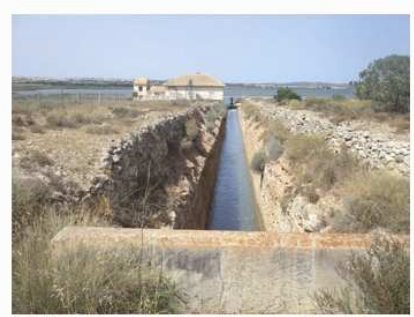

RPC 1 Canal de las Salinas: Canal de aproximadamente $7 \mathrm{~m}$ de anchura $\mathrm{y}$ agua desde la laguna de La Mata a la de

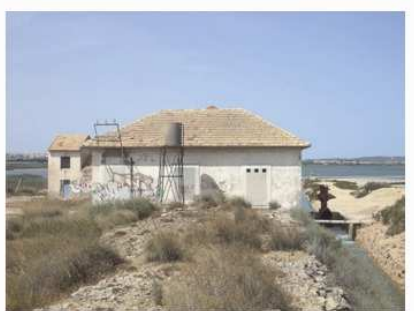

RPC_2_Arquitectura Tradicional en el entorno dela laguna deta Mata (Casa de La Máquina $\vee$, Casa de La Loma)

\section{UP2: MARJALES, SALADARES E INSTALACIONES SALINERAS DE LA LAGUNA DE TORREVIEJA}

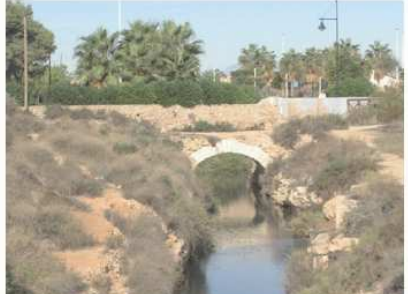

RPC 3 Acequión de Torrevieja y puente: Canal de aproximadamente $9 \mathrm{~m}$ de anchura y $2.000 \mathrm{~m}$ de longitud consanchura y $2.000 \mathrm{~m}$ de longitud consde de sileria, en abjeto laguna de Torrevieja

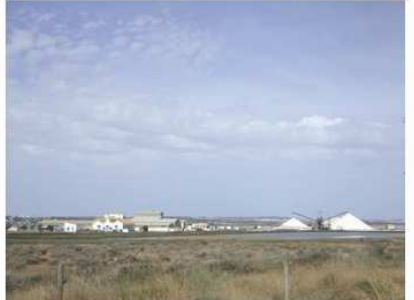

RPC_4_Conjunto de edificios, cintas transportadoras y depósitos (montañas) para la producción de sal.

\section{UP3: VIÑEDOS Y SECANOS DE LA MATA}

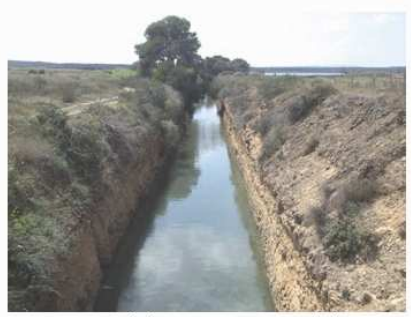

RPC_5_Canal de La Mata: Canal de aproximadamente $8 \mathrm{~m}$ de anchura $y$ $1.750 \mathrm{~m}$ de longitud que permite introducir agua del mar Mediterráneo en la Laguna de La Mata.

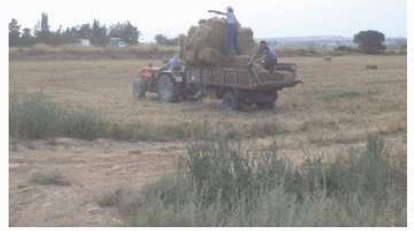

RPC_8_Siega y empacado

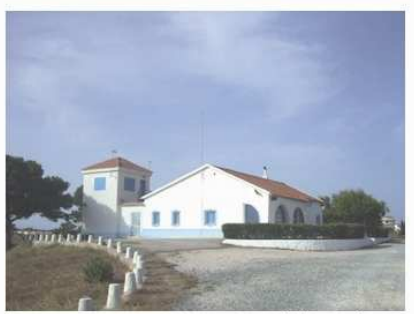

RPC 6 Antigua Casa Forestal (actual Centro de Visitantes del parque Natural)

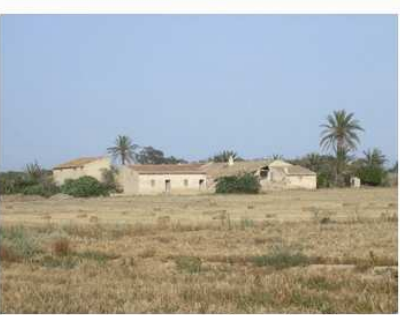

RPC_7 A Arquitectura Tradicional en la franja de tierra situada entre la Laguna de La Mata y la carretera nacional N332 (Casa de Falt, Casa de Sala, Casa de las Palmeres) 


\section{UP4: REGADÍOS TRADICIONALES de las LAGUNAS DE LA MATA Y TORREVIEJA}

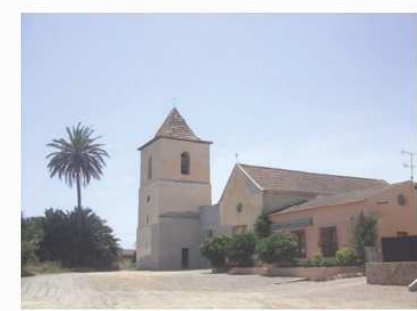

RPC_9_Arquitectura Tradicional en los huertos tradicionales de la Laguna de Torrevieja (conjunto de La Marquesa, Lo Reche, Morales, La Cisterna, Del Reloj y

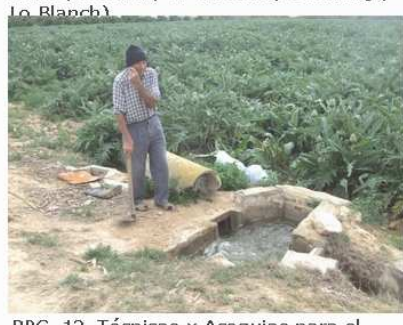

RPC_12_Técnicas y Acequias para e riego a manta

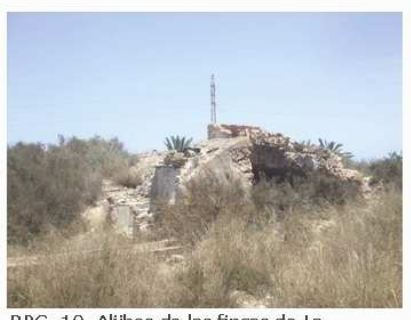

RPC_10_Ajjibes de las fincas de La marquesa, del Cuartel, de Lo Reche y de Lo Vigo

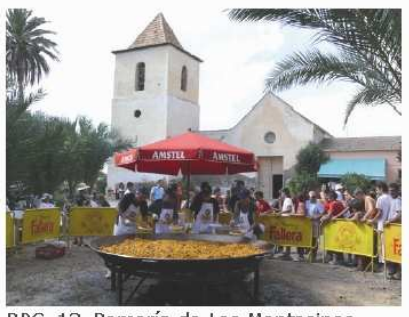

RPC_13_Romería de Los Montesinos

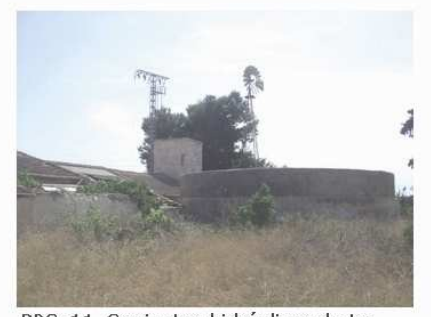

RPC_11_Conjuntos hidráulicos de Lo Reche y La Molineta

UP5: REGADIOS EXTENSIVOS de Ia LAGUNA de TORREVIEJA

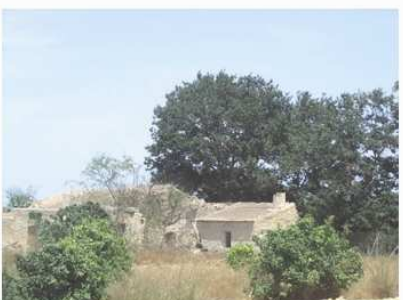

RPC_14_Arquitectura Tradicional en los nuevos regadíos de la laguna de Torrevieja (Casa de la Coronela, Casa de la Rambla, Casa Grande, Casa de Lo Timor, Villa Antón, Casa del pura

UP6: ALTOS DEL MONCAYO Y LA ATALAYA

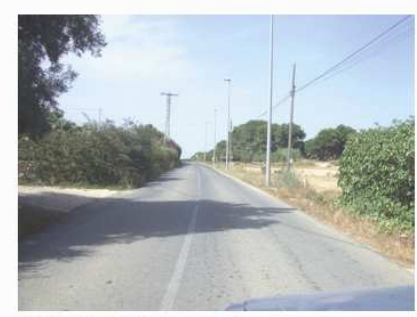

RPC_15_Antiguos caminos rurales de Dos (entre los Montesinos y Guardamar) y Ratero (entre Lo Pepín y La Inquisición

\section{UP7: DUNAS de GUARDAMAR}

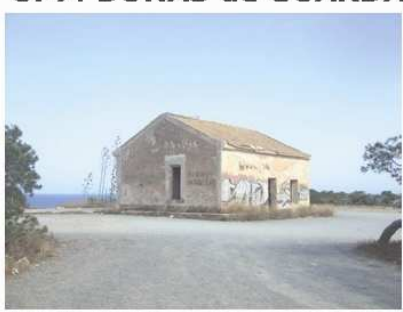

RPC_16_Antigua casa de peones camineros 


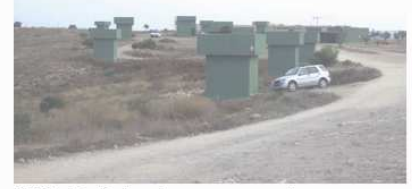

RPC_17_Estructuras para palomas (colombicultura)

UP9: CONECTOR DE LA RAMBLA DE LA FAYONA

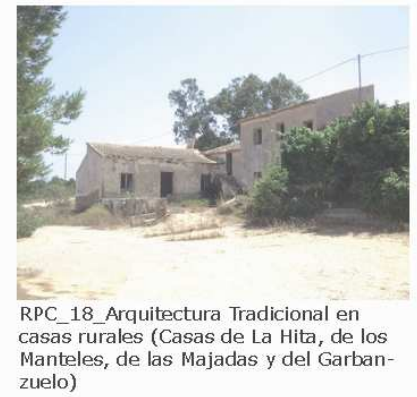

UP10: URBANIZACION EL RASO

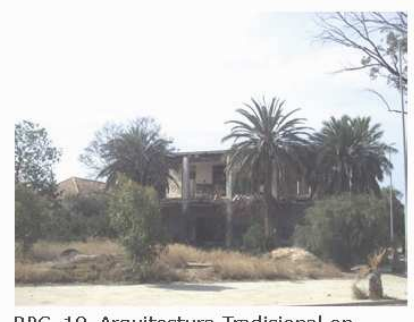

RPC_19_Arquitectura Tradicional en casas rurales (Casa del Raso)

UP11: URBANIZACION CIUDAD QUESADA

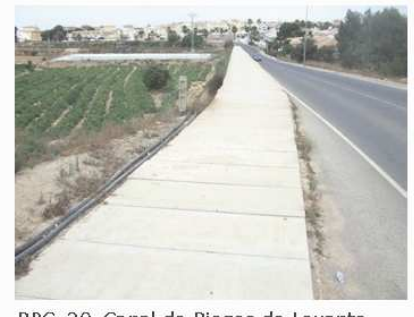

RPC_20_Canal de Riegos de Levante

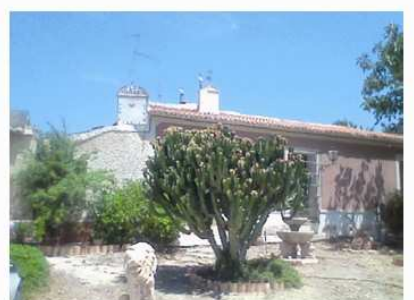

RPC_20b_Casa de la Niña de lo Marabú

UP12: URBANIZACIONES ENTRE LAS LAGUNAS DE LA MATA Y DE TORREVIEJA

No observados 
VALORACIÓNY GESTIÓN DEL PAISAJE SEGÚN EL CONVENIO EUROPEO DEL PAISAJE YEL

REGLAMENTO DEL PAISAJE DE LA COMUNIDAD VALENCIANA: APLICACIÓN MEDIANTE UN ESTUDIO

DE PAISAJE A UNESPACIO ABIERTO EN LA COMUNIDAD VALENCIANA

DOCTORANDO: JUAN JOSÉ GALÁN VIVAS (Universidad Politécnica de Valencia, enero 2011)

UP13: URBANIZACION LOS BALCONES

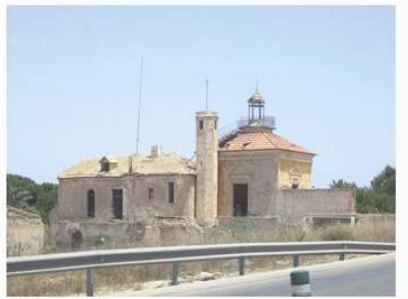

RPC_21_Casa y Torre de los Balcones

(patrimonio arquitectónico)

UP14: CONECTOR SUR LAGUNA DE TORREVIEJA - MAR MEDITERRÁNEO

No observados

UP15: FRENTE LITORAL Y CASCO URBANO TORREVIEJA

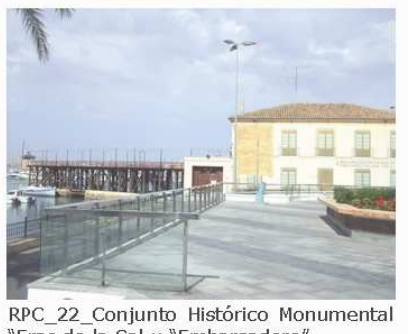

"Eras de la Sal y "Embarcadero"

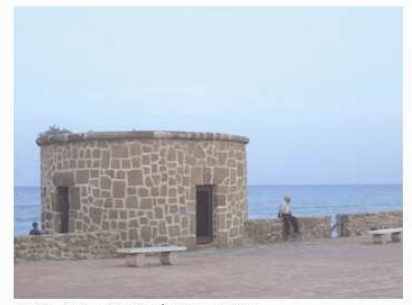

RPC_25_Torre de La Mata

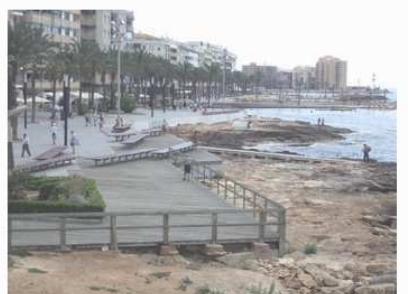

RPC 28_Paseo Marítimo Juan Aparicio: paseo con playas de arena en la céntrica Playas de Las Rocas.

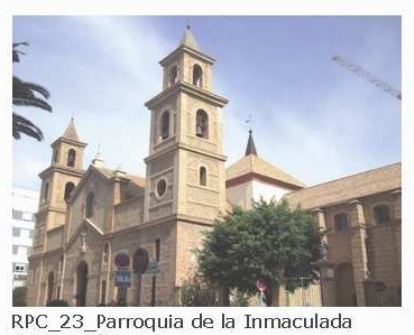

RPC_23_Parroquia de la Inmaculada Concepción

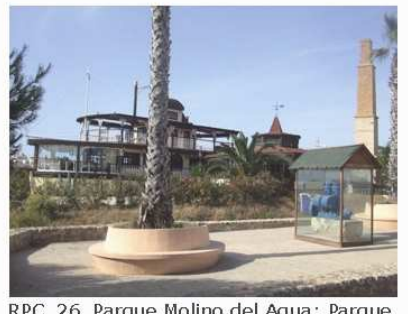

RPC 26 Parque Molino del Agua: Parque de $1 \overline{7}, 3$ has en el que se incluye el antiguo Molino del Agua (referencias del año 1772) y una zona de playa y dunas. Declarado Paraje Natural

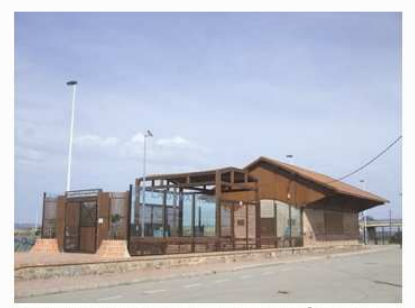

RPC 29 Centro de interpretación de industria salinera

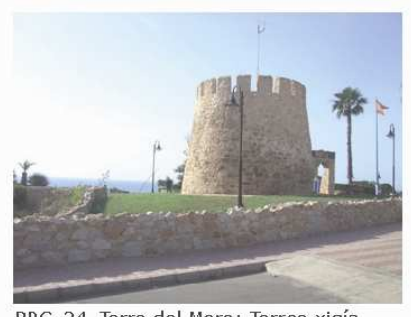

RPC_24_Torre del Moro: Torreo vigía medieval (siglo XIV)

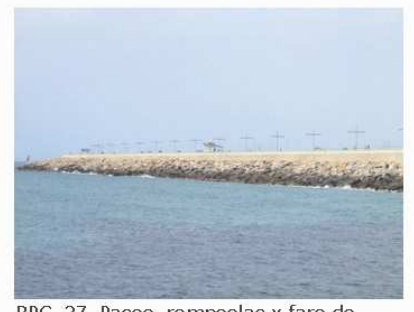

RPC_27_Paseo, rompeolas y faro de Torrevieja

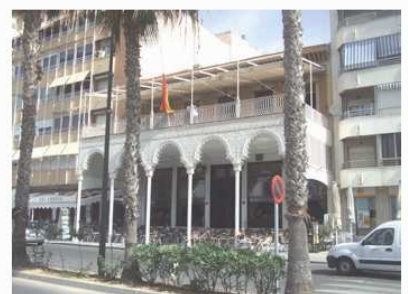

RPC_30_Sociedad Cultural Casino de Torrevieja 
VALORACIÓNY GESTIÓN DEL PAISAJE SEGÚN EL CONVENIO EUROPEO DEL PAISAJE YEL

REGLAMENTO DEL PAISAJE DE LA COMUNIDAD VALENCIANA: APLICACIÓN MEDIANTE UN ESTUDIO DE PAISAJE A UNESPACIO ABIERTO EN LA COMUNIDAD VALENCIANA

DOCTORANDO: JUAN JOSÉ GALÁN VIVAS (Universidad Politécnica de Valencia, enero 2011)

\section{c) Recursos paisajísticos visuales:}

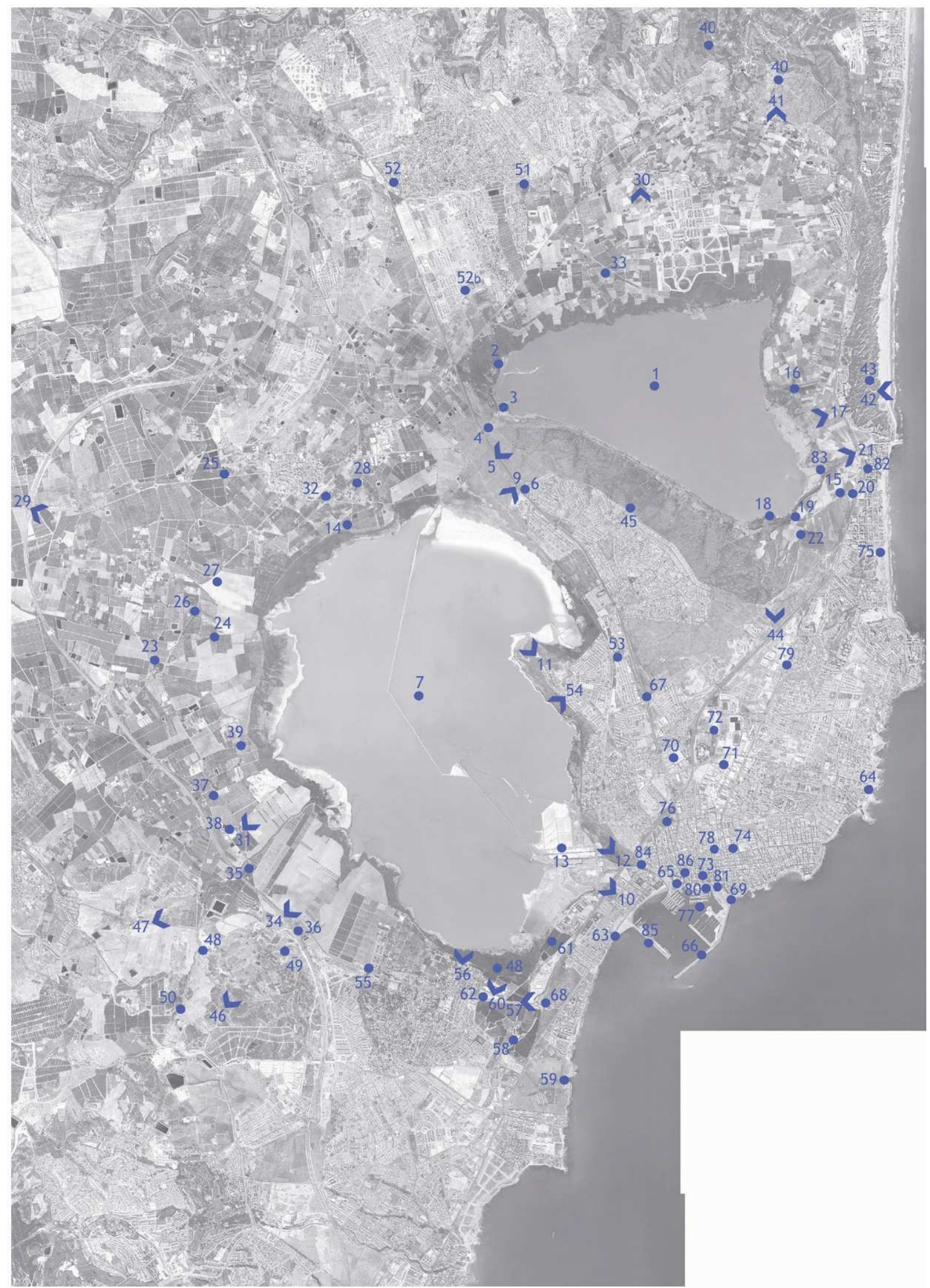

Fig. 5.30: Plano localizador de los recursos paisajísticos visuales en el ámbito estricto (escala aproximada 1:75.000) 
VALORACIÓNY GESTIÓN DEL PAISAJE SEGÚN EL CONVENIO EUROPEO DEL PAISAJE YEL

REGLAMENTO DEL PAISAJE DE LA COMUNIDAD VALENCIANA: APLICACIÓN MEDIANTE UN ESTUDIO

DE PAISAJE A UNESPACIO ABIERTO EN LA COMUNIDAD VALENCIANA

DOCTORANDO: JUAN JOSÉ GALÁN VIVAS (Universidad Politécnica de Valencia, enero 2011)

UP1: MARJALES Y SALADARES DE LA LAGUNA DE LA MATA

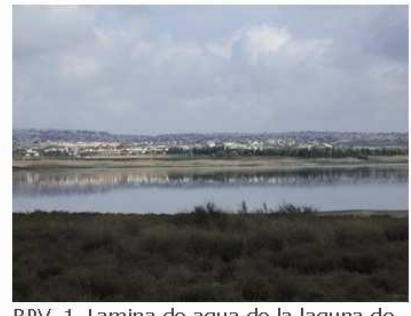

RPV 1_Lamina de agua de la laguna de La Mata

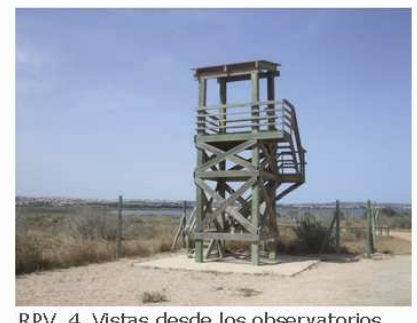

RPV_4_Vistas desde los observatorio de aves de la laguna de La Mata

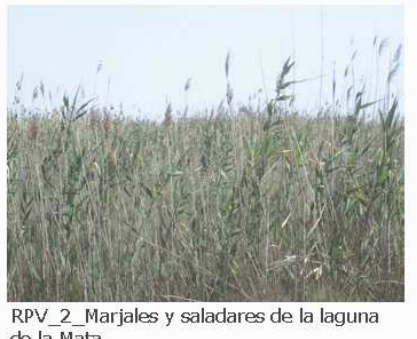

de la Mata

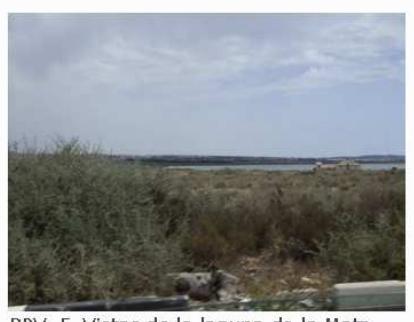

RPV_5_Vistas de la laguna de la Mata desce la Cva05

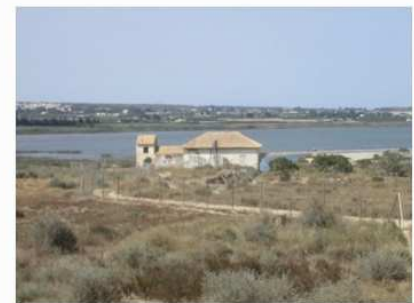

RPV_3_Casas de La Máquina y de La Loma

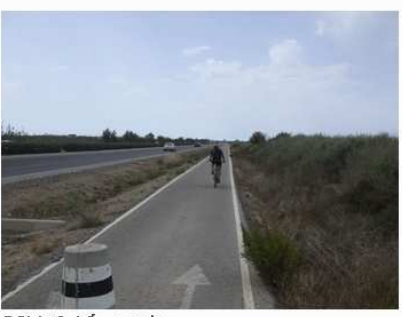

RPV 6 Vía verde

\section{UP2: MARJALES, SALADARES E INSTALACIONES SALINERAS DE LA LAGUNA DE TORREVIEJA}

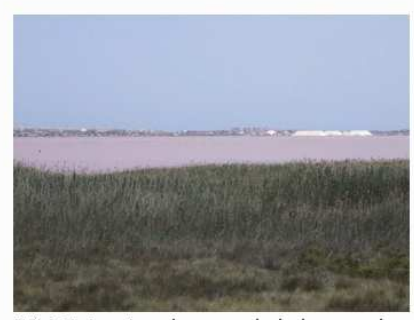

RPV_7_Lamina de agua de la laguna de La Torrevieja

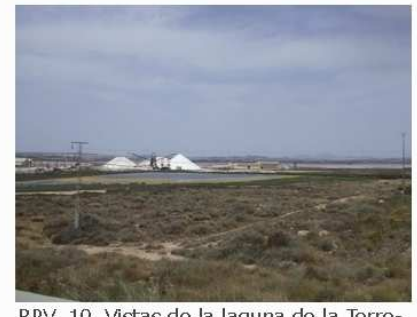

RPV_10_Vistas de la laguna de la Torrevieja desde la carretera N332

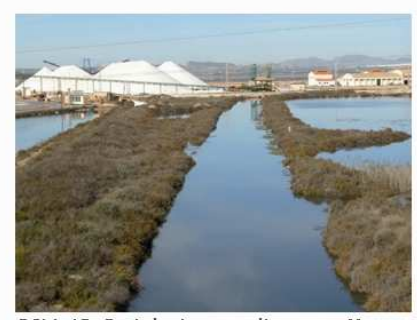

RPV 13 Instalaciones salineras y Montañas de Sal

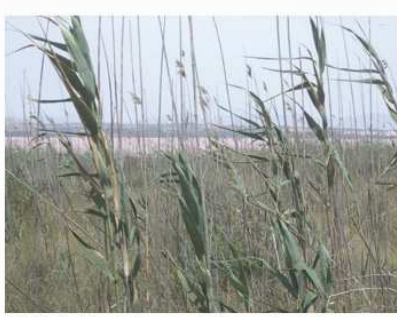

RPV_8_Marjales y saladares de la laguna de la Torrevieja

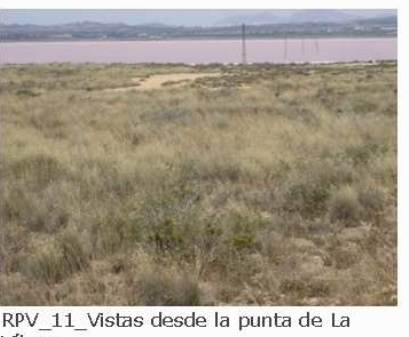
Vibora

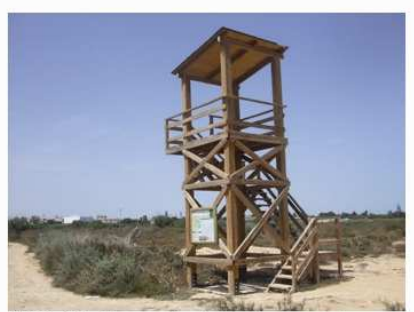

RPV_14_Observatorio de Aves en la Ruta Salada

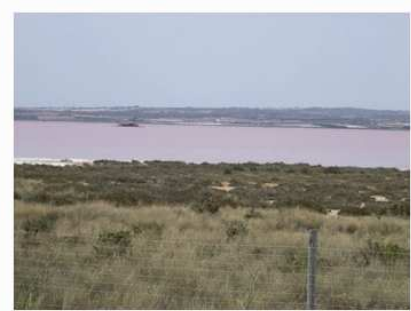

RPV 9 Vistas de la laguna de la Torrevieja desde la CV905

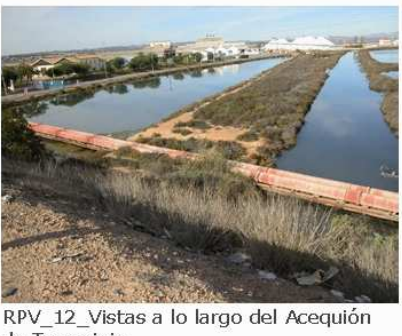
de Torrevieja 


\section{UP3: VIÑEDOS Y SECANOS DE LA MATA}

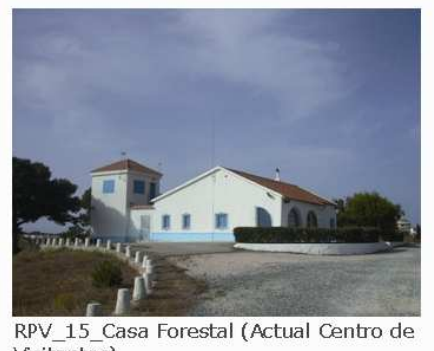

Visitantes)

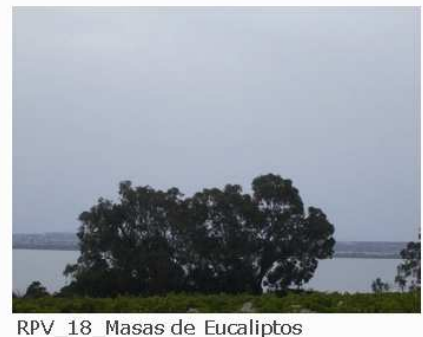

RPV 18 Masas de Eucaliptos

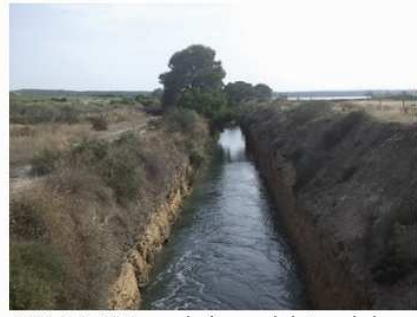

RPV_21_Vistas a lo largo del Canal de La Mata

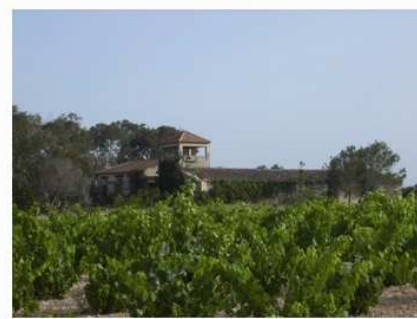

RPV_16_Casas rurales (Casa de Falt, Casa de Sala y Casa de las Palmeras)

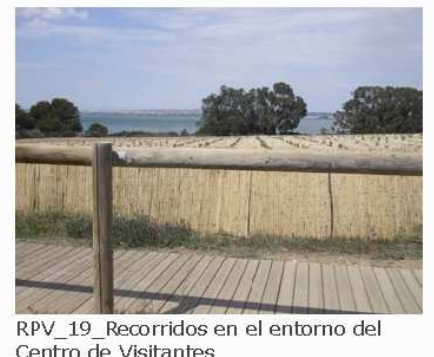

Centro de Visitantes

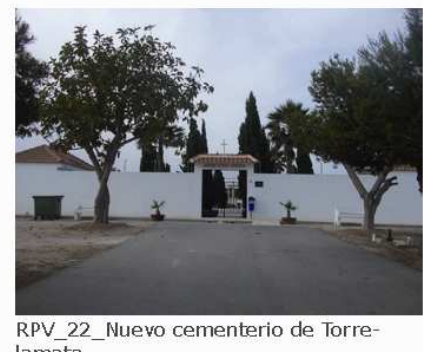

RPV_22_Nuevo cementerio de Torre-

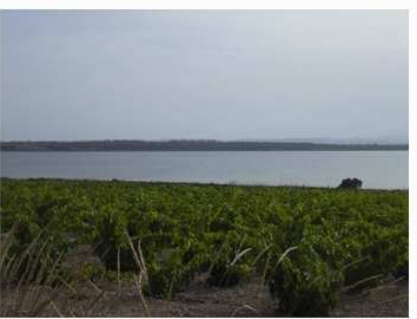

RPV_17_Vistas de la laguna sobre los viñedos

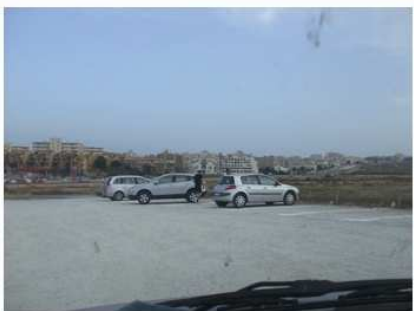

RPV 20 Aparcamientos en el entorno del Centro de Visitantes

UP4: REGADÍOS TRADICIONALES de las LAGUNAS DE LA MATA Y TORREVIEJA

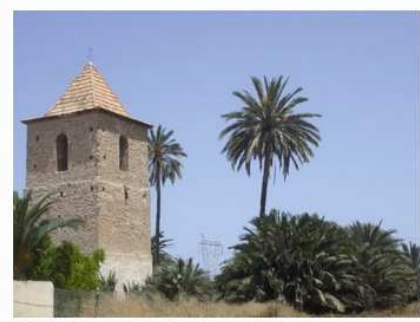

RPV_23_Finca de La Marquesa

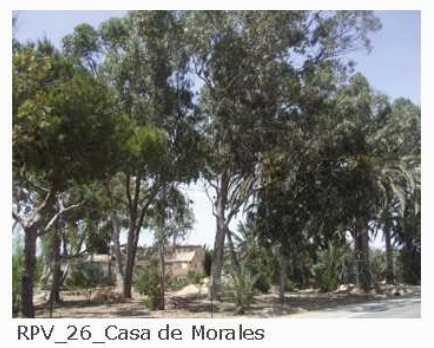

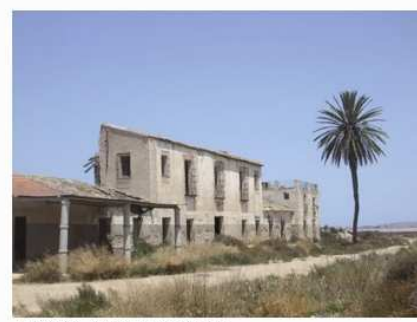

RPV_24_Casa de Lo Peche

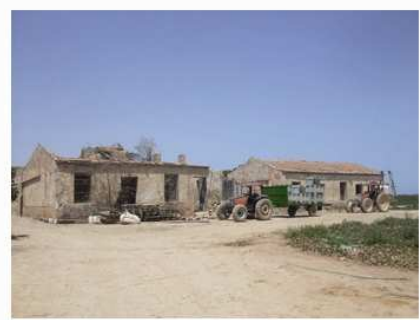

RPV 27 Casas de La Cisterna

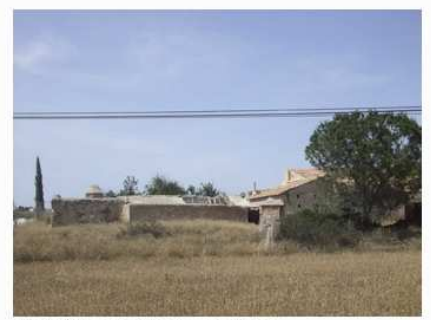

RPV 25_Casas de Lo Vigo

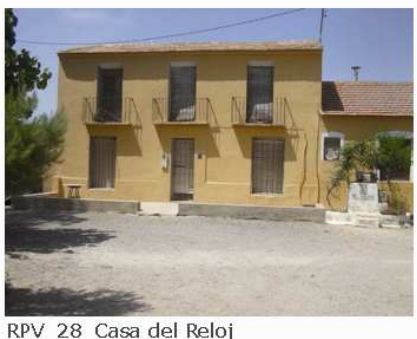

RPV 28 Casa del Reloj 
VALORACIÓNY GESTIÓN DEL PAISAJE SEGÚN EL CONVENIO EUROPEO DEL PAISAJE YEL

REGLAMENTO DEL PAISAJE DE LA COMUNIDAD VALENCIANA: APLICACIÓN MEDIANTE UN ESTUDIO

DE PAISAJE A UNESPACIO ABIERTO EN LA COMUNIDAD VALENCIANA

DOCTORANDO: JUAN JOSÉ GALÁN VIVAS (Universidad Politécnica de Valencia, enero 2011)

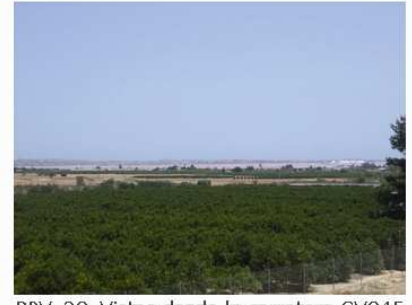

RPV_29_Vistas desde la carretera CV945

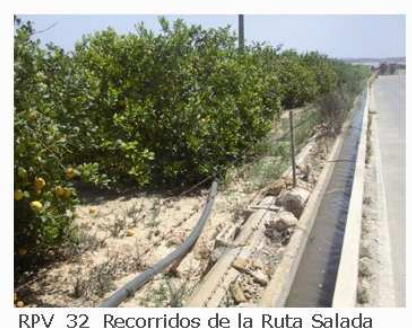

(Los Montesinos)

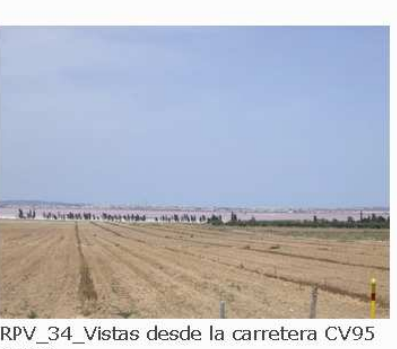
y $\mathrm{AP7}$

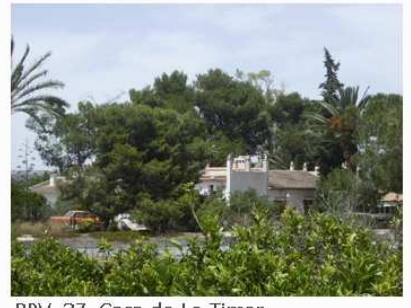

RPV_37_Casa de Lo Timor

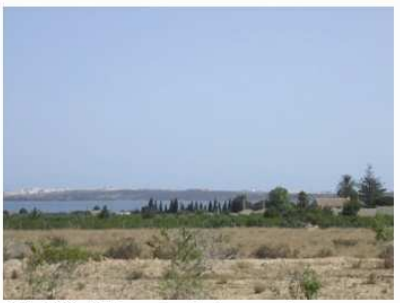

RPV_30_Vistas desde la carretera CV895

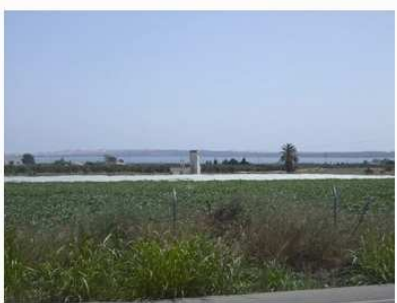

RPV_33_Recorridos en las huertas del Campico de Guardamar, El Raso y Ciudad Quesada

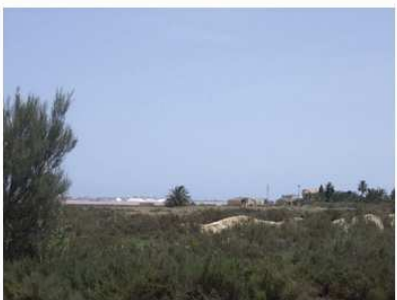

RPV_31_Vistas desde la carretera CV943

UP6: ALTOS DEL MONCAYO Y LA ATALAYA

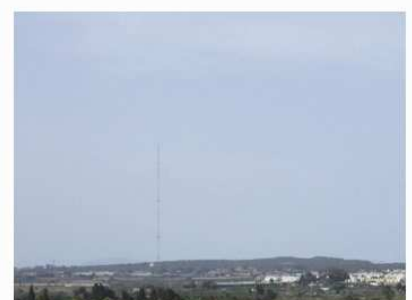

RPV_40_Altos y laderas del Moncayo y la Atalaya

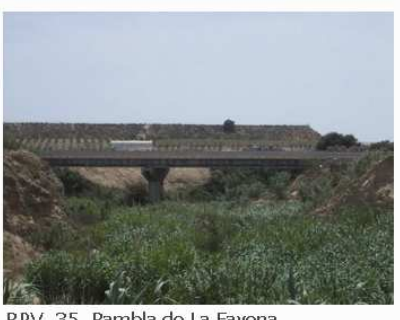

RPV_35_Rambla de La Fayona

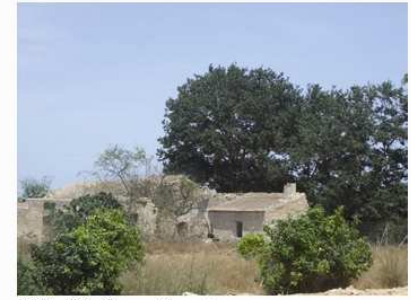

RPV 38 Casa Grande

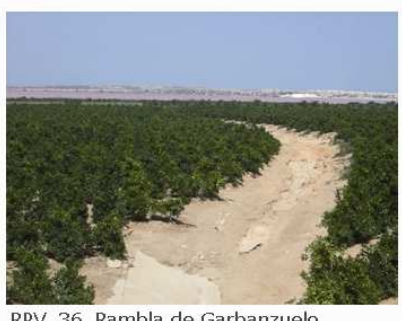

RPV_36_Rambla de Garbanzuelo

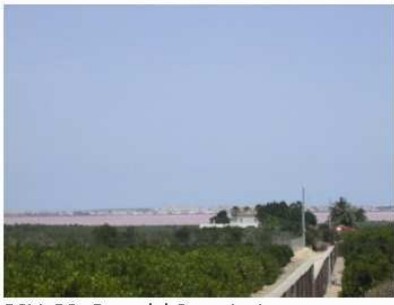

RPV 39 Casa del Purgatorio

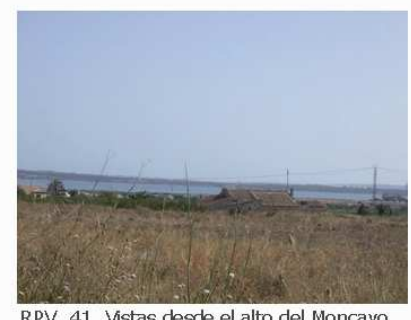

PV_41_Vistas desde el alto del Moncayo y la Atalaya 
UP7: DUNAS de GUARDAMAR

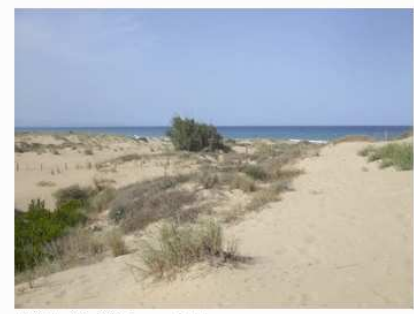

RPV_42_Vistas al Mar

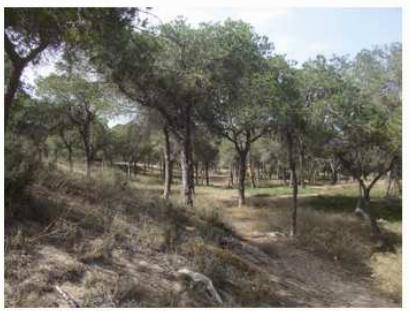

RPV_43_Recorridos a través de las Dunas de Guardamar

UP8: ALTO de LA HOYA y PINADAS del CHAPARRAL

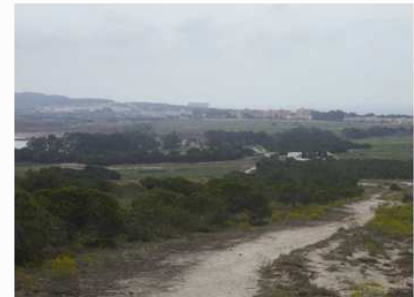

RPV_44_Vistas desde el Alto de la Hoya
RPV_45_Recorridos entre las urbanizaciones del anticlinal del Chaparral y la laguna

UP9: CONECTOR DE LA RAMBLA DE LA FAYONA

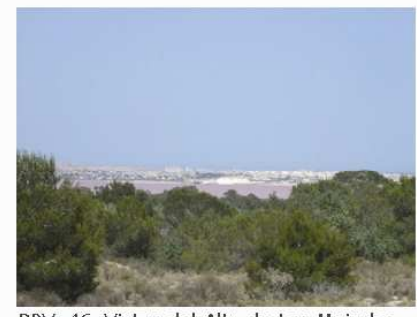

RPV_46_Vistas del Alto de Las Majadas y Falla de San Miguel

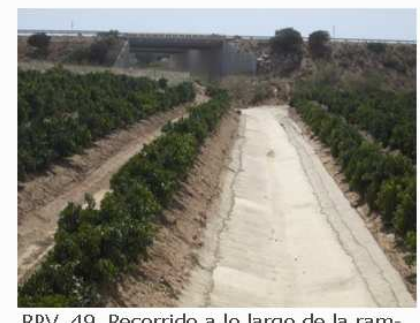

RPV_49_Recorrido a lo largo de la rambla de Garbanzuelo

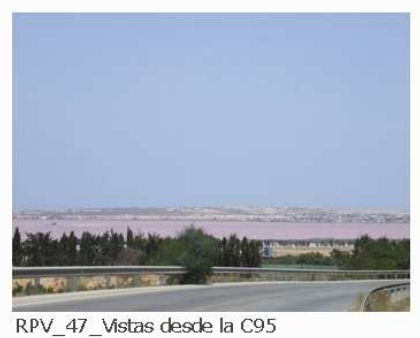

RPV_47_Vistas desde la C95

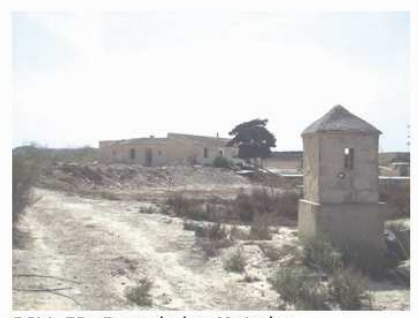

RPV_50_Casa de las Majadas

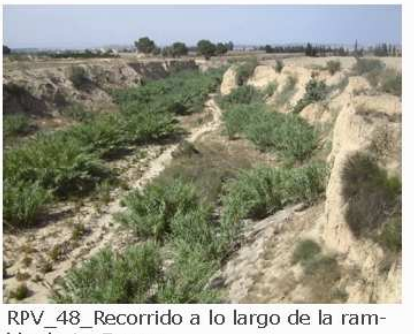

RPV_48_Recorrido a lo largo de la rambla de La Fayona

\section{UP10: URBANIZACION EL RASO}

No observados 


\section{UP11: URBANIZACION CIUDAD QUESADA}
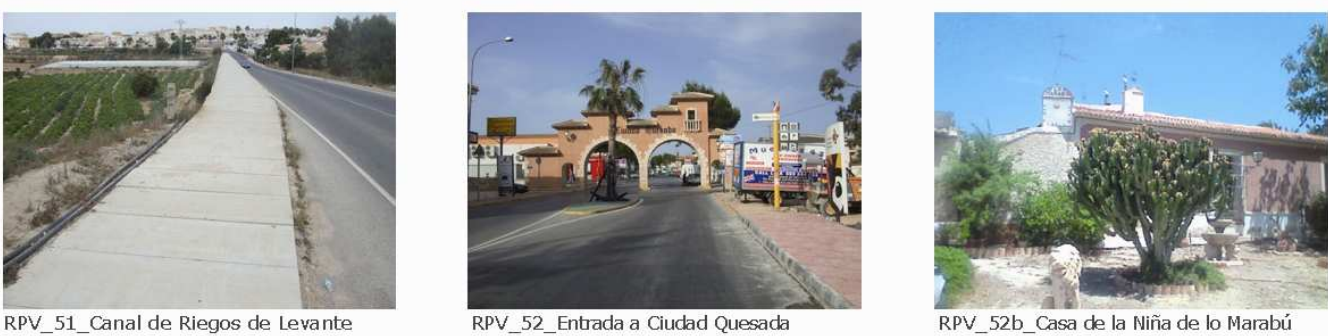

UP12: URBANIZACIONES ENTRE LAS LAGUNAS DE LA MATA Y DE TORREVIEJA

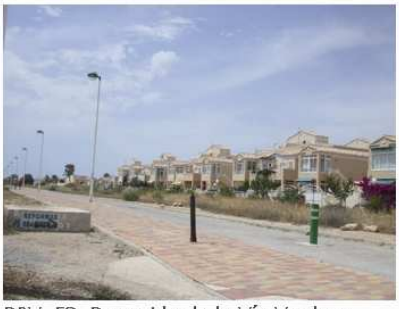

RPV_53_Recorrido de la Vía Verde a

través de las urbanizaciones

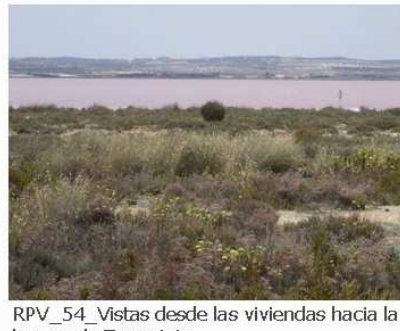

laguna de Torrevieja

UP13: URBANIZACION LOS BALCONES

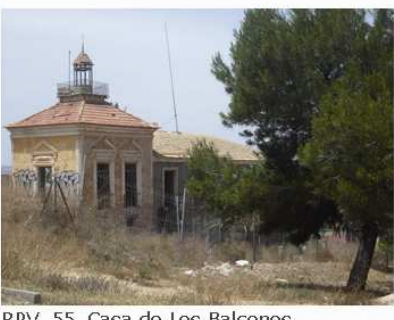

RPV_55_Casa de Los Balcones

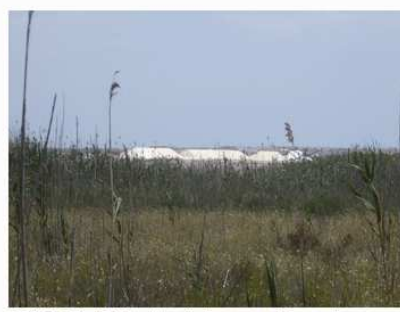

RPV_56_Vistas hacia las marjales y lagun de Torrevieja desde la carretera CV95 y desde el límite del parque

UP14: CONECTOR SUR LAGUNA DE TORREVIEJA - MAR MEDITERRÁNEO

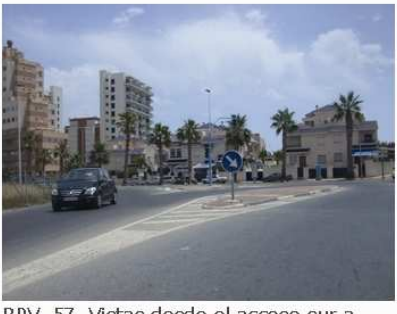

RPV_57_Vistas desde el acceso sur a Torrevieja (Cv95)

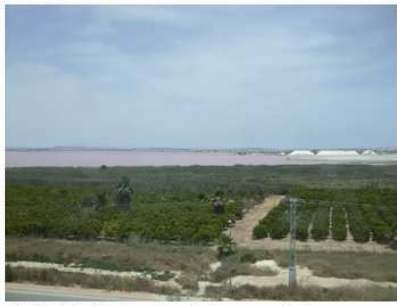

RPV 60 Vistas hacia las marjales y laguna de Torrevieja desde el Hospital de Torrevieja

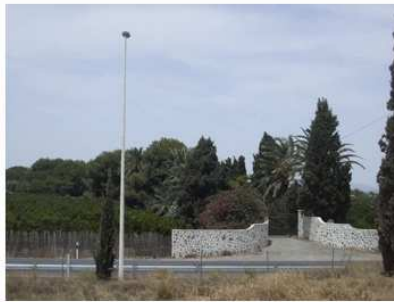

RPV_58_La Ceñuela

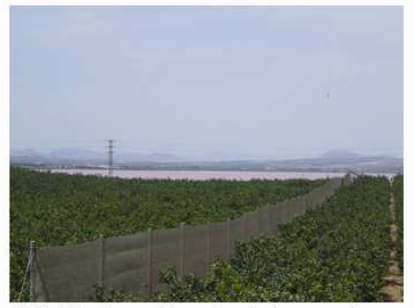

RPV_61_Recorrido entre la laguna de Torrevieja y las dotaciones próximas (Hospital, desaladora depuradora de aguas)

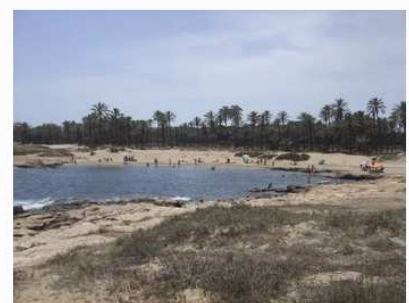

RPV_59_Cala Ferris y playa del Rocío

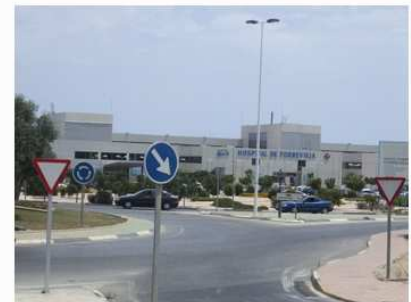

RPV 62 Hospital de Torrevieja 
VALORACIÓNY GESTIÓN DEL PAISAJE SEGÚN EL CONVENIO EUROPEO DEL PAISAJE YEL

REGLAMENTO DEL PAISAJE DE LA COMUNIDAD VALENCIANA: APLICACIÓN MEDIANTE UN ESTUDIO

DE PAISAJE A UNESPACIO ABIERTO EN LA COMUNIDAD VALENCIANA

DOCTORANDO: JUAN JOSÉ GALÁN VIVAS (Universidad Politécnica de Valencia, enero 2011)

\section{UP15: FRENTE LITORAL Y CASCO URBANO TORREVIEJA}

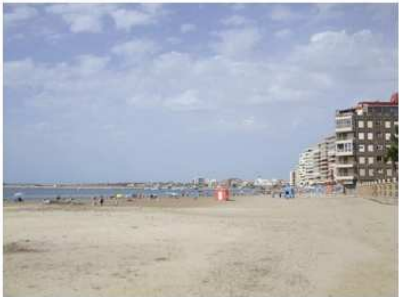

RPV_63_Playas de arena y vistas hacia el mar

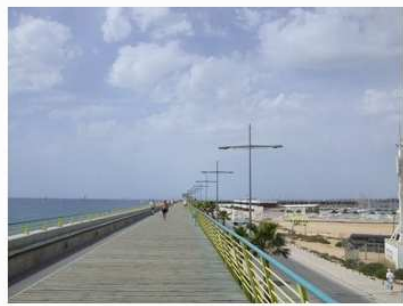

RPV_66_Faro de Torrevieja, rompeolas y paseo asociado

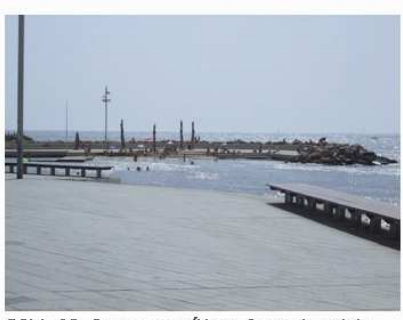

RPV 69 Paseo marítimo Juan Aparicio

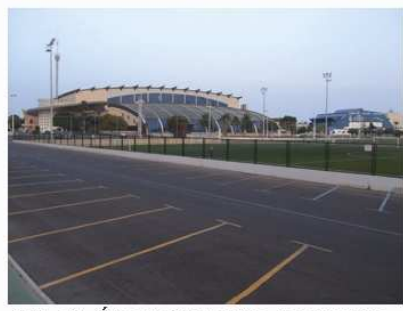

RPV_72_Área polideportiva y educativa

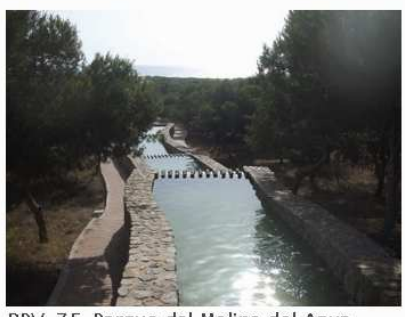

RPV 75 Parque del Molino del Agua

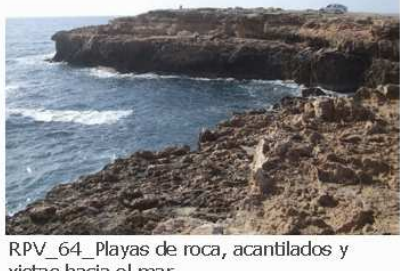

vistas hacia el mar

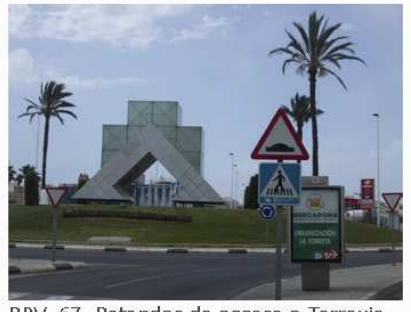

RPV 67 Rotondas de acceso a Torrevieja desde la carretera CV905

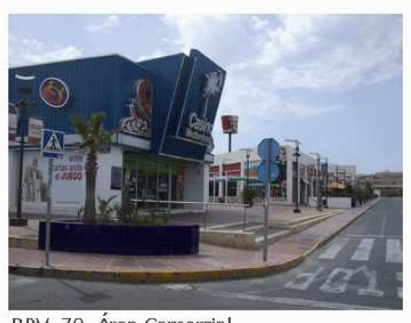

RPV_70_Área Comercial

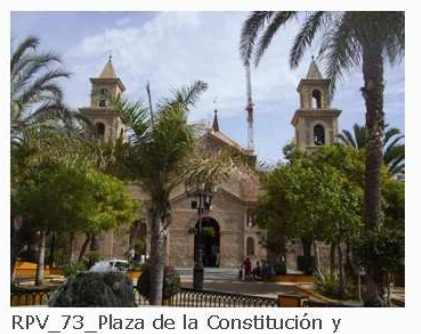

RPV_73_Plaza de la Constitución y Ayuntamiento

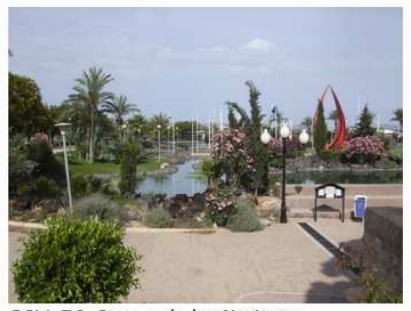

RPV 76 Parque de las Naciones

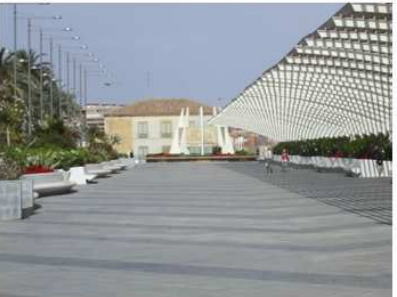

RPV_65_Muelle y Eras de la Sal

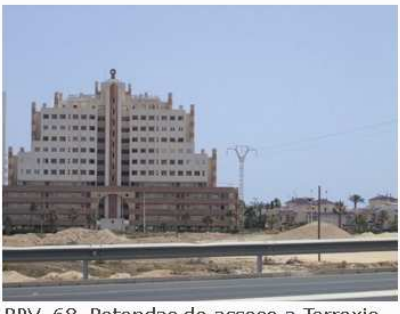

RPV 68 Rotondas de acceso a Torrevieja desde la carretera N332

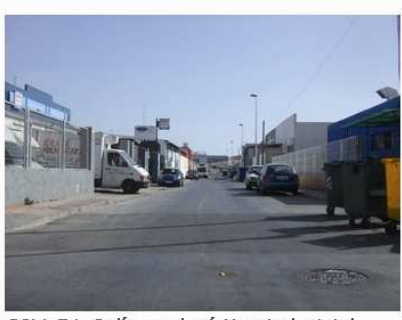

RPV_71_Polígono logístico-industrial

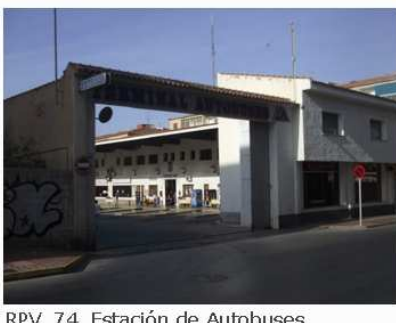

RPV_74_Estación de Autobuses

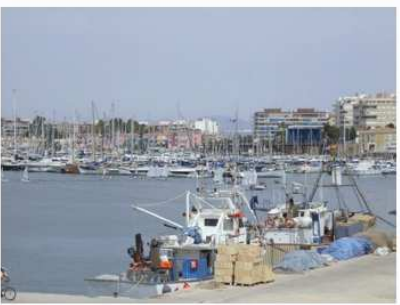




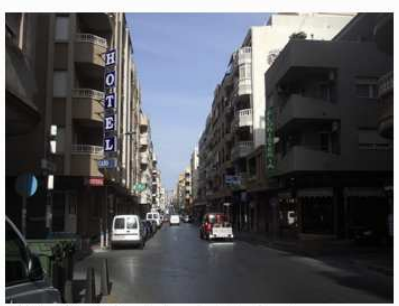

RPV 78 Calle Antonio Machado

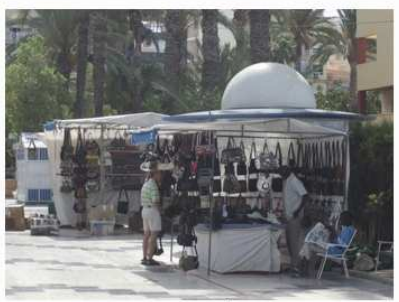

RPV_81_Mercadillo Turístico de Torrevieja

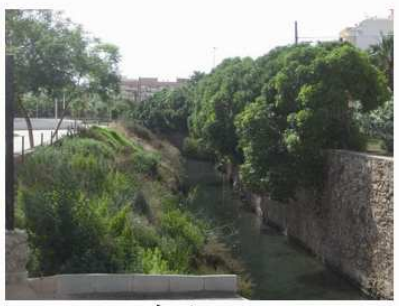

RPV_84_Acequión de Torrevieja

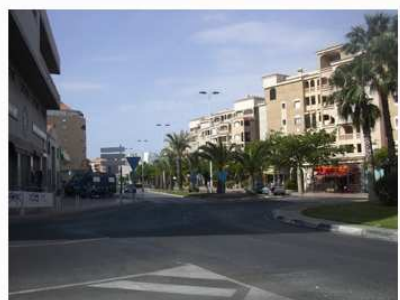

RPV 79 Avenida arbolada

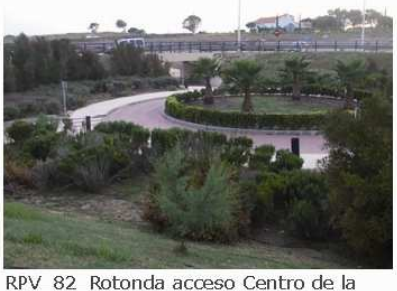
Mata

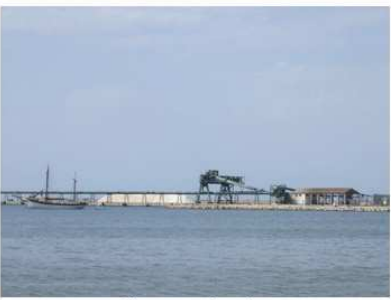

RPV 85_Muelle carga de sal

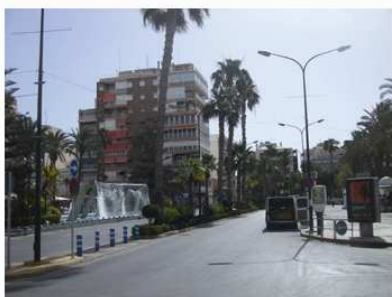

RPV_80_Paseo Vistalegre

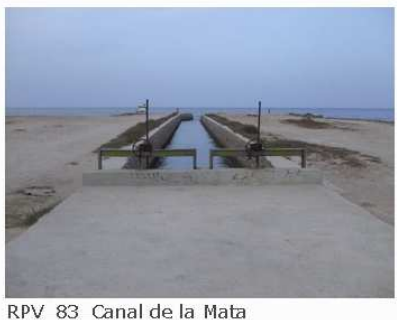

RPV_83_Canal de la Mata

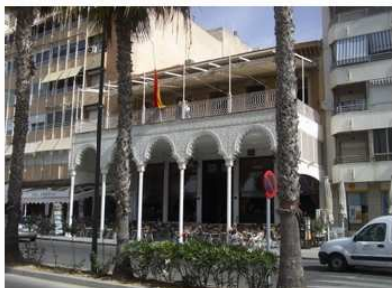

RPV_86_Sociedad Cultural Casino de Torrevieja

\section{4.e. Análisis Visual: Visibilidad del Paisaje}

5.4.e.1. Objetivos

La finalidad del análisis visual es determinar el grado de visibilidad del territorio, considerando para ello los posibles puntos o líneas desde los que se percibe mayormente el paisaje. Dichos puntos o líneas son definidos en el artículo 36 del Reglamento de Paisaje de la Comunidad Valenciana como "Puntos de Observación".

Los puntos de observación definidos en el ámbito del presente estudio se han clasificado en principales o secundarios en función principalmente del número de observadores potenciales, la distancia y la duración de la visión.

Una vez determinadas las zonas visibles desde cada punto de observación, principal o secundario, se ha procedido a determinar las zonas de máxima visibilidad, las de visibilidad media, las de visibilidad baja y las no visibles o zonas de sombra de acuerdo a las indicaciones a la metodología propuesta en el capitulo 4 de la presente tesis.

\section{4.e.2. Metodología}

Los puntos de observación seleccionados han incluido:

(1) Las vías de comunicación (considerando como puntos (o líneas) de observación principales las correspondientes a vías de uso más intenso):

\section{- Principales:}

- Autovía AP-7

- Carretera Nacional N332

- Carretera CV95 (IMD de 24.197 vehículos / día)

- Carretera CV905 (IMD de 33.942 vehículos / día)

\section{- Secundarios:}

- Carretera CV895 (IMD de 8.153 vehículos / día)

- Carretera CV945 (IMD de 12.333 vehículos / día) 
(2) Los accesos urbanos y las principales rotondas

- Principales:

- Rotonda en la CV-905 que da acceso a Ciudad Quesada

- Rotonda entre la CV-905, CV 945 y CV 985

- Secundarios:

- Accesos a Los Montesinos

- Entrada al Parque Natural por la N-332

- Accesos a Torrevieja desde la carretera CV905, CV95 y N-332

- Accesos a la autopista AP-7 desde la CV-945, CV-95

(3) Las zonas de alta concurrencia de población:

- Principales:

- Paseos marítimos, puerto y playas de Torrevieja

(4) Miradores naturales y puntos de observación del territorio

- Secundarios:

- Alto de la Atalaya

- Alto del Moncayo

- Alto de la Hoya

- Alto de las Majadas

(5) Los recorridos de valor paisajístico

- Secundarios:

- Vía verde a su paso entre las lagunas

- Puntos singulares dentro del Parque Natural

- Centro de Visitantes (antigua Casa Forestal)

- Diversos observatorios de aves

Para cada uno de los puntos se ha determinado las zonas visibles y no visibles haciendo para ello uso de la cartografía SIG disponible y siguiendo las siguientes premisas o condiciones de cálculo:

1. Considerar un modelo de relieve que incorpore la topografía, la vegetación arbórea existente (se aplica una altura de 7 metros a las masas arbóreas forestales y 3 metros a los frutales de regadío) así como la edificación existente a la que se asigna una altura media de 12 metros.

2. Considerar una altura del observador de 1,5 metros tanto a pie como en vehículos.

3. Dado el carácter mayoritariamente llano del área de trabajo, considerar para cada punto o línea (carreteras) de observación una distancia máxima de las visuales de hasta $10 \mathrm{kms}$.

4. Trabajar con una malla de celdas de $10 \times 10$ metros.

Los resultados parciales y el plano final de visibilidad se recogen en el punto siguiente: 


\section{4.e.3. Resultados del Análisis Visual}

5.4.e.3.1. Visibilidad desde los puntos de observación principales
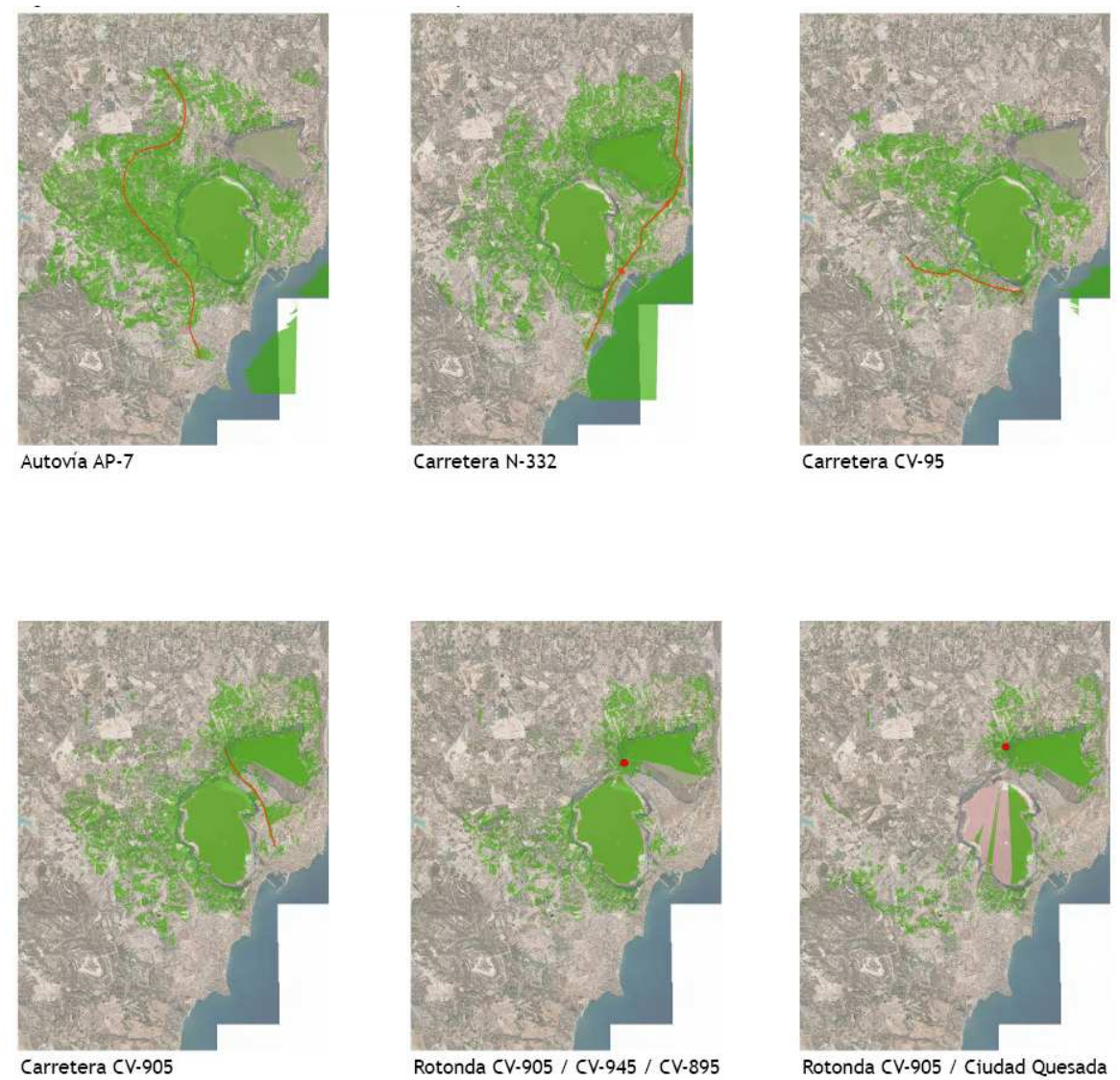

Fig. 5.31: Áreas visibles desde cada uno de los puntos de observación principales del ámbito estricto

El plano siguiente muestra las áreas con una visibilidad máxima (territorio visible desde alguno de los puntos de observación principales). Tal y como se concluye del plano, el carácter llano del área de trabajo y la posición elevada de algunos de los puntos o líneas de observación confiere una visibilidad máxima a un porcentaje muy alto del territorio.

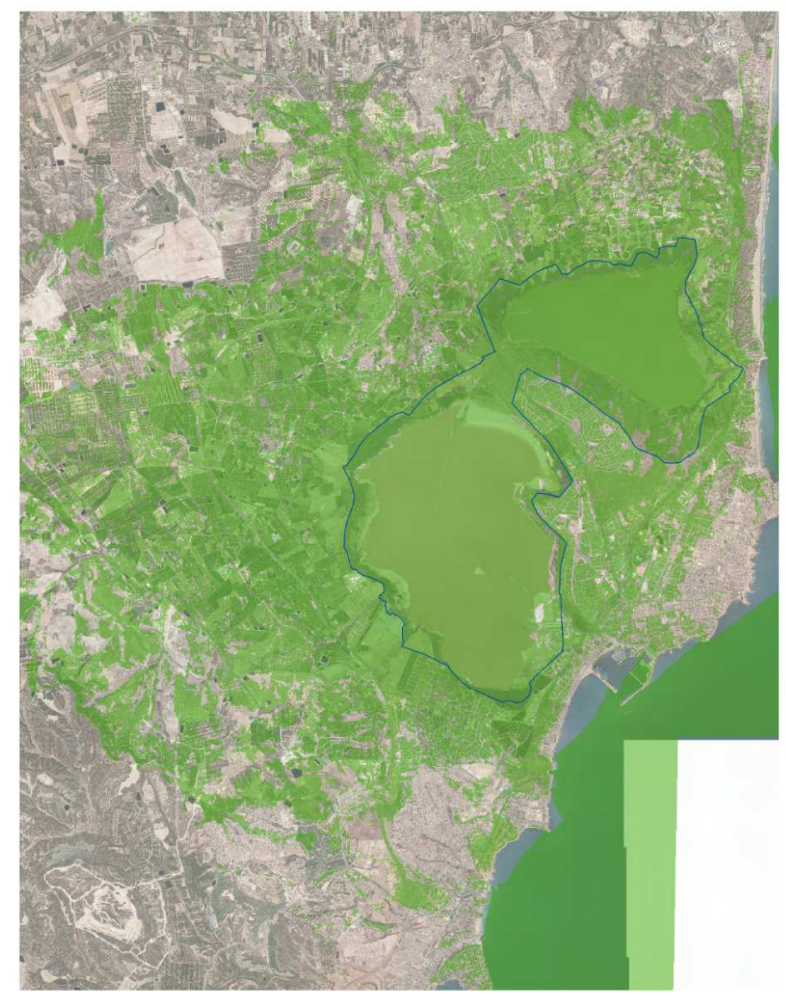

Fig. 5.32: Área visible desde alguno de los puntos de observación principales del ámbito estricto (Zona de visibilidad máxima) 


\section{4.e.3.2. Visibilidad desde los puntos de observación secundarios}

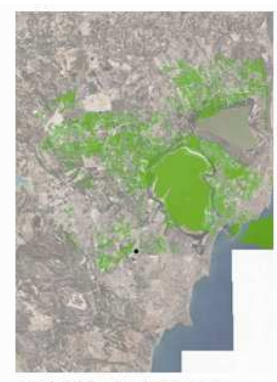

Mirador: Alto de las Majadas

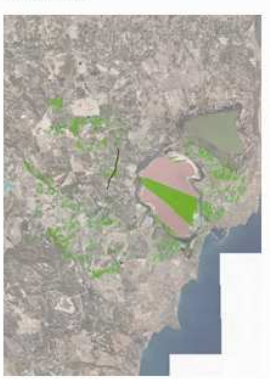

Carretera CV-940

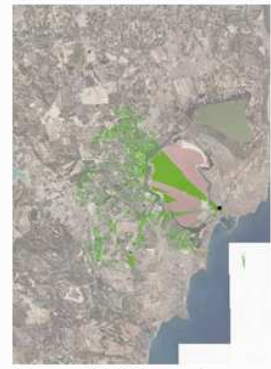

Cruce $\mathrm{N}-332$ con Acequión de Torrevieja

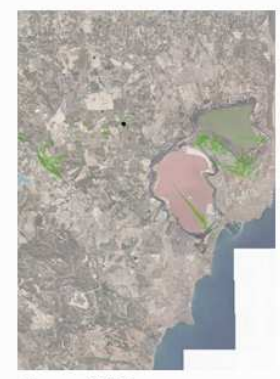

Cruce AP-7 con paso elevado

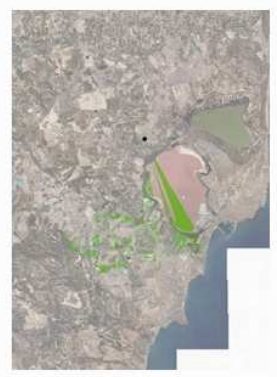

Acceso oeste Los Montesinos

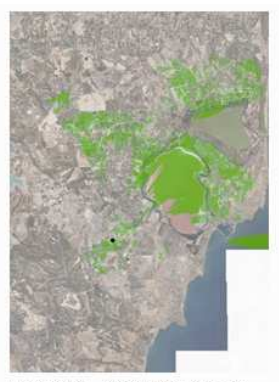

Mirador: San Miguel de las Salinas

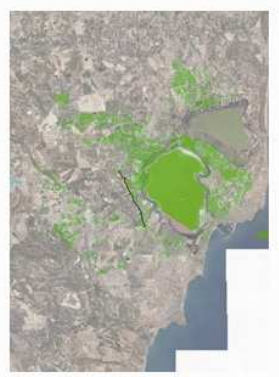

Carretera CV-943

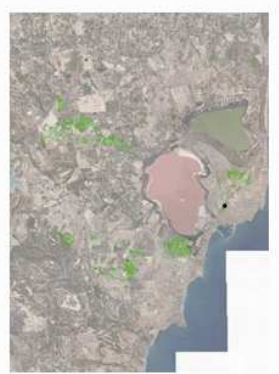

Rotonda N-332 con CV-905
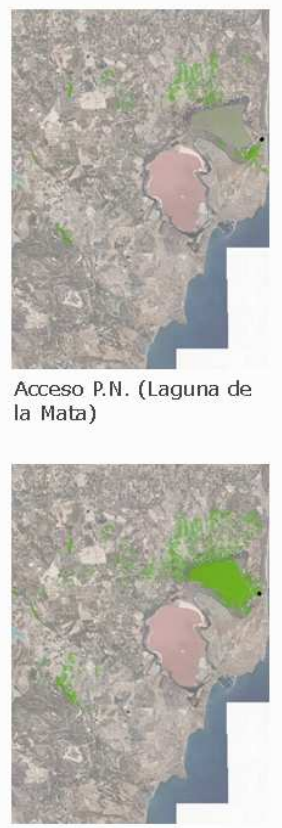

Casa forestal

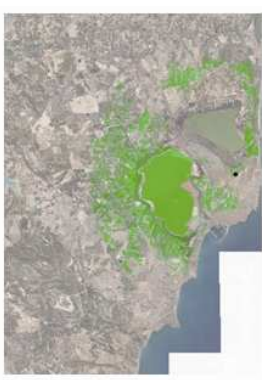

Mirador: Alto de la Hoya

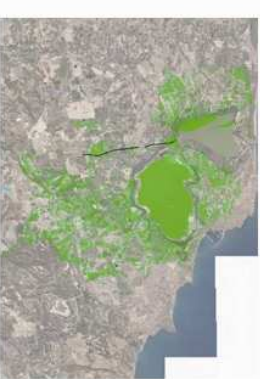

Carretera CV-945

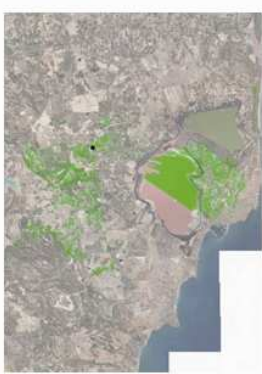

Cruce AP-7 con CV-945

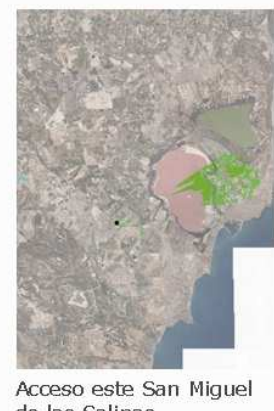

de las Salinas

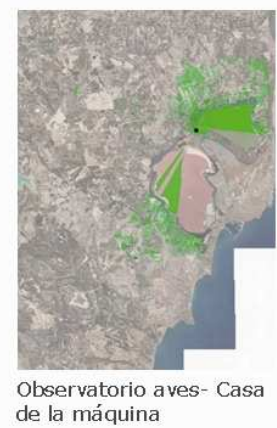

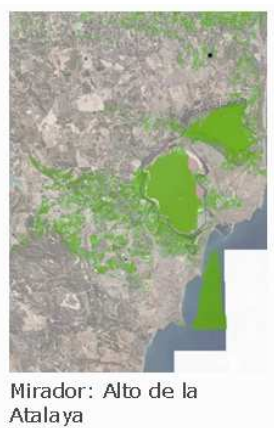
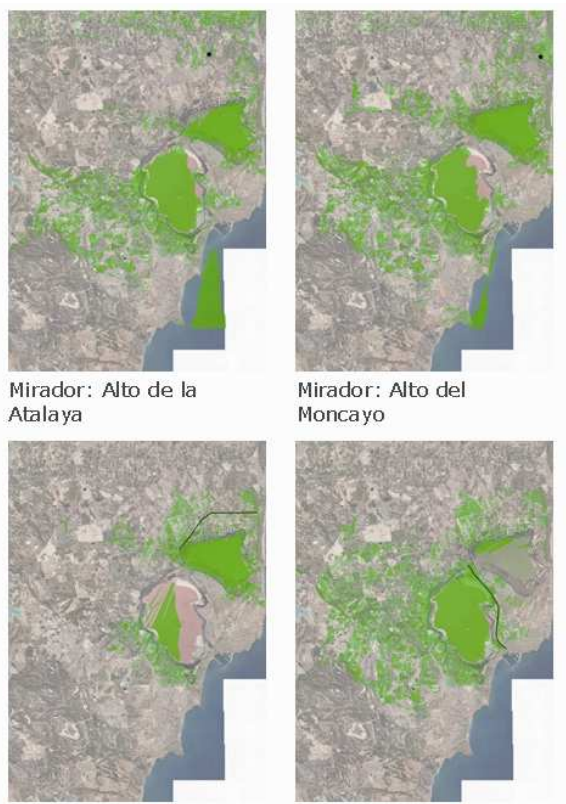

Carretera CV-895

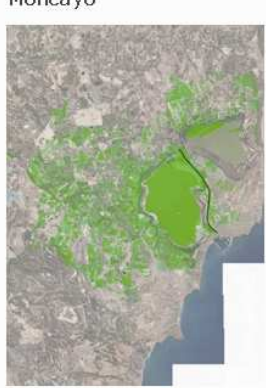

Via Verde

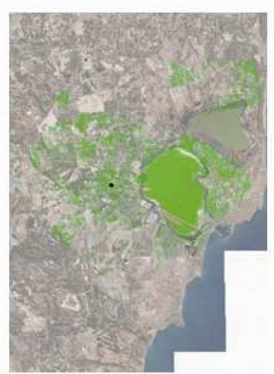

Cruce AP-7 con CV-940

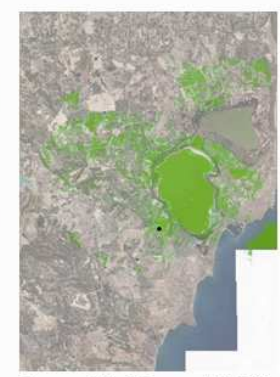

Cruce CV-95 con CV-943
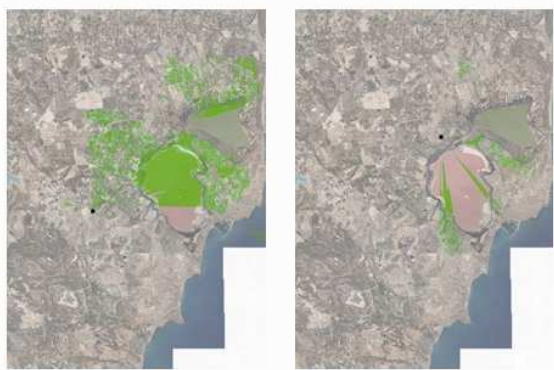

Acceso oeste San Miguel de Acceso este Los Monlas Salinas tesinos
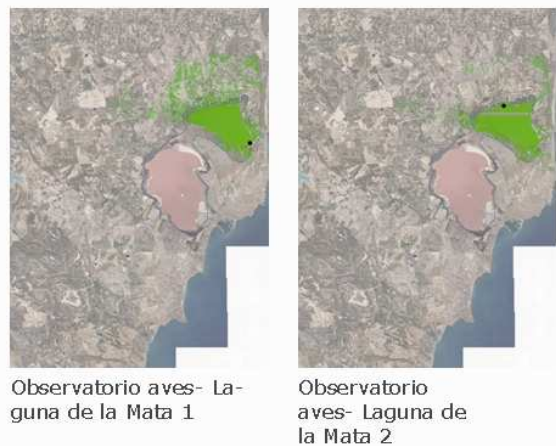

Fig. 5.33: Áreas visibles desde cada uno de los puntos de observación secundarios del ámbito estricto 
El plano siguiente muestra en tono azul las áreas con una visibilidad media (territorio visible desde más de la mitad de los puntos o líneas de observación secundarios) y sin colorear los puntos con una visibilidad baja o nula (territorio visible desde menos de la mitad de los puntos o líneas de observación secundarios).

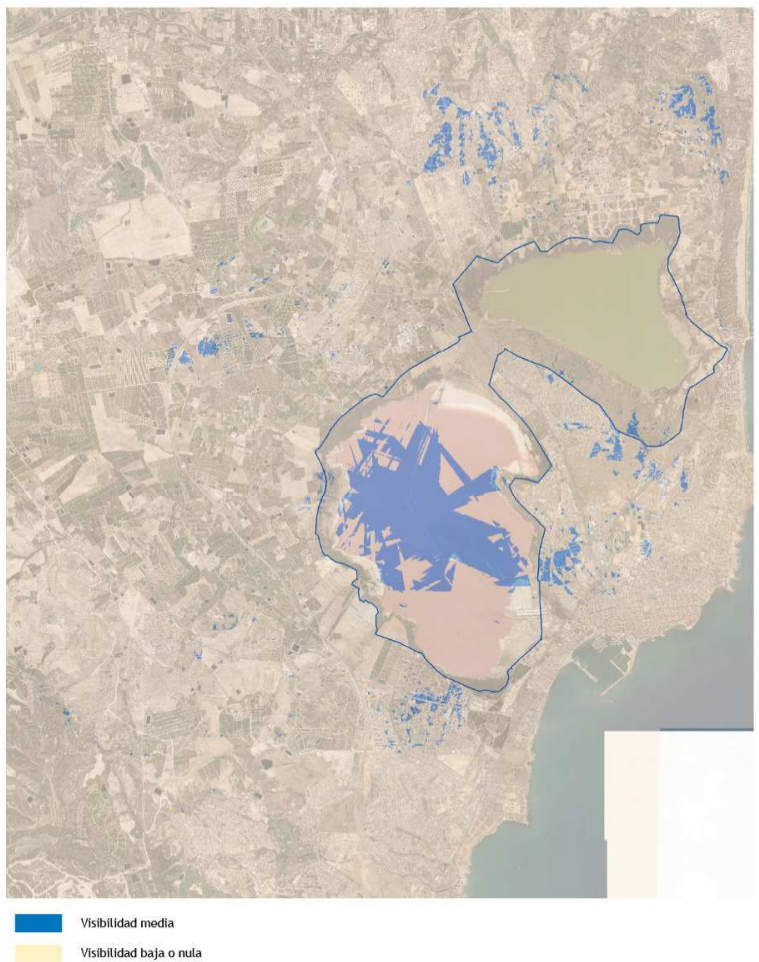

Fig. 5.34: Áreas de visibilidad media (azul) y de visibilidad baja (beige)

\section{4.e.3.3. Visibilidad final.}

Finalmente, el plano total de visibilidad recoge los tres niveles previstos (máxima, media y baja). En este caso, dado que las zonas con visibilidad media (de acuerdo a los puntos de observación secundarios) son zonas con visibilidad máxima desde los puntos de observación principales, quedan adscritas en esta segunda categoría:

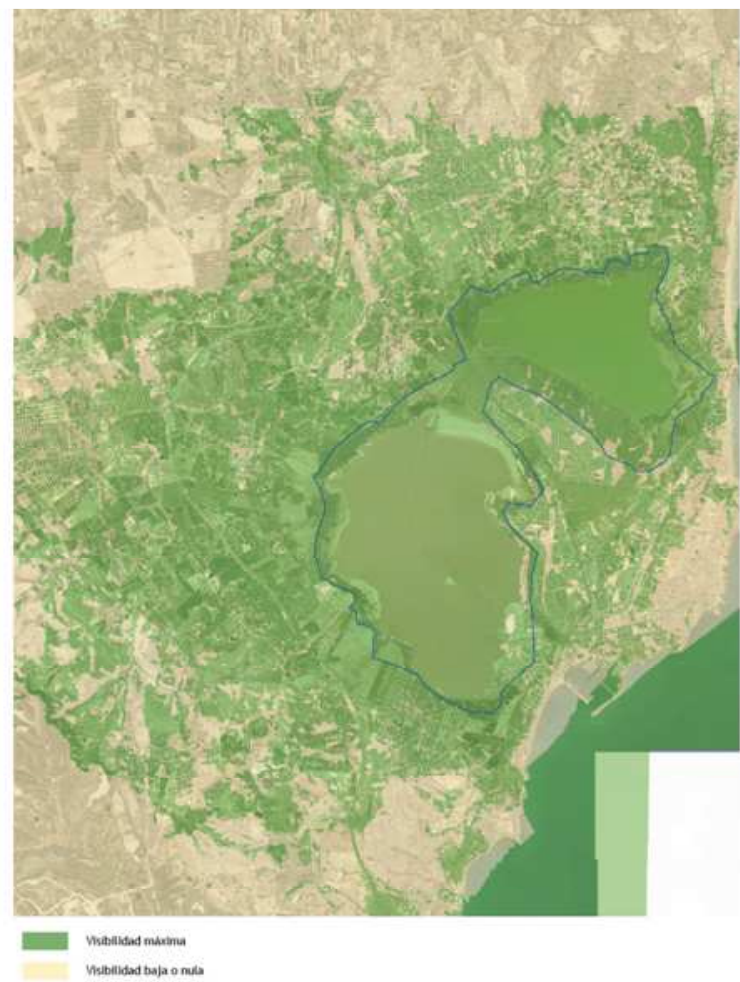

Fig. 5.35: Plano final de visibilidad: Áreas de visibilidad alta (verde) y de visibilidad baja (beige) 


\section{4.f. Valoración del Paisaje (apoyado en la FASE 2 del Plan de Participación Pública)}

\section{4.f.1. Introducción:}

Una vez definidas las unidades y recursos Paisajísticos, se ha procedido a determinar su valor paisajístico preliminar (muy bajo, bajo, medio, alto o muy alto) como media de los valores de calidad paisajística, determinada por un equipo pluridisciplinar de expertos en paisaje, y de preferencia paisajística, propuesta por una muestra representativa de la población residente o visitante de los 5 municipios afectados.

Los valores paisajísticos preliminares así definidos para cada unidad de paisaje o recurso paisajístico han sido a su vez ajustados en función de su visibilidad y de la posible existencia de alguna figura de la legislación en materia de protección de espacios naturales y patrimonio cultural que pudiese afectarles. En este último punto, cabe destacar la existencia de importantes figuras de protección en el ámbito estricto del estudio, entre las que sobresale por su relevancia y superficie el propio Parque Natural, ha implicado que el valor paisajístico de varias unidades de paisaje y recursos paisajísticos, se viese a su vez ajustado, no solo por su visibilidad, sino por la existencia de dichas figuras de protección.

\section{4.f.2. Plan de Participación Pública: FASE2 (Valoración del Paisaje)}

\section{4.f.2.1. Objetivos}

El objetivo de la Fase2 del Plan de Participación Pública del Estudio de Paisaje del Parque Natural de Las Lagunas de la Mata y Torrevieja fue determinar la preferencia y calidad paisajística de las distintas unidades y recursos paisajísticos incluidos en el interior del Parque y en su entorno inmediato.

\section{4.f.2.2. Metodología}

Atendiendo a la metodología propuesta en la presente tesis y al Reglamento de Paisaje de la Comunidad Valenciana, la preferencia y calidad paisajística de las unidades y recursos serán definidas respectivamente mediante consulta pública a la población y mediante consulta a un equipo pluridisciplinar de expertos. La media de ambos valores proporcionará un valor paisajístico preliminar, que deberá ser ponderado en función de la visibilidad y ajustado en caso de existir alguna figura de protección que afecte a la unidad o recurso.

La consulta a la población en la Fase 2 del Plan de Participación Pública del Estudio de Paisaje del Parque Natural de Las Lagunas de la Mata y Torrevieja se desarrolló mediante:

- Asistencia a Seminarios Informativos realizados en Torrevieja, Guardamar del Segura, Rojales, Los Montesinos y San Miguel de Salinas.

- Cumplimentación de formularios disponibles en las webs de la Consellería de Medio Ambiente, Agua, Urbanismo y Vivienda, en las webs de los ayuntamientos antes listados y en el Centro de Visitantes del Parque.

- Cumplimentación de formularios mediante encuestas a pie de calle realizadas sobre una muestra representativa de la población.

- Consulta a expertos entre los que se incluyó técnicos de las administraciones municipales y autonómica, profesores universitarios y personas que por su ejercicio profesional se encuentran vinculadas a la gestión de espacios incluidos dentro del ámbito del estudio.

\section{4.f.2.3. Consideraciones previas}

Las unidades de paisaje y los recursos paisajísticos valorados por la población y expertos han sido los determinados en la Fase 1 del Plan de Participación Pública, ajustados y ampliados en los posteriores trabajos de redacción del estudio.

En relación a la población consultada y a la realización de encuestas, dada la inserción del Parque en un entorno densamente habitado, éstas han sido mayormente realizadas en los distintos municipios y no en el interior del parque. De este modo se ha intentado recoger la opinión de los residentes o visitantes de la zona que hacen un uso esporádico del parque, promover el conocimiento de los valores del mismo y facilitar el futuro desarrollo de medidas que faciliten su conexión con otros espacios de valor paisajístico o medioambiental próximos.

Las consultas se realizaron mediante la cumplimentación de un cuestionario (ver anexo VIII) distribuido entre expertos y presentado a la población mediante encuestas a pie de calle o en las webs institucionales de apoyo. 


\section{4.f.2.4. Niveles de participación}

- Encuestas: Durante la fase 2 se realizaron un total de 80 encuestas y se recibieron 6 formularios descargados desde las webs en las que el Plan de Participación Pública estuvo activo.

- Consultas a expertos: Entre los expertos contactados para solicitar su posible colaboración en la FASE2 del Plan de Participación Pública se incluyeron técnicos de los Ayuntamientos de Torrevieja, Guardamar del Segura, Rojales, Los Montesinos y San Miguel de Salinas, profesores de las distintas Universidades de la Comunidad Valenciana, técnicos de la Consellería de Medio Ambiente, Agua, Urbanismo y Vivienda y del Parque Natural de las lagunas de La Mata-Torrevieja, recibiéndose un total de 15 respuestas al cuestionario.

Tabla 5.13: Comparación entre los perfiles inicialmente previstos y finalmente encuestados en la fase2 del plan de participación pública.

\begin{tabular}{|c|c|c|c|}
\hline Variable encuestado & Valores & Objetivo encuestas & Encuestas realizadas \\
\hline \multirow{5}{*}{$\begin{array}{c}\text { Lugar de realización de las } \\
\text { encuestas }\end{array}$} & Torrevieja & $50-60 \%$ & $53 \%$ \\
\hline & Montesinos & $10 \%$ & $8 \%$ \\
\hline & Guardamar & $15-20 \%$ & $15 \%$ \\
\hline & Rojales & $15-20 \%$ & $13 \%$ \\
\hline & San Miguel de las Salinas & $10 \%$ & $10 \%$ \\
\hline \multirow{2}{*}{$\begin{array}{l}\text { Motivo de la presencia en } \\
\text { la zona }\end{array}$} & Residente & $66 \%$ & $81,39 \%$ \\
\hline & Turista-motivos laborales & $33 \%$ & $18,61 \%$ \\
\hline \multirow{2}{*}{ Nacionalidad } & Español & $81 \%$ & $97,00 \%$ \\
\hline & Extranjero & $19 \%$ & $3,00 \%$ \\
\hline \multirow{3}{*}{ Edad } & $0-18$ & $13 \%$ & $6,98 \%$ \\
\hline & $18-65$ & $68 \%$ & $76,74 \%$ \\
\hline & $>65$ & $19 \%$ & $16,28 \%$ \\
\hline \multirow{2}{*}{ Sexo } & Hombres & $50 \%$ & $48,84 \%$ \\
\hline & Mujeres & $50 \%$ & $51,16 \%$ \\
\hline
\end{tabular}

\section{4.f.3. Resultados del Plan de Participación Pública: FASE2: Valor paisajístico preliminar}

\section{4.f.3.1. Introducción}

En las consultas realizadas a la población y expertos se utilizó un formulario con imágenes representativas de las 15 Unidades de Paisaje definidas y de los distintos recursos paisajísticos (ambientales, culturales y visuales), a los que los participantes asignaron uno de los siguientes valores:

- Preferencia o Calidad Paisajística muy baja: VALOR 1

- Preferencia o Calidad Paisajística baja: VALOR 2

- Preferencia o Calidad Paisajística media: VALOR 3

- Preferencia o Calidad Paisajística alta: VALOR 4

- Preferencia o Calidad Paisajística muy alta: VALOR 5

Las medias obtenidas para los valores de preferencia y calidad paisajística se vincularon a los intervalos siguientes:

- Preferencia o Calidad Paisajística muy baja: VALOR comprendido entre [1 y 1,75[

- Preferencia o Calidad Paisajística baja: VALOR comprendido entre $[1,75$ y 2,5[

- Preferencia o Calidad Paisajística media: VALOR comprendido entre $[2,5$ y 3,5$]$

- Preferencia o Calidad Paisajística alta: VALOR comprendido entre ]3,5 y 4,25]

- Preferencia o Calidad Paisajística muy alta: VALOR comprendido entre ]4,25 y 5,0]

\section{4.f.3.2 Preferencia, calidad y valor paisajístico preliminar de las unidades de paisaje}

Unidades de paisaje: preferencia paisajística: Tal y como se recoge en la tabla siguiente, la población consultada mostró una alta preferencia por las unidades de paisaje asociadas a las lagunas de la Mata y Torrevieja, a las dunas del Guardamar y a los paisajes forestales, mayormente arbolados, del Chaparral y del conector de la rambla de la Fayona. Se observa a su vez una preferencia media por las distintas unidades de paisaje de carácter agrícola, por el paisaje forestal del alto del Moncayo, por la Unidad de Paisaje que incluye el casco urbano de Torrevieja y su frente litoral y por el conector de carácter lacustre-agrícola-litoral entre cala Ferris y la laguna de Torrevieja (UP14). 
Presentan un nivel de preferencia bajo el conjunto de urbanizaciones que rodean el Parque Natural. La población no asignó un valor de preferencia muy alto o muy bajo a ninguna unidad de Paisaje.

Tabla 5.14: Preferencia paisajística de las unidades de paisaje.

\begin{tabular}{|c|c|c|c|c|}
\hline Código & \multicolumn{2}{|c|}{ Descripción } & $\begin{array}{c}\text { Media } \\
\text { población }\end{array}$ & Valor \\
\hline UP2 & \multicolumn{2}{|c|}{ Laguna Torrevieja } & 4,08 & \\
\hline UP1 & \multicolumn{2}{|c|}{ Laguna La mata } & 3,98 & \\
\hline UP7 & \multicolumn{2}{|c|}{ Dunas Guardamar } & 3,83 & \\
\hline UP9 & \multicolumn{2}{|c|}{ Conector Fayona } & 3,67 & \\
\hline UP8 & \multicolumn{2}{|c|}{ La Hoya y Chaparral } & 3,52 & \\
\hline UP3 & \multicolumn{2}{|c|}{ Viñedos de La Mata } & 3,38 & \\
\hline UP15 & \multicolumn{2}{|c|}{ Torrevieja + costa } & 3,35 & \\
\hline UP4 & \multicolumn{2}{|c|}{ Regadios trad. } & 3,30 & \\
\hline UP5 & \multicolumn{2}{|c|}{ Regadios extens. } & 3,15 & \\
\hline UP6 & \multicolumn{2}{|c|}{ Alto Moncayo } & 3,08 & \\
\hline UP14 & \multicolumn{2}{|c|}{ Conector Mediter. } & 2,87 & \\
\hline UP13 & \multicolumn{2}{|c|}{ Urb Los Balcones } & 2,14 & \\
\hline UP12 & \multicolumn{2}{|c|}{ Urb Chaparral } & 2,06 & \\
\hline UP10 & \multicolumn{2}{|c|}{ Urb El Raso } & 1,84 & \\
\hline UP11 & \multicolumn{2}{|c|}{ Urb Ciudad Quesada } & 1,77 & \\
\hline Muy alto & Alto & Medio & Bajo & Muy bajo \\
\hline
\end{tabular}

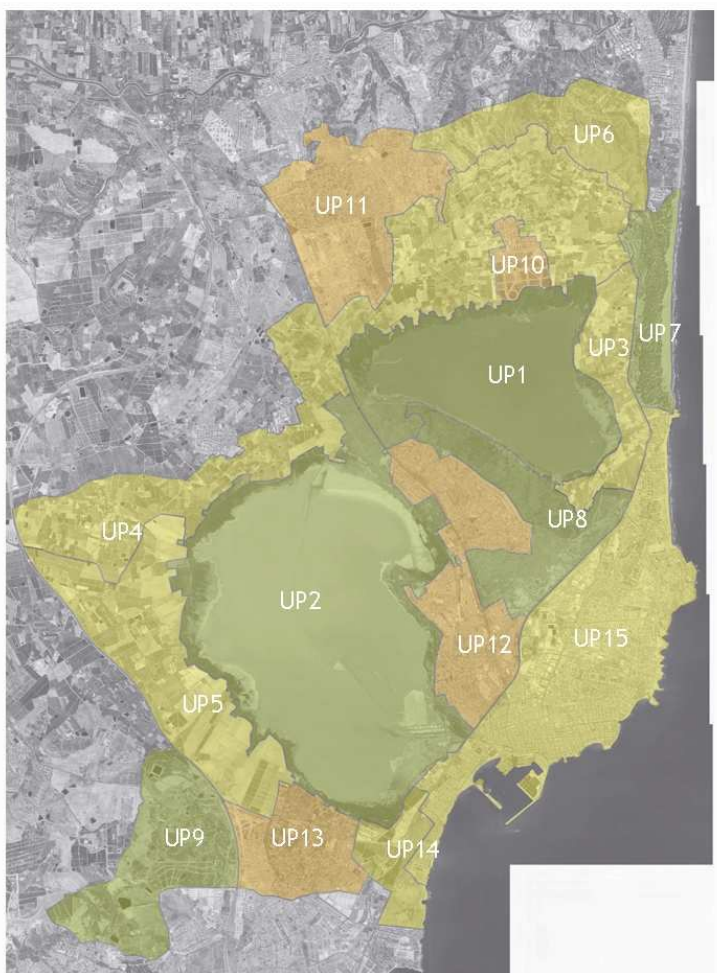

Unidades de paisaje: calidad paisajística: Tal y como se recoge en la tabla siguiente los expertos consultados asignaron una calidad paisajística muy alta a las dunas de Guardamar y a la laguna de la Mata, una calidad alta a la laguna de Torrevieja, conector de la rambla de la Fayona, secanos-viñedos de la Mata y al alto de la Hoya y pinadas del Chaparral. La calidad media fue asignada a los espacios agrícolas de regadío, al alto del Moncayo, conector entre cala Ferris y la laguna de Torrevieja y al casco urbano de Torrevieja y su frente litoral. Se asignó a su vez una calidad baja a las urbanizaciones situadas entre las lagunas de la Mata y Torrevieja y a la urbanización de los Balcones y muy baja a las urbanizaciones de El Raso y Ciudad Quesada.

Tabla 5.15: Calidad paisajística de las unidades de paisaje.

\begin{tabular}{|c|c|c|c|}
\hline Código & Descripción & $\begin{array}{c}\text { Media } \\
\text { expertos }\end{array}$ & Valor \\
\hline UP7 & Dunas Guardamar & 4,60 & \\
\hline UP1 & Laguna La mata & 4,27 & \\
\hline UP2 & Laguna Torrevieja & 4,13 & \\
\hline UP9 & Conector Fayona & 4,13 & \\
\hline UP3 & Viñedos de La Mata & 3,93 & \\
\hline UP8 & La Hoya y Chaparral & 3,87 & \\
\hline UP4 & Regadios trad. & 3,40 & \\
\hline UP6 & Alto Noncayo & 3,33 & \\
\hline UP14 & Conector Mediter. & 3,00 & \\
\hline UP5 & Regadios extens. & 2,93 & \\
\hline UP15 & Torrevieja + costa & 2,67 & \\
\hline UP13 & Urb Los Baloones & 2,27 & \\
\hline UP12 & Urb Chaparral & 1,87 & \\
\hline UP10 & Urb El Raso & 1,73 & \\
\hline UP11 & Urb Ciudad Quesada & 1,47 & \\
\hline Nay alto & Medio & & \\
\hline
\end{tabular}

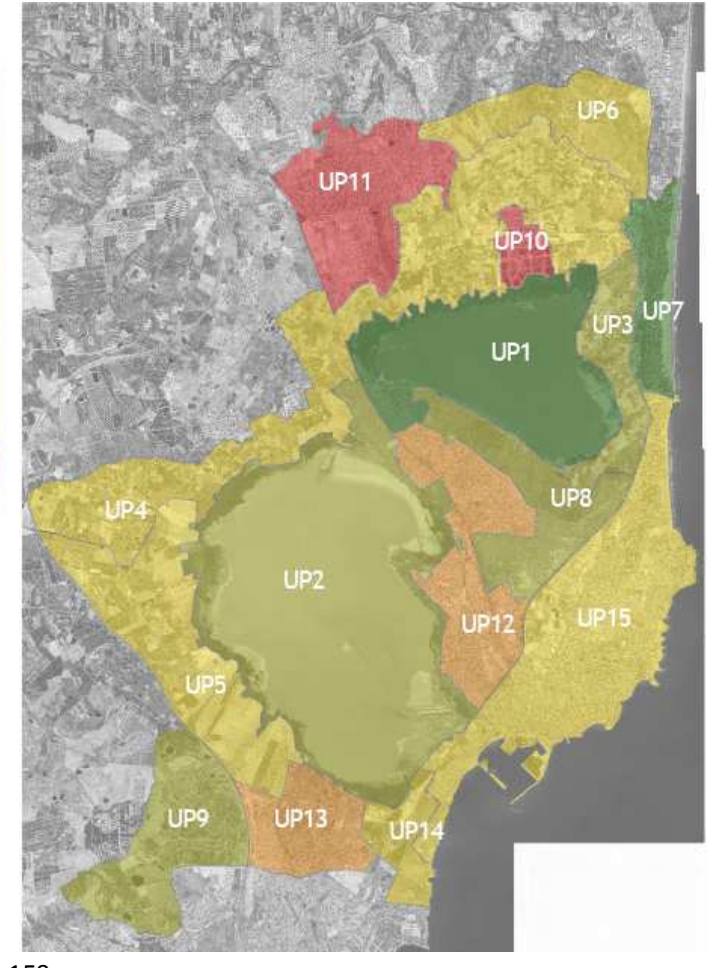


Unidades de paisaje: Valor paisajístico preliminar y consideraciones previas: La media de los valores correspondientes a la calidad y preferencia paisajística permite determinar un "valor paisajístico preliminar" a ajustar posteriormente en función de su visibilidad y presencia de espacios protegidos.

La comparación de los valores de calidad y preferencia paisajísticas muestra una posición más extrema de los expertos en lo referente a la asignación de valores muy altos y muy bajos. Este hecho puede deberse tanto al menor $n^{\circ}$ de opiniones de expertos en comparación con la población como a su conocimiento de recursos o valores asociados a las unidades de paisaje desconocidos para parte de la población.

En lo referente a la unidad de paisaje que incluye el casco urbano de Torrevieja y su frente litoral, la comparación de los valores asignados por población y expertos a recursos o espacios incluidos dentro de ésta, sugiere una marcada disociación entre los espacios litorales (playas de roca y arena y paseos marítimos) y los espacios urbanos internos, que resultan mucho menos valorados.

Las unidades de paisaje con valor preliminar alto corresponden a los ámbitos lacustres, forestales (con excepción del alto del Moncayo) y a los secanos-viñedos de la Mata. El valor paisajístico preliminar medio se localiza en las zonas de regadíos, en el frente litoral y urbano de Torrevieja y en el conector entre Cala Ferris y la laguna de Torrevieja. El valor bajo en el conjunto de urbanizaciones que rodean parcialmente el parque, excepto en Ciudad Quesada, cuyo valor paisajístico preliminar es muy bajo. No se asignó a ninguna unidad paisajística un valor paisajístico preliminar muy alto.

Tabla 5.16: Valor Paisajístico Preliminar de las unidades de paisaje.

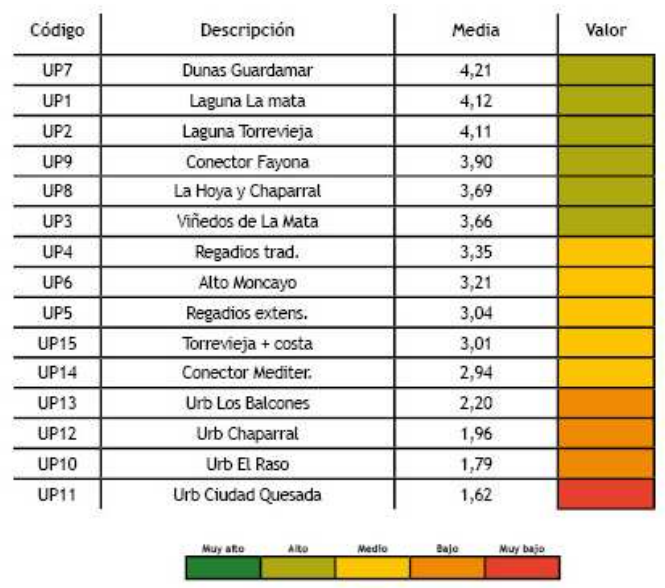

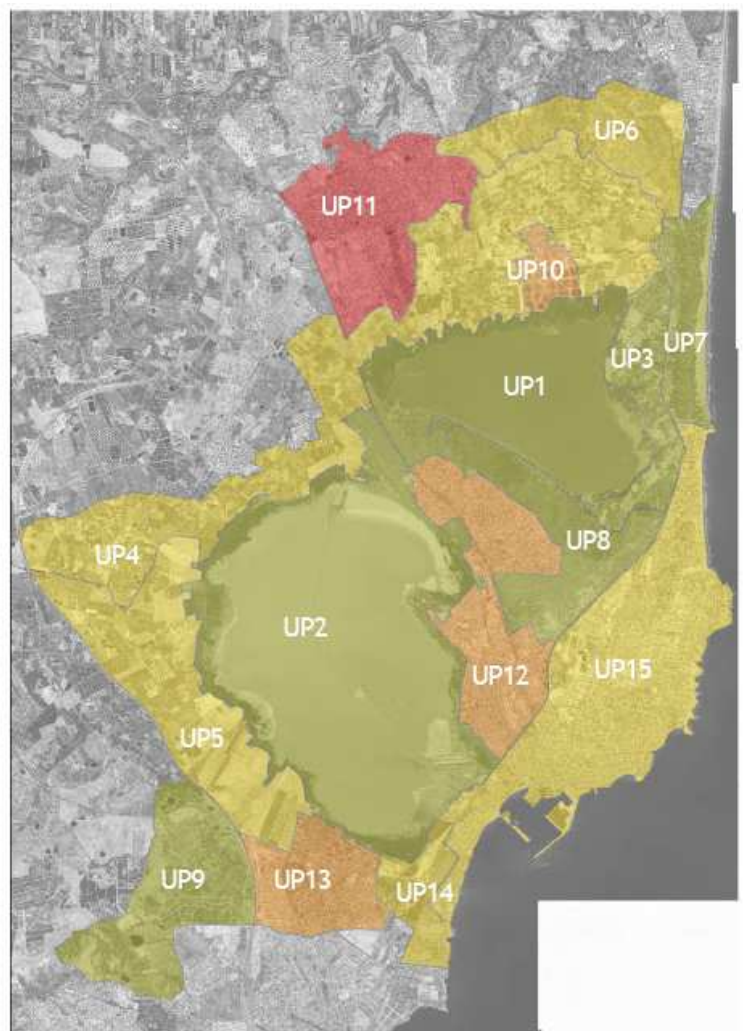

\section{4.f.3.3 Preferencia, calidad y valor preliminar paisajístico de los recursos paisajísticos ambientales}

Recursos paisajísticos ambientales: Preferencia paisajística: Tal y como se recoge en la tabla siguiente la población consultada mostró una alta preferencia por los recursos medioambientales asociados a espacios litorales (calas, playas de arena y roca), espacios forestales arbolados y palmerales, saladares y marjales y la laguna de La Mata. El resto de recursos paisajísticos ambientales presentados obtuvieron una calidad paisajística media. 
VALORACIÓNY GESTIÓN DEL PAISAJE SEGÚN EL CONVENIO EUROPEO DEL PAISAJE YEL

REGLAMENTO DEL PAISAJE DE LA COMUNIDAD VALENCIANA: APLICACIÓN MEDIANTE UN ESTUDIO DE PAISAJE A UNESPACIO ABIERTO EN LA COMUNIDAD VALENCIANA

DOCTORANDO: JUAN JOSÉ GALÁN VIVAS (Universidad Politécnica de Valencia, enero 2011)

Tabla 5.17: Preferencia paisajística de los recursos paisajísticos ambientales

\begin{tabular}{|c|c|c|c|}
\hline Código & Descripción & $\begin{array}{c}\text { Media } \\
\text { población }\end{array}$ & Valor \\
\hline RPA23 & Cala Ferris & 3,99 & \\
\hline RPA17 & Playas dunas Guard & 3,98 & \\
\hline RPA26 & Playas roca Torrey & 3,92 & \\
\hline RPA16 & Pinadas dunas Guard & 3,91 & \\
\hline RPA2O & Pinadas Fayona & 3,85 & \\
\hline RPA22 & Palmeral Lo Ferris & 3,74 & \\
\hline RPA1 & Laguna Mata & 3,72 & \\
\hline RPA7 & Saladares Torrevieja & 3,70 & \\
\hline RPA2 & Marjales mata & 3,63 & \\
\hline RPA15 & Pinares Moncayo & 3,59 & \\
\hline RPA18 & Pinadas Chaparra! & 3,57 & \\
\hline RPA3 & Saladares Mata & 3,51 & \\
\hline RPA25 & Playas arena Torrev & 3,51 & \\
\hline RPA21 & Almendros & 3,48 & \\
\hline RPA13 & Rambla Fayona & 3,45 & \\
\hline RPA6 & Marjales Torrevieja & 3,43 & \\
\hline RPA24 & Arbolado La Ceñuela & 3,34 & \\
\hline RPA14 & Rambla Garbanzuelo & 3,30 & \\
\hline RPAB & Cubetas salinas & 3,29 & \\
\hline RPA27 & Parque Molino Agua & 3,26 & \\
\hline RPA5 & Laguna Torrevieja & 3,24 & \\
\hline RPA19 & Pastizales La Hoya & 3,21 & \\
\hline RPAG & Viñedos de La Mata & 3,16 & \\
\hline RPA10 & Carrizales Hondo & 3,07 & \\
\hline RPA4 & Microreserva & 2,97 & \\
\hline RPA12 & Pinos CV943 & 2,91 & \\
\hline RPA11 & Rambla Marabu & 2,86 & \\
\hline syctes & B.o & & \\
\hline
\end{tabular}

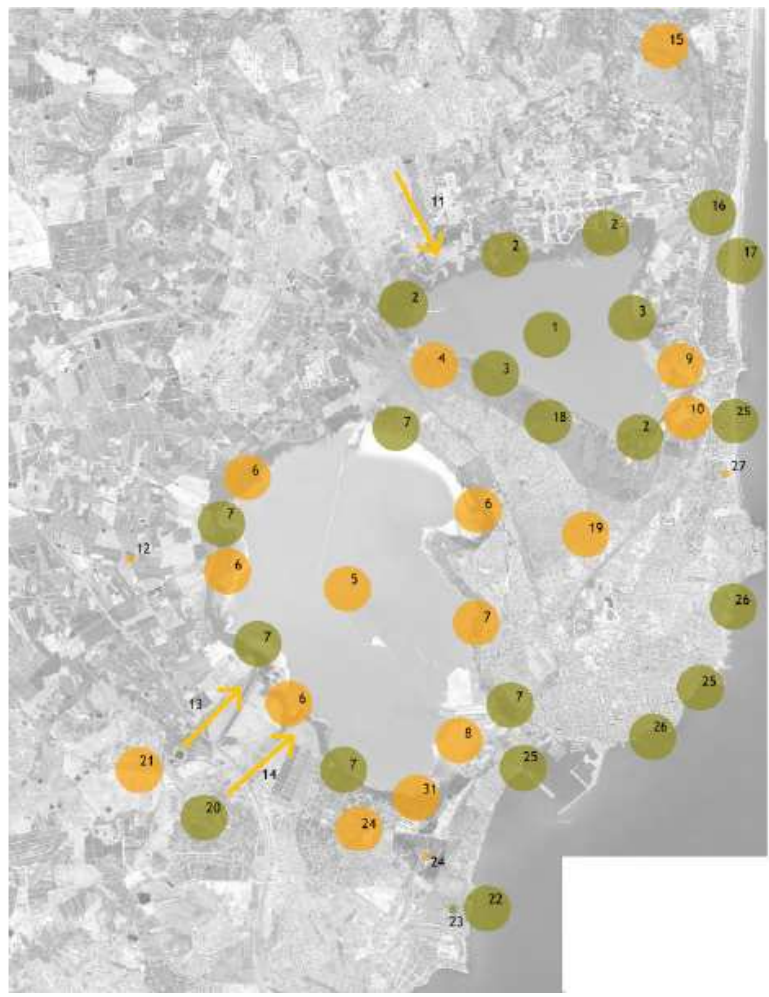

Recursos paisajísticos ambientales: Calidad paisajística: Los expertos consultados asignaron una calidad muy alta a las playas, dunas y pinadas de Guardamar, a las playas de roca de Torrevieja, al conjunto de marjales de las laguna de Torrevieja y La Mata, a los saladares de la Laguna de Torrevieja y a la laguna de La Mata. Se asignó una calidad alta a la laguna de Torrevieja, a los saladares de la laguna de La Mata, a los pinares de zonas forestales, a las ramblas de la Fayona y Garbanzuelo, a los palmerales existentes y a las playas de arena de Torrevieja. Se asignó por último una calidad media a los pastizales de La Hoya, a los restos de la rambla de Lo Marabú y a los pinos que se alinean a lo largo de la carretera CV943.

Tabla 5.18: Calidad paisajística de los recursos paisajísticos ambientales

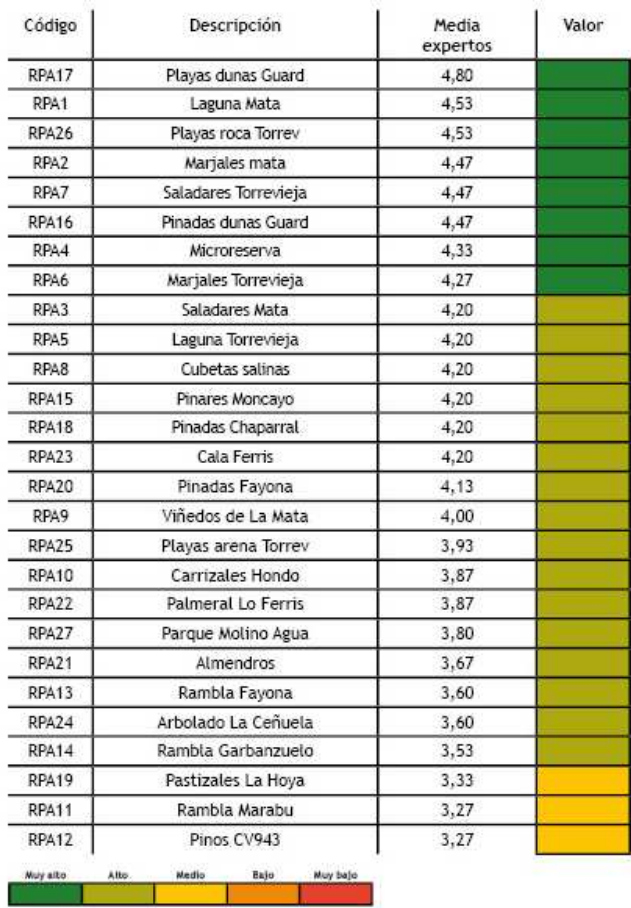

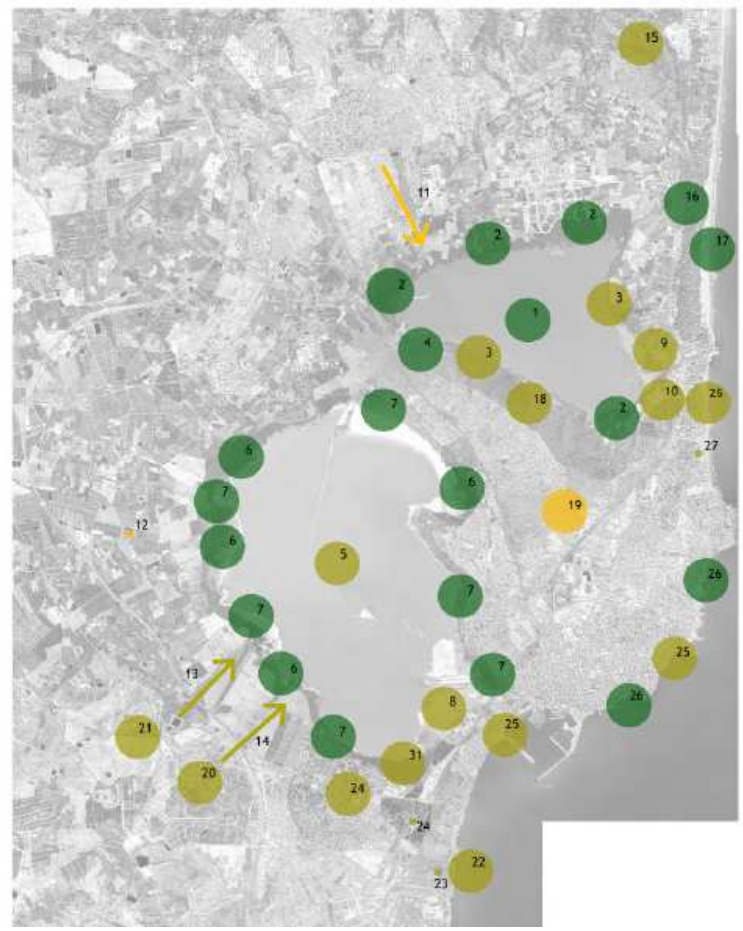


Recursos paisajísticos ambientales: Valor paisajístico preliminar y consideraciones previas: La media de los valores correspondientes a la calidad y preferencia paisajística permite determinar un "valor paisajístico preliminar" a ajustar posteriormente en función de su visibilidad y presencia de espacios protegidos.

Tabla 5.19: Valor paisajístico preliminar de los recursos paisajísticos ambientales

\begin{tabular}{|c|c|c|c|}
\hline Código & Descripción & Media & Valor \\
\hline RPA17 & Playas dunas Guard & 4,39 & \\
\hline RPA26 & Playas roca Torrev & 4,23 & \\
\hline RPA16 & Pinadas dunas Guard & 4,19 & \\
\hline RPA1 & Laguna Mata & 4,13 & \\
\hline RPA23 & Cala Ferris & 4,09 & \\
\hline RPA7 & Saladares Torrevieja & 4,08 & \\
\hline RPA2 & Marjales mata & 4,05 & \\
\hline RPA20 & Pinadas Fayona & 3,99 & \\
\hline RPA15 & Pinares Moncayo & 3,90 & \\
\hline RPA18 & Pinadas Chaparral & 3,88 & \\
\hline RPA3 & Saladares Mata & 3,86 & \\
\hline RPA6 & Marjales Torrevieja & 3,85 & \\
\hline RPA22 & Palmeral Lo Ferris & 3,81 & \\
\hline RPA8 & Cubetas salinas & 3,75 & \\
\hline RPA25 & Playas arena Torrev & 3,72 & \\
\hline RPA5 & Laguna Torrevieja & 3,72 & \\
\hline RPA4 & Microreserva & 3,65 & \\
\hline RPA9 & Viñedos de La Mata & 3,58 & \\
\hline RPA21 & Almendros & 3,57 & \\
\hline RPA27 & Parque Molino Agua & 3,53 & \\
\hline RPA13 & Rambla Fayona & 3,53 & \\
\hline RPA24 & Arbolado La Ceñuela & 3,47 & \\
\hline RPA 10 & Carrizales Hondo & 3,47 & \\
\hline RPA14 & Rambla Garbanzuelo & 3,42 & \\
\hline RPA19 & Pastizales La Hoya & 3,27 & \\
\hline RPA12 & Pinos $\mathrm{CV} 943$ & 3,09 & \\
\hline RPA11 & Rambla Marabu & 3,06 & \\
\hline mey atho & $\operatorname{mase}$ & & \\
\hline
\end{tabular}

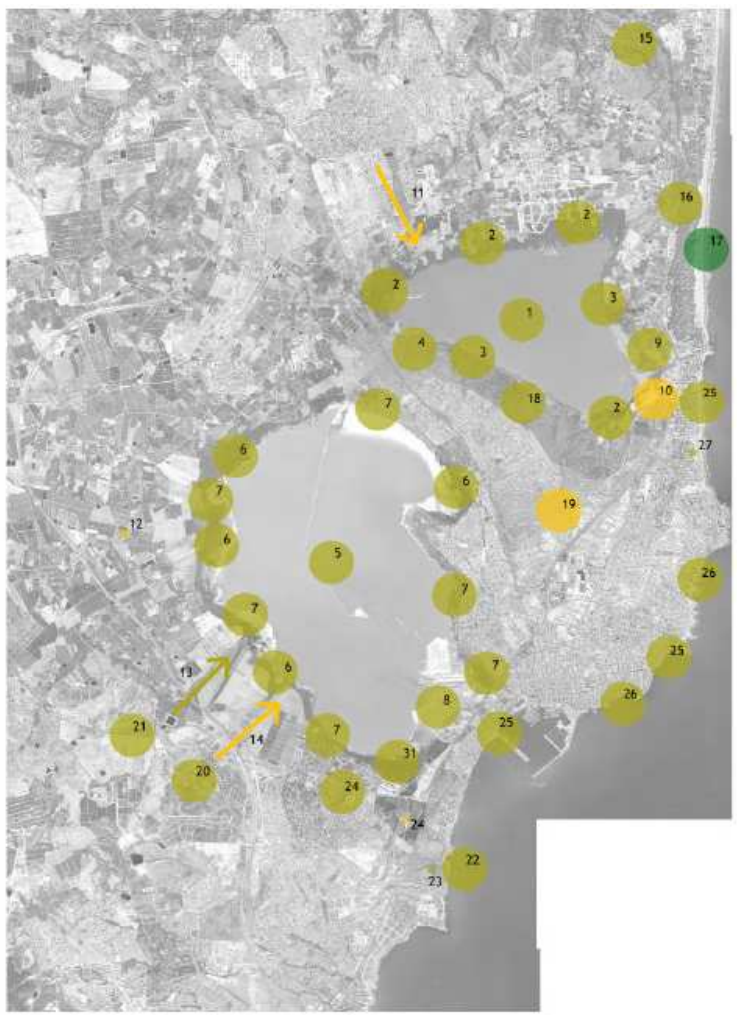

La comparación de los valores de calidad y preferencia paisajísticas muestra una posición más extrema de los expertos en lo referente a la asignación de valores muy altos y muy bajos. Este hecho puede deberse tanto al menor $n^{\circ}$ de opiniones de expertos en comparación con la población como a su mayor conocimiento técnicocientífico de algunos de los recursos valorados.

El único recurso medioambiental con valor paisajístico preliminar muy alto son las dunas de Guardamar. Dentro de la categoría de recursos medioambientales con valor paisajístico preliminar alto se incluyen las lagunas de la Mata y Torrevieja, sus respectivas orlas de saladares y marjales, las playas de arena y roca de Torrevieja, los viñedos de la Mata, la rambla de la Fayona, los pinares en suelo forestal y el parque del Molino del agua. Con un valor medio quedan situadas las ramblas del Garbanzuelo y Lo Marabú (la primera de ellas probablemente perjudicada por el tratamiento duro de su cauce y la segunda por su práctica desaparición en suelo urbanizado), los herbazales del alto de La Hoya y los pinos situados a la margen de la carretera CV943. 


\section{4.f.3.4 Preferencia, calidad y valor preliminar paisajístico de los recursos paisajísticos culturales}

Recursos paisajísticos culturales: Preferencia paisajística: Tal y como se expone en la tabla siguiente la población consultada mostró una alta preferencia por los recursos culturales siguientes: Torres del Moro y de la Sal, rompeolas y faro de Torrevieja y el paseo marítimo Juan Aparicio de Torrevieja, el resto de recursos culturales considerados obtuvo una preferencia media excepto el Canal de Riegos de Levante (ahora cubierto) y los caminos rurales de Dos y Ratero (ahora asfaltados), que obtuvieron una preferencia baja.

Tabla 5.20: Preferencia paisajística de los recursos paisajísticos culturales

\begin{tabular}{|c|c|c|c|}
\hline Código & Descripción & $\begin{array}{c}\text { Media } \\
\text { población }\end{array}$ & Valor \\
\hline RPC27 & Rompeolas y Faro & 3,86 & \\
\hline $\mathrm{RPC} 24$ & Torre del Moro & 3,85 & \\
\hline RPC25 & Torre de la Sal & 3,85 & \\
\hline $\mathrm{RPC} 28$ & Paseo Juan Aparicio & 3,58 & \\
\hline RPC5 & Canal Mata & 3,47 & \\
\hline $\mathrm{RPC} 3$ & Acequión & 3,45 & \\
\hline $\mathrm{RPC1}$ & Canal Salinas & 3,34 & \\
\hline $\mathrm{RPC} 23$ & Iglesia Rosario & 3,33 & \\
\hline RPC9 & Arq tradicional Huertos & 3,23 & \\
\hline RPC26 & Parque Nolino Agua & 3,17 & \\
\hline RPC6 & Casa Forestal & 3,09 & \\
\hline $\mathrm{RPC} 22$ & Eras de la Sal & 3,06 & \\
\hline $\mathrm{RPC12}$ & Tecnicas y acequias & 3,03 & \\
\hline RPC29 & Centro Salinero & 3,03 & \\
\hline RPC13 & Romeria & 3,02 & \\
\hline $\mathrm{RPC} 30$ & Casino Torrevieja & 3,02 & \\
\hline RPC7 & Arq tradicional viñedos & 2,97 & \\
\hline RPC14 & Arq Trad regadios exten. & 2,93 & \\
\hline RPC8 & Siega y empacado & 2,92 & \\
\hline RPC19 & Casa Fiasco & 2,92 & \\
\hline $\mathrm{RPC4}$ & Inst. Salineras & 2,87 & \\
\hline $\mathrm{RPC2}$ & Arq tradicional Laguna & 2,84 & \\
\hline RPC10 & Aljibes & 2,79 & \\
\hline RPC21 & Casa Balcones & 2,71 & \\
\hline RPC18 & Arq Tradic. Fayona & 2,67 & \\
\hline RPC16 & Casa Peones Camineros & 2,58 & \\
\hline RPC17 & Palomeros & 2,58 & \\
\hline RPC11 & Conjuntos hidraulicos & 2,57 & \\
\hline $\mathrm{RPC} 20$ & Canal Riegos Levante & 2,47 & \\
\hline RPC15 & Caminos Dos/Ratero & 2,30 & \\
\hline
\end{tabular}

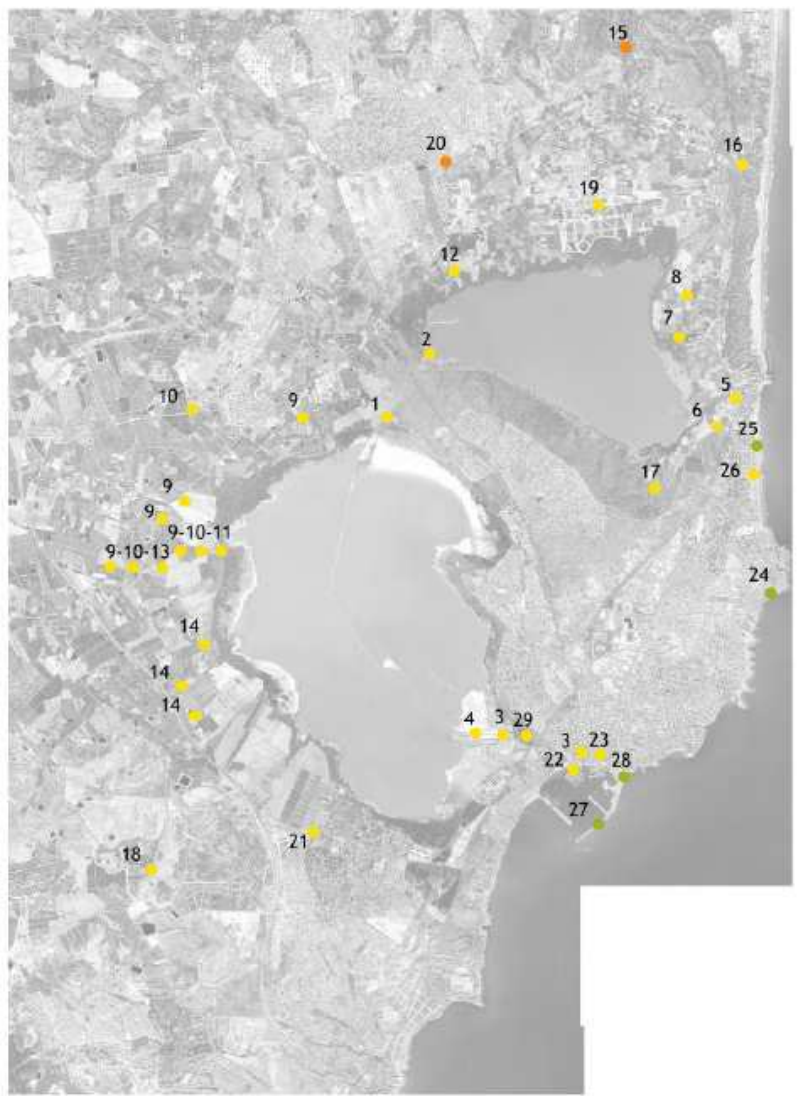

Recursos paisajísticos culturales: Calidad paisajística: Los recursos paisajísticos culturales valorados por los expertos como de calidad muy alta incluyeron la torre de la Sal, la torre del Moro, el canal de las Salinas, la arquitectura tradicional en la zona de regadíos tradicionales y la iglesia del Rosario en Torrevieja. Se asignó una calidad alta a los canales de La Mata y el Acequión, así como a la arquitectura tradicional presente en otras zonas del ámbito de estudio distintas de los regadíos tradicionales, a las instalaciones salineras, a las técnicas y red de acequias empleadas para el riego a manta, así como a elementos singulares como el rompeolas y faro de Torrevieja, el paseo Juan Aparicio, las eras y muelle de la Sal, la Sociedad Cultural Casino de Torrevieja o los antiguos aljibes. El resto de recursos paisajísticos culturales se valoró como de calidad media, excepto en los casos del canal de Riegos de Levante y los palomeros del alto de la Hoya que fueron valorados como de calidad baja. 
Tabla 5.21: Calidad paisajística de los recursos paisajísticos culturales

\begin{tabular}{|c|c|c|c|}
\hline Código & Descripción & $\begin{array}{l}\text { Media } \\
\text { expertos }\end{array}$ & Valor \\
\hline $\mathrm{RPC25}$ & Torre de la Sal & 4,60 & \\
\hline $\mathrm{RPC24}$ & Torre del Moro & 4,53 & \\
\hline $\mathrm{RPC1}$ & Canal Salinas & 4,40 & \\
\hline RPC9 & Arq tradicional Huertos & 4,33 & \\
\hline $\mathrm{RPC23}$ & Iglesia Rosario & 4,27 & \\
\hline RPC5 & Canal Nata & 4,20 & \\
\hline $\mathrm{RPC6}$ & Casa Forestal & 4,20 & \\
\hline $\mathrm{RPC7}$ & Arq tradicional vñedos & 4,13 & \\
\hline RPC18 & Arq Tradic, Fayona & 4,07 & \\
\hline $\mathrm{RPC3}$ & Acequión & 4,00 & \\
\hline $\mathrm{RPC21}$ & Casa Balcones & 3,93 & \\
\hline $\mathrm{RPC22}$ & Eras de la Sal & 3,93 & \\
\hline $\mathrm{RPC2}$ & Arq tradicional Laguna & 3,80 & \\
\hline $\mathrm{RPC14}$ & Arq Trad regadios exten. & 3,80 & \\
\hline RPC16 & Casa Peones Camineros & 3,80 & \\
\hline $\mathrm{RPC27}$ & Rompeolas y Faro & 3,80 & \\
\hline RPC29 & Centro Salinero & 3,73 & \\
\hline RPC10 & Aljibes & 3,67 & \\
\hline $\mathrm{RPC} 19$ & Casa Fiasco & 3,67 & \\
\hline $\mathrm{RPC} 28$ & Paseo Juan Aparicio & 3,67 & \\
\hline $\mathrm{RPC4}$ & Inst. Salineras & 3,60 & \\
\hline RPC12 & Tecnicas y acequias & 3,60 & \\
\hline RPC30 & Casino Torrevieja & 3,53 & \\
\hline RPC26 & Parque Molino Agua & 3,33 & \\
\hline RPC8 & Siega y empacado & 3,27 & \\
\hline RPC15 & Caminos Dos/Ratero & 3,20 & \\
\hline RPC11 & Conjuntos hidraulicos & 3,13 & \\
\hline $\mathrm{RPC13}$ & Romeria & 3,00 & \\
\hline $\mathrm{RPC17}$ & Palomeros & 2,40 & \\
\hline $\mathrm{RPC20}$ & Canal Riegos Levante & 2,07 & \\
\hline
\end{tabular}

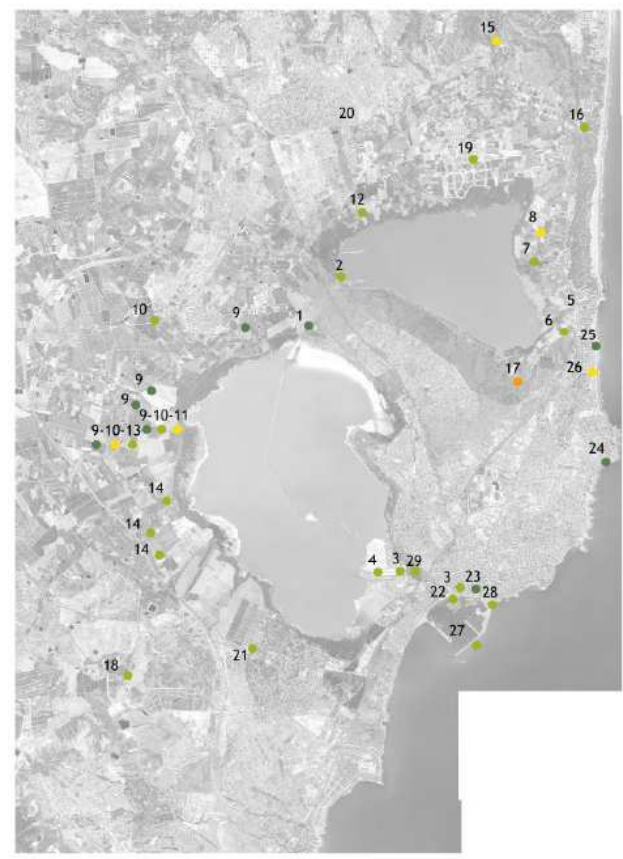

Recursos Paisajísticos Culturales: Valor paisajístico preliminar y consideraciones previas: Al igual que en la valoración de las unidades de paisaje y de otros recursos paisajísticos, se observa que, en comparación con la población, el juicio de los expertos otorga valores más extremos (muy alto o muy bajo) a algunos de los recursos paisajísticos culturales. Esta diferencia puede deberse tanto al menor no de opiniones como a su mayor conocimiento técnico-científico de algunos de los recursos valorados. Como resultado de calcular el Valor paisajístico preliminar como media de los valores de preferencia y calidad paisajística se obtiene la tabla siguiente en la que cabe destacar la ausencia de recursos paisajísticos culturales de valor muy alto y la inclusión en la categoría de valor bajo de los palomeros del alto de La Hoya y del canal de Riegos de Levante. En la categoría de valor alto quedan incluidos el conjunto de canales que conectan las lagunas de la Mata y de Torrevieja al mar y entre sí, la arquitectura tradicional en la banda de regadíos tradicionales al oeste del ámbito del estudio, la iglesia del Rosario de Torrevieja y el conjunto conformado por el paseo de Juan Aparicio, rompeolas y faro de esa misma ciudad. En la categoría de valor medio quedan incluidos el resto de recursos paisajísticos culturales, incluidos la arquitectura tradicional, aljibes, redes de acequias y técnicas de riego a manta o antiguos caminos rurales.

Tabla 5.22: Valor paisajístico preliminar de los recursos paisajísticos culturales.

\begin{tabular}{c|c|c|c|} 
Código & Descripción & Media & Valor \\
\hline RPC25 & Torre de la Sal & 4,22 & \\
\hline RPC24 & Torre del Moro & 4,19 & \\
\hline RPC1 & Canal Salinas & 3,87 & \\
\hline RPC5 & Canal Mata & 3,83 & \\
\hline RPC27 & Rompeolas y Faro & 3,83 & \\
\hline RPC23 & Iglesia Rosario & 3,80 & \\
\hline RPC9 & Arq tradicional Huertos & 3,78 & \\
\hline RPC3 & Acequión & 3,73 & \\
\hline RPC6 & Casa Forestal & 3,65 & \\
\hline RPC28 & Paseo Juan Aparicio & 3,62 & \\
\hline RPC7 & Arq tradicional vinedos & 3,55 & \\
\hline RPC22 & Eras dela la Sal & 3,50 & \\
\hline RPC29 & Centro Salinero & 3,38 & \\
\hline RPC18 & Arq Tradic. Fayona & 3,37 & \\
\hline RPC14 & Arq Trad regadios exten. & 3,37 & \\
\hline RPC21 & Casa Balcones & 3,32 & \\
\hline RPC2 & Arq tradicional Laguna & 3,32 & \\
\hline RPC12 & Tecnicas y acequias & 3,32 & \\
\hline RPC19 & Casa Fiasco & 3,29 & \\
\hline RPC30 & Casino Torrevieja & 3,28 & \\
\hline RPC26 & Parque Molino Agua & 3,25 & \\
\hline RPC4 & Inst. Salineras & 3,24 & \\
\hline RPC10 & Aljibes & 3,23 & \\
\hline RPC16 & Casa Peones Camineros & 3,19 & \\
\hline RPC8 & Siega y empacado & 3,09 & \\
\hline RPC13 & Romeria & 3,01 & \\
\hline RPC11 & Conjuntos hidraulicos & 2,85 & \\
\hline RPC15 & Caminos Dos/Ratero & 2,75 & \\
\hline RPC17 & Palomeros & 2,49 & \\
\hline RPC20 & Canal Riegos Levante & 2,27 & \\
\hline & & & \\
\hline & & & \\
\hline
\end{tabular}
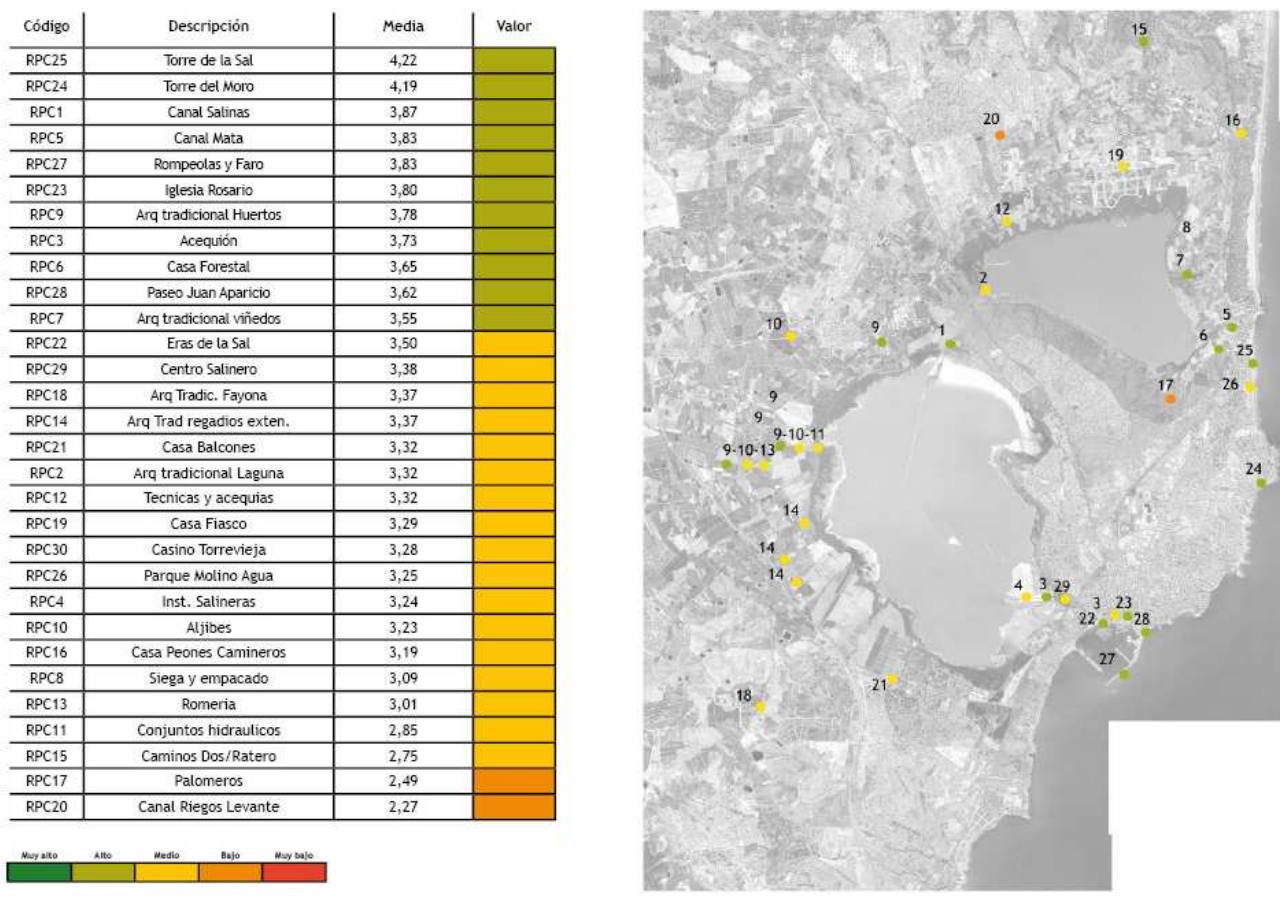


\section{4.f.3.5 Recursos paisajísticos visuales: Preferencia, calidad y valor preliminar paisajístico}

Recursos paisajísticos visuales: Preferencia paisajística: De acuerdo a la opinión de la población consultada el ámbito del estudio carece de recursos paisajísticos de preferencia muy alta o muy baja. Entre los recursos con preferencia alta se incluyen las láminas de agua de las lagunas de La Mata y Torrevieja así como sus marjales y saladares asociados, las dunas de Guardamar, las playas de roca de Torrevieja, Cala Ferris, las instalaciones salineras y el muelle de carga de sal, el puerto de Torrevieja, el Acequión, las vistas a la laguna de Torrevieja desde la carretera CV-905 (carretera de Crevillente), las vistas de las lagunas de La Mata sobre los viñedos próximos y las masas arbóreas de eucaliptos junto a la laguna de la Mata.

Como recursos o zonas de preferencia baja quedan incluidos la mayor parte del casco urbano de Torrevieja y las rotondas y accesos a esta misma ciudad, la Vía Verde a su paso a través de las urbanizaciones situadas entre las lagunas de La Mata y Torrevieja, el cementerio y los aparcamientos situados dentro del Parque Natural y los accesos a Ciudad Quesada.

Con una preferencia media quedan incluidos el resto de recursos visuales, entre los que cabe destacar edificios o espacios singulares dentro del casco urbano de Torrevieja (rompeolas, faro, muelle y eras de la Sal, parque del Molino del Agua, parque de las Naciones, hospital y área deportiva de Torrevieja) vistas y recorridos a los largo de las ramblas de la Fayona y el Garbanzuelo y de los canales de La Mata, así como vistas desde elevaciones topográficas, desde carreteras y ejemplos de arquitectura tradicional, cuya preferencia de mayor a menor rango sería la siguiente:

- VISTAS desde Elevaciones Topográficas: Alto de las Majadas > Alto de la Hoya > Altos y accesos junto a San Miguel de Salinas > Alto del Moncayo.

- VISTAS desde Carreteras: Vistas a la laguna de Torrevieja desde la CV905 > Vistas a la laguna de Torrevieja y de la Mata desde la N332 > Vistas desde la AP7 y CV95 > Vistas a la laguna de Torrevieja desde el cruce de la carretera CV945 con la AP7, Vistas de la laguna de La Mata desde la carretera CV895 > Vistas a la laguna de la Mata desde la CV905 > Vistas de la laguna de Torrevieja desde la CV943.

- Arquitectura tradicional: Casa de la Marquesa $>$ Casa de Lo Vigo $>$ Casa de Morales $>$ Casa de Timor $>$ Casa de las Palmeras $>$ Casa de Sala $>$ Casa de Lo Reche $>$ Casa de la Máquina $>$ Casa Grande $>$ Casa del Purgatorio $>$ Casa Forestal (actual Centro de Visitantes de La Mata) $>$ Casa del Reloj $>$ Casa de los Balcones $>$ Casa de la Cisterna $>$ Casa de las Majadas $>$ Casa del Raso

Tabla 5.23: Preferencia paisajística de los recursos paisajísticos visuales

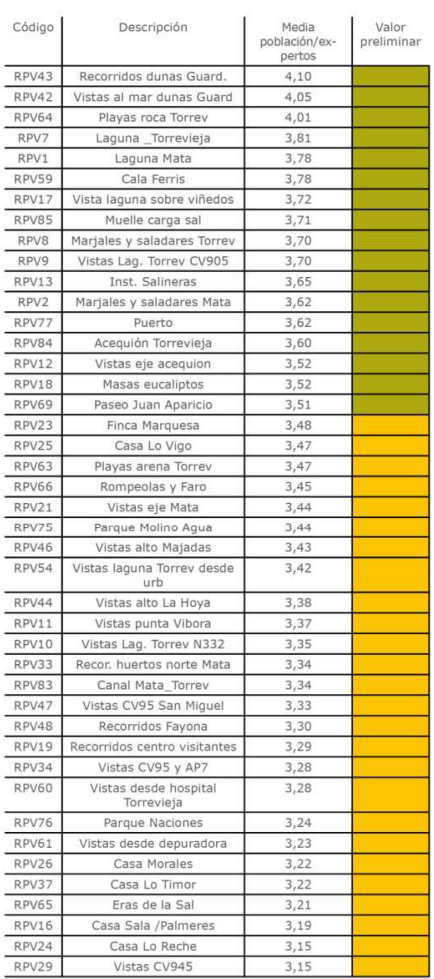

\begin{tabular}{|c|c|c|c|c|}
\hline Muy alto & Alto & \multicolumn{1}{|c|}{ Medio } & Bajo bajo \\
\hline
\end{tabular}
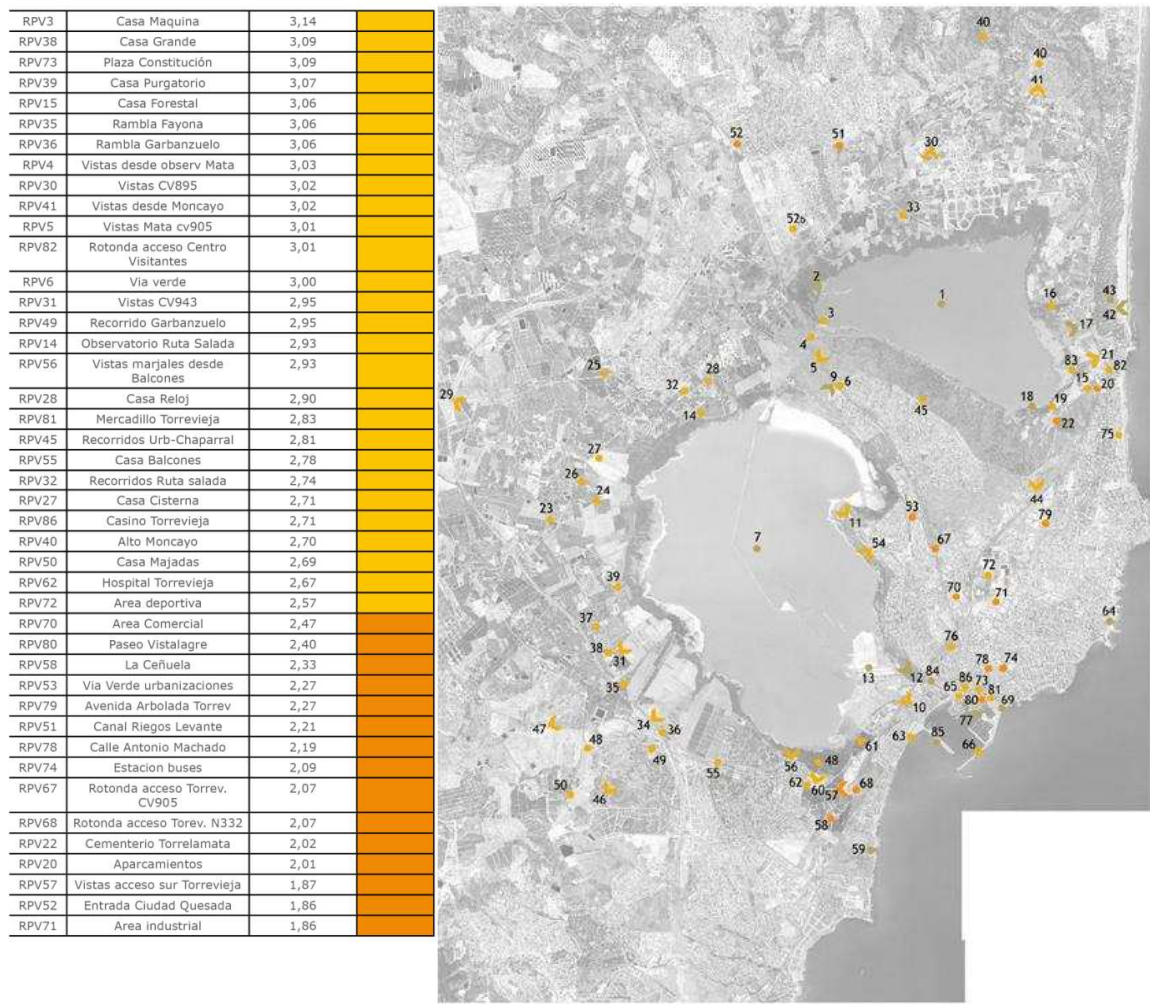


\section{Recursos paisajísticos visuales: Calidad paisajística:}

La tabla siguiente expone la calidad paisajística otorgada por lo expertos a los 86 recursos paisajísticos visuales considerados. Con valor muy alto quedan incluidos las vistas y recorridos desde las dunas de Guardamar, las láminas de agua saladares y marjales de las lagunas de Torrevieja y de La Mata, las vistas sobre los viñedos de La Mata, las playas rocosas de Torrevieja, cala Ferris, las vistas de la laguna de Torrevieja desde la carretera CV905 y la Casa de la Máquina.

Con calidad visual alta se incluyen gran parte de los ejemplos de arquitectura tradicional existente en el ámbito rural del estudio, el recorrido a lo largo de la rambla de la Fayona, las instalaciones y muelle salinero, las vistas a lo largo del canal de La Mata y Acequión de Torrevieja, las vistas desde las elevaciones que rodean el Parque Natural así como las vistas hacia la lagunas desde gran parte de las carreteras próxima o espacios y edificios singulares en el casco urbano de Torrevieja (plaza de la Constitución, paseo Juan Aparicio, parques del Molino del Agua y las Naciones o el muelle de carga de sal).

Dentro de los recursos con calidad media se incluyen algunos ejemplos de arquitectura rural tradicional, el recorrido a lo largo de la rambla del Garbanzuelo, las masas de eucaliptos en torno a la laguna de La Mata o espacios y edificios singulares en Torrevieja como las eras de la sal, el rompeolas o el faro.

Con calidad baja se valoran las áreas deportivas y residenciales de Torrevieja, el paso de la Vía Verde a lo largo de la urbanización de San Luis y los aparcamientos del parque natural. Por último, se asigna una calidad muy baja a las áreas comerciales e industriales de Torrevieja, a su acceso desde las carreteras CV905 y 332 y al acceso a Ciudad Quesada.

Tabla 5.24: Calidad paisajística de los recursos paisajísticos visuales
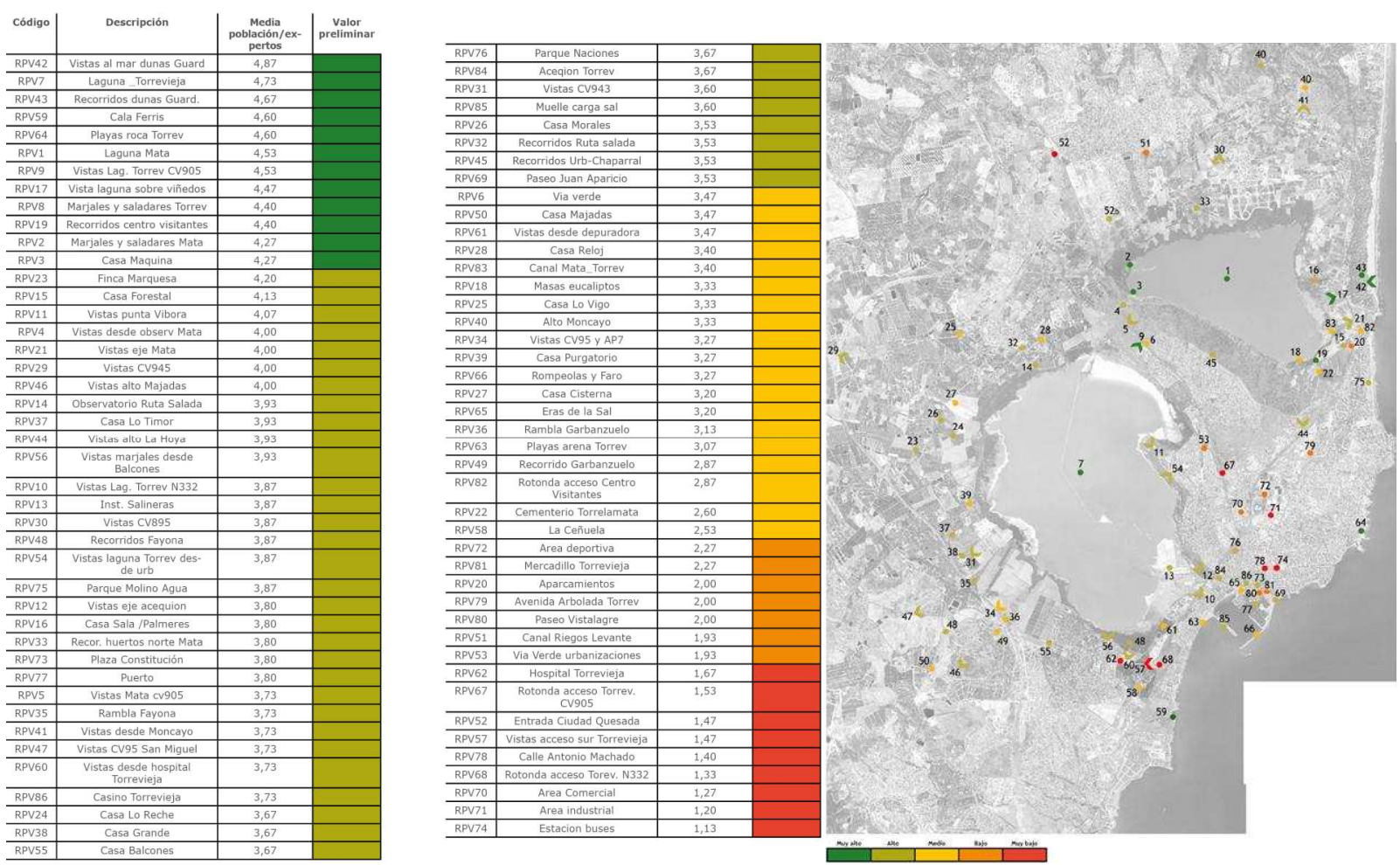

Recursos Paisajísticos Visuales: Valor paisajístico preliminar y consideraciones previas: Al igual que en la valoración de las unidades de paisaje y de otros recursos paisajísticos, se observa que, en comparación con la población, el juicio de los expertos otorga valores más extremos (muy alto o muy bajo) a algunos de los recursos paisajísticos culturales. Esta diferencia puede deberse tanto al menor o de opiniones como a su mayor conocimiento técnico-científico de algunos de los recursos valorados.

Tal y como se expone en la tabla siguiente, los recursos visuales quedan incluidos en las cinco categorías posibles. Con valor muy alto figuran las vistas y recorridos por las dunas de Guardamar, las playas y acantilados de Torrevieja y la lámina de agua de la laguna de Torrevieja. Con valor muy bajo el acceso a Ciudad Quesada, la 
VALORACIÓN Y GESTIÓN DEL PAISAJE SEGÚN EL CONVENIO EUROPEO DEL PAISAJE YEL

REGLAMENTO DEL PAISAJE DE LA COMUNIDAD VALENCIANA: APLICACIÓN MEDIANTE UN ESTUDIO

DE PAISAJE A UNESPACIO ABIERTO EN LA COMUNIDAD VALENCIANA

DOCTORANDO: JUAN JOSÉ GALÁN VIVAS (Universidad Politécnica de Valencia, enero 2011)

estación de autobuses de Torrevieja y sus áreas industriales y accesos desde el sur. Con valor bajo las áreas residenciales, comerciales y dotacionales de Torrevieja, o el recorrido de la Vía Verde a través de la urbanización San Luis.

El resto de recursos quedan adscritos en las categorías de alta y media calidad visual e incluyen la mayor parte de edificios rurales, vistas desde elevaciones y vistas desde carreteras, que quedan ordenadas según su valor preliminar de acuerdo al siguiente orden decreciente:

- VISTAS desde Elevaciones Topográficas: Alto de las Majadas $>$ Alto de la Hoya > Altos y accesos junto a San Miguel de Salinas > Alto del Moncayo.

- VISTAS desde Carreteras: Vistas a la laguna de Torrevieja desde la CV905 > Vistas a la laguna de Torrevieja y de la Mata desde la N332 > Vistas a la laguna de Torrevieja desde el cruce de la carretera CV945 con la AP7 > Vistas de la laguna de La Mata desde la carretera CV895 > Vistas a la laguna de la Mata desde la CV905 > Vistas de la laguna de Torrevieja desde la CV943 > Vistas desde la AP7 y CV95.

- Arquitectura tradicional: Casa de la Marquesa $>$ Casa de La Maquina $>$ Casa Forestal (actual centro de visitantes) $>$ Casa de Lo Timor $>$ Casa de las Palmeras y Casa de Sala $>$ Casa Lo Reche $>$ Casa de Lo Vigo $>$ Casa Grande $>$ Casa Morales $>$ Casa de los casa de Lo Vigo $>$ Casa de Morales $>$ Casa de los Balcones > Casa del Purgatorio > Casa de las Majadas > Casa de la Cisterna.

Tabla 5.25: Valor paisajístico preliminar de los recursos paisajísticos visuales.
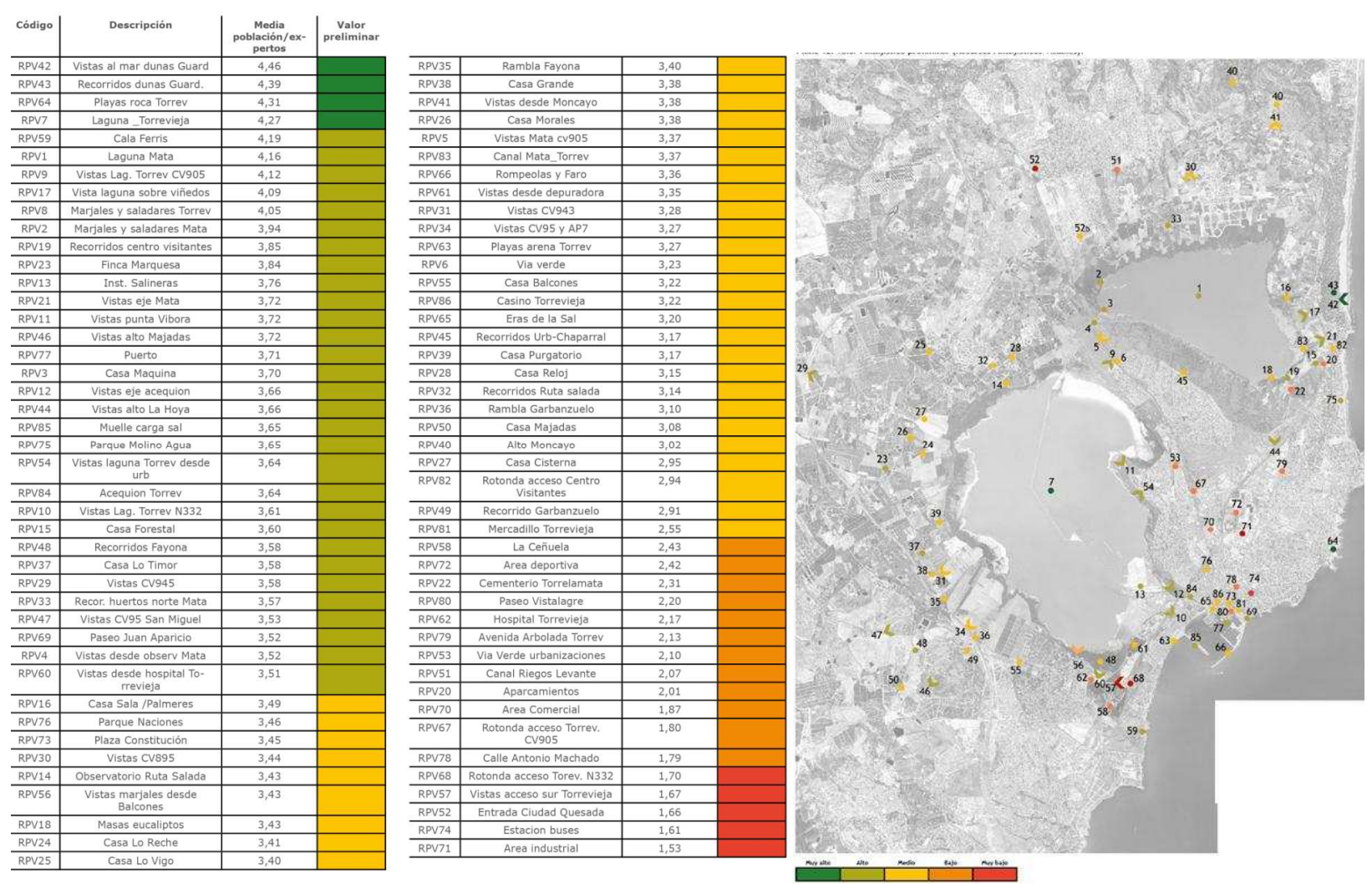

\section{4.f.4. Valor Paisajístico}

5.4.f.4.1. Metodología

De acuerdo a la metodología propuesta en la presente tesis y al Reglamento de Paisaje de la Comunidad Valenciana, el valor paisajístico de las unidades de paisaje y recursos paisajísticos "se establecerá un valor en función de su calidad paisajística, las preferencias de la población y su visibilidad".

El valor paisajístico final de cada unidad o recurso paisajístico se ha determinado ponderando el Valor paisajístico preliminar (media de la calidad y preferencia paisajística) según su visibilidad y asignando un valor paisajístico máximo a los paisajes ya reconocidos por una figura de la legislación en materia de protección de espacios naturales y patrimonio cultural. 
A efectos del desarrollo de las fases siguientes del estudio y con el objeto de facilitar la definición de programas orientados a mejorar la calidad del paisaje y de los recursos paisajísticos, la ponderación según el grado de visibilidad de las Unidades o Recursos paisajísticos ha aumentado en un rango el valor aquellas unidades 0 recursos paisajísticos con visibilidad máxima y con valor paisajístico alto o muy alto (en este último caso quedarían en la misma categoría) y ha disminuido en un rango el valor de aquellas unidades o recursos paisajísticos con visibilidad máxima y con valor paisajístico bajo o muy bajo (en este último caso quedarían en la misma categoría).

Las tablas y planos siguientes recogen los valores paisajísticos finales de las unidades y recursos paisajísticos incluidos en el ámbito del estudio.

\section{4.f.4.2. Valor paisajístico de las unidades de paisaje}

Tabla 5.26: Valor paisajístico final de las unidades de paisaje.

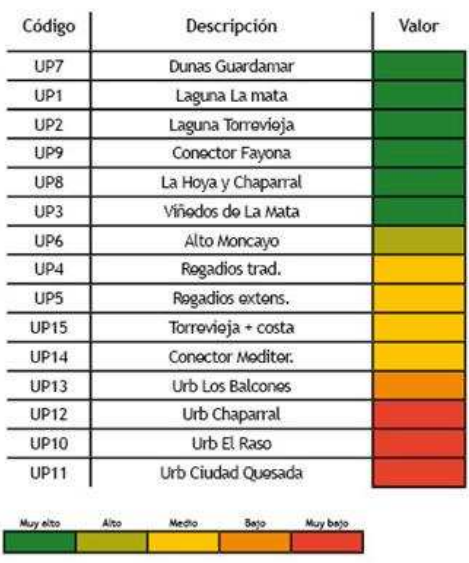

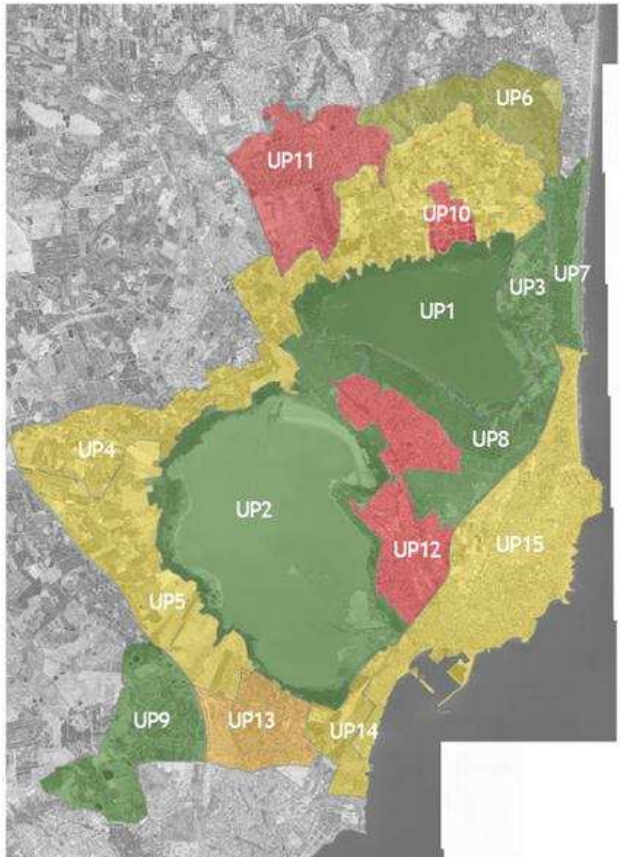

\section{4.f.4.3. Valor Paisajístico de los Recursos Paisajísticos Ambientales}

Tabla 5.27: Valor paisajístico final de los recursos paisajísticos ambientales.

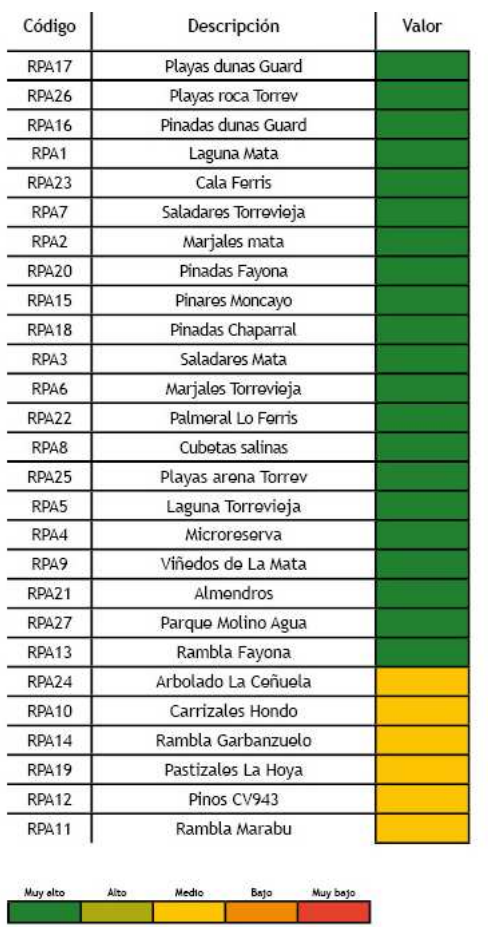

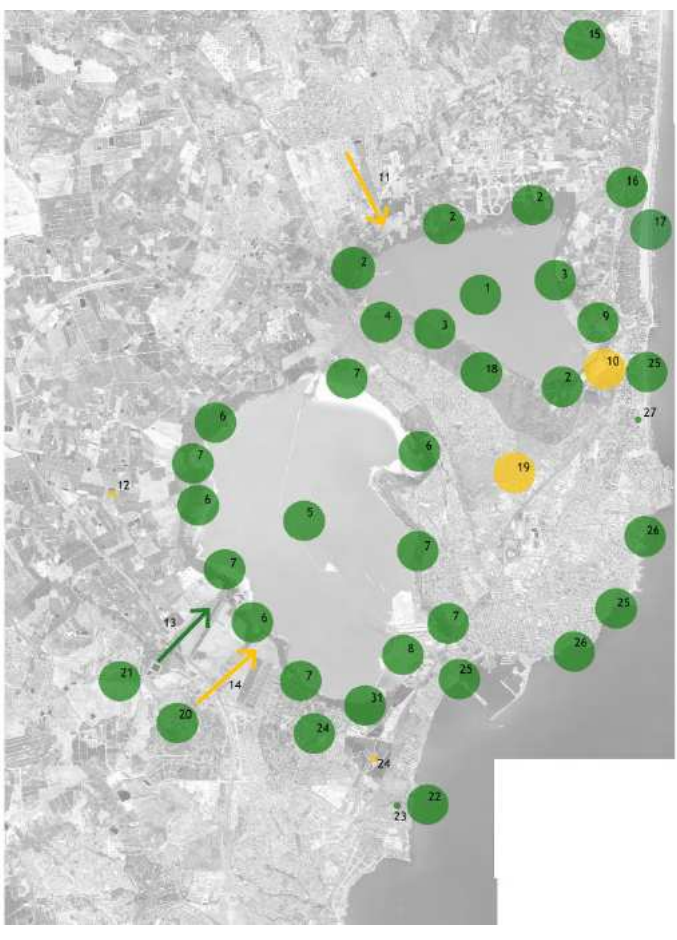


VALORACIÓN Y GESTIÓN DEL PAISAJE SEGÚN EL CONVENIO EUROPEO DEL PAISAJE YEL

REGLAMENTO DEL PAISAJE DE LA COMUNIDAD VALENCIANA: APLICACIÓN MEDIANTE UN ESTUDIO DE PAISAJE A UNESPACIO ABIERTO EN LA COMUNIDAD VALENCIANA

DOCTORANDO: JUAN JOSÉ GALÁN VIVAS (Universidad Politécnica de Valencia, enero 2011)

\section{4.f.4.4. Valor paisajístico de los recursos paisajísticos culturales}

Tabla 5.28: Valor paisajístico final de los recursos paisajísticos culturales.

\begin{tabular}{c|c|c|} 
Código & Descripción & Valor \\
\hline RPC25 & Torre de la Sal & \\
\hline RPC24 & Torre del Moro & \\
\hline RPC1 & Canal Salinas & \\
\hline RPC5 & Canal Mata & \\
\hline RPC27 & Rompeolas y Faro & \\
\hline RPC9 & Arq tradicional Huertos & \\
\hline RPC3 & Acequión & \\
\hline RPC6 & Casa Forestal & \\
\hline RPC28 & Paseo Juan Aparicio & \\
\hline RPC7 & Arq tradicional viñedos & \\
\hline RPC30 & Casino Torrevieja & \\
\hline RPC23 & Iglesia Rosario & \\
\hline RPC22 & Eras de la Sal & \\
\hline RPC29 & Centro Salinero & \\
\hline RPC18 & Arq Tradic. Fayona & \\
\hline RPC14 & Arq Trad regadios exten. & \\
\hline RPC21 & Casa Balcones & \\
\hline RPC2 & Arq tradicional Laguna & \\
\hline RPC12 & Tecnicas y acequias & \\
\hline RPC19 & Casa Fiasco & \\
\hline RPC26 & Parque Molino Agua & \\
\hline RPC4 & Inst. Salineras & \\
\hline RPC10 & Aljibes & \\
\hline RPC16 & Casa Peones Camineros & \\
\hline RPC8 & Siega y empacado & \\
\hline RPC13 & Romeria & \\
\hline RPC11 & Conjuntos hidraulicos & \\
\hline RPC15 & Caminos Dos/Ratero & \\
\hline RPC17 & Palomeros & \\
\hline RPC20 & Canal Riegos Levante & \\
\hline & & \\
\hline
\end{tabular}

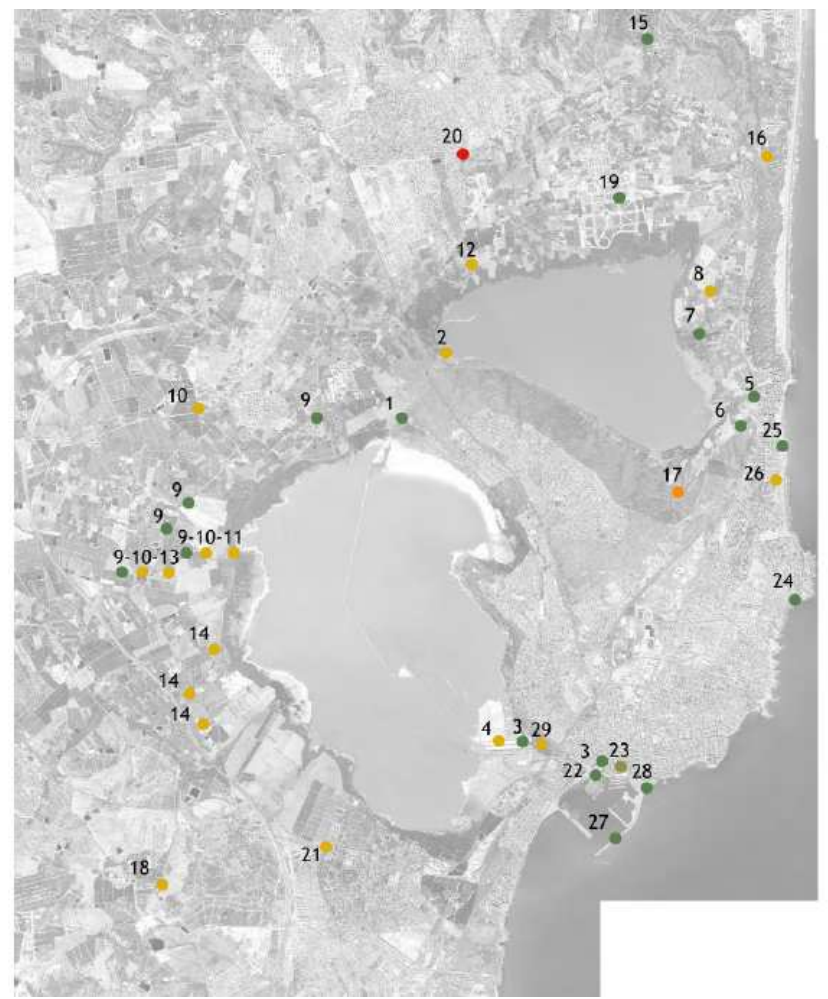

\section{4.f.4.5. Valor paisajístico de los recursos paisajísticos visuales}

Tabla 5.29: Valor paisajístico final de los recursos paisajísticos visuales.

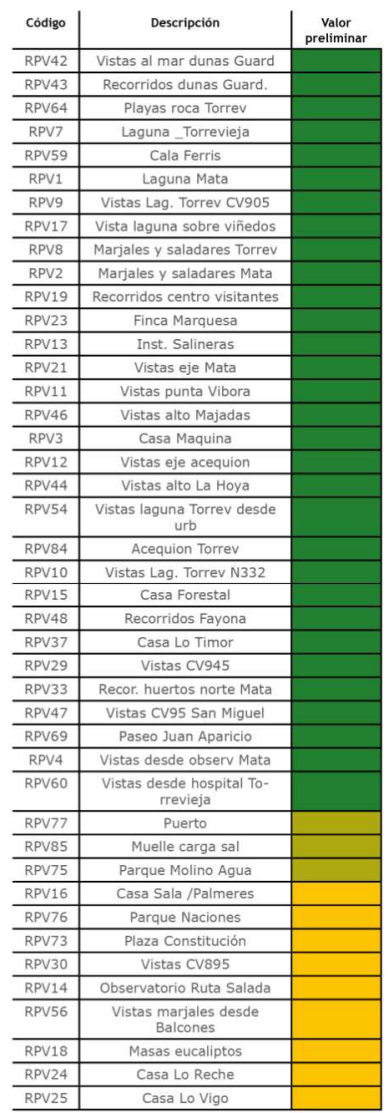

\begin{tabular}{|c|c|}
\hline RPV35 & Rambla Fayona \\
\hline RPV38 & Casa Grande \\
\hline RPV41 & Vistas desde Moncayo \\
\hline RPV26 & Casa Morales \\
\hline RPV5 & Vistas Mata cv905 \\
\hline RPV83 & Canal Mata_Torrev \\
\hline RPV66 & Rompeolas y Faro \\
\hline RPV61 & Vistas desde depuradora \\
\hline RPV31 & Vistas CV943 \\
\hline RPV34 & Vistas CV 95 y AP7 \\
\hline RPV63 & Playas arena Torrev \\
\hline RPV6 & Via verde \\
\hline RPV55 & Casa Balcones \\
\hline RPV86 & Casino Torrevieja \\
\hline RPV65 & Eras de la Sal \\
\hline RPV45 & Recorridos Urb-Chaparral \\
\hline RPV39 & Casa Purgatorio \\
\hline RPV28 & Casa Reloj \\
\hline RPV32 & Recorridos Ruta salada \\
\hline RPV36 & Rambla Garbanzuelo \\
\hline RPV50 & Casa Majadas \\
\hline RPV40 & Alto Moncayo \\
\hline RPV27 & Casa Cisterna \\
\hline RPV82 & $\begin{array}{l}\text { Rotonda acceso Centro } \\
\text { Visitantes }\end{array}$ \\
\hline RPV49 & Recorrido Garbanzuelo \\
\hline RPV81 & Mercadillo Torrevieja \\
\hline RPV80 & Paseo Vistalagre \\
\hline RPV79 & Avenida Arbolada Torrev \\
\hline RPV51 & Canal Riegos Levante \\
\hline RPV78 & Calle Antonio Machado \\
\hline RPV58 & La Ceñuela \\
\hline RPV72 & Area deportiva \\
\hline RPV22 & Cementerio Torrelamata \\
\hline RPV62 & Hospital Torrevieja \\
\hline RPV53 & Via Verde urbanizaciones \\
\hline RPV20 & Aparcamientos \\
\hline RPV70 & Area Comercial \\
\hline $\begin{array}{ll}\text { RPV67 } \\
\end{array}$ & $\begin{array}{l}\text { Rotonda acceso Torrev. } \\
\text { CV905 }\end{array}$ \\
\hline RPV68 & Rotonda acceso Torev. N332 \\
\hline RPV57 & Vistas acceso sur Torrevieja \\
\hline RPV52 & Entrada Ciudad Quesada \\
\hline RPV74 & Estacion buses \\
\hline RPV71 & Area industrial \\
\hline
\end{tabular}

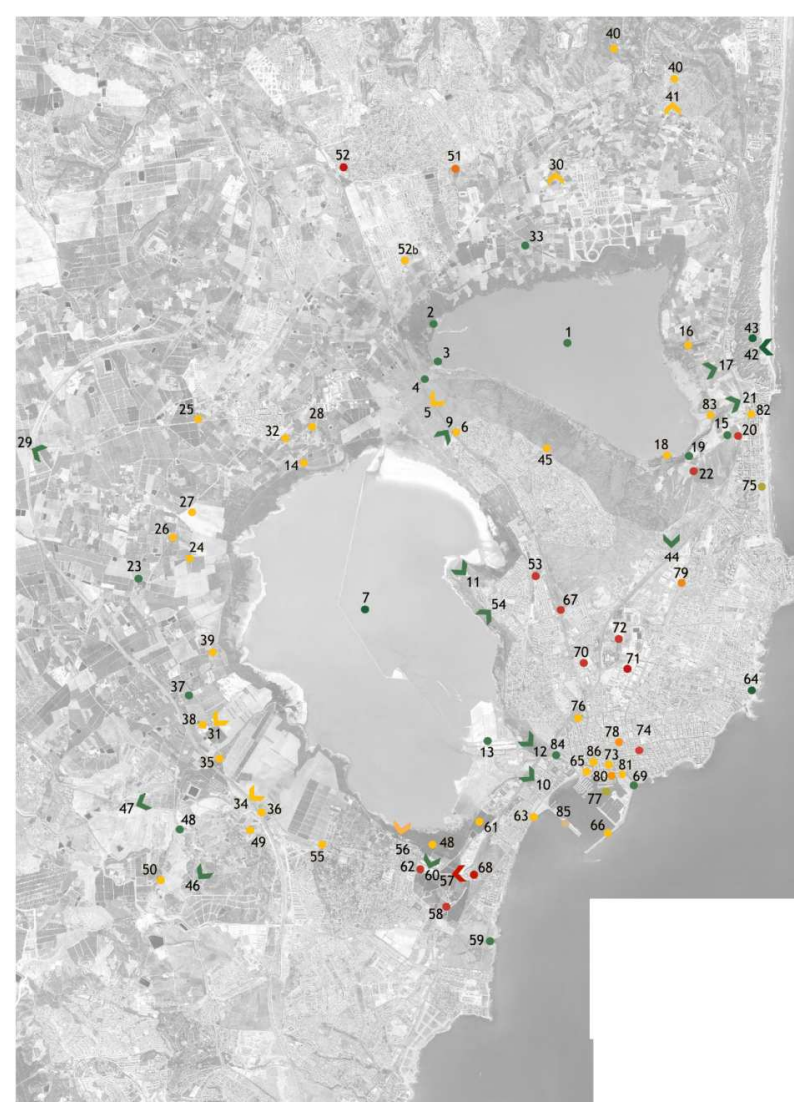




\section{4.f.5 Valoración del paisaje: Conclusiones y estrategias preliminares}

\section{4.f.5.1. Unidades de paisaje}

El análisis de los valores paisajísticos de las Unidades y Recursos Paisajísticos pone de manifiesto, entre otros, los siguientes aspectos:

\section{a) Unidades de paisaje de valor muy alto:}

- "UP1: Laguna de la Mata" y "UP2: Laguna de Torrevieja": Se trata de zonas incluidas dentro del Parque Natural y sujetas a protección.

- "UP8: Alto de la Hoya y el Chaparral": La parte correspondiente a la pinada del Chaparral queda incluida dentro del Parque Natural mientras que la correspondiente al Alto de la Hoya queda incluida dentro del área del Plan de Ordenación de los Recursos Naturales del parque, en el que se regulan sus usos. A este respecto cabe reseñar elevada visibilidad del alto de la Hoya y la conveniencia de estudiar acciones que permitan actuar sobre elementos o recursos de baja valoración situados en éste.

- "UP3: Secanos y Viñedos de La Mata”: Queda incluida dentro del área del Plan de Ordenación de los Recursos Naturales del parque, en el que se regulan sus usos. Las condiciones que permitan la coexistencia de la actividad productiva y la preservación de los valores medioambientales, culturales y paisajísticos del parque deberían ser contempladas en las fases siguientes del presente estudio de Paisaje. Al tratarse de una unidad paisajística de muy alto valor cabría sugerir recomendaciones que potencien su protección y puesta en valor de sus recursos.

- "UP14: Conector de la rambla de la Fayona": Espacio sin figuras de protección específicas aparte de las debidas a las propias de la existencia de dominios públicos hidráulicos y de vías pecuarias. Sus valores medioambientales y visuales, así como su importancia en la conexión del Parque Natural de las Lagunas de La Mata - Torrevieja con el futuro Parque de la Dehesa de Campoamor - Sierra de Escalona, sugieren el desarrollo de medidas que garanticen su preservación y reforzamiento como espacio natural con usos agrícolas regulados.

- "UP7: Dunas de Guardamar": Espacio de alto valor medioambiental y gran potencial para el uso público. Integrado en la Red Natura 2000, Lugar de Interés Comunitario y Monte de Utilidad Pública. Se detecta su frágil conexión con otros espacios de interés medioambiental situados al oeste de la carretera N332.

\section{b) Unidades de paisaje de valor alto:}

- "UP6: Alto del Moncayo": Espacio elevado y parcialmente ocupado por una zona de acceso restringido (zona militar). Su importancia en las visuales disponibles desde el Parque Natural y en la conexión de este último con el corredor del río Segura sugieren la necesidad de preservar y potenciar su carácter como espacio forestal arbolado.

\section{c) Unidades de paisaje de valor medio:}

- "UP4: Regadíos tradicionales de las laguna de la Mata y Torrevieja", "UP5: Regadíos extensivos de la Laguna de Torrevieja": Espacios parcialmente incluido en el ámbito del Plan de Ordenación de los Recursos Naturales (PORN) del Parque Natural de La Mata - Torrevieja, al que se anexan espacios con valores similares que facilitan la conexión ecológica y visual del Parque. Las posibles acciones o programas de paisaje a desarrollar en el conjunto de la unidad deberían considerar primeramente los usos y normas definidos en el PORN e incorporar posibles recomendaciones que garanticen el mantenimiento de los valores existentes o que orienten posibles cambios.

- "UP 15: Frente Litoral y Casco Urbano de Torrevieja": Presenta una clara dicotomía entre la franja litoral, parcialmente incluida dentro del dominio público marítimo, en la que se localizan recursos altamente valorados (playas, acantilados, torres-vigía, etc) y la zona del casco urbano. Las posibles acciones o programas a desarrollar deberían potenciar la adecuada preservación y conexión de los primeros y su conexión transversal con el Parque Natural, así como la mejor relación visual de la fachada urbana y carretera Nacional N332 con el Parque Natural.

- "UP 14: Conector del Sur de la laguna de Torrevieja con el mar Mediterráneo": Unidad de paisaje heterogénea y de carácter estratégico para:

- (1) Evitar la fusión de las zonas urbanas situadas al norte y sur del conector.

- (2) Facilitar la conexión de la playa del Rocío y Cala Ferris con el parque Natural y

- (3) Generar un espacio de alto valor paisajístico en el acceso sur al casco urbano de Torrevieja.

\section{d) Unidades de paisaje de valor bajo:}

- "UP13: Urbanización Los Balcones": Espacio de bajo valor paisajístico que incluye un área deficientemente urbanizada limítrofe con el Parque Natural y que, de acuerdo al Plan de Ordenación de 
los Recursos Naturales del mismo, deberá ser objeto de un Plan Especial que resuelva los impactos existentes.

\section{e) Unidades de paisaje de valor muy bajo:}

- "UP10" Urbanización El Raso": Espacio con un valor paisajístico preliminar bajo, que adquiere un valor paisajístico muy bajo debido a su alta visibilidad. Su zona sur queda incluida dentro del área del Plan de Ordenación de los Recursos Naturales del parque en el que se determina su uso como zona verde que facilite la transición entre la urbanización y el parque natural. Las recomendaciones a incluir en el estudio de paisaje sugerirían la conveniencia de que la citada zona verde integre aspectos vinculados a su carácter previo agrícola y con las formaciones vegetales y valores medioambientales del propio Parque Natural.

- "UP12" Urbanizaciones entre las Lagunas de La Mata y Torrevieja": Espacio con un valor paisajístico preliminar bajo, que adquiere un valor paisajístico muy bajo dada su alta visibilidad. Los posibles programas o recomendaciones para dicha unidad irían a priori dirigidas a mejorar el encuentro de las urbanizaciones con el Parque y con la carretera CV-905, a potenciar la conexión entre las lagunas de La Mata y de Torrevieja a través de las urbanizaciones y a generar una experiencia adecuada en el tramo de la Vía Verde que discurre a través de éstas.

- "UP11 Urbanización de Ciudad Quesada": Espacio con un valor paisajístico muy bajo y de máxima visibilidad. Su zona sur queda incluida dentro del área del Plan de Ordenación de los Recursos Naturales del parque en el que se determina su uso como zona verde que facilite la transición entre la urbanización y el parque natural. Las recomendaciones a incluir en el Estudio de Paisaje sugerirían la conveniencia de que la citada zona verde integre aspectos vinculados a su uso previo agrícola y a las formaciones vegetales y valores medioambientales del parque Natural así como acciones dirigidas a amortiguar la fuerte intrusión visual de la urbanización en el parque natural.

\section{4.f.5.2. Recursos Paisajísticos}

El análisis de los valores paisajísticos asignados a los Recursos Paisajísticos pone de manifiesto, entre otros, los siguientes aspectos:

Recursos Paisajísticos Ambientales: Del total de 27 recursos paisajísticos ambientales considerados, 21 presentan un valor paisajístico muy alto. Dicho nivel de valor se alcanza en la mayor parte de los casos debido a su posición en zonas de máxima visibilidad y a su reconocida importancia medioambiental. Muchos de los recursos quedan incluidos en zonas protegidas, si bien, en otros casos, como la rambla de la Fayona cabe destacar la ausencia de figuras de protección aparte de las propias de un dominio público hidráulico.

Recursos Paisajísticos Culturales: Del total de 30 recursos paisajísticos culturales considerados, 11 presentan un valor paisajístico muy alto. Dicho nivel de valor se alcanza en la mayor parte de los casos debido a su posición en zonas de máxima visibilidad e incluyen tanto elementos altamente protegidos (Bienes de Interés Comunitario como las Torres de la Sal y del Moro, todos ellos en Torrevieja), como elementos sin una protección específica (por ejemplo las antiguas casa rurales en las zonas de viñedos y de regadíos tradicionales o las instalaciones salineras) para los que cabría desarrollar programas que permitan su puesta en valor. Algunos Bienes de Interés Comunitario como el muelle y las eras de la Sal o la Sociedad Cultural Casino de Torrevieja presentan tras el proceso de valoración, un valor paisajístico medio que se incrementa a muy alto al ser patrimonio cultural protegido. No se registran recursos paisajísticos culturales de valor bajo o muy bajo.

Recursos Paisajísticos Visuales: Entre los 86 recursos paisajísticos visuales considerados se incluyen 34 recursos de valor muy alto o alto, fundamentalmente ubicados en el ámbito litoral o del parque natural y con algún grado de protección. En dicha categoría se incluyen a su vez espacios de alto o muy alto valor visual (vistas hacia la laguna de Torrevieja desde las carreteras CV-905, N332 o CV945 o vistas desde puntos elevados (alto de las Majadas o de la Hoya)), que careciendo de protección, son de gran importancia para preservar o mejorar la percepción del paisaje en el entorno del Parque Natural. Entre los recursos paisajísticos visuales con valoración baja o muy baja se incluyen espacios vinculados fundamentalmente a ámbitos urbanos altamente frecuentados y espacios vinculados más directamente al parque (aparcamientos, vía verde a su paso por las urbanizaciones del anticlinal del Chaparral), etc., que deberían ser objeto de propuestas en I programas a definir en las fases siguientes del estudio. 


\section{4.g. Objetivos de Calidad paisajística (apoyado en la FASE3 del Plan de Participación Pública)}

5.4.g.1. Introducción:

Conforme a la metodología propuesta y al Reglamento de Paisaje de la Comunidad Valenciana, las acciones para la ordenación, gestión y protección del paisaje en el ámbito del estudio se estructuran a partir de la formulación de:

- Objetivos de Calidad Paisajística: Los objetivos de calidad paisajística han sido definidos para las distintas unidades de paisaje en un proceso abierto a la participación pública, en el que se ha diferenciado entre objetivos de calidad genéricos, entendiendo como tales los correspondientes a los cuatro tipos de intervención principales previstos en el Reglamento de Paisaje (conservación, restauración, gestión y transformación del paisaje), y objetivos de calidad paisajísticos específicos, en los que se concretan en mayor medida los objetivos a lograr en cada unidad o recurso paisajístico.

- Sistema de Espacios Abiertos (o Infraestructura Verde): El sistema de espacios abiertos toma como base el propuesto para el ámbito ampliado (sur de la provincia de Alicante), detallándolo dentro del ámbito estricto y proporcionando a su vez un elemento de apoyo para la futura definición de los respectivos sistemas de espacios abiertos de los cinco municipios afectados.

Dicho sistema de espacios abiertos ha sido por otro lado diagnosticado en lo referente a sus implicaciones económicas y urbanísticas, evidenciándose, el carácter productivo y agrario de una parte muy sustancial del mismo y su conformación tanto con suelos no urbanizables como urbanizables y urbanos.

- Catalogo del paisaje, en el que se incluyen las unidades o recursos paisajísticos objeto de protección especial así como aquellos que hayan obtenido un valor alto o muy alto en el desarrollo del estudio.

- Programas del Paisaje, Los programas de paisaje propuestos en el presente estudio incorporan las propuestas manifestadas por la población y expertos consultados, tienen por fin la implementación de los objetivos de calidad paisajística y han sido desarrollados a partir de una serie de estrategias de intervención y de un plan de ordenación paisajística que integra el conjunto de acciones.

- Normativa y Recomendaciones Paisajísticas, en las que se incluyen las normas siguientes:

- Normas de aplicación directa

- Normas de Integración Paisajística genéricas

- Normas y Recomendaciones de Integración paisajística específicas, diferenciándose entre aquellas propuestas para:

- Sistema de Espacios Abiertos: regulando los usos y actividades para sus distintas zonas

- Elementos o zonas incluidas en el Catálogo de Paisaje

- Ámbitos homogéneos:

- Zonas agrícolas

- Zonas salineras

- Zonas urbanas y urbanizables colindantes con el parque

- Infraestructuras de transporte y recorridos en el Parque y su entorno

- Saladares secos y zonas con matorral y bosque termo-mediterráneo

- Ramblas y Acequión de Torrevieja

En el desarrollo de las propuestas y programas se han considerado las particulares condiciones que concurren en el Parque Natural de las lagunas de La Mata-Torrevieja, cuyo entorno altamente urbanizado y en el que se alcanza una población cercana a 500.000 habitantes en temporada alta, hace necesario estudiar actuaciones y asignar medios humanos y materiales que permitan compatibilizar la preservación de los valores medioambientales, culturales y paisajísticos del Parque con su función social como zona de uso público.

En concreto en el presente apartado se exponen los objetivos de calidad paisajística establecidos para cada unidad de paisaje y para los distintos tipos de recursos paisajísticos. Dichos objetivos fueron determinados a partir de la FASE3 y última del plan de participación pública, en la que se solicitó a población y expertos que sugirieran posibles acciones para la mejora, gestión y protección del paisaje, proporcionando de este modo y de forma adicional, una valiosa información para la definición de programas de paisaje. 


\section{4.g.2. Plan de Participación Pública: FASE 3 (Propuestas para la Protección, Gestión y Ordenación del} Paisaje)

\section{4.g.2.1. Objetivos}

El objetivo de la FASE 3 del Plan de Participación Pública del Estudio de Paisaje del Parque Natural de las Lagunas de La Mata y Torrevieja fue recoger las sugerencias de expertos y población residente y visitante obre los aspectos a corregir, mejorar o potenciar en el paisaje de los ámbitos siguientes:

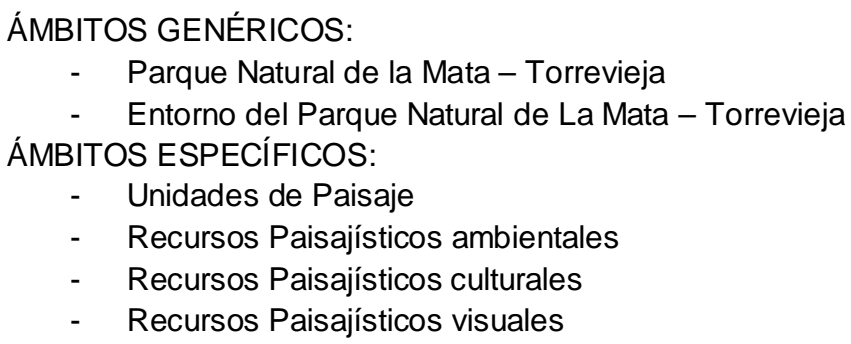

Tal y como se expuso previamente, las unidades y recursos paisajísticos fueron definidas y valoradas mediante un proceso en el que se consultó a expertos y a la población interesada o afectada. Las propuestas de estos mismos dos grupos respecto a la intervención y gestión del paisaje, apoya seguidamente la definición de unos objetivos de calidad paisajística genéricos y específicos, así como la de los programas de paisaje.

\section{4.g.2.2. Metodología}

Atendiendo a la metodología propuesta en la presente tesis y al Reglamento de Paisaje de la Comunidad Valenciana, las acciones o programas de paisaje deben permitir materializar los objetivos de calidad en cada unidad de paisaje o recurso paisajístico. Dichos objetivos de calidad (gestión, protección, ordenación, o cualquier combinación de éstos), se encuentran en el caso particular del presente estudio, altamente condicionados por las figuras de protección existentes en el parque y su entorno, motivo por el que la participación pública en la FASE3 se centra en la definición de acciones sobre el paisaje y no en la definición de objetivos de calidad.

\section{4.g.2.3. Consideraciones previas}

Serán de aplicación las mismas consideraciones expuestas en las FASES 1 y 2 del Plan de Participación Pública, que apoyaron respectivamente la caracterización y valoración del paisaje.

\section{4.g.2.4. Niveles de participación}

- Encuestas: Durante la fase 3 se realizaron un total de 75 encuestas y se recibieron 5 formularios descargados desde las webs en las que el Plan de Participación Pública estuvo activo.

- Consultas a expertos: Entre los expertos contactados para solicitar su posible colaboración en la FASE3 del Plan de Participación Pública se incluyeron técnicos de los Ayuntamientos de Torrevieja, Guardamar del Segura, Rojales, Los Montesinos y San Miguel de Salinas, profesores de las distintas universidades de la Comunidad Valenciana, técnicos de la Consellería de Medio Ambiente, Agua, Urbanismo y Vivienda y del Parque Natural de las lagunas de La Mata-Torrevieja, recibiéndose un total de 11 respuestas al cuestionario.

Tabla 5.30: Comparación entre los perfiles inicialmente previstos y finalmente encuestados en la fase 3 del plan de participación pública.

\begin{tabular}{c|c|c|c} 
Variable encuestado & Valores & Objetivo encuestas & Encuestas realizadas \\
\hline \multirow{4}{*}{$\begin{array}{c}\text { Lugar de realización de las } \\
\text { encuestas }\end{array}$} & Torrevieja & $50-60 \%$ & $45 \%$ \\
\cline { 2 - 4 } & Montesinos & $10 \%$ & $10 \%$ \\
\cline { 2 - 4 } & Guardamar & $15-20 \%$ & $20 \%$ \\
\cline { 2 - 4 } & Rojales & $15-20 \%$ & $10 \%$ \\
\hline \multirow{2}{*}{$\begin{array}{c}\text { Motivo de la presencia en } \\
\text { la zona }\end{array}$} & Ran Miguel de las Salinas & $10 \%$ & $15 \%$ \\
\cline { 2 - 4 } & Turista-motivos laborales & $66 \%$ & $75,50 \%$ \\
\hline \multirow{2}{*}{\begin{tabular}{c} 
Nacionalidad \\
\cline { 2 - 4 }
\end{tabular}} & Español & $33 \%$ & $24,50 \%$ \\
\hline \multirow{2}{*}{ Edad } & Extranjero & $81 \%$ & $97,00 \%$ \\
\cline { 2 - 4 } & $0-18$ & $19 \%$ & $3,00 \%$ \\
\cline { 2 - 4 } & $18-65$ & $13 \%$ & $70,00 \%$ \\
\hline \multirow{2}{*}{ Sexo } & $>65$ & $19 \%$ & $11,25 \%$ \\
\cline { 2 - 4 } & Hombres & $50 \%$ & $50,00 \%$ \\
\hline
\end{tabular}




\section{4.g.3: Resultados del plan de participación pública para la Protección, Gestión y Ordenación del Paisaje:}

En los apartados siguientes se exponen las propuestas referentes al paisaje realizadas por población y expertos en los ámbitos genéricos y específicos previstos en la fase 3 del plan de participación pública. Con el objeto de poder agrupar posteriormente dichas propuestas se establecieron los siguientes tipos de programas de paisaje:

- TIPO 1: PROGRAMAS DE CONEXIÓN: agruparán propuestas centradas en el establecimiento de conectores entre el parque y otras zonas próximas de interés medioambiental o altamente habitadas.

- TIPO 2: PROGRAMAS DE USO: agruparán propuestas centradas en el uso del parque natural o de los otros ámbitos geográficos considerados. Dichas propuestas podrán centrarse en actividades, recorridos, instalaciones o difusión.

- TIPO 3: PROGRAMAS DE INTEGRACIÓN EN EL PAISAJE: agruparán propuestas centradas en la integración en el paisaje de infraestructuras, urbanizaciones o instalaciones.

- TIPO 4: PROGRAMAS DE GESTIÓN Y MANTENIMIENTO: agruparán propuestas centradas en la gestión y mantenimiento de los espacios productivos (agrícolas o salineros), de los espacios naturales y de las áreas urbanizadas.

- TIPO 5: PROGRAMAS DE MEJORA DEL PATRIMONIO MEDIOAMBIENTAL: agruparán propuestas centradas en la mejora del patrimonio medioambiental, con especial atención a los recursos hídricos, vegetación y fauna.

- TIPO 6: PROGRAMAS DE MEJORA DEL PATRIMONIO CULTURAL: agruparán propuestas centradas en la rehabilitación y puesta en valor del patrimonio cultural arquitectónico, ingenieril y etnográfico.

Dado lo extenso de los listados que recogen las propuestas de población y expertos se han establecido a su vez las siguientes categorías dentro de cada listado:

- DEMANDA MUY ALTA: apoyadas por más de un $40 \%$ de los participantes (texto en negrita)

- DEMANDA ALTA: apoyadas por entre un $20 \%$ y un $40 \%$ de los participantes (texto estándar)

- DEMANDA MEDIA: apoyadas por entre un $5 \%$ y un $20 \%$ de los participantes (texto en gris oscuro)

- DEMANDA BAJA: apoyadas por menos de un $5 \%$ de los participantes (texto en gris claro) 


\section{4.g.3.1 Propuestas para los ámbitos genéricos \\ 1) Parque Natural \\ 1.1) Usos del Parque}

El análisis comparado de las propuesta realizadas por la población y expertos muestra que para el primero de los grupos son prioritarias las acciones de Gestión y Mantenimiento (aumentar la vigilancia, promocionar el parque) mientras que los expertos centran sus sugerencias en aspectos vinculados al Uso del Parque (señalizar, jerarquizar y diferenciar recorridos, regular el acceso público al parque, etc.).

Se observa entre los técnicos del parque consultados una especial preocupación por lograr un equilibrio entre el uso público del mismo y la preservación de sus valores ambientales (vegetación y fauna). En este aspecto cabe destacar que dada la alta presión de la población en gran parte del perímetro del parque, sería necesario vincular la promoción del uso del parque a un incremento de los recursos humanos disponibles para su vigilancia y mantenimiento.

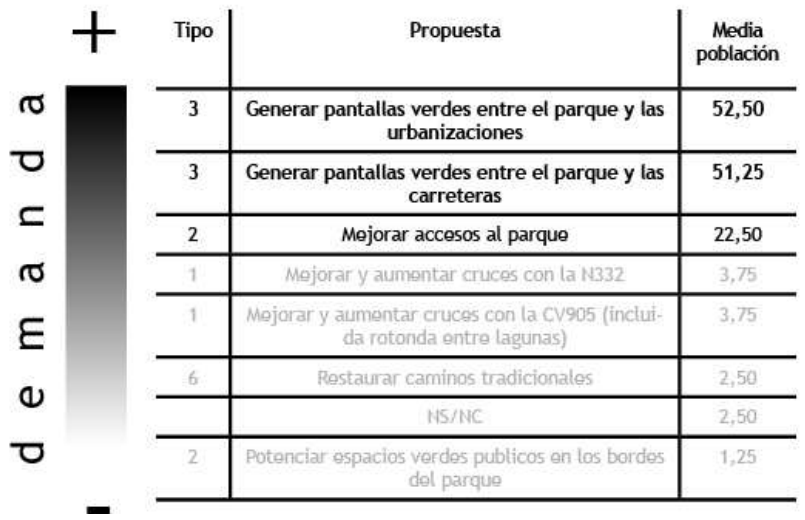

\begin{tabular}{c|c|c} 
Tipo & Propuesta & $\begin{array}{c}\text { Media } \\
\text { expertos }\end{array}$ \\
\hline 3 & $\begin{array}{c}\text { Generar pantallas verdes entre el parque y las } \\
\text { urbanizaciones }\end{array}$ & $\mathbf{6 3 , 6 4}$ \\
\hline 3 & $\begin{array}{c}\text { Generar pantallas verdes entre el parque y las } \\
\text { carreteras }\end{array}$ & 54,55 \\
\hline 1 & Mejorar y aumentar cruces con la N332 & 18,18 \\
\hline 2 & $\begin{array}{c}\text { Potenciar espacios verdes publicos en los bordes } \\
\text { del parque }\end{array}$ & 18,18 \\
\hline & NS/NC & 18,18 \\
\hline 1 & $\begin{array}{c}\text { Mejorar y aumentar cruces con la CV905 (inclui- } \\
\text { da rotonda entre lagunas) }\end{array}$ & 9,09 \\
\hline 6 & Restaurar caminos tradicionales & 9,09 \\
\hline & \multicolumn{2}{|c}{}
\end{tabular}

\section{2) Paisaje Interno del Parque Natural}

El análisis comparado de las propuesta realizadas por la población y expertos muestra una coincidencia en las acciones prioritarias (limpiar el parque e incrementar la superficie arbolada), que se vinculan respectivamente a programas de Gestión/mantenimiento y de Mejora del patrimonio medioambiental.

Los expertos proponen a su vez acciones dirigidas a la mejora de zonas concretas (área de depósito de lodos) o la recuperación del patrimonio cultural situado junto a las lagunas (torres vigías).

El incremento de zonas arboladas puede cumplir importantes funciones pero debería en cualquiera de los casos realizarse en zonas que no sean las propias de otras formaciones vegetales más específicas (por ejemplo saladares o marjales).

\begin{tabular}{|c|c|c|c|}
\hline & Tipo & Propuesta & $\begin{array}{c}\text { Media } \\
\text { población }\end{array}$ \\
\hline 0 & 2 & Limpiar más el parque & 53,75 \\
\hline & 5 & Incrementar la superficie arbolada & 48,75 \\
\hline & 2 & Mejorar la señaletica & 7,50 \\
\hline & 6 & Aumentar zonas arboladas & 6,25 \\
\hline & 5 & $\begin{array}{l}\text { Reforzar vegetación en las laderas del alto de la } \\
\text { Hoya y la Casilla }\end{array}$ & 5,00 \\
\hline & 2 & Potonciar recorrides a lo largo de los canalos & 2,50 \\
\hline & 2 & Potenciar recorridos a to largo de las ramblas & 2,50 \\
\hline & & NS/NC & 2,50 \\
\hline
\end{tabular}

\begin{tabular}{c|c|c} 
Tipo & Propuesta & $\begin{array}{c}\text { Media } \\
\text { expertos }\end{array}$ \\
\hline 5 & Incrementar la superficie arbolada & 45,45 \\
\hline 2 & Limpiar más el parque & 36,36 \\
\hline 2 & Mejorar la señaletica & 27,27 \\
\hline 3 & Mejorar las áreas do depósito de sales residuales & 18,18 \\
\hline 6 & Recuperar el patrimonio arquitectonico (torres & 18,18 \\
\hline 2 & vigia) & \\
\hline 5 & Rotenciar recorridos a lo largo de las ramblas & 18,18 \\
\hline
\end{tabular}




\section{3) Conexiones Visuales y Físicas del Parque Natural}

Población y expertos coinciden en la necesidad de espacios verdes arbolados en la transición del parque con las infraestructuras y zonas urbanizadas colindantes (programas de integración en el paisaje) así como en la mejora de los accesos al mismo, con especial énfasis en los cruces de la carretera N332.

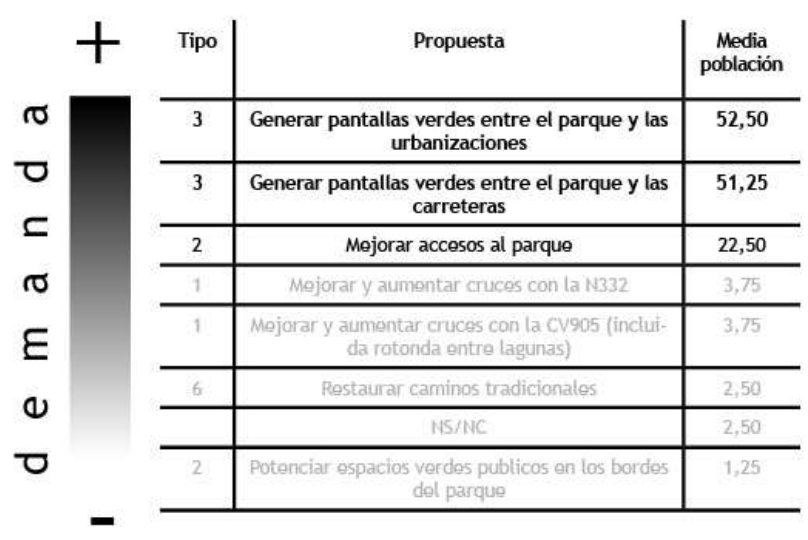

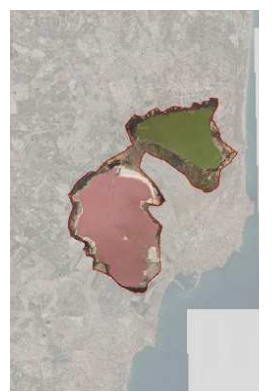

\begin{tabular}{c|c|c} 
Tipo & Propuesta & $\begin{array}{c}\text { Media } \\
\text { expertos }\end{array}$ \\
\hline 3 & $\begin{array}{c}\text { Generar pantallas verdes entre el parque y las } \\
\text { urbanizaciones }\end{array}$ & 63,64 \\
\hline 3 & $\begin{array}{c}\text { Generar pantallas verdes entre el parque y las } \\
\text { carreteras }\end{array}$ & 54,55 \\
\hline 1 & Mejorar y aumentar cruces con la N332 & 18,18 \\
\hline 2 & $\begin{array}{c}\text { Potenciar espacios verdes publicos en los bordes } \\
\text { del parque }\end{array}$ & 18,18 \\
\hline 1 & NS/NC & 18,18 \\
\hline 6 & Mejorar y aumentar cruces con la CV905 (inclui- \\
da rotonda entre lagunas) & 9,09 \\
\hline & Restaurar caminos tradicionales & 9,09 \\
\hline
\end{tabular}

\section{2) Entorno del Parque Natural}

El análisis comparado de las propuestas realizadas por la población y expertos muestra una coincidencia en la necesidad de integrar paisajísticamente las urbanizaciones e infraestructuras próximas al parque natural así como en limitar el posible crecimiento de las primeras.

Los expertos consultados coinciden a su vez en la importancia de mantener el paisaje agrícola, tanto de huertos como de viñedos en el entorno del parque.

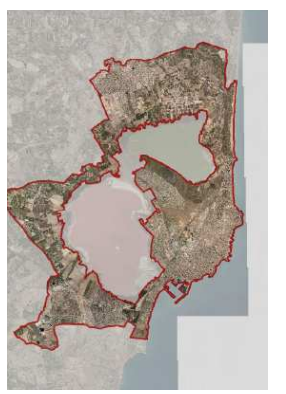

\begin{tabular}{|c|c|c|}
\hline 十 $\quad$ Tipo & Propuesta & $\begin{array}{c}\text { Media } \\
\text { población }\end{array}$ \\
\hline 3 & No aumentar las urbanizaciones & 43,75 \\
\hline 5 & $\begin{array}{l}\text { Aumentar y extender zonas verdes (especies } \\
\text { autóctonas) }\end{array}$ & 40,00 \\
\hline 3 & Integrar paisajisticamente las urbanizaciones & 32,50 \\
\hline 3 & Integrar las infraestructuras de transporte & 12,50 \\
\hline 1 & $\begin{array}{l}\text { Mantener la actividad agrícola en las zonas de } \\
\text { viñedos }\end{array}$ & 5,00 \\
\hline 4 & $\begin{array}{l}\text { Mantener la actividad agrícola en las zonas de } \\
\text { huerta }\end{array}$ & 5,00 \\
\hline 2 & Soñalizar mejor los accoso al parque & 3,75 \\
\hline 2 & $\begin{array}{l}\text { Mejorar accesos al parque desde zonas urba- } \\
\text { nizadas }\end{array}$ & 3,75 \\
\hline 1 & $\begin{array}{c}\text { potenciar corredores naturales a lo largo de las } \\
\text { Ramblas }\end{array}$ & 3,75 \\
\hline 2 & Crear recorridos en bici & 3,75 \\
\hline & Demoler las urbanizaciones & 2,50 \\
\hline 2 & $\begin{array}{l}\text { Crear recorridos públicos a través de las zonás } \\
\text { de huertos extensivos }\end{array}$ & 2,50 \\
\hline 3 & Mejorar paisaje en accosos urbanos & 1,25 \\
\hline 1 & Mejorar cruces de la vía verde & 1,25 \\
\hline & INS/NC & 1,25 \\
\hline
\end{tabular}

\begin{tabular}{|c|c|c|}
\hline Tipo & Propuesta & $\begin{array}{c}\text { Media } \\
\text { expertos }\end{array}$ \\
\hline 3 & Integrar paisajisticamente las urbanizaciones & 72,73 \\
\hline 3 & No aumentar las urbanizaciones & 36,36 \\
\hline 5 & $\begin{array}{l}\text { Aumentar y extender zonas verdes (especies } \\
\text { autóctonas) }\end{array}$ & 36,36 \\
\hline 3 & Integrar las infraestructuras do transporte & 27,27 \\
\hline 1 & $\begin{array}{l}\text { Mantener la actividad agricola en las zonas do } \\
\text { viñedos }\end{array}$ & 27,27 \\
\hline 4 & $\begin{array}{l}\text { Mantener la actividad agricola en las zonas de } \\
\text { huerta }\end{array}$ & 18,18 \\
\hline \multirow[t]{2}{*}{3} & Mejorar paisaje en accosos urbanos & 18,18 \\
\hline & NS/NC & 18,18 \\
\hline 2 & Señalizar mejor los accoso al parque & 9,09 \\
\hline 1 & $\begin{array}{l}\text { potenciar corredores naturales a lo largo de las } \\
\text { Ramblas }\end{array}$ & 9,09 \\
\hline 1 & Mejorar cruces de la vía verde & 9,09 \\
\hline
\end{tabular}




\section{4.g.3.2 Propuestas para los ámbitos específicos (Unidades y Recursos Paisajísticos) \\ 1) Unidades de Paisaje \\ 1.1) UP1: Laguna de La Mata}

Tanto población como expertos coinciden en que la unidad de paisaje de la laguna de La Mata presenta un paisaje adecuado así como en la conveniencia de aumentar la presencia de vegetación arbustiva o arbórea al sur del canal de las Salinas (espacio entre las lagunas de La Mata y Torrevieja).

La población centra a su vez sus propuestas en acciones asociadas al mantenimiento (limpieza o control de vertidos).

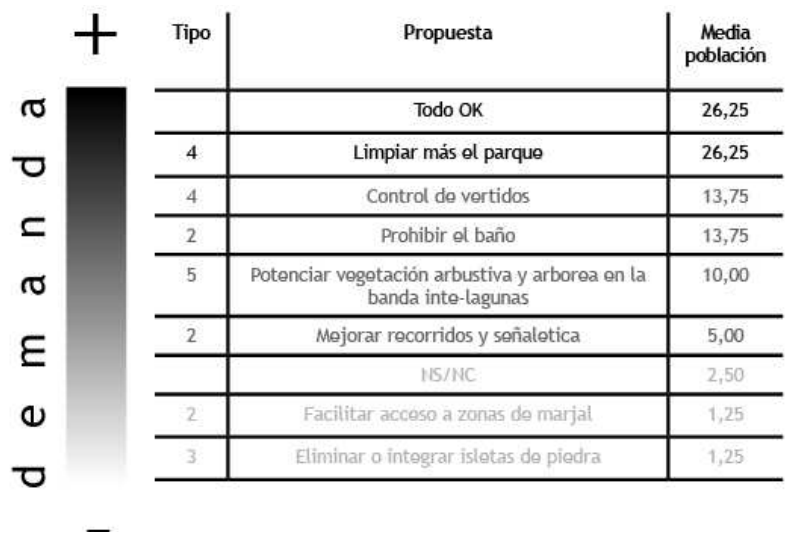

\begin{tabular}{c|c|c} 
Tipo & Propuesta & $\begin{array}{c}\text { Media } \\
\text { expertos }\end{array}$ \\
\hline & Todo OK & 27,27 \\
\hline 5 & $\begin{array}{c}\text { Potenciar vegetación arbustiva y arborea en la } \\
\text { banda inte-lagunas }\end{array}$ & 18,18 \\
\hline 2 & Mejorar recorridos y señaletica & 18,18 \\
\hline 2 & Facilitar acceso a zonas de marjal & 9,09 \\
\hline 4 & Control de vertidos & 9,09 \\
\hline 2 & Prohibir el baño & 9,09 \\
\hline
\end{tabular}

\section{2.) UP2: Laguna de Torrevieja}

La unidad de paisaje de la laguna de Torrevieja es percibida tanto por expertos como por población como una unidad en la que cabe un grado de mejora del paisaje mayor que en la de la laguna de La Mata.

En particular los expertos indican la necesidad de desarrollar propuestas dirigidas a mejorar el uso público (recorridos, señalética y potenciación del eje definido por el Acequión) así como la restauración de la zona de depósito de lodos, aspecto este último indicado también por la población, a la vez que el interés en poder visitar las instalaciones salineras.

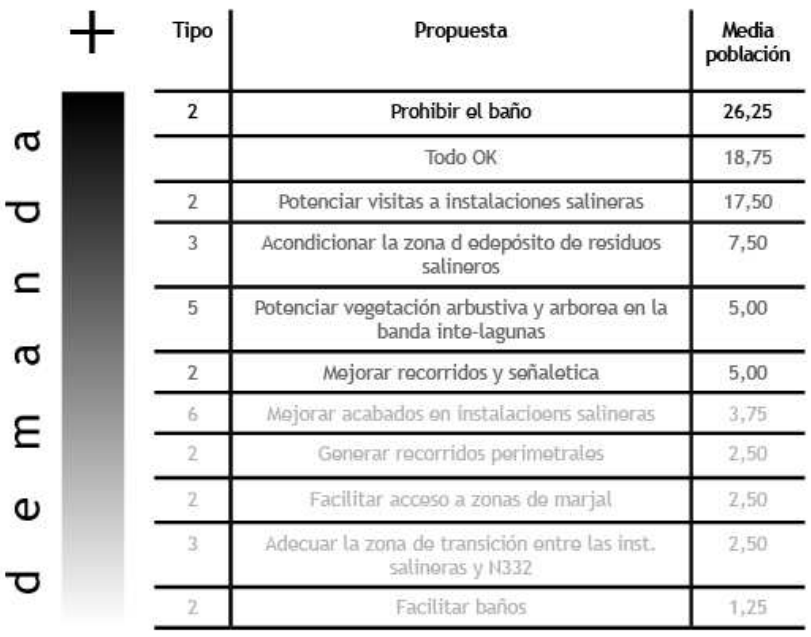

\begin{tabular}{c|c|c} 
Tipo & Propuesta & $\begin{array}{c}\text { Media } \\
\text { expertos }\end{array}$ \\
\hline 2 & Mejorar recorridos y señaletica & 27,27 \\
\hline 2 & $\begin{array}{c}\text { Potenciar recorrido paralelo al acequión de } \\
\text { Torrevieja }\end{array}$ & 27,27 \\
\hline 5 & $\begin{array}{c}\text { Potenciar vegetación arbustiva y arborea en la } \\
\text { banda inte-lagunas }\end{array}$ & 18,18 \\
\hline 2 & Prohibir el baño & 18,18 \\
\hline 3 & Acondicionar la zona d edepósito de residuos \\
salineros & 18,18 \\
\hline 2 & NS/NC & 18,18 \\
\hline 6 & Mejorar acabados en instalacioens salineras & 9,09 \\
\hline 3 & Adecuar la zona de transición entre las inst. & 9,09 \\
\hline & salineras y N332 & 9,09 \\
\hline
\end{tabular}




\section{3.) UP3: Viñedos y secanos de La Mata}

Tanto población como expertos coinciden en que la unidad de paisaje $n \div 3$ presenta un paisaje adecuado y en la necesidad de promover acciones que garanticen la continuidad de la actividad vitícola y el aumento de ingresos de los agricultores.

Los expertos consultados mencionan su vez aspectos puntuales como la mejora paisajística del borde de la carretera N332 y del aparcamiento del Centro de Visitantes así como la necesidad de establecer unos criterios paisajísticos para el cercado de parcelas.

\begin{tabular}{|c|c|c|c|c|c|c|}
\hline & Tipo & Propuesta & $\begin{array}{c}\text { Media } \\
\text { población }\end{array}$ & Tipo & Propuesta & $\begin{array}{c}\text { Media } \\
\text { expertos }\end{array}$ \\
\hline ర & 4 & $\begin{array}{l}\text { Incentivar cultivo de vid (ayudas a la produc- } \\
\text { ción y comercialización) }\end{array}$ & 52,50 & 4 & $\begin{array}{l}\text { Incentivar cultivo de vid (ayudas a la producción } \\
\text { y comercialización) }\end{array}$ & 36,36 \\
\hline & & Todo OK & 26,25 & 4 & $\begin{array}{l}\text { Potenciar usos complementarios a la agricultura } \\
\text { (hosteleria, servicios, etc) }\end{array}$ & 27,27 \\
\hline & 4 & $\begin{array}{l}\text { Potenciar usos complementarios a la agricultura } \\
\text { (hosteleria, servicios, etc) }\end{array}$ & 12,50 & 3 & Adecuar encuentro con la N332 & 27,27 \\
\hline & 4 & Controlar población de conejos & 12,50 & 3 & Integrar aparcamiento del Parque Natural & 27,27 \\
\hline & 4 & Limpiar restos de actividad agricola. & 3,75 & & Todo OK & 18,18 \\
\hline & 4 & Introducción del cultivo ecológico & 3,75 & 3 & Estandarizar cerramientos y muros agricolas & 18,18 \\
\hline & \multirow[t]{2}{*}{6} & Rostaurar patrimonio arquitectónico & 2,50 & 6 & Restaurar patrimonio arquitectónico & 9,09 \\
\hline & & HS/NC & 2,50 & 2 & Mejorar recorridos y señaletica & 9,09 \\
\hline & 2 & Mejorar recorridos y señaletica & 1,25 & 2 & Potenciar eje del canal de La Mata & 9,09 \\
\hline & 3 & Estandarizar cermamientos y muros agricolas & 1,25 & 4 & Limpiar restos de actividad agricola & 9,09 \\
\hline & & & & 3 & Regular cultivos bajo plástico & 9,09 \\
\hline & & & & & HS/NC & 9,09 \\
\hline
\end{tabular}

\section{4) UP4: Huertos tradicionales de La Mata y Torrevieja}

Las propuestas de la población se centran en incentivar la actividad agrícola, sugiriendo el fomento del riego por goteo o la introducción de actividades complementarias a la agricultura (hostelería o servicios).

Los expertos mencionan este mismo tipo de propuestas pero priorizan la restauración del patrimonio cultural arquitectónico (con especial mención a la finca de la Marquesa) o la regulación del cultivo bajo plástico y de los cercados de las parcelas.

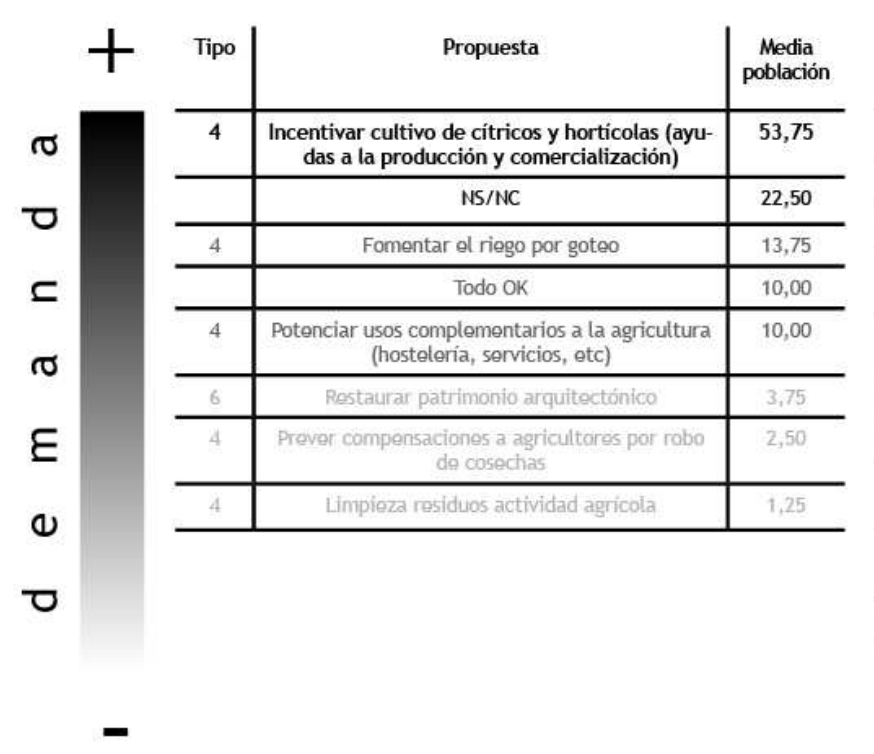

\begin{tabular}{c|c|c} 
Tipo & Propuesta & $\begin{array}{c}\text { Media } \\
\text { expertos }\end{array}$ \\
\hline 6 & Restaurar patrimonio arquitectónico & 45,45 \\
\hline 3 & Regular cultivos bajo plástico & 36,36 \\
\hline & NS/NC & 27,27 \\
\hline 2 & $\begin{array}{c}\text { Crear zona de servicios y recepción de visitantes } \\
\text { en La Marquesa }\end{array}$ & 18,18 \\
\hline 4 & $\begin{array}{c}\text { Potenciar usos complementarios a la agricultura } \\
\text { (hosteleria, servicios, etc) }\end{array}$ & 18,18 \\
\hline 3 & Estandarizar cerramientos y muros agricolas & 18,18 \\
\hline 4 & Limpieza residuos actividad agricola & 18,18 \\
\hline 4 & $\begin{array}{c}\text { Incentivar cultivo de cítricos y hortícolas (ayu- } \\
\text { das a la producción y comercialización) }\end{array}$ & 9,09 \\
\hline 2 & $\begin{array}{c}\text { Generar recorridos peatonales /ciclistas en } \\
\text { zonas agricolas }\end{array}$ & 9,09 \\
\hline 4 & Introducción de nuevos sistemas de riego & 9,09 \\
\hline
\end{tabular}




\section{5) UP5: Regadíos Extensivos de la Laguna de Torrevieja}

Se observa que en esta unidad tanto la población como los expertos hacen un número menor de propuestas. En el primero de los grupos se proponen acciones dirigidas a facilitar la permanencia de la actividad agrícola y a la restauración del patrimonio arquitectónico.

Los expertos centran sus sugerencias en hacer la unidad parcialmente accesible al público, en regular los cultivos bajo plástico y cerramientos (en algunos casos muy visibles), en restaurar el patrimonio arquitectónico y en asignar a los edificios algunos usos compatibles con la normativa del Parque Natural.

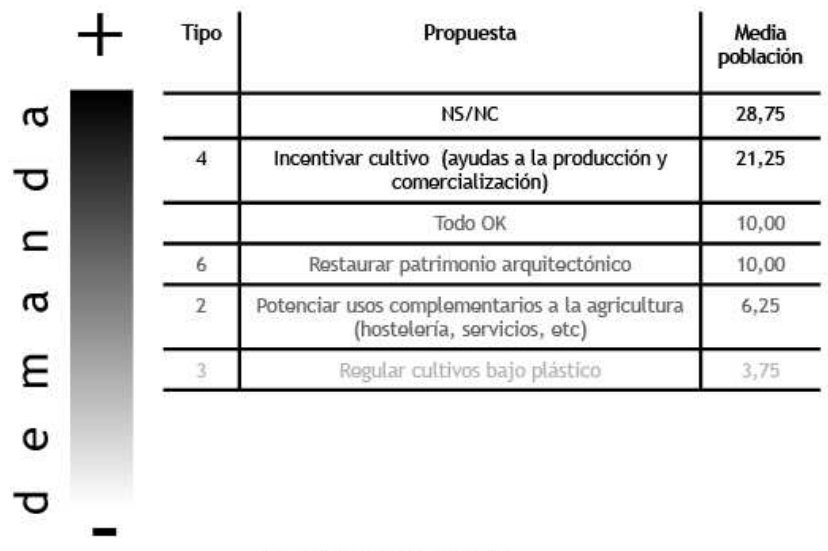

\begin{tabular}{c|c|c} 
Tipo & Propuesta & $\begin{array}{c}\text { Media } \\
\text { expertos }\end{array}$ \\
\hline 3 & Regular cultivos bajo plástico & 27,27 \\
\hline & NS/NC & 27,27 \\
\hline & Todo OK & 18,18 \\
\hline 2 & $\begin{array}{c}\text { Crear recorridos públicos en caminos con dere- } \\
\text { cho de paso o en el borde con la UP2 }\end{array}$ & 18,18 \\
\hline 4 & Limpieza de residuos actividad agricola & 18,18 \\
\hline 6 & Restaurar patrimonio arquitectónico & 9,09 \\
\hline 2 & Potenciar usos complementarios a la agricultura & 9,09 \\
\hline 3 & (hostelería, servicios, otc) & 9,09 \\
\hline
\end{tabular}

\section{6) UP6: Altos de la Atalaya y del Moncayo}

Tanto la población como los expertos encuentran que el estado actual de la unidad es correcto y emiten pocas propuestas.

En el caso de la población la sugerencia mayoritaria es incrementar y extender las pinadas existentes mientras que los expertos proponen una acción en la misma línea por medio de la recolonización de suelos agrícolas de secano por vegetación natural. Ambos grupos afirman que la unidad de paisaje debería disponer en sus cotas más altas de un mirador debidamente acondicionado.

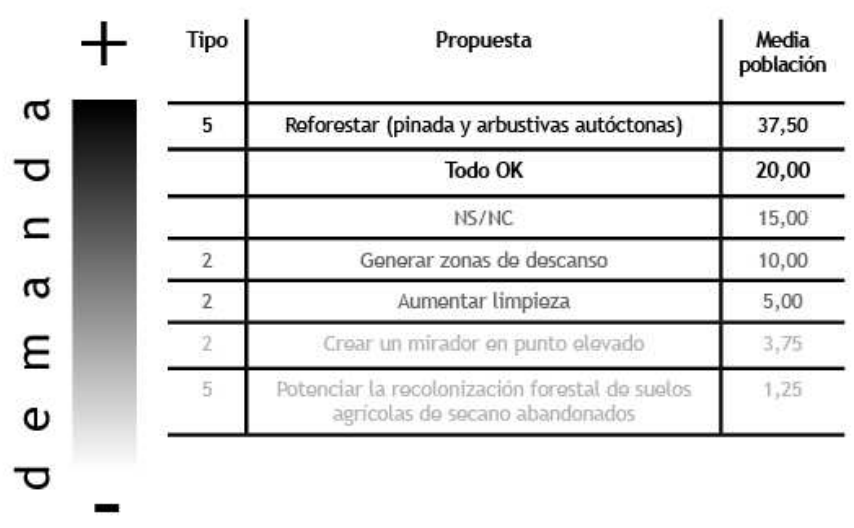

\begin{tabular}{c|c|c} 
Tipo & Propuesta & $\begin{array}{c}\text { Media } \\
\text { expertos }\end{array}$ \\
\hline & Todo OK & 18,18 \\
\hline & NS/NC & 18,18 \\
\hline 5 & $\begin{array}{c}\text { Potenciar la recolonización forestal de suolos } \\
\text { agricolas de secano abandonados }\end{array}$ & 9,09 \\
\hline 1 & $\begin{array}{c}\text { Potenciar uso peatonal ciclista de las caminos } \\
\text { rurales do Dos y Ratero }\end{array}$ & 9,09 \\
\hline 2 & Crear un mirador en punto olevado & 9,09 \\
\hline 2 & Aumentar limpieza & 9,09 \\
\hline 2 & Soterrar lineas oléctricas & 9,09 \\
\hline
\end{tabular}




\section{7) UP7: Dunas de Guardamar}

La población consultada estima que el estado de la unidad es correcto y sugiere que se tomen medidas para evitar el paso de personas fuera de los recorridos balizados y que se gestione y potencie la masa forestal existente.

Esta última propuesta es la más indicada por los expertos consultados, quienes sugieren a su vez que se mejore la señalización y que se potencie la conexión con el parque natural de las lagunas de La Mata y Torrevieja.

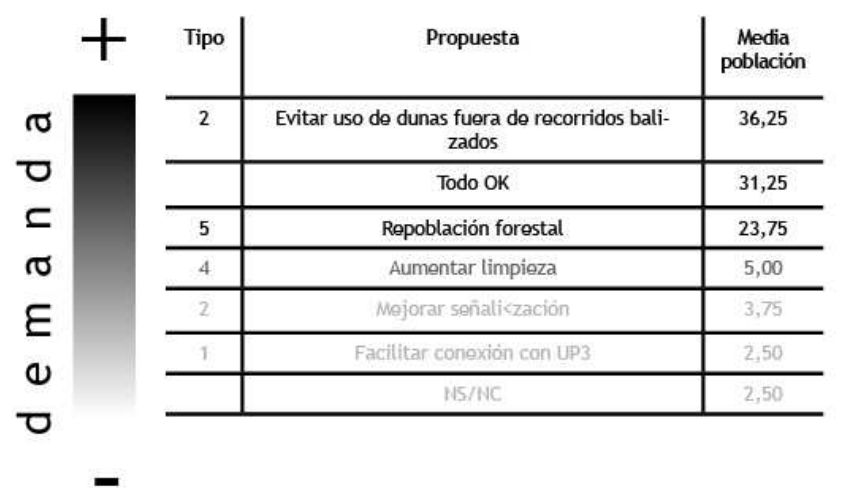

\begin{tabular}{c|c|c} 
Tipo & Propuesta & $\begin{array}{c}\text { Media } \\
\text { expertos }\end{array}$ \\
\hline 5 & Repoblación forestal & 36,36 \\
\hline 2 & $\begin{array}{c}\text { Evitar uso de dunas fuera de recorridos bali- } \\
\text { zados }\end{array}$ & 18,18 \\
\hline 2 & Mejorar señali<zación & 18,18 \\
\hline 1 & Facilitar conexión con UP3 & 9,09 \\
\hline & NS/NC & 9,09 \\
\hline
\end{tabular}

\section{8) UP8: Alto de la Hoya y pinada del Chaparral}

La población consultada estima que el estado de la unidad es correcto y sugiere que se tomen medidas para evitar el paso de personas fuera de los recorridos balizados y que se gestione y potencie la masa forestal existente.

Esta última propuesta es la más indicada por los expertos consultados, quienes sugieren a su vez que se mejore la señalización y que se potencie la conexión con el parque natural de las lagunas de La Mata y Torrevieja.
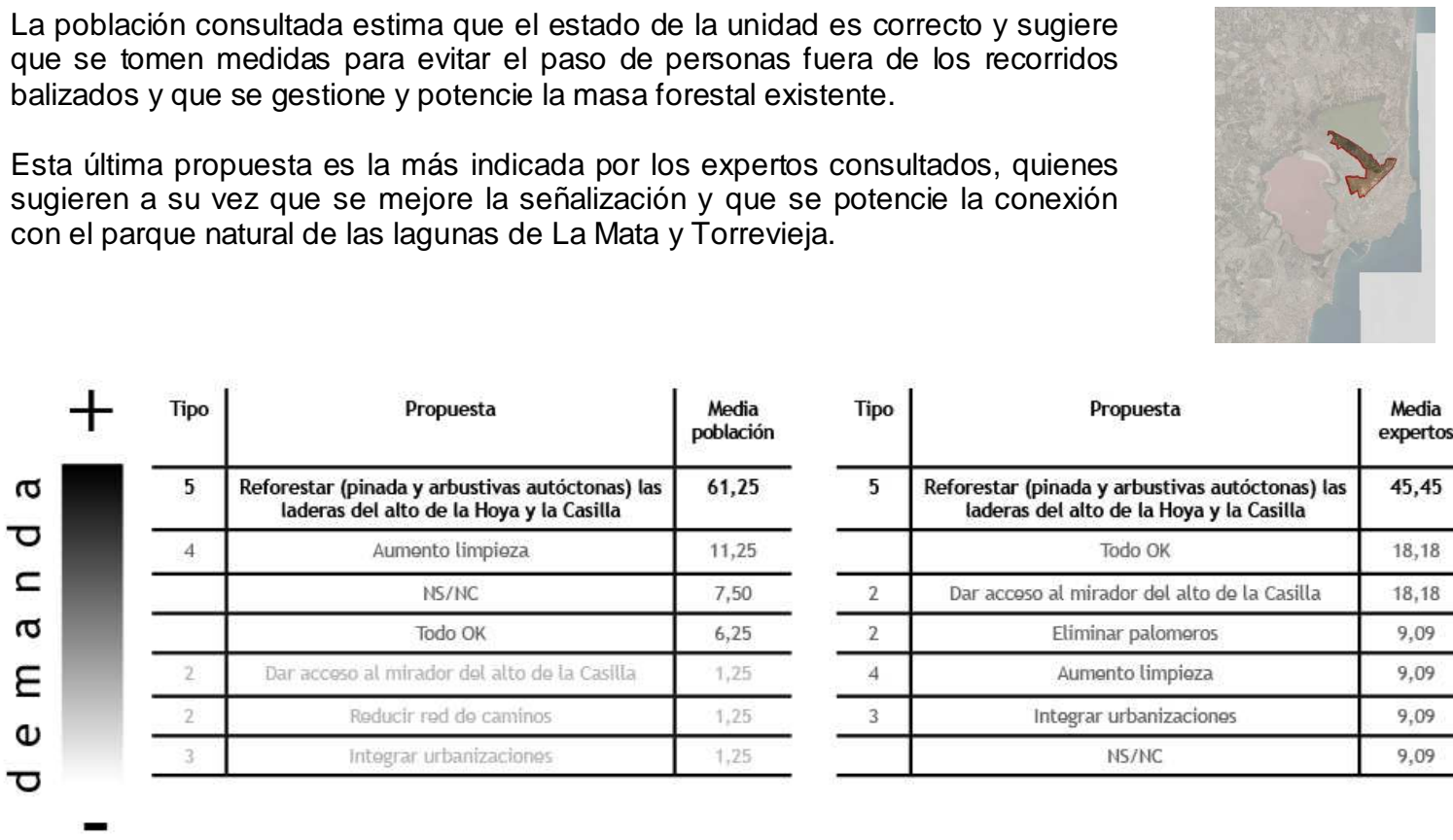

\begin{tabular}{c|c|c} 
Tipo & Propuesta & $\begin{array}{c}\text { Media } \\
\text { expertos }\end{array}$ \\
\hline 5 & $\begin{array}{c}\text { Reforestar (pinada y arbustivas autóctonas) las } \\
\text { laderas del alto de la Hoya y la Casilla }\end{array}$ & $\mathbf{4 5 , 4 5}$ \\
\hline & Todo OK & 18,18 \\
\hline 2 & Dar accoso al mirador del alto de la Casilla & 18,18 \\
\hline 2 & Eliminar palomeros & 9,09 \\
\hline 4 & Aumento limpieza & 9,09 \\
\hline 3 & Integrar urbanizaciones & 9,09 \\
\hline & NS/NC & 9,09 \\
\hline
\end{tabular}

\section{9) UP9: Conector de la Rambla de La Fayona:}

La población consultada no tiene una opinión clara formada sobre la rambla de la Fayona pero sugiere su restauración ambiental y su vinculación a recorridos peatonales.

Una parte importante de los encuestados encuentran sin embargo que su estado actual es correcto. Por el contrario, los expertos consultados inciden en la importancia de la rambla como conector entre la laguna de Torrevieja y el futuro parque natural de la Dehesa de Campoamor - Sierra Escalona y la necesidad de ampliar la anchura de la zona protegida en ambas márgenes así como de reforzar la presencia de formaciones vegetales asociadas a cursos temporales de agua.

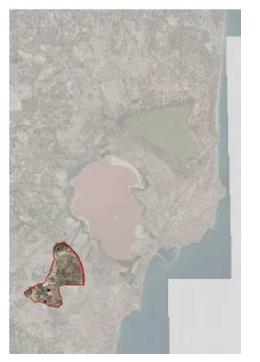




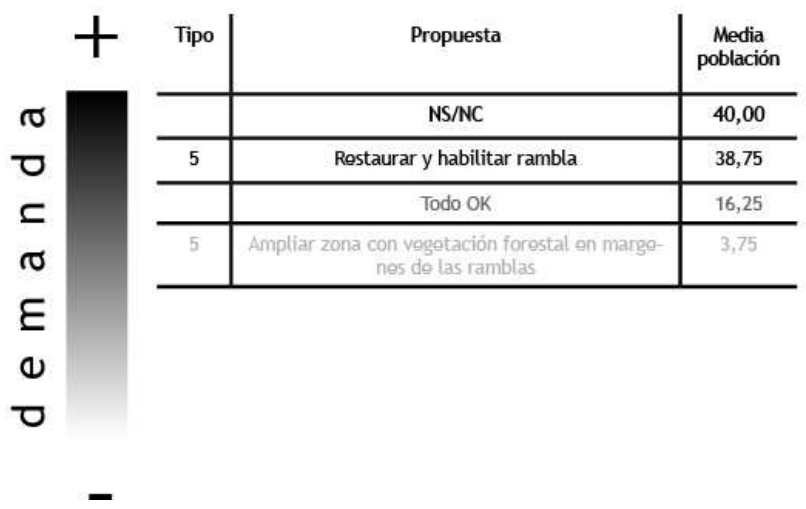

\begin{tabular}{c|c|c} 
Tipo & Propuesta & $\begin{array}{c}\text { Media } \\
\text { expertos }\end{array}$ \\
\hline $\mathbf{5}$ & $\begin{array}{c}\text { Ampliar zona con vegetación forestal en } \\
\text { margenes de las ramblas }\end{array}$ & $\mathbf{4 5 , 4 5}$ \\
\hline $\mathbf{2}$ & $\begin{array}{c}\text { Generar recorridos (lecho y cota alta) a lo largo } \\
\text { de las ramblas de La Fayona y Garbanzuolo } \\
\text { (conector con PN Campoamor) }\end{array}$ & 36,36 \\
\hline $\mathbf{5}$ & Restaurar y habilitar rambla & 36,36 \\
\hline & NS/NC & 36,36 \\
\hline 5 & $\begin{array}{c}\text { Potenciar la recolonización forestal de suelos } \\
\text { agricolas de secano abandonados }\end{array}$ & 18,18 \\
\hline 1 & Ampliar crucos de ramblas con carroteras (CV- \\
95, AP7) & 18,18 \\
\hline
\end{tabular}

\subsection{0) UP10: Urbanización El Raso:}

Las propuestas de la población consultada van dirigidas a limitar la construcción de nuevos edificios, a integrar la urbanización existente y a generar una zona verde de transición con el Parque Natural.

Los expertos consultados proponen el desarrollo de acciones dirigidas a integrar la urbanización y la aplicación de medidas concretas para aumentar el arbolado en el viario, controlar la contaminación lumínica, restaurar la Casa del Raso y dar recomendaciones sobre las especies vegetales a emplear en los jardines privados.
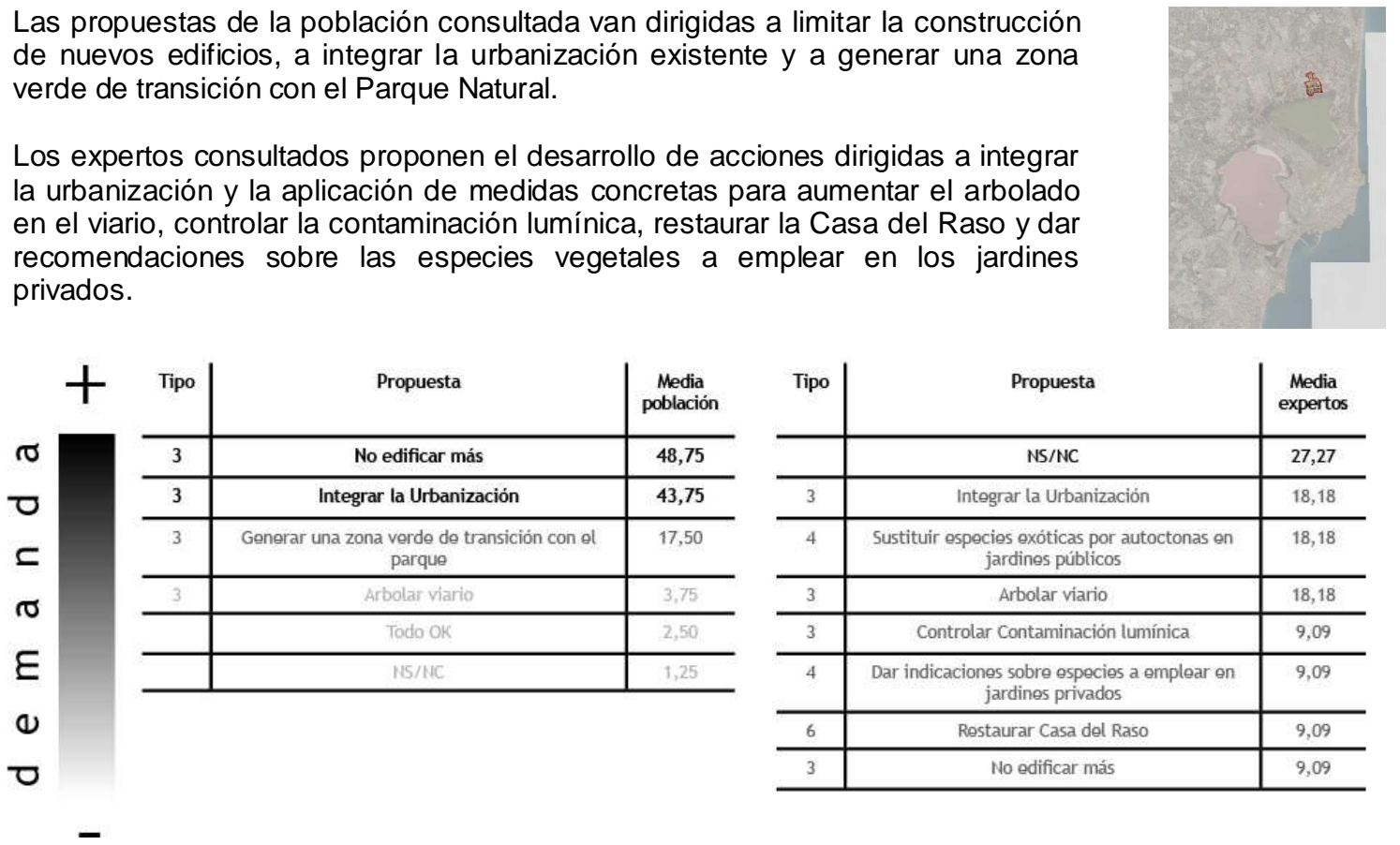

\begin{tabular}{c|c|c} 
Tipo & Propuesta & $\begin{array}{c}\text { Media } \\
\text { expertos }\end{array}$ \\
\hline & NS/NC & 27,27 \\
\hline 3 & Integrar la Urbanización & 18,18 \\
\hline 4 & $\begin{array}{c}\text { Sustituir especies exóticas por autoctonas en } \\
\text { jardines públicos }\end{array}$ & 18,18 \\
\hline 3 & Arbolar viario & 18,18 \\
\hline 3 & Controlar Contaminación lumínica & 9,09 \\
\hline 4 & Dar indicaciones sobre especies a emplear en & 9,09 \\
\hline 6 & jardines privados & 9,09 \\
\hline 3 & Restaurar Casa del Raso & 9,09 \\
\hline
\end{tabular}

\subsection{1) UP11: Urbanización Ciudad Quesada}

La población consultada manifiesta de forma mayoritaria la necesidad de evitar el crecimiento de la urbanización, de integrar la urbanización existente y de generar una zona verde de transición con el Parque Natural.

Los expertos consultados proponen el desarrollo de acciones dirigidas a integrar la urbanización y la aplicación de medidas concretas para aumentar el arbolado en el viario, controlar la contaminación lumínica y dar recomendaciones sobre las especies vegetales a emplear en los jardines privados.

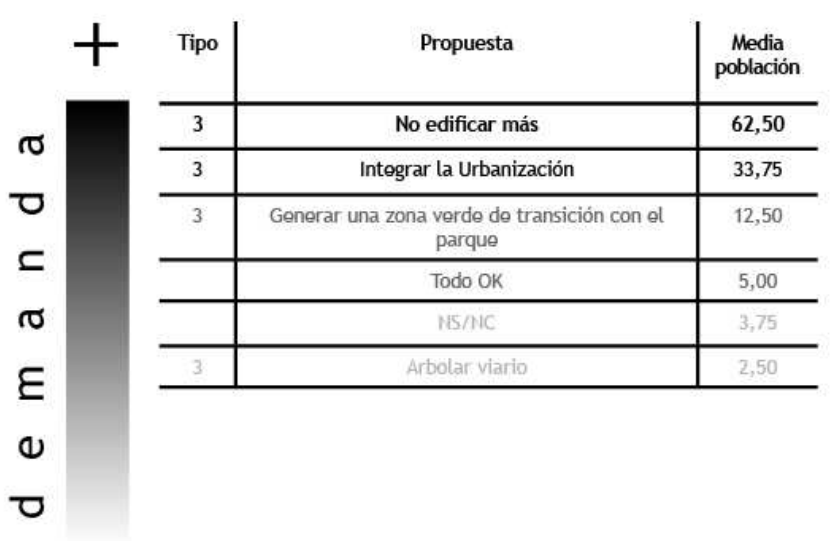

\begin{tabular}{c|c|c} 
Tipo & Propuesta & $\begin{array}{c}\text { Media } \\
\text { expertos }\end{array}$ \\
\hline 3 & Integrar la Urbanización & 27,27 \\
\hline & NS/NC & 27,27 \\
\hline & Demoler la Urbanización & 18,18 \\
\hline 4 & $\begin{array}{c}\text { Sustituir especies exóticas por autoctonas on } \\
\text { jardines públicos }\end{array}$ & 18,18 \\
\hline 3 & Arbolar viario & 18,18 \\
\hline 3 & No edificar más & 18,18 \\
\hline 3 & Controlar Contaminación luminica & 9,09 \\
\hline 4 & Dar indicaciones sobre especies a emplear en & 9,09 \\
\hline 2 & jardines privados & \\
\hline
\end{tabular}




\subsection{2) UP12: Urbanizaciones entre las lagunas de La Mata y Torrevieja}

La población consultada manifiesta de forma muy mayoritaria $(72,5 \%)$ la necesidad de evitar el crecimiento de las urbanizaciones, de integrar las existentes en el paisaje y de generar zonas verdes de transición con el Parque Natural.

Los expertos consultados proponen el desarrollo de acciones dirigidas a integrar la urbanización y la aplicación de medidas concretas para aumentar el arbolado en el viario, controlar la contaminación lumínica y dar recomendaciones sobre las especies vegetales a emplear en los jardines privados.

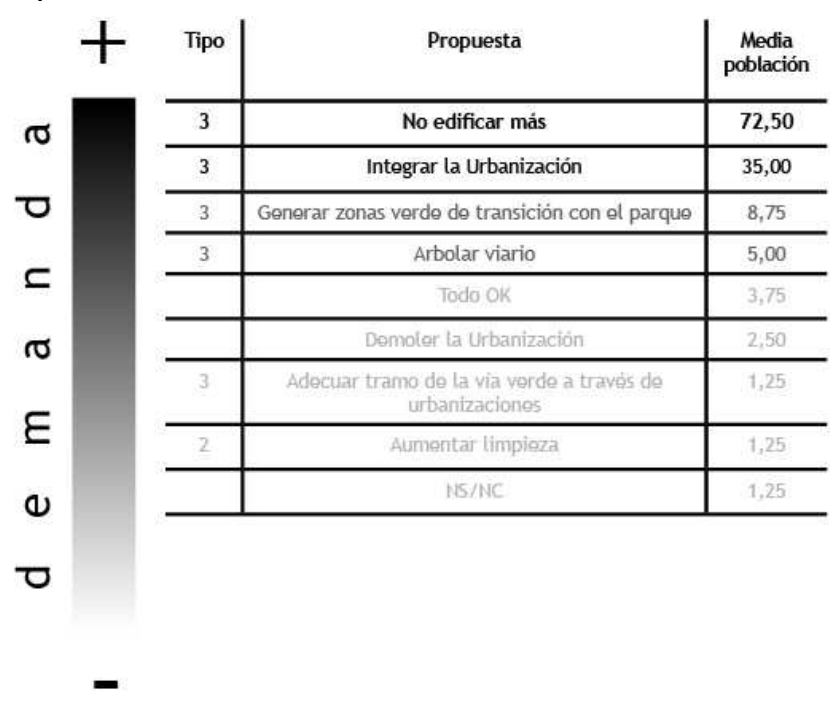

\begin{tabular}{c|c|c} 
Tipo & Propuesta & $\begin{array}{c}\text { Media } \\
\text { expertos }\end{array}$ \\
\hline & NS/NC & 27,27 \\
\hline 3 & Integrar la Urbanización & 18,18 \\
\hline & Demoler la Urbanización & 18,18 \\
\hline 4 & Sustituir especies exóticas por autoctonas en & 18,18 \\
\hline 3 & jardines públicos & \\
\hline 2 & Arbolar viario & 18,18 \\
\hline 3 & Aumentar limpieza & 18,18 \\
\hline 4 & Controlar Contaminación luminica & 9,09 \\
\hline 3 & Generar zonas verde de transición con el parque & 9,09 \\
\hline 3 & jdecuar tramo de la via verde a través de & 9,09 \\
\hline 3 & urbanizaciones & 9,09 \\
\hline & No edificar más & 9,09 \\
\hline
\end{tabular}

\subsection{3) UP13: Urbanización Los Balcones}

Las propuestas de la población consultada van dirigidas a limitar la construcción de nuevos edificios y a integrar la urbanización existente.

A diferencia de otras urbanizaciones consideradas, un porcentaje significativo de los encuestados indican que el paisaje actual de la urbanización es correcto, aspecto éste que puede estar influido por la sustancial presencia de arbolado en el viario y jardines privados.

Los expertos consultados indican la necesidad de reordenar o reubicar la edificación de la zona no urbanizada (objeto de Plan Especial de acuerdo al PORN del Parque Natural) y proponen medidas concretas como aumentar el arbolado en el viario, controlar la contaminación lumínica, dar recomendaciones sobre las especies vegetales a emplear en los jardines privados y generar una zona verde de transición con el parque.

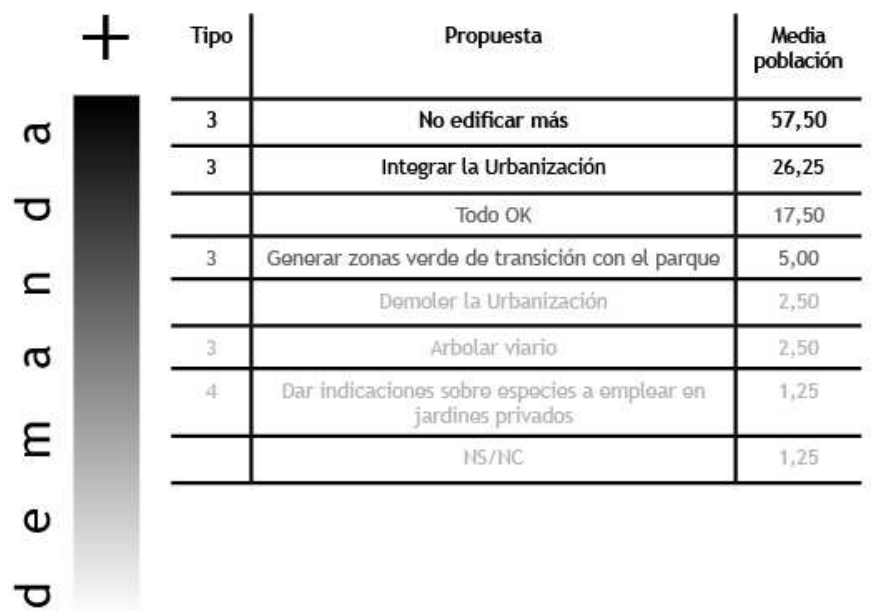

\begin{tabular}{c|c|c} 
Tipo & Propuesta & $\begin{array}{c}\text { Media } \\
\text { expertos }\end{array}$ \\
\hline & Demoler la Urbanización & 27,27 \\
\hline 3 & Arbolar viario & 27,27 \\
\hline & NS/NC & 27,27 \\
\hline 4 & Sustituir especies exóticas por autoctonas en & 18,18 \\
\hline 3 & jardines públicos & \\
\hline 3 & Integrar la Urbanización & 9,09 \\
\hline 4 & Controlar Contaminación lumínica & 9,09 \\
\hline 3 & Generar zonas verde de transición con el parque & 9,09 \\
\hline 3 & Nardines privados & 9,09 \\
\hline 2 & Aumentar la limpieza & 9,09 \\
\hline & \multicolumn{2}{|c}{}
\end{tabular}




\subsection{4) UP14: Conector Sur Laguna de Torrevieja - Mar Mediterráneo}

La población consultada encuentra que la unidad de paisaje № 14 constituye un "espacio de oportunidad" para conectar el parque natural con el mar Mediterráneo y propone la aplicación de algún tipo de protección que preserve su carácter abierto y no edificado.

A pesar de la fragmentación debida a la presencia de infraestructuras y de la imposibilidad de acceder a las fincas privadas, se indica que la unidad presenta un estado correcto.

Los expertos consultados manifiestan mayoritariamente un desconocimiento de la unidad, lo que puede explicarse por su carácter heterogéneo. El espacio es sin embargo percibido como un potencial conector entre el Parque Natural y el mar Mediterráneo y como una posible gran dotación verde para Torrevieja en una posición estratégica.

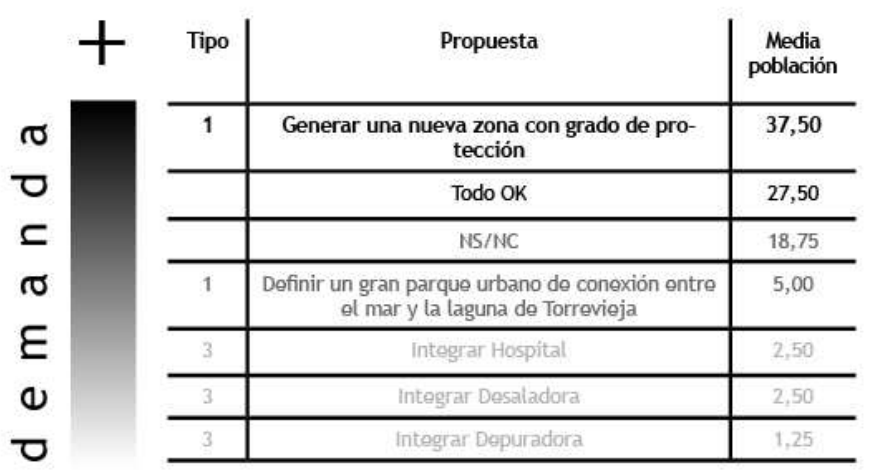

$-$

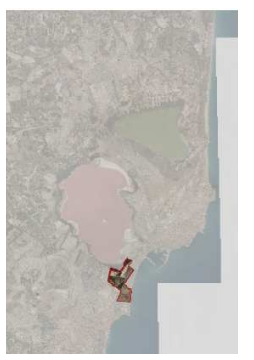

\subsection{5) UP15: Frente Litoral de Torrevieja}

Tanto la población como los expertos consultados manifiestan mayoritariamente que el estado del frente litoral de Torrevieja es satisfactorio o no realizan ninguna sugerencia. Ambos grupos sugieren la necesidad de limitar el acceso rodado en los tramos de costa mejor conservados (por ejemplo cala Ferris o las playas de roca), de no permitir nuevas edificaciones y de mejorar la limpieza de las playas. Entre los expertos se sugiere a su vez la conveniencia de mejorar los paseos marítimos antiguos, de incorporar un carril bici y de crear espacios abiertos que liberen el paseo y abran recorridos hacia el parque natural

\begin{tabular}{|c|c|c|c|}
\hline & Tipo & Propuesta & $\begin{array}{c}\text { Media } \\
\text { población }\end{array}$ \\
\hline$\sigma$ & & Todo OK & 17,50 \\
\hline & 2 & Limitar tráfico rodado en el frente litoral & 11,25 \\
\hline & 2 & Aumentar limpieza & 11,25 \\
\hline ( & 3 & No edificar más & 10,00 \\
\hline & & NS/NC & 10,00 \\
\hline & 4 & Mejorar paseos maritimos antiguos & 7,50 \\
\hline 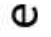 & 2 & Facilitar acceso a playas de roca & 1,25 \\
\hline & 2 & Inoorporar carril bici & 1,25 \\
\hline
\end{tabular}

\begin{tabular}{c|c|c} 
Tipo & Propuesta & $\begin{array}{c}\text { Media } \\
\text { expertos }\end{array}$ \\
\hline & NS/NC & 45,45 \\
\hline & Todo OK & 18,18 \\
\hline 2 & Limitar tráfico rodado en el frente litoral & 18,18 \\
\hline 4 & Mejorar paseos maritimos antiguos & 9,09 \\
\hline 2 & Incorporar carril bici & 9,09 \\
\hline 1 & $\begin{array}{c}\text { Crear espacios libres que liberen el paseo y } \\
\text { abran recorridos hacia ol parque }\end{array}$ & 9,09 \\
\hline
\end{tabular}




\subsection{6) UP15: Casco Urbano de Torrevieja}

La población consultada sugiere fundamentalmente medidas para disminuir el tráfico rodado en el casco urbano de Torrevieja y el aumento de las plazas de aparcamiento.

Estas medidas son a su vez sugeridas por los expertos encuestados, si bien, en este último grupo se sugieren acciones adicionales como aumentar el arbolado viario, generar una red urbana de carriles bici, limitar el tránsito rodado en algunas zonas del centro urbano o generar un frente arbolado entre el casco urbano y el parque natural (parque lineal).
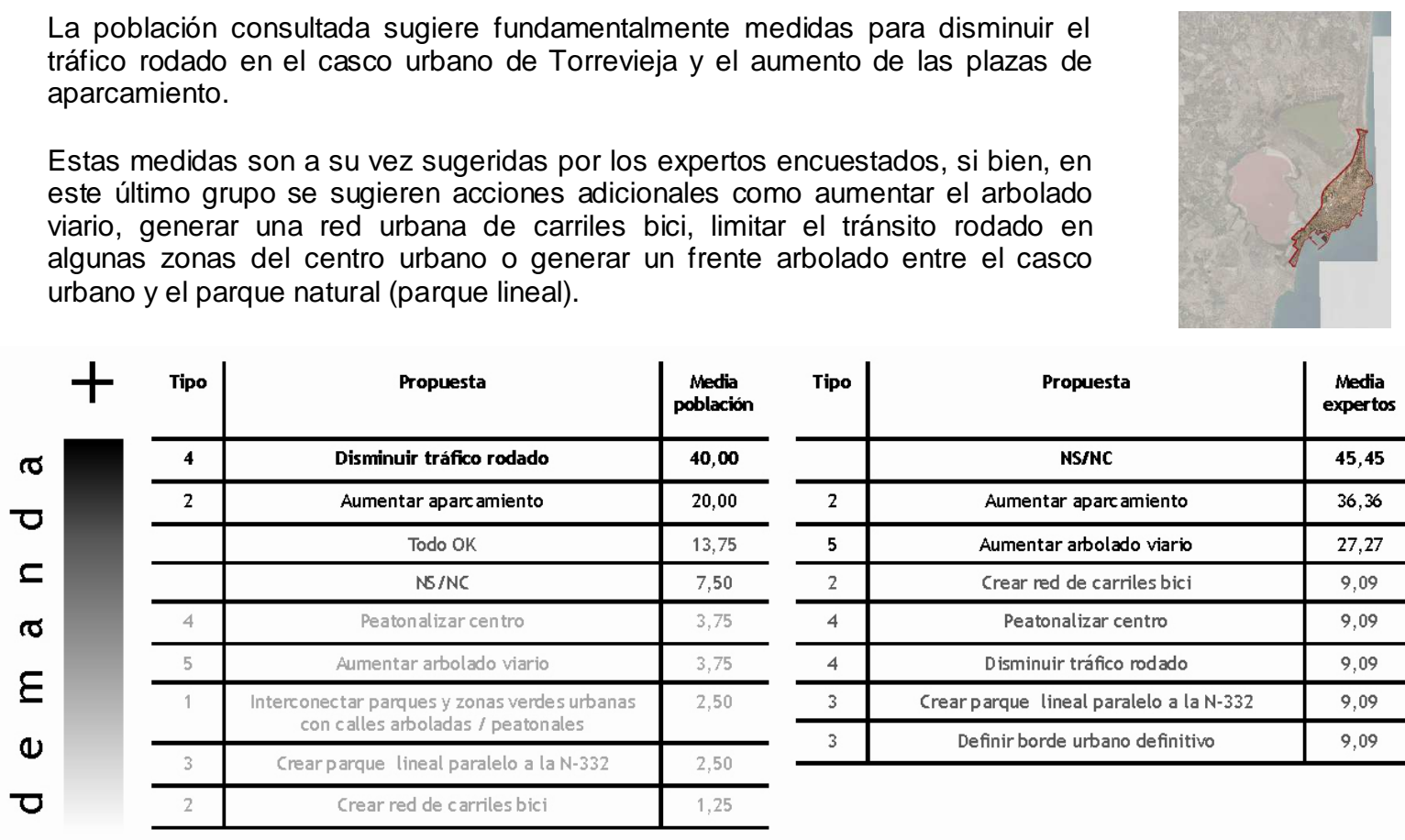

\begin{tabular}{c|c|c} 
Tipo & Propuesta & $\begin{array}{c}\text { Media } \\
\text { expertos }\end{array}$ \\
\hline & NS/NC & $\mathbf{4 5 , 4 5}$ \\
\hline 2 & Aumentar aparc amiento & 36,36 \\
\hline 5 & Aumentar arbolado viario & 27,27 \\
\hline 2 & Crear red de carriles bici & 9,09 \\
\hline 4 & Peatonalizar centro & 9,09 \\
\hline 4 & Disminuir tráfico rodado & 9,09 \\
\hline 3 & Crear parque lineal paralelo a la $\mathrm{N}-332$ & 9,09 \\
\hline 3 & Definir borde urbano definitivo & 9,09 \\
\hline
\end{tabular}

\section{2) Recursos Paisajísticos}

\section{1) Recursos Paisajísticos Ambientales}

Población y expertos coinciden en la necesidad de restaurar zonas degradadas, de potenciar la rambla de La Fayona y de mejorar las playas de arena y los sistemas dunares existentes.

En el caso de la población se incide de forma mayoritaria en la importancia de aumentar las pinadas y zonas forestales arboladas, mientras que en el caso de los expertos se incide de forma específica en disminuir la anchura de algunos recorridos en torno a la laguna de La Mata.

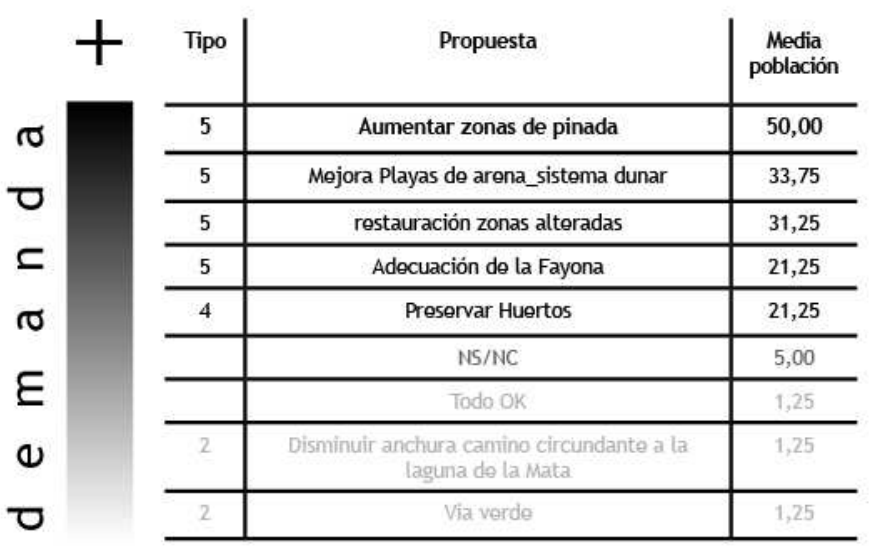

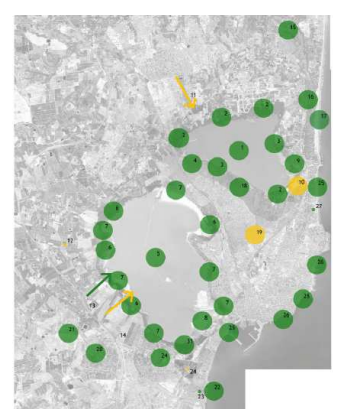

\begin{tabular}{c|c|c} 
Tipo & Propuesta & $\begin{array}{c}\text { Media } \\
\text { expertos }\end{array}$ \\
\hline 5 & restauración zonas alteradas & 36,36 \\
\hline 5 & Adecuación de la rambla de la Fayona & 27,27 \\
\hline & Todo OK & 18,18 \\
\hline 2 & Disminuir anchura camino circundante a la \\
& laguna de la Mata & 18,18 \\
\hline 5 & Mejora Playas de arena_sistema dunar & 9,09 \\
\hline & $8,12,13,15$ & 9,09 \\
\hline & $11,14,16$ & 9,09 \\
\hline
\end{tabular}




\section{2) Recursos Paisajísticos Culturales}

Tanto la población como los expertos consultados manifiestan mayoritariamente la necesidad de restaurar el patrimonio arquitectónico y de restaurar los canales de La Mata, de las Salinas y el Acequión de Torrevieja.

En menor grado, ambos grupos sugieren el mantenimiento de las infraestructuras de riego y aljibes. La población encuestada sugiere la adecuación de la Vía Verde y los expertos inciden en la importancia de restaurar la Casa de Máquinas.

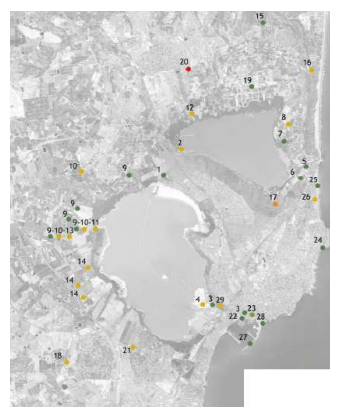

\begin{tabular}{|c|c|c|c|}
\hline & Tipo & Propuesta & $\begin{array}{c}\text { Media } \\
\text { población }\end{array}$ \\
\hline$\sigma$ & 6 & Restaurar patrimonio arquitectónico & 76,25 \\
\hline 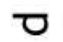 & \multirow[t]{2}{*}{6} & Restaurar canales & 21,25 \\
\hline$\subset$ & & NS/NC & 15,00 \\
\hline & 4 & Adecuar la vía verde & 12,50 \\
\hline & \multirow[t]{4}{*}{6} & Mantener infraestructuras de riego y aljibes & 8,75 \\
\hline & & playas & 2,50 \\
\hline U & & Proservar actividad agricola & 2,50 \\
\hline & & torre del Moro & 1,25 \\
\hline
\end{tabular}

\begin{tabular}{c|c|c} 
Tipo & Propuesta & $\begin{array}{c}\text { Media } \\
\text { expertos }\end{array}$ \\
\hline 6 & Restaurar patrimonio arquitectónico & 54,55 \\
\hline 6 & Restaurar canales & 27,27 \\
\hline 6 & Casa de la Maquina & 18,18 \\
\hline 6 & Mantener infraestructuras de riego y aljibes & 9,09 \\
\hline
\end{tabular}

\section{3) Recursos Paisajísticos Visuales}

Las propuestas de la población y expertos consultados se dirigen principalmente hacia la mejora de las vistas desde las carreteras y a la mejora de las señalizaciones. En este apartado se observa un bajo nivel de respuestas, consecuencia probablemente del carácter a menudo más indefinido de los recursos paisajísticos visuales.

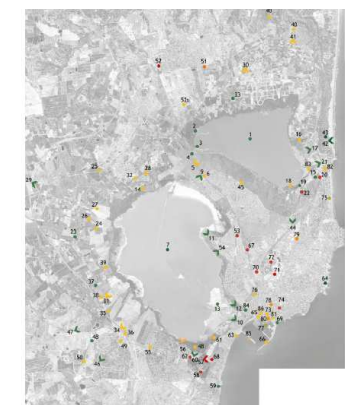

\begin{tabular}{|c|c|c|}
\hline 十 & Propuesta & $\begin{array}{c}\text { Media } \\
\text { población }\end{array}$ \\
\hline \multirow[t]{2}{*}{3} & Mejorar vistas desdo carreteras & 21,25 \\
\hline & NS/NC & 12,50 \\
\hline 3 & Mejorar vistas desdo Via verde_senderos & 11,25 \\
\hline 3 & Mejorar vistas desde urbanizaciones & 10,00 \\
\hline 2 & Mejorar señalización & 3,75 \\
\hline 3 & Mejorar vistas desde cv905 & 3,75 \\
\hline 4 & Poteger y mantener playas & 3,75 \\
\hline 5 & Aumentar pinadas & 2,50 \\
\hline & Todo OK & 1,25 \\
\hline 4 & Preservar huertos & 1,25 \\
\hline 2 & Crear milradores & 1,25 \\
\hline
\end{tabular}

\begin{tabular}{c|c|c} 
Tipo & Propuesta & $\begin{array}{c}\text { Media } \\
\text { expertos }\end{array}$ \\
\hline 2 & Mejorar señalización & 27,27 \\
\hline & NS/NC & 27,27 \\
\hline 3 & Mejorar vistas desde carreteras & 9,09 \\
\hline
\end{tabular}




\section{4.g.4: Objetivos de Calidad Paisajística:}

\section{4.g.4.1. Introducción}

El desarrollo del presente Estudio en el Parque Natural de La Mata - Torrevieja implica que la mayor parte de la superficie considerada en el ámbito estricto tiene ya otorgado un grado máximo de protección ambiental, lo que sugiere, que el objetivo de calidad paisajística predominante será el de "protección del paisaje", al que sin embargo podrán añadirse objetivos de "gestión", fundamentalmente en áreas agrícolas y salineras o de "ordenación" en zonas con baja calidad del paisaje o con conflictos paisajísticos severos.

\section{4.g.4.2. Objetivos de calidad paisajística para las unidades de paisaje en el ámbito estricto del estudio UP1: LAGUNA DE LA MATA \\ Genéricos:}

Específicos:

Protección

- $\quad$ Preservar y mejorar los recursos ecológicos y medioambientales.

- Restaurar el patrimonio arqueológico y arquitectónico e integrarlo en recorridos visitables.

- $\quad$ Establecer conectores sin interferencias con el tráfico rodado con la laguna de Torrevieja.

- Desarrollar un recorrido peatonal-ciclista completo en torno a la laguna de La Mata.

- Minimizar la intrusión de las urbanizaciones colindantes.

- Minimizar la intrusión acústica de las infraestructuras de transporte colindantes (CV-905).

\section{UP2: LAGUNA DE TORREVIEJA}

\section{Genéricos:}

Protección estricta de zonas naturales

- Ordenación (de área de interés especial industria salinera (zona situada entre salinas y carretera N332), de zona de depósitos de lodos salineros y de zona edificada en la Punta de la Específicos: Víbora)

- $\quad$ Preservar y mejorar los recursos ecológicos y medioambientales.

- Restaurar el patrimonio arqueológico y arquitectónico e integrarlo en recorridos visitables.

- $\quad$ Establecer conectores sin interferencias con el tráfico rodado con la laguna de La Mata.

- Desarrollar un recorrido peatonal-ciclista completo en torno a la laguna de Torrevieja.

- Minimizar la intrusión de las urbanizaciones colindantes.

- Minimizar la intrusión acústica de las infraestructuras de transporte colindantes (N332, CV905).

\section{UP3: VIÑEDOS Y SECANOS DE LA MATA}

Genéricos:

\section{Específicos:}

Protección

Gestión

- $\quad$ Preservar y potenciar el paisaje tradicional de viñedos.

- $\quad$ Establecer un encuentro visual adecuado con la carretera N332.

- Restaurar el patrimonio arquitectónico, vincularlo a recorridos y asignarle nuevos usos compatibles con la normativa del parque natural.

- Generar actividades y servicios vinculados a la actividad agrícola, compatibles con la normativa del Parque Natural y que den uso, en la medida de lo posible, a las edificaciones existentes a restaurar.

\section{UP4: HUERTOS TRADICIONALES DE LA MATA Y TORREVIEJA}

Genéricos:

Específicos:

$$
\text { Protección }
$$

Gestión

- Preservar y potenciar el paisaje tradicional de huertas y cítricos

- Integrar tramos de un recorrido escénico rodado ciclista en torno a las lagunas

- Integrar tramos de un recorrido escénico peatonal ciclista en torno a las lagunas

- Restaurar el patrimonio arquitectónico e hidráulico, vincularlo a recorridos y asignarle nuevos usos compatibles con la normativa del parque natural.

Generar actividades y servicios vinculados a la actividad agrícola, compatibles con la normativa del Parque Natural y que den uso, en la medida de lo posible, a las edificaciones existentes a restaurar. 


\title{
UP5: REGADÍOS EXTENSIVOS DE LA LAGUNA DE TORREVIEJA
}

Genéricos:

\section{Específicos:}

Protección

Gestión

- $\quad$ Preservar y potenciar el paisaje de huertas y cítricos

- Integrar tramos de un recorrido escénico rodado ciclista en torno a las lagunas

- Integrar tramos de un recorrido escénico peatonal ciclista en torno a las lagunas

- Restaurar el patrimonio arquitectónico e hidráulico, vincularlo a recorridos y asignarle nuevos usos compatibles con la normativa del parque natural.

- Generar actividades y servicios vinculados a la actividad agrícola, compatibles con la normativa del Parque Natural y que den uso, en la medida de lo posible, a las edificaciones existentes a restaurar.

\author{
UP6: ALTOS DE LA ATALAYA Y DEL MONCAYO \\ Genéricos: \\ - Protección \\ Gestión
}

Específicos:

- $\quad$ Preservar y potenciar el paisaje forestal de pinar existente.

- Facilitar y promover el uso de los caminos rurales que conectan el Río Segura con la laguna de La Mata.

- $\quad$ Generar un recorrido y miradores a lo largo de los puntos elevados.

\section{UP7: DUNAS DE GUARDAMAR}

\section{Genéricos:}

Específicos:

Protección

- Preservar y potenciar las pinadas litorales y dunas de Guardamar.

- $\quad$ Establecer un corredor de conexión entre las dunas y la laguna de La Mata.

- $\quad$ Establecer una conexión ciclista entre Torrevieja y Guardamar.

\section{UP8: ALTO DE LA HOYA Y PINADA DEL CHAPARRAL}

\section{Genéricos:}

- Protección

- Gestión

Específicos:

$$
\text { Ordenación }
$$

- Extender las pinadas del Chaparral a las laderas del alto de las Casillas y La Hoya sin bloquear las vistas desde la Nacional 332 a la laguna de la Mata.

- Crear un corredor verde de conexión entre las algunas de La Mata y Torrevieja mediante la extensión de las pinadas del Chaparral a la cuña no urbanizable situada entre la urbanización del Chaparral y la zona urbanizable al sur del hospital de San Jaime

- Crear una zona verde de carácter natural y agrícola entre el Parque Natural y la zona urbanizable al sur del Hospital San Jaime

Reducir las redes de recorridos en las laderas del alto de la Hoya.

- $\quad$ Mejorar la calidad visual del entorno inmediato de la nacional N332.

\section{UP9: CONECTOR DE LA RAMBLA DE LA FAYONA}

Genéricos:

$$
\text { Protección }
$$

Gestión

\section{Específicos:}

Definir y proteger un corredor agrícola forestal entre las ramblas de la Fayona y Garbanzuelo .

- $\quad$ Potenciar la vegetación de carácter natural en las ramblas de la Fayona y Garbanzuelo y en sus bandas laterales.

- Definir sendos recorridos peatonales apoyados en las ramblas de la Fayona y Garbanzuelo y mejorar los cruces con las carreteras AP7, CV 95 y CV943 (La Fayona) y con la carretera CV95 y AP7 (Garbanzuelo).

- $\quad$ Definir recorridos peatonales-ecuestres y un mirador en el Alto de las Majadas.

- $\quad$ Restaurar y asignar usos a la Casa de las Majadas y a la Casa del Garbanzuelo. 


\section{UP10: URBANIZACIÓN EL RASO}

\section{Genéricos:}

\section{Específicos:}

Gestión

Ordenación

- Tratar los bordes de la urbanización del Raso con el entorno agrícola y el Parque Natural (zona verde de transición).

- $\quad$ Sustituir en las zonas ajardinadas públicas la vegetación exótica por vegetación autóctona

- Aumentar la presencia de arbolado en las calles de la urbanización, considerando para ello la modificación de la sección del viario y los sentidos de circulación.

Potenciar el uso de vegetación autóctona en jardines privados.

\section{UP11: URBANIZACIÓN CIUDAD QUESADA}

Genéricos:

Específicos:

Gestión

Ordenación

Tratar los bordes de la urbanización Ciudad Quesada con el entorno agrícola y el Parque Natural (zona verde de transición).

- Sustituir en las zonas ajardinadas públicas la vegetación exótica por vegetación autóctona.

- Aumentar la presencia de arbolado en las calles de la urbanización, considerando para ello la modificación de la sección del viario y los sentidos de circulación.

- Potenciar el uso de vegetación autóctona en jardines privados.

UP12: URBANIZACIONES ENTRE LAS LAGUNAS DE LA MATA Y TORREVIEJA

Genéricos:

Específicos:

Gestión

Ordenación

- Tratar los bordes de las urbanizaciones La Siesta, El Chaparral, San Luis, El Limonar y La Torreta III con la carretera CV905 y el Parque Natural.

Reforzar la traza de la Vía Verde a través de la Urbanización Torreta III como zona verde con un carácter natural.

Aumentar la presencia de arbolado en las calles de la urbanización, considerando para ello la modificación de la sección del viario y los sentidos de circulación.

Potenciar el uso de vegetación autóctona en jardines privados.

- Controlar los accesos al parque desde las urbanizaciones (vallas acompañadas de barreras arbustivas).

\section{UP13: URBANIZACIÓN LOS BALCONES}

Genéricos:

Específicos:

Gestión

Ordenación

- $\quad$ Tratar los bordes de la urbanización Los Balcones con el entorno agrícola y el Parque Natural (zona verde de transición).

Sustituir en las zonas ajardinadas públicas la vegetación exótica por vegetación autóctona

- Aumentar la presencia de arbolado en las calles de la urbanización, considerando para ello la modificación de la sección del viario, los sentidos de circulación y las posibilidades de ambas medidas para erarquizar el viario de la urbanización y su legibilidad.

Potenciar el uso de vegetación autóctona en jardines privados.

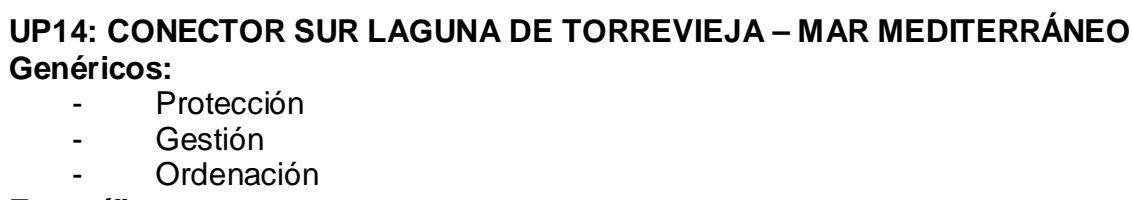

Específicos:

Definir un parque agrícola - forestal entre la laguna de Torrevieja y la Playa del Rocío - Cala Ferris que permita conseguir los siguientes tres fines: (1) facilitar la integración de las grandes dotaciones públicas incluidas en la unidad (EDAR, Hospital, Cementerio y desaladora), (2) Definir un conector y recorridos peatonales ciclistas entre la laguna de Torrevieja y la Playa del Rocío - Cala Ferris, (3) Generar un espacio de alta calidad paisajística en el acceso sur a Torrevieja y en el cruce de las carreteras N332 y CV905. 
- $\quad$ Definir un recorrido que se inserte en el anillo peatonal entorno a la laguna de Torrevieja y que discurra entre el parque natural y la banda edificada / agrícola constituida por la depuradora, cementerio, desaladora, hospital de Torrevieja y campos de naranjos.

- Adecuar paisajísticamente el espacio entre la carretera N332, la depuradora de aguas residuales y la planta desaladora.

- $\quad$ Preservar la actividad agrícola en la unidad (cítricos)

- Facilitar el uso adecuado de las playas del Rocío y Cala Ferris.

\author{
UP15: CASCO URBANO Y FRENTE LITORAL DE TORREVIEJA \\ Genéricos: \\ - Protección \\ - Gestión \\ Ordenación
}

Específicos:

- Adecuar paisajísticamente el espacio entre la carretera N332 y el frente urbano de Torrevieja (todo el tramo al este de la carretera y el tramo de la unidad de paisaje al oeste de la misma (zona de Urbanización La Torreta y Zona Comercial)).

- Potenciar las conexiones transversales entre el frente litoral y el Parque Natural mediante las actuaciones siguientes: (1) Recuperación del canal de la Mata y vinculación a un espacio verde lineal o (2) Potenciación del eje definido por el Acequión de Torrevieja y redefinición de las zonas verdes asociadas a éste. (3) Creación de conexiones peatonales-ciclistas entre el Parque Natural y el Casco Urbano de Torrevieja y coordinación de las mismas con la zona deportiva, comercial y principales áreas verdes de Torrevieja.

\title{
5.4.h. Sistema de espacios abiertos
}

\section{4.h.1. Definición}

De acuerdo a la metodología propuesta en la presente tesis y al Reglamento de Paisaje de la Comunidad Valenciana, el sistema de espacios abiertos del ámbito estricto del presente estudio recoge "el conjunto integrado y continuo de espacios en general libres de edificación, de interés medioambiental, cultural, visual, recreativo y las conexiones ecológicas y funcionales que los relacionan entre sí".

Tal y como se expone en el plano adjunto, dicho sistema de espacios abiertos se extiende sobre una superficie de 8.593,23 hectáreas e incorpora los espacios de valor paisajístico alto o muy alto, el frente litoral, tanto urbanizado como no urbanizado, así como las conexiones del Parque Natural con el mar Mediterráneo y con otros espacios ambientales estratégicos próximos, aspecto este último, en el que ha sido esencial considerar la propuesta de sistema de espacios abiertos de carácter regional desarrollada para el ámbito ampliado del presente estudio.

El sistema de espacios abiertos así definido tiene en consecuencia una lectura y función a varias escalas, desarrollando en más detalle el sistema de espacios abiertos del sur de Alicante y ofreciendo la posibilidad de orientar y apoyar la definición de los respectivos sistemas de los 5 municipios afectados por el PORN del Parque Natural. 


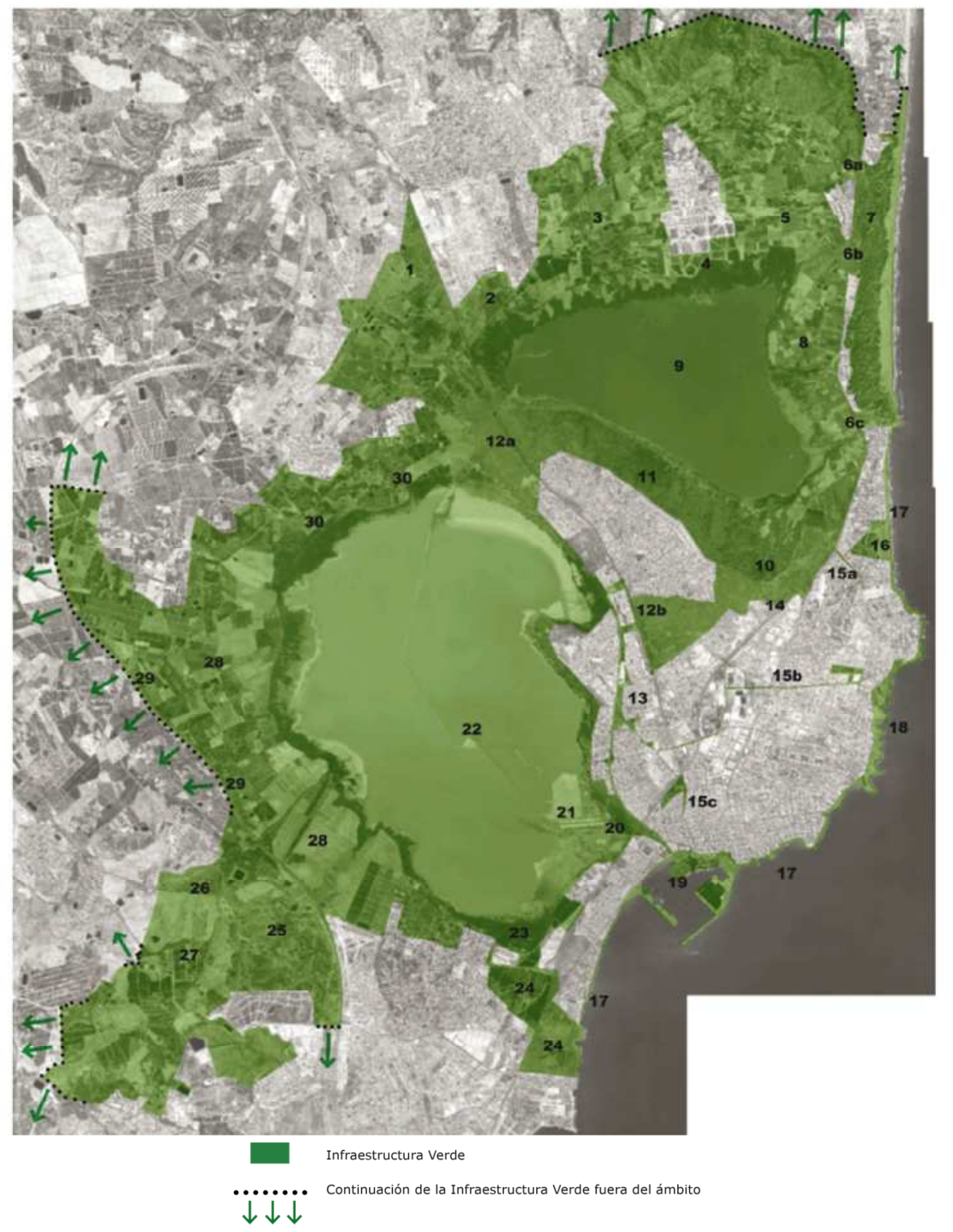

$\dddot{\downarrow} \downarrow \downarrow$

Huertos Vía verde - Ciudad Quesada
Zona verde Lo Marabú
Huertos de EI Raso
Zona verde El Raso
Huertos Campico de Guardamar
Conector norte Dunas de Guardamar-Laguas de la Mata
Conector centro Dunas de Guardamar-Laguna de la Mata
Conector Canal de la Mata
Dunas de Guardamar
Viñedos de La Mata
Laguna, marjales y saladares de La Mata
Alto de la Hoya
Pinada El Chaparral
Conector oeste Interlagunar
Conector Este Interlagunar
Vía verde
Conector Alto Casillas-Alto de la Hoya
Conector urbano Torrevieja Norte

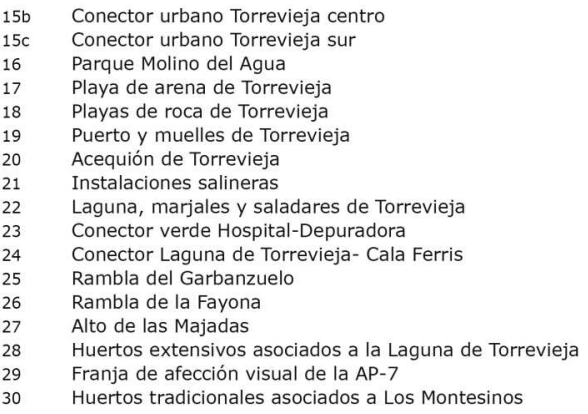

Fig. 5.36: Sistema de Espacios Abiertos (o Infraestructura Verde) del ámbito estricto (escala aproximada 1:100.000)

\section{4.h.2. Diagnóstico del Sistema de Espacios Abiertos (Ámbito Estricto del Estudio)}

Se procede a continuación a valorar las consecuencias territoriales, paisajísticas y socio-económicas del Sistema de espacios abiertos, considerando para ello distintas variables: 
VALORACIÓN Y GESTIÓN DEL PAISAJE SEGÚN EL CONVENIO EUROPEO DEL PAISAJE YEL

REGLAMENTO DEL PAISAJE DE LA COMUNIDAD VALENCIANA: APLICACIÓN MEDIANTE UN ESTUDIO DE PAISAJE A UNESPACIO ABIERTO EN LA COMUNIDAD VALENCIANA

DOCTORANDO: JUAN JOSÉ GALÁN VIVAS (Universidad Politécnica de Valencia, enero 2011)

a) Diagnóstico respecto a la diversidad de Paisajes: El sistema de espacios abiertos incluye zonas situadas en la totalidad de unidades de paisaje contempladas en el ámbito estricto, bien como consecuencia de su valor intrínseco o bien por su función conectora, de transición o de penetración en espacios urbanizados:

Tabla 5.31: Superficie y porcentaje de las distintas unidades de paisaje en el sistema de espacios abiertos del ámbito estricto.

\begin{tabular}{c|r|r} 
Unidad de Paisaje & $\begin{array}{c}\text { Superficie en el Sistema de } \\
\text { Espacios Abiertos (has) }\end{array}$ & $\begin{array}{c}\text { Porcentaje en el Sistema de } \\
\text { Espacios Abiertos (\%) }\end{array}$ \\
\hline UP01 & $1.087,00$ & 12,65 \\
\hline UP02 & $2.348,00$ & 27,32 \\
\hline UP03 & 309,00 & 3,60 \\
\hline UP04 & $1.458,00$ & 16,97 \\
\hline UP05 & 802,70 & 9,34 \\
\hline UP06 & 333,50 & 3,88 \\
\hline UP07 & 227,00 & 2,64 \\
\hline UP08 & 409,40 & 4,76 \\
\hline UP10 & 28,35 & 0,33 \\
\hline UP11 & 6,68 & 0,08 \\
\hline UP12 & 39,47 & 0,46 \\
\hline UP13 & 52,23 & 0,61 \\
\hline UP14 & 148,20 & 1,72 \\
\hline RET0 & $1.343,70$ & 15,64 \\
\hline
\end{tabular}

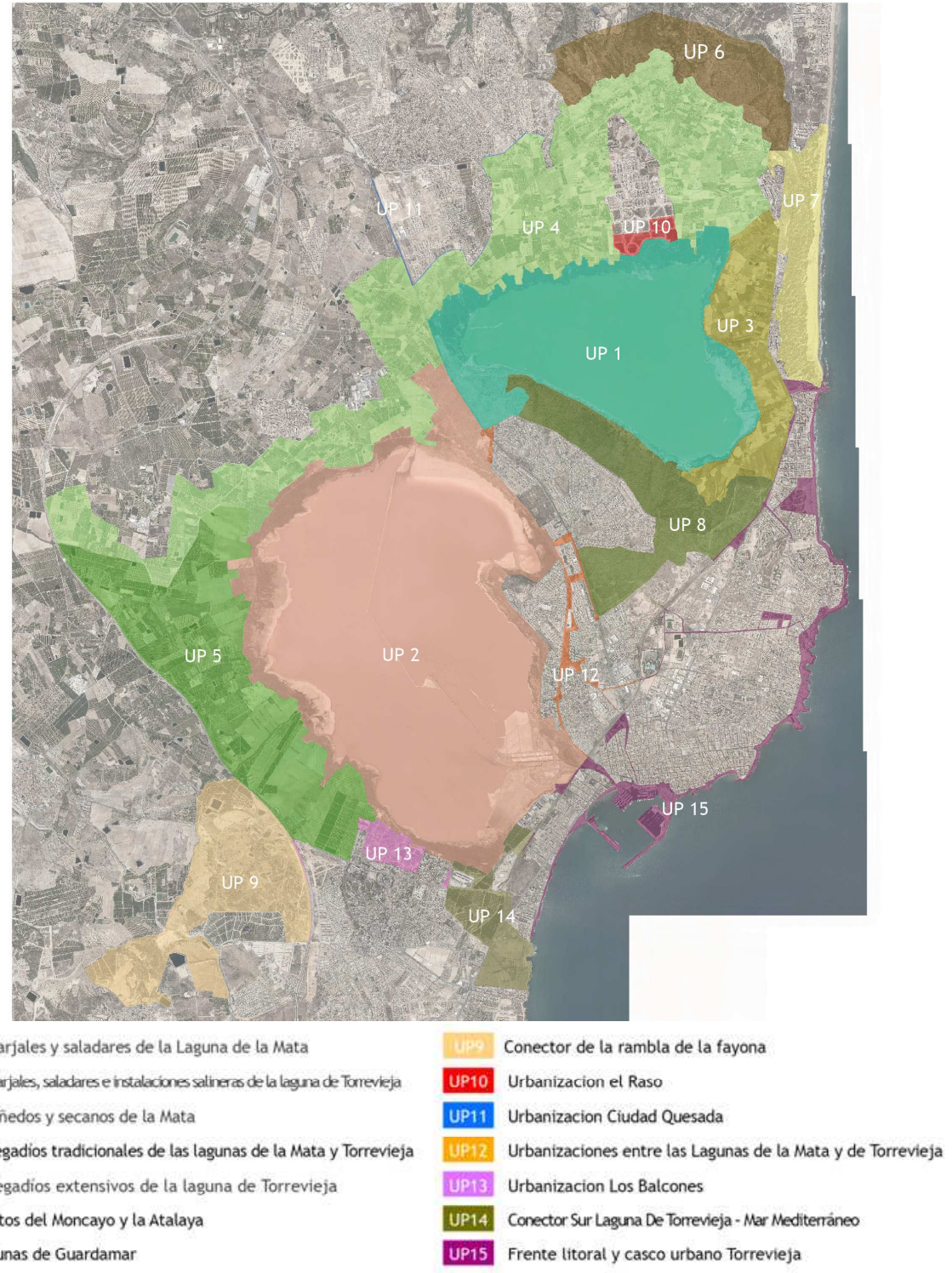

Fig. 5.37: Intersección del sistema de espacios abiertos con las unidades de paisaje del ámbito estricto (escala aproximada 1:125.000) 
b) Diagnóstico respecto a los usos del suelo: El plano y tabla siguientes recogen las áreas destinadas a los distintos usos del suelo que se localizan dentro de la sistema de espacios abiertos del Parque Natural y de su entorno, poniendo de manifiesto el carácter productivo de una porcentaje muy sustancial de dicho sistema y la necesidad de realizar consideraciones de tipo económico y productivo en cualquier acción dirigida a proteger, gestionar o modificar sus paisajes.

Tabla 5.32: Superficie y porcentaje de los distintos usos del suelo en el sistema de espacios abiertos del ámbito estricto.

\begin{tabular}{l|c|c} 
Uso del suelo & $\begin{array}{c}\text { Superficie en el Sistema de } \\
\text { Espacios Abiertos (has) }\end{array}$ & $\begin{array}{c}\text { Porcentaje en el Sistema de } \\
\text { Espacios Abiertos (\%) }\end{array}$ \\
\hline bosque & 650,91 & 7,57 \\
\hline frutal de regadío & $2.035,23$ & 23,68 \\
\hline herbáceos de regadío & 988,29 & 11,50 \\
\hline invernadero & 18,71 & 0,22 \\
\hline marjal & 313,74 & 3,65 \\
\hline matorral & 679,70 & 7,91 \\
\hline playa & 92,16 & 1,07 \\
\hline sin cultivar & 414,28 & 4,82 \\
\hline viñedo & 71,93 & 0,84 \\
\hline lagunas e instalaciones salineras & $2.452,00$ & 28,53 \\
\hline saladares & 590,44 & 6,87 \\
\hline urbanizado, infraestructuras y varios & 285,81 & 3,33 \\
\hline
\end{tabular}

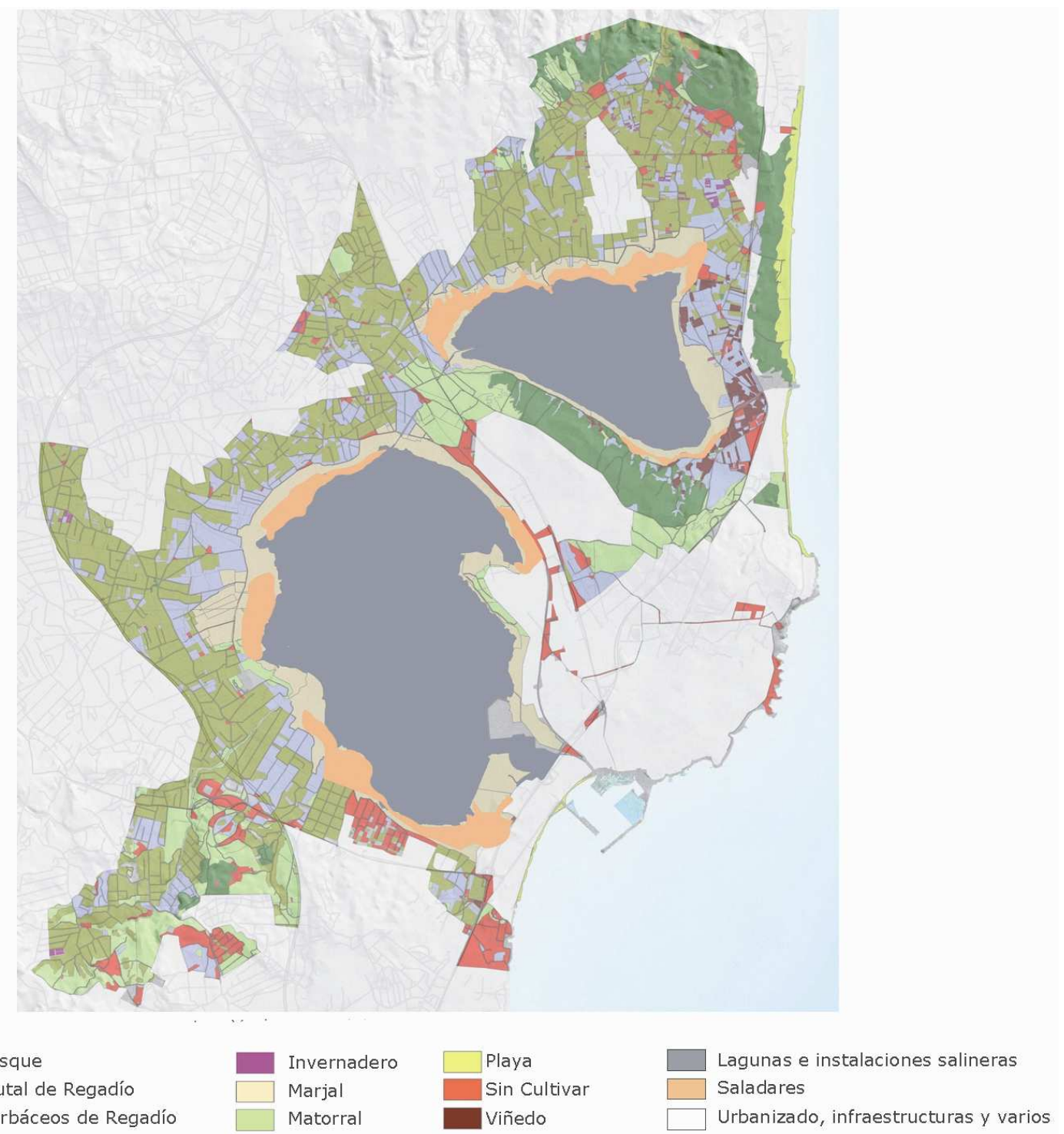

Fig. 5.38: Intersección del sistema de espacios abiertos con el plano de usos del suelo del ámbito estricto (escala aproximada 1:125.000) 
c) Diagnóstico respecto a la clasificación urbanística: El sistema de espacios abiertos propuesto se extiende por suelo urbano (en el que incorpora las principales zonas verdes urbanas y se proponen espacios y viales de conexión), urbanizable (en el que pretende orientar la posición y carácter de las futuras zonas verdes) y en suelo no urbanizable, suelo este último que incluye áreas de uso agrícola, salinero o zonas naturales. Obviamente, dadas las características particulares del ámbito del estudio, el área protegida del Parque Natural constituye el elemento principal del sistema de espacios abiertos (el $33 \%$ corresponde al ámbito del Parque y el $21 \%$ a su zona de amortiguación).

Tabla 5.33: Superficie y porcentaje de las distintas clases de suelo en el sistema de espacios abiertos del ámbito estricto.

\begin{tabular}{l|c|c} 
Clasificación del Suelo & $\begin{array}{c}\text { Superficie en el Sistema de } \\
\text { Espacios Abiertos (has) }\end{array}$ & $\begin{array}{c}\text { Porcentaje en el Sistema de } \\
\text { Espacios Abiertos }\end{array}$ \\
\hline Suelo urbano & 91,16 & 1,06 \\
\hline Suelo Urbanizable & 395,49 & 4,60 \\
\hline Suelo no urbanizable & $8.106,55$ & 94,34 \\
\hline
\end{tabular}

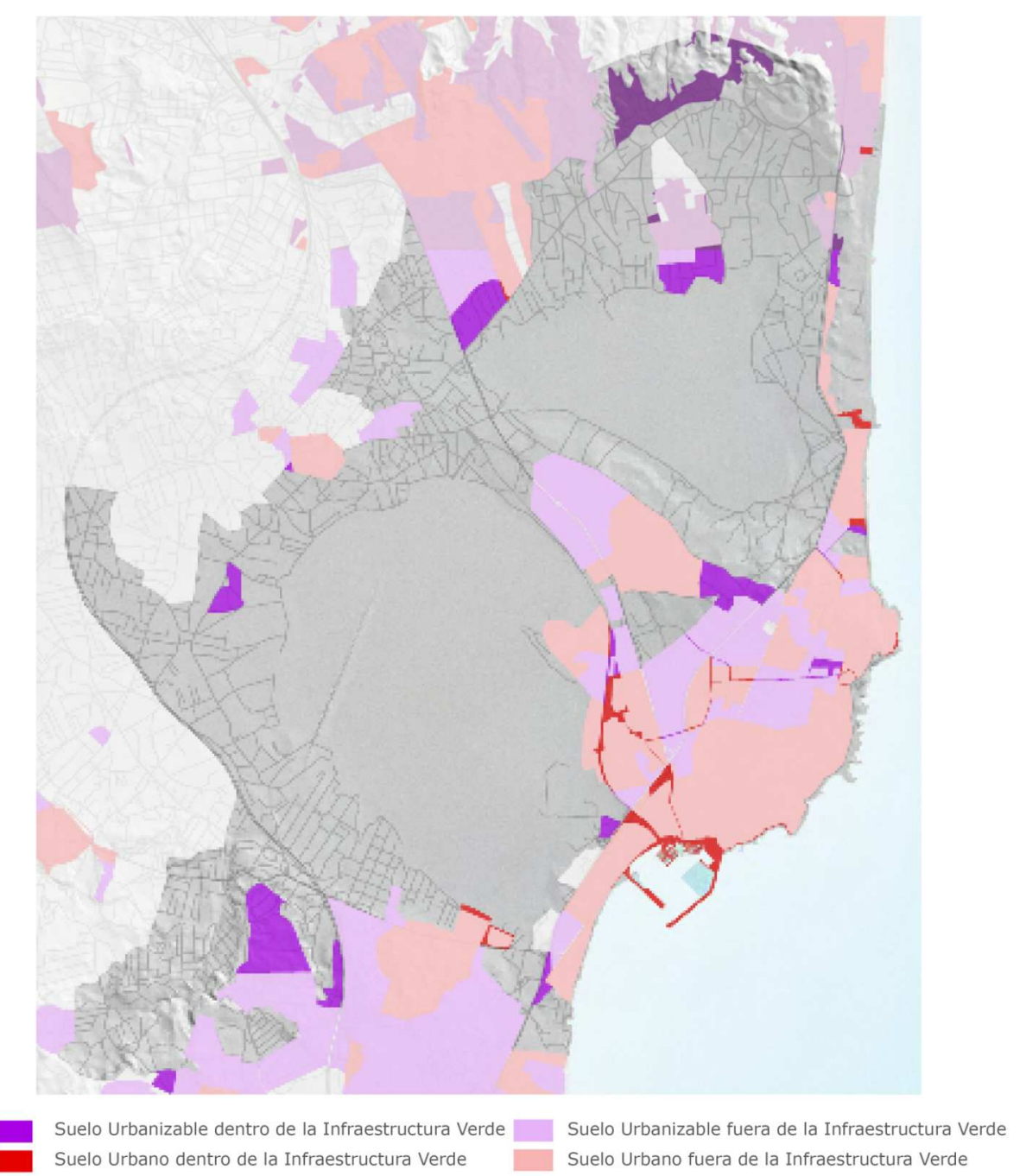

Fig. 5.39: Intersección del sistema de espacios abiertos con el plano de clasificación del suelo del ámbito estricto (escala aproximada 1:125.000) 
d) Diagnóstico respecto a la productividad del suelo: Las conclusiones del estudio económico de las actividades productivas que se desarrollan en el sistema de espacios abiertos quedan recogidas en la tabla y plano siguientes, en los que se pone de manifiesto que dicho sistema es en sí un espacio con un marcado carácter productivo y cuya preservación, gestión o transformación debe de considerar necesariamente las implicaciones económicas de las actividades que han dado lugar a los paisajes existentes o posibles.

Tabla 5.34: Superficie y productividad para las principales actividades económicas que se desarrollan sobre el sistema de espacios abiertos del ámbito estricto.

\begin{tabular}{c|r|r|r|r|r|r|r} 
Actividad & $\begin{array}{c}\text { Agricultura } \\
\text { extensiva } \\
\text { (hortícolas) }\end{array}$ & $\begin{array}{c}\text { Agricultura } \\
\text { Intensiva } \\
\text { (hortícolas) }\end{array}$ & $\begin{array}{c}\text { Agricultura } \\
\text { extensiva } \\
\text { (cítricos) }\end{array}$ & $\begin{array}{c}\text { Agricultura } \\
\text { intensiva } \\
\text { (cítricos) }\end{array}$ & $\begin{array}{c}\text { Agricultura } \\
\text { (viñedos } \\
\text { moscatel) }\end{array}$ & $\begin{array}{c}\text { Agricultura } \\
\text { (viñedos } \\
\text { merseguera) }\end{array}$ & $\begin{array}{c}\text { Salinas } \\
\text { (cifras } \\
\text { estimativas }\end{array}$ \\
\hline $\begin{array}{c}\text { Superficie } \\
\text { (has) }\end{array}$ & 342,80 & 833,63 & 1115,49 & 1165,90 & 45,13 & 19,32 & 2452,00 \\
\hline $\begin{array}{c}\text { Costes } \\
(\boldsymbol{\epsilon} / \mathbf{h a})\end{array}$ & $15.000,00$ & $19.000,00$ & 6800,00 & 7950,00 & N. D. & N. D. & 6061,21 \\
\hline $\begin{array}{c}\text { Ingresos } \\
(\boldsymbol{\epsilon} / \mathbf{h a})\end{array}$ & $30.000,00$ & $30.000,00$ & 8800,00 & 8800,00 & 2160,00 & 1600,00 & 6839,66 \\
\hline $\begin{array}{c}\text { Beneficio } \\
(\boldsymbol{\epsilon} / \text { ha) }\end{array}$ & $\mathbf{1 5 . 0 0 0 , 0 0}$ & $\mathbf{1 1 . 0 0 0 , 0 0}$ & $\mathbf{2 0 0 0 , 0 0}$ & $\mathbf{9 5 0 , 0 0}$ & N. D. & N. D. & $\mathbf{7 7 8 , 4 5}$ \\
\hline
\end{tabular}

$\left(^{*}\right)$ Fuentes de información agrícola: "Estudio técnico de-económico de los procesos de producción agrícola y de trasformación de las principales orientaciones hortofrutícolas de la Región de Murcia" (Pedro Segura, Adán García, Benjamín Costantini), AMOPA, 2006; "Informe del Sector agrícola valenciano, Generalitat Valenciana, 2006); "Costes y Precios en Hortofruticultura" (P. Caballero, M. D. De Miguel, J. F. Juliá), datos económicos viñedos facilitados por D. Eduardo Paredes, agricultor y Secretario de la Asociación de Agricultores de la Mata $\left.{ }^{\star *}\right)$ : Fuentes de información salinera: Cuentas de Resultados de la Empresa (Registro Mercantil, 2008, Madrid)

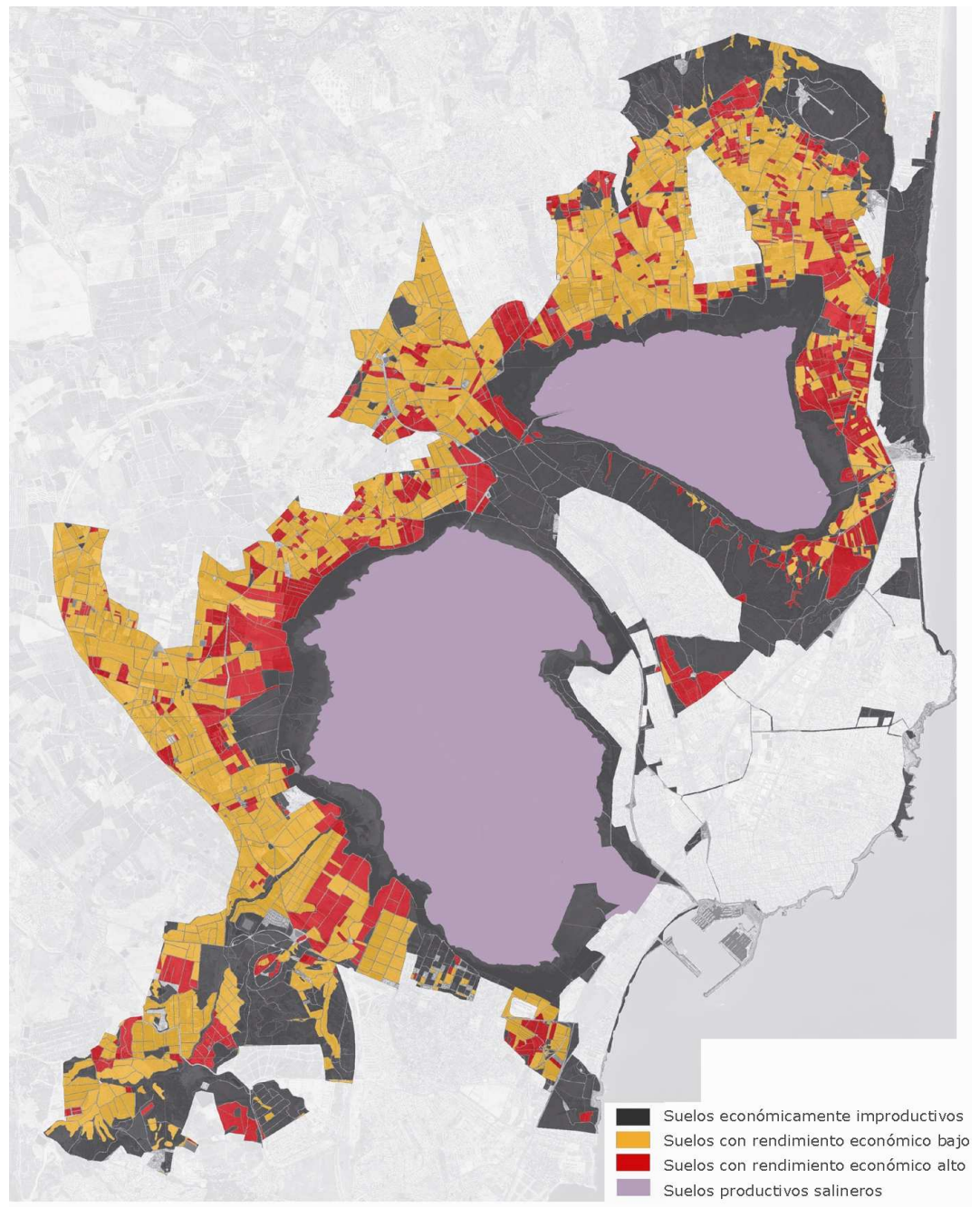

Fig. 5.40: Intersección del sistema de espacios abiertos con el plano de clasificación del suelo del ámbito estricto (escala aproximada 1:125.000) 
e) Diagnóstico respecto a los Recursos Paisajísticos: Tal y como se expone en los planos siguientes, el sistema de espacios abiertos propuesto incluye y conecta la mayor parte de los recursos paisajísticos ambientales y visuales existentes en el ámbito de estudio y en su entorno, incorporando o facilitando a su vez el adecuado acceso a muchos de los recursos paisajísticos culturales. Tal y como se explicó anteriormente, los valores paisajísticos de los recursos recogidos en los planos, fueron determinados en la fase 2 del plan de participación pública atendiendo a la opinión de expertos y de la población.

\section{Sistema de Espacios abiertos y Recursos Paisajísticos Ambientales:}

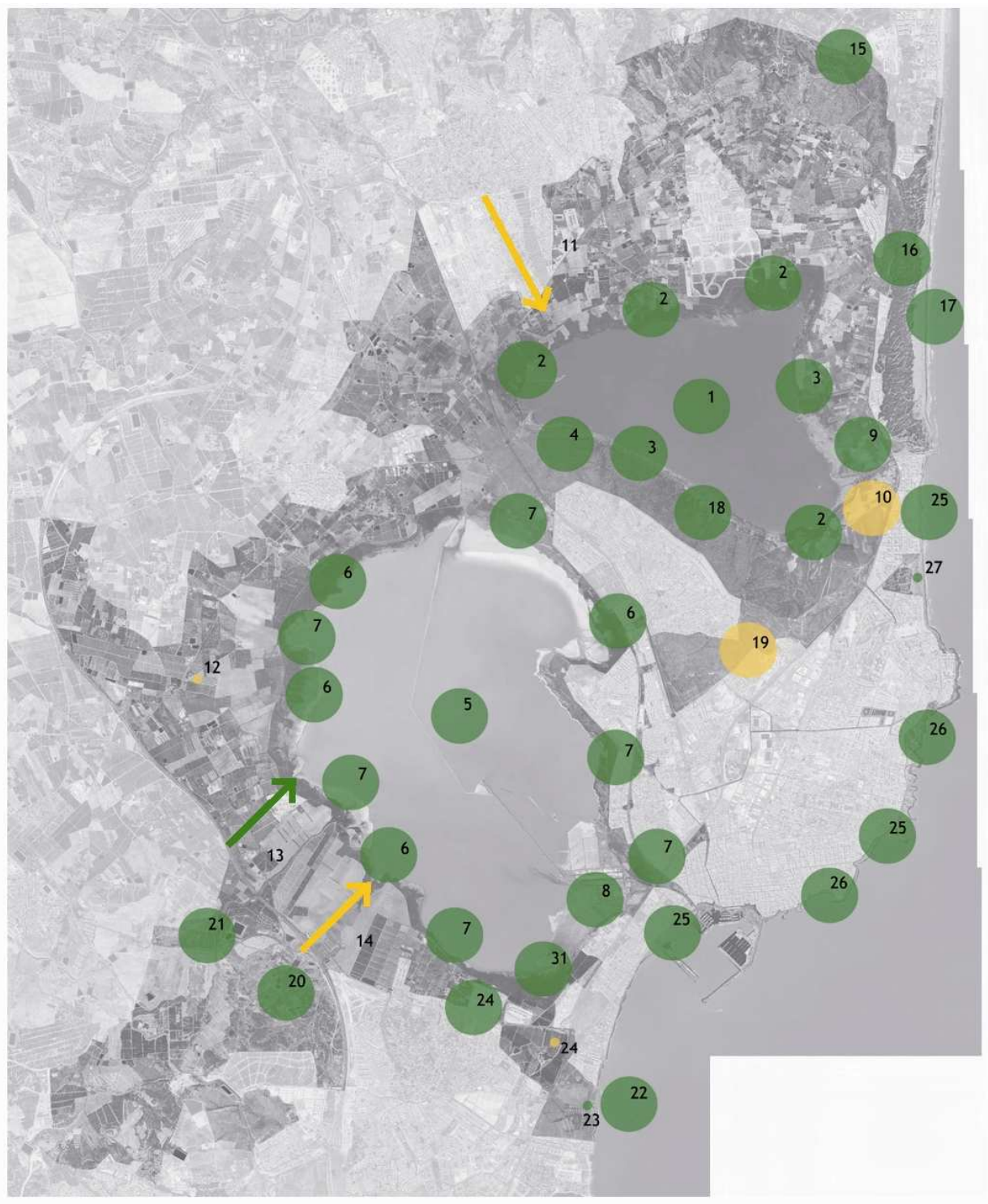

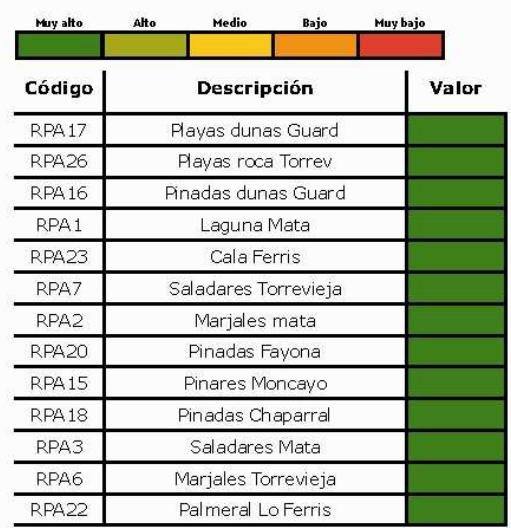

\begin{tabular}{c|c|c|}
\hline RPA8 & Cubetas salinas & \\
\hline RPA25 & Playas arena Torrev & \\
\hline RPA5 & Laguna Torrevieja & \\
\hline RPA4 & Microreserva & \\
\hline RPA9 & Viñedos de La Mata & \\
\hline RPA21 & Al mendros & \\
\hline RPA27 & Parque Molino Agua & \\
\hline RPA13 & Rambla Fayona & \\
\hline RPA24 & Arbolado La Ceñuela & \\
\hline RPA10 & Carrizales Hondo & \\
\hline RPA14 & Rambla Garbanzuelo & \\
\hline RPA19 & Pastizales La Hoya & \\
\hline RPA12 & Pinos CV943 & \\
\hline RPA11 & Rambla Marabu & \\
& &
\end{tabular}

Fig. 5.41: Intersección del sistema de espacios abiertos con los recursos paisajísticos medioambientales del ámbito estricto (escala aproximada $1: 100.0000$ 


\section{Sistema de Espacios abiertos y Recursos Paisajísticos Culturales:}

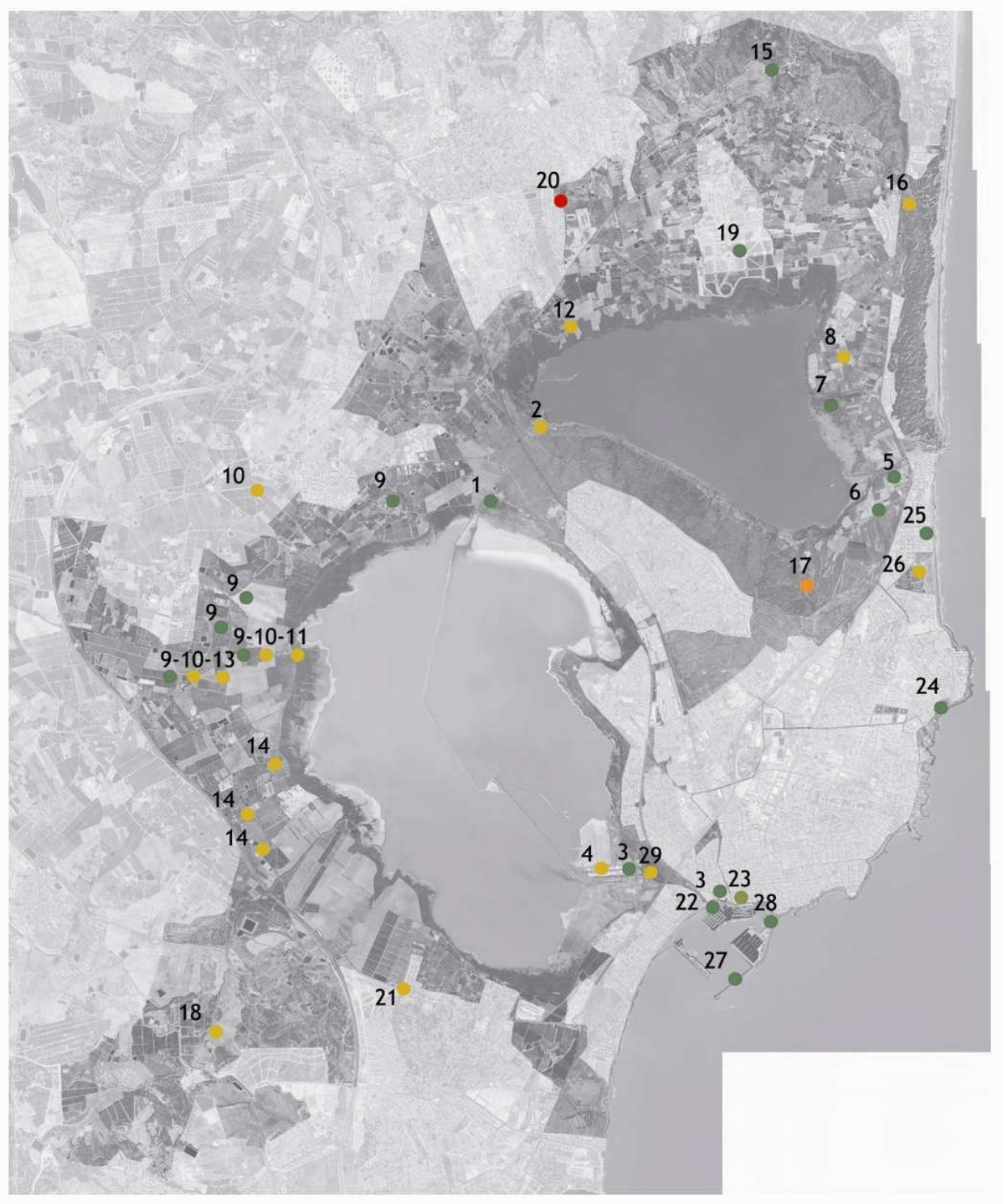

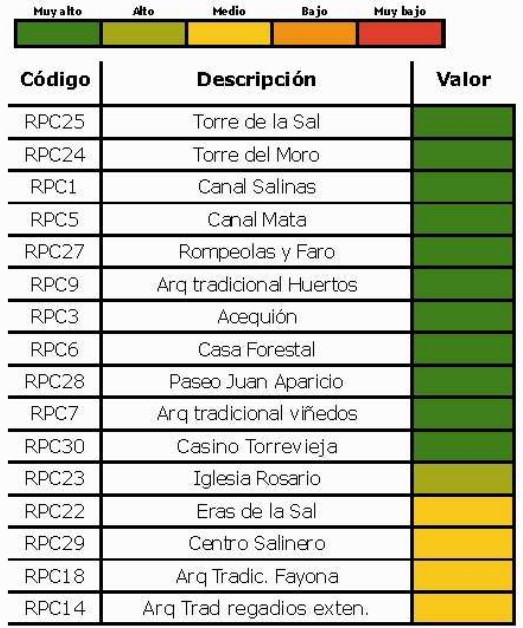

\begin{tabular}{c|c|c|}
\hline RPC21 & Casa Balcones & \\
\hline RPC2 & Arq tradicional Laguna & \\
\hline RPC12 & Tecnicas y acequias & \\
\hline RPC19 & Casa Fiasco & \\
\hline RPC26 & Parque Molino Agua & \\
\hline RPC4 & Inst. Salineras & \\
\hline RPC10 & Aljibes & \\
\hline RPC16 & Casa Peones Camineros & \\
\hline RPC8 & Siega y empacado & \\
\hline RPC13 & Romeria & \\
\hline RPC11 & Conjuntos hidraulicos & \\
\hline RPC15 & Caminos Dos/Ratero & \\
\hline RPC17 & Palomeros & \\
\hline RPC20 & Canal Riegos Levante & \\
\hline
\end{tabular}

Fig. 5.42: Intersección del sistema de espacios abiertos con los recursos paisajísticos culturales del ámbito estricto (escala aproximada 1:100.0000) 
VALORACIÓN Y GESTIÓN DEL PAISAJE SEGÚN EL CONVENIO EUROPEO DEL PAISAJE YEL

REGLAMENTO DEL PAISAJE DE LA COMUNIDAD VALENCIANA: APLICACIÓN MEDIANTE UN ESTUDIO DE PAISAJE A UNESPACIO ABIERTO EN LA COMUNIDAD VALENCIANA

DOCTORANDO: JUAN JOSÉ GALÁN VIVAS (Universidad Politécnica de Valencia, enero 2011)

\section{Sistema de Espacios abiertos y Recursos Paisajísticos Visuales:}
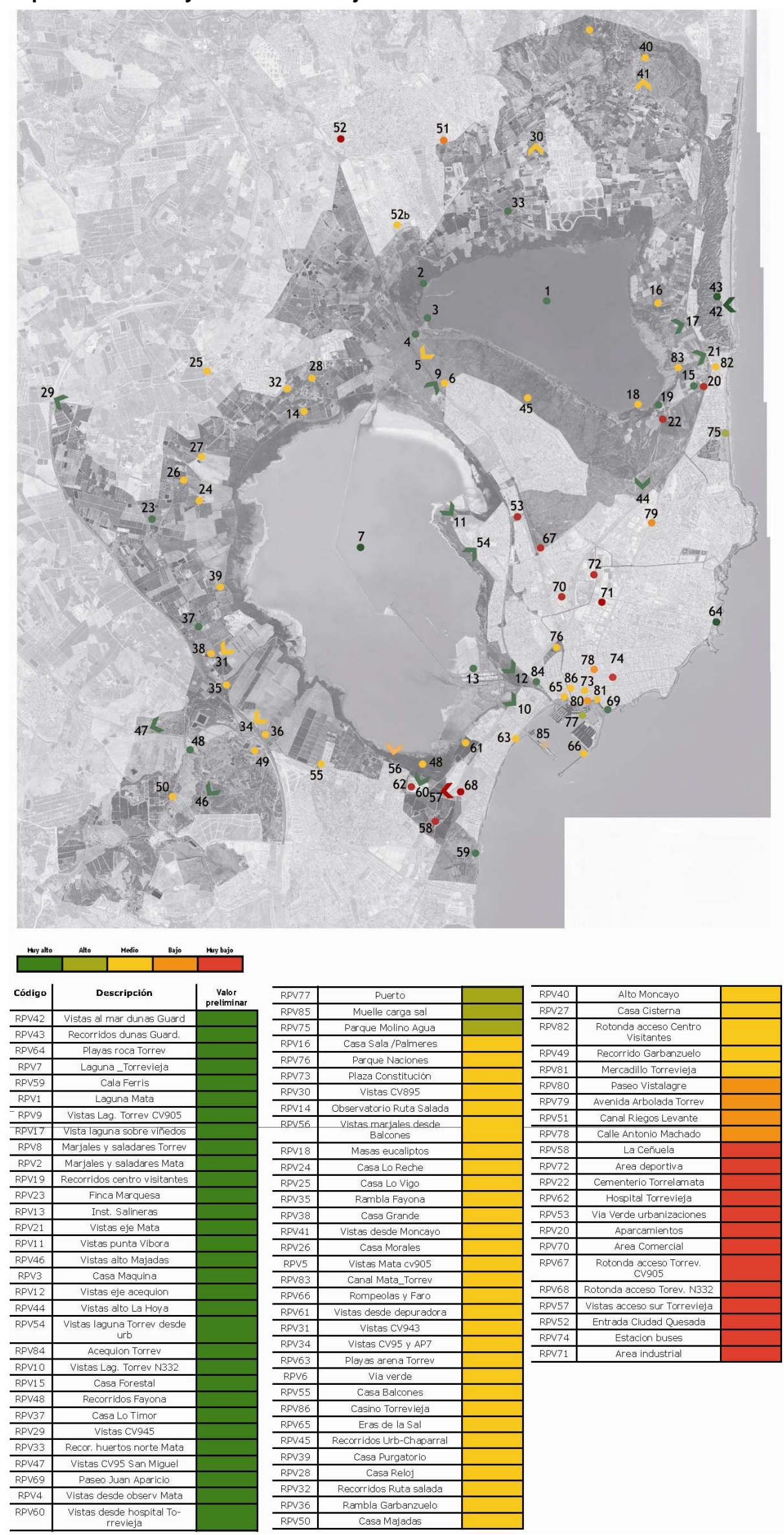

Fig. 5.43: Intersección del sistema de espacios abiertos con los recursos paisajísticos visuales del ámbito estricto (escala aproximada 1:100.0000) 


\section{4.i. Catálogo de Paisaje}

El Catalogo de Paisaje del presente estudio incluye, de acuerdo al Reglamento de Paisaje de la Comunidad Valenciana:

- Las Unidades de Paisaje o Recursos Paisajísticos objeto de protección especial conforme a la legislación de protección de Espacios Naturales y los entomos de los bienes y conjuntos incluidos en el perímetro de su declaración como bien de interés cultural conforme a la legislación de patrimonio cultural.

- Las Unidades de Paisaje y los Recursos Paisajísticos a los que se haya reconocido un valor alto o muy alto.

Atendiendo a las conclusiones del proceso de valoración del paisaje, se deberán incluir dentro del Catálogo las siguientes unidades de paisaje:

- UP1 Laguna de la Mata

- UP2 Laguna de Torrevieja

- UP3 Secanos y Viñedos de La Mata

- UP6 Alto del Moncayo

- UP8 Alto de la Hoya y el Chaparral

- UP7 Dunas de Guardamar

- UP14 Conector de la rambla de la Fayona

Dichas unidades incluyen total o parcialmente espacios situados dentro del Parque Natural de las lagunas de La Mata-Torrevieja (UP1: Laguna de la Mata, UP2: Laguna de Torrevieja, UP8: Alto de la Hoya y el Chaparral y UP3: Secanos y Viñedos de La Mata), así como las dunas de Guardamar (espacio incluido como LIC en la Red Natura 2000 y Monte de Utilidad Pública) y las elevaciones del Moncayo (Monte de Utilidad Pública), incluidas respectivamente en las Unidades de Paisaje: UP7: Dunas de Guardamary UP6: Alto del Moncayo.

En lo referente a recursos paisajísticos y de acuerdo a las conclusiones del proceso de valoración del paisaje, quedarían incluidos en el catálogo los siguientes recursos paisajísticos:

\section{Recursos paisajísticos ambientales:}

- RPA17 Playas dunas Guardamar

- RPA26 Playas roca Torrevieja

- RPA16 Pinadas dunas Guardamar

- RPA1 Laguna Mata

- RPA23 Cala Ferris

- RPA7 Saladares Torrevieja

- RPA2 Marjales mata

- RPA20 Pinadas Fayona

- RPA15 Pinares Moncayo

- RPA18 Pinadas Chaparral

- $\quad$ RPA3 Saladares entorno a la laguna de la Mata

- RPA6 Marjales entorno a la laguna de Torrevieja

- RPA22 Palmeral de Lo Ferris

- RPA8 Cubetas salinas

- RPA25 Playas de arena de Torrevieja

- RPA5 Laguna de Torrevieja

- RPA4 Micro reservas del Parque Natural

- RPA9 Viñedos de La Mata

- RPA21 Campos de Almendros en el entorno de las ramblas de La Fayona y Garbanzuelo

- RPA27 Parque Molino Agua (Torrevieja)

- RPA13 Rambla de la Fayona

\section{Recursos Paisajísticos Culturales:}

- $\quad$ RPC25 Torre de la Sal (Torrevieja)

- RPC24 Torre del Moro (Torrevieja)

- RPC1 Canal de las Salinas

- RPC5 Canal de la Mata

- $\quad$ RPC27 Rompeolas y Faro de Torrevieja 
- RPC9 Arquitectura tradicional en los Huertos entorno a las lagunas de la mata y Torrevieja

- RPC3 Acequión de Torrevieja

- RPC6 Casa Forestal de la Mata

- RPC28 Paseo Marítimo Juan Aparicio (Torrevieja)

- $\quad$ RPC7 Arquitectura tradicional en el entorno de los Viñedos de la Mata

- RPC30 Sociedad Cultural Casino de Torrevieja

- $\quad$ RPC23 Iglesia de la Inmaculada Concepción (Torrevieja)

\section{Recursos Paisajísticos Visuales:}

- RPV42 Vistas al mar desde las dunas de Guardamar

- RPV43 Recorridos dunas Guardamar

- RPV64 Playas roca Torrevieja

- RPV7 Laguna_Torrevieja

- $\quad$ RPV59 Cala Ferris

- RPV1 Laguna Mata

- RPV9 Vistas a las lagunas de Torrevieja la Mata desde la carretera CV905

- RPV17 Vista a la laguna de la Mata sobre viñedos

- RPV8 Marjales y saladares de la laguna de Torrevieja

- $\quad$ RPV2 Marjales y saladares de la laguna de la Mata

- RPV19 Recorridos desde el centro de visitantes de la Mata

- RPV23 Finca de la Marquesa

- RPV13 Instalaciones Salineras

- $\quad$ RPV21 Vistas a lo largo del canal de la Mata

- RPV11 Vistas desde la punta de la Víbora (Laguna de Torrevieja)

- RPV46 Vistas desde el alto de las Majadas

- RPV3 Casa Maquina

- $\quad$ RPV12 Vistas a lo largo del Acequión de Torrevieja

- RPV44 Vistas desde el alto de La Hoya

- $\quad$ RPV54 Vistas a la laguna de Torrevieja desde las Urbanizaciones colindantes

- RPV84 Acequión de Torrevieja

- RPV10 Vistas a las lagunas de Torrevieja y La Mata desde la carretera N332

- RPV15 Casa Forestal

- RPV48 Recorridos a lo largo de la rambla de la Fayona

- RPV37 Casa Lo Timor

- $\quad$ RPV29 Vistas a la laguna de Torrevieja desde la carretera CV945 y CV943

- RPV33 Recorridos entre los huertos entorno a la laguna de la Mata

- RPV47 Vistas a la laguna de Torrevieja desde San Miguel de Salinas (carretera CV95)

- $\quad$ RPV69 Paseo marítimo Juan Aparicio (Torrevieja)

- RPV4 Vistas desde observatorios en el entorno de las lagunas de la Mata y Torrevieja

- $\quad$ RPV60 Vistas desde el hospital Torrevieja

- $\quad$ RPV77 Puerto de Torrevieja (incluye el conjunto histórico monumental de las Eras de la Sal y Embarcadero)

- $\quad$ RPV85 Muelle carga sal (Torrevieja)

- $\quad$ RPV75 Parque Molino Agua (Torrevieja)

Finalmente, en lo referente a unidades o recursos paisajísticos de protección especial, considerando la Ley de Protección de Espacios Naturales y los entornos de los bienes y conjuntos incluidos en el perímetro de su declaración como bien de interés cultural conforme a la legislación de patrimonio cultural, han quedado incluidos los siguientes Bienes de Interés Comunitario (todos ellos quedan doblemente incluidos en el catalogo al haber sido considerados recursos paisajísticos de valor muy alto o alto):

- $\quad$ CONJUNTO HISTÓRICO MONUMENTAL "ERAS DE LA SAL" y "EMBARCADERO

- PARROQUIA DE LA INMACULADA CONCEPCIÓN. BIC Monumento

- Sociedad cultural casino de torReVIEja. BiC Monumento

- TORRE DEL MORO . BIC Monumento

- TORRE LA MATA. BIC Monumento 


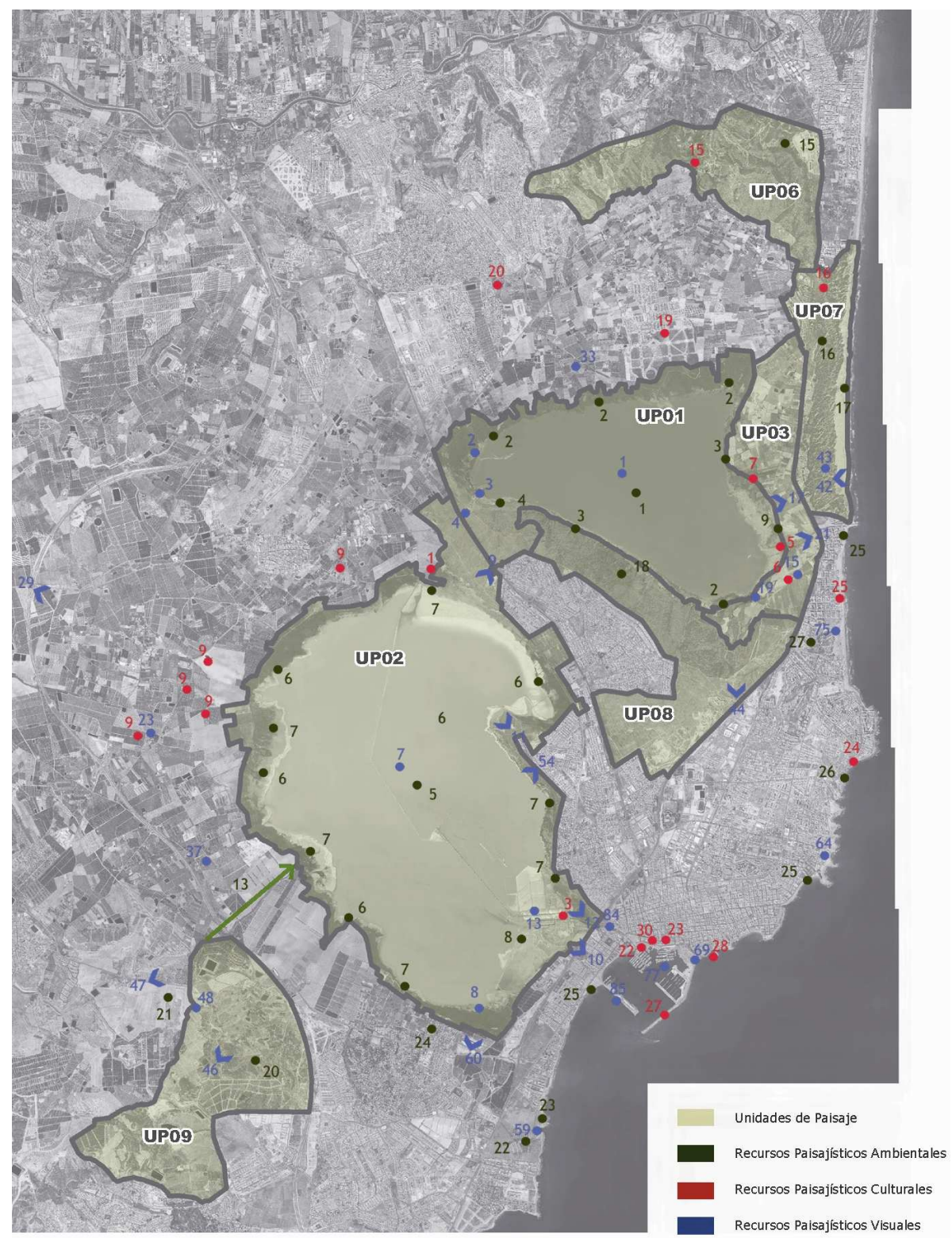

Fig. 5.44: Espacios y recursos paisajísticos incluidos en el Catálogo de paisaje (escala aproximada 1:100.0000)

La normativa de Paisaje aplicable a los elementos y espacios incluidos en el catálogo se detalla en el anexo VII (Normativa de Paisaje) de la presente tesis.

\section{4.j. Plan de Ordenación Paisajística 5.4.j.1 Consideraciones preliminares}

A diferencia de los estudios de paisaje previstos por la legislación valenciana, que se aplican de forma global sobre un determinado ámbito territorial, el presente estudio incomora adicionalmente el objetivo de contribuir a la gestión del Parque Natural de las lagunas de La Mata y Torrevieja. Por dicho motivo se desarrollarán análisis y propuestas específicas que permitan conseguir la mejora de la calidad paisajística del parque y de su entorno inmediato, entendiendo por tal, el área de amortiguación definida en el Plan de Ordenación de los Recursos Naturales (PORN) del Sistema de Zonas Húmedas del Sur de Alicante así como los espacios naturales, agrícolas, salineros o urbanizados que permiten su conexión con otras áreas próximas de interés medioambiental y paisajístico.

Para la consecución de dicho objetivo se considera necesario, dados los objetivos de calidad paisajística y las necesidades indicadas por los gestores del Parque Natural: 
- Apoyar desde la perspectiva del paisaje la definición de recorridos, miradores y espacios públicos acordes con la normativa vigente y con el futuro Plan de Uso Público del Parque, que faciliten el uso y disfrute público del parque sin perjuicio para sus valores medioambientales, culturales y productivos

- Proponer medidas y estrategias para la integración paisajística de infraestructuras y zonas urbanizadas próximas.

- Desarrollar normas y recomendaciones para la gestión de los distintos espacios productivos que se dan dentro del Parque (agrícolas, salineros, etc.)

- Definir conectores del Parque Natural con el sistema de espacios abiertos del Sur de Alicante.

\section{4.j.1.1 Consideraciones sobre el uso público del Parque}

El contexto y las propias características del Parque Natural de las lagunas de La Mata - Torrevieja generan sobre éste una presión antrópica especialmente intensa como consecuencia de los factores siguientes:

- Presencia de una población, que en temporada turística alta, alcanza las 500.000 personas, a una distancia de menos de 3 kilómetros de los límites del Parque.

- Existencia de un perímetro mayormente urbanizado en el que se incluyen fundamentalmente zonas residenciales tanto de alta como de media densidad, no existiendo en muchos casos una zona de amortiguación entre el parque y las citadas zonas residenciales.

- Acceso incontrolado al parque desde las zonas residenciales anteriormente expuestas.

- Presencia de infraestructuras de transporte altamente utilizadas en los límites del área de amortiguación del Parque.

- Existencia de actividades productivas en el interior (salinas) y zona de amortiguación del parque natural (agricultura y actividades complementarias).

Considerando como objetivo principal del parque la preservación de sus valores medioambientales y paisajísticos, la elevada presión antrópica sugiere a su vez, la necesidad de programar adecuadamente su uso público y el habilitar los medios y equipos humanos suficientes.

\section{4.j.1.2 Consideraciones sobre el marco normativo del parque natural}

Los planos siguientes muestran la zonificación prevista en el Plan Rector de Usos y Gestión del Parque Natural (PRUG) y en el área de amortiguación de impactos tal y como queda recogida en el Plan de Ordenación de los Recursos Naturales (PORN) del Sistemas de Zonas Húmedas del Sur de Alicante.
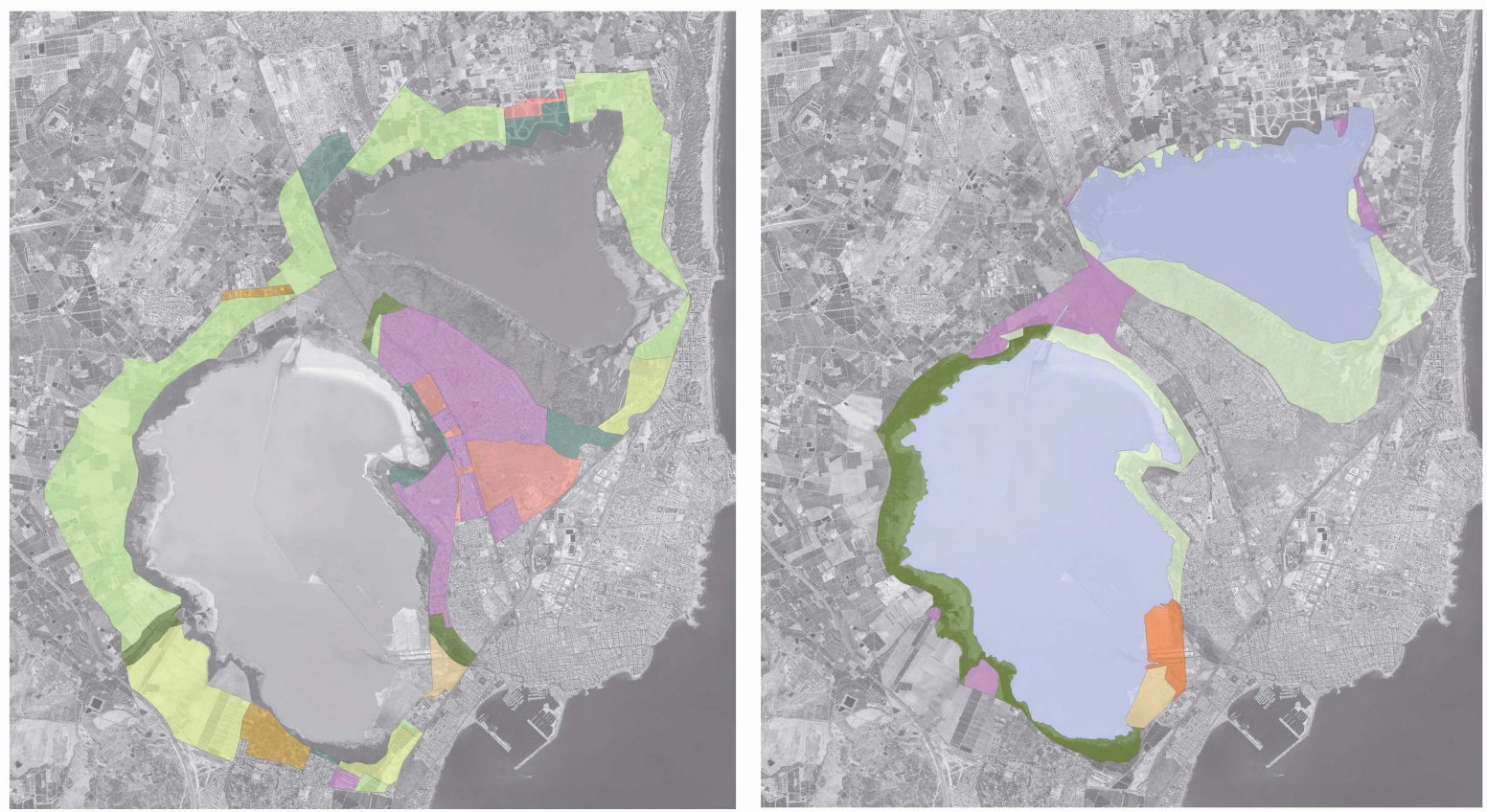

Areas consolidadas

Areas sujetas a Plan Especi

Áreas de interés Especial Industria Saline

Areas de Interés Especial natur

Areas de Predominio Agricola

Fig. 5.45: Zonificación del área de amortiguación prevista en el Plan de Ordenación de los Recursos Naturales (PORN) del sistema de zonas húmedas del sur de Alicante (plano de la izquierda) y del interior del Parque Natural según el Plan Rector de Usos y Gestión (PRUG) (plano de la derecha). 


\section{4.j.1.3 Consideraciones sobre el planeamiento y normativa de aplicación}

Las propuestas desarrolladas en la presente tesis han considerado el Plan Rector de Usos y Gestión del Parque Natural de las lagunas de La Mata - Torrevieja, el Plan de Ordenación de los Recursos Naturales del Sistema de Zona Húmedas del Sur de Alicante, el planeamiento urbanístico vigente en los términos municipales afectados y las infraestructuras de transporte existentes y previstas.

El conjunto de propuestas que afectan al Uso y Gestión del Parque ha sido elaborado en colaboración con el personal técnico y la dirección del mismo y pretende apoyar desde la perspectiva del paisaje al futuro Plan de Uso Público del Parque Natural.

\section{4.j.1.4 Consideraciones territoriales}

La localización del Parque Natural de La Mata - Torrevieja y de su área de amortiguación en suelos pertenecientes a 5 municipios y su necesaria vinculación ecológica y ambiental con espacios fuera de los límites del parque, ofrece una oportunidad única para contribuir, desde la ordenación del Parque, a una planificación sostenible de carácter supramunicipal. Dicha contribución se concreta en aspectos como la conexión del parque y su relación con los espacios urbanizados o infraestructuras de transporte próximas, en el análisis de la productividad económica de la actividad agrícola y salinera en el parque y su entorno, así como en el desarrollo de programas de carácter supramunicipal que afectan tanto a elementos o espacios físicos como a actividades formativas o servicios compartidos.

\section{4.j.2. Análisis de visuales, circulaciones y conflictos paisajísticos.}

A pesar de que el conjunto de información recopilada y elaborada durante los trabajos previos (caracterización y valoración del paisaje, determinación de los objetivos de calidad y definición y diagnóstico del sistema de espacios abiertos del sur de Alicante), proporcionaron una base adecuada para avanzar en la parte propositiva del estudio, se consideró necesario, con el objeto de dar respuesta a los problemas específicos del Parque Natural, estudiar en mayor grado de detalle los aspectos siguientes:

- Análisis visual desde las principales vías de transporte.

- Circulaciones rodadas, peatonales y ciclistas en el Parque Natural y su entorno.

- Principales conflictos y problemas detectados.

\section{4.j.2.1. Vistas desde las principales vías de transporte}

El carácter llano de la topografía, la ausencia de una vegetación arbórea de alto porte y la posición de las carreteras sobre plataformas ligeramente elevadas permite disponer en muchos tramos de amplias vistas sobre las lagunas de La Mata y Torrevieja.

Dichas vistas, que se pretende mantener y potenciar, se dan en particular desde las autovía AP7 al sur del peaje de Los Montesinos, desde la mayor parte de la carretera N332 excepto en el tramo en que discurre en trinchera al cruzar el alto de Las Casillas, desde la carretera CV905 excepto cuando atraviesa las urbanizaciones del Chaparral, desde amplios tramos de la carretera CV943, desde la carretera CV895 y desde la carretera CV95 al oeste de la urbanización Los Balcones y en el entorno de San Miguel de Salinas.

El plano mostrado en la figura 5.46 recoge a su vez los principales recursos y zonas visualmente conflictivas en el ámbito de trabajo, los principales puntos elevados (posibles miradores) desde los que se puede obtener vistas amplias sobre el conjunto del territorio, así como las elevaciones topográficas que enmarcan las visuales y la cuenca endorreica de las lagunas de La Mata y Torrevieja, dichas elevaciones se encuentran edificadas en distintas zonas, generando una marcada intrusión visual en el paisaje del Parque Natural. 


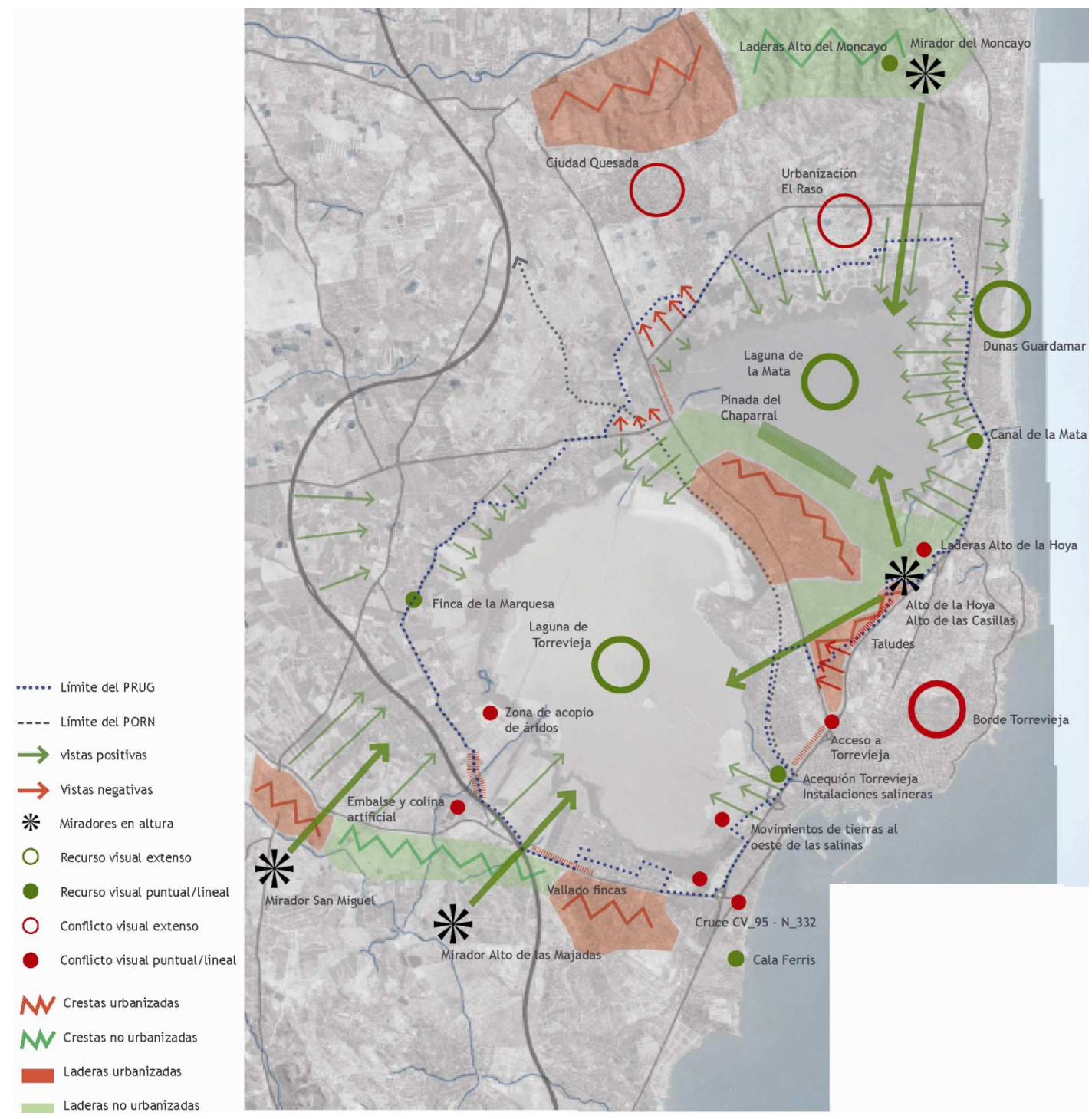

Fig. 5.46. Análisis de vistas, miradores al paisaje y laderas limitantes de cuencas visuales en el ámbito estricto del estudio (escala aproximada $1: 125.000)$

\section{4.j.2.2. Circulaciones y Accesos Actuales al Parque Natural:}

- Tráfico Rodado: Las carreteras que delimitan la mayor parte del área de amortiguación del Parque Natural presentan un tráfico muy intenso (caso de la carretera nacional N332, de la carretera CV 95 (IMD: 24.197vehículos/día) o CV905 (33.942 vehículos/día) y un tráfico medio o bajo (caso de la carretera CV945 (IMD 12.333) o caso de la carretera CV895 (IMD 8.153)).

- Transporte público: El municipio de Torrevieja dispone de un eficiente servicio de autobuses y está conectado con Guardamar del Segura. La ausencia de un transporte público entre las urbanizaciones y cascos urbanos que rodean las lagunas potencia sin embargo el uso del vehículo privado para acceder a los servicios disponibles en Torrevieja y a la zona de playas.

\section{- Recorridos ciclistas:}

- En el entorno del parque y en el ámbito del PORN: En su conjunto el área en estudio (incluido el parque, su entorno y el casco urbano de Torrevieja) no presenta una red extensa ni interconectada para circulación de bicicletas. La principal vía ciclista es la definida por la Vía Verde ubicada sobre la antigua línea férrea Torrevieja - Albatera, cuyo recorrido presenta en algunos tramos vistas amplias sobre la laguna de Torrevieja y en otros discurre por zonas urbanizadas de escaso interés. Adicionalmente existe una pista - bici adosada a la carretera CV905. Finalmente, los caminos rurales al oeste de la laguna de Torrevieja y al norte y oeste de la laguna de La Mata son aptos para el uso ciclista pero no se encuentran señalizados y el acceso a éstos resulta difícil. La ampliación de la carretera N332 incluirá la 
creación de una pista ciclista que atravesará de norte a sur él ámbito e estudio y que para vertebrar un sistema de recorridos ciclistas debería verse complementada por una red secundarias tanto en el casco urbano de Torrevieja como en las carreteras locales.

- Dentro del Parque Natural (ámbito del PRUG): En el entorno del Centro de Visitantes de La Mata se inician dos recorridos para bicicletas de aproximadamente 2,5 y $3 \mathrm{kms}$ de distancia que discurren respectivamente paralelos a la orilla sur de la laguna de la Mata y hasta el alto de La Hoya. Ambos recorridos deben ser realizados por el mismo trayecto en la ida y en la vuelta.

\section{- Recorridos peatonales:}

- En el entorno del parque y en el ámbito del PORN: En su conjunto el área en estudio (incluido el parque y su entorno) carecen de una red continua de caminos y senderos peatonales. Los caminos rurales al oeste de la laguna de Torrevieja (incluyendo la Ruta Salada), al norte y este de la laguna de la Mata y en el entorno de las ramblas de La Fayona y del Garbanzuelo no están interconectados, existiendo por el contrario fuertes barreras entre ellos (cruces con carreteras o extensas zonas sin caminos accesibles). Se observa a su vez una falta de recorridos que permitan apreciar la diversidad ecológica y paisajística del parque así como un balizamiento y acabado deficiente de los firmes. La Vía verde, cuyo recorrido discurre en la zona de amortiguación del parque, constituye un excelente conector ciclista y peatonal con el corredor del río Segura pero atraviesa tramos urbanos de escaso atractivo visual y habitabilidad (falta de sombra) y su conexión con el frente litoral es deficiente a pesar de existir un amplio paso bajo la nacional N322. Se observa a su vez una red de caminos excesivamente densa y altamente visibles en las laderas del Alto de la Hoya.

- Dentro del Parque Natural (ámbito del PRUG): Los recorridos peatonales dentro del Parque Natural se concentran en la orilla sur de la laguna de La Mata y en la pinada del Chaparral, donde discurren entre las urbanizaciones y las citadas lagunas.

- Accesos al parque (área PRUG): Los accesos al parque resultan difíciles de encontrar y se localizan fundamentalmente en el centro de visitantes de la Mata, en el inicio de la vía verde (si bien en este caso sólo se accede a una zona dentro del área de amortiguación del Parque) y en el entorno de la casa de Máquinas. Desde el casco urbano de Los Montesinos, la finca de La Marquesa y las urbanizaciones del Raso y de Ciudad Quesada existen accesos escasamente señalizados a la zona de amortiguación del Parque. Esta situación se reproduce o se agrava en la zona sur de la laguna de Torrevieja, en la que los caminos rurales no resultan accesibles al público al atravesar fincas privadas o zonas abandonadas (área situada junto a la depuradora y desaladora de Torrevieja).

Los canales de La Mata y el acequión de Torrevieja (conectores naturales entre el Parque Natural y el frente litoral) han recibido un tratamiento desigual. En el primero de ellos el soterramiento del Canal a su paso por el casco urbano de Torrelamata y el cruce no resuelto con la carretera N332 han privado al Parque de uno de sus principales accesos potenciales. En el caso del acequión de Torrevieja, la desvinculación de la red de recorridos del parque y el tratamiento poco consistente de las zonas verdes situadas en Torrevieja le restan valor como acceso al parque.

\section{- Conclusiones:}

El análisis de las circulaciones y de los accesos en el parque pone de manifiesto:

1. una descoordinación entre los distintos tipos de circulaciones (rodada, peatonal o ciclista) existentes o posibles en el parque y su entorno.

2. una falta de conexión y continuidad en los recorridos

3. la ausencia o deficiente tratamiento de los cruces entre los recorridos peatonales / ciclistas y las infraestructuras de transporte

4. Una carencia de accesos desde las urbanizaciones y cascos urbanos que rodean el parque natural

5. Una deficiente señalización de los recorridos existentes.

La creación de nuevos recorridos y accesos en el Parque y su entorno que permitiesen su disfrute público requeriría en cualquier caso de una estrategia integral y de la existencia de medios humanos y técnicos que permitan compatibilizar la intensificación del uso con la preservación de los valores medioambientales del Parque. 


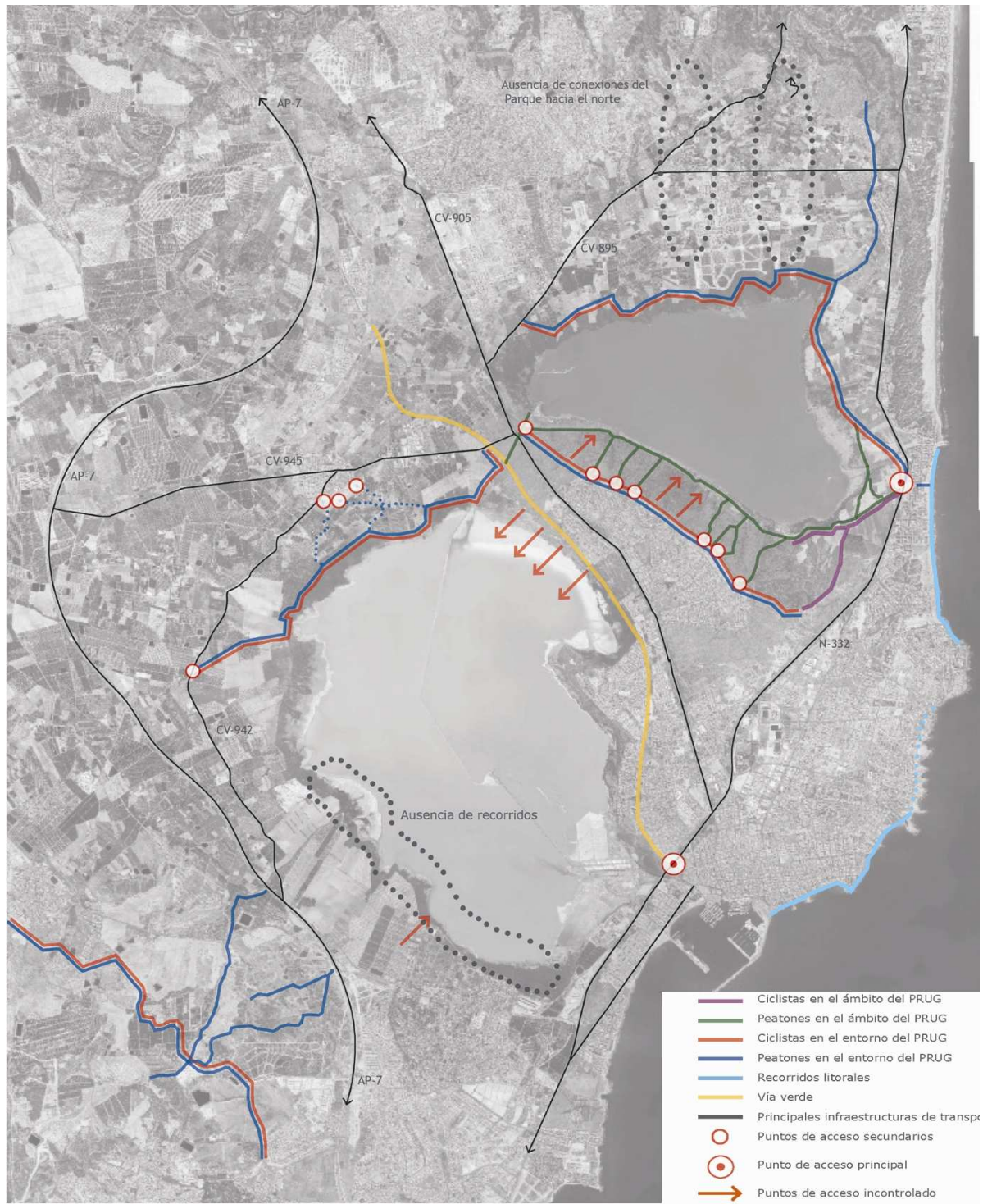

Fig. 5.47. Análisis de circulaciones en el entorno del parque natural de las lagunas de La Mata- Torrevieja (escala aproximada 1:100.000)

\section{4.j.2.3. Conflictos:}

El plano siguiente recoge los principales conflictos y problemas detectados en el Parque Natural y su entorno.

Dichos conflictos se vinculan fundamentalmente con:

- Ausencia de circulaciones y recorridos peatonales y ciclistas.

- Intrusión visual de urbanizaciones e infraestructuras de transporte.

- Abandono de la actividad agrícola.

- Desconexión con otros espacios de alto interés paisajístico y medioambiental (Dehesa de Campoamor, frente litoral, dunas de Guardamar, alto del Moncayo).

- Deterioro por falta de uso del patrimonio arquitectónico e hidráulico.

- Presencia de elementos de alto impacto visual (vallas, edificios fuera de escala, topografías artificiales).

El plano que se muestra a continuación y la tabla 5.12, sintetizan a su vez los conflictos indicados por población y expertos en el proceso de participación pública (fase1). 


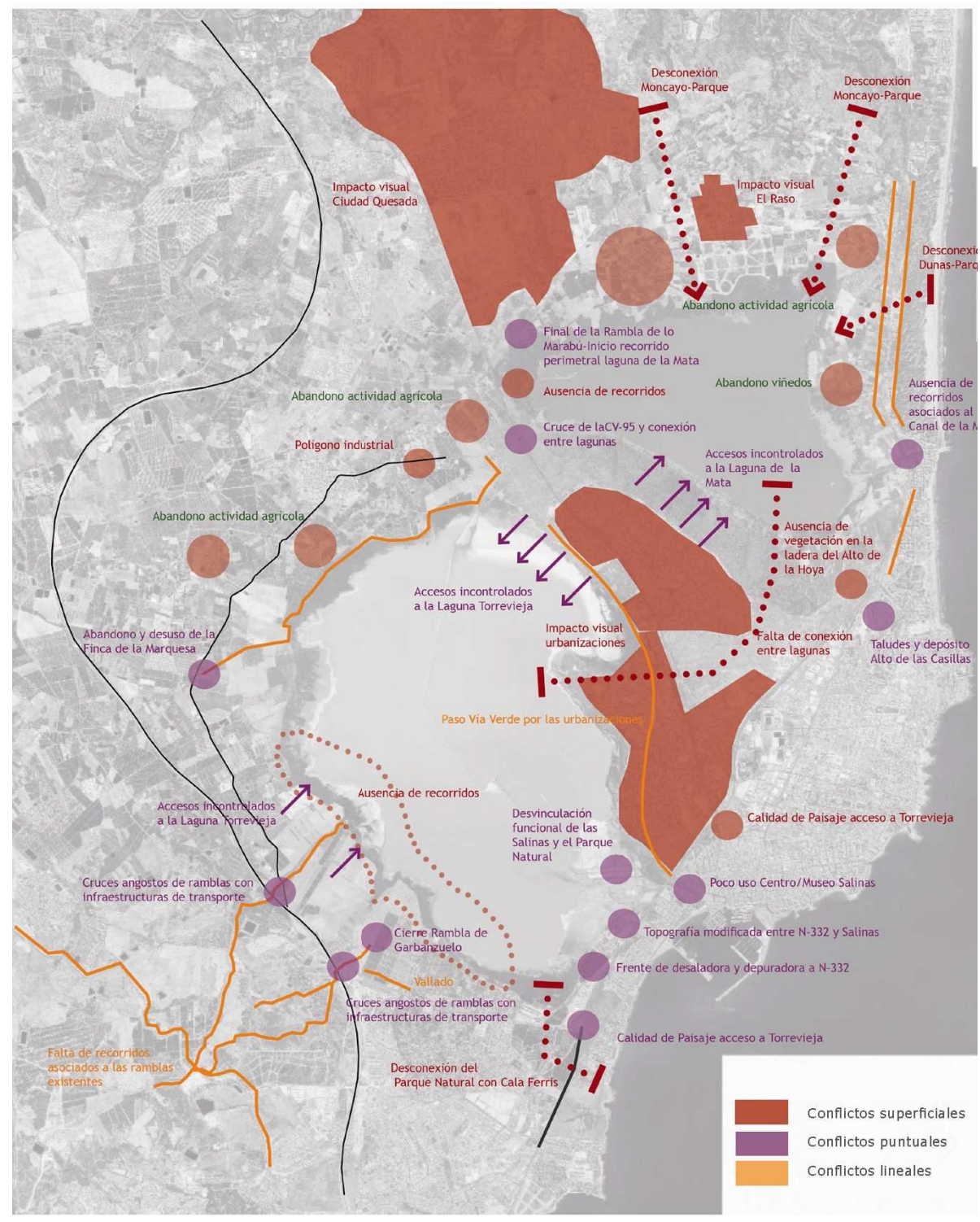

Fig. 5.48. Principales conflictos paisajísticos en el ámbito estricto (escala aproximada 1:100.000)

\section{4.j.3 Estrategias de Paisaje}

Con el objeto de articular los distintos programas de paisaje a proponer dentro del ámbito del estudio se establecen las siguientes estrategias de actuación:

ESTRATEGIA 1 Conexiones del Parque: Definir conectores ecológicos del parque Natural con otras zonas de interés medioambiental o paisajístico haciendo para ello uso suelos agrícolas, ramblas, canales de conexión de las lagunas con el mar y zonas forestales.

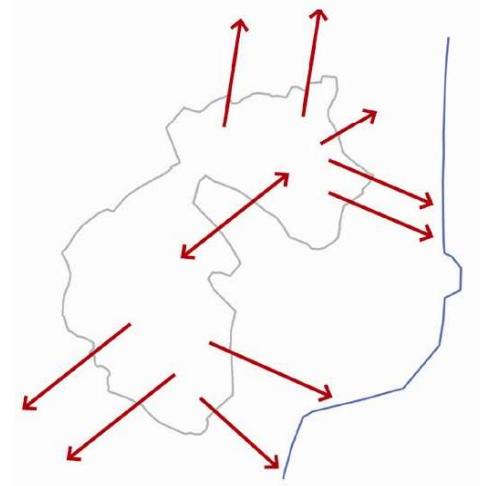


ESTRATEGIA 2: Circulación y recorridos: Generar 2 anillos de circulación perimetrales a las lagunas:

- Un anillo exterior destinado al tráfico rodado y ciclista que interconecte los accesos al parque y que se apoye en carreteras existentes.

- Un anillo interior destinado al uso peatonal y ciclista, apoyado fundamentalmente en caminos rurales y antiguos caminos salineros, y localizado fundamentalmente en el límite entre el área de amortiguación y el Parque Natural o dentro del área de amortiguación.

- Unos conectores adecuados entre los anillos anteriores y el frente litoral que prioricen al peatón y al ciclista frente al tráfico rodado

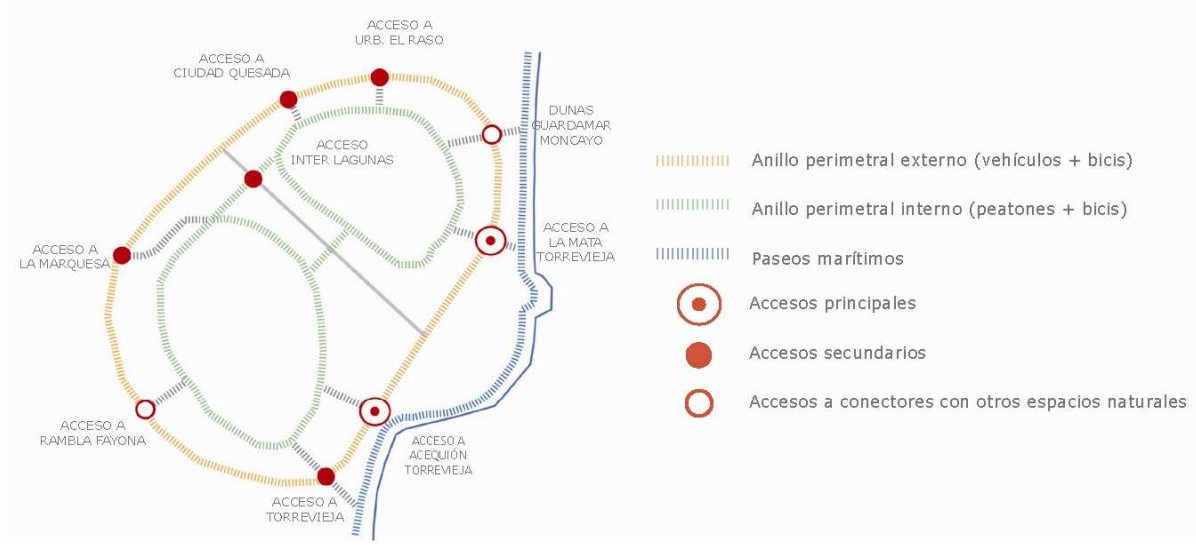

ESTRATEGIA 3: Coordinación de sistemas de movilidad: Resolver adecuadamente y dando preferencia a peatones y ciclistas los cruces entre las distintas redes de transporte e introduciendo, adicionalmente, el transporte público como sistema de comunicación intermunicipal y como elemento de apoyo a visitas parciales al parque.

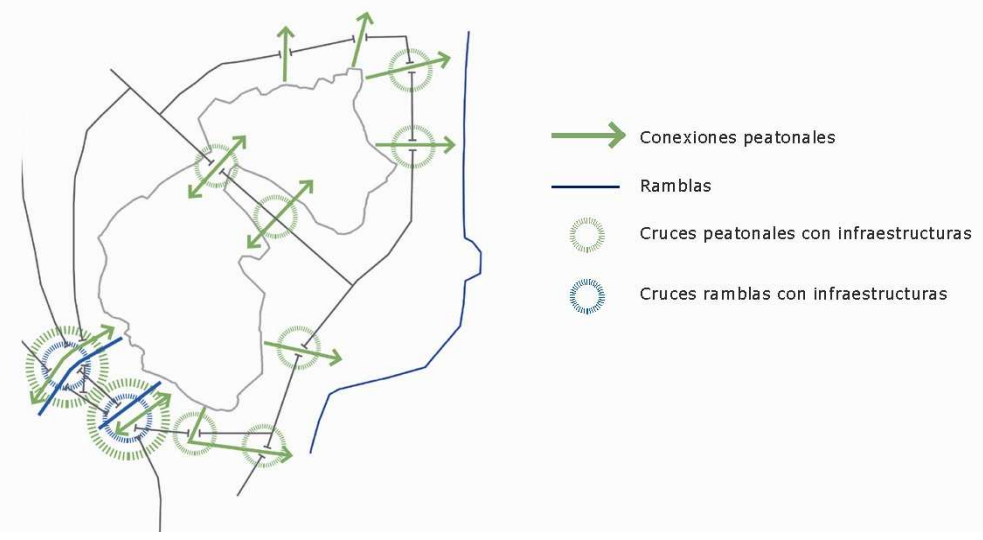

\section{ESTRATEGIA 4: Integración de Urbanizaciones e Infraestructuras de Transporte:}

- Proponer en las urbanizaciones y zonas urbanas intervenciones de borde e internas que mejoren su integración en el paisaje y la calidad /habitabilidad de su paisaje interno.

- Proponer en las infraestructuras tratamientos de borde que mejoren su integración en el paisaje y la calidad de las vistas para los conductores.

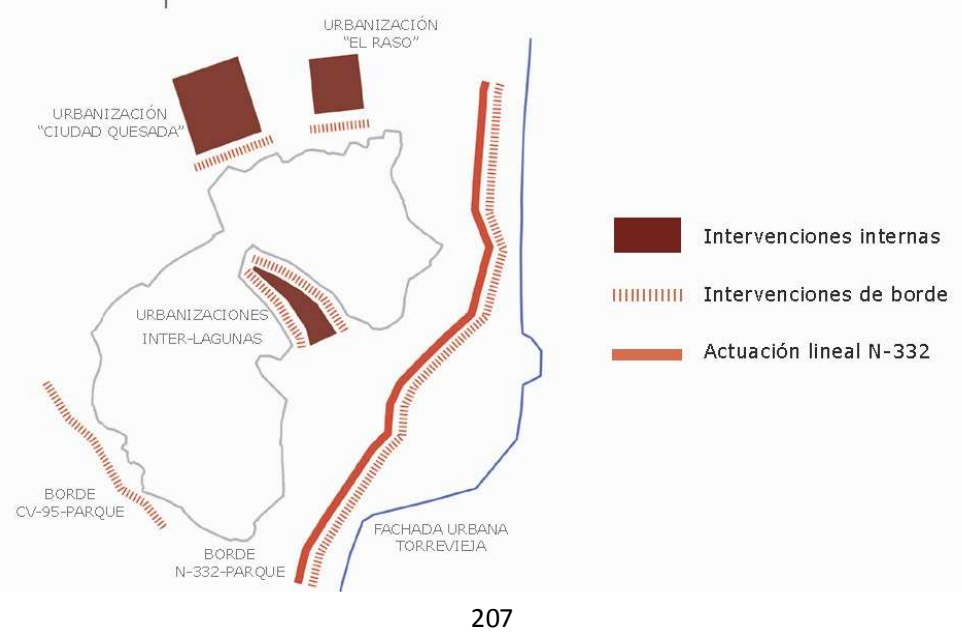




\section{ESTRATEGIA 5: Gestión y Uso del territorio:}

Favorecer la permanencia de actividades productivas reguladas (agricultura y salinera) y promover actividades complementarias compatibles con la normativa del Parque Natural.

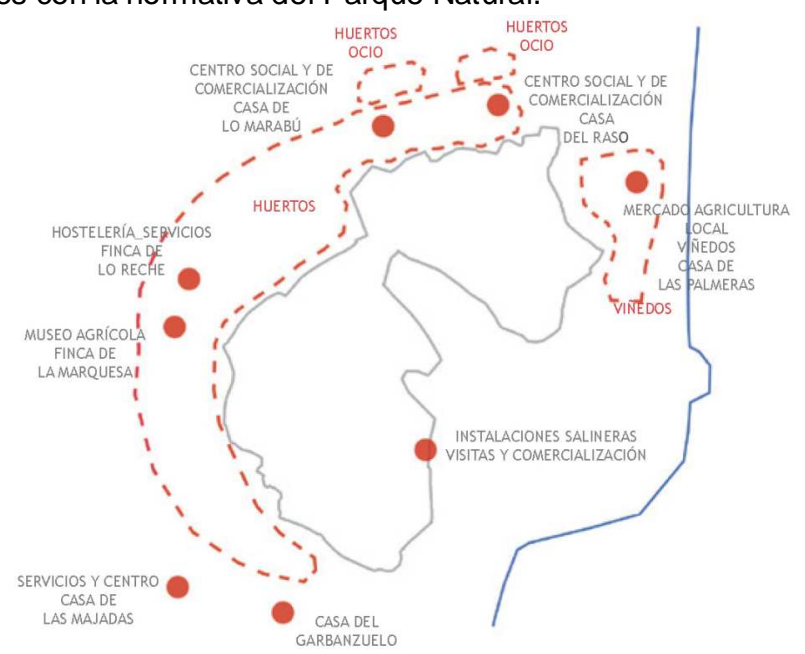

\section{ESTRATEGIA 6: Normativas paisajísticas:}

Proporcionar recomendaciones paisajísticas para las áreas productivas, urbanizadas, urbanizables y naturales existentes en el Parque Natural.

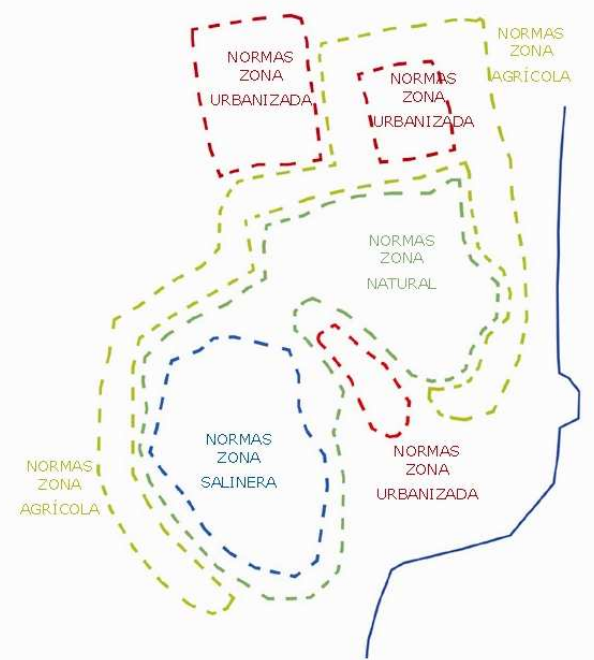

\section{ESTRATEGIA 7: Formaciones vegetales autóctonas:}

Aumentar la superficie de bosque termomediterráneo (con sotobosque asociado) en aquellas zonas ecológicamente adecuadas. Promover la regeneración de las formaciones vegetales vinculadas a los suelos y lagunas salobres (carrizal, tarayal y, especialmente, saladar)

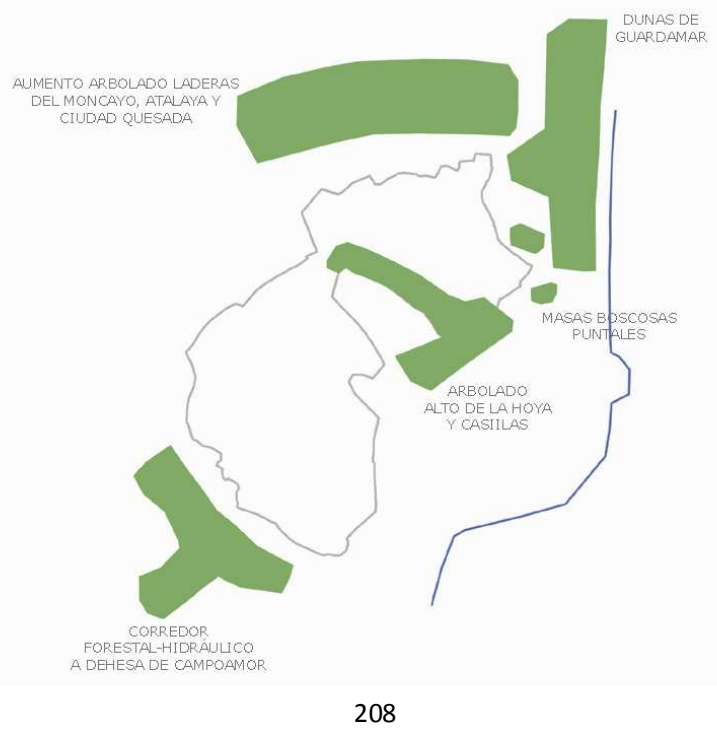


ESTRATEGIA 8: Patrimonio arquitectónico e hidráulico:

Restaurar el patrimonio arquitectónico e hidráulico, asociarlo a recorridos y vincularlo a actividades compatibles con la normativa del parque y de su área de amortiguación.

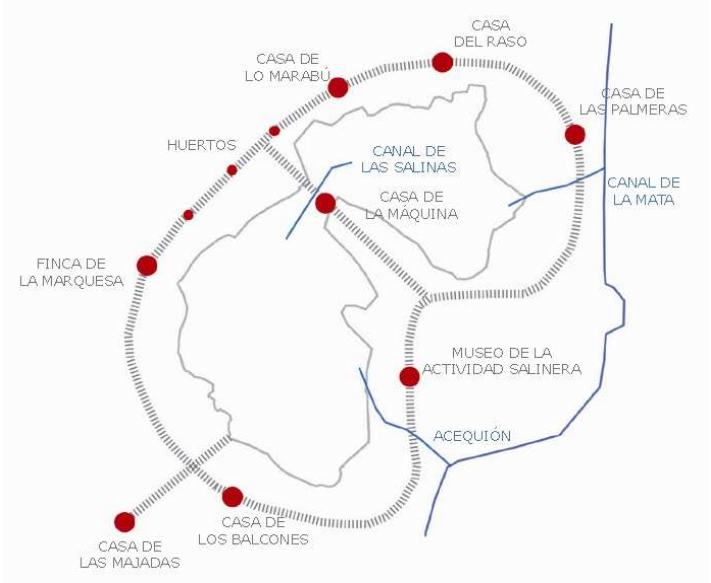

\section{4.j.4 Plan de Ordenación Paisajística}

Se expone a continuación el conjunto de actuaciones de carácter constructivo propuestas para la gestión, protección y ordenación del paisaje dentro del ámbito estricto del estudio de paisaje. Estas actuaciones quedarán a su vez integradas en los posteriores programas de paisaje y han sido agrupadas en función de su carácter en los apartados siguientes:

- Recorridos y accesos

- Vegetación y zonas verdes

- Topografía y Obra Civil

- Patrimonio arquitectónico e hidráulico

5.4.j.4.1. Recorridos y accesos:

Tal y como se expone en el plano siguiente, el plan de ordenación paisajística del Parque Natural de las lagunas de la Mata - Torrevieja y su entorno, incluye las siguientes propuestas referidas al uso y recorridos del parque:

\section{Anillo de circulación perimetral:}

1. Creación de un anillo perimetral de circulación rodada y ciclista apoyado fundamentalmente en las carreteras que rodean la zona de amortiguación del Parque Natural. Dicho anillo incorporaría un carril bici (con firme tipo slurry o asfaltico) preferentemente en el lado que limita con el parque, desligándose dicho carril de la carretera en algunas zonas puntuales (especialmente en tramos paralelos a la nacional N332, en la que, las obras de desdoblamiento, prevén ya un carril bici en el lado este).

2. Tratamiento del anillo perimetral de circulación rodada y ciclista como recorrido escénico con vistas amplias al paisaje extenso del Parque Natural y de sus lagunas.

3. Incorporación de una línea de autobús intermunicipal con paradas en las distintas urbanizaciones y cascos urbanos (Torrevieja y Los Montesinos) que rodean el Parque Natural. Dicha línea debería facilitar el acceso por transporte público a las playas y a las áreas de servicios y dotaciones de Torrevieja. Adicionalmente, la línea de autobús permitiría visitar tramos independientes de los distintos recorridos previstos en el Parque Natural y su entorno para lo cual sería aconsejable que los usuarios pudiesen cargar sus bicicletas.

4. Integración del anillo perimetral de circulación ciclista en una red regional, que en particular debería conectar con:

- Red de carriles bici y paseos marítimos de Torrevieja (ver en plano indicaciones de ejes posibles estructurantes de dicha red)

- Vía verde en la antigua traza del ferrocarril Torrevieja-Albatera

- Caminos del Ratero y Dos (en dirección a Guardamar del Segura)

- Dunas de Guardamar

- Recorrido peatonal - ciclista a lo largo del canal del Campo de Cartagena 


\section{Anillos de circulación internos:}

1. Creación de sendos anillos de circulación peatonal / ciclista entorno a las lagunas de La Mata y Torrevieja, situados ambos preferentemente en el límite interno del área de amortiguación y apoyados fundamentalmente en caminos rurales existentes y en los antiguos caminos salineros que rodeaban las lagunas. Puntualmente, los anillos podrán discurrir por zonas incluidas dentro del Parque Natural (ámbito del PRUG), haciendo uso para ello de recorridos ya abiertos al público (caminos al sur de la laguna de La Mata), o de tramos cerrados al uso público de los antiguos caminos salineros que rodeaban las lagunas.

2. Dicho anillos deberán proporcionar al visitante una experiencia directa y cercana de los distintos paisajes y formaciones vegetales existentes en el Parque Natural. Por su trazado y por la estratégica disposición de vallas deberán impedir el acceso público a áreas restringidas.

3. Los recorridos incluidos en dicho anillo han sido subdivididos en tramos con un carácter y señalización específica. Los tramos tienen su origen y final en puntos significados del parque, conectados a su vez con caminos secundarios que permiten acceder al anillo exterior (de tráfico rodado y ciclista), a zonas de aparcamiento y a las paradas de la línea de autobús intermunicipal propuesto anteriormente.

4. Integración de los anillos internos de circulación ciclista en una red regional, que en particular conectaría con:

- Recorridos al frente costero: siendo en este punto especialmente necesarias la conexión con las dunas de Guardamar, las rutas a lo largo del canal de La Mata y del Acequión de Torrevieja (a recuperar como elementos visibles y estructuradores de sendos parques lineales), la conexión con la Playa del Rocío y cala Ferrís a través de un posible parque forestal agrícola que cumpliría un cuádruple fin: (1): conectar el sur de la Laguna de Torrevieja con el frente litoral, (2):consolidar un espacio abierto que evite la creación de un continuo urbanizado entre el casco urbano de Torrevieja y la costa de Orihuela, (3): proporcionar un acceso de alta calidad paisajística al sur del casco urbano de Torrevieja desde las carreteras N332 y CV95, y (4): relacionar visualmente las grandes dotaciones presentes en la zona (hospital, desaladora y depuradora).

- Recorridos a lo largo de las ramblas de La Fayona y El Garbanzuelo que conecten con el futuro Parque Natural de la Dehesa de Campoamor / Sierra Escalona y con el posible recorrido peatonal /ciclista adosado al canal del campo de Cartagena.

- Recorrido peatonal/ciclista de la vía Verde (que conecte a su vez con el corredor del río Segura)

- Recorridos sobre los caminos rurales de Dos y Ratero al alto del Moncayo y Guardamar del Segura

- Recorridos de la Ruta Salada (Los Montesinos)

5. Interconexión de las lagunas de La Mata y de Torrevieja: El presente Plan de Ordenación Paisajística considera esencial el recuperar la conexión ecológica entre las lagunas de La Mata y Torrevieja, gravemente obstaculizada en la actualidad por las urbanizaciones existentes y el intenso tráfico de la carretera CV-905. Para ello se proponen medidas que implican plantaciones y obra civil y que se localizan en las siguientes zonas.

- a) Conexión Oeste: Se localiza en el entorno del Canal de Salinas y se apoya en un amplio corredor de 500 metros de anchura en los que la carretera CV905 pasa a discurrir a través de un túnel de forma que las circulaciones peatonales y ciclistas y el corredor de fauna no se vean obstaculizadas por el tráfico rodado.

- b) Conexión Este: Se apoya en la futura zona verde situada junto al alto de La Hoya (en su cara hacia la laguna de La Mata) y en la cuña de suelo no urbanizable que discurre entre dicho alto y la carretera CV905, que pasaría a su vez en dicho punto a discurrir por un túnel de 100 metros de forma que el tráfico rodado no obstaculice el paso de peatones, ciclistas y fauna a la zona verde que enlaza con el corredor de la Vía Verde, y a través de éste, con la laguna de Torrevieja.

\section{Accesos al Parque:}

Se contempla la definición de Accesos con distintos grados de jerarquía al Parque Natural y a sus zonas de amortiguación:

1. ACCESOS PRINCIPALES: Localizados en los puntos donde se prevé una mayor afluencia. Llevarán asociados un aparcamiento apto para autobuses, un centro de información y distintos servicios para los visitantes. Se localizarían en: 
- El actual Centro de Visitantes de La Mata: situado en la antigua casa forestal y pendiente de reordenación en la zona del aparcamiento y en el entorno del cementerio de Torrelamata.

- $\quad$ El entorno del Centro de Interpretación de la Industria Salinera, situado en el parque del Acequión de Torrevieja, a reordenar de forma que este último se estructure entorno al Acequión y a la vía Verde e incorpore la vegetación propia de los saladares próximos. Dicho acceso se vincularía a un posible centro de atención al visitante en las salinas, desde el que podrían partir visitas guiadas a las instalaciones salineras y en el que se ubicaría un punto de venta de productos de las propias salinas.

2. ACCESOS SECUNDARIOS: Localizados en los puntos donde se prevé una afluencia media, llevarán asociados un aparcamiento para automóviles $(10-20)$ y un punto de información. Adicionalmente podrían estar asociados a servicios complementarios (museos municipales, hostelería, restauración, etc.) mayormente ubicados en edificios existentes. Se localizarían en:

- Entorno del Hospital - Desaladora de Torrevieja.

- Cruce del Barranco de La Fayona con la carretera CV943

- Finca de La Marquesa

- Los Montesinos

- Casa de La Máquina.

- Futura zona verde al sur de Ciudad Quesada

- Casa del Raso (futura zona verde en la urbanización del Raso).

- Final del canal de La Mata.

- Futuro centro de interpretación forestal (antigua casa de peones camineros junto a la carretera N332).

3. ACCESOS TERCIARIOS: Localizados en los puntos donde se prevé una afluencia baja, podrían llevar opcionalmente un pequeño aparcamiento para automóviles (3-7) y un cartel de información. Se localizarían en:

- Accesos al Parque Natural desde la urbanización del Chaparral

- Accesos al Parque Natural desde la urbanización de San Luis y La Torreta

- Cruce del barranco del Garbanzuelo con la carretera CV943

- Acceso desde la Casa de Los Balcones

- Acceso desde las urbanización de Los Balcones

- Accesos desde las conexiones ciclistas entre el casco urbano de Torrevieja y el Parque Natural.

\section{Miradores sobre el Parque:}

Se propone un sistema de miradores en puntos elevados situados en el entorno de las lagunas. Los miradores serían accesibles por recorridos peatonales/ciclistas y dispondrían de paneles explicativos del territorio visible y de la vegetación y fauna. Se localizarían en los siguientes puntos (entre paréntesis se indica el código identificador en el plano adjunto):
a. Alto de Las Majadas (1)
b. Alto de La Hoya (2)
c. Alto de la Casilla (3)
d. Alto del Moncayo (4)
e. Mirador de la antigua planta de áridos. (5) 


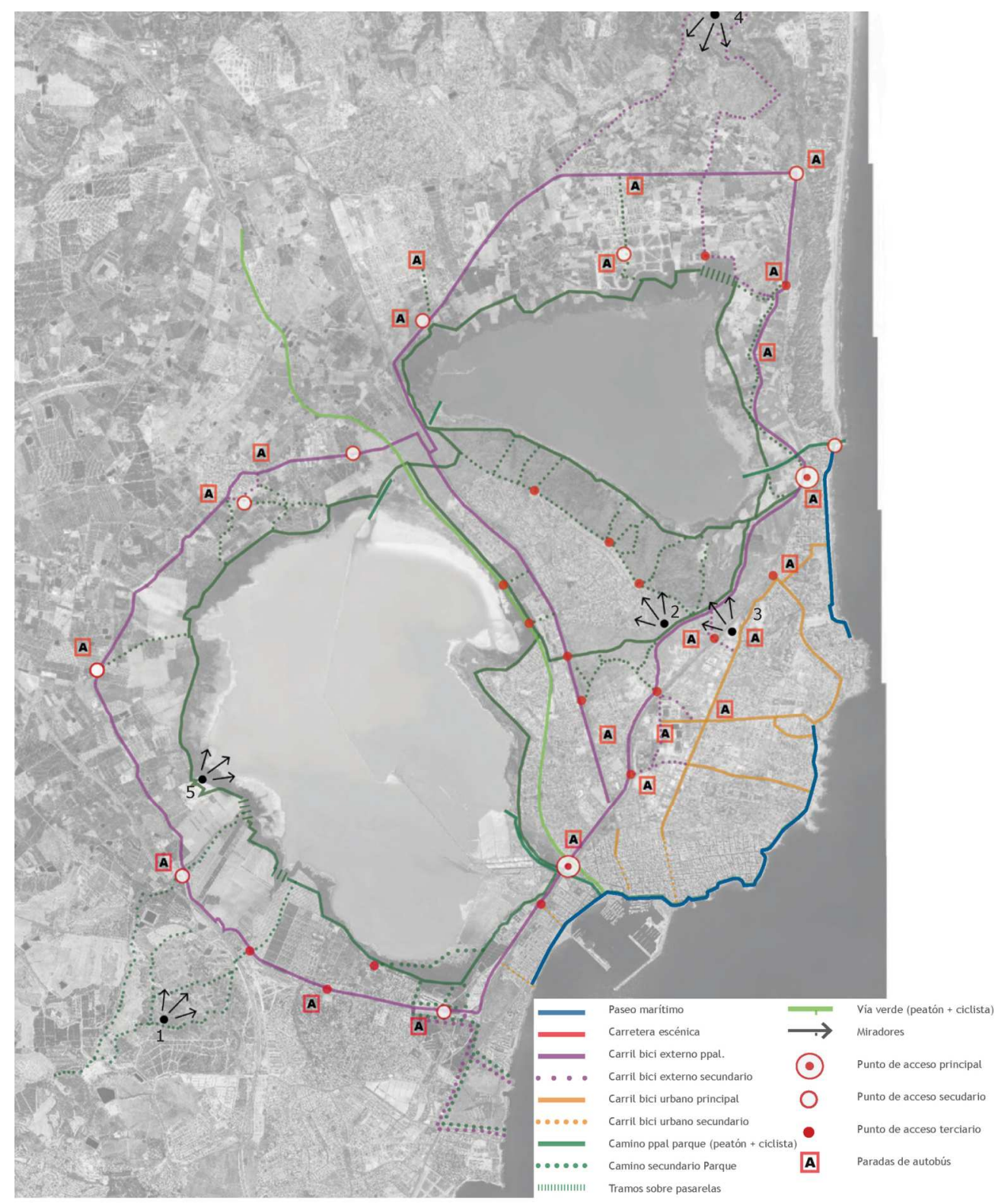

Fig. 5.49. Sistema propuesto de recorridos y miradores en el ámbito estricto (escala aproximada 1:100.000)

\section{4.j.4.2. Intervenciones sobre la vegetación y sobre las zonas verdes:}

Las actuaciones propuestas sobre la vegetación se desarrollan en dos tipos de ámbitos:

- Parque Natural y Zona de amortiguación (naturales, agrícolas o urbanizadas)

- Zonas periféricas (urbanas, agrícolas o forestales)

Dichas actuaciones presentan por otro lado un carácter:

- Extenso: tratamientos o acciones sobre superficies extensas (repoblaciones, creación de nuevas zonas verdes o parques agrícolas, etc.)

- Lineal o puntual: acciones en bandas (habitualmente vinculado a fachadas urbanas, infraestructuras de transporte, o arbolado de alineación urbano) y acciones puntuales (en puntos concretos de recorridos o junto a edificios rehabilitados).

Las actuaciones propuestas vinculadas a la vegetación se localizan fundamentalmente fuera del ámbito del Parque Natural y se concentran en la zona de amortiguación y zonas periféricas (urbanizaciones de Ciudad Quesada y El Raso). Las actuaciones aparecen identificadas en los textos y planos siguientes con un identificador consistente en un $n^{\circ}$ de color rojo. 
VALORACIÓNY GESTIÓN DEL PAISAJE SEGÚN EL CONVENIO EUROPEO DEL PAISAJE YEL

REGLAMENTO DEL PAISAJE DE LA COMUNIDAD VALENCIANA: APLICACIÓN MEDIANTE UNESTUDIO DE PAISAJE A UNESPACIO ABIERTO EN LA COMUNIDAD VALENCIANA

DOCTORANDO: JUAN JOSÉ GALÁN VIVAS (Universidad Politécnica de Valencia, enero 2011)

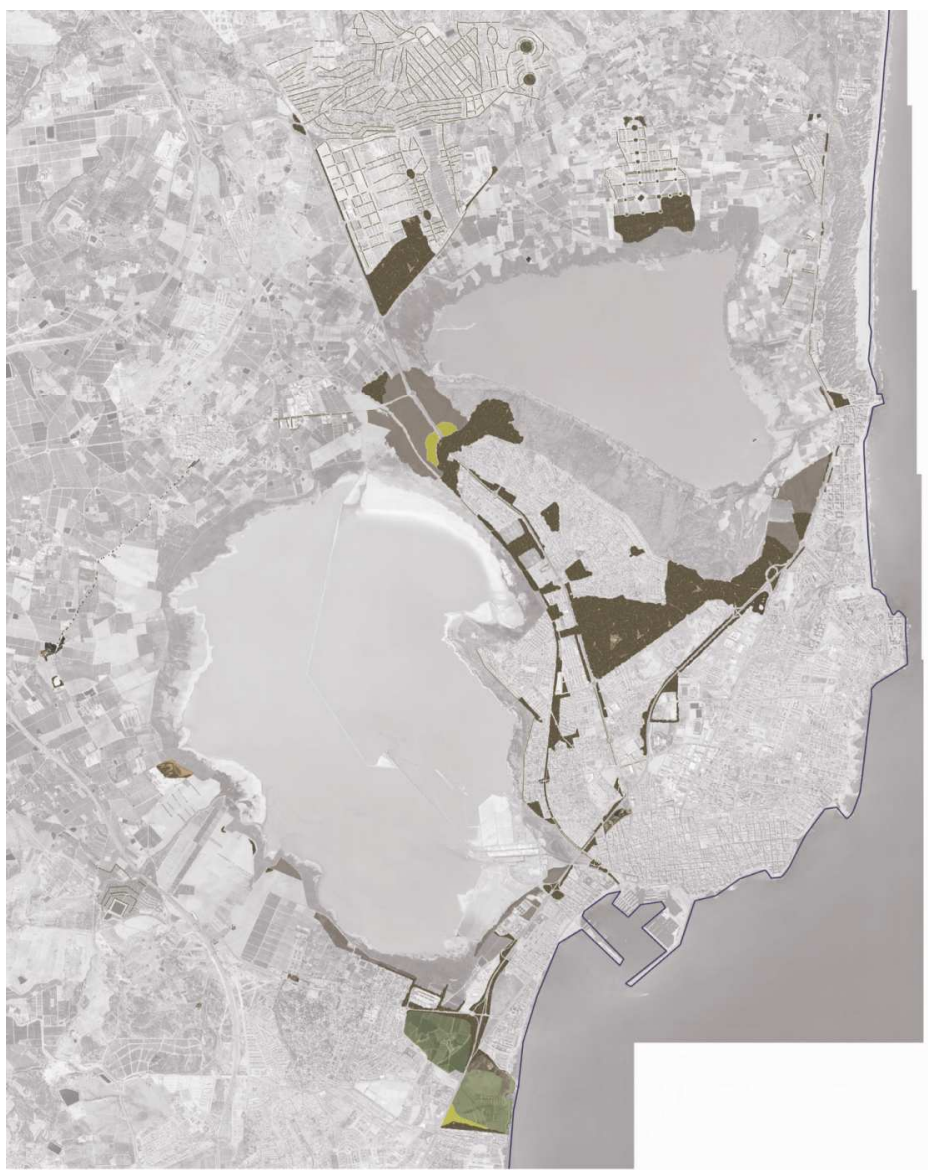

Fig. 5.50. Principales intervenciones propuestas sobre la vegetación en el ámbito estricto (escala aproximada 1:125.000)

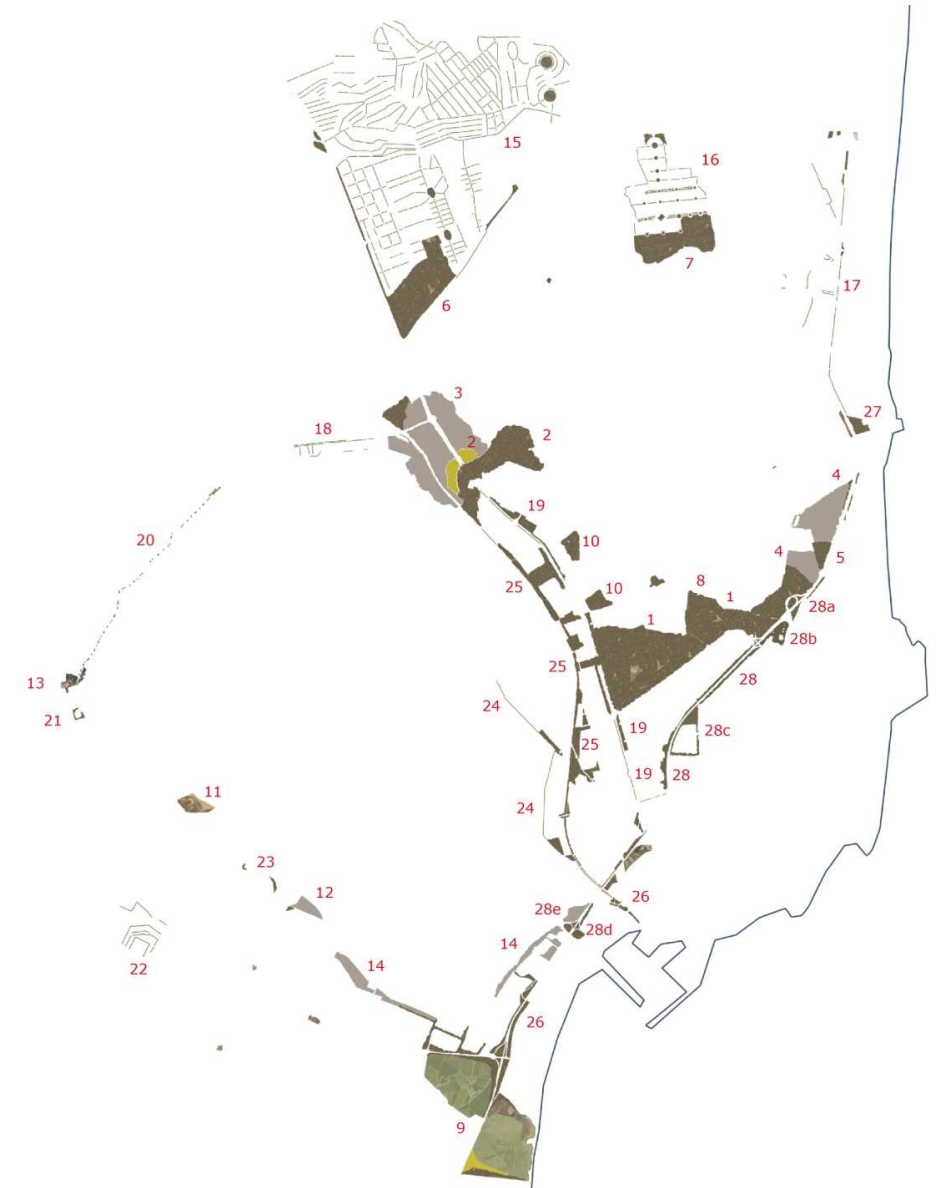

Fig. 5.51. Principales intervenciones propuestas sobre la vegetación en el ámbito estricto. En rojo los códigos identificativos de las intervenciones (ver descripción en texto siguiente) (escala aproximada 1:125.000) 
Actuaciones Extensas sobre la Vegetación: Se han considerado las siguientes:

1. Repoblación con pinar y sotobosque termo mediterráneo (lentiscar) de las laderas del alto de la Hoya y de la cuña de suelo no urbanizable entre dicho alto y la carretera CV-905 (ver código 1 en figura 5.51). Esta actuación se localiza en suelos cuya cota y salinidad no resultan idóneas para el saladar y mediante ella se pretende:

- Consolidar un espacio abierto arbolado que evite la fusión de la urbanización del Chaparral con el casco urbano de Torrevieja y que genere un gran conector ecológico entre las lagunas de La Mata y Torrevieja.

- Dar continuidad a la pinada del Chaparral (ampliamente valorada por la población)

- Proporcionar recorridos en zonas sombreadas.

- Mejorar las vistas de las laderas norte del alto de La Hoya, actualmente escasamente vegetadas y muy visibles desde la carretera N332.

- Enmarcar por el sur las vistas de la laguna de la Mata desde la carretera N332 en el punto en que la primera se hace visible.

2. Repoblación con pinar y sotobosque termo mediterráneo (lentiscar) de las zonas altas del conector oeste entre las lagunas de La Mata y Torrevieja (ver código 2 en figura 5.51). Esta actuación se localiza en suelos cuya cota y salinidad no resultan idóneas para el saladar y mediante ella se pretende:

- Generar una zona arbolada al oeste de la urbanización de San Luis que acompañe a su vez los recorridos del conector oeste entre las lagunas de La Mata y Torrevieja.

- Dar continuidad a la pinada del Chaparral (ampliamente valorada por la población).

3. Gestión y potenciación del saladar entre los extremos oeste de la laguna de la Mata y Torrevieja (entorno del Canal de las Salinas) (ver código 3 en figura 5.51). Mediante esta actuación se pretende:

- Acelerar la implantación del saladar sobre terrenos agrícolas abandonados.

- Mantener un paisaje de visuales extensas.

4. Gestión y potenciación del saladar en las zonas agrícolas abandonadas situadas entre el cementerio de La Mata, la antigua Casa Forestal, el alto de la Hoya y la carretera N332. (ver código 4 en figura 5.51). Mediante esta actuación se pretende:

- Acelerar la implantación del saladar sobre terrenos agrícolas abandonados.

- Mantener un paisaje de visuales extensas, especialmente desde la carretera N332.

5. Inserción de una cuña de pinar y bosque termo mediterráneo al oeste de un tramo de la carretera N332 desde el que no se dispone de vistas de la laguna (ver código 5 en figura 5.51). Mediante esta actuación se pretende:

- Generar una secuencia de zonas arboladas en la nacional 332 en aquellos tramos en los que por motivos topográficos no se dispone de visuales extensas.

6. Creación de una zona verde de carácter forestal agrícola al sur de Ciudad Quesada. Dicha zona debería incluir formaciones vegetales propias del entorno (saladar, pinar, tarayal, y puntualmente carrizal) así como zonas de huertos privados o de ocio para los residentes de la urbanización. La actuación está ya contemplada en el PORN del Parque Natural e iría acompañada de la rehabilitación y asignación de nuevos usos a la Casa de la Niña de Lo Marabú. (ver código 6 en figura 5.51).

7. Creación de una zona verde de carácter forestal agrícola al sur de la urbanización El Raso. Dicha zona debería incluir formaciones vegetales propias del entorno (saladar, pinar, tarayal, y puntualmente carrizal) así como zonas de huertos privados o de ocio para los residentes de la urbanización. La actuación está ya contemplada en el PORN del Parque Natural e iría acompañada de la rehabilitación y asignación de nuevos usos a la Casa del Raso. (ver código 7 en figura 5.51).

8. Creación de una zona verde de carácter forestal en el alto de la Hoya. Dicha zona debería incluir fundamentalmente una vegetación formada por pinar y sotobosque termo mediterráneo, integrándose en el continuo arbolado propuesto en el conector este entre las lagunas de La Mata y Torrevieja. La actuación está ya contemplada en el PORN del Parque Natural (ver código 8 en figura 5.51).

9. Creación de un parque agrícola forestal entre la laguna de Torrevieja y la playa del Rocío / cala Ferris (ver código 9 en figura 5.51). Dicho parque incluiría un sistema de corredores arbolados 
(pinar y sotobosque) que marcarían los ejes de conexión entre los marjales situados al sudeste de la laguna de Torrevieja, el hospital y la desaladora de Torrevieja, la finca de la Ceñuela, un paso elevado singular sobre la carretera N332, la finca de Lo Ferrís y el mar Mediterráneo. Acompañando a dichos corredores se mantendría la actividad agrícola y el uso y acceso privado en el resto del parque, fundamentalmente dedicado a la producción de cítricos (Finca La Ceñuela) y de hortícolas o herbáceos en regadío (Finca Lo Ferris). Mediante esta actuación se pretende (1): conectar el sur de la Laguna de Torrevieja con el frente litoral, (2):consolidar un espacio abierto que evite la creación de un continuo urbanizado entre el casco urbano de Torrevieja y la costa de Orihuela, (3): proporcionar un acceso de alta calidad paisajística al sur del casco urbano de Torrevieja desde las carreteras N33 y CV95, y (4): relacionar visualmente las grandes dotaciones presentes en la zona (hospital, desaladora y depuradora).

10. Desarrollar con un patrón de bosque y sotobosque termo mediterráneo los vacíos urbanos existentes en la urbanización del Chaparral y San Luis (ver código 10 en figura 5.51).

11. Reordenar y revegetar con pinar y lentiscar/tarayal la zona este de la planta de tratamiento de áridos situada al sur de la laguna de Torrevieja (ver código 11 en figura 5.51). Mediante esta actuación se pretende generar un mirador sobre las acumulaciones de áridos existentes y disminuir su impacto sobre el paisaje visibles desde la laguna y las carreteras cercanas.

12. Reintroducción del saladar al sureste de la desembocadura de la rambla del Garbanzuelo. (ver código 12 en figura 5.51).

13. Gestión y Saneamiento de las masas arbóreas existentes en la finca de La Marquesa, finca Lo Ferris, finca de La Ceñuela, casa de las Palmeras, finca Lo Reche, etc. (ver código 13 en figura 5.51).

Actuaciones Lineales sobre la Vegetación: Se han considerado las siguientes:

1. Regeneración de saladares en las orillas sur y sureste de la laguna de Torrevieja (zonas lindantes con la depuradora de aguas residuales y con la urbanización de Los Balcones) (ver código 14 en en figura 5.51).

2. Introducción de arbolado urbano (especies autóctonas) en la urbanización de Ciudad Quesada mediante la reducción de calzadas en parte del viario urbano y creación de pantallas arboladoarbustivas en los bordes externos de la urbanización (ver código 15 en figura 5.51). Mediante esta actuación se pretende:

- Mejorar la calidad del paisaje y la habitabilidad del espacio público de la urbanización.

- Facilitar la integración de la edificación desde la distancia.

3. Introducción de arbolado urbano (especies autóctonas) en la urbanización del Raso mediante la reducción de calzadas en parte del viario urbano y creación de pantallas arbolado-arbustivas en los bordes externos de la urbanización (ver código 16 en figura 5.51). Mediante esta actuación se pretende:

- Mejorar la calidad del paisaje y la habitabilidad del espacio público de la urbanización.

- Facilitar la integración de la edificación desde la distancia.

4. Creación de pantallas vegetales (pinar y lentiscar) junto a las urbanizaciones situadas a lo largo del tramo norte de la carretera N332 (ver código 17 en figura 5.51).

5. Creación de pantallas vegetales arbóreo arbustivas junto a la carretera CV945 a su paso por el área industrial al este de Los Montesinos (ver código 18 en figura 5.51).

6. Creación de pantallas vegetales arbóreo arbustivas en los tramos de la carretera CV905 que atraviesan zonas urbanas y urbanizaciones. (ver código 19 en figura 5.51).

7. Prolongación del patrón discontinuo de pinos situados junto a la carretera CV943 (ver código 20 en figura 5.51).

8. Creación de una pantalla arbórea arbustiva entorno al centro de transformación de Los Montesinos. (ver código 21 en figura 5.51).

9. Integración mediante plantación de alineaciones estratégicas de pinos y arbustos en la elevación artificial en la que se ubica la balsa de riego situada junto a la casa de Los Gallutes. (ver código 22 en figura 5.51). 
10. Plantación estratégica de bosquetes de pinos y de agrupaciones de palmera datilera a lo largo del tramo sur del anillo de circulación peatonal en torno a la laguna de Torrevieja. (ver código 23 en figura 5.51).

11. Creación de pantallas y masas vegetales arbóreo arbustivas en la fachada oeste de la urbanización Torreta Florida (ver código 24 en figura 5.51).

Actuaciones Mixtas (Lineales - Extensas) sobre la Vegetación: Se han considerado las siguientes:

1. Reordenación de la Vía Verde (reducción de la sección de las calzadas, ampliación de las zonas verdes a los lados de la vía verde y plantación en éstas con pinar y sotobosque mediterráneo) y creación de zonas verdes de conexión con las zonas verdes propuestas o existentes a lo largo de la carretera CV905 (ver código 25 en figura 5.51). Mediante esta actuación se pretende:

- Introducir en la vía verde elementos del paisaje vegetal propio de la zona (frente a la jardinería de especies exóticas actual).

- Hacer más habitable la vía verde (proporcionando una sombra intensa).

- Generar una pantalla vegetal entre la vía verde y las urbanizaciones que la flanquean.

- Transformar la Vía Verde en el elemento vertebrador de los espacios verdes situados en las urbanizaciones de san Luis y La Torreta.

2. Reordenación del parque del Acequión de Torrevieja: Vertebración del parque a lo largo del Acequión e introducción de patrones vegetales y formales vinculados al paisaje del Parque Natural. (ver código 26 en figura 5.51).

3. Creación del parque del Canal de La Mata: Vertebración del parque a lo largo del canal de La Mata e introducción de patrones vegetales y formales vinculados al paisaje del Parque Natural. (ver código 27 en figura 5.51).

4. Creación de un sistema mixto de bandas boscoso arbustivas a lo largo de la carretera N332 (ver código 28 en figura 5.51) y vinculación de dichas bandas a las siguientes zonas boscosas o saladares extensos:

- Nudo viario al norte del alto de Casillas (ver código 28a en figura 5.51).

- Entorno del mirador del alto de Casillas. (ver código 28b en figura 5.51).

- Entorno de la zona polideportiva de Torrevieja (ver código 28c en figura 5.51).

- Nudo viario de acceso a las salinas. (ver código $28 \mathrm{~d}$ en figura 5.51).

- Terrenos baldíos y con topografía alterada el este de la estación depuradora de Torrevieja y al sur de las instalaciones salineras (ver código 28e en figura 5.51).

Tal y como se expone en las 5 secciones siguientes la posición de algunas de las masas y alineaciones arbóreo arbustivas ha sido definida con el objeto de ocultar parcialmente la edificación desde recorridos internos del Parque Natural o desde el sistema de carreteras que lo circundan:

1) Sección a través de Ciudad Quesada (E-E'): Se concluye la importancia de la presencia del estrato arbóreo en la zona norte del futuro parque agrícola forestal de dicha urbanización y de la introducción de arbolado en el viario. Se desestima la creación de pantallas vegetales en las zonas de huertas o saladares próximos a la laguna de la Mata por su incompatibilidad con la actividad agrícola y el carácter del paisaje de huertos (en el primer caso) o con el paisaje bidimensional del saladar (en el segundo).

2) Sección a través de la Urbanización del Raso (D-D'): Se concluye la importancia de la presencia del estrato arbóreo en la franja de suelo entre la urbanización y la carretera CV895 así como al norte del futuro parque agrícola forestal de dicha urbanización. En este caso, y a diferencia de Ciudad Quesada, la posición de la urbanización en una zona llana resta efectividad al arbolado viario como pantalla visual de la edificación pero presenta un efecto positivo sobre el paisaje urbano y su habitabilidad.

3) Sección a través de las urbanizaciones de la anticlinal del Chaparral (C-C'): Las secciones muestran la importancia de generar una pantalla verde junto a la fachada de las urbanizaciones lindante con el parque y los beneficios de integrar bandas o zonas verdes a lo largo de la carretera CV905.

4) Sección a través de los viñedos de La Mata (A-A'): La altura de los edificios situados en Torrelamata y la no conveniencia de realizar plantaciones arbóreas que rompan la profundidad visual del paisaje de viñedos y las vistas de la laguna de la Mata desde la carretera N332, recomiendan la disposición de una pantalla vegetal de pinar y sotobosque en la franja libre entre la citada carretera y la fachada edificada de Torrelamata.

5) Sección a través de las instalaciones salineras (B-B'): La posición elevada de la carretera N332 en esta zona hace inviable ocultar la edificación situada en su lado este. En lo referente a la plataforma sobre la que se ubica la carretera, se sugiere en su cara este su integración visual mediante plantaciones arbustivas y herbáceas, reforzadas con plantaciones arbóreas en la base. En los taludes oeste, dado el carácter extenso de los saladares se desestima la introducción de arbolado. 

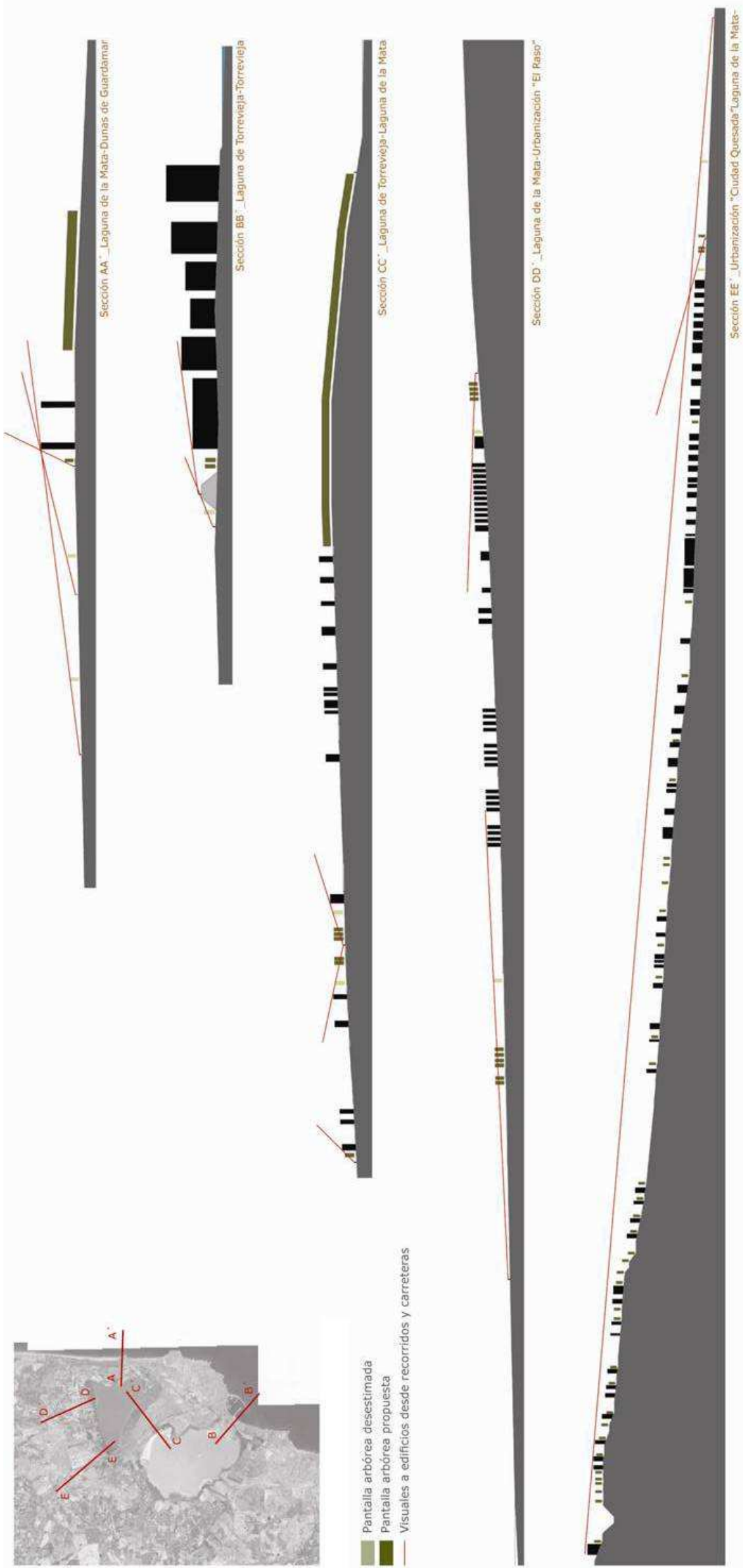

Fig. 5.52. Estudio mediante secciones de la ubicación de posibles pantallas arbóreas en el entorno del parque natural de las lagunas de La Mata y Torrevieja 


\section{4.j.4.3. Intervenciones sobre la topografía y obra civil en elementos hidráulicos y carreteras:}

Las principales actuaciones propuestas serían las siguientes (no se incluye la obra civil asociada a la rehabilitación de edificios, creación de zonas verdes, etc.)

1. Restituir topografías en zonas con relieves altamente modificados y con un impacto negativo en el paisaje. Dichas situaciones se localizarían en los puntos siguientes:

- 1.a. Zona de acopio y procesado de áridos (ver código 1 en figura 5.57). En esta zona se prevé tender y naturalizar los taludes en la zona de acopio principal y secundaria con el fin de generar un mirador sobre la laguna de Torrevieja, quedando la zona oeste funcional para la actividad actualmente en desarrollo.
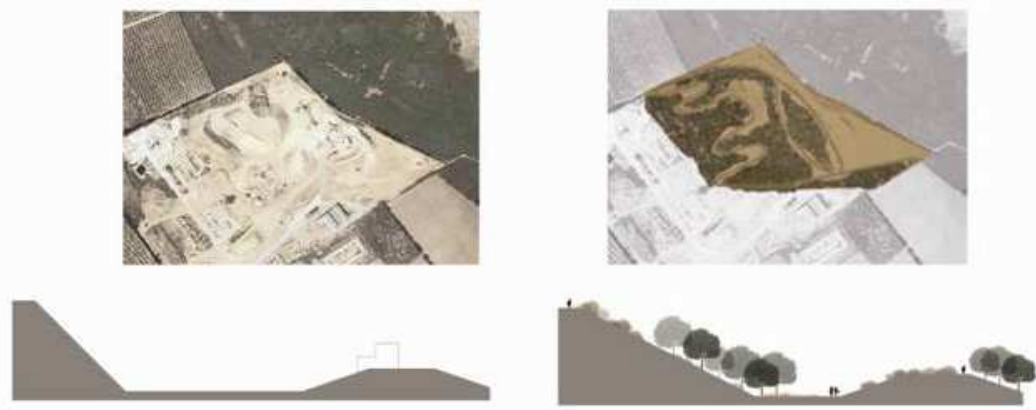

Figura 5.53: Planta y sección con propuesta de intervención en zona de acopio de áridos lindante con el parque natural

- 1.b. Nudo de acceso sur a las salinas (ver código 2 en figura 5.57). Zona actualmente con escombros en la que se propone recuperar una topografía llana y proceder a la revegetación con saladares / herbazales y masas de pinar/tarayal.
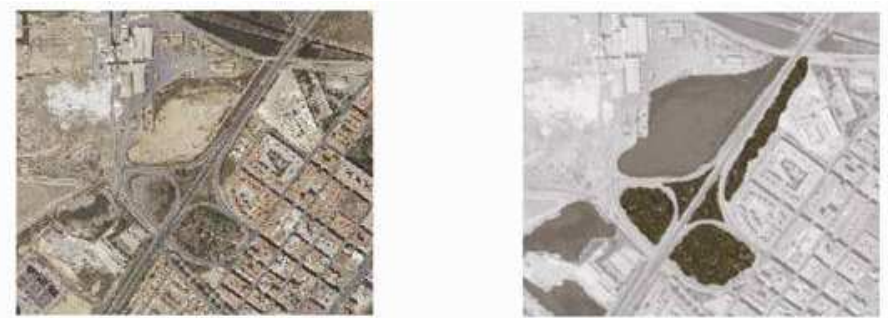

Fig. 5.54: Propuesta de intervención en nudo de acceso sur a las salinas de Torrevieja.

- 1.c. Talud oeste de la depuradora y zona próxima al área de acumulación de lodos salinos (ver código 3 en figura 5.57). En esta zona se propone tender y revegetar los taludes y recuperar la topografía llana en el entorno de la laguna

2. Suavizar y revegetar taludes en los márgenes de las carreteras:

- 2.a Tramos en trinchera de la carretera nacional N332 en el entorno de la laguna de Torrevieja (ver código 4 en figura 5.57)

- 2.b. Tramos en plataforma de la carretera nacional N332 en el entorno del Acequión de Torrevieja

- (ver código 5 en figura 5.57)

3. Recuperar la sección abierta del canal de La Mata en su tramo urbano (ver código 6 en figura 5.57)

4. Construir o recuperar recorridos.

- 4.a. Nuevos carriles bici adosados a carreteras (ver principales tramos en figura 5.49)

- 4.b. Nuevos caminos con firme de terrizo (ver principales tramos en figura 5.49)

- 4.c. Nuevos caminos mixtos tarima de madera - terrizo (ver principales tramos en figura 5.49)

- 4.d. Mejora de firmes en caminos existentes integrados en nuevos recorridos (ver figura 5.49)

5. Resolver cruces de recorridos y cursos de agua con infraestructuras de transporte.

- 5.a. Cruces de recorridos con las infraestructuras de transporte: (ver los distintos tipos de soluciones propuestas en figura 5.57 )

- 5.b. Acondicionar cruces de las rambla de La Fayona y del Garbanzuelo con infraestructuras de transporte (ver código 7 en figura 5.57)

- 5.c. Ampliar cruce del Acequión de Torrevieja con la carretera N332 (ver código 8 en figura 5.57) 
6. Modificación de secciones en el viario de urbanizaciones con el objeto de incorporar vegetación y de mejorar la movilidad peatonal.

- 6.a. En Ciudad Quesada: (ver figura 5.53 y código 9 en figura 5.57).

- 6.b. En la urbanización El Raso: (ver figura 5.54 y código 10 en figura 5.57).

- 6.c. En las urbanizaciones del Chaparral: (ver figura 5.54 y código 11 en figura 5.57).

- 6.d. En los tramos urbanos de la Vía Verde: (ver código 12 en figura 5.57).
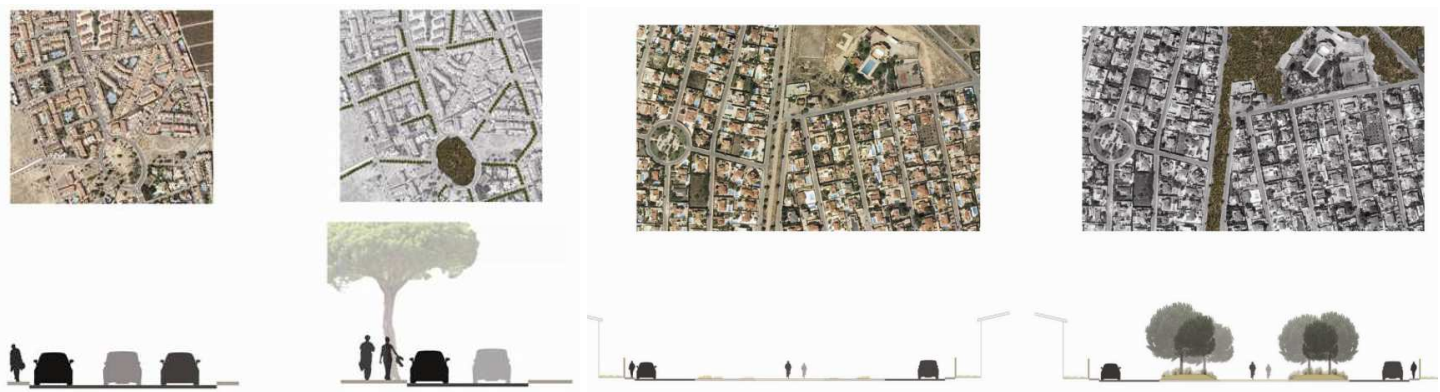

Fig. 5.55: Propuesta de cambios de sección en el viario de Ciudad Quesada.
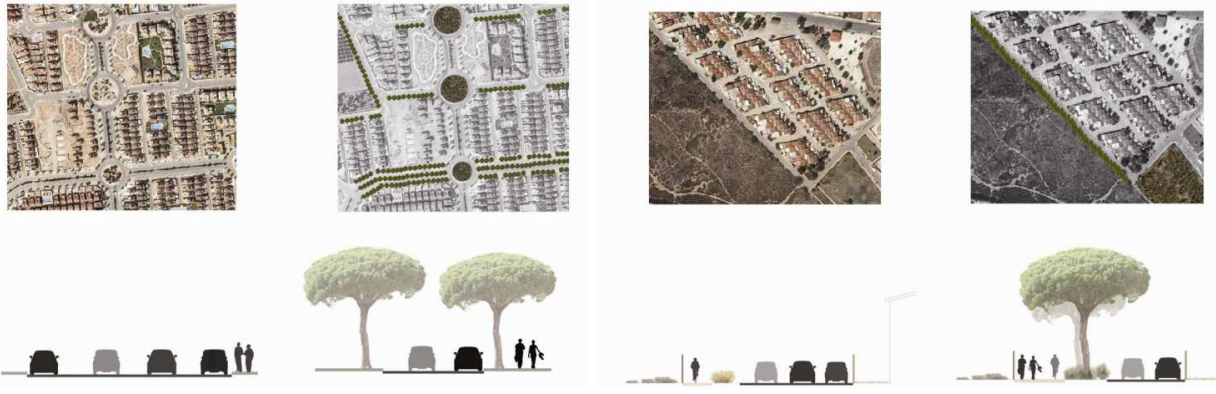

Fig. 5.56: Propuesta de cambios de sección en el viario de la urbanización El Raso (izda.) urbanizaciones del Chaparral (dcha.)
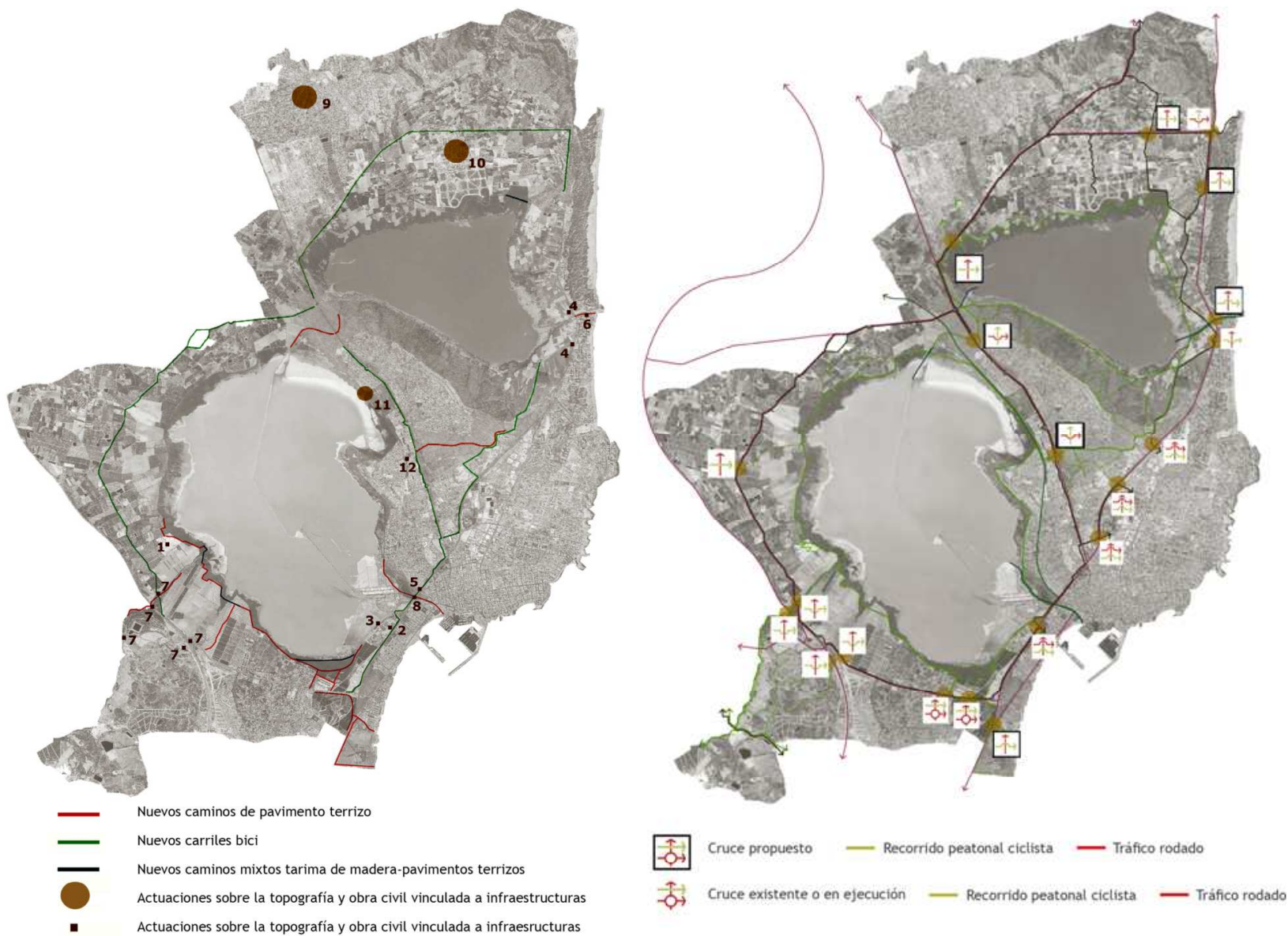

Fig. 5.57: Propuesta de intervenciones sobre la topografía y elementos de obra civil (plano de la izquierda) y relación entre circulaciones rodadas y blandas (peatonales y ciclistas) en los cruces próximos al parque natural (plano de la derecha) 


\section{4.j.4.4. Intervenciones sobre el patrimonio arquitectónico e hidráulico:}

El ámbito estricto del presente estudio de paisaje dispone de un valioso patrimonio de arquitectura rural e ingeniería hidráulica. Las propuestas que se exponen a continuación buscan su restauración y asignación de nuevos usos con el objeto de garantizar su adecuado mantenimiento y disfrute público.
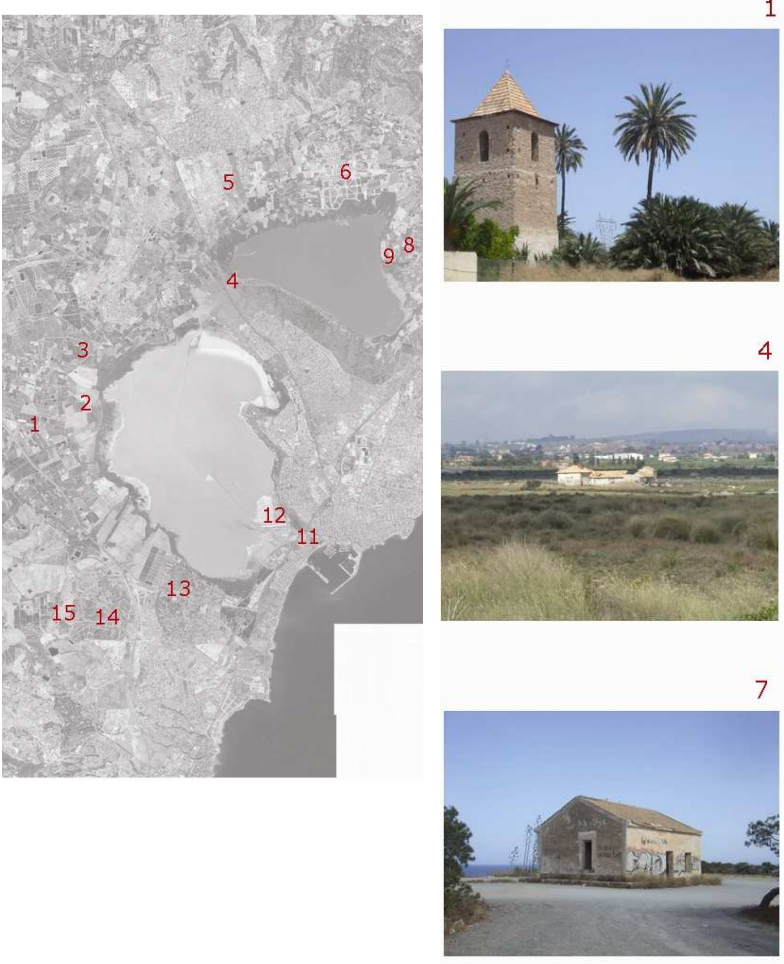

10

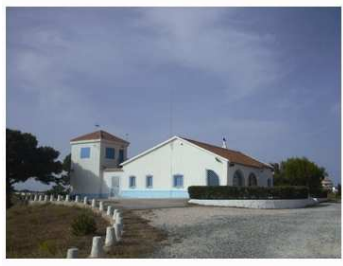

13
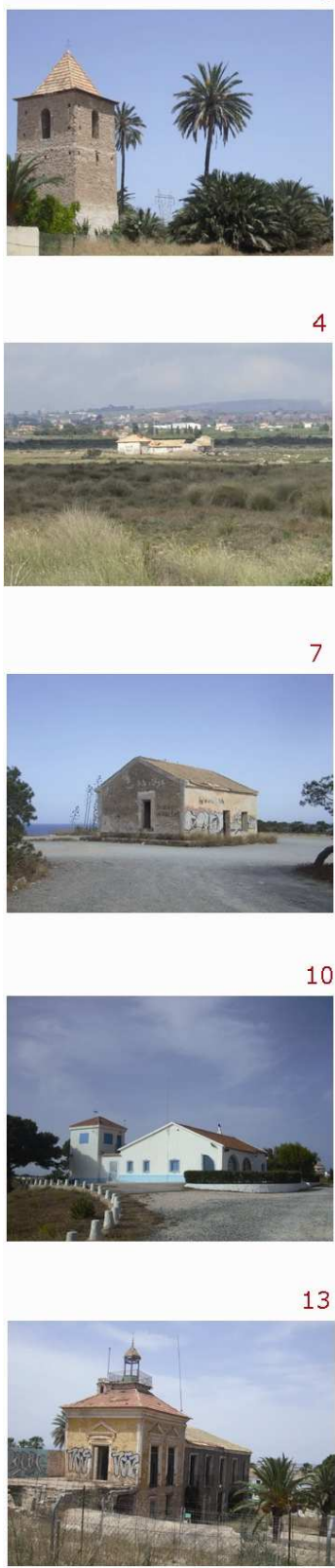
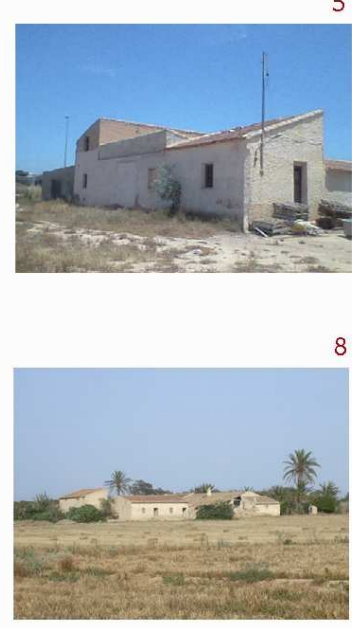

11
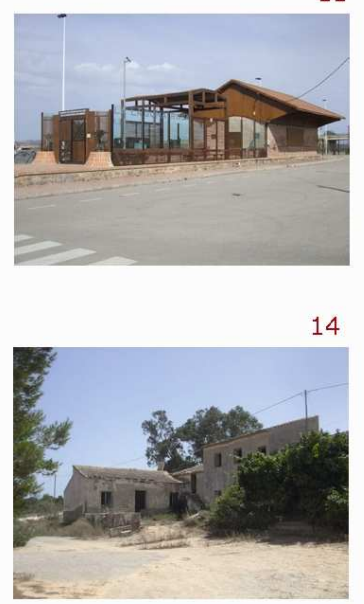
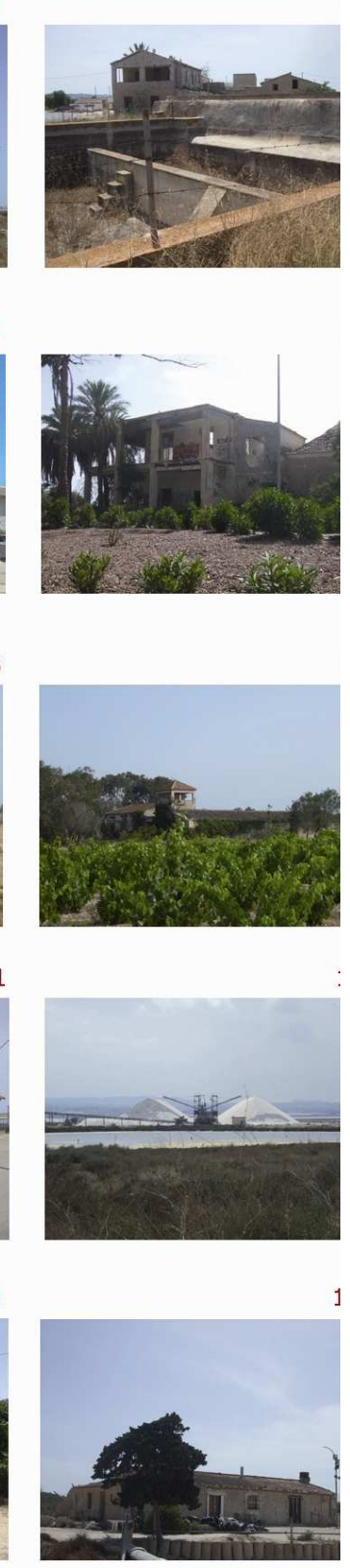

1. Finca La Marquesa + Ermita + Aljibe: Museo Agrícola + Mercado agricultura local + Punto información Parque + Aparcamiento.

2. Finca de Lo Reche + Aljibe: Uso Hostelero / Restauración.

3. Casa de Los Diez + Infraestructuras Hidráulicas: Hostelero / restauración.

4. Casa de la Máquina: Centro de información y museo hidráulico.

5. Casa de la Niña de Lo Marabú: Museo Etnográfico + Centro Social Ciudad Quesada + Punto Información Parque + Aparcamiento + Parada Bus

6. Casa del Raso: Centro Social Urbanización El Raso + Punto Información Parque + Aparcamiento + Parada Bus.

7. Casa de Peones Camineros: Centro de Interpretación Forestal + Punto de Información Parque+ Aparcamiento + Parada Bus.

8. Casa de Las Palmeras: Museo del Vino de la Mata + Mercado de productos agrícolas locales + Aparcamiento + Parada Bus.

9. Casa de Sala: Uso Hostelero o Albergue.

10. Centro de la laguna de La Mata: Centro de Interpretación del Parque+ Sala Expositiva Parque + Aparcamiento + Parada Bus.

11. Centro de la laguna de Torrevieja: Centro de Interpretación del Parque+ Museo Actividad Salinera + Aparcamiento + Parada Bus.

12. Instalaciones Salineras: Punto de Atención Público + Visitas Guiadas + Punto de Venta.

13. Casa de los Balcones: Uso Hostelero / Restauración + Parada Bus.

14. Casa del Garbanzuelo: Uso Hostelero (casa rural).

15. Casa de las Majadas: Uso Hostelero / Albergue, Centro Hípica.

Fig.5.58: Propuesta de rehabilitación y asignación de nuevos usos al patrimonio arquitectónico situado en el entorno del parque natural de las lagunas de La Mata-Torrevieja 


\section{4.j.5. Plan director de ordenación paisajística}

5.4.j.5.1 Plano General: El Plano que se muestra en la presente página recoge de forma esquemática el sistema de recorridos y los usos propuestos para el parque natural, su entorno y los edificios rehabilitados:

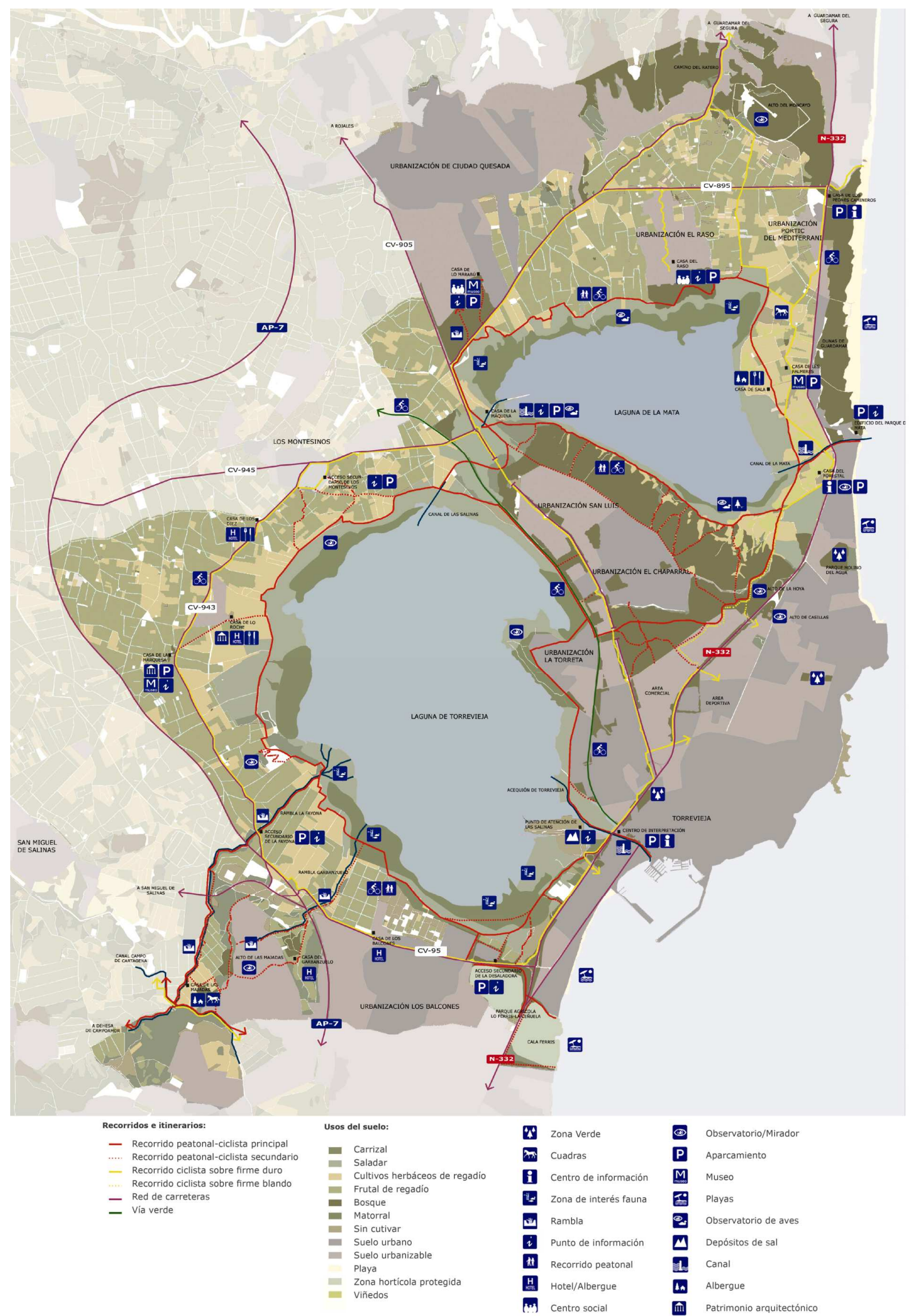

Fig. 5.59: Plano de ordenación paisajística del parque natural de las lagunas de La Mata y Torrevieja y su entorno (escala 1:75.000). 


\section{4.j.5.2. Itinerarios previstos}

Los itinerarios previstos se agrupan en las siguientes 4 categorías:

- Anillo de circunvalación de la laguna de Torrevieja

- Anillo de circunvalación de la laguna de La Mata

- Rutas de conexión entre las lagunas de La Mata y Torrevieja

- Rutas periféricas: Rutas hacia el frente litoral u otros espacios de interés medioambiental o paisajístico próximos.

Para cada una de las siguientes categorías se diferencian a su vez distintos itinerarios que deberían quedar diferenciados sobre el terreno por una señalética específica, y que en el caso de las rutas en torno a la laguna de La Mata y a la de Torrevieja, se encadenan hasta completar sendos circuitos circulares. Con el objeto de permitir a los visitantes, (especialmente aquellos que realicen las visitas a pie y no en bicicleta), el realizar tramos del conjunto de recorridos propuestos, los inicios y finales de éstos cuentan, en muchos casos, con aparcamientos (dotados de puntos de información) o paradas próximas de la línea de autobús intermunicipal propuesta.

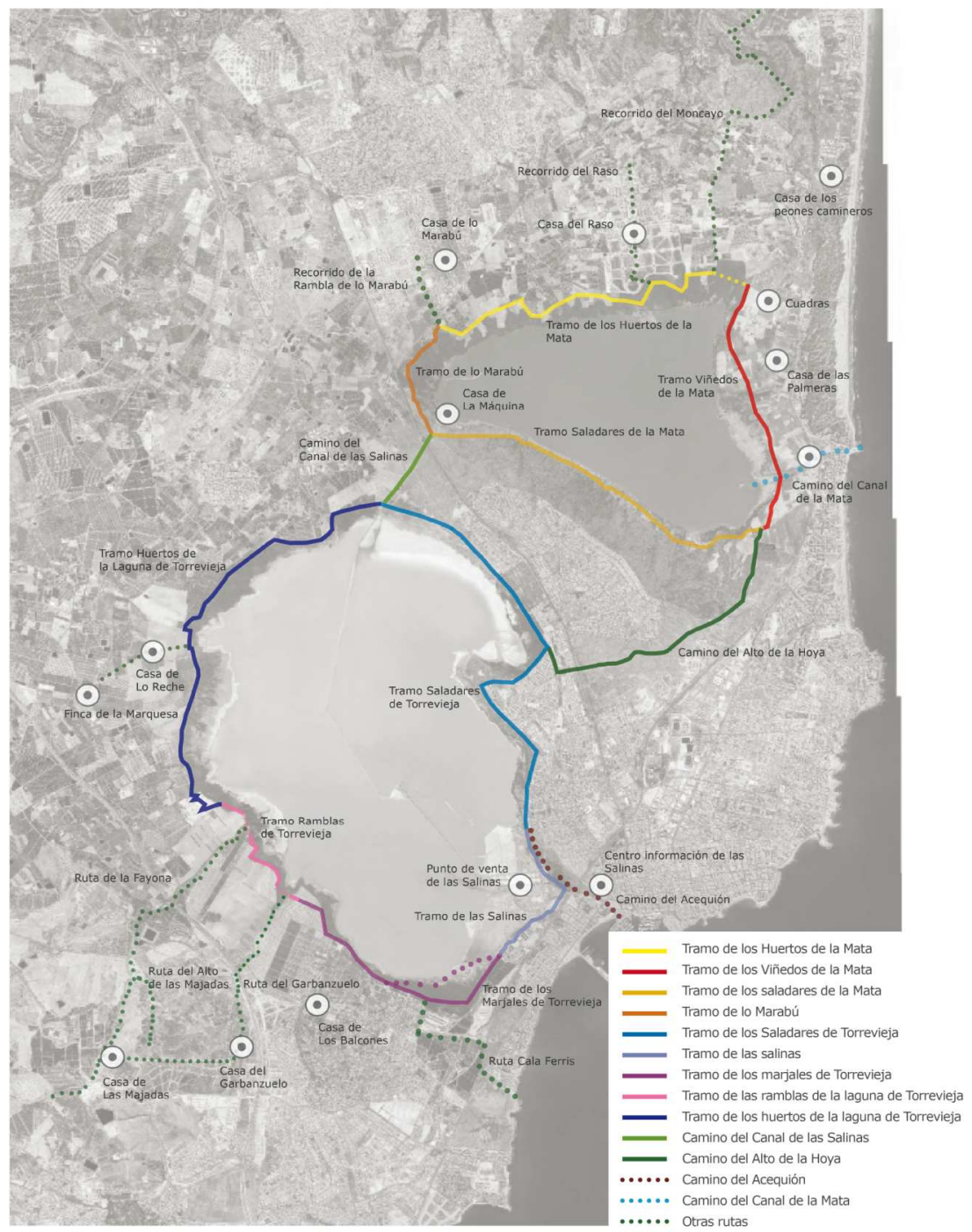

Fig. 5.60: Plano general de ordenación paisajística del parque natural de las lagunas de La Mata y Torrevieja y de su entorno (escala aproximada 1:125.000).

\section{1.- ANILLO CIRCUNVALACIÓN LAGUNA DE TORREVIEJA}

Distancia total: 20.400 metros

Incluye los tramos siguientes:

\subsection{TRAMO DE LOS SALADARES DE TORREVIEJA}

Distancia: $6.500 \mathrm{~m}$

Recorrido por la orilla norte de la laguna de Torrevieja que discurre a lo largo de los extensos saladares situados entre el Acequión de Torrevieja y el extremo sur del Canal de las Salinas. Este trayecto ofrece vistas de la Laguna de Torrevieja y de su singular espacio de la Punta de la Víbora, compartiendo a su vez parte de su recorrido con la Vía Verde (ruta ciclista sobre la traza de la antigua vía férrea Torrevieja- Albatera). 


\subsection{TRAMO HUERTOS DE LA LAGUNA DE TORREVIEJA}

Distancia: $5.800 \mathrm{~m}$

Recorrido entre los huertos tradicionales de Los Montesinos y Torrevieja y las marjales/saladares de la laguna de Torrevieja. Jalonado por distintas casas rurales, aljibes y muestras del patrimonio arquitectónico e hidráulico, como la finca de La Marquesa o de Lo Reche, cuya rehabilitación ha facilitado la asignación de nuevos usos destinados a la población local y visitantes. El recorrido permite a su vez conocer los sistemas tradicionales de producción agrícola y disponer de excelentes vistas de la laguna de Torrevieja.

\subsection{TRAMO DE LAS RAMBLAS DE TORREVIEJA}

Distancia: $1.700 \mathrm{~m}$

Recorrido corto entre la desembocadura de Las Ramblas de La Fayona y del Garbanzuelo. Zona con marjales/saladares y áreas pantanosas desde la que se accede a las Rutas de las ramblas de La Fayona y del Garbanzuelo que ascienden hacia la sierra de Escalona y la dehesa de Campoamor. Zona de alto valor ecológico por la confluencia del sistema lagunar y de ramblas.

\subsection{TRAMO DE LAS MARJALES DE TORREVIEJA}

\section{Distancia: $3.600 \mathrm{~m}$}

Recorrido a lo largo de extensos marjales que limita con algunas de las más importantes dotaciones públicas de Torrevieja como la depuradora, el hospital y la desaladora, generándose un paisaje mixto de infraestructuras y carrizales. El recorrido incluye una conexión con la playa del Rocío y con la singular cala Ferris y su palmeral.

\subsection{TRAMO DE LAS SALINAS}

Distancia: $2.800 \mathrm{~m}$

Se trata de un tramo de distancia media que rodea y atraviesa la zona de instalaciones salineras. A lo largo del recorrido se pueden observar los impresionantes depósitos de sal de una de las mayores salinas del mundo en volumen de producción. También se pueden ver las zonas de depósitos de lodos salinos, los edificios y cintas transportadoras de la sal. En este tramo se localizaría un centro de atención al visitante de las salinas desde el que partirían visitas guiadas a las instalaciones y en el que se ubicaría un punto de venta de productos exclusivos de las salinas.

\section{2.- ANILLO CIRCUNVALACIÓN LAGUNA DE LA MATA}

Distancia total: 15.500 metros

Incluye los tramos siguientes:

\subsection{TRAMO DE LOS SALADARES DE LA MATA}

Distancia: $5.300 \mathrm{~m}$

Recorrido entre el cementerio de Torrelamata y el extremo norte del Canal de Las Salinas. Atraviesa algunas de las zonas de mayor valor ecológico del Parque Natural (saladares excepcionalmente conservados, microrreserva de orquídeas y pinares del Chaparral). Incluye un observatorio de aves y una zona de descanso y dispone de tramos sombreados por antiguas plantaciones de eucaliptos.

\subsection{TRAMO DE LO MARABÚ}

Distancia: $1.900 \mathrm{~m}$

Recorrido que discurre entre saladares secos y marjales con un alto valor faunístico y en los que se da la presencia de zonas de nidificación del aguilucho cenizo. Desde su extremo este se puede acceder a la Casa de la Máquina, punto en el que se origina el canal de las Salinas y en el que se bombea el agua de la laguna de La Mata a la laguna de Torrevieja.

\subsection{TRAMO HUERTOS DE LA MATA}

Distancia: $4.400 \mathrm{~m}$

Recorrido entre los marjales y los huertos tradicionales de La Mata. Su trayecto discurre próximo a Ciudad Quesada y a la urbanización de El Raso. A lo largo del camino se pueden observar los sistemas de riego tradicionales y algunos de los huertos tradicionales mejor conservados en la zona. Este recorrido permite a su vez acceder a los nuevos parques forestales-agrícolas propuestos en las zonas de amortiguación situadas entre el Parque Natural y las dos urbanizaciones antes citadas, y en los que se sugiere crear sendas zonas verdes inspiradas en los sistemas ecológicos del parque y en los antiguos huertos agrícolas. Dichas zonas verdes integrarían respectivamente La Casa de la Niña de Lo Marabú (Ciudad Quesada) y la Casa del Raso, dos ejemplos a rehabilitar de la arquitectura rural tradicional, y a los que se ha asignaría nuevos usos para las comunidades próximas y para los visitantes del Parque.

\subsection{TRAMO DE LOS VIÑEDOS DE LA MATA}

Distancia: 3.900

Recorrido que discurre por un singular paisaje de herbáceos extensivos y viñedos, de secano (entre los que se incluyen cepas de la variedad protegida Merseguera). A lo largo de esta ruta se puede disfrutar de amplias vistas sobre los saladares y la lamina de agua de la laguna de La Mata, se puede visitar la casa de las Palmeras (posible museo del vino de La Mata y centro de un mercado de productos agrícolas locales) o hacer uso de los nuevos servicios disponibles en las rehabilitables casa de Salas y la casa de Falt. En un punto intermedio del recorrido se encuentra ubicado el Centro de Visitantes de La Mata, uno de los accesos principales al Parque Natural y en el que se dispone de distintos servicios y exposiciones públicas. 


\section{3.- RUT AS DE INTERCONEXIÓN ENTRE LAS LAGUNAS DE LA MATA Y TORREVIEJA: 3.1. CAMINO DEL ALTO DE LA HOYA}

Distancia: $4.800 \mathrm{~m}$

Recorrido entre las lagunas de La Mata y Torrevieja que discurre por las zonas más elevadas del Parque. Ofrece vistas excepcionales de ambas lagunas y una transición entre los marjales-saladares y el bosque termo-mediterráneo, en el que destacan las extensas pinadas del Chaparral a las que se adosan nuevas zonas de pinar y lentiscar. La parte sur-oriental del recorrido ofrece una conexión directa con la Vía Verde y la laguna de Torrevieja, discurriendo parte del trayecto sobre la carretera CV905, que pasa a transitar en túnel en dicha zona.

\subsection{CAMINO CANAL DE LAS SALINAS}

Distancia: $1.500 \mathrm{~m}$

Recorrido de corta distancia que comunica las lagunas de La Mata y Torrevieja cuyo trazado se apoya en el Canal de las Salinas. Atraviesa una extensa zona de saladares e incluye en su zona norte la Casa de la Máquina, edificio desde el que se bombea el agua de la laguna de la Mata a la laguna de Torrevieja. Con el objeto de garantizar la adecuada circulación de peatones, ciclistas y fauna, el recorrido se inserta en un corredor de 500 metros de anchura ubicado sobre un tramo en túnel de la carretera CV905.

\section{4.- RUT AS PERIFÉRICAS}

\subsection{CAMINO DEL ACEQUIÓN.}

Distancia: $2000 \mathrm{~m}$

Recorrido que discurre paralelo al Acequión de Torrevieja y que se origina en las playas de arena de la laguna de Torrevieja, atraviesa los saladares que flanquean las instalaciones salineras y los espectaculares depósitos de sal, para pasar a continuación bajo la carretera nacional N332 y entrar en el posible parque lineal del Acequión, inspirado en las formaciones vegetales y morfología de la laguna de Torrevieja. El punto final del recorrido lo constituye la desembocadura del Acequión en la playa marítima del mismo nombre, pudiendo disponerse en dicho punto de vistas del muelle desde el que se cargan los buques que transportan la sal.

\subsection{CAMINO DEL CANAL DE LA MATA}

Distancia: 1200 metros

Recorrido que discurre paralelo al canal de La Mata y que se origina en los saladares y playas de la laguna del mismo nombre para atravesar a continuación los singulares viñedos del Parque Natural y alcanzar el paso elevado mediante el que, peatones y ciclistas, pueden pasar sobre la carretera nacional N332 y acceder al parque lineal del canal de la Mata, en el que se ha procedido a descubrir y rehabilitar el canal, convirtiéndolo en el elemento vertebrador de un parque inspirado en las formaciones vegetales y morfología de la laguna de La Mata. El punto final del recorrido lo constituye la desembocadura del canal en el mar Mediterráneo en un punto próximo al torreón de La Mata y a un nuevo edificio de información y servicio a los visitantes del Parque.

\subsection{RUTA DE LA FAYONA}

Distancia: $3.800 \mathrm{~m}$

Recorrido que conecta la Laguna de Torrevieja con la Dehesa de Campoamor y Sierra Escalona. Todo el trayecto tiene lugar a lo largo de la Rambla de la Fayona, siendo ésta una zona de alto valor ecológico rodeada por áreas agrícolas. Desde la ruta se puede acceder al alto de las Majadas, con magníficas vistas sobre la laguna de Torrevieja así como a la Casa de las Majadas, en la que se propone la ubicación de distintos servicios a los visitantes

\subsection{RUTA DEL GARBANZUELO}

Distancia: $3700 \mathrm{~m}$

Recorrido que conecta la laguna de Torrevieja con la dehesa de Campoamor y la sierra Escalona y cuyo origen se localiza en los carrizales y zona pantanosa en la que desemboca la Rambla. Tras un recorrido inicial paralelo a la rambla del Garbanzuelo y tras atravesar por sendos viaductos las carreteras CV95 y AP7, la ruta se bifurca en dos recorridos, el primero de los cuales discurre a lo largo de la rambla, mientras que el segundo permite acceder a la rehabilitada Casa del Garbanzuelo, desde la que es posible continuar el trayecto hasta el alto de las Majadas (con amplias vistas sobre el Mediterráneo y la laguna de Torrevieja) para enlazar a continuación con la ruta de la rambla de la Fayona a la altura de la Casa de Las Majadas.

\subsection{RUTA DEL ALTO DE LAS MAJADAS}

Distancia: $1.100 \mathrm{~m}$

Recorrido que se origina en la Ruta de la Rambla de la Fayona y que permite acceder a través de una zona de excepcional valor y riqueza faunística al alto de las Majadas, desde el que se dispone de vistas excelentes hacia el mar Mediterráneo y la laguna de Torrevieja y desde el que se puede acceder a la ruta del Garbanzuelo o retomar la ruta de La Fayona.

\subsection{RUTA DEL MONCAYO}

Distancia: 2800 metros

Recorrido sobre la traza del camino rural del Ratero que permite llegar a las inmediaciones del Alto del Moncayo, desde el que se dispone de amplias vistas de la laguna de La Mata. A lo largo de este recorrido se atraviesan los huertos del Campico de Guardamar, un espacio de especial valor etnográfico en el que se puede observar ejemplos de técnicas agrícolas tradicionales, y acceder a las zonas boscosas regeneradas que se localizan en las cotas más altas. 


\subsection{RECORRIDO DE LA RAMBLA DE LO MARABÚ}

\section{Distancia: 1000 metros}

Recorrido que se origina en la Casa de Las Niña de Lo Marabú (posible museo etnográfico municipal de Rojales y centro comunitario de la zona sur de Ciudad Quesada) para atravesar a continuación el nuevo parque forestal agrícola propuesto al sur de la citada urbanización, en el que coexisten zonas con morfología y vegetación inspirada en el parque natural y zonas de huertos de ocio, estos últimos mantenidos por la población local y en los que se preservan las técnicas agrícolas tradicionales. La ruta, discurre paralela a la rambla de lo Marabú para atravesar a continuación la carretera CV895 y desembocar en el recorrido perimetral de la laguna de La Mata.

\subsection{RECORRIDO DEL RASO}

Distancia: 1200 metros

Recorrido que se origina en la entrada a la urbanización El Raso para discurrir a continuación junto a la casa del Raso (posible edificio de servicios y centro comunitario de la zona sur de la urbanización del mismo nombre). La ruta atraviesa a continuación el nuevo parque forestal agrícola situado al sur de la citada urbanización, en el que coexisten zonas con morfología y vegetación inspirada en el parque natural y zonas de huertos de ocio, estos últimos mantenidos por la población local y en los que se preservan las técnicas agrícolas tradicionales. La ruta desemboca finalmente en el recorrido perimetral de la laguna de La Mata.

\subsection{RUTA CALA FERRIS}

Distancia: $2700 \mathrm{~m}$

Recorrido que se origina en los carrizales y saladares de la laguna de Torrevieja que flanquean internamente las grandes dotaciones públicas situadas al sureste de dicha ciudad (depuradora, desaladora y hospital) y que pasa a continuación a discurrir por una serie de bandas arboladas (pinar y sotobosque termomediterráneo) que desembocan en la carretera CV95. Una vez atravesada dicha carretera, se accede al Parque Agrícola Forestal de La Ceñuela - Lo Ferrís, en el que se incluyen una serie de bandas arboladas con el mismo criterio expuesto antes, y por las que discurren caminos de uso público junto a zonas agrícolas protegidas y de uso y acceso privado. Como punto singular de la ruta se incluye el paso elevado singular sobre la carretera N332, que conectando las fincas de La Ceñuela y Lo Ferris, permite acceder a los tramos finales de la ruta que finalizan en las excepcionales playas vírgenes del Rocío y Cala Ferris.

\section{4.j.6. Visualización de las propuestas}

Las imágenes recogidas en el ANEXO V de la presente tesis y de las que se expone seguidamente una muestra, ilustran mediante bocetos el antes y después de algunas de las actuaciones propuestas, cuyo desarrollo deberá concretarse a través de los correspondientes programas de paisaje y de los proyectos vinculados a éstos: 

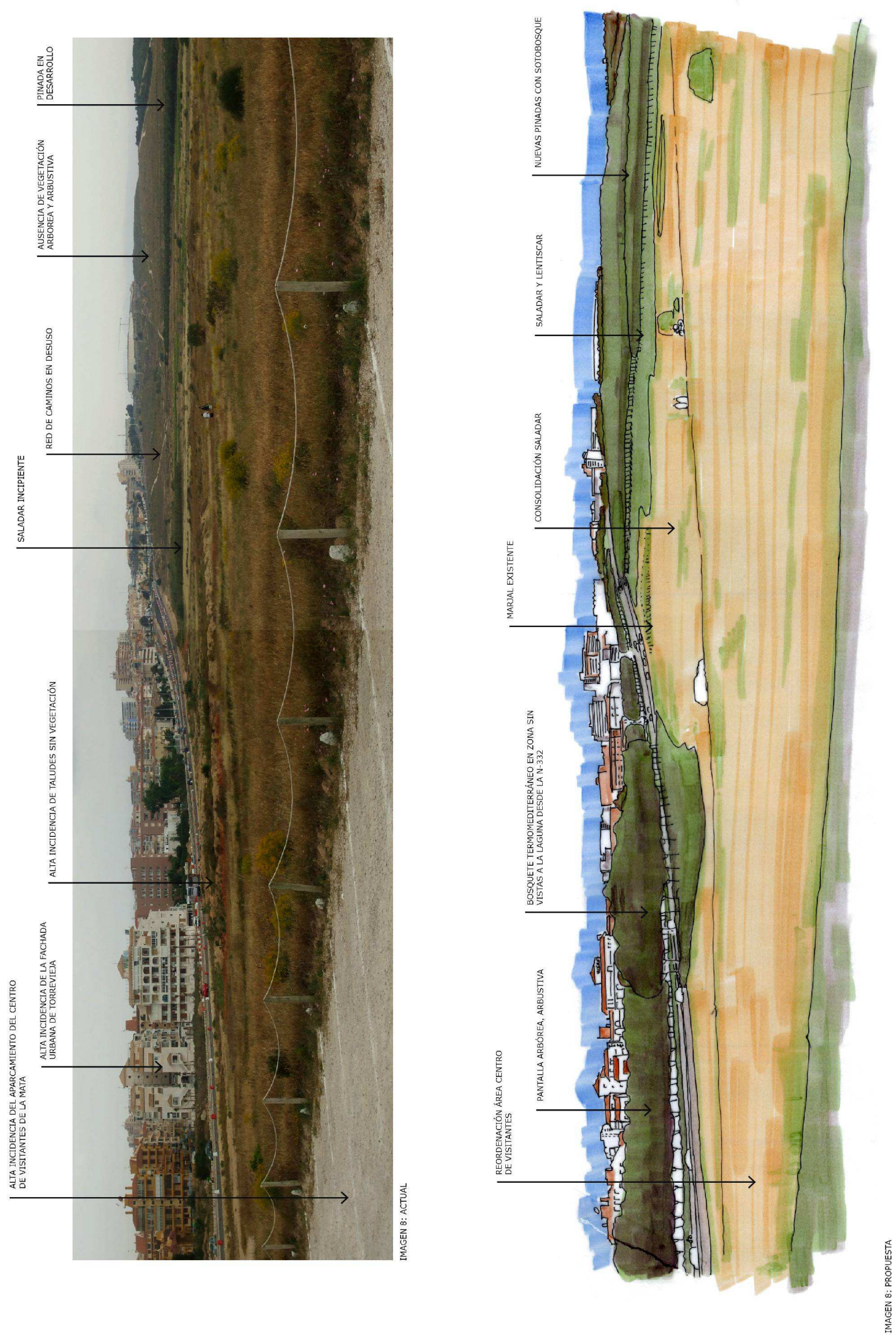

Fig. 5.61: Alto de la Hoya: Situación actual y representación de la situación propuesta tras la realización de las intervenciones propuestas en el plan de ordenación paisajística. 


\section{4.k. Programas de Paisaje}

\section{4.k.1 Listado de Programas de Paisaje}

Los programas de paisaje recogidos en el presente estudio han sido definidos con el fin de permitir cumplir los objetivos de calidad paisajísticos establecidos para cada unidad de paisaje y para el conjunto del ámbito estricto del estudio.

Tal y como se expuso anteriormente los programas de paisaje se adscribirían a uno de los 6 tipos siguientes:

- $\quad$ TIPO 1: PROGRAMAS DE CONEXIÓN: agruparán propuestas centradas en el establecimiento de conectores entre el parque y otras zonas próximas de interés medioambiental o altamente habitadas.

- $\quad$ TIPO 2: PROGRAMAS DE USO: agruparán propuestas centradas en el uso del parque natural o de los otros ámbitos geográficos considerados. Dichas propuestas podrán centrarse en actividades, recorridos, instalaciones o difusión.

- $\quad$ TIPO 3: PROGRAMAS DE INTEGRACIÓN PAISAJÍSTICA: agruparán propuestas centradas en la integración en el paisaje de infraestructuras, urbanizaciones o instalaciones.

- TIPO 4: PROGRAMAS DE GESTIÓN Y MANTENIMIENTO: agruparán propuestas centradas en la gestión y mantenimiento de los espacios productivos (agrícolas o salineros), de los espacios naturales y de las áreas urbanizadas.

- $\quad$ TIPO 5: PROGRAMAS DE MEJORA DEL PATRIMONIO MEDIOAMBIENTAL: agruparán propuestas centradas en

- la mejora del patrimonio medioambiental, con especial atención a los recursos hídricos, vegetación y fauna.

- TIPO 6: PROGRAMAS DE MEJORA DEL PATRIMONIO CULTURAL: agruparán propuestas centradas en la rehabilitación y puesta en valor del patrimonio cultural arquitectónico, ingenieril y etnográfico.

Los programas de paisaje así definidos presentan un carácter genérico y son susceptibles de acoger distintos proyectos o acciones, de carácter constructivo, social, administrativo o divulgativo. Estos programa de paisaje genéricos (PPG) se listan en la tabla siguiente:

Tabla 5.35: Listado de programas de paisaje genéricos previstos en el ámbito estricto del estudio

\begin{tabular}{|c|c|c|}
\hline $\mathbf{N}^{\circ}$ & Tipo & Programa \\
\hline PPG01 & 1 & Mejora de conexión territorial del Parque Natural de las lagunas de la Mata y Torrevieja \\
\hline PPG02 & 2 & $\begin{array}{l}\text { Definición de red de recorridos y accesos en base a los siguientes objetivos: } \\
\text { - Definir sendos anillos peatonales ciclistas en el entorno inmediato de las lagunas de la Mata y } \\
\text { Torrevieja a distancia suficiente de las zonas de acceso restringido o desaconsejable. } \\
\text { - Definir sendos anillos de tráfico vehicular - ciclista en el entorno de las lagunas de La Mata y To- } \\
\text { rrevieja + linea intermunicipal de autobús con paradas en puntos de acceso al parque (con posibili- } \\
\text { dad de cargar bicis) } \\
\text { - Mejorar la Red de recorridos (interconexiones, señalización, presencia de zonas de sombra, etc) }\end{array}$ \\
\hline PPG03 & 3 & Restauración de zonas afectadas por movimientos de tierras \\
\hline PPG04 & 3 & Integración paisajistica de zonas urbanizadas \\
\hline PPG05 & 1 y 3 & Integración paisajistica de infraestructuras de transporte y mejora de cruces \\
\hline PPG06 & 4 & Fomento de la actividad agrícola en el entorno del Parque Natural \\
\hline PPG07 & 4 & Potenciación de relación entre actividad salinera y Parque Natural \\
\hline PPG08 & 4 & Promoción del Parque Natural y de su uso responsable \\
\hline PPG09 & 4 & Vigilancia y servicios disponibles en el Parque Natural \\
\hline PPG10 & 5 & $\begin{array}{l}\text { Potenciación de las formaciones vegetales autóctonas con especial atención a: } \\
\text { - Regeneración de saladares } \\
\text { - Incremento de zonas con bosque termo mediterráneo (con estrato arbóreo y arbustivo) en cotas } \\
\text { altas y suelos no salinos. }\end{array}$ \\
\hline PPG11 & 6 & Restauración del patrimonio arquitectónico e hidráulico \\
\hline PPG12 & 6 & Creación de conectores entre el Parque Natural y el frente litoral \\
\hline
\end{tabular}

\section{4.k.2. Fichas de los Programas de Paisaje}

Las fichas de los distintos Programas de Paisaje Genéricos que se recogen en el anexo VI de la presente tesis recogen la información requerida para cada programa según el Reglamento de Paisaje de la Comunidad Valenciana y las adiciones propuestas en la presente tesis.

Las fichas que se exponen a continuación, correspondientes a los Programas de Paisaje no 1 (Mejora de Conexión Territorial del Parque Natural) y n2ㄹ (Definición de Red de Recorridos y Accesos), ilustran la estructura y contenidos de dichas fichas. En el primero de los programas se exponen medidas de tipo administrativo y en el segundo acciones de tipo ejecutivo-constructivo: 

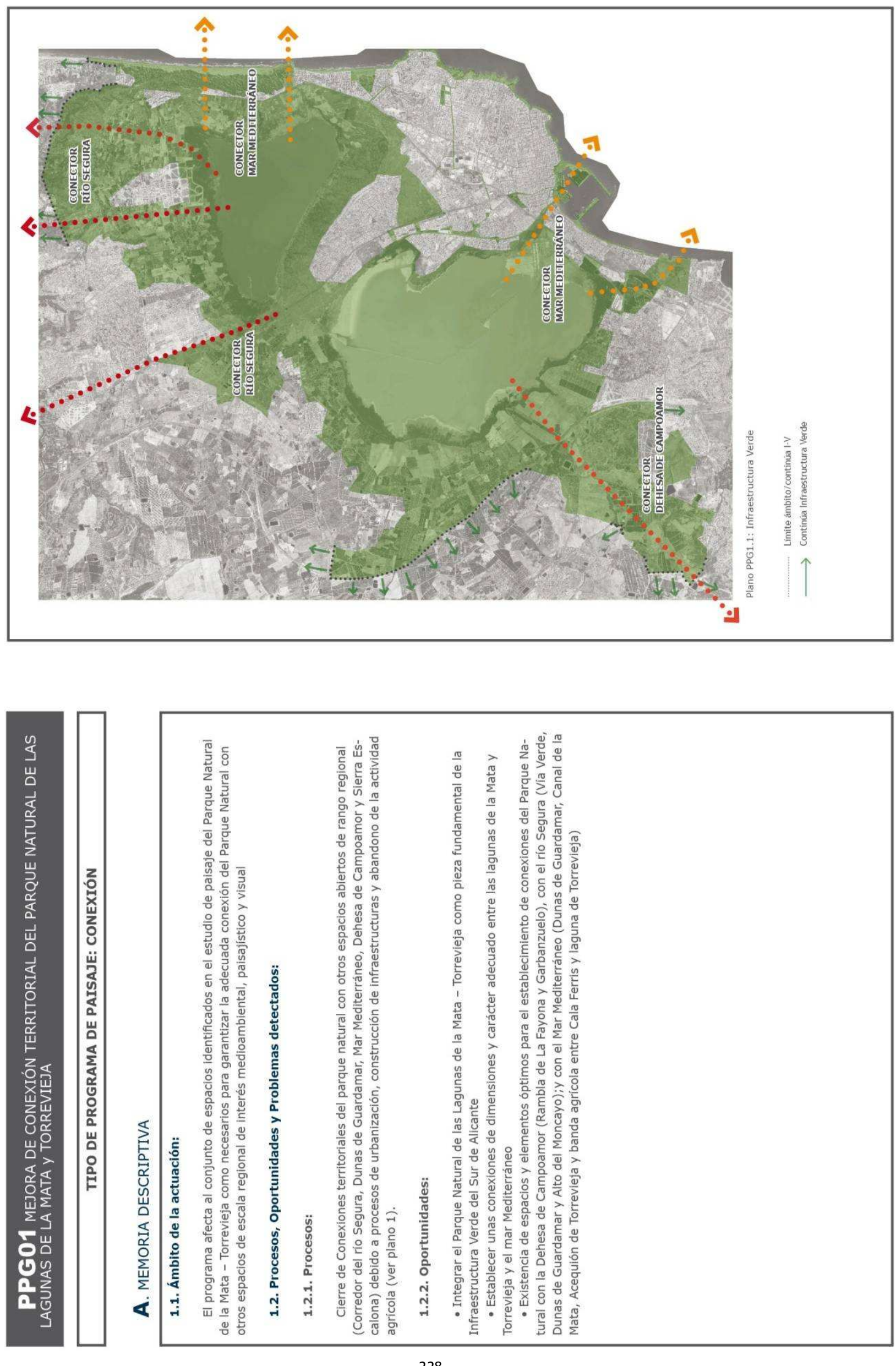


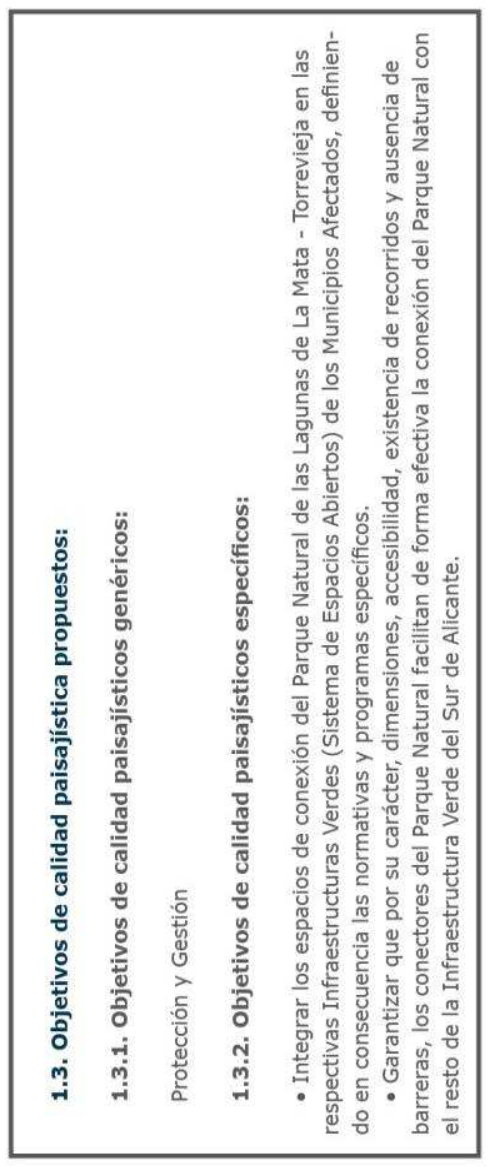

\begin{tabular}{|c|c|c|c|c|c|c|c|c|}
\hline 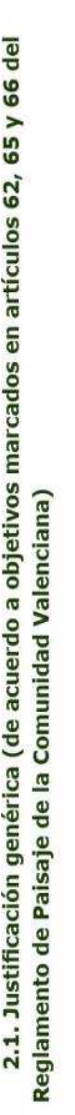 & 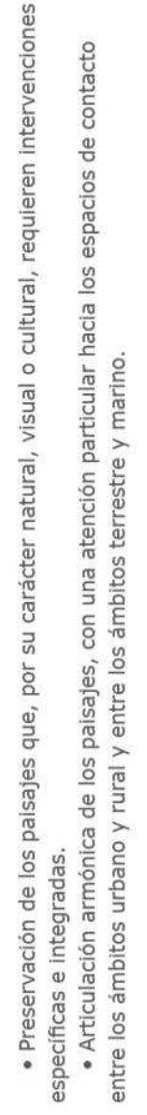 & 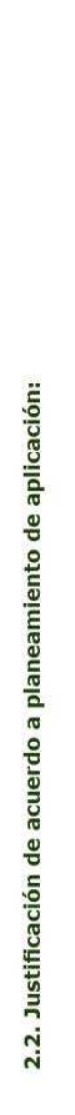 & 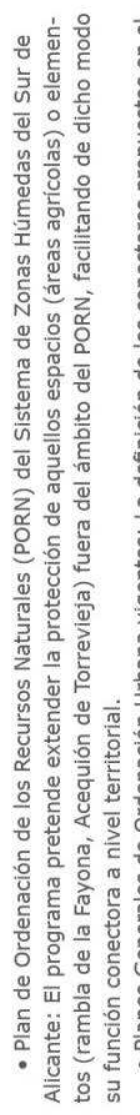 & 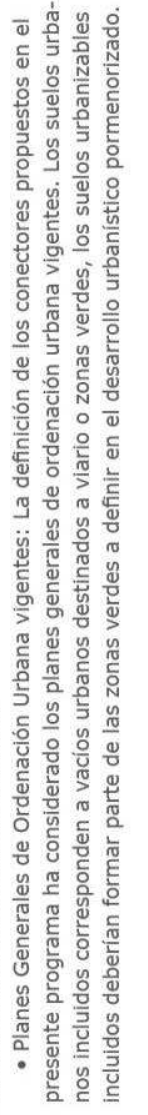 & 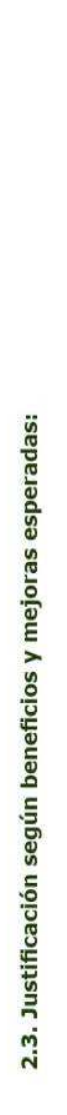 & 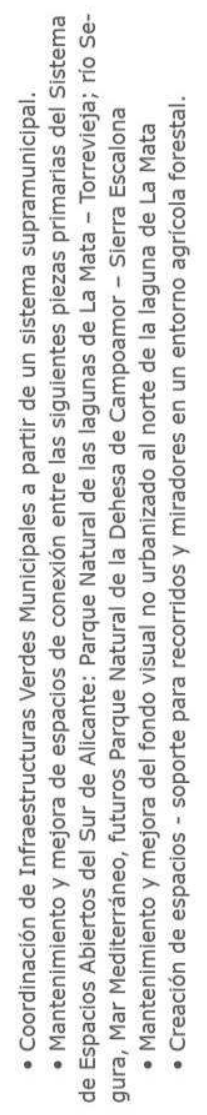 & 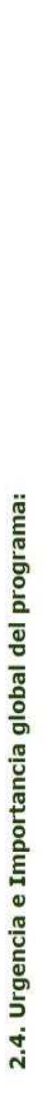 & 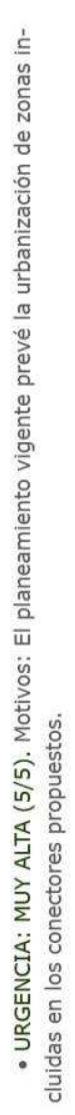 \\
\hline
\end{tabular}

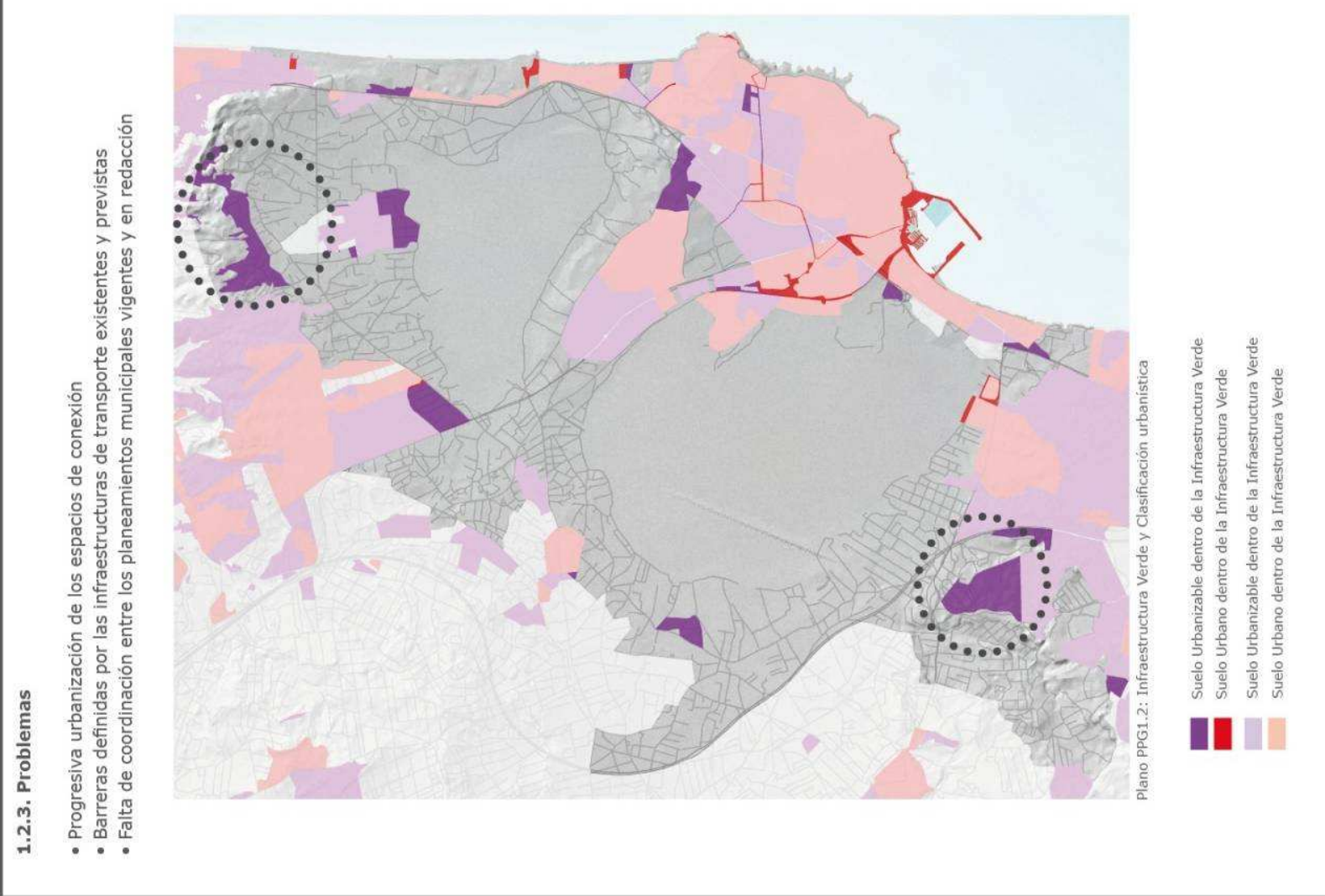


VALORACIÓNY GESTIÓN DEL PAISAJE SEGÚN EL CONVENIO EUROPEO DEL PAISAJE YEL

REGLAMENTO DEL PAISAJE DE LA COMUNIDAD VALENCIANA: APLICACIÓN MEDIANTE UN ESTUDIO

DE PAISAJE A UNESPACIO ABIERTO EN LA COMUNIDAD VALENCIANA

DOCTORANDO: JUAN JOSÉ GALÁN VIVAS (Universidad Politécnica de Valencia, enero 2011)
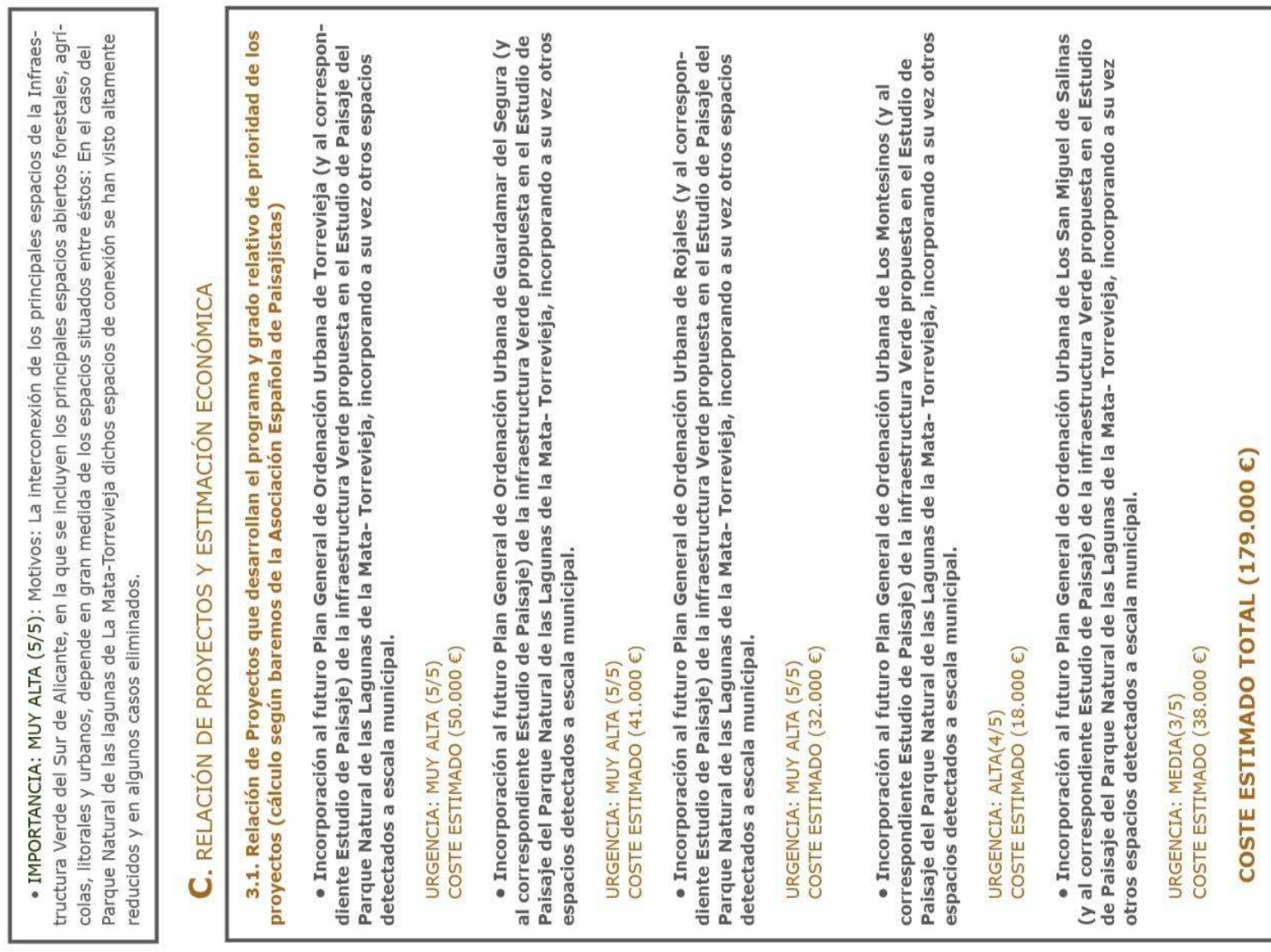

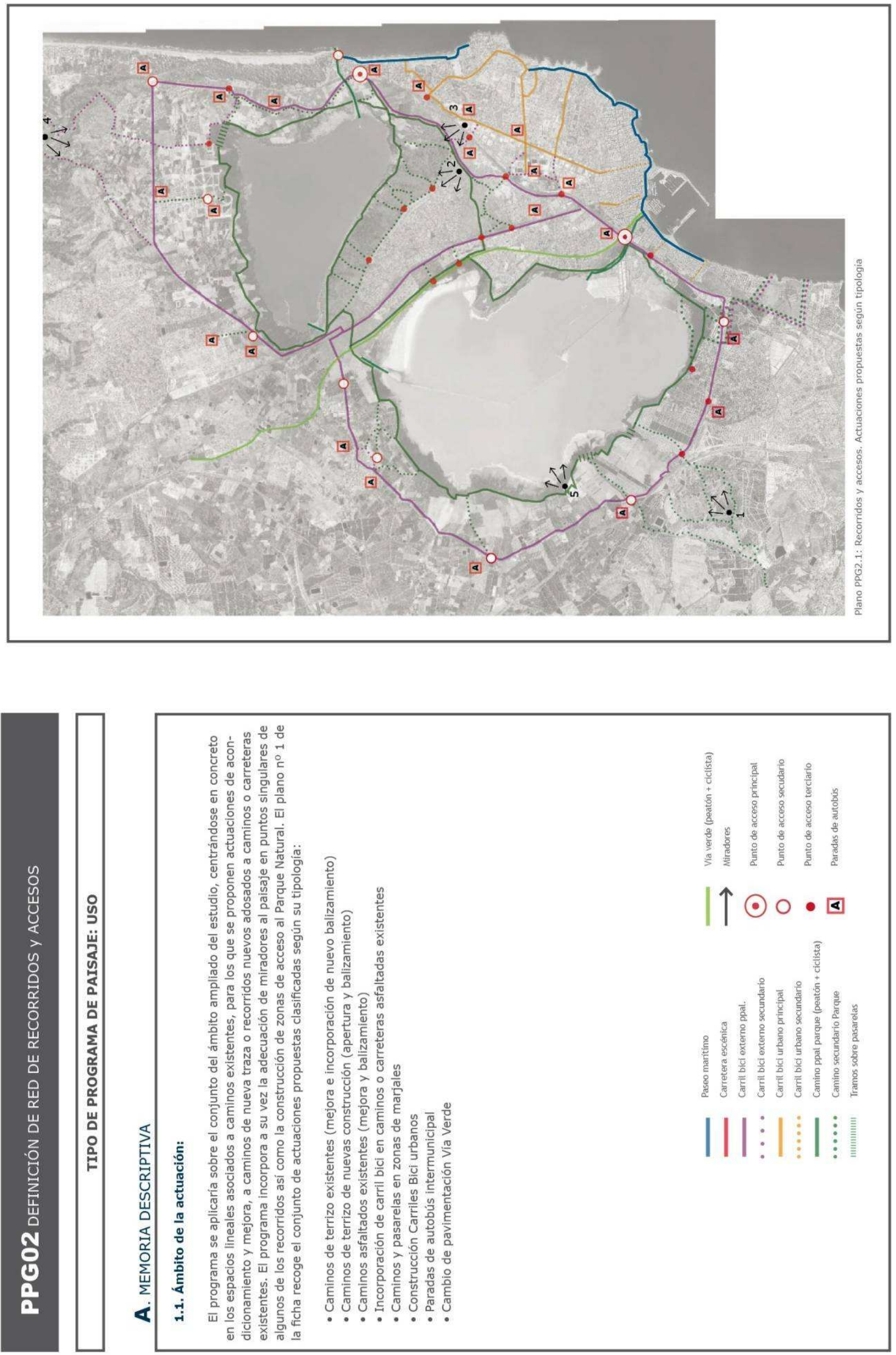

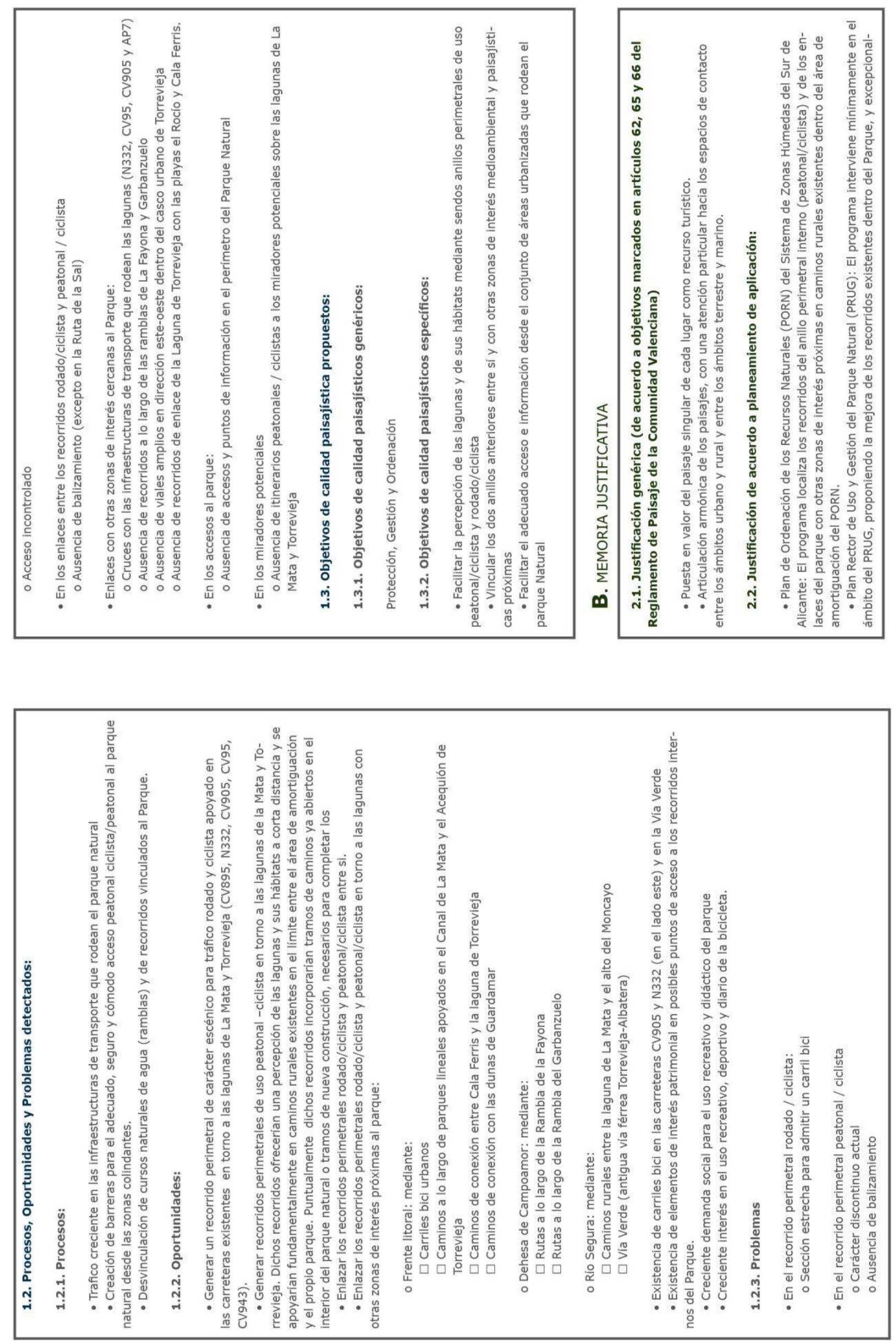

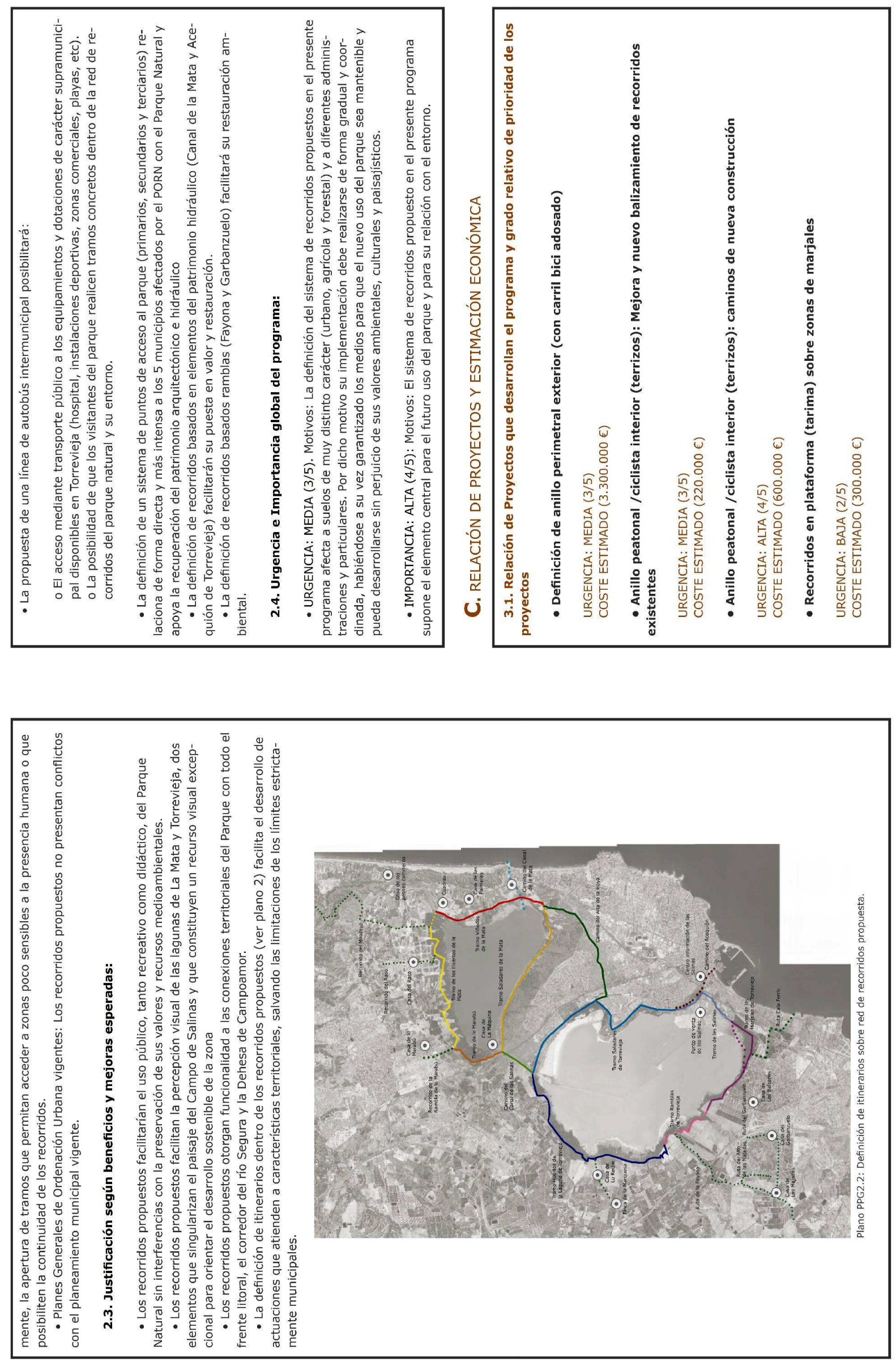
VALORACIÓNY GESTIÓN DEL PAISAJE SEGÚN EL CONVENIO EUROPEO DEL PAISAJE YEL

REGLAMENTO DEL PAISAJE DE LA COMUNIDAD VALENCIANA: APLICACIÓN MEDIANTE UN ESTUDIO 


\section{4.k.3 Actuaciones propuestas por unidades de paisaje}

Tal y como puede observarse en las fichas recogidas en el anexo $V$ de la presente tesis, los programas de paisaje propuestos afectan a ámbitos que, en la mayor parte de casos, incluyen suelos situados en distintas unidades de paisaje. Por este motivo y con el objeto de mostrar las implicaciones de los programas en cada unidad se listan seguidamente las actuaciones que serían de aplicación en cada una de éstas (ver plano de unidades de paisaje del ámbito estricto en la figura 5.26):

\begin{tabular}{|c|c|}
\hline \multicolumn{2}{|c|}{ ACTUACIONES PROPUESTAS EN UP1: LAGUNA DE LA MATA } \\
\hline $\begin{array}{l}\text { Tipo de } \\
\text { Programa }\end{array}$ & Actuaciones \\
\hline 1 & $\begin{array}{l}\text { Cierre del recorrido perimetral en torno a la laguna de la Mata en el tramo al oeste de la casa de la } \\
\text { Maquina }\end{array}$ \\
\hline 2 & $\begin{array}{l}\text { Creación de un corredor ecológico y peatonal entre las lagunas de La Mata y Torrevieja sin cruces con el } \\
\text { tráfico rodado (CV-905) }\end{array}$ \\
\hline 4 & $\begin{array}{l}\text { Generación de una zona verde de carácter natural-agrícola con huertos de ocio al sur de la Urbanización } \\
\text { El Raso }\end{array}$ \\
\hline 5 & $\begin{array}{l}\text { Consolidación de los saladares y extensión de la vegetación arbustiva y arbórea a ambos lados del Canal } \\
\text { de las Salinas }\end{array}$ \\
\hline 6 & Identificación y restauración de las Torres Salineras y restos arqueológicos. \\
\hline 6 & Restauración de la casa de la Maquina \\
\hline 6 & Restauración y vinculación a usos públicos de la casa del Raso \\
\hline
\end{tabular}

\begin{tabular}{|c|l|}
\hline \multicolumn{2}{|c|}{ ACTUACIONES PROPUESTAS EN UP2: LAGUNA DE TORREVIEJA } \\
$\begin{array}{c}\text { Tipo de } \\
\text { Programa }\end{array}$ & \begin{tabular}{l} 
Actuaciones \\
\hline 1
\end{tabular} \\
\hline 1 & $\begin{array}{l}\text { Reforzamiento y mejora del eje de conexión con el casco urbano de Torrevieja a lo largo del Acequión y } \\
\text { Ce la Vía Verde. } \\
905)\end{array}$ \\
\hline 2 & $\begin{array}{l}\text { Definición de un recorrido peatonal y de acceso público en el perímetro de la laguna (a través } \\
\text { preferentemente de las unidades de paisaje lindantes con la UP2) }\end{array}$ \\
\hline 3 & $\begin{array}{l}\text { Restauración paisajística de la zona situada entre las instalaciones salineras y la carretera N332 y de la } \\
\text { zona de depósitos de lodos salineros y de la zona edificapa en la punta de la Víbora. }\end{array}$ \\
\hline 3 & Restauración paisajística de la zona edificada en la Punta de la Víbora. \\
\hline 5 & Preservación y mejora de los recursos ecológicos y medioambientales \\
\hline 5 & Consolidación de los saladares a ambos lados del canal de las Salinas \\
\hline 5 & Identificación y restauración de de las torres salineras y restos arqueológicos \\
\hline
\end{tabular}

\begin{tabular}{|c|l|}
\hline \multicolumn{2}{|c|}{ UP3: VIÑEDOS Y SECANOS DE LA MATA } \\
\hline $\begin{array}{c}\text { Tipo de } \\
\text { Programa }\end{array}$ & \multicolumn{1}{c|}{ Actuaciones } \\
\hline 1 & $\begin{array}{l}\text { Reforzamiento y mejora del eje de conexión con el casco urbano de Torrevieja a lo largo del canal de La } \\
\text { Mata. }\end{array}$ \\
\hline 2 & $\begin{array}{l}\text { Definición en la UP3 del tramo del recorrido peatonal ciclista que rodearía ambas lagunas (considerar } \\
\text { señalética, zonas de descanso, vistas, etc.) }\end{array}$ \\
\hline 3 & $\begin{array}{l}\text { Adecuación paisajística del borde con la carretera N332: suavizar y revegetar taludes, establecer } \\
\text { secuencia de visuales con arbolado en zonas sin vistas hacia la laguna de La Mata. }\end{array}$ \\
\hline 3 & $\begin{array}{l}\text { Definición de recomendaciones paisajísticas para el tratamiento de caminos, para el cercado de parcelas, } \\
\text { para el control de robo de cosechas y para prácticas agrícolas }\end{array}$ \\
\hline 4 & Preservar y proteger el paisaje de viñedos y la comercialización de los productos y subproductos de la vid \\
\hline 6 & Restauración de las Casas de Las Palmeras, de Sala y de Dalt \\
\hline 6 & $\begin{array}{l}\text { Creación de un centro - museo del vino y de un punto de venta de productos agrícolas locales en los } \\
\text { edificios restaurados. }\end{array}$ \\
\hline
\end{tabular}




\begin{tabular}{|c|c|}
\hline \multicolumn{2}{|c|}{ UP4: HUERTOS TRADICIONALES DE LA MATA Y TORREVIEJA } \\
\hline $\begin{array}{l}\text { Tipo de } \\
\text { Programa }\end{array}$ & Actuaciones \\
\hline 1 & $\begin{array}{l}\text { Definición de un recorrido escénico rodado ciclista a lo largo de las carreteras CV943, CV945 y CV895 } \\
\text { (como parte del recorrido escénico rodado-ciclista que rodearía las Lagunas). }\end{array}$ \\
\hline 2 & $\begin{array}{l}\text { Definición en la UP4 del tramo del recorrido peatonal ciclista que rodearía ambas lagunas (considerar } \\
\text { señalética, zonas de descanso, vistas) }\end{array}$ \\
\hline 2 & Restauración y vinculación a recorridos de los restos de aljibes y de las redes tradicionales de riego. \\
\hline 3 & Adecuación paisajística de los límites de la unidad correspondiente a Ciudad Quesada. \\
\hline 3 & Integración de la subestación eléctrica situada junto a la finca de La Marquesa \\
\hline 3 & $\begin{array}{l}\text { Definición de recomendaciones paisajísticas para el tratamiento de caminos, para el cercado de parcelas, } \\
\text { para el control de robo de cosechas y para prácticas agrícolas (incluido cultivos bajo plástico) }\end{array}$ \\
\hline 4 & $\begin{array}{l}\text { Potenciación de la agricultura de cítricos y hortícolas (especialmente en los márgenes de la carretera } \\
\text { CV905 (carretera de Crevillente)). }\end{array}$ \\
\hline 4 & $\begin{array}{l}\text { Generación de una zona verde de carácter natural-agrícola con huertos de ocio al sur de Ciudad } \\
\text { Quesada (incluyendo como elementos articuladores la rambla y la casa de Lo Marabú) }\end{array}$ \\
\hline 6 & $\begin{array}{l}\text { Restauración y asignación de nuevos usos (compatibles con el PORN del Parque natural) a los edificios } \\
\text { representativos de la arquitectura rural tradicional. }\end{array}$ \\
\hline 6 & Restauración y vinculación a usos públicos de la casa de lo Marabú \\
\hline
\end{tabular}

\begin{tabular}{|c|l|}
\hline \multicolumn{2}{|c|}{ UP5: REGADIOOS EXTENSIVOS DE LA LAGUNA DE TORREVIEJA } \\
\hline $\begin{array}{c}\text { Tipo de } \\
\text { Programa }\end{array}$ & \multicolumn{1}{c|}{ Actuaciones } \\
\hline 1 & $\begin{array}{l}\text { Definición de un recorrido escénico rodado ciclista a lo largo de la carretera CV95 (como parte del } \\
\text { recorrido escénico rodado-ciclista que rodearía las Lagunas). }\end{array}$ \\
\hline 1 & $\begin{array}{l}\text { Establecimiento de recorridos entre la laguna de Torrevieja y la UP9 a lo largo de las ramblas de la } \\
\text { Fayona y Garbanzuelo. }\end{array}$ \\
\hline 2 & $\begin{array}{l}\text { Definición en la UP5 del tramo del recorrido peatonal ciclista que rodearía ambas lagunas (considerar } \\
\text { señalética, zonas de descanso, vistas) }\end{array}$ \\
\hline 3 & $\begin{array}{l}\text { Definición de recomendaciones paisajísticas para el tratamiento de caminos, para el cercado de parcelas, } \\
\text { para el control de robo de cosechas y para prácticas agrícolas (incluido cultivos bajo plástico) }\end{array}$ \\
\hline 3 & $\begin{array}{l}\text { Adecuación paisajística de los límites de la unidad correspondiente a la urbanización Los Balcones y con } \\
\text { la carretera CV95. }\end{array}$ \\
\hline 3 & Integración de zona de acumulación y tratamiento de áridos \\
\hline 6 & $\begin{array}{l}\text { Restauración y asignación de nuevos usos (compatibles con el PORN del Parque Natural) a los edificios } \\
\text { representativos de la arquitectura rural tradicional. }\end{array}$ \\
\hline
\end{tabular}

\begin{tabular}{|c|l|}
\hline \multicolumn{2}{|c|}{ UP6: ALTOS DE LA ATALAYA Y DEL MONCAYO } \\
\hline $\begin{array}{c}\text { Tipo de } \\
\text { Programa }\end{array}$ & Actuaciones \\
\hline 2 & Adecuación para el uso ciclista y peatonal de los caminos rurales de Dos y de Ratero \\
\hline 5 & Ampliación del bosque termo-mediterráneo en las laderas de los altos del Moncayo y La Atalaya. \\
\hline
\end{tabular}

\begin{tabular}{|c|l|}
\hline UP7: DUNAS DE GUARDAMAR \\
\hline $\begin{array}{c}\text { Tipo de } \\
\text { Programa }\end{array}$ & Actuaciones \\
\hline 1 & Creación de un corredor de conexión entre la laguna de La Mata y las dunas de Guardamar \\
\hline 1 & Definición recorridos longitudinales y transversales a la banda de dunas \\
\hline 2 & Creación de un carril bici adosado a la carretera N332 entre Torrevieja y Guardamar del Segura \\
\hline 3 & Tratamiento del perímetro de las urbanizaciones del Moncayo, La Rosa y Portic del Mediterrani. \\
\hline
\end{tabular}

\begin{tabular}{|c|l|}
\hline \multicolumn{1}{|c|}{ UP8: : ALTO DE LA HOYA Y PINADA DEL CHAPARRAL } \\
\hline $\begin{array}{c}\text { Tipo de } \\
\text { Programa }\end{array}$ & \multicolumn{1}{|c|}{ Actuaciones } \\
\hline 3 & Tratamiento de los márgenes y taludes de la nacional 332 \\
\hline 5 & $\begin{array}{l}\text { Creación de una zona verde de carácter natural y agrícola de secano entre el Parque Natural y la zona } \\
\text { urbanizable al sur del Hospital San Jaime. }\end{array}$ \\
\hline 5 & $\begin{array}{l}\text { Ampliación de las zonas de bosque termomediterráneo en las laderas del alto de la Hoya y en la banda } \\
\text { no urbanizable entre las lagunas de la Mata y Torrevieja }\end{array}$ \\
\hline
\end{tabular}




\begin{tabular}{|}
$\mid$\begin{tabular}{c|l|}
\hline UP9: CONECTOR DE LA RAMBLA DE LA FAYONA \\
$\begin{array}{c}\text { Tipo de } \\
\text { Programa }\end{array}$ & \multicolumn{1}{c|}{ Actuaciones } \\
\hline 1 & Ampliación de cruces de las ramblas de La Fayona y Garbanzuelo con las carreteras CV95, CV943 y AP7 \\
\hline 2 & $\begin{array}{l}\text { Definición de recorridos peatonales - ciclistas y a caballo en el entorno de las ramblas de la Fayona y } \\
\text { Garbanzuelo y en el alto de las Majadas }\end{array}$ \\
\hline 5 & $\begin{array}{l}\text { Potenciación de la vegetación de ramblas y el bosque termo-mediterráneo en las ramblas y márgenes } \\
\text { respectivamente }\end{array}$ \\
\hline 6 & Restauración y posible asignación de usos a la casa de las Majadas y a la casa del Garbanzuelo \\
\hline
\end{tabular}
\end{tabular}

\begin{tabular}{|c|l|}
\hline \multicolumn{2}{|c|}{ UP10: URBANIZACIÓN EL RASO } \\
\hline $\begin{array}{c}\text { Tipo de } \\
\text { Programa }\end{array}$ & \multicolumn{1}{c|}{ Actuaciones } \\
\hline 4 & Ajuste e incremento de la vegetación arbórea en el viario y espacio público de la urbanización \\
\hline 4 & Potenciación de la vegetación autóctona en jardines privados \\
\hline 6 & $\begin{array}{l}\text { Restauración de la Casa del Raso y posible asignación de nuevos usos públicos vinculados a la } \\
\text { comunidad y al Parque Natural }\end{array}$ \\
\hline
\end{tabular}

\begin{tabular}{|c|l|}
\hline \multicolumn{2}{|c|}{ UP11: URBANIZACIÓN CIUDAD QUESADA } \\
\hline $\begin{array}{c}\text { Tipo de } \\
\text { Programa }\end{array}$ & \multicolumn{1}{c|}{ Actuaciones } \\
\hline 4 & Ajuste e incremento de la vegetación arbórea en el viario y espacio público de la urbanización \\
\hline 4 & Potenciación de la vegetación autóctona en jardines privados \\
\hline 6 & $\begin{array}{l}\text { Restauración de la Casa de la Niña de Los Marabú y posible asignación de nuevos usos públicos } \\
\text { vinculados a la comunidad y al parque Natural }\end{array}$ \\
\hline
\end{tabular}

\begin{tabular}{|c|c|}
\hline $\begin{array}{l}\text { Tipo de } \\
\text { Programa }\end{array}$ & Actuaciones \\
\hline 3 & Adecuación paisajística de la Vía Verde a su paso por la Urbanización Torreta III \\
\hline 4 & Ajuste e incremento de la vegetación arbórea en el viario y espacio público de la urbanización \\
\hline 4 & Potenciación de la vegetación autóctona en jardines privados \\
\hline 4 & $\begin{array}{l}\text { Definición de bandas arbóreas-arbustivas en las zonas situadas entre las urbanizaciones y la carretera } \\
\text { CV905 }\end{array}$ \\
\hline 4 & Reforzamiento de las barreras de separación entre el Parque Natural y las urbanizaciones colindantes. \\
\hline
\end{tabular}

\begin{tabular}{|c|l|}
\hline \multicolumn{2}{|c|}{ UP13: URBANIZACIÓN LOS BALCONES } \\
\hline $\begin{array}{c}\text { Tipo de } \\
\text { Programa }\end{array}$ & \multicolumn{1}{c|}{ Actuaciones } \\
\hline 2 & Integración de carril bici adosado a la carretera CV95 \\
\hline 4 & $\begin{array}{l}\text { Definición de una zona verde de transición entre la urbanización Los Balcones (incluida la zona pendiente } \\
\text { de Plan Especial) y el Parque Natural. }\end{array}$ \\
\hline 4 & Ajuste e incremento de la vegetación arbórea en el viario y espacio público de la urbanización \\
\hline 4 & Potenciación de la vegetación autóctona en jardines privados \\
\hline 6 & $\begin{array}{l}\text { Restauración de la Casa de Los Balcones y posible asignación de nuevos usos públicos vinculados a la } \\
\text { Comunidad y al Parque Natural }\end{array}$ \\
\hline
\end{tabular}

\begin{tabular}{|c|c|}
\hline \multicolumn{2}{|c|}{ UP14: CONECTOR SUR LAGUNA DE TORREVIEJA - CALA FERRIS } \\
\hline $\begin{array}{l}\text { Tipo de } \\
\text { Programa }\end{array}$ & Actuaciones \\
\hline 1 & $\begin{array}{l}\text { Creación de un parque agrícola forestal en los espacios abiertos incluidos en la Unidad de Paisaje } \\
\text { mediante convenio - acuerdo entre los propietarios públicos y privados del suelo. }\end{array}$ \\
\hline 2 & $\begin{array}{l}\text { Establecimiento de un recorrido perimetral al parque natural entre la estación depuradora y el hospital de } \\
\text { Torrevieja }\end{array}$ \\
\hline 2 & Definición de zonas de acceso, aparcamiento y recorridos en las playas del Rocío y cala Ferris \\
\hline 3 & $\begin{array}{l}\text { Adecuación paisajística de la franja de transición entre la nacional } 332 \text { y las dotaciones públicas de la } \\
\text { Unidad (EDAR, desaladora, hospital y cementerio) }\end{array}$ \\
\hline
\end{tabular}




\begin{tabular}{|c|c|}
\hline \multicolumn{2}{|c|}{ UP15: CASCO URBANO Y FRENTE LITORAL DE TORREVIEJA } \\
\hline $\begin{array}{l}\text { Tipo de } \\
\text { Programa }\end{array}$ & Actuaciones \\
\hline 1 & $\begin{array}{l}\text { Definición de conexiones peatonales - ciclistas entre el Parque Natural y el Casco Urbano de Torrevieja } \\
\text { y coordinación de dichas conexiones con la zona deportiva, comercial y principales zonas } \\
\text { verdes de Torrevieja }\end{array}$ \\
\hline 3 & Adecuación paisajística del espacio entre la carretera N332 y el frente urbano de Torrevieja. \\
\hline 4 & $\begin{array}{l}\text { Recuperación del Canal de la Mata y asociación a un espacio verde lineal de conexión con el Parque } \\
\text { Natural }\end{array}$ \\
\hline 4 & $\begin{array}{l}\text { Potenciación del eje definido por el Acequión de Torrevieja y redefinición de las zonas verdes asociadas a } \\
\text { éste a su paso por la Unidad de Paisaje. }\end{array}$ \\
\hline 6 & Adecuación paisajística y de uso del Alto de las Casillas \\
\hline
\end{tabular}

\subsection{Normativa de Paisaje.}

Dentro del presente tomo de la tesis se incluyen exclusivamente las recomendaciones paisajísticas o las normas paisajísticas redactadas específicamente como parte del estudio de paisaje del Parque Natural de las Lagunas de La Mata-Torrevieja. Dentro del anexo VII de la tesis se incluyen, adicionalmente, las normas del planeamiento vigente con implicaciones paisajísticas dentro del ámbito estricto del estudio así como las normas estándar de aplicación general y de integración paisajística previstas por el Reglamento de Paisaje de la Comunidad Valenciana y de aplicación en el citado ámbito.

\subsection{I.1 Normas de Integración Paisajística Específicas:}

Las Normas de Integración Paisajística Específicas se definen especialmente en el presente estudio y se aplicarían sobre ámbitos geográficos concretos (unidades de paisaje) o sobre sistemas o elementos territoriales tales como redes de infraestructuras o zonas con determinado uso o tipo de vegetación:

1) Zonas de viñedos y herbáceos de secano (Unidad de paisaje no3):

- Vallas, muros y cerramientos:

\section{RECOMENDACIONES}

- Deberán ser de altura menor a 1 metro y de carácter no penetrable únicamente si se estima necesario para la adecuada protección de los cultivos (tanto en parcelas de superficie menor como mayor de 1 hectáreas). Los cerramientos no penetrables podrán incluir malla cinegética acompañada de cañizo. Los cerramientos penetrables deberán tener una altura máxima de 1 metro y estarán construidos preferentemente con postes de madera y elementos horizontales constituidos por elementos de madera, cuerda o cable.

\section{- Cultivos:}

\section{RECOMENDACIONES}

- Por motivos de carácter del paisaje y de mantenimiento del patrón de vistas abiertas, no se permitirá el cultivo de frutales o especies arbóreas.

- Se potenciará la presencia puntual de higueras en los lindes de caminos.

- Se potenciará preferentemente el cultivo de la vid, en especial de la variedad Merseguera

- Se potenciara el cultivo de herbáceos de secano y de especies hortícolas.

- Técnicas de cultivo:

\section{RECOMENDACIONES:}

- No se realizarán cultivos bajo plástico ni en forma de invernaderos ni de túneles. Excepcionalmente, estos últimos podrían ser utilizados previa autorización de los órganos competentes en materia de Espacios Naturales y Paisaje

- Los cultivos en la Unidad de Paisaje 꾼 deberán realizarse en secano, salvo autorización expresa de los órganos competentes en materia de Espacios Naturales y Paisaje, autorizando al introducción de riego localizado por motivos de aumento de la productividad del viñedo.

\section{- Caminos rurales:}

\section{RECOMENDACIONES}

- Los caminos deberán presentar un acabado preferentemente en terrizo, salvo aquellos actualmente asfaltados.

- Los caminos presentarán un balizamiento indicativo del recorrido del sistema de itinerarios del Parque Natural del que forman parte.

- Los encuentros de los caminos con las parcelas agrícolas en cultivo deberán ser adecuadamente mantenidos, pudiendo encontrarse: 
- Ausencia de elementos de transición entre la zona de cultivo y el camino: las zonas de cultivo deberán mantenerse trabajadas y limpias hasta el encuentro con el camino.

- Presencia de cerramientos penetrables (ver recomendaciones propuestas al efecto).

- Presencia de cerramientos no penetrables (ver recomendaciones desarrolladas al efecto)

- Presencia de cordones de vegetación arbustiva y herbácea: la masa vegetal deberá incluir preferentemente especies autóctonas y deberá ser gestionada con el objeto de no impedir la actividad agrícola, no invadir los caminos ni superar los 1.5 metros de altura.

- Presencia de muros: deberán estar realizados en piedra seca

- Taludes: deberán estar acompañados de cordones de vegetación arbustiva y herbácea.

- Construcciones en el medio agrícola:

RECOMENDACIONES:

- No se admitirán, salvo autorización expresa de los órganos competentes en materia de Espacios Naturales y Paisaje, nuevas construcciones en la unidad de paisaje ㄲo 3 .

- Se promoverá la restauración de los edificios existentes a los que se les atribuya desde la Dirección del Parque Natural y Ayuntamientos afectados un valor arquitectónico, cultural o etnográfico.

- Los edificios podrán ir acompañados de vegetación autóctona de elevado porte que refuerce su presencia en el paisaje y que no bloquee completamente su vista desde las carreteras o principales caminos.

- Independientemente del uso residencial, agrícola o terciario de los edificios restaurados, se evitará la construcción de cerramientos perimetrales, tanto en obra como vegetales, que bloqueen la vista de los edificios desde los caminos colindantes.

- Uso:

\section{RECOMENDACIONES}

- Se incluirá en el balizamiento de los caminos información referente a los cultivos y técnicas de cultivo propias de la zona así como indicaciones sobre la prohibición al público de acceder a las parcelas.

2) Zonas agrícolas de regadío (Unidades de paisaje no 4 y 5):

- Vallas, muros y cerramientos:

RECOMENDACIONES

- Se promoverá el adecuado mantenimiento de los muros de contención de tierras, especialmente aquellos situados entre parcelas y caminos. Los muros se construirán o restaurarán de acuerdo a las técnicas y materiales tradicionales.

- Las posibles nuevas vallas deberán ser de altura menor a 1 metro y de carácter no penetrable si se estima necesario para la adecuada protección de los cultivos (tanto en parcelas de superficie menor como mayor de 1 hectáreas). Los cerramientos no penetrables podrán incluir malla cinegética acompañada de cañizo. Los cerramientos penetrables deberán tener una altura máxima de 1 metro y estarán construidos preferentemente con postes de madera y elementos horizontales constituidos por elementos de madera, cuerda o cable.

- Se desincentivará la construcción de vallas de malla metálica de triple torsión y postes metálicos.

- No se permitirán muros ni cerramientos de carácter o materiales urbanos o propios del medio rural local.

- No se permitirá la construcción de vallas o pantallas de altura superior a 1,5 metros.

- Sistemas e infraestructuras hidráulicas:

\section{RECOMENDACIONES}

- La potenciación del riego a manta deberá ir acompañada de la restauración de las infraestructuras de riego que lo posibilitan.

- El acabado y materiales a emplear en las acequias de riego deberán ser acordes con los propios de la agricultura local tradicional, prestándose un especial cuidado a los puntos de partición y embalsado de aguas.

- Se permitirá la presencia de vegetación herbácea y arbustiva en los márgenes de caminos e infraestructuras de riego en la medida que no perjudiquen su funcionalidad y percepción visual. 


\section{- Cultivos:}

\section{RECOMENDACIONES}

- Por motivos de mantenimiento del carácter del paisaje y del patrón de vistas abiertas, se potenciará el cultivo de hortícolas y herbáceas extensivas en regadío frente al cultivo de cítricos u otros frutales.

- Se promoverá la diversidad de cultivos, asociando dicha promoción a campañas para el consumo local de productos agrícolas especializados.

\section{- Técnicas de cultivo}

\section{RECOMENDACIONES:}

- Dada su incidencia sobre las vistas hacia las lagunas y sobre la escorrentía superficial, no se permitirá el cultivo en invernaderos.

- Se permitirá el cultivo bajo plástico en túneles de altura inferior a 0,5 metros previa autorización de los órganos competentes en materia de Espacios Naturales y Paisaje.

- Se promoverá el uso del riego a manta.

- Se permitirá el riego localizado y el riego por aspersión (en herbáceos extensivos) previa autorización expresa de de los órganos competentes en materia de Espacios Naturales y Paisaje.

- Las zonas regadas por riego localizado o aspersión deberán compartir en la medida de lo posible la red de distribución de agua y embalses que integran la red de riego tradicional.

\section{- Caminos rurales:}

\section{RECOMENDACIONES}

- Los caminos deberán presentar un acabado preferentemente en terrizo, salvo aquellos actualmente asfaltados o realizados en hormigón.

- Los caminos presentarán un balizamiento indicativo del recorrido del sistema de itinerarios del Parque Natural del que forman parte.

- Los encuentros de los caminos con las parcelas agrícolas en cultivo deberán ser adecuadamente mantenidos, pudiendo encontrarse:

i. Ausencia de elementos de transición entre los cultivos y los caminos: en ese caso, las zonas de cultivo deberán mantenerse trabajadas y limpias hasta el encuentro con el camino

ii. Presencia de cerramientos penetrables (ver recomendaciones desarrolladas al efecto)

iii. Presencia de cerramientos no penetrables (ver recomendaciones desarrolladas al efecto)

iv. Presencia de cordones de vegetación arbustiva y herbácea: la masa vegetal deberá incluir preferentemente especies autóctonas y deberá ser gestionada con el objeto de no impedir la actividad agrícola, no invadir los caminos ni superar los 1.5 metros de altura.

v. Presencia de muros: deberán estar realizados preferentemente en piedra seca.

vi. Taludes: deberán estar acompañados de cordones de vegetación arbustiva y herbácea.

- Construcciones en el medio agrícola:

RECOMENDACIONES:

- No se admitirán, salvo autorización expresa de los órganos competentes en materia de Espacios Naturales y Paisaje, nuevas construcciones en las Unidades de Paisaje no 4 y 5.

- Se promoverá la restauración de los edificios existentes a los que se les atribuya desde la Dirección del Parque Natural y Ayuntamientos afectados un valor arquitectónico, cultural o etnográfico.

- Los edificios podrán ir acompañados de vegetación autóctona de elevado porte que refuerce su presencia en el paisaje y que no bloquee completamente su vista desde las carreteras o principales caminos

- Independientemente de su uso residencial, agrícola o terciario de los edificios restaurados, se evitará la construcción de cerramientos perimetrales, tanto en obra como vegetales, que bloqueen la vista de los edificios desde los caminos colindantes.

- Uso:

\section{RECOMENDACIONES}

- Se incluirá en el balizamiento de los caminos información referente a los cultivos y técnicas de cultivo propias de la zona así como indicaciones sobre la prohibición al público de acceder a las parcelas. 
3) Zona de Industria Salinera. (aplicable en unidad de paisaje no 2)

- Uso y Actividad salinera: RECOMENDACIÓN

- Con el objeto de mantener las vistas hacia la laguna de Torrevieja y hacia las instalaciones salineras desde la carretera nacional N332 y los accesos a las salinas, no se permitirán edificaciones en los suelos incluidos en el vigente Plan General de Ordenación Urbana de Torrevieja como Sector S-8 (Polígono Industrial Salinas).

- Las zonas que rodean las instalaciones salineras en dirección a la carretera nacional N332 deberán presentar un uso como zona verde con vegetación compuesta fundamentalmente por formaciones vegetales autóctonas (saladar y masas puntuales arbóreo-arbustivas de carácter termo mediterráneo).

- Edificios, instalaciones y cerramientos del área salinera:

\section{RECOMENDACION}

- Emplear en los cerramientos de la zona de instalaciones salineras el vallado estándar del Parque Natural (postes de madera y mallazo) acompañando la valla de vegetación arbustiva / tarayal según características edafológicas del tramo concreto.

- Mantener en un adecuado estado de conservación y acabado las fachadas, tejados y cubiertas de los edificios. Emplear preferentemente colores neutros / y o claros en las fachadas (blancos, grises) y unificar el tratamiento cromático en todos los edificios.

- Realizar un adecuado mantenimiento (limpieza y pintado) de las instalaciones y estructuras (grúas, cintas transportadoras, etc). Emplear colores preferentemente neutros.

- Mantener adecuadamente el estado de los firmes y de las zonas de acopio de materiales. Ubicar estas últimas en áreas de escasa visibilidad y considerar la creación de barreras visuales blandas en su perímetro externo.

- Evitar la acumulación incontrolada de escombros / áridos.

- Potenciar el recorrido a lo largo del Acequión de Torrevieja como ruta interpretativa de la actividad salinera (desde la laguna hasta los muelles salineros).

- Promover la imagen de los depósitos de sal como representativa de Torrevieja.

4) Zonas urbanas y urbanizables. (aplicables a Unidades de paisaje $n=10,11,12,13$ y 15, extensibles a UP8 y UP14 en caso de darse procesos de urbanización)

- Ubicación y adaptación a la topografía:

\section{RECOMENDACIONES}

- Las nuevas zonas urbanas en el ámbito estricto del Estudio deberán preservar sin urbanizar el sistema de espacios abiertos propuesto, con especial atención a los corredores entre las lagunas de La Mata y Torrevieja, al corredor al río Segura sobre el alto del Moncayo, a los conectores entre el Parque Natural y el Mar Mediterráneo y al conector a la Dehesa de Campoamor.

- Volumetrías y tipologías edificatorias:

\section{RECOMENDACIONES}

- Las volumetrías de las nuevas zonas urbanizadas mantendrán las características de las propias de las zonas colindantes, procurando concentrar la edificabilidad con el fin de liberar suelo para las zonas públicas y verdes y no rebasando (en el caso de urbanizaciones residenciales) las dos alturas y planta baja.

- Las tipologías y estilos arquitectónicos en las nuevas zonas urbanizadas no presentarán limitaciones en la medida que permitan cumplir las recomendaciones dadas en lo referente a volumetrías, adaptación a la topografía existente y a la creación de un sistema de espacios abiertos de calidad dentro de la urbanización.

- El tratamiento cromático de fachadas deberá realizarse en colores neutros y claros.

- Viario y espacio público:

\section{RECOMENDACIONES}

- El viario de las urbanizaciones deberá contar con aceras de anchura suficiente para incluir arbolado de alineación. Dicho arbolado incluirá fundamentalmente especies autóctonas y contará con un riego por goteo que garantice el adecuado suministro de agua durante los primeros años. 
- La anchura de las calzadas y especialmente, los sentidos de circulación por calle, deberán ajustarse a la densidad de tráfico prevista.

- La dotación de plazas de aparcamiento deberá ajustarse a las necesidades reales de las urbanizaciones, considerando el uso de las plazas de aparcamiento privadas dentro de cada parcela así como la posibilidad de incluir pequeñas bolsas de aparcamiento que complementen la dotación total hasta cumplir los mínimos exigidos por la normativa de aplicación.

- El mobiliario urbano, elementos de alumbrado y pavimento de aceras deberá ser definido con el objetivo de generar un espacio público de calidad.

- Aquellas urbanizaciones situadas entre espacios primarios del sistema de espacios abiertos asociado al parque natural (laguna de La Mata, laguna de Torrevieja, alto del Moncayo, río Segura, dehesa de Campoamor y mar Mediterráneo) deberán de incluir corredores internos de conexión de anchura suficiente para integrar recorridos peatonales-ciclistas en un entorno definido por formaciones vegetales de carácter natural (principalmente bosque termo mediterráneo).

- Tratamiento de bordes:

\section{RECOMENDACIONES}

- Las urbanizaciones deberán disponer de unas franjas de transición de al menos 15 metros de anchura hacia las infraestructuras de transporte y hacia el parque natural. Dichas franjas deberán incluir bosque termo mediterráneo (con estrato arbóreo y arbustivo) salvo en las transiciones en zonas de saladar en, las que se introducirá dicha formación acompañada de una banda arbóreo arbustiva próxima a la primera línea de edificios. Con el objeto de garantizar la supervivencia de las plantaciones termo mediterráneas en sus primeros años se deberá incluir en dichas zonas un sistema de riego de bajo consumo y uso estricto en periodos de alto déficit hídrico.

- Adicionalmente a las franjas antes indicada,s se recomienda ubicar entre la primera línea de edificios y la infraestructura de transporte o parque natural un vial acompañado de carril bici. La circulación peatonal se apoyará en la acera exterior del vial o en un recorrido por la franja vegetal de transición antes descrita.

- Zonas verdes:

\section{RECOMENDACIONES}

- Las nuevas zonas verdes de las áreas urbanizadas situadas dentro del ámbito del estudio deben de incluir entre sus objetivos la escasa necesidad de recursos hídricos, el bajo mantenimiento y el uso de aquellas formaciones vegetales autóctonas que se ajusten a las características específicas del lugar.

- Las nuevas zonas verdes podrán incluir a su vez espacios vinculados a las zonas agrícolas colindantes o preexistentes, dotando a dichas zonas agrícolas de un uso público y de elementos que preserven la agricultura y técnicas agrícolas tradicionales.

- Los recorridos dentro de las zonas verdes deberán estar preferentemente tratados con materiales blandos y permeables.

- Las zonas verdes dispondrán de las instalaciones de riego necesarias para el adecuado mantenimiento de las plantaciones durante sus primeros años.

5) Infraestructuras de transporte y recorridos en el parque natural y su entorno (aplicables a todas las unidades de paisaje).

\section{- En carreteras:}

\section{RECOMENDACIONES}

- En las transiciones entre infraestructuras de transporte y zonas urbanizadas, se definirán bandas tratadas con formaciones vegetales autóctonas (ver Recomendaciones incluidas en Zonas Urbanas y Urbanizables). Dichas bandas deberán ser incrementadas en anchura hasta los 25 metros en transiciones hacia posibles zonas industriales o con grandes dotaciones/servicios.

- Los taludes en tramos de las infraestructuras que discurran en trincheras de menos de 2 metros de altura, deberán tener una pendiente lo suficientemente baja para permitir su colonización por especies arbustivas y herbáceas y una coronación en la que decrezca progresivamente la pendiente (borde romo).

- En la medida que se cumpla la normativa de aplicación en carreteras, los elementos de delimitación en los márgenes de éstas deberán ser acordes con el paisaje circundante (urbano o rural). 
- En viales peatonales/ciclistas internos del Parque y de su entorno:

\section{RECOMENDACIONES}

- En lo referente a vallados y elementos de límite se considerarán las recomendaciones dadas en los apartados de Zonas de viñedo y hortícolas de secano y de Zonas agrícolas de regadío de la presente Normativa

- Los recorridos peatonales/ciclistas deberán realizarse en materiales blandos e irán acompañados de un balizamiento indicativo del itinerario del que forman parte.

6) Saladares secos y Zonas con matorral y bosque termo mediterráneo (aplicables a Unidades de Paisaje no 1, 2, 3, 4, 6, 7, 8, 9 y 14)

- Consideraciones Genéricas:

\section{RECOMENDACIONES}

- Las zonas de saladares secos deberán ser gestionadas de forma que se garantice su continuidad en superficies extensas así como las visuales extensas sobre las masas de vegetación (evitar la inclusión de arbustos o arbolado).

- En las zonas con vegetación termo mediterránea se potenciará la presencia de los estratos arbóreo, arbustivo y herbáceo, salvo en zonas en las que por condicionantes edafo climáticos el estrato arbóreo resulte poco viable.

- Se promoverá la colonización por formaciones vegetales autóctonas en zonas de cultivo de secano abandonadas.

- Los caminos y sendas deberán tener sus márgenes adecuadamente mantenidos, limpios y, preferentemente sin cerramientos en las parcelas colindantes. En caso se ser dichos cerramientos necesarios, se realizarán preferentemente en alturas inferiores a 1,2 metros y con materiales blandos o piedra natural.

7) Ramblas y Acequión de Torrevieja (aplicables a Unidades de Paisaje no 2 y 15):

- Consideraciones Genéricas:

\section{RECOMENDACIONES}

- Las ramblas y el Acequión de Torrevieja deberán vertebrar recorridos de conexión del parque natural con otros espacios abiertos colindantes. Dichos recorridos se localizarán en lo referente a las ramblas, en cotas seguras y podrán ir acompañados de recorridos secundarios en los lechos de los cauces.

- La vegetación en los corredores de las ramblas y en el entorno del Acequión deberá estar conformada por las formaciones vegetales autóctonas propias los entornos que atraviesen. En el caso de las ramblas se potenciará la presencia de vegetación de ramblas en los lechos y de matorral termo mediterráneo con pinar o de saladar en los márgenes.

\subsection{I.2 Normas de Integración Paisajística del sistema de espacios abiertos:}

Las normas de Integración Paisajística del sistema de espacios abiertos, tienen por objeto regular el grado de protección y los usos en las distintas zonas del mismo.

A efectos de la definición de dichas normas se asumen como zonas del sistema de espacios abiertos las dadas por su intersección con las unidades de paisaje (ver plano recogido en la figura 5.37):

\section{Sistema de espacios abiertos incluido en la UP1: Laguna de La Mata:}

- Grado de Protección: máximo (zona incluida dentro del Parque Natural)

- Usos permitidos: Los contemplados en el Plan Rector de Usos y Gestión y en el Plan de Uso Público del Parque Natural

\section{Sistema de espacios abiertos incluido en la UP2: Laguna de Torrevieja}

- Grado de Protección: máximo (zona incluida dentro del Parque Natural)

- Usos permitidos: Los contemplados en el Plan Rector de Usos y Gestión y en el Plan de Uso Público del Parque Natural 


\section{Sistema de espacios abiertos incluido en la UP3: Viñedos y Secanos de La Mata}

- Grado de Protección: máximo (en las zonas incluidas dentro del Parque Natural y en el resto)

- Usos permitidos: Los contemplados en el Plan Rector de Usos y Gestión, en el Plan de Uso Público del Parque Natural, así como en el Plan de Ordenación de los Recursos Naturales del sistema de zonas húmedas del sur de Alicante. (agrícola y puntalmente, servicios, en edificios restaurados).

\section{Sistema de espacios abiertos incluido en la UP4: Huertos tradicionales de La Mata y Torrevieja}

- Grado de Protección: alto (zona parcialmente incluida en el área de amortiguación de impactos del Parque Natural).

- Usos permitidos: Los contemplados en el Plan de Ordenación de los Recursos Naturales del sistema de zonas húmedas del sur de Alicante. (agrícola y puntalmente, servicios en edificios restaurados)

\section{Sistema de espacios abiertos incluido en la UP5: Regadíos Extensivos de la Laguna de Torrevieja}

- Grado de Protección: alto (zona parcialmente incluida en el área de amortiguación de impactos del Parque Natural)

- Usos permitidos: Los contemplados en el Plan de Ordenación de los Recursos Naturales del sistema de zonas húmedas del sur de Alicante. (agrícola)

\section{Sistema de espacios abiertos incluido en la UP6: Altos de la Atalaya y del Moncayo}

- Grado de Protección: alto

- Usos permitidos: espacio natural, forestal, agrícola de secano, infraestructuras de telecomunicaciones/militar (antena existente y zona anexa) Se recomienda la potenciación del desarrollo de bosque termo-mediterráneo sobre suelos forestales o agrícolas en abandono. Se recomienda evitar los movimientos de tierras y abancalamiento, la construcción de balsas, los usos urbanísticos así como la ampliación del uso agrícola de cualquier tipo.

Sistema de espacios abiertos incluido en la UP7: Dunas de Guardamar

- Grado de Protección: máximo (zona incluida en la Red Natura 2000 y LIC)

- Usos permitidos: Espacio natural.

Sistema de espacios abiertos incluido en la UP8: Alto de la Hoya y pinada del Chaparral:

- Grado de Protección: máximo (en las zonas incluidas dentro del Parque Natural y en su área de amortiguación de impactos).

- Usos permitidos: Los contemplados en el Plan Rector de Usos y Gestión, en el Plan de Uso Público del Parque Natural, así como en el Plan de Ordenación de los Recursos Naturales del sistema de zonas húmedas del sur de Alicante (espacio natural, agrícola de secano, dotaciones (únicamente admitidas las existentes: cementerio), centro de colombicultura). Se recomienda la potenciación del desarrollo de bosque termo-mediterráneo sobre suelos forestales o agrícolas en abandono. Se recomienda evitar los movimientos de tierras y abancalamientos, los usos urbanísticos, la construcción de balsas así como la ampliación del uso agrícola de cualquier tipo.

\section{Sistema de espacios abiertos incluido en la UP9: Conector de la Rambla de La Fayona:}

- Grado de Protección: alto

- Usos permitidos: espacio natural, forestal, agrícola. Se recomienda la potenciación del desarrollo de bosque termo-mediterráneo sobre suelos forestales o agrícolas en abandono. Se recomienda la potenciación del desarrollo de bosque termo-mediterráneo sobre suelos forestales o agrícolas en abandono. Se recomienda evitar los movimientos de tierras y abancalamientos, los usos urbanísticos, la construcción de balsas así como la ampliación del uso agrícola de cualquier tipo.

Sistema de espacios abiertos incluido en la UP10: Urbanización EI Raso: corresponde a la zona verde entre la Urbanización del Raso y la laguna de La Mata

- Grado de Protección: alto (ver lo indicado en el Plan de Ordenación de Recursos Naturales del sistema de zonas húmedas delsSur de Alicante)

- Usos permitidos: Zona verde de uso recreativo extensivo y de carácter agrícola-natural (ver lo previsto en el Plan de Ordenación de Recursos Naturales del Sistema de Zonas Húmedas del Sur de Alicante)

Sistema de espacios abiertos incluido en la UP11: Urbanización Ciudad Quesada: No hay suelos incluidos. 
Sistema de espacios abiertos incluido en la UP12: Urbanizaciones entre las lagunas de La Mata y Torrevieja: corresponde a la Vía Verde y a vacíos que faciliten la conexión entre las lagunas de La Mata y de Torrevieja

- Grado de Protección: máximo

- Usos permitidos: Zonas verdes con formaciones vegetales autóctonas, preferentemente con un estrato arbóreo potente.

Sistema de espacios abiertos incluido en la UP13: Urbanización Los Balcones: corresponde a una franja de suelo con edificaciones fuera de ordenación.

- Grado de Protección: máximo

- Usos permitidos: Zona verde de uso recreativo extensivo y de carácter agrícola-natural.

Sistema de espacios abiertos incluido en la UP14: Conector Sur Laguna de Torrevieja - Mar Mediterráneo

- Grado de Protección: alto,

- Usos permitidos: Zona verde de uso mixto agrícola y recreativo extensivo. Se recomienda que en las superficies con uso recreativo extensivo, se introduzcan formaciones vegetales autóctonas con un estrato arbóreo potente.

Sistema de espacios abiertos incluido en la UP15: Frente Litoral y Casco Urbano de Torrevieja: incorpora un sistema interconectado de viales y zonas verdes urbanas así como la totalidad del frente litoral de Torrevieja

- Grado de Protección: máximo

- Usos permitidos: Uso recreativo (zonas verdes y zona litoral), circulación (en viales urbanos) y servicios/portuario (en los tramos de costa urbanizados o destinados a uso portuario). Se recomienda que en las zonas verdes se introduzcan formaciones vegetales autóctonas con un estrato arbóreo potente y que en los viales urbanos se potencien los espacios peatonales, la circulación de bicicletas y la presencia de arbolado de sombra.

\subsection{I.3 Normas de Integración Paisajística del Catálogo de paisaje:}

La Normativa de Integración Paisajística que afecta a los espacios o elementos incluidos en el catálogo de paisaje ha quedado definida para el caso de los espacios en las Normativas de Paisaje expuestas anteriormente. En el caso de los elementos puntuales, será necesario un estudio pormenorizado de los mismos y de sus espacios de afección visual.

\section{4.m. Aspectos económicos asociados a la valoración, protección, gestión y ordenación del paisaje} 5.4.m.1. Introducción:

Tal y como se expone en el capítulo de métodos, la introducción de aspectos económicos en el presente estudio tendría por fin:

\section{a. Disponer de un indicador indirecto de la preferencia o valor del paisaje:}

- Modo: Mediante la incorporación en los planes de participación pública de preguntas en las que se requiera a la población que indique su disposición a contribuir económicamente de forma personal a la mejora, protección y gestión del paisaje, y en caso afirmativo, la cantidad con la que lo haría dentro de una serie de rangos predeterminados.

- Utilidad: Considerando que la contribución económica personal es un indicador del interés real de una persona por proteger /gestionar aquello que más valora o por mejorar aquello que más le perturba, se espera disponer de un validador de los niveles de preferencia paisajísticos obtenidos por estricta preferencia visual.

b. En la determinación de la estabilidad funcional de un territorio (y de sus paisajes asociados): Esta variable se vinculó a un estudio de las productividades del suelo y ha sido desarrollado en el apartado 5.4.h (diagnóstico del sistema de espacios abiertos) y, en menor medida, en el apartado 5.4.d (caracterización del paisaje). A partir de la estabilidad funcional del paisaje, se previó su posible transformación y se propusieron las posibles medidas de ordenación, gestión u ordenación.

c. En la determinación y valoración de vías adicionales de financiación para las acciones de paisaje

- Modo: Mediante la inclusión en el plan de participación pública de cuestiones que permitan explorar y cuantificar posibles vías para apoyar la gestión del territorio y paisaje (disposición a pagar por utilizar espacios naturales, posible interés en productos agrícolas locales, etc) 
- Utilidad: Definir justificadamente posibles vías adicionales de financiación para las acciones de protección, gestión y ordenación del paisaje. Dichas vías se considerarían complementarias a las asignables desde instituciones públicas, fundaciones, etc.

Adicionalmente, el cuestionario empleado, aparte de permitir recabar datos para los puntos (a) y (c) señalados anteriormente, debería proporcionar información útil para:

1. Permitir constatar si la asociación propuesta en la presente tesis entre valor paisajístico (muy alto, alto, medio, bajo y muy bajo) y los objetivos de calidad paisajística genéricos (protección, gestión, ordenación o una combinación de éstos) es correcta en términos de aspiraciones de la población.

2. Apreciar posibles diferencias según nivel de formación, nivel de renta o sexo en la valoración del paisaje o en el grado de apoyo personal a su gestión, protección u ordenación. Este análisis desarrollaría a escala local el realizado dentro del Plan Visual de la Comunidad Valenciana (STEINITZ, MUÑOZ, 2008), del que se concluyó la ausencia de diferencias significativas en la preferencia del paisaje, y se dedujo, en consecuencia, la viabilidad de una política de paisaje común para toda la población y áreas de la Comunidad Valenciana.

El cuestionario propuesto incluyó para cada unidad de paisaje las siguientes preguntas y opciones (se indica en una segunda columna la función concreta de cada cuestión):

\begin{tabular}{|c|c|}
\hline Cuestión & Funciones de la cuestión \\
\hline $\begin{array}{l}\text { 1. ¿Consideraría adecuado que en esta Unidad de Paisaje se diesen } \\
\text { cambios significativos como consecuencia de la introducción de } \\
\text { nuevos usos del suelo, actividades, etc? } \\
\text { - OPCION1: SI } \\
\text { - OPCION2: NO }\end{array}$ & $\begin{array}{l}\text { • Requerir del encuestado que muestre su opinión } \\
\text { indirecta sobre el grado de transformación asumible en la } \\
\text { unidad }\end{array}$ \\
\hline $\begin{array}{l}\text { 2. ¿Estaría dispuesto a contribuir económicamente de forma personal } \\
\text { para que el paisaje de la Unidad de conservase en su estado } \\
\text { actual? } \\
\text { - OPCION1: NO } \\
\text { OPCION2: SI } \\
\circ \quad \text { OPCIÓN 2a: Pagaría hasta } 2 \text { euros/año } \\
\circ \quad \text { OPCION 2b: Estaría dispuesto a pagar entre } 2 \\
\text { y } 10 \text { euros/año } \\
\text { OPCION 2c: Estaría dispuesto a pagar más de } \\
10 \text { euros/año }\end{array}$ & $\begin{array}{l}\text { - Valorar indirectamente el valor asignado al paisaje por } \\
\text { los particulares invitándoles a contribuir de forma personal a } \\
\text { su protección (las cantidades listadas han sido } \\
\text { seleccionadas por considerarse indicativas de tres grados } \\
\text { crecientes de interés). }\end{array}$ \\
\hline $\begin{array}{l}\text { 3. Estaría dispuesto a contribuir económicamente de forma personal } \\
\text { para que el paisaje de la unidad se mejorase de acuerdo a las } \\
\text { sugerencias indicadas en la encuesta anterior? } \\
\text { - OPCION1: NO } \\
\text { OPCIÓN2: SI } \\
\circ \quad \text { OPCION2a: Pagaría hasta } 2 \text { euros/año } \\
\circ \quad \begin{array}{l}\text { OPClÓN2b: Estaría dispuesto a pagar entre } 2 \text { y } \\
10 \text { euros/año } \\
\text { OPClÓN2c: Estaría dispuesto a pagar más de } \\
10 \text { euros/año }\end{array}\end{array}$ & $\begin{array}{l}\text { - Valorar indirectamente el valor asignado al paisaje por } \\
\text { los particulares invitándoles a contribuir de forma personal a } \\
\text { su mejora (las cantidades listadas han sido seleccionadas } \\
\text { por considerarse indicativas de tres grados crecientes de } \\
\text { interés). }\end{array}$ \\
\hline $\begin{array}{l}\text { 4. ¿Le parece que la administración pública debería hacerse cargo de } \\
\text { los costes de conservación o mejora del paisaje en la Unidad de } \\
\text { Paisaje? } \\
\text { - OPCION1: NO } \\
\text { OPCIÓN2: SI } \\
\text { OPCION2a: Si, debería hacerse cargo } \\
\quad \begin{array}{l}\text { íntegramente de dichos gastos. } \\
\text { OPCION2b: Si, conjuntamente con los } \\
\text { particulares (agricultores, industria salinera, } \\
\text { propietarios de viviendas, etc }\end{array}\end{array}$ & $\begin{array}{l}\text { - Determinar el interés de los particulares en que las } \\
\text { administraciones públicas invierta en la conservación y } \\
\text { mejora del paisaje. } \\
\text { - Constatar, por comparación con las preguntas } \\
\text { anteriores, las posibles divergencias entre el grado de } \\
\text { implicación económica personal y el esperado de los entes } \\
\text { públicos } \\
\text { la Determinar en qué medida la población considera que } \\
\text { la conservación y mejora del paisaje debe ser un trabajo } \\
\text { conjunto de las administraciones públicas y de los } \\
\text { particulares afectados }\end{array}$ \\
\hline
\end{tabular}

El mismo tipo de cuestiones se propuso para los recursos paisajísticos, concretando las preguntas en los grupos de recursos de mayor relevancia:

- Patrimonio Arquitectónico Rural

- Vistas desde Carreteras

- Actividad agrícola

- Accesos al parque

Finalmente se incluyeron tres cuestiones dirigidas a determinar si la población muestra mayor predisposición a contribuir económicamente, con su tiempo personal o por medio de un sobrecoste en productos con "denominación de origen" en la protección o mejor gestión de espacios concretos. En este caso y dado el objeto del estudio, el espacio elegido fue el propio Parque Natural: 


\begin{tabular}{|c|c|}
\hline Cuestión & Funciones de la cuestión \\
\hline $\begin{array}{l}\text { Estaría dispuesto a pagar por hacer uso del Parque Natural de } \\
\text { las Lagunas de La Mata y Torrevieja } \\
\text { - OPCION1: NO } \\
\text { OPCION2: SI } \\
\circ \quad \text { OPCION2a: Pagaría entre } 1 \text { y } 3 \text { euros } \\
\circ \quad \text { OPCION2b: Pagaría entre } 3 \text { y } 5 \text { euros } \\
\circ \quad \text { OPCION2c: Pagaría más } 5 \text { euros }\end{array}$ & $\begin{array}{l}\text { - Determinar el interés del encuestado en contribuir } \\
\text { económicamente y de forma personal en la mejora de un } \\
\text { espacio concreto (el Parque Natural) } \\
\text { - Detectar las posibles divergencias entre el grado de } \\
\text { implicación económica del particular en un espacio concreto } \\
\text { (Parque Natural) y un espacio genérico (Unidad de Paisaje) } \\
\text { - Proporcionar a los gestores del Parque Natural un dato } \\
\text { objetivo sobre el interés de la población en el citado espacio. }\end{array}$ \\
\hline $\begin{array}{l}\text { 2. Estaría dispuesto a dedicar parte de sus tiempo libre a la mejora } \\
\text { del paisaje del Parque natural y de su entorno } \\
\text { - OPCION1: NO } \\
\text { - OPCION2: SI }\end{array}$ & $\begin{array}{l}\text { - Determinar el interés del encuestado en contribuir } \\
\text { mediante su tiempo personal en la mejora de un espacio } \\
\text { concreto (el Parque Natural) } \\
\text { - Detectar las posibles divergencias entre el grado de } \\
\text { implicación personal del particular en un espacio concreto } \\
\text { (Parque Natural) y un espacio genérico (Unidad de Paisaje) } \\
\text { - Proporcionar a los gestores del Parque Natural un dato } \\
\text { objetivo sobre el interés de la población en el citado espacio. }\end{array}$ \\
\hline $\begin{array}{l}\text { Estaría dispuesto a pagar un poco más por un producto local } \\
\text { - } \quad \text { OPCION1: NO } \\
\text { - OPCION2: SI }\end{array}$ & $\begin{array}{l}\text { - Determinar la viabilidad de posibles productos locales } \\
\text { con “denominación de origen”, cuya calidad y mayor precio } \\
\text { permita el mantenimiento y mejora del Parque Natural y de } \\
\text { su entorno } \\
\text { - Proporcionar un dato objetivo sobre la viabilidad de } \\
\text { productos locales con denominación de origen asociada al } \\
\text { Parque Natural. }\end{array}$ \\
\hline
\end{tabular}

Con el objeto de poder determinar posibles divergencias entre distintos grupos de población en el valor asignado por la población al paisaje y su disposición a contribuir o a requerir de terceros que contribuyan a su conservación o mejora, se requirió de los encuestados que proporcionasen los siguientes datos personales:

- Sexo

- Edad

- Lugar de Residencia

- Formación: (EGB /Formación Profesional / Bachillerato / Diplomatura / Licenciatura

- $\quad$ Nivel de renta: (muy bajo / bajo / medio / alto / muy alto)

\section{4.m.2. Resultados del Plan de Participación Pública}

\section{4.m.2.1. Niveles de participación:}

- Encuestas: Al tratarse de una zona con una elevada heterogeneidad de población, se estableció una muestra lo más representativa posible de la misma. Para ello se planteó que el porcentaje de entrevistados fuera entorno a un 50-60\% en Torrevieja, a un 10\% en Los Montesinos y San Miguel de Salinas y a un $15-20 \%$ en Rojales y Guardamar del Segura, así como que el $19 \%$ fuera de nacionalidad diferente a la española. Con respecto al sexo, que fuese lo más equitativo posible. Durante la fase 3 se realizaron un total de 75 encuestas a pie de calle.

- Consultas expertos: Entre los expertos contactados para solicitar su posible colaboración en la FASE3 del Plan de Participación Pública se incluyeron técnicos de los Ayuntamientos de Torrevieja, Guardamar del Segura, Rojales, Los Montesinos y San Miguel de Salinas, profesores de las distintas Universidades de la Comunidad Valenciana, técnicos de la Consellería de Medio Ambiente, Agua, Urbanismo y Vivienda y del Parque Natural de las lagunas de La Mata-Torrevieja, recibiéndose un total de 19 respuestas al cuestionario.

Tabla 5.36: Comparación entre los perfiles de los encuestados inicialmente previstos y finalmente encuestados en la fase3 del plan de participación pública (en la que se incluyeron las preguntas referentes a aspectos económicos del paisaje.

\begin{tabular}{c|c|c|c} 
Variable encuestado & Valores & Objetivo encuestas & Encuestas realizadas \\
\hline \multirow{4}{*}{$\begin{array}{c}\text { Lugar de realización de las } \\
\text { encuestas }\end{array}$} & Torrevieja & $50-60 \%$ & $45 \%$ \\
\cline { 2 - 4 } & Montesinos & $10 \%$ & $10 \%$ \\
\cline { 2 - 4 } & Guardamar & $15-20 \%$ & $20 \%$ \\
\cline { 2 - 4 } & Rojales & $15-20 \%$ & $10 \%$ \\
\cline { 2 - 4 } & San Miguel de las Salinas & $10 \%$ & $15 \%$ \\
\hline \multirow{3}{*}{$\begin{array}{c}\text { Motivo de la presencia en } \\
\text { la zona }\end{array}$} & Residente & $66 \%$ & $24,50 \%$ \\
\cline { 2 - 4 } & Turista-motivos laborales & $33 \%$ & $97,00 \%$ \\
\hline \multirow{2}{*}{\begin{tabular}{c} 
Nacionalidad \\
\cline { 2 - 4 }
\end{tabular}} & Español & $81 \%$ & $3,00 \%$ \\
\hline \multirow{2}{*}{ Edad } & Extranjero & $19 \%$ & $10,00 \%$ \\
\cline { 2 - 4 } & $0-18$ & $13 \%$ & $78,75 \%$ \\
\cline { 2 - 4 } & $18-65$ & $68 \%$ & $11,25 \%$ \\
\cline { 2 - 4 } & $>65$ & $19 \%$ & $50,00 \%$ \\
\hline \multirow{2}{*}{ Sexo } & Hombres & $50 \%$ & $50,00 \%$ \\
\hline
\end{tabular}




\section{4.m.2.2: Resultados:}

Los datos recogidos en las encuestas pueden ser consultados en el ANEXO I de la presente tesis y han sido agrupados en las tablas siguientes:

1. Tablas que recogen el desacuerdo de la población/expertos con cambios significativos en las unidades de paisaje, comparan estos resultados con los niveles de preferencia / calidad obtenidos en la FASE2 del Plan de Participación Pública y comparan los Objetivos de Calidad Paisajística asociables al desacuerdo con cambios en el paisaje con los deducidos por asociación con el valor paisajístico.

2. Tablas que muestran la disposición de la población/expertos a contribuir económicamente a la mejora o conservación del paisaje (por unidades de paisaje o recursos paisajísticos).

3. Tablas que muestran la opinión de la población/expertos sobre el grado deseable de implicación de agentes públicos y privados en la conservación y mejora del paisaje (por unidades de paisaje o recursos paisajísticos).

4. Tablas que muestran la disposición de la población y expertos en contribuir económicamente o con su tiempo libre en acciones concretas para la mejora o conservación del paisaje.

Anticipando lo recogido en el capítulo 7 (Conclusiones) y en el Anexo I (Valoración económica del paisaje) de la presente tesis, se resumen las conclusiones extraídas de los 4 tipos de tablas anteriormente expuestos.

\section{Sobre el valor paisajístico y la disposición de la población a contribuir en la mejora o protección del} paisaje:

1.1. La disposición a contribuir económicamente de forma personal en la protección o mejora del paisaje se podría considerar un indicador indirecto del valor paisajístico (la disposición es siempre mayor en paisajes altamente valorados).

2. Sobre el valor paisajístico y su asociación a objetivos de calidad paisajística:

2.1. Los niveles de valor paisajístico obtenidos según la metodología propuesta por el Reglamento de Paisaje de la Comunidad Valenciana y por la presente tesis son coherentes y se pueden asociar con los niveles de acuerdo/desacuerdo con cambios en el paisaje.

2.2. Los objetivos de calidad paisajística genéricos (protección, gestión, ordenación o mixtos) podrían ser deducidos, sin discrepancias significativas, tanto del valor paisajístico como del acuerdo/desacuerdo con cambios en el paisaje.

\section{Sobre las vías de financiación de la protección, gestión y ordenación del paisaje:}

3.1. La financiación de la mejora o protección del paisaje a través de contribuciones voluntarias personales es poco viable, siendo en cualquier caso más posible en espacios o elementos altamente valorados.

3.2. La población entiende que la mejora y protección del paisaje debe ser fundamentalmente financiada desde los organismos públicos con la participación de los particulares afectados o implicados (especialmente en espacios urbanizados o productivos).

3.3. La viabilidad de financiar acciones de protección o mejora del paisaje a través de contribuciones personales (entradas, pago de sobrecoste de producto local de calidad, etc. ) se incrementa cuando se es requerida para acciones o espacios concretos y altamente valorados. 


\section{DISCUSION DE RESULTADOS}


VALORACIÓN Y GESTIÓN DEL PAISAJE SEGÚN EL CONVENIO EUROPEO DEL PAISAJE YEL

REGLAMENTO DEL PAISAJE DE LA COMUNIDAD VALENCIANA: APLICACIÓN MEDIANTE UN ESTUDIO

DE PAISAJE A UNESPACIO ABIERTO EN LA COMUNIDAD VALENCIANA

DOCTORANDO: JUAN JOSÉ GALÁN VIVAS (Universidad Politécnica de Valencia, enero 2011) 


\section{DISCUSIÓN DE RESULTADOS:}

\subsection{Flexibilidad, aplicabilidad y utilidad de los estudios de paisaje}

La metodología propuesta permitió generar la documentación prevista en el ámbito seleccionado, reforzando a su vez la parte propositiva prevista en los estudios de paisaje (objetivos de calidad paisajística, programas, normativa, recomendaciones y plan de ordenación paisajística). Quedarían por valorar los aspectos siguientes:

1. ¿Sería aplicable la metodología en otro ámbito geográfico?: En este punto, se estima que la metodología propuesta se estructura a partir de fases aplicables y convenientes en cualquier ámbito geográfico (caracterización del paisaje, valoración del paisaje, formulación de objetivos de calidad paisajística, definición de mecanismos para conseguir dichos objetivos (normativa, programas, etc) y procesos de participación pública). Dicha aplicabilidad deriva de que la metodología no se vincula a un listado concreto de conceptos a estudiar o proponer sino que deja mayormente abierta la selección de éstos a la experiencia de los autores del estudio y a las especificidades del ámbito de trabajo.

2. ¿Sería aplicable la metodología en otra escala de trabajo?: El desarrollo de la aplicación práctica en un ámbito ampliado y estricto permitió definir unidades de paisaje, sistemas de espacios abiertos o programas de paisaje en un marco regional y local. En este punto, se estima que la documentación a producir en un estudio de paisaje se puede estructurar a partir de un índice similar e independiente de la escala de trabajo. Cabe sin embargo incidir en lo siguiente:

a. Las escalas de trabajo deben ajustarse en función del carácter suprarregional, regional o local del estudio. Dichas escalas de trabajo van asociadas al grado de detalle en la observación y de valoración de las unidades o recursos paisajísticos o en la definición de sistemas espaciales.

b. La unidad de paisaje en escalas regionales se desvincula más de variables territoriales como los usos del suelo o cobertura vegetal y se asocia más a combinaciones de éstas de acuerdo a patrones característicos.

c. Se asume una adaptación de los estándares de valoración en función del ámbito de trabajo (la valoración de las unidades y recursos paisajísticos o la clasificación como principales o secundarios de los de puntos de observación se realiza asumiendo que los valores máximos y mínimos se deben dar dentro del ámbito del estudio).

d. Al aumentar las dimensiones del ámbito de trabajo, las partes propositivas del estudio (normativas, directrices, programas de paisaje, etc) adquieren un carácter más general y deben ser más susceptibles de enmarcar las partes propositivas de estudios de carácter más local.

3. ¿Apoya adecuadamente la documentación generada la definición de documentos de planeamiento territorial y urbanístico sensibles al paisaje?: Conforme a lo propuesto por el Reglamento de Paisaje de la Comunidad Valenciana, la documentación producida en un estudio de paisaje afectaría a la planificación territorial y al planeamiento urbanísticos por medio de:

a. La definición de espacios con una ordenación urbanística diferenciada: sistema de espacios abiertos.

b. La definición de directrices en la planificación territorial a partir de objetivos de calidad paisajística de carácter regional o suprarregional.

c. La definición de normativa de integración paisajística: que podrá ser reforzada mediante su inclusión o adaptación en la normativa, ordenanzas o regulaciones de la planificación territorial y el planeamiento urbanístico.

La documentación producida fue muy positivamente valorada por técnicos de las administraciones locales afectadas y de la Consellería de Medio Ambiente, Agua, Urbanismo y Vivienda. Se estima a su vez que parte de la documentación producida (por ejemplo, los planos de visibilidad, la asignación de valores paisajísticos a las unidades o recursos 0 , sencillamente, la agrupación en un único documento de información territorial procedente de distintas fuentes) puede tener indirectamente una alta utilidad en el desarrollo del planeamiento urbanístico (por ejemplo orientando la localización de nuevos crecimientos urbanos o industriales) o la integración de proyectos de alta incidencia paisajística (por ejemplo, las infraestructuras). Se apreció sin embargo, que al no estar el estudio de paisaje asociado a un Plan General de Ordenación Urbana ni a un Plan de Acción Territorial, carece de un efecto vinculante. Ante esta situación cabría su inclusión en un posible Plan Especial para el ámbito y entorno del Parque 
Natural de las lagunas de La Mata Torrevieja y su uso orientativo para el desarrollo de estudios de paisaje en los las revisiones de los Planes Generales de los municipios afectados.

4. ¿Sustenta adecuadamente la documentación generada la realización de acciones concretas?: Las acciones de paisaje se articulan en la metodología propuesta y en la definida por el Reglamento de Paisaje de la Comunidad Valenciana en torno a los programas de paisaje, cuyas fichas explicativas, proporcionaron a las administraciones locales y autonómicas información esencial para la posible definición posterior de acciones o proyectos concretos dentro de un marco global. En la aplicación práctica desarrollada se aprecia que muchos de los programas, especialmente los más costosos, tienen, como consecuencia de intervenciones previas inadecuadas, un fin paliativo o corrector.

\subsection{Transversalidad de los estudios de paisaje}

La metodología propuesta se basa en una visión acorde a los planteamientos del Convenio Europeo del Paisaje: (1) El paisaje constituye una cualidad territorial y no se asocia a ámbitos geográficos concretos o a espacios con un determinado valor, (2) El paisaje es dinámico y su planificación debe asumir el cambio como base para su gestión, ordenación o protección, (3) El estudio y transformación del paisaje debe de ocurrir tomando en cuenta a la población, (4) La planificación del paisaje debe ser coordinada con la planificación territorial y sectorial.

Adicionalmente, la metodología propuesta y la prevista en el Reglamento de Paisaje de la Comunidad Valenciana, incorporan explícitamente en la caracterización de las unidades y de los recursos paisajísticos la dimensión ambiental, cultural y visual del paisaje, dando cabida de este modo a aspectos de alta transversalidad o a cualidades intangibles. Dada su importancia en la evolución del paisaje, la metodología propuesta incorpora a su vez su dimensión productiva-económica.

Se observa en este punto que la metodología prevista en Cataluña para la redacción de catálogos del paisaje detalla un número mayor de aspectos (estéticos, ecológicos, productivos, históricos, de uso social, mitológicos, religiosos y espirituales y simbólicos e identitarios) que los previstos en la presente tesis, si bien, muchos de ellos se podrían incluir dentro de la dimensión cultural del paisaje (aspectos históricos, mitológicos, religiososespirituales y simbólicos-identitarios), de la dimensión ambiental (aspectos ecológicos) o de la dimensión productivo-económica. En este análisis comparativo se observa a su vez que la metodología propuesta incorpora de forma expresa aspectos asociados a la importancia visual, evita explícitamente una valoración específica estética del paisaje, haciendo por el contrario una valoración conjunta de la preferencia/calidad paisajística y adscribiendo como recurso paisajístico aquellos elementos o espacios de valor estético reconocido e, indirectamente, inconora aspectos asociados al uso social del territorio y del paisaje mediante su consideración como recursos paisajísticos culturales o visuales.

\subsection{Escalas, contextualización y ámbitos territoriales en la planificación del paisaje}

Se considera que el desarrollo dentro del ámbito ampliado de trabajos conducentes a la caracterización del paisaje y a la definición de un sistema de espacios abiertos de carácter regional proporcionaron una información sin la que no se habría podido garantizar:

1. La conectividad territorial del ámbito estricto del estudio.

2. La inclusión de los elementos primarios del medio físico o humano.

3. La correcta consideración de las dinámicas que transforman el paisaje.

Dichos trabajos exigieron sin embargo una fuerte asignación de recursos por lo que se entiende que, idóneamente, deberían ser objeto de estudios de paisaje específicos de carácter regional y que únicamente en ausencia de estos últimos cabe su realización como parte de un estudio de paisaje de carácter local.

Se concluye por lo tanto la conveniencia de programar desde la administración autonómica el desarrollo secuencial y ordenado de estudios de paisaje en los ámbitos siguientes:

- Comunidad Autónoma $>$ Regiones $>$ (Ámbitos supramunicipales) > Ámbitos locales (ajustados con el objeto de definir unidades de paisaje coherentes).

En lo referente a los usos o clases de suelo en los que se desarrolle el estudio de paisaje, la realización de la aplicación práctica puso de manifiesto su utilidad en suelos no urbanizables, urbanizables, o urbanos, si bien en 
éstos últimos, dado su carácter fuertemente consolidado, se detecta un menor margen de maniobra en las propuestas. Dicha situación se constata igualmente en suelos altamente protegidos, en los que suelen existir fuertes regulaciones específicas que, indirectamente, condicionan el paisaje y su posible evolución.

\subsection{Metodología para la caracterización del paisaje:}

La caracterización del paisaje a escala regional y local permitió, de acuerdo a la metodología propuesta por la Countryside Agency para el Reino Unido y asumida en la presente tesis, la definición de unidades de paisaje regionales, subdividibles a escala local. Esta estrategia se estima coherente con la distinción de matices al trabajar en escalas de mayor detalle.

La simplificación de las fichas correspondientes a las unidades de paisaje se basó en el uso de una serie de descriptores y en la utilización de un lenguaje escueto tanto textual como cartográfico. Los trabajos que siguieron a la caracterización del paisaje estuvieron sin embargo bien apoyados por la información recogida durante la caracterización del paisaje y la fase 1 del plan de participación pública. Cabe sin embargo indicar que, algunos aspectos como el uso social, los valores históricos o intangibles del paisaje o el desarrollo de un plano específico de cada unidad y de los recursos mejorarían la descripción de cada unidad.

En el caso de los recursos paisajísticos, se observó que muchos de ellos quedaban simultáneamente adscritos a varias categorías (medioambiental, cultural o visual), siendo la categoría de recursos paisajísticos visuales la que indirectamente recogía con más frecuencia recursos paisajísticos de otro tipo. Esta situación obedece a que, así como los recursos culturales y ambientales son complementarios en razón de su origen, los recursos visuales atienden a una importancia perceptiva. Antes esto, cabe la opción de acotar más el concepto de recurso paisajístico visual, asociándolo a espacios que permiten ver ciertos elementos, a recorridos de valor escénico, a elementos fisiográficos que delimiten visuales o a elementos de interés visual cuyo valor no obedezca a motivos culturales o ambientales.

En lo referente a la definición de unidades de paisaje, se concluye que, estas son especialmente operativas si definen espacios que (1) aceptan una caracterización sintética y (2) que permiten la aplicación consistente de acciones de gestión, protección u ordenación en cada una de ellas. En este punto se realizó dentro de la aplicación práctica un esfuerzo tanto a nivel de unidades regionales, como locales, por intentar reducir el no de unidades sin perder por ello los dos objetivos de operatividad antes marcados. Se apreció sin embargo que en ciertos lugares con una fuerte heterogeneidad paisajística pero con un factor unitario de alto peso como la fisiografía o la vocación territorial, la definición de unidades de paisaje a partir de criterios de oportunidad o potencialidad puede ser positiva.

Se abre en consecuencia una posible discusión sobre si la caracterización del paisaje (definición de unidades de paisaje) debe ser siempre previa a la definición de objetivos de calidad paisajística o de acciones sobre el paisaje, o si contrariamente, la detección preliminar de vocaciones u objetivos paisajísticos comunes, puede guiar la definición de unidades de paisaje que, aun siendo menos homogéneas a nivel formal, permitan formular objetivos de calidad y programas de paisaje comunes. En concreto, esta situación se dio especialmente dentro del desarrollo de la aplicación práctica en los siguientes dos casos:

- A nivel del ámbito ampliado (regional): Unidad de Paisaje no3 (Laderas y colinas en torno a las lagunas de la Mata y Torrevieja): En este caso, se definió una unidad de paisaje en un espacio ocupado por urbanizaciones y zonas agrícola-forestales cuyo denominador común era su situación sobre el sistema de elevaciones topográficas que rodea las lagunas de la Mata y Torrevieja. A pesar de su alta heterogeneidad, la existencia de un objetivo paisajístico común como era el contener e integrar las urbanizaciones y establecer una matriz forestal entre ellas orientó la definición de la unidad de paisaje y facilitó la posterior definición de programas de paisaje comunes.

- A nivel del ámbito estricto (local): Unidad de Paisaje no14 (Conector Sur Laguna de Torrevieja . mar Mediterráneo): En este caso, se definió una unidad de paisaje en un espacio ocupado por suelos costeros, agrícolas, naturales y dotacionales (depuradora, hospital y desaladora de Torrevieja), que en su conjunto, y a pesar de su heterogeneidad, conforman el único corredor no edificado todavía entre la laguna de Torrevieja y el mar Mediterráneo y en el que, la definición de la propia unidad, permitió que se agrupasen espacios percibidos hasta entonces como independientes, y que se definiesen acciones comunes para su ordenación/gestión/protección. 
La inclusión de los recursos paisajísticos, como complemento de las unidades de paisaje, permitió identificar elementos puntuales, lineales o extensos de alto interés cultural, ambiental o visual. Dichos recursos son de hecho fundamentales para entender el paisaje dado, que a diferencia de la visión, a menudo "aérea", que la unidad de paisaje nos ofrece del territorio, los recursos se asocian a elementos o espacios más concretos, visibles e identificables a "pie de tierra" por un posible observador.

Se percibe sin embargo que a pesar de que la identificación de dichos recursos proporciona una información fundamental para los apartados propositivos del estudio de paisaje (definición del sistema de espacios abiertos, programas de paisaje y normativa paisajística), su valor, esencialmente positivo, orienta acciones de protección y no da información específica sobre los conflictos paisajísticos puntuales, lineales o extensos que se dan en el territorio, y cuya resolución se fundamentaría en acciones básicamente de gestión y ordenación. Previendo esta situación, la metodología propuesta incluyó en las fichas de las unidades de paisaje, y con el mismo nivel de importancia, la identificación de recursos y de conflictos paisajísticos, e integró ambos conceptos en la fase correspondiente a la caracterización del paisaje del plan de participación pública.

El posterior desarrollo del estudio de paisaje mostró la importancia que dicha detección de conflictos paisajísticos tuvo en la definición de los objetivos de calidad paisajística y de los programas de paisaje, dotándolos de una fuerte componente de ordenación y mejora del paisaje, esencial en territorios con valores paisajísticos bajos o medios (como son muchos de los existentes en las áreas más habitadas del mundo desarrollado), y permitiendo superar la visión estrictamente protectora que, casi inevitablemente, se asocia a los elementos paisajísticamente positivos y que se intentaba precisamente superar con la nueva visión del paisaje propugnada por el Convenio Europeo.

Finalmente, en lo referente a la participación pública, se detectó que resultó especialmente útil para detectar "tipos de paisaje" (más que para definir "unidades de paisaje", al estar estas últimas asociadas a un concepto poco conocido por la población y al ser frecuentemente asociado al de "uso del suelo") así como para identificar conflictos y recursos paisajísticos culturales y visuales, al estar éstos vinculados al uso específico o a la visión subjetiva que la población tiene del territorio.

\subsection{Utilidad y metodologías para el análisis visual y su integración en la planificación del paisaje}

El análisis visual conforme a la metodología propuesta en la presente tesis (básicamente coincidente con la recogida en el Reglamento de Paisaje de la Comunidad Valenciana), requiere de un intenso trabajo de campo y gabinete y permite obtener un plano de visibilidad "adquirida" del territorio, cuya utilidad debe ser valorada en función de su posterior uso en el desarrollo de las partes propositivas del estudio de paisaje o en otros documentos de planificación o de proyectos.

En este punto se concluye que el análisis visual conforme a la metodología propuesta permitiría:

1) Ajustar en función de su grado de visibilidad los valores paisajísticos de las unidades de paisaje y recursos paisajísticos (eventualmente también podría hacerlo sobre los conflictos paisajísticos, aumentando la gravedad de aquellos más visibles).

2) Disponer de un mapa o plano de "visibilidad adquirida" del paisaje que localiza las áreas más y menos vistas del territorio, y que, por lo tanto, podría ser de utilidad en un futuro para ubicar elementos de baja calidad visual.

Se debe destacar sin embargo que el plano de visibilidad "adquirida" del territorio es calculado en base a unos puntos de observación seleccionados en función, básicamente, de la frecuentación del territorio en un momento concreto, y que por lo tanto, la creación de nuevas zonas de alta frecuentación (por ejemplo, nuevas infraestructuras de transporte o nuevas zonas urbanizadas) podría cambiar sensiblemente dicho plano.

De igual forma, llevada a un extremo, la aplicación extrema de criterios de visibilidad a la hora de planificar el territorio, podría suponer la ubicación de los elementos visualmente negativos en zonas poco visibles, y viceversa, a centrar las acciones de mejora del paisaje exclusivamente en los corredores o zonas por donde circula la población. Esta aproximación del territorio, con "escenarios" y "bambalinas" sería contraproducente, al generar por un lado grandes desequilibrios en la calidad del paisaje y, por otro, al estar asociada a un plano de visibilidad, que en caso de verse modificado, podría dejar altamente visibles zonas de baja calidad visual. 
Con el objeto de paliar este riesgo, la metodología prevista en el Reglamento de Paisaje de la Comunidad Valenciana y en la presente tesis, prevén la ubicación de algunos puntos de observación (es decir a partir de los que se calcula la visibilidad "adquirida" del paisaje), en zonas, que a pesar de ser poco frecuentadas, permiten apreciar la singularidad del paisaje.

Por otro lado, y con el objeto de evitar la polarización del paisaje en zonas de alta y baja calidad paisajística, cabría defender la búsqueda de una alta calidad integral del paisaje en todo el territorio, tanto en sus zonas urbanas como en las industriales, agrícolas, infraestructurales o naturales, jugando en este punto un papel determinante la planificación pormenorizada y el desarrollo de proyectos que integren la variable paisajística en su diseño interior, en el de sus bordes y en su relación con el entorno.

La valoración de los resultados del análisis visual desarrollado como parte de la aplicación práctica de la presente tesis puede hacerse por lo tanto en dos vertientes:

1) Operatividad de la metodología propuesta y validez de los datos obtenidos

2) Utilidad de los datos obtenidos en la planificación del paisaje.

Se analizan seguidamente ambas vertientes:

1. Operatividad de la metodología propuesta y validez de los datos obtenidos: En lo referente a la operatividad de la metodología propuesta, se observa que, mediante el uso de herramientas SIG, se pudo sistematizar y simplificar considerablemente el cálculo de los niveles de visibilidad "adquirida", si bien, dado el carácter esencialmente llano del ámbito seleccionado, los resultados no permitieron identificar zonas con visibilidad media, quedando todas las áreas adscritas a los niveles de visibilidad alta o baja. En este punto debe destacarse que una topografía más variable hubiese generado un plano de visibilidades más variado y hubiese permitido que el factor "visibilidad" influyese de forma más clara en los valores de las unidades o recursos paisajísticos.

Igualmente, se constató que, dada la precisión y niveles de actualización de la cartografía SIG disponible, es necesario hacer ajustes importantes antes de proceder a calcular las áreas visibles desde cada punto o línea de observación, obteniéndose, aun después de dichos ajustes, resultados de fiabilidad media que deben ser comprobados y ajustados a partir de observaciones in situ.

2. Utilidad de los datos obtenidos en la planificación del paisaje: Tal y como se indicó anteriormente, la utilidad del plano de visibilidad adquirida del paisaje, obtenido como resultado del análisis visual, puede ser considerada desde dos perspectivas:

a. Ajuste de los valores paisajísticos de las unidades y recursos paisajísticos (y eventualmente de los conflictos paisajísticos): En este punto, la metodología propuesta para el ajuste resultó operativa y se considera que, ajustando únicamente las zonas altamente visibles (al alza los recursos o unidades con valores altos o muy altos y a la baja los recursos o unidades con valores bajos o muy bajos), se consigue el efecto deseado que no es otro que priorizar las acciones en las zonas muy visibles.

b. Uso del plano de visibilidad en el planeamiento y en proyectos: Asumido que el plano de visibilidad adquirida depende de los niveles de frecuentación del territorio en un momento dado, se constata que dicho plano puede ser de utilidad, no sólo en la definición del sistema de espacios abiertos o de los programas de paisaje, (a incluir en el estudio de paisaje), sino en el planeamiento urbanístico (por ejemplo, detectando zonas en las que el desarrollo de nuevas zonas urbanas o industriales tenga una menor incidencia visual) 0 en la preparación de proyectos (por ejemplo, facilitando la integración de edificios aislados o de infraestructuras). En este punto debe sin embargo reseñarse que el grado de precisión de un análisis visual desarrollado a nivel regional o local (dado por el no de puntos de observación y la fiabilidad del cálculo de cuencas visuales mediante las herramientas SIG) puede ser insuficiente para una intervención concreta, cabiendo en dicho caso y tal y como se prevé en los estudios de integración paisajística, la posibilidad de hacer un análisis visual más detallado.

Considerando en particular el análisis visual realizado como parte del estudio de paisaje incluido dentro de la presente tesis y su utilidad en las partes propositivas del mismo, se concluiría lo siguiente: 
- La selección de los puntos de observación condiciona el plano de visibilidad a obtener. Con el objeto de sistematizar la selección de los mismos se recomienda considerar los niveles de tráfico en las infraestructuras de transporte y seleccionar puntos desde los que se percibe la totalidad del territorio, espacios de alta calidad escénica o espacios altamente frecuentados. La asignación de niveles de importancia a los puntos de observación (principales o secundarios) debería hacerse de acuerdo a estándares RELATIVOS con el objeto de que el análisis visual responda al ámbito concreto del estudio.

- El cálculo de cuencas visuales mediante programas SIG resulta altamente operativo pero requiere de un trabajo previo de actualización y ajuste de ciertas capas de información, y debe ser cotejado y corregido a partir de observaciones in situ.

- El plano de visibilidad obtenido puede y debe ser utilizado con distintos fines:

- Ajuste del valor paisajístico de unidades y recursos paisajísticos (así como del nivel de gravedad de los conflictos paisajísticos).

- Ubicación de futuras zonas urbanizadas o nuevas infraestructuras a definir en otros documentos de planeamiento o proyecto.

Como aspectos que se estima que precisarían un estudio más detallado en la metodología propuesta se destacarían los siguientes:

1. Definición de puntos de observación no asociados a espacios de alta afluencia.

2. Mejora de la fiabilidad de las cuencas visuales calculadas mediante programas SIG (en este punto se considera esencial disponer de cartografías actualizadas).

\subsection{Utilidad y metodología para la valoración del paisaje:}

Al igual que con el análisis visual del paisaje, el desarrollo de la aplicación práctica debería permitir primeramente estimar la utilidad de la valoración del paisaje en la planificación y, secundariamente, la operatividad de la metodología propuesta en la presente tesis (mayormente coincidente con la definida en el Reglamento de Paisaje de la Comunidad Valenciana).

En lo referente a la utilidad de la valoración del paisaje dentro de la planificación, se observa que la asignación de valores concretos a las unidades y recursos paisajísticos posibilitó:

- Definir los espacios y elementos a incluir en el Catálogo de Paisaje (que serán objeto de protección mediante una normativa específica)

- Establecer, en función de su valor, unos objetivos de calidad paisajísticos genéricos (protección, gestión, ordenación o una combinación de los anteriores) para las unidades y recursos paisajísticos.

- Proporcionar en un futuro un criterio objetivo (el valor paisajístico) para orientar el planeamiento (evitando por ejemplo transformar sustancialmente unidades o recursos paisajísticos altamente valorados) o para diagnosticar la incidencia de acciones o proyectos que modifiquen el paisaje.

La no definición de valores de calidad paisajística eliminaría un aspecto metodológicamente complejo pero, al mismo tiempo, privaría a las administraciones o particulares de un importante parámetro que justifique la toma de decisiones.

En este punto, la metodología valenciana, al considerar la preferencia paisajística, como valor asignado por la población, la calidad paisajística, como valor asignado por expertos, y al definir el valor paisajístico preliminar como media de ambos, evita expresamente entrar en la generación de modelos o ecuaciones explicativas del valor, aceptando por el contrario un acercamiento empírico y esencialmente participativo.

El análisis de la aplicación práctica de la metodología propuesta para la valoración del paisaje permite concluir lo siguiente:

1) La determinación de la calidad paisajística (por expertos) tiende a asignar valores más extremos a las unidades de paisaje y a los recursos paisajísticos. Esto se explica por la mayor dispersión propia de un número menor de datos y a un conocimiento por los expertos de aspectos negativos y positivos desconocidos para la mayor parte de la población. 
2) La determinación de la preferencia paisajística (por la población) tiende a asignar valores menos extremos a las unidades de paisaje y a los recursos paisajísticos. Esto se explica por la menor dispersión propia de un número mayor de datos y a un menor conocimiento de aspectos no claramente visibles o perceptibles.

3) La definición del VALOR PAISAJISTICO PRELIMINAR como media aritmética de los valores asignados por expertos y población para cada unidad o recurso paisajístico se considera operativa y acorde a los objetivos de la participación pública. Dicha media aritmética no restaría finalmente valor paisajístico a los espacios o elementos protegidos por su interés medioambiental o cultural, dado que, de acuerdo con la metodología propuesta de valoración, éstos adquieren a posteriori y de forma directa un valor paisajístico muy alto. De igual modo, dado que no se observan generalmente discrepancias cualitativas entre los juicios de la población de expertos, la realización de una media aritmética no es susceptible de centrar opiniones muy contrapuestas.

4) La asignación de valores de calidad o preferencia paisajística en escalas de 1 a 5 (o de 1 a 10) es fácilmente entendida por los expertos o población y permite generar rangos de calidad o preferencia adecuados.

5) Se considera adecuada la asignación de valores paisajísticos RELATIVOS a las unidades de paisaje o recursos paisajísticos. Dicho criterio relativo se entiende que es más adecuado para los fines de un estudio de paisaje que un criterio de valoración absoluto, en el que, de acuerdo a una escala de carácter nacional o universal, las unidades o recursos paisajísticos podrían quedar bajamente valoradas. En este punto, se entiende que será en los estudios de paisaje de rango mayor (por ejemplo, regionales, nacionales, etc.) en los que las unidades o recursos paisajísticos de la zona del estudio en curso habrán sido valorados en un contexto más amplio. Se asume a su vez la posible divergencia entre valores de, por ejemplo, un mismo recurso paisajístico, en función de que se valore a nivel local, regional o nacional, entendiéndose que los estudios de paisaje a nivel local, regional o nacional tienen precisamente la función de proteger, ordenar y gestionar lo mejor, peor y más anodino dentro de sus respectivos ámbitos.

6) Para el ajuste del valor paisajístico preliminar en función de la visibilidad de la unidad o recurso paisajístico, y considerada una escala de 1 a 5 para el valor paisajístico (en la que 1 es el valor mínimo y 5 el máximo), se recomienda seguir el siguiente procedimiento de ajuste:

1. EN ZONAS CON VISIBILIDAD ALTA:

a. Aumentar en un punto el valor paisajístico de las unidades o recursos con valor paisajístico alto o muy alto.

b. Disminuir en un punto el valor paisajístico de las unidades o recursos con valor paisajístico bajo o muy bajo.

c. Mantener el valor paisajístico de las unidades o recursos con valor paisajístico medio.

2. EN ZONAS CON VISIBILIDAD MEDIA:

a. Aumentar en 0,5 puntos el valor paisajístico de las unidades o recursos con valor paisajístico alto o muy alto.

b. Disminuir en 0,5 puntos el valor paisajístico de las unidades o recursos con valor paisajístico bajo o muy bajo.

c. Mantener el valor paisajístico de las unidades o recursos con valor paisajístico medio.

3. EN ZONAS CON VISIBILIDAD BAJA O NULA:

a. Mantener en todos los casos los valores paisajísticos de las unidades o recursos paisajísticos.

En una consideración global, se estima que la valoración del paisaje en los términos propuestos, permitió disponer de criterios para la definición de objetivos de calidad paisajística y de los programas de paisaje asociados, proporcionó una información útil para orientar tanto la planificación urbanística como la definición de proyectos de alta incidencia territorial e integró de forma especialmente intensa la participación pública en el proceso de valoración.

Como aspectos que se estima que precisarían un estudio más detallado en la metodología propuesta se destacarían los siguientes:

1. Valoración de los conflictos o problemas paisajísticos con el objeto de poder priorizar posteriormente su corrección.

2. Definición de un procedimiento para promediar los valores de calidad y preferencia paisajística. 


\subsection{Objetivos de calidad paisajística}

La interpretación que desde el Reglamento de Paisaje de la Comunidad Valenciana se hace de los objetivos de calidad paisajística, definidos en el Convenio Europeo del Paisaje como las "aspiraciones de las poblaciones en lo que concierne a las características paisajísticas de su entorno", e interpretadas en el citado Reglamento como objetivos de protección, de restauración, de gestión, de ordenación del paisaje o cualquier combinación de las opciones anteriores, resulta limitante y de poca aplicación en las unidades de paisaje, donde a menudo predomina la combinación de las distintas opciones. El Reglamento deja por otro lado un margen escaso a la incorporación de aspiraciones más concretas manifestadas por la población. Por dicho motivo, se propuso en la metodología de la presente tesis diferenciar entre objetivos de calidad paisajística "genéricos" (los previstos por el Reglamento) y "específicos", entendiendo éstos últimos como objetivos más concretos para cada unidad o recurso paisajístico apoyados parcialmente en lo manifestado por la población dentro del marco del plan de participación pública.

Adicionalmente, la metodología propuesta sugiere asociar los objetivos de calidad paisajística genéricos al valor paisajístico, asumiendo que las unidades o recursos paisajísticos con valores altos o muy altos deberían tener asociados objetivos de protección/gestión, los de valor bajo o muy bajo de ordenación/gestión, y los de valores medios, principalmente de gestión.

El análisis de los resultados obtenidos en la aplicación práctica pone de manifiesto lo siguiente:

- El ámbito del estudio de paisaje, en la medida que tenga una cierta coherencia interna que lo diferencie de su entorno, es susceptible de tener unos objetivos de calidad paisajística globales.

- Los objetivos de calidad paisajística "específicos" son los que permiten principalmente generar programas y normativas de paisaje, quedando los objetivos "genéricos" como indicativos de un acercamiento global.

- La asociación del valor de una unidad o recursos paisajístico a unos determinados tipos de objetivos de calidad paisajística genéricos (protección, gestión u ordenación) permite sistematizar la definición de los segundos, si bien, como se indicaba anteriormente, estos objetivos genéricos resultan poco útiles en la posterior definición de programas o normativas de paisaje.

- La participación pública es especialmente importante en la definición de objetivos de calidad paisajística. Sin embargo, dada la dificultad que muchos participantes encuentran en formular objetivos, se recomienda solicitarles que indiquen cómo creen que la unidad o recurso paisajístico debería evolucionar y las acciones que estiman oportunas.

En una consideración global, se estima que la definición de objetivos de calidad paisajística en los términos propuestos facilita tanto su propia definición como la de los programas de paisaje que permitan su consecución. Tal y como se ha expuesto, cabría sin embargo considerar la utilidad real de los objetivos de calidad de tipo genérico y la posible necesidad de definir unos objetivos de calidad paisajística globales para el conjunto del ámbito del estudio de paisaje.

\subsection{Sistema de espacios abiertos}

El sistema de espacios abiertos definido en la aplicación práctica ocupa un $78 \%$ del ámbito del estudio. Dicho porcentaje es excepcionalmente elevado como consecuencia de incluir un parque natural, que de hecho supone el $34 \%$ del ámbito del estudio y un $44 \%$ del sistema de espacios abiertos.

El proceso de delimitación del sistema de espacios abiertos pudo sistematizarse correctamente a partir de la metodología propuesta, siendo esencial el haber determinado previamente un sistema de espacios abiertos de carácter regional y surgiendo las principales dudas al tener que precisar la anchura de los conectores y los límites de los espacios agrícolas a incluir en el sistema. En este punto resultó especialmente útil realizar la delimitación usando elementos lineales naturales o artificiales (barrancos, ramblas, canales caminos, etc) a los que se adicionó unas bandas de afección visual o ecológica.

Los principales riesgos encontrados en la definición del sistema de espacios abiertos fueron su posible sobredimensionamiento, definiendo en ese caso una zona que podría delimitar o asfixiar las posibilidades del planeamiento urbanístico, o, contrariamente, su infradimensionamiento, que incapacitaría al sistema para cumplir sus funciones ecológicas y visuales. El primero de los errores se aprecia que suele ser debido a una incorrecta asimilación del sistema de espacios abiertos con el suelo no urbanizable, y el segundo, a su percepción como un 
conjunto de parajes de alto interés natural o visual, conectados mediante un sistema de elementos lineales (carreteras escénicas, caminos peatonales o pistas ciclistas).

La aplicación del procedimiento de diagnóstico previsto en la metodología permitió por otro lado valorar su viabilidad en los términos actuales, sus posibles conflictos con el planeamiento urbanístico vigente, su efectividad como conector de suelos urbanizados con suelos rurales o forestales así como establecer una zonificación directa del sistema de espacios abiertos en función de su intersección con las unidades de paisaje. Adicionalmente, éste último aspecto resultó especialmente útil en el momento de definir la normativa de paisaje y los usos del suelo permitidos dentro del citado sistema.

En lo referente a la utilidad del sistema de espacios abiertos se constata que, dicho sistema constituye una de las herramientas más potentes previstas en la legislación valenciana para integrar el paisaje en la planificación urbanística.

Así, los sistemas de espacios abiertos definidos en los estudios de paisaje constituyen "zonas de ordenación urbanística" y, de acuerdo al artículo 36.1.c de la Ley Urbanística Valenciana (16/2005), forman parte de la ordenación estructural del territorio, debiéndose determinar para dichos sistemas sus usos globales y tipos básicos de edificación permitidos. Adicionalmente, y según el artículo 45.1.e de la citada Ley, los sistemas de espacios abiertos "determinarán los criterios para presenvar terrenos del proceso urbanizador aun cuando éstos no presenten valores ni riesgos naturales intrínsecos, tales como evitar conurbaciones no deseables, limitar expansiones hipertrofiadas del desarrollo urbano, asegurar corredores de recíproca comunicación entre espacios rurales, configurar entomos paisajísticos abiertos para dotar de calidad de vida a los núcleos urbanos, separar usos incompatibles, preservar el carácter intermunicipal del viario, evitar tanto la excesiva dispersión como la concentración de asentamientos u otros fines análogos tendentes a vertebrar el desarrollo urbano y territorial".

Conforme a lo expuesto, se puede apreciar que los sistemas de espacios abiertos constituyen una concreción espacial directa y territorialmente vinculante, de las propuestas recogidas en los estudios de paisaje y que su delimitación y posterior definición de normativa paisajística asociada (en la que se regulan los usos de sus distintas zonas), deben ser cuidadosamente consideradas para garantizar que el sistema cumple sus funciones, sin sobrepasarlas o no alcanzarlas.

A este respecto, se aprecia que la metodología propuesta permitió generar en la aplicación práctica, un sistema que cumple los objetivos fijados por la legislación valenciana quedando explicada su elevada superficie por el elevado porcentaje que, respecto al ámbito del estudio, suponen el parque natural y su zona de amortiguación.

\subsection{Programas de paisaje}

En respuesta a unos objetivos de calidad paisajística de marcado carácter territorial y ordenador, los programas de paisaje propuestos en la aplicación práctica tuvieron en muchos casos una orientación amplia y transversal, afectando a los sistemas de comunicación, a la integración paisajística, a la gestión del territorio, a los sistemas naturales (agua, vegetación), a la conservación del patrimonio, a la consolidación del sistema de espacio abiertos propuesto, a la concienciación ciudadana o a la actividad económica.

Dichos objetivos de calidad paisajística y programas de paisaje se consideran coherentes con la visión del paisaje propugnada por el Convenio Europeo y la legislación valenciana, por las que el paisaje es la cualidad percibida del territorio, y que por lo tanto, al ser protegido, gestionado u ordenado, orienta la evolución de dicho territorio.

En particular se establecieron en la aplicación práctica 12 programas de paisaje, de los que 3 , tuvieron un marcado carácter corrector de impactos y unos costes de aplicación especialmente elevados. Esta particularidad refuerza la sugerencia previa de incluir específicamente en los estudios de paisaje la caracterización y valoración de conflictos paisajísticos, frecuentes, muy a menudo, en territorios altamente intervenidos como los que se encuentran en la mayor parte de la Comunidad Valenciana.

En relación a la utilidad de los programas de paisaje así definidos, debe de recordarse que los programas listan, describen y presupuestan una serie de acciones y proyectos concretos, cuya ejecución es de hecho la que permitiría el cumplimiento de los objetivos de calidad paisajística. En este punto se aprecia que dada la elevada cuantía de algunos de los programas, su descomposición en acciones o proyectos, así como la indicación de la 
"importancia" y "urgencia" de cada uno de ellos, resulta fundamental para que las administraciones o particulares afectados puedan priorizar su ejecución. Adicionalmente, las indicaciones dadas en los programas pueden ser de utilidad para orientar o valorar la idoneidad de futuros proyectos.

Se aprecia a su vez que los ámbitos de aplicación de los programas definidos en la aplicación práctica no se corresponden en muchos casos con las unidades de paisaje sino con sistemas territoriales como las redes de transporte, la cubierta vegetal, etc. A pesar de que esto no es incompatible con lo previsto por el Reglamento de Paisaje de la Comunidad Valenciana, sugiere, tal y como se comentó anteriormente, la necesidad de reflexionar sobre la utilidad de las unidades de paisaje como espacios para la aplicación de acciones específicas.

En lo referente a la participación pública se constató que el conjunto de propuestas realizadas por la población y expertos en la fase3 del plan de participación, resultaron de gran utilidad para establecer los objetivos de calidad paisajística y los programas de paisaje. Dichas propuestas tuvieron sin embargo a menudo un carácter puntual, requiriendo su agrupación bajo epígrafes más amplios.

Finalmente, la preparación de un plan de ordenación paisajística incorporaba un nuevo apartado respecto a la documentación prevista en la legislación valenciana para los estudios de paisaje. La preparación del citado plan en la aplicación práctica y su posterior valoración por las administraciones afectadas permite concluir lo siguiente:

- Con el objeto de ser útil a efectos de desarrollo del estudio de paisaje, el plan debe ser preparado después de formular los objetivos de calidad paisajística y de recoger las propuestas de población y expertos, y antes de definir los programas de paisaje.

- La definición de unas estrategias para la ordenación, protección y gestión del paisaje resulta de gran utilidad para el desarrollo del plan y la reducción del número de programas.

- El plano de ordenación paisajística permite transmitir de forma sintética a la población y administraciones afectadas el conjunto de acciones ejecutivas previstas en el estudio de paisaje, facilitando su posible implicación y apoyo.

\subsection{Normativa de paisaje}

Conforme a la metodología propuesta, la normativa de paisaje definida en la aplicación práctica consideró:

- La componente paisajística de la normativa urbanística o de protección de espacios naturales vigente en el ámbito del estudio.

- Las normas de aplicación directa o de integración paisajística previstas en el Reglamento de Paisaje de la Comunidad Valenciana y aplicables o de interés en el ámbito del estudio.

A dichas normas, se incomoraron específicamente:

- Recomendaciones paisajísticas referidas a los elementos que configuran las unidades de paisaje o sistemas territoriales (cauces, infraestructuras, etc.).

- Normas que regulen los usos y grado de protección de las distintas zonas del sistema de espacios abiertos.

Considerando la frecuente existencia de normativas detalladas en los ámbitos urbanos, se entiende que gran parte de las recomendaciones y normas propuestas en la aplicación práctica se refieran a los espacios no urbanos. Debe sin embargo reseñarse que, conforme al artículo 42 del Reglamento de Paisaje de la Comunidad Valenciana, la normativa de paisaje puede influir de forma muy determinante en el desarrollo de nuevas edificaciones o zonas urbanizadas. Dicho artículo determina en sus puntos 3 y 4 lo siguiente: "las Normas de Integración Paisajística que constituyan criterios para el desarrollo de la ordenación urbanística pormenorizada se incluirán en las Fichas de Planeamiento previstas en la legislación urbanística vigente" y "aquellas que se refieran al tratamiento formal de los espacios públicos o de las edificaciones resultantes, pertenecientes a la ordenación estructural, se integrarán en las Normas Urbanísticas del plan al que acompañe".

Se concluye en consecuencia, que así como el sistema de espacios abiertos suponía una delimitación espacial que se introducía en el planeamiento como zona de ordenación urbanística, la normativa de paisaje se introduce en el planeamiento urbanístico en calidad de normas o de criterios para generar ordenaciones pormenorizadas. Se aprecia en este punto una diferencia respecto a las herramientas previstas en la comunidad de Cataluña, en la que los catálogos de paisaje generaban criterios y acciones para la posterior definición de directrices o normas en los Planes Territoriales o Planes de Ordenación Urbanística Municipal. 


\subsection{Participación pública}

Los objetivos fundamentales de la metodología propuesta en lo referente a la participación pública eran:

1. Recoger las opiniones del conjunto de la población residente y visitante en las partes analíticas y propositivas de un estudio de paisaje

2. Simplificar el desarrollo de plan de participación pública con el objeto de que dicho plan, sin perjuicio de la calidad de sus resultados, no lastrase en tiempo ni recursos, la redacción del estudio de paisaje.

Con el objeto de cumplir los objetivos antes citados se preparó un plan estructurado en tres fases (caracterización, valoración y propuestas de paisaje), que se desarrolló a lo largo de dos meses y medio y en el que se recogió la opinión tanto de grupos de interés como de muestras representativas de la población residente y visitante.

El plan de participación pública permitió recopilar una gran cantidad de información, que debió ser rápidamente procesada en las dos primeras fases para alimentar las siguientes. Dicha información se consideró de gran utilidad debiendo sin embargo hacerse las siguientes observaciones:

1. En la caracterización del paisaje, la población identifica adecuadamente recursos y conflictos paisajísticos pero encuentra dificultades en lo que se refiere a los recursos paisajísticos visuales. Igualmente se observa que los participantes identifican más fácilmente los tipos de paisaje que las unidades de paisaje dado que las segundas, requieren una mayor concreción y delimitación física.

2. En la valoración del paisaje resulta efectivo el sistema de valoración de 1 a 5 mediante imágenes representativas, si bien la selección de éstas última debe hacerse con la máxima neutralidad con el fin de no condicionar a los participantes.

3. En la sugerencia de propuestas sobre el paisaje se observa que muchas de las realizadas por la población son de carácter puntual, lo que exige una abstracción y agrupación por parte del equipo redactor del estudio de paisaje.

4. Con el objeto de facilitar la participación, es fundamental el uso de un lenguaje sencillo y de imágenes o planos.

5. Las opiniones recogidas entre grupos de interés y en webs a las que los participantes acceden por motivación propia, son a menudo escasas y bastante sesgadas. Por dicho motivo se recomienda la realización de encuestas a pie de calle en muestras representativas de la población.

6. La participación en las webs y la asistencia a los seminarios programados fue escasa, lo que puede explicarse por una escasa difusión y publicitación del plan de participación, especialmente en su inicio.

La metodología propuesta en la presente tesis se considera aplicable en otros contextos y que puede aportar importante información tanto a la parte analítica como propositiva de los estudios de paisaje. En lo relativo a costes y plazos, resulta altamente efectiva si bien debe de preverse un periodo y medios suficientes para la difusión del plan de participación, tanto entre grupos de interés como entre la población en general.

\subsection{Integración de variables económicas}

Tal y como se explica en el capítulo de métodos, una vez desestimada la realización de una valoración económica específica del paisaje, la integración de las variables económicas se concentró en las líneas siguientes:

- Inclusión de aspectos económicos en la caracterización del paisaje (productividad y precio del suelo).

- Consideración de las implicaciones económicas de:

a. Inclusión y regulación de los usos del suelo en el sistema de espacios abiertos.

b. Ejecución de los proyectos o acciones incluidas en los programas de paisaje

- Exploración de posibles vías suplementarias para financiar las acciones de protección, gestión y ordenación del paisaje.

Las variables económicas consideradas (productividad y precio del suelo) resultan fundamentales para explicar la estabilidad o posibles cambios en los usos del suelo, así como para diagnosticar los efectos económicos de las regulaciones o propuestas incluidas en los estudios de paisaje.

En lo referente a la exploración de vías de financiación de las acciones de paisaje a partir de la contribución directa de la población, se encontró que son escasamente viables, y que, de plantearse, serían más factibles si 
se aplicasen en la protección o mejora de espacios o elementos altamente valorados (dándose una fuerte correlación entre valor paisajístico y disposición a contribuir) o en los que la población percibe una clara oportunidad social.

Como síntesis de los trabajos realizados en la vertiente económica del paisaje, se concluye que la integración de variables económicas como la productividad y el precio del suelo, sería fácilmente realizable tanto en la metodología propuesta como en la prevista por el Reglamento de Paisaje de la Comunidad Valenciana, aportando en contrapartida una mayor consistencia a los programas de paisaje y a la viabilidad del sistema de espacios abiertos.

6.13. Mecanismos de incorporación del paisaje a las herramientas de planeamiento territorial y urbanístico (directrices/normas/recomendaciones o determinación de espacios físicos con un tratamiento urbanístico específico)

Siguiendo los planteamientos del Reglamento de Paisaje de la Comunidad Valenciana, la metodología propuesta y testada en la presente tesis, prevé la incorporación del paisaje en la planificación territorial y el planeamiento urbanístico mediante tres vías principales:

- ESPACIAL: Delimitación y regulación (transferida esta última al planeamiento urbanístico) de un sistema de espacios de especial interés visual, cultural y ambiental: sistema de espacios abiertos

- NORMATIVA: Definición de normas y recomendaciones que se incorporen u orienten la normativa de los planes territoriales o urbanísticos: Normativa de paisaje

- PROGRAMATICA: Definición de programas (con proyectos o acciones asociadas) que concreten acciones para cumplir los objetivos de calidad paisajística: Programas de Paisaje y Plan de Ordenación Paisajística.

Dado que la discusión sobre cada una de las tres vías ha sido realizada anteriormente, se realiza seguidamente una valoración conjunta sobre la utilidad que la información producida puede tener en el planeamiento territorial y urbanístico.

A este respecto, se constata que la metodología propuesta en la presente tesis, delimita espacios para un tratamiento urbanístico específico, define explícitamente normas y recomendaciones y detalla a un alto nivel las acciones deseables para la ordenación, gestión y protección del paisaje. Se puede concluir en consecuencia que dichos estudios asumen internamente trabajos que en otras metodologías no se contemplan (delimitación de espacios), se sugieren (acciones de paisaje) o se transfieren a otros documentos (definición de normativas).

Dada esta situación cabría plantearse las siguientes cuestiones y comentarios:

1. ¿Es la información producida conforme a la metodología propuesta útil e integrable en el planeamiento territorial y urbanístico?: El Reglamento de Paisaje de la Comunidad Valenciana, y por extensión la metodología propuesta en la tesis, son explícitos en la forma en la que los estudios de paisaje deben de afectar al planeamiento territorial y urbanístico. En la práctica, se observa sin embargo, que la definición de normativa de paisaje, del sistema de espacios abiertos y de los programas de paisaje generan frecuentes dudas por tres motivos:

a. Explicación fraccionada, y en algunos casos poco clara en el reglamento, de los conceptos, contenidos y utilidad posterior de la normativa de paisaje, de los sistemas de espacios abiertos, de los catálogos de paisaje y de los programas de paisaje.

b. Ausencia de guías metodológicas o ejemplos aplicados (que deberían incluir tanto un estudio de paisaje como un plan general de ordenación urbana o plan de acción territorial que incorpore las determinaciones del primero y que permitiesen ver su utilidad).

c. Percepción errónea del estudio de paisaje como un documento de análisis y diagnóstico más que como un documento propositivo.

En este punto, la metodología propuesta ha pretendido definir en mayor detalle los aspectos menos claros de los estudios de paisaje, quedando por conocer la facilidad con que la información generada en la aplicación práctica sería introducida en las revisiones de los planes generales de ordenación urbana afectados (Torrevieja, Los Montesinos, Rojales, San Miguel de Salinas y Guardamar del Segura).

2. ¿Sería preferible eliminar o transferir a otros documentos la concreción de alguno de los apartados propositivos actualmente incluidos en los estudios de paisaje? Dado que prácticamente 
se admite con carácter universal que las herramientas de planificación del paisaje deben incluir o predefinir una normativa de paisaje y una serie de propuestas dirigidas a la consecución de los objetivos de calidad paisajística, la discusión se centraría en la necesidad de definir y regular un sistema espacial específico (sistema de espacios abiertos). En este punto, se aprecia que la visión transversal (y específicamente visual) que desde el paisaje se tiene del territorio permiten la definición de sistemas espaciales multifuncionales que aúnan con efectos altamente positivos y sinérgicos criterios ambientales, culturales, visuales y urbanísticos. Se concluye en consecuencia que la eliminación de alguno de los apartados propositivos de los estudios de paisaje (en los términos contemplados en la presente tesis y en el reglamento de paisaje de la Comunidad Valenciana) les restarían efectividad y operatividad.

En relación a la trasferencia de la concreción de los apartados propositivos de los estudios de paisaje (normas, sistemas espaciales) a los planes territoriales y urbanísticos, se podría considerar que esto facilitaría su adecuada interrelación con otras normativas o con la ordenación espacial global, pero al mismo tiempo y con un efecto negativo, podría darse una desvinculación de las partes analíticas respecto a las partes propositivas de la planificación del paisaje, no concretándose adecuadamente estas últimas o haciéndolo desde los planteamientos tradicionales del planeamiento urbanístico.

Esta última discusión es especialmente importante en la medida que alude indirectamente a la conveniencia de integrar el paisaje en las herramientas habituales de planeamiento o de generar herramientas específicas que afecten a las primeras, considerándose al respecto que la segunda opción resulta más efectiva y operativa.

3. ¿Existen aspectos no tratados en las partes propositivas de los estudios de paisaje que deberían ser introducidos?: Considerada la dimensión espacial, normativa y programática de las determinaciones previstas en los estudios de paisaje, así como su fundamentación en un proceso de participación pública, se puede concluir que cubren adecuadamente todos los temas tratables en la planificación territorial. 
VALORACIÓN Y GESTIÓN DEL PAISAJE SEGÚN EL CONVENIO EUROPEO DEL PAISAJE YEL

REGLAMENTO DEL PAISAJE DE LA COMUNIDAD VALENCIANA: APLICACIÓN MEDIANTE UN ESTUDIO

DE PAISAJE A UNESPACIO ABIERTO EN LA COMUNIDAD VALENCIANA

DOCTORANDO: JUAN JOSÉ GALÁN VIVAS (Universidad Politécnica de Valencia, enero 2011) 
VALORACIÓNY GESTIÓN DEL PAISAJE SEGÚN EL CONVENIO EUROPEO DEL PAISAJE YEL

REGLAMENTO DEL PAISAJE DE LA COMUNIDAD VALENCIANA: APLICACIÓN MEDIANTE UN ESTUDIO

DE PAISAJE A UNESPACIO ABIERTO EN LA COMUNIDAD VALENCIANA

DOCTORANDO: JUAN JOSÉ GALÁN VIVAS (Universidad Politécnica de Valencia, enero 2011)

\section{CONCLUSIONES}


VALORACIÓN Y GESTIÓN DEL PAISAJE SEGÚN EL CONVENIO EUROPEO DEL PAISAJE YEL

REGLAMENTO DEL PAISAJE DE LA COMUNIDAD VALENCIANA: APLICACIÓN MEDIANTE UN ESTUDIO

DE PAISAJE A UNESPACIO ABIERTO EN LA COMUNIDAD VALENCIANA

DOCTORANDO: JUAN JOSÉ GALÁN VIVAS (Universidad Politécnica de Valencia, enero 2011) 


\section{CONCLUSIONES:}

Las conclusiones de la presente tesis se derivan de la propuesta metodológica para la redacción de estudios de paisaje que faciliten la integración del paisaje en la planificación territorial (ver capitulo no 4 ) y de los resultados obtenidos en la aplicación práctica de dicha metodología (ver capitulo $n^{0}$ 5), desarrollada en un ámbito concreto y representativo de las dinámicas territoriales actuales en la Comunidad Valenciana y en zonas costeras mediterráneas.

Las conclusiones se han dividido en tres tipos. Un primer tipo de carácter genérico, que hacen referencia a la planificación paisajística y al papel de los estudio de paisaje como herramienta de planificación, unas segundas, que aluden a los distintos aspectos considerados en la propuesta metodológica para la redacción de estudios de paisaje y un tercer tipo que valoran las contribuciones de la tesis en la planificación del paisaje.

El conjunto de conclusiones han sido definidas tras una valoración de los resultados con las administraciones afectadas por el estudio de paisaje desarrollado (Dirección General de Territorio y Paisaje, Dirección del Parque Natural de las Lagunas de La Mata y Torrevieja y ayuntamientos con suelos incluidos dentro del parque natural o en su zona de amortiguación).

\subsection{Conclusiones generales:}

1. Se concluye que los estudios de paisaje, tal y como quedan establecidos en el Reglamento de Paisaje de la Comunidad Valenciana, constituyen una herramienta válida y efectiva para la planificación del paisaje y para una mejora sustancial de la ordenación territorial y de la planificación urbanística, aportando una perspectiva transversal, introduciendo criterios visuales, ecológicos y culturales y facilitando la integración de elementos nuevos o preexistentes. Se sugiere la consideración de los ajustes metodológicos recogidos en la presente tesis, y muy especialmente, la definición de marcos autonómicos y regionales en la planificación del paisaje así como la efectiva integración de las determinaciones de los estudios de paisaje en los Planes Generales de Ordenación Urbana. Se constata a su vez la necesidad de que los estudios de paisaje incorporen aspectos económicos y de gestión del territorio así como que integren aspectos vinculados a los crecimientos urbanos e infraestructuras, facilitando criterios para su ubicación, conformación y acabado desde la perspectiva del paisaje.

2. La marcada diversidad del ámbito seleccionado para el desarrollo del estudio de paisaje incluido en la presente tesis, permitió poner a prueba y validar la metodología propuesta en escalas, situaciones y contextos muy distintos: áreas urbanas y periurbanas, espacios litorales con diferentes niveles de urbanización, zonas agrícolas con distintas productividades y presión para el cambio de uso, espacios naturales con diferentes niveles de protección, etc.

Esta diversidad de contextos confiere una alta aplicabilidad a las conclusiones obtenidas. Debe indicarse sin embargo que los procedimientos para el análisis visual deberían ser testados en topografías más variadas y que las conclusiones de tipo sociológico deberían ser cotejadas en otros ámbitos sociodemográficos, por ejemplo en áreas con poblaciones más homogéneas. En este último punto debe sin embargo indicarse que los resultados del estudio son plenamente coincidentes con los obtenidos en el Plan Visual desarrollado para el conjunto de la Comunidad Valenciana (STEINITZ, MUÑOZ, 2008).

3. La metodología propuesta permitió desarrollar un estudio de paisaje de carácter supramunicipal en un periodo de 10 meses, incluyendo un plan de participación pública y unos trabajos preliminares de carácter regional. Considerada la extensión y complejidad del ámbito, se concluye que la brevedad de dicho periodo fue posible mediante una optimización del uso de los recursos y el tiempo, y que dicha optimización radicó en:

- Una rápida recogida de las bases cartográficas y documentales necesarias para los trabajos.

- Un efectivo trabajo y contacto con las administraciones públicas afectadas.

- Una sistematización y calendarización estricta del plan de participación pública.

- La automatización de los trabajos de análisis visual

- Una sistematización y simplificación de las fichas de unidades de paisaje y programas de paisaje

- La asignación de un tiempo suficiente (4-5 meses) para el desarrollo de las partes propositivas del estudio 
4. La efectiva integración de los estudios de paisaje en la planificación territorial requiere de una estrategia para su progresiva definición desde las escalas regionales a las locales así como de la disponibilidad y fácil acceso a bases cartográficas actualizadas, tanto en lo referente al medio físico como al humano.

5. El trabajo práctico desarrollado como parte de la tesis pone de manifiesto que la temprana consideración de criterios paisajísticos en la ordenación territorial y en el desarrollo de proyectos facilita la positiva evolución visual del territorio y la integración paisajística. Por el contrario, la consideración tardía de dichos criterios o su errónea asociación a aspectos de detalle o acabado, genera entornos de baja calidad visual y el desarrollo de intervenciones de alto impacto ecológico y visual, cuya remediación resulta a menudo imposible o muy costosa.

6. La planificación del paisaje en general y los estudios de paisaje en particular, deben asumir que los trabajos de caracterización y valoración del paisaje constituyen pasos previos para concretar acciones y determinaciones dirigidas a la ordenación, protección y gestión del paisaje. Sin esta dimensión propositiva, la aportación del paisaje a la planificación territorial quedaría gravemente limitada como consecuencia de un acercamiento estrictamente descriptivo, ajeno a su carácter dinámico y a su potencial para orientar, junto a otros factores, la ordenación territorial.

7. La consideración en los estudios de paisaje de ámbitos que no se ajustan necesariamente a límites administrativos los hace especialmente útiles para el análisis y la definición de acciones de carácter supramunicipal o que afecten a sistemas o redes territoriales tales como las infraestructuras, sistemas hidrológicos, etc. En este punto debe indicarse que, dado que la legislación Valenciana requiere la redacción de estudios de paisaje en todo Plan General de Ordenación Urbana (P.G.O.U) o en todo Plan de Acción Territorial (P.A.T), resultaría urgente concluir el estudio de paisaje previsto para el conjunto de la Comunidad Valenciana (PAT de Paisaje de la Comunidad Valenciana) así como desarrollar estudios de paisaje de carácter regional, asociando estos últimos a posibles PAT, con el fin de que tengan un efecto vinculante.

8. La caracterización del paisaje estructurada en base a la definición de unidades de paisaje y recursos paisajísticos resulta efectiva pero podría ser complementada con la identificación específica de conflictos paisajísticos (al mismo nivel que los recursos). Dichos conflictos deberían ser valorados con el objeto de determinar su gravedad y sustentarían en los apartados propositivos del estudio de paisaje (definición de objetivos de calidad paisajística, sistema de espacios abiertos, programas y normativa de paisaje) un acercamiento menos enfocado a la protección y más orientado a la resolución de los frecuentes problemas paisajísticos que se dan en territorios altamente intervenidos, como son de hecho los que se dan en la mayor parte de nuestro entorno.

9. La definición de unidades de paisaje en base a criterios analíticos es válida a nivel descriptivo pero puede ser en algunos casos poco funcional a nivel de la definición de acciones de protección, gestión u ordenación del paisaje. Por dicho motivo se sugiere un acercamiento más sintético, que detecte las vocaciones o potencialidades territoriales y que se retroalimente de la definición preliminar de objetivos de calidad paisajística y de programas de paisaje. Se propone en otras palabras, que, frente a una secuencia estrictamente lineal en la redacción de los estudios de paisaje (caracterización>valoración>objetivos de calidad paisajística > sistema de espacios abiertos, programas y normativa de paisaje), se contemple una secuencia ciclica previa que permita definir unidades de pasaje más operativas y vinculables a programas de paisaje específicos.

10. La viabilidad de las determinaciones de los estudios de paisaje requiere que se refuercen los aspectos económicos en cada uno de sus apartados (caracterización, valoración, delimitación de sistemas de espacios abiertos y definición de programas de paisaje). Esto resulta especialmente importante en territorios, como el de la Comunidad Valenciana, donde la mayor parte del suelo tenga un uso productivo.

11. La integración de aspectos económicos en los estudios de paisaje permite disponer de indicadores indirectos de las preferencias paisajísticas de la población así como explorar vías para la custodia y gestión del territorio y del paisaje. 
12. La inclusión en los estudios de paisaje de un plan de ordenación paisajística, entendido como documento que sintetice las actuaciones físicas a desarrollar en los programas de paisaje, permite evitar la excesiva compartimentación temática y de espacios de intervención que puede darse con una aplicación estricta del Reglamento de Paisaje actual, así como transmitir de forma sintética a población y administraciones las propuestas incluidas en el estudio de paisaje.

13. La efectiva y adecuada participación de la población en la planificación del paisaje requiere de una formación previa en aspectos territoriales y paisajísticos. Dicha formación debería darse en los distintos niveles y modalidades de enseñanza.

14. La metodología prevista en el Reglamento de Paisaje de la Comunidad para la integración de planes de participación pública en la redacción de estudios de paisaje requiere ser coordinada con la estructura de dichos estudios. El procedimiento propuesto en la presente tesis, estructurado en 3 fases vinculadas respectivamente a la caracterización, valoración y desarrollo de propuestas para la gestión, protección y ordenación del paisaje, permitió una participación continuada de la población y expertos en la redacción del estudio.

15. Los procesos de participación pública deberían incluir la consulta a muestras representativas de la población residente o visitante con el objeto de complementar las consultas y aportaciones de los grupos con intereses o vinculaciones directas a las áreas en estudio.

16. El estudio de las preferencias paisajísticas de la población y de su disposición a contribuir de forma personal en la protección, gestión y mejora del paisaje, pone de manifiesto que dichas preferencias y disposición son, básicamente, independientes del perfil socio_demográfico de los individuos, lo que proporciona un carácter más universal a las valoraciones y acciones de paisaje apoyadas en planes de participación pública.

17. Se detecta una mayor disposición e interés de la población en proteger y mejorar los espacios y elementos con alto valor paisajístico que en reordenar, restaurar y mejorar los espacios y elementos con bajo valor. Esto sugiere la necesidad de aumentar el apoyo social a este segundo tipo de acciones, haciendo evidentes sus potencialidades y mostrando los beneficios que se derivarían de la intervención sobre éstos.

18. Las normativas de paisaje no pueden desvincularse de normativas de otro tipo que afecten a los elementos que configuren el paisaje. Es por ello que se recomienda que las normativas paisajísticas valoren el efecto paisajístico de otras normativas de aplicación, generen normativas específicas de integración paisajística y refuercen sus determinaciones con recomendaciones.

19. Es necesario avanzar en las herramientas técnicas para el análisis visual del paisaje así como disponer de estudios sociodemográficos regionales y locales que faciliten los procesos de consulta pública.

7.2. Conclusiones sobre la metodología propuesta

7.2.1. Ámbitos de los estudios de paisaje:

1) El correcto desarrollo de estudios de paisaje precisa de la existencia de estudios de paisaje de rango superior que den un contexto el trabajo y que faciliten la propuesta de conectores. En el caso de la Comunidad Valenciana sería especialmente urgente la conclusión del Plan de Acción Territorial de Paisaje de la Comunidad Valenciana, que a su vez cabría vincular con el Atlas de los Paisajes de España.

2) En ausencia de estudios de paisaje de rango superior se recomienda definir un ámbito ampliado en el que, tras una caracterización simplificada del paisaje, se definan por medio de un sistema de espacios abiertos de carácter regional, los principales conectores territoriales.

3) De acuerdo a las conclusiones previas, se recomienda que los estudios de paisaje a escala supra-regional, regional y local se realicen cronológicamente en dicho orden. Este planteamiento "de arriba abajo (upbottom) puede dilatar en el tiempo la integración del paisaje en el planeamiento municipal pero garantiza, por el contrario, su coherencia y permite el adecuado tratamiento de los espacios o elementos estructurantes del territorio (la suma de varias planificaciones locales correctas no tiene porque generar necesariamente una buena planificación regional). 


\subsubsection{Caracterización del paisaje:}

1) La definición de TIPOS de PAISAJE a escalas regionales puede constituir un valioso apoyo para la definición de UNIDADES de PAISAJE, al constituir estas últimas una particularización de los tipos en unos ámbitos concretos.

2) De acuerdo al modelo británico, el concepto de unidad de paisaje puede ser aplicado a distintas escalas, observándose una mayor coincidencia con los usos de suelo o con el tipo de cubierta vegetal en las escalas de detalle.

3) La definición analítica (por suma de elementos de caracterización) de las unidades de paisaje puede hacer que éstas tengan una menor utilidad en la determinación de acciones para la protección, gestión y ordenación del territorio y paisaje. Frente a esto, cabe la opción de realizar una definición sintética, e incluso por detección de vocaciones u oportunidades territoriales. En este punto se sugiere que la propia caracterización se pueda retroalimentar y ajustar a partir de las fases de valoración, de formulación de objetivos de calidad y de definición de programas de paisaje

4) La definición de recursos paisajísticos, de acuerdo a las condiciones propuestas por el Reglamento de Paisaje de la Comunidad Valenciana, genera frecuentemente la adscripción simultánea del mismo espacio o elemento como recurso paisajístico medioambiental, cultural o visual. Dicha situación no debe generar sin embargo problemas en la posterior definición de objetivos de calidad paisajística dado que éstos se pueden definir para un espacio o elemento que sea a la vez un recurso paisajístico de distinto tipo.

5) Por razones operativas y de desarrollo del estudio de paisaje se recomienda acotar el $n^{0}$ de unidades de paisaje, no descartando que la alta heterogeneidad de un territorio puede ser un hecho diferencial que de sentido a una unidad de paisaje.

6) Por razones operativas y de desarrollo del estudio de paisaje se recomienda acotar el $n^{\circ}$ de recursos paisajísticos, seleccionando únicamente aquellos claramente relevantes.

7) La identificación explicita de conflictos paisajísticos (y su posterior valoración). Proporcionaría a la caracterización del paisaje un mayor carácter proactivo y una mayor utilidad en la definición posterior de objetivos de calidad paisajística y de programas de paisaje.

8) La participación pública resulta especialmente operativa en la detección de recursos paisajísticos, siendo menos efectiva en la definición de unidades de paisaje.

\subsubsection{Análisis visual:}

1) El análisis visual está fuertemente condicionado por los puntos de observación, cuya selección debe de realizarse atendiendo a criterios de frecuentación o de visión de espacios representativos del ámbito del estudio, y cuya clasificación como principales o secundarios debe de realizarse atendiendo a criterios relativos del citado ámbito.

2) El análisis visual puede ser simplificado mediante el uso de herramientas SIG, exigiendo sin embargo una actualización y ajuste de ciertas capas y una posterior validación mediante observaciones in situ.

3) Dado que el plano obtenido considera el $n^{\circ}$ de observadores, se debe entender que dicho plano recoge la "visibilidad adquirida" del territorio. La utilidad de dicho plano excede la propia del ajuste del valor paisajístico de unidades y recursos paisajísticos, pudiendo servir como elemento de apoyo para el planeamiento urbanístico y la integración de proyectos.

\subsubsection{Valoración del paisaje:}

1) Existe por lo general una alta convergencia entre las preferencias paisajísticas (comunicadas por la población) y las calidades paisajísticas (comunicadas por expertos), si bien en el segundo caso, el conocimiento más exhaustivo y técnico del territorio, hace que los juicios de valor de los expertos sean más extremos. 
2) La determinación del VALOR PAISAJÍSTICO PRELIMINAR como media aritmética de los valores de preferencia y calidad paisajística resulta operativa y asume plenamente la implicación de la población en la planificación del paisaje.

3) La metodología propuesta para la valoración del paisaje mediante asignación de valores relativos al ámbito del estudio y comprendidos entre 1 y 5 , resulta altamente operativa y da continuidad a las metodologías empleadas en el Plan Visual de la Comunidad Valenciana (STEINITZ, MUÑOZ, 2008).

4) La metodología propuesta para el ajuste del valor paisajístico preliminar en función de la visibilidad resultó altamente operativa. Se considera en este punto, que la corrección del valor paisajístico únicamente en aquellas unidades o recursos paisajísticos altamente visibles consigue los fines que se buscaba al introducir la visibilidad en la valoración del paisaje.

5) La valoración de los conflictos paisajísticos en un procedimiento similar al empleado con las unidades y recursos paisajísticos, permitiría fundamentar la priorización de ciertas acciones de ordenación o mejora del paisaje.

\subsubsection{Objetivos de calidad paisajística:}

1) Adicionalmente a las indicaciones actuales del Reglamento de Paisaje de la Comunidad Valenciana de formular objetivos de calidad paisajística para cada unidad o recurso paisajístico, se sugiere la conveniencia de definir unos objetivos de calidad paisajística para el conjunto del ámbito de cada estudio de paisaje.

2) La vinculación de los objetivos de calidad paisajísticos "genéricos" (protección, gestión u ordenación) a los valores paisajísticos (muy alto, alto, medio, bajo o muy bajo) de las distintas unidades o recursos en los términos previstos en la metodología propuesta, resulta coherente y operativa, si bien, la utilidad de dichos objetivos de calidad paisajística genéricos, es posteriormente relativa.

3) Los objetivos de calidad paisajística "específicos", proporcionan la base real para la definición de programas y para la aplicación de las políticas de paisaje.

\subsubsection{Sistema de espacios abiertos:}

1) El propio concepto del sistema de espacios abiertos como red intercomunicada, exige la existencia de conexiones procedentes de su entorno. Por dicho motivo se reitera la necesidad de generar estudios de paisaje suprarregional y regional que definan un sistema primario de espacios abiertos, a delimitar más ajustadamente en estudios de paisaje de carácter local.

2) La funcionalidad ecológica y paisajística de los espacios incluidos en el sistema de espacios abiertos requiere de la definición de conectores con dimensiones suficientes. En este punto es esencial incluir las zonas de afección visual de las infraestructuras (considerar distancias mínimas de 300 metros y máximas en función de la topografía y calidad del paisaje) y exceder los espacios incluidos en los dominios públicos hidráulicos y costeros. Estos aspectos son especialmente relevantes en la medida que, a menudo, se interpreta erróneamente que el sistema de espacios abiertos debe incluir exclusivamente un sistema de recorridos y dominios públicos, y no los espacios visibles desde éstos, que constituyen de hecho su paisaje y el marco físico y ecológico que puede hacer que cumplan sus funciones.

3) Las implicaciones territoriales del sistema de espacios abiertos, que se recuerda que constituyen "zonas de ordenación urbanística", sugiere la necesidad de realizar un diagnóstico que permita valorar su adecuado dimensionamiento y su efecto sobre:

I. La diversidad de paisajes: se valorará positivamente la inclusión e interconexión de espacios pertenecientes a distintas unidades de paisaje, facilitando la protección de los espacios de alto valor y la mejora de los espacios de escaso valor.

II. Los usos del suelo: se valorará positivamente la interconexión de distintos usos de suelo. Se podrá determinar el porcentaje del sistema de espacios abiertos correspondiente a cada uso del suelo y constatar el peso relativo de los suelos forestales, agrícolas y urbanizados. 
III. La clasificación urbanística: Se podrá valorar el sistema de espacios abiertos en base a los siguientes criterios:

a. En suelo urbano: suponen a menudo un \% bajo del sistema de espacios abiertos pero son estratégicamente esenciales en la medida que: (1) posibilitan la conexión de los espacios urbanizados con los espacios abiertos que los rodean, (2) permiten definir redes verdes urbanas, evitando la creación de espacios verdes aislados y posibilitando la creación de sistemas primarios de circulación blanda en las ciudades (peatonal y ciclista).

b. En suelo urbanizable: permiten ubicar las zonas verdes reglamentarias en espacios en los que apoyen o refuercen el sistema de espacios abiertos, generando zonas de transición con las futuras zonas edificadas y facilitando el acceso desde estas últimas a una red externa de espacios abiertos.

c. En suelo no urbanizable: permiten regular la evolución del paisaje de los suelos forestales, agrícolas, fluviales y litorales de mayor valor o de importancia estratégica como conectores o como entorno visual de infraestructuras.

IV. La estabilidad espacial: la frecuente inclusión de suelos productivos en el sistema de espacios abiertos sugiere la necesidad de conocer su productividad con el fin de prever posibles cambios.

V. La inclusión o adecuado acceso de los recursos paisajísticos o unidades de paisaje de mayor valor: Se valorará positivamente aquellos sistemas que garanticen la calidad visual entorno a los recursos paisajísticos y que incluyan o faciliten el acceso a estos últimos o a las unidades de paisaje de mayor valor.

VI. El control y acotamiento de las zonas urbanizadas y la calidad de su entorno: se valorará positivamente los sistemas que eviten conurbaciones no deseables, que limiten expansiones hipertrofiadas del desarrollo urbano, que configuren entornos paisajísticos abiertos para dotar de calidad de vida a los núcleos urbanos, que eviten tanto la excesiva dispersión como la concentración de asentamientos y que separen usos del suelo incompatibles.

VII. La conectividad espacios naturales, agrícolas y urbanos: se valorará positivamente los sistemas que establezcan conectores entre los espacios naturales, agrícolas o urbanos de mayor interés y que prevean para dichos conectores unas dimensiones acordes a la importancia de los elementos que conectan y a su adecuado funcionamiento ecológico y visual.

VIII. La calidad visual en el entorno de las infraestructuras de transporte.

\subsubsection{Programas de paisaje:}

1) Se recomienda incluir en el plan de participación pública la posibilidad de que la población se manifieste específicamente tanto sobre los objetivos de calidad paisajística como sobre acciones concretas dirigidas a la mejora, protección, restauración o gestión del paisaje. Dichas sugerencias pueden guiar parcialmente la posterior definición de los programas de paisaje.

2) La adscripción de los programas a unidades de paisaje resulta inadecuada para sistemas territoriales tales como las infraestructuras, cauces, recorridos, etc., que a menudo son compartidos entre varias unidades. Por dicha circunstancia se recomienda que los programas de aplicación sobre ámbitos físicos, se propongan sobre los espacios que les son propios, pudiéndose luego diferenciar dentro del programa los sectores que se localizan en cada unidad.

3) Se deberá considerar que los programas de paisaje pueden referirse tanto a acciones físicas, como administrativas, sociales o culturales. Por dicho motivo se recomienda considerar los siguientes tipos de programas:

1. Ejecutivos o constructivos (implican el desarrollo de proyectos ejecutivos)

2. Administrativos

3. Sociales / divulgativos / formativos /culturales

4. De gestión territorial y del paisaje.

4) Se recomienda incluir en la ficha de cada programa una indicación relativa a la URGENCIA y otra relativa a la IMPORTANCIA del mismo. Estas variables (valoradas por ejemplo en un rango de 1 a 5 ) pueden apoyar, junto con la valoración económica de la implementación del programa, la toma de decisiones y priorización de acciones por las administraciones o instituciones competentes. 


\subsubsection{Normativa de paisaje:}

1) En el caso de las normas de aplicación directa y las normas de integración paisajística genéricas (listadas ambas en el Reglamento de Paisaje de la Comunidad Valenciana) se recomienda indicar aquellas de interés en el ámbito del estudio de paisaje, identificando a su vez los motivos de dicha inclusión y las zonas donde pueden ser relevantes.

2) En el caso de las normas de de integración paisajística especificas (las desarrolladas específicamente para cada estudio de paisaje) se aconseja su adscripción a unidades de paisaje o a sistemas territoriales (infraestructuras, cauces, etc.). Dichas normas pueden ser complementadas con RECOMENDACIONES PAISAJÍSTICAS, de menor efecto legal pero útiles a efectos de orientar la modificación, gestión o protección del paisaje y de los sistemas de elementos que lo configuran (edificios, muros y cerramientos, vegetación natural, cultivos, etc.)

3) Para la definición de las normas de integración paisajística del sistema de espacios abiertos, en las que se detallan los usos y actividades en las distintas zonas de éste, se recomienda tomar como zonas las definidas por la intersección del sistema de espacios abiertos con las unidades de paisaje.

4) En ámbitos en los que se detecte la presencia de suelos urbanizables o deficiencias en los espacios públicos urbanos, se deberán establecer normas de integración paisajística que orienten respectivamente la ordenación pormenorizada del suelo urbanizable o el diseño y gestión de los espacios públicos.

\subsubsection{Plan de participación pública:}

1) Se recomienda que el plan de participación pública incluya la realización de encuestas sobre un grupo representativo de la población residente o visitantes del ámbito del estudio de paisaje. Dichas encuestas permitirán incorporar las opiniones del conjunto de la sociedad a las dadas por grupos de personas con intereses o inquietudes particulares.

2) Se recomienda que el plan de participación pública se estructure en tres fases en las que se permita a la población manifestarse respectivamente sobre los tipos de paisaje y recursos paisajísticos (caracterización del paisaje), sobre el valor de las unidades y recursos paisajísticos (valoración del paisaje) y sobre las acciones a desarrollar para proteger, gestionar u ordenar el paisaje (definición de objetivos de calidad paisajística y de programas de paisaje). Dicha secuencia en FASES permite dar continuidad y alimentar el plan de participación pública con las conclusiones de la fase previa pero exige disponer de un calendario estricto y concentrado que evite la excesiva duración del plan de participación, de una generación rápida de conclusiones en cada fase por el equipo redactor y el uso de cuestionarios y materiales explicativos sintéticos y de fácil comprensión por el publico general. La realización de encuestas sería en cualquier caso complementaria a la realización de talleres, seminarios y encuentros presenciales dirigidos a las personas con un interés más directo en los aspectos propios del estudio de paisaje.

3) Se recomienda que el plan de participación pública se desarrolle de forma ágil y con un uso óptimo pero suficiente de los recursos que permiten la información y participación de la población. En este punto es necesario reseñar que el plan de participación debe de alimentar y guiar la redacción del estudio de paisaje, no debiendo en ningún caso ser tratado como un mero trámite administrativo ni como un fin en sí mismo.

\subsubsection{Plan de ordenación paisajística:}

1) A partir de la aplicación práctica realizada se sugiere que la metodología de redacción de estudios de paisaje incluya la realización de un plan de ordenación paisajística. Dicho plan permite concretar los aspectos de intervención física derivados de los objetivos de calidad paisajística y prepara la posterior definición de programa de paisaje de tipo ejecutivo. Igualmente el plan de ordenación paisajística permite generar una imagen sintética y global de las acciones propuestas, evitando la sectorización y mostrando a la población y administraciones afectadas los beneficios derivados de la aplicación de los programas de paisaje. En este punto resulta esencial la generación de cartografías y de simulaciones en tres dimensiones de las propuestas. 


\subsubsection{Integración de variables económicas:}

1. Se concluye que la integración de variables económicas como la productividad y el precio del suelo, sería fácilmente realizable tanto en la metodología propuesta como en la prevista por el Reglamento de Paisaje de la Comunidad Valenciana, aportando en contrapartida una mayor consistencia a los programas de paisaje y al diagnostico de la viabilidad del sistema de espacios abiertos.

\subsubsection{Mecanismos de incorporación del paisaje a las herramientas de planeamiento territorial y urbanístico (directrices/normas/recomendaciones o determinación de espacios físicos con un tratamiento urbanístico específico):}

1. La definición en detalle y en un mismo documento de los apartados analíticos y propositivos (espaciales, normativos y programáticos) de la planificación del paisaje, facilita una mayor coherencia de los segundos pero exige un cuidadoso trabajo de integración de las determinaciones de los apartados propositivos en las herramientas de planificación territorial y planeamiento urbanístico.

2. Es preciso explicar adecuadamente (mediante guías metodológicas o ejemplos aplicados) el modo por el que las determinaciones espaciales (sistema de espacios abiertos) o normativas de los estudios de paisaje afectarían o se integrarían en la planificación territorial y planeamiento urbanístico.

\subsection{Valoración de las contribuciones de la tesis en la planificación del paisaje}

\subsubsection{Aportaciones}

Las principales aportaciones de la tesis a la planificación del paisaje serían las siguientes:

1. Desarrollo, a partir de las indicaciones del reglamento de paisaje de la Comunidad Valenciana, de una metodología para la planificación del paisaje caracterizada por su alta transversalidad y por ser aplicable en distintas escalas y contextos

2. Propuesta de una metodología simplificada para la consulta pública en la totalidad del estudio de paisaje (tanto en las partes analíticas como en las propositivas) y dirigida a recoger las opiniones del conjunto de la población.

3. Constatación de la conveniencia de secuenciar en el tiempo la planificación del paisaje desde las escalas regionales a las locales, contemplando, en caso de ausencia de estudios de paisaje de rango superior, la importancia de desarrollar trabajos de caracterización y delimitación del sistema de espacios abiertos en un ámbito ampliado con el fin de contextualizar adecuadamente el ámbito estricto.

4. Determinación de la importancia en la caracterización del paisaje de:

a. Caracterizar y valorar los conflictos paisajísticos (al mismo nivel que las unidades y recursos paisajísticos).

b. Definir unidades de paisaje que sean funcionales en la ordenación y gestión territorial, aplicando para ello métodos sintéticos, detectando vocaciones u oportunidades territoriales y retroalimentando la definición de unidades con la formulación de objetivos de calidad paisajista preliminares.

5. Determinación de la importancia en la valoración del paisaje de:

a. Considerar y dar peso suficiente a las preferencias de la población frente a los juicios de calidad de expertos, determinando a partir de ambos un valor paisajístico preliminar.

b. Sistematizar los procedimientos para valorar el paisaje mediante consulta pública y para ajustar el valor paisajístico de unidades, recursos (y conflictos) en función de su visibilidad.

6. Sistematización del procedimiento técnico para determinar la visibilidad adquirida del territorio.

7. Diferenciación entre objetivos de calidad paisajísticos genéricos y específicos, vinculando los primeros al valor paisajístico.

8. Sistematización del procedimiento para definir un sistema de espacios abiertos que facilite el mantenimiento y mejora de la calidad ambiental, visual y cultural del territorio.

9. Integración de la definición de los programas de paisaje en un procedimiento apoyado en los objetivos de calidad paisajística y en un plan de ordenación paisajística.

10. Sistematización de la definición de normativa paisajística y adición de la figura de "recomendación paisajística".

11. Incorporación de variables económicas (por ejemplo productividad y precio del suelo) a la planificación del paisaje y al diagnóstico de la estabilidad territorial-paisajística.

12. Exploración de vías de financiación para la protección, gestión u ordenación del paisaje. 


\subsubsection{Nuevas líneas de trabajo y aspectos a desarrollar}

A lo largo de la tesis se han detectado las siguientes nuevas líneas de trabajo o investigación:

1. Integración de variables económicas en la planificación del paisaje: El carácter productivo de la mayor parte del territorio en los países desarrollados implica que su paisaje está fuertemente determinado por los procesos económicos que sobre él se desarrollan. Los trabajos realizados en la tesis y las experiencias existentes en la redacción de estudios de paisaje, ponen de manifiesto la necesidad de conocer dichos procesos para poder proteger, gestionar u ordenar consistentemente el paisaje.

Dicho conocimiento debe permitir determinar en una fase de caracterización y diagnóstico del paisaje, no solo las actividades económicas que se dan en una determinada zona, sino su estabilidad o posibilidad de permanencia. Con dicho objeto, se sugiere introducir en los análisis parámetros económicos objetivos y medibles como la productividad o el precio del suelo.

Las sugerencias que puedan hacerse en las partes propositivas de los estudios de paisaje, tanto en lo referente a la permanencia de actividades escasamente productivas en suelos con paisajes protegidos, como a la modificación de los procedimientos productivos en suelos con paisajes a gestionar o a la introducción de nuevos usos en los paisajes a ordenar, debería, adicionalmente, estar sustentada por un conocimiento más profundo de las actividades económicas existentes o propuestas, aportando, si cabe, una mayor transversalidad a los estudios de paisaje.

2. Ajustes en la caracterización del paisaje: Los ajustes en las metodologías de caracterización del paisaje deberían tener por objeto hacer que los espacios o elementos definidos en dicha caracterización, constituyan a su vez el soporte real para la definición de objetivos de calidad paisajística, de normativas de paisaje o de programas paisajísticos. En este punto, y tal y como se expuso anteriormente, se propone investigar en las siguientes líneas:

- Definición de unidades de paisaje mediante metodologías sintéticas que, aparte de analizar parámetros físicos, sociales y culturales concretos, detecten vocaciones u oportunidades territoriales.

- Reforzamiento del conflicto paisajístico como parte de la caracterización. Esta sugerencia se encuentra especialmente indicada en territorios con valores paisajísticos medios o bajos (como son de hecho gran parte de los suelos altamente intervenidos en los países desarrollados) y reforzaría la componente ordenadora de los estudios de paisaje frente a la componente protectora que comúnmente se deriva de la consideración de los recursos paisajísticos.

- Retroalimentación de la caracterización del paisaje, y especialmente de la definición de unidades de paisaje, a partir de una definición previa de objetivos de calidad paisajística preliminares que detecten las vocaciones $u$ oportunidades territoriales.

3. Financiación de acciones de paisaje: Esta línea de trabajo estaría intensamente asociada a los trabajos de custodia del territorio y a la creación de comunidades participativas, tanto en la definición del planeamiento como en la aplicación de éste. En este punto se constatan dificultades de tipo social y cultural que deben ser estudiadas y resueltas. En particular, se observa una desvinculación del individuo respecto a la gestión de su entorno, una frecuente y marcada transferencia de responsabilidades y deberes a las administraciones públicas y una escasa disposición del individuo a contribuir o implicarse de forma personal. Curiosamente, el desarrollo de la aplicación práctica, puso de manifiesto un mayor interés de en estos temas por parte de los residentes procedentes del norte de Europa, donde existe una mayor tradición participativa, que de los nacionales.

Asumida que la financiación de las acciones propuestas en los programas de paisaje debe ser básicamente asumida por el sector público o por los agentes privados afectados o beneficiados, las propuestas en esta línea deberían sin embargo garantizar el mantenimiento de las acciones desarrolladas y garantizar su permanencia, posibilitando a su vez la formación de comunidades más sólidas en base a proyectos comunes.

\subsubsection{Sugerencias a la metodología actual de redacción de estudios de paisaje en la Comunidad valenciana}

El conjunto de sugerencias metodológicas para la redacción de estudios de paisaje en la Comunidad Valenciana, ha quedado recogido en el apartado 7.2 (Conclusiones metodológicas) de la presente tesis y se sintetiza en la tabla siguiente. 
VALORACIÓNY GESTIÓN DEL PAISAJE SEGÚN EL CONVENIO EUROPEO DEL PAISAJE YEL

REGLAMENTO DEL PAISAJE DE LA COMUNIDAD VALFNCIANA:APLICACIÓN MEDIANTE UN ESTUDIO

DE PAISAJE A UNESPACIO ABIERTO EN LA COMUNIDAD VALENCIANA

DOCTORANDO: JUAN JOSÉ GALÁN VIVAS (Universidad Politécnica de Valencia, enero 2011)

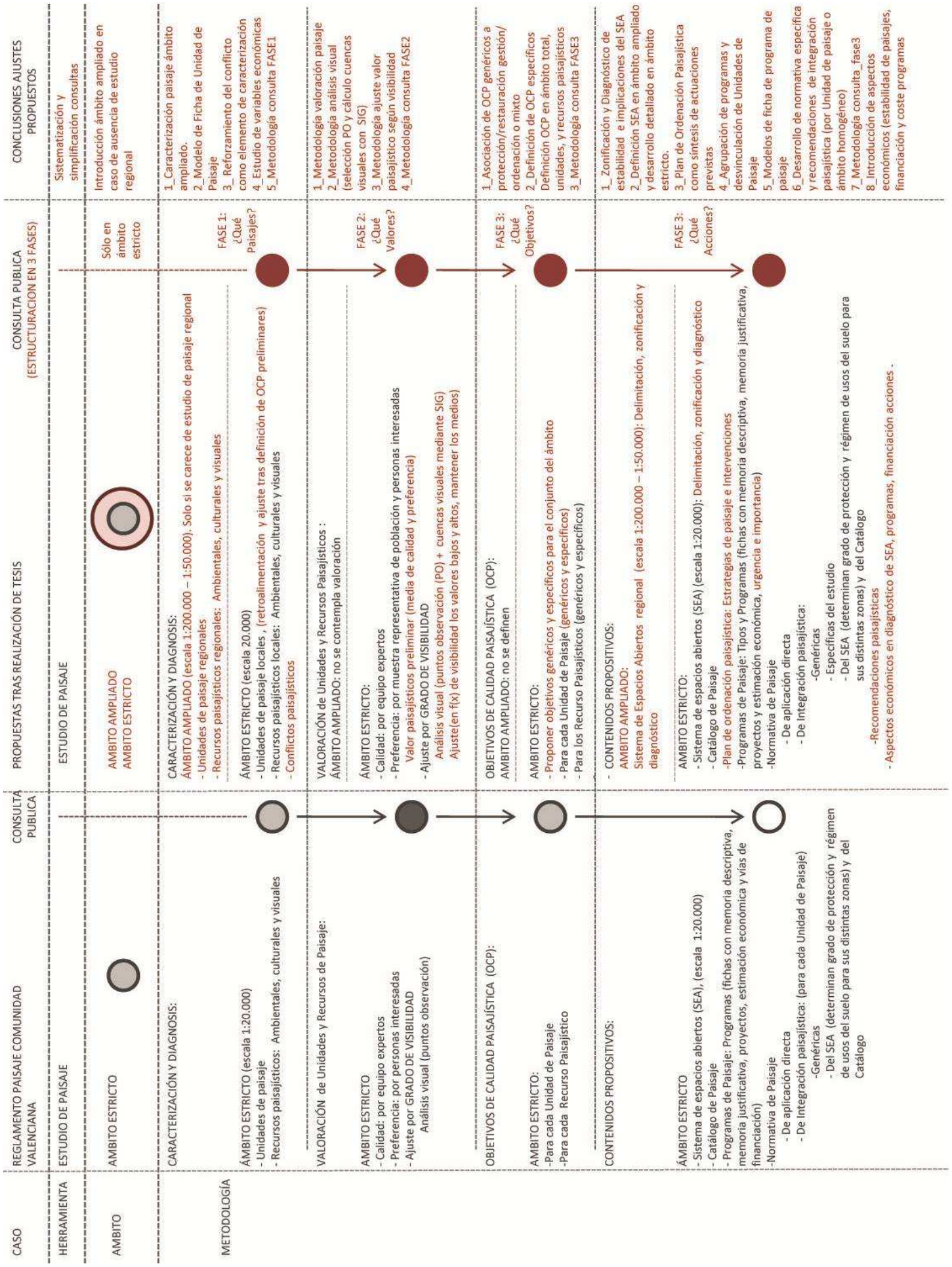

Tabla 7.1: Conclusiones sobre la metodología propuesta y aportaciones/ajustes (en rojo) respecto a las indicaciones del Reglamento de Paisaje de la Comunidad Valenciana 
VALORACIÓN Y GESTIÓN DEL PAISAJE SEGÚN EL CONVENIO EUROPEO DEL PAISAJE YEL

REGLAMENTO DEL PAISAJE DE LA COMUNIDAD VALENCIANA: APLICACIÓN MEDIANTE UN ESTUDIO

DE PAISAJE A UNESPACIO ABIERTO ENLA COMUNIDAD VALENCIANA

DOCTORANDO: JUAN JOSÉ GALÁN VIVAS (Universidad Politécnica de Valencia, enero 2011)

\section{GLOSARIO}


VALORACIÓN Y GESTIÓN DEL PAISAJE SEGÚN EL CONVENIO EUROPEO DEL PAISAJE YEL

REGLAMENTO DEL PAISAJE DE LA COMUNIDAD VALENCIANA: APLICACIÓN MEDIANTE UN ESTUDIO

DE PAISAJE A UNESPACIO ABIERTO EN LA COMUNIDAD VALENCIANA

DOCTORANDO: JUAN JOSÉ GALÁN VIVAS (Universidad Politécnica de Valencia, enero 2011) 


\section{GLOSARIO:}

Se expone a continuación por orden alfabético las definiciones correspondientes a los principales términos empleados en la presente tesis. Dichas definiciones han sido seleccionadas a partir del Estudio Terminológico recogido en el apartado 3.2. del capítulo 3 de la presente tesis.

- Actividades de Participación: Métodos y mecanismos que se definen en el Plan de Participación Pública y que permiten ejercer los derechos de los ciudadanos en materia de participación pública (Reglamento de Paisaje de la Comunidad Valenciana).

- Calidad Paisajística: Se entiende por calidad paisajística el grado de excelencia de un determinado paisaje o recurso paisajístico. . De acuerdo al Reglamento de Paisaje de la Comunidad Valenciana será propuesta de forma justificada por un equipo pluridisciplinar de expertos en paisaje, a partir de la calidad de la escena, la singularidad o rareza, la representatividad, el interés de su conservación y su función como parte de un paisaje integral. La calidad se manifestará como muy baja, baja, media, alta o muy alta. La administración competente para la aprobación del correspondiente instrumento de paisaje podrá fijar una calidad distinta a la propuesta de forma justificada. (Reglamento de Paisaje de la Comunidad Valenciana).

- Capacidad del Paisaje: Grado admisible de transformación de un determinado paisaje sin que éste sufra efectos adversos inaceptables en su carácter (Countryside Agency).

- Carácter del Paisaje: Patrón reconocible de elementos definitorios del paisaje que se da en un determinado Tipo de paisaje y que es percibido como tal por la población. (Countryside Agency).

- Caracterización del Paisaje: Descripción, clasificación y delimitación cartográfica de las Unidades de Paisaje de un territorio determinado y de los Recursos Paisajísticos que las singularizan (Reglamento de Paisaje de la Comunidad Valenciana).

- Carta de Paisaje: Instrumento de concertación de estrategias entre los agentes públicos y privados, aplicables a escala local, supramunicipal o comarcal, con el fin de llevar a cabo actuaciones de protección, gestión y ordenación del paisaje, que tengan por objetivo mantener sus valores. (Ley de Ordenación, Gestión y Protección del Paisaje de Cataluña).

- Catálogo de Paisaje: Instrumentos previstos en la legislación paisajística valenciana que identifican y establecen el régimen jurídico necesario para la preservación y recuperación de los paisajes de mayor valor. De acuerdo al Reglamento de Paisaje de la Comunidad Valenciana, los Catálogos de Paisaje incluirán:

- Las Unidades de Paisaje o Recursos Paisajísticos objeto de protección especial conforme a la legislación de protección de Espacios Naturales y los entornos de los bienes y conjuntos incluidos en el perímetro de su declaración como bien de interés cultural conforme a la legislación de patrimonio cultural.

- Las Unidades de Paisaje y los Recursos Paisajísticos a los que se haya reconocido un valor alto o muy alto.

- $\quad$ Cuenca Visual: Zona que es visible desde un punto o conjunto de puntos (línea, superficie).

- Custodia del Territorio: Conjunto de estrategias e instrumentos para la conservación de la natura y el paisaje que promueve la participación del propietario de los terrenos, la sociedad civil organizada, la ciudadanía e incluso las empresas privadas.

- Estudio de Paisaje: Documentos que establece los principios, estrategias y directrices, que permitan adoptar medidas específicas destinadas a la catalogación, valoración y protección del paisaje en sus respectivos ámbitos de aplicación (Reglamento de Paisaje de la Comunidad Valenciana). Los estudios de paisaje: (a) Establecen los objetivos de calidad paisajística del ámbito de estudio; (b) Analizan las actividades y procesos que inciden en el paisaje; (c) Indican las medidas y acciones necesarias para cumplir los objetivos de calidad paisajística. 
- Fragilidad Visual Adquirida del paisaje: Fragilidad Visual del paisaje ajustada en función de la presencia potencial de observadores.

- Fragilidad Visual del Paisaje: Susceptibilidad de un paisaje al cambio cuando se desarrolla una actividad sobre él.

- Gestión del Paisaje: Objetivo Genérico de Calidad Paisajística, materializable mediante el conjunto de acciones encaminadas, desde una perspectiva de desarrollo sostenible, a garantizar el mantenimiento regular de un paisaje, con el fin de guiar y armonizar las transformaciones inducidas por los procesos sociales, económicos y medioambientales. (Convenio Europeo del Paisaje).

- Normativa de Paisaje (Normas de Integración paisajística): Criterios de carácter paisajístico a los que los planes y proyectos deberán ajustarse salvo que existan motivos de interés público generales o derivados de la estructura del paisaje en dicha unidad que justifiquen su excepción (Reglamento de Paisaje de la Comunidad Valenciana). A efectos de su redacción en la Comunidad Valenciana se distinguirá entre:

- Normas de aplicación directa.

- Normas de Integración Paisajística (genéricas o específicas)

- Objetivo Específico de Calidad Paisajística: Concreción a nivel de Unidad de Paisaje o de Recursos Paisajístico de los objetivos de Protección, reordenación o gestión del paisaje hasta un punto que facilite la definición de programas de Paisaje.

- Objetivo Genérico de Calidad Paisajística: Formulación, por parte de las autoridades públicas competentes, de las aspiraciones de las poblaciones en lo que concierne a las características paisajísticas de su entorno (Convenio Europeo del Paisaje). De acuerdo al Reglamento de Paisaje de la Comunidad Valenciana se definirán para cada Unidad de Paisaje o Recurso Paisajístico en función de su valor paisajístico y se ajustarán a una de las siguientes opciones:

- Conservación y mantenimiento del carácter existente. (asimilable a Protección del Paisaje)

- Restauración del carácter

- Mejora del carácter existente a partir de la introducción de nuevos elementos o la gestión de los existentes (asimilable a Gestión del Paisaje)

- Creación de un nuevo paisaje. (asimilable a Ordenación del Paisaje)

- Una combinación de los anteriores

- Ordenación del Paisaje: Objetivo Genérico de Calidad Paisajística, materializable mediante el conjunto de acciones orientadas a generar un nuevo paisaje acorde con las aspiraciones de la población y a criterios de desarrollo sostenible.

- Ordenación del Territorio: Expresión espacial de la política económica, social, cultural y ecológica de toda la sociedad, cuyos objetivos fundamentales son el desarrollo socioeconómico y equilibrado de las regiones, la mejora de la calidad de vida, la gestión responsable de los recursos naturales, la protección del medio ambiente y, por último, la utilización racional del territorio. (Carta Europea de Ordenación del Territorio, 1983).

- Ordenación estructural: Determinaciones (establecidas mediante el Plan General para todo el Territorio Municipal) que sirven para dar coherencia a la ordenación urbanística del territorio en su conjunto, y, en particular, las siguientes (Ley Urbanística Valenciana, 2005):

a) Directrices definitorias de la estrategia de evolución urbana y ocupación del territorio.

b) Clasificación del suelo.

c) División del territorio en zonas de ordenación urbanística, determinando para cada una de ellas sus usos globales y tipos básicos de edificación.

d) Ordenación del Suelo No Urbanizable. Red Primaria de reservas de suelo dotacional público y equipamientos de titularidad privada cuya función o relevancia contribuyan a la articulación de la ciudad.

e) Tratamiento de los bienes de dominio público no municipal.

f) Ordenación de los centros cívicos y de las actividades susceptibles de generar tránsito intenso.

g) Expresión de los objetivos, directrices y criterios de redacción de los instrumentos de desarrollo del Plan General, delimitando los sectores definitorios de ámbitos mínimos de planeamiento 
parcial o de reforma interior, los usos o intensidades de cada sector, así como su aprovechamiento tipo.

h) Para sectores de suelo urbanizable de uso residencial, y, en su caso, urbanos: fijación del porcentaje mínimo de edificación con destino a vivienda de protección pública.

- Paisaje: Cualquier parte del territorio tal como la percibe la población, cuyo carácter sea el resultado de la acción y la interacción de factores naturales y/o humanos (Convenio Europeo del Paisaje, 2000).

- Participación pública: Procesos previsto para facilitar la implicación directa de la población en la toma de decisiones en el ámbito de lo público y en su aplicación posterior. Dichos procesos persiguen profundizar en los principios democráticos y requieren para su correcto desarrollo de: (1) una adecuada información/formación de la población participante, (2) el establecimiento de los cauces adecuados para que dicha participación sea fácil y abierta y (3) una implicación de los participantes en la definición, ajuste y aplicación de aquellos temas a los que han sido invitados a participar.

- Plan de Acción Territorial de Paisaje de la Comunidad Valenciana: Plan de Acción Territorial que tendrá por objeto identificar y proteger los paisajes de interés regional y, en su caso, de relevancia local, en el territorio valenciano, se delimitarán los ámbitos territoriales que deban ser objeto de planificación y actuación a escala supramunicipal en materia de paisaje y, en particular, los recorridos escénicos y las zonas de afección visual desde las vías de comunicación. Su contenido y determinaciones se ajustarán a lo previsto para los Estudios de Paisaje en el Reglamento de Paisaje de la Comunidad Valenciana.

- Plan de Acción Territorial: Instrumentos de ordenación territorial que desarrollan, en ámbitos territoriales concretos o en el marco de sectores específicos, los objetivos y criterios de la Ley de Ordenación del Territorio y de Protección del Paisaje así como la Estrategia Territorial de la Comunidad Valenciana. El ámbito de los planes de acción territorial puede comprender, en todo o en parte, varios términos municipales. Los planes de acción territorial serán de carácter sectorial o integrado, según sus objetivos y estrategias estén vinculados a uno o a varios sectores de la acción pública. (Ley de Ordenación y Protección del Paisaje de la Comunidad Valenciana, 2004).

- Plan de Participación Pública: Documento que define la estrategia de participación pública y la desarrolla detalladamente para cada una de las fases del proceso de elaboración. (Reglamento de Paisaje de la Comunidad Valenciana).

- Plan de Reforma Interior: Plan que, en suelo urbano, establece o completa la ordenación pormenorizada en operaciones de renovación urbana a fin de moderar densidades, reequipar barrios enteros, modernizar su destino urbanístico o preservar el patrimonio arquitectónico de interés. (Ley Urbanística Valenciana, 2005).

- Plan Especial: Plan que, en desarrollo, complemento o incluso modificación del planeamiento general y parcial, cumplen cualquiera de los siguientes cometidos: crear o ampliar reservas de suelo dotacional; definir y proteger las infraestructuras o vías de comunicación, el paisaje y el medio rural; adoptar medidas para la mejor conservación de inmuebles de interés cultural o arquitectónico; definir las condiciones de urbanización y edificación de ámbitos concretos sujetos a actuaciones urbanísticas singulares; concretar el funcionamiento de las redes de infraestructuras; y vincular áreas o parcelas, urbanas o urbanizables, a la construcción o rehabilitación de viviendas sujetas a algún régimen de protección pública. (Ley Urbanística Valenciana, 2005).

- Plan General: Plan que define el modelo de evolución urbana y su ordenación urbanística estructural, para términos municipales completos y los desarrollan pormenorizadamente en todo o parte del suelo urbano. (Ver definición de Ordenación estructural) (Ley Urbanística Valenciana, 2005).

- Plan Parcial: Plan que, siguiendo las directrices del Plan General, ordenan pormenorizadamente sectores concretos de suelo urbanizable. (Ley Urbanística Valenciana, 2005).

- Plan Urbanístico: El que se refiere a la ordenación del espacio urbano comprendiendo la previsión de desarrollo y asignando los diferentes usos del suelo. (Real Academia de la Lengua). 
- Planeamiento Territorial (o Planificación Territorial): Ver Planeamiento Urbanístico y Ordenación Territorial.

- Planeamiento Urbanístico (o Planificación Urbanística): Conjunto de instrumentos técnicos y normativos que se redactan para ordenar el uso del suelo y regular las condiciones para su transformación o, en su caso, conservación.

- Planificación del Paisaje: Conjunto de conocimientos e instrumentos técnicos y normativos de carácter territorial que permiten conocer y orientar la evolución (protección, gestión u ordenación) del paisaje a partir de criterios perceptivos, medioambientales, ecológicos, culturales, urbanísticos, económicos y sociales.

- Política de Paisaje: Formulación, por parte de las autoridades públicas competentes, del marco jurídico-legal, principios generales, estrategias, directrices y mecanismos de participación pública y de coordinación intersectorial que permitan la adopción de medidas específicas con vistas a la protección, gestión y ordenación del paisaje.

- Preferencia Paisajística: Se entiende por preferencia paisajística el nivel de aceptación de un determinado paisaje o recurso paisajístico. De acuerdo al Reglamento de Paisaje de la Comunidad Valenciana se definirá a partir de los valores atribuidos al paisaje por los agentes sociales y las poblaciones concernidas y se definirá a partir de procesos de consulta y participación pública.

- Programas de Paisaje: Documentos que concretan las actuaciones para garantizar la preservación, mejora y puesta en valor de los paisajes que por su valor natural, visual, cultural o urbano requieren intervenciones específicas e integradas (Reglamento de Paisaje de la Comunidad Valenciana). Dichos Programas concretarán las medidas, actuaciones y proyectos de paisaje necesarios para cumplir los Objetivos de Calidad Paisajística definidos con participación pública para el ámbito considerado.

- Protección del Paisaje: Objetivo Genérico de Calidad Paisajística, materializable mediante el conjunto de acciones que permitan conservar y mantener el carácter general de un paisaje o los aspectos significativos o característicos naturales y antrópicos que lo constituyen. (Convenio Europeo del Paisaje).

- Público Interesado: sector de la población que puede verse afectado por procedimientos de toma de decisiones de las políticas territoriales o que tenga un interés en el lugar (Reglamento de Paisaje de la Comunidad Valenciana). En relación al paisaje se establecen dos grandes grupos:

- Grupos de interés: organismos y agencias públicas, autoridades locales, asociaciones no gubernamentales, grupos académicos y científicos. Tienen interés tanto local como regional y pueden contribuir en todas las escalas tanto a escala regional como un proyecto local.

- Grupos del lugar: residentes locales, visitantes, grupos locales. Son individuos que viven y trabajan en un área en particular o la visitan y tiene un interés particular en esa zona.

- Puntos de Observación: Lugares del territorio desde donde se percibe principalmente el paisaje. (Reglamento de Paisaje de la Comunidad Valenciana).

- Recurso Paisajístico: Elemento lineal o puntual o extenso singular de un paisaje o grupo de éstos que definen su individualidad y que tienen un valor visual, ecológico, cultural y/o histórico. (Reglamento de Paisaje de la Comunidad Valenciana).

- Sistema de Espacios Abierto: Conjunto integrado y continúo de espacios en general libres de edificación, de interés medioambiental, cultural, visual, recreativo y las conexiones ecológicas y funcionales que los relacionan entre sí (Reglamento de Paisaje de la Comunidad Valenciana). La adscripción de una determinada zona al sistema de espacios abiertos implicará la aplicación de normativas de paisaje específicas así como la regulación específica de usos del suelo. El sistema de espacios abiertos podrá incluir suelos no urbanizables, urbanizables y urbanos, facilitando de este modo la efectiva conexión y acceso al paisaje así como la adecuada planificación pormenorizada del suelo urbanizable. 
- Tipo de Paisaje: Clase genérica de Paisaje atribuible a espacios que presenten configuraciones parecidas de elementos primarios definitorios del paisaje (geología, topografía, hidrología, vegetación y patrones históricos de influencia humana (usos del suelo, asentamientos, etc)). (Countryside Agency).

- Unidad de Paisaje: Área geográfica con una configuración estructural, funcional o perceptivamente diferenciada, única y singular, que ha ido adquiriendo los caracteres que la definen tras un largo período de tiempo. Se identifica por su coherencia interna y sus diferencias con respecto a las unidades contiguas. (Reglamento de Paisaje de la Comunidad Valenciana).

- Urbanismo: Conjunto de conocimientos relativos a la planificación, desarrollo, reforma y ampliación de los edificios y espacios de las ciudades (Real Academia de la Lengua).

- Valor económico del Paisaje: Valor económico de un lugar atribuible exclusivamente a la calidad de su paisaje o entorno perceptivo.

- Valor paisajístico preliminar: Valor relativo que se asigna a cada Unidad de paisaje y a cada Recurso Paisajístico por razones ambientales, sociales, culturales o visuales y que se establece en función de su calidad paisajística y de las preferencias de la población (Reglamento de Paisaje de la Comunidad Valenciana).

- Valor paisajístico: Valor relativo que se asigna a cada Unidad de paisaje y a cada Recurso Paisajístico por razones ambientales, sociales, culturales o visuales y que se establece en función de su calidad paisajística, las preferencias de la población y su visibilidad. (Reglamento de Paisaje de la Comunidad Valenciana).

- Valoración económica del Paisaje: Conjunto de técnicas, conocimientos y procedimientos que permiten determinar el valor económico del paisaje.

- Visibilidad del Paisaje: La visibilidad del paisaje determina la importancia relativa de lo que se ve y se percibe. Dicha importancia es función de la superficie o conjunto de puntos desde los que es posible ver un determinado paisaje o elemento, de la situación y condiciones de los potenciales observadores, de las cualidades intrínsecas del paisaje y del no de observadores potenciales. De acuerdo al Reglamento de Paisaje de la Comunidad Valeriana la visibilidad del paisaje es función de la combinación de distintos factores como son los puntos de observación, la distancia, la duración de la vista, y el número de observadores potenciales. 
VALORACIÓN Y GESTIÓN DEL PAISAJE SEGÚN EL CONVENIO EUROPEO DEL PAISAJE YEL

REGLAMENTO DEL PAISAJE DE LA COMUNIDAD VALENCIANA: APLICACIÓN MEDIANTE UN ESTUDIO

DE PAISAJE A UNESPACIO ABIERTO EN LA COMUNIDAD VALENCIANA

DOCTORANDO: JUAN JOSÉ GALÁN VIVAS (Universidad Politécnica de Valencia, enero 2011) 


\section{REFERENCIAS BIBLIOGRÁFICAS}


VALORACIÓN Y GESTIÓN DEL PAISAJE SEGÚN EL CONVENIO EUROPEO DEL PAISAJE YEL

REGLAMENTO DEL PAISAJE DE LA COMUNIDAD VALENCIANA: APLICACIÓN MEDIANTE UN ESTUDIO

DE PAISAJE A UNESPACIO ABIERTO EN LA COMUNIDAD VALENCIANA

DOCTORANDO: JUAN JOSÉ GALÁN VIVAS (Universidad Politécnica de Valencia, enero 2011) 


\section{REFERENCIAS BIBLIOGRÁFICAS:}

- ABELSON, P., (1996), "Project Appraisal and Valuation of the Environment: general principles and six case studies in developing countries", Ed. The MacMillan Press Ltd.

- $\quad$ ALMENAR, R.; ARNAL, C.; BONO, E.; CERDÀ, A.; DIAGO, M.; DOLÇ, C.; GAJA, F.; GARCIA, E.; LÓPEZ OLIVARES, D.; OLCINA, J.; OLMOS, J.; PICÓ, M.; SALES, V.; TORRES, V.;ULL, M. À.; VERA, F., (2006). "Llibre Verd del territori valencià". Congrés Escola Valenciana i societat sostenible. Escola Valenciana. Federació D'Associacions per la llengua.

- $\quad$ ALMENAR, R.; BONO, E.; DIAGO, M; DUART, P.; GARCÍA, E.; MARTÍNEZ IGLESIAS, M.; MERELLES TORMO, A.; PASCUAL, A.; SÁNCHEZ GARCÍA, A. M.; SANTOS ORTEGA, A., (2007), "La situación del Pais Valencia 2007. Indicadors $i$ tendències de desenvolupament social $i$ sostenibilitat mediambiental', Col•lecció Testimonis, núm. 12.

- APPLETON, J., (1975), "Landscape Evaluation: the Theoretical Vacuum", Ed. Institute of British Geographers, Transactions 66

- APPLETON, J., (1975), "The Experience of Landscape”, Ed. Wiley.

- APPLEYARD, D.; LYNCH, K.; MYER, J. R,. (1966), "The View from the Road", MIT Press.

- $\quad$ ARAMBURU, Ma. P., CIFUENTES, P.; ESCRIBANO, R.; GALIANA, F.; GARCÍA ABRIL, A.; GONZÁLEZ ALONSO, S.; GRANDE, Må. A.; MARTÍN, Mํ. A.; MILARA, R.; PUIG, J.; RAMOS, A.; RODRÍGUEZ LOMBARDERO, I. SOLANA, J. Y TORRECILLA, I., (1994), "Casos Prácticos en Planificación Física y Evaluación de Impactos", Departamento de Proyectos y Planificación Rural. ETS Ingenieros de Montes de Madrid.

- $\quad$ ARAMBURU, Mà.P.; ESCRIBANO, R; RAMOS, L. Y RUBIO, R., (2003), "Cartografía del paisaje de la Comunidad de Madrid", Consejería de Medio Ambiente de la Comunidad de Madrid.

- $\quad$ ARRIAZA, M.; CAÑAS-ORTEGA, J.F.; CAÑAS-MADUEÑO, J.A. Y RUIZ AVILÉS, P., (2004). "Assessing the visual quality of rural landscapes", Landscape and Urban Planning, Vol. 69:114-125.

- $\quad$ ARTHUR, L.M. ET AL., (1977), "Scenic Assessment: An Overview“. Landscape Planning, Vol. 4:109-129.

- BAKER ASSOCIATES PLANNING CONSULTANTS, (2005), "Integrated Approach to Sustainable Rural Planning in East Northamptonshire", (octubre 2005), Countryside Agency \& East Northamptonshire District Council.

- BARBA CASANOVA, Rosa, (2010), "1970-2000 Obras y Escritos", Asflor Ediciones.

- BOURASSA, S. C.; HOESLY, M; SUN, J., (2006), "The price of Aesthetic Externalities", The Appraisal Journal.

- BUSQUeTS, J. (coord.), (2010), "La Política de Paisaje en Cataluña", Departamento de Política Territorial y Obras Públicas.

- BUSQUETS, J., (2010), Las cartas del paisaje, "La política de paisaje en Cataluña”, Departamento de Política Territorial y Obras Públicas.

- BUSQUeTS, J.; CORTINA, A., (2009), La Gestión del paisaje como proceso, "Gestión del paisaje: Manual de protección, gestión y ordenación del paisaje". Ariel Patrimonio.

- CMAUV, (2008), "La nueva Política de Paisaje de la Comunidad Valenciana". Generalitat Valenciana, Consellería de Medio Ambiente, Agua, Urbanismo y Vivienda.

- CMAUV, (2008), "Plan de Acción Territorial para la Protección de la Huerta de Valencia", Generalitat Valenciana, Consellería de Medio Ambiente, Agua, Urbanismo y Vivienda.

- CMAUV, (2010), "Plan de Acción Territorial del Paisaje de la Comunidad Valenciana", Generalitat Valenciana, Consellería de Medio Ambiente, Agua, Urbanismo y Vivienda.

- COLIN, P., (1978). "Landscape Economics", Ed. The MacMillan Press Ltd. 
- CORRAL TORRES, I., (2004), Plan Estratégico de Desarrollo Turístico de Boa Vista, "Gestión del paisaje: Manual de protección, gestión y ordenación del paisaje". Ariel Patrimonio.

- COURTNeY, P.; HILL, G., ROBERTS, D., (2002), "The Role of the Natural Heritage in Rural Development: An empirical analysis of economic linkages in Scotland". RICS Foundation and University of Gloucestershire.

- CTH, (2006), "Plan de Acción Territorial del Litoral de la Comunidad Valenciana", Generalitat Valenciana, Consellería de Territorio y Vivienda.

- CTH, (2006), "Reglamento de Paisaje de la Comunidad Valenciana. Generalitat Valenciana", Consellería de Territorio y Vivienda.

- DÍAZ MARTín, M.; GALIANA, F., (1996), "Estudio paisajístico de la Huerta de Valencia". Ayuntamiento de Valencia.

- DPTOP, (2010), "Catálogo de Paisaje de las Tierras de Lérida", Departamento de política territorial y obras públicas de la Generalitat de Cataluña / Observatorio del Paisaje de Cataluña.

- DPTOP, (2010), "La política de paisaje de Cataluña", Departamento de política territorial y obras públicas de la Generalitat de Cataluña.

- DPTOP, (2010), "Normas de Ordenación Territorial: Directrices de paisaje (Plan Territorial de las Comarcas de Gerona)", Departamento de política territorial y obras públicas de la Generalitat de Cataluña.

- DRAMSTAD, WENCHE E., (2005), "Principios de ecología del paisaje en arquitectura del paisaje y planificación territorial”, Fundación Conde Valle Salazar

- DUNN, M.C., (1974), "Landscape evaluation techniques: an appraisal and review of the literature", Centre for Urban and Regional Studies. University of Birmingham.

- ESCRIBANO, Ma. M.; DE FRUTOS, M.; IGLESIAS, E. MATAIX; C. Y TORRECILLA, I., (1991). "EI Paisaje. Unidades temáticas ambientales", Secretaría de Estado para las Políticas del Agua y Medio Ambiente, MOPT.

- ESCRIBANO, Mํ. M.; DE FRUTOS, M.; IGLESIAS, E. MATAIX; C.; TORRECILLA, I., (1987), “EI Paisaje. Unidades temáticas ambientales de la Secretaría de Estado para las Políticas del Agua y Medio Ambiente, MOPT; primera edición". Madrid.

- ESTEBAN, J., (2010), Las directrices del paisaje; "La política de paisaje en Cataluña”, Departamento de Política Territorial y Obras Públicas.

- FARINOS, J., (2006), La Estrategia Territorial Europea en el Nuevo Paradigma de la Territorialidad, "Una nueva cultura del Territorio", CUIMPB.

- FINES, K.D., (1968), "Landscape Evaluation: a research Project in East Sussex", Regional Studies, 2: pag. 41-55

- FLEISCHER, A.; TSUR, Y., (1997); "Measuring the Recreational Value of Agricultural Landscape in the valleys of Hula and Jezreel (Israel)", Department of Agricultural Economics and Management, Jerusalem.

- FORESTRY COMMISSION, (1975), "Grants to Woodland Owners", Forestry Commission, Edinburgh

- FORESTRY COMMISSION, (1975), "Landscaping, Planning and Economics, Paper 11", Forestry Commission, Edinburgh

- FORMAN, R. T.T.; GODRON, M., (1986), "Landscape Ecology", John Wiley and Sons.

- GalianA, F., (2004), "Paisaje y Medio Ambiente". Máster en Jardinería y Paisaje, Universidad Politécnica de Valencia.

- GalianA, F.; BALAGUER, M.; MARQUES, A. MARTí, A.; DíAZ MARTíN, M., (2001), "Inventario y valoración del paisaje en el Plan de Acción Territorial del Entomo Metropolitano de Alicante-Elche (PATEMAE)", Consellería D' Obres Públiques, Urbanisme y Transports (COPUT); Generalitat Valenciana (sin publicar). 
- GALIANA, F.; VALLES, Mạ.; MARTí, A., (2002), "Inventario y Valoración del paisaje en el Litoral de la Comunidad Valenciana", Consellería D' Obres Públiques, Urbanisme y Transports (COPUT); Generalitat Valenciana (sin publicar).

- GANYET, J; (2009), Cuatro años de la Ley de protección, gestión y ordenación del paisaje de Cataluña: un balance positivo, "Ordenación y Gestión del Paisaje en Europa", Observatorio del Paisaje de Cataluña.

- GARCÍA ASENSIO, J.M.; CAÑAS, I., (2001), La valoración del paisaje, "Gestión Sostenible de Paisajes Rurales. Técnicas e Ingeniería". Capítulo 3:33-52. Fundación Alfonso Martín Escudero; Mundi-Prensa.

- GARROD, G.; WILLIS, K. G., (2000). "Economic Valuation of the Environment: Methods and case Studies". Ed. Edward Elgar, Cheltenham, UK; Northampton, MA, USA.

- GRegory, R.; LICHTENSTEIN, S, SLOVIC, P., (1993), "Valuing environmental resources: a constructive", Journal of Risk and Urcentaity, ํำ 7.

- GREIG, P.J., (1977). "Forecasting the Demand Response to Changes in Recreational Site Characteristics", USDA Forest Service.

- GUADALAJARA, N.; SALVADOR, P.; GÓMEZ, F., (1992), "La dotación de árboles y de espacios verdes urbanos, y su relación con los precios de las viviendas en Valencia", Centro Studi e Di Economia Territoriale - Ce.S.E.T; Firenze.

- HELLIWELL, D. R., (1967), "The Amenity Value of Trees and Woodlands", Arboricultural Association Journal, 1.

- HELLIWELL, D. R., (1974), “Discount Rates in Land Use Planning”, Forestry o 47.

- JONES, G.R. et AL., (1976), "Scenic and Recreational highway Study for the State of Washington", Landscape Planning, Vol.3: 151-302.

- LANDSCAPE CHARACTER SUPPLEMENTARY PLANNING DOCUMENT of the Derbyshire landscape character assessment, (2006), High Peak Borough Council

- LANDSCAPE STRATEgy FOR LANCASHIRE, (2000), Lancashire City Council y Countryside Agency.

- LAVERNE, R. J.; WINSON-GEIDEMAN K., "003), "The influence of trees and landscaping on Rental Rates at Office Buildings", Journal of Arboriculture.

- LITTON, R.B., (1972). Aesthetic Dimensions of the Landscape. "Natural Environments Studies in Theoretical and Applied Analysis: 262-291". The Johns Hopkins University Press. Baltimore.

- LYNCH, K., (1960), "The Image of the City", MIT Press.

- LYNCH, K., (1995),“City Sense and Design”, MIT Press.

- MATA OlMO, R.; SANZ HeRRÁlZ, C, (2003), "Atlas de los Paisajes de España”, Ministerio de Medio Ambiente.

- MATA, R., (2003), Plan Territorial Insular de Menorca, "Gestión del Paisaje: Manual de protección, gestión y ordenación del paisaje". Ariel Patrimonio.

- MATA, RAFAEL, TARROJA, ÀlEX; (COORDS.) (2006) El paisaje y la gestión del territorio. Criterios paisajísticos en la ordenación del territorio y el urbanismo. Diputación de Barcelona. Colección Territorio y Gobierno: Visiones Vol.5.

- MISHAN, E.J. (1967), "Nomalization of Public Investment Criteria: an Amendment", Economic Journal, 79.

- MOPT, (1992), "Guía para la Elaboración de Estudios del Medio Físico. Contenido y Metodología". Secretaría de Estado para las Políticas del Agua y Medio Ambiente, Ministerio de Obras Públicas y Transportes.

- MUÑOZ CRIADO, A., STEINITZ, C., (2009), Estudio de Paisaje Visual de la Comunidad Valenciana, "La nueva Política de Paisaje de la Comunidad Valenciana", Generalitat Valenciana, Consellería de Medio Ambiente, Agua, Urbanismo y Vivienda. 
- NASH, C.A.; PEARCE, D. W.; STANLEY, J, (2008), "An Evaluation of Cost-Benefit Analysis Criteria", Scottish Journal of Political Economy, 22.

- NELO, O., (director), (2010), "La Política de Paisaje en Cataluña”, Departamento de Política Territorial y Obras Públicas.

- NELSON, G; HANSZ, J. A; CYPHER, M. L., (2005), "The Influence of Artificial Water Canals on Residential Sale Prices". The Appraisal Journal.

- NOGUE, J.; SALA, P, (2006); "Prototipo de catálogo de paisaje", Observatorio del paisaje de Cataluña.

- NOGUE, J; PUIGBeRT, L; BRETCHA, G., (2009), "Ordenación y Gestión del Paisaje en Europa", Observatorio del Paisaje de Cataluña.

- OBSERVATORIO DEL PAISAJE DE CATAluña, (2006), "Prototipo de catálogo de paisaje", Observatorio del paisaje de Cataluña.

- OBSERVATORIO DEL PAISAJE DE CATALUÑa, (2009), "Ordenación y Gestión del Paisaje en Europa" Observatorio del Paisaje de Cataluña.

- OTERO, I., (1979), "El análisis cuantitativo de los elementos del Medio Natural en orden a la Planificación Física", Tesis Doctoral. ETS de Ingenieros de Montes. Universidad Politécnica de Madrid.

- PAÜL, V.; QUERALT, A., (2009), Las políticas y los instrumentos de protección, gestión y ordenación del paisaje en España, "Ordenación y Gestión del Paisaje en Europa", Observatorio del Paisaje de Cataluña.

- PEARCE, D. W.; (1971), "Cost - Benefit Analysis", Ed. MacMillan.

- PlanNING FOR SUStainABLE SETTLEMENTS IN THE HIGH WEALD AONB, (2005), Countryside Agency y High Weald AONB.

- PLANNING POLICY STATEMENT № 11: REGIONAL SPATIAL STRATEGIES, (2004), Office of the Deputy Prime Minister.

- PNEU, (2005), "BLUE PLAN. A sustainable Future for the Mediterranean", Programa de Naciones Unidas para el Medio Ambiente.

- PREECE, R.A. (1991), "Designs on the Landscape", Belhaven Press.

- PREM, M., (2007), "Gestión paisajística en el Mediterráneo", EAXXI: Congreso Internacional de Paisaje, Territorio y Desarrollo, Valencia.

- RAMOS, A. (Coord.), (1979), "Planificación física y ecología. Modelos y métodos", EMESA.

- RAMOS, A. (Coord.), (1987), "Diccionario de la Naturaleza. Hombre, Ecología y Paisaje”, Espasa-Calpe.

- RAMOS, A., RAMOS, F., CIFUENTES, P., FERNÁNDEZ-CAÑADAS, M., (1976), "Visual landscape evaluation, a grid technique", Landscape Planning, Vol.3: 67-88.

- REGLAMENTO DE PAISAJE DE LA COMUNIDAD VALENCIANA, (2006), Generalitat Valenciana

- ReNARD, FRANÇOISE BRETON; TRUJILLO MARTINEZ A. J., (2006), Paisajes Litorales, "El paisaje y la gestión del territorio. Criterios paisajísticos en la ordenación del territorio y el urbanismo", Diputación de Barcelona. Colección Territorio y Gobierno: Visiones Vol.5.

- RODDEWIG, R.; FREY, J. D., (2006), "Testing the Reliability of Contingent Valuation in the Real Estate Marketplace". The Appraisal Journal.

- RODRÍGUEZ Y SILVA, F.; MOLINA MARTínEZ J. R. HERRERA MACHUCA, M. A., (2007), "Gestión del Medio Natural atendiendo al comportamiento de los incendios forestales y a la valoración socioeconómica del recurso Paisaje", Wildfire.

- SALA, P.; NOGUE, J., (2006); "Prototipo de catálogo de paisaje”, Observatorio del paisaje de Cataluña.

- SEGUín, J. F, (2009), Identificación y cualificación de los paisajes: la experiencia francesa de los atlas de paisaje, "Ordenación y Gestión del Paisaje en Europa", Observatorio del Paisaje de Cataluña.

- SMARDON, R.C., (1986), "Historical Evolution of Visual Resource Management within Three Federal Agencies", Journal of Environmental Management. 
- SOlANA GUTIÉRREZ, J. Y ÁLVAREZ IBÁÑEZ, Mạ.M., (1999), Análisis de Preferencias Paisajísticas en la Sierra de los Ancares, "Homenaje a Don Ángel Ramos Fernández (1926-1998), tomo I: 905-928". Real academia de Ciencias, Exactas, Físicas y naturales; Academia de la Ingeniería y Escuela Técnica Superior de Ingenieros de Montes, UPM.

- STEINITZ, C. F; CANFIELD, T., (2008), "Visual Landscape: Readings", University of Harvard.

- STEINITZ, C., (1990) "Towards a Sustainable Landscape with High Visual Preference and High Ecological Integrity: the Loop Road in Acadia National Park, U.S.A."; Landscape \& Urban Planning, 1990, vol. 19, no3, pp. 213-250.

- STEINITZ, C., (2007), "The Visual Landscape of the Veneto: Past, Present and Future"; Universita Ca' Foscari.

- STEINITZ, C.; ARIAS, H.M.; BASSETT, S.; FLAXMAN, M.; GOODE, T.; MADDOCK III, T.; MOUAT, D.; PEISER, R. \& SHEARER, A., (2003), "Altemative Futures for Changing Landscapes. The Upper San Pedro River Basin in Arizona and Sonora". Island Press.

- STEINITZ, C.; MUÑOZ CRIADO, A. (2009), Estudio de Paisaje Visual de la Comunidad Valenciana, "La nueva Política de Paisaje de la Comunidad Valenciana", Generalitat Valenciana, Consellería de Medio Ambiente, Agua, Urbanismo y Vivienda.

- STREMLOW, M., (2009), Paisaje y desarrollo sostenible: proyecciones de futuro. Resultados del proyecto suizo Paysage 2020, "Ordenación y Gestión del Paisaje en Europa", Observatorio del Paisaje de Cataluña.

- TARROJA, ÀleX; CAMAGNI, ROBERTO (coords), (2006), "Una nueva cultura del territorio. Criterios sociales y ambientales en las políticas y el gobiemo del territorio". Diputación de Barcelona. Colección Territorio y Gobierno: Visiones Vol.4.

- THE LANDSCAPE INSTITUTE, (2002), "Guidelines for Landscape and Visual Impact Assessment", The Landscape Institute y The Institute of Environmental Management and Assessment.

- VERBIC, M.; ERKER, R., (2007), "Economic Valuation of Environmental Values of the Landscape Development and Protection Area of Volcji Potokatal", Institute for Economic Research, Ljubljana, Eslovenia.

- WASCHER, D.; SCHRÖDER, R., (2009), Las políticas de paisaje en los países Bajos, "Ordenación y Gestión del Paisaje en Europa", Observatorio del Paisaje de Cataluña.

- WILLIS, K.G.; BENSON, J.F., (1989). "Recreational Values of Forests", Forestry Commission.

- WILLIS, K.G.; GARROD, G. D.; HARVEY, D.R. (1998)., "A review of Cost-Benefit analysis as Applied to the Evaluation of new road proposals in the UK', Transportation Research Part D: Transport and Environment 3.

- WRIGHT, G., (1974), "Appraisal of Visual landscape qualities in a region selected for accelerated growth", Landscape Planning, Vol. 1: 307-327

- ZOIDO, FLORENCIO, (2006), "El Convenio Europeo del Paisaje" 
VALORACIÓN Y GESTIÓN DEL PAISAJE SEGÚN EL CONVENIO EUROPEO DEL PAISAJE YEL

REGLAMENTO DEL PAISAJE DE LA COMUNIDAD VALENCIANA: APLICACIÓN MEDIANTE UN ESTUDIO

DE PAISAJE A UNESPACIO ABIERTO EN LA COMUNIDAD VALENCIANA

DOCTORANDO: JUAN JOSÉ GALÁN VIVAS (Universidad Politécnica de Valencia, enero 2011) 